Prepared in cooperation with the U.S. Department of Transportation Federal Highway Administration and the Massachusetts Department of Transportation

\title{
Quality of Stormwater Runoff Discharged from Massachusetts Highways, 2005-07
}

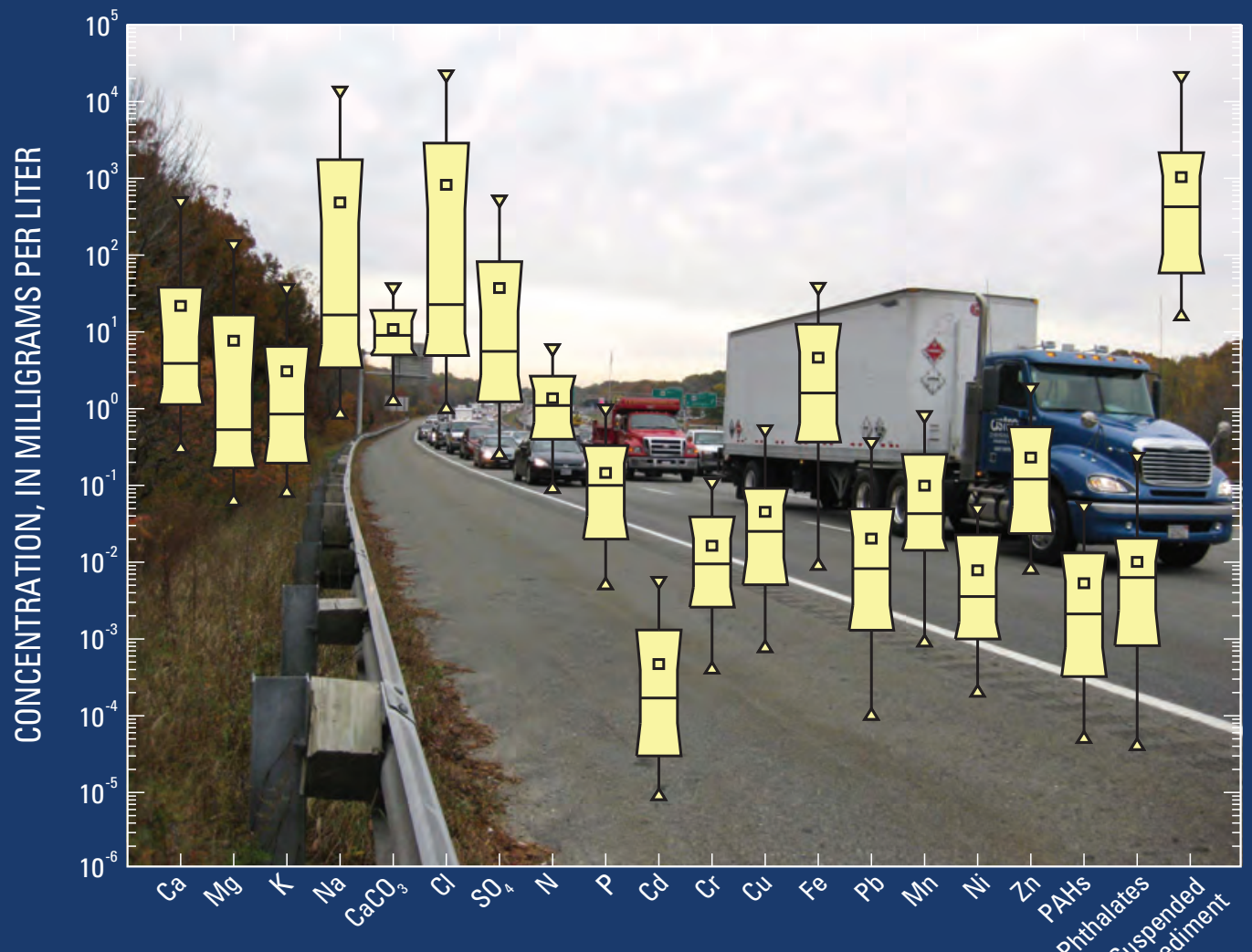


Cover. Distribution of event-mean concentrations for selected constituents in approximately 140 composite samples of highway runoff collected at 12 highway-monitoring stations on 8 highways in Massachusetts; background photograph of rush-hour traffic on Interstate 95 in Lexington by Kimberly W. Campo, U.S. Geological Survey. 


\section{Quality of Stormwater Runoff Discharged from Massachusetts Highways, 2005-07}

By Kirk P. Smith and Gregory E. Granato

Prepared in cooperation with the U.S. Department of Transportation Federal

Highway Administration and the Massachusetts Department of Transportation

Scientific Investigations Report 2009-5269 


\section{U.S. Department of the Interior \\ KEN SALAZAR, Secretary \\ U.S. Geological Survey \\ Marcia K. McNutt, Director}

U.S. Geological Survey, Reston, Virginia: 2010

For more information on the USGS—-the Federal source for science about the Earth, its natural and living resources,
natural hazards, and the environment, visit http://www.usgs.gov or call 1-888-ASK-USGS
For an overview of USGS information products, including maps, imagery, and publications,
visit http://www.usgs.gov/pubprod
To order this and other USGS information products, visit http://store.usgs.gov

Any use of trade, product, or firm names is for descriptive purposes only and does not imply endorsement by the U.S. Government.

Although this report is in the public domain, permission must be secured from the individual copyright owners to reproduce any copyrighted materials contained within this report.

Suggested citation:

Smith, K.P., and Granato, G.E., 2010, Quality of stormwater runoff discharged from Massachusetts highways, 2005-07: U.S. Geological Survey Scientific Investigations Report 2009-5269, 198 p. 


\section{PREFACE}

Knowledge of the characteristics of highway runoff (concentrations of constituents and the physical and chemical processes which produce this runoff) is important for decision makers, planners, and highway engineers to assess and mitigate possible adverse impacts of highway runoff on the Nation's receiving waters. In 2004, the Federal Highway Administration, the Massachusetts Department of Transportation, and the U.S. Geological Survey began an investigation to characterize the concentrations of selected dissolved major ions, total nitrogen and phosphorus, selected total-recoverable metals, suspended sediment, and semivolatile organic compounds measured in flow-weighted composite samples of stormwater collected from typical highway-drainage conveyance structures on eight highways in Massachusetts during a 2-year sampling period.

Office of Natural Environment

Federal Highway Administration

55 Broadway, 10th Floor

Cambridge, MA 02142

Massachusetts Department of Transportation

10 Park Plaza

Boston, MA 02116

U.S. Geological Survey

10 Bearfoot Road

Northborough, MA 10532 
THIS PAGE INTENTIONALLY LEFT BLANK 


\section{Contents}

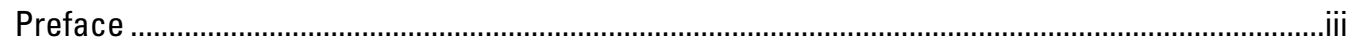

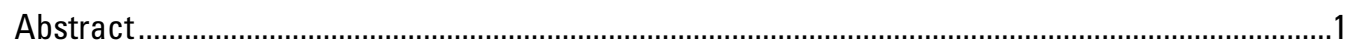

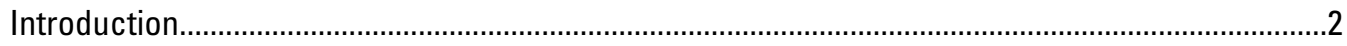

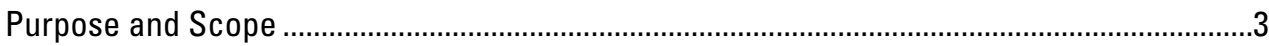

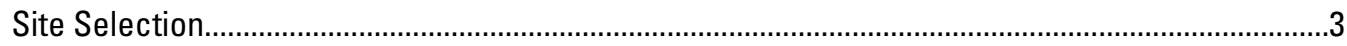

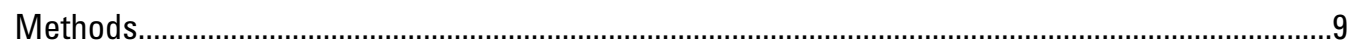

Continuous Monitoring of Highway Drainage Systems ............................................................

Design of Highway-Drainage Monitoring Systems....................................................

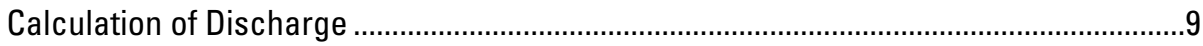

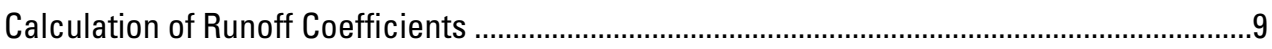

Calculation of Event-Mean Values of Specific Conductance ..................................................12

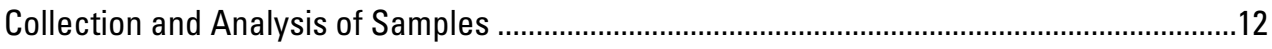

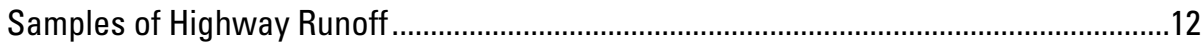

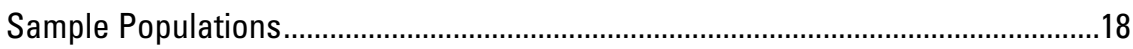

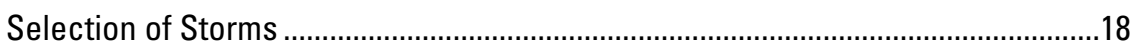

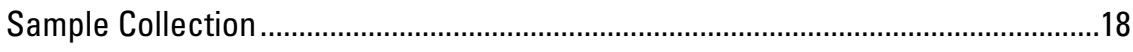

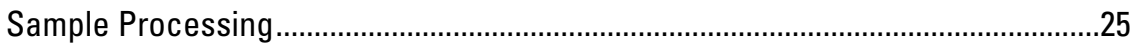

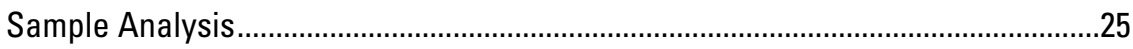

Samples of Highway-Runoff Sediment .....................................................................25

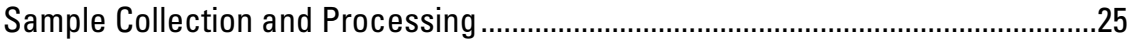

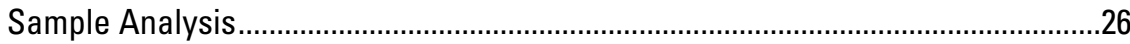

Samples of Background Soil, Highway-Berm Soil, and Other Miscellaneous

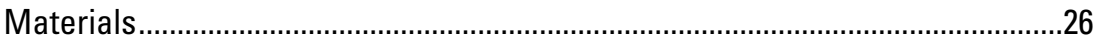

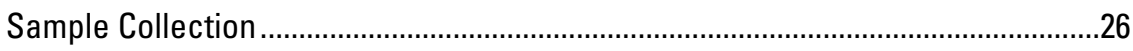

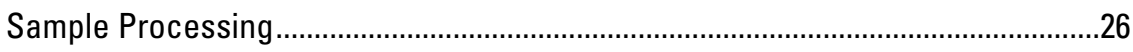

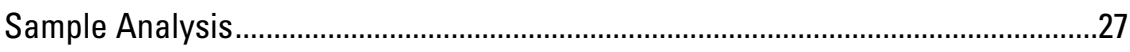

Estimation of Constituents Contributed to Runoff from Road Salt..........................................27

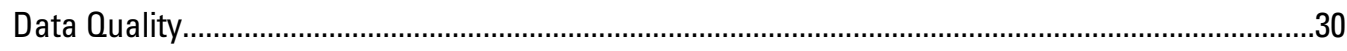

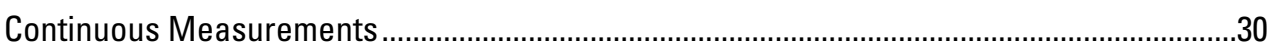

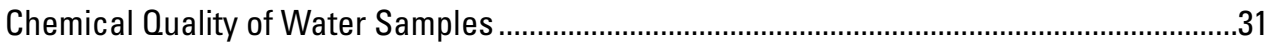

Field Quality-Control Samples ..................................................................................

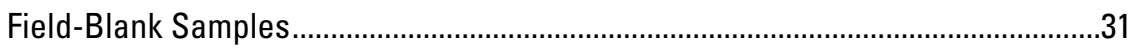

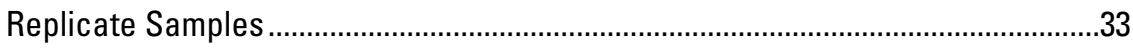

Field-Spiked and Replicate Field-Spiked Samples.................................................38

Laboratory Quality Assurance and Quality-Control Samples.............................................38

Laboratory Spiked Samples ..................................................................................43

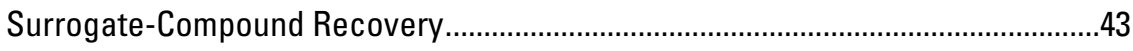

Laboratory-Blind Samples...............................................................................44

Sampling Methods, Chemical Quality, and Particle Size for Suspended Sediment and

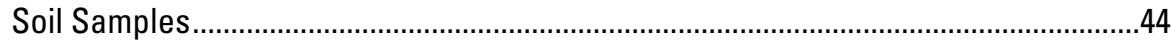

Effectiveness of Sampling Methods for Suspended Sediment........................................4

Automated Collection of Samples of Suspended Sediment, Controlled Experiment................................................................................................... 44 
Automated Collection of Samples of Suspended Sediment, Field Experiment......45

Sample Splitting

Chemical Quality and Particle Size of Suspended Sediment, Soil Samples, and Other Miscellaneous Samples ...............................................................................51

Reference Samples ………….........................................................................

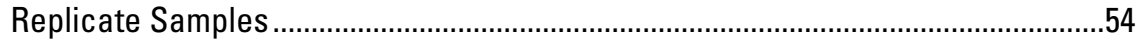

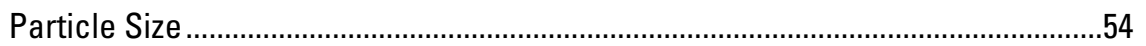

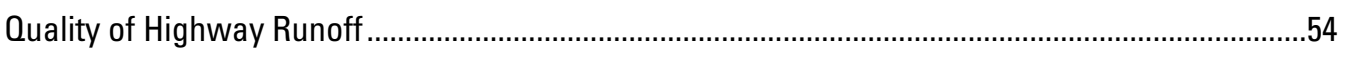

Intrasite Evaluation of Constituents in Samples of Runoff from the Principal Highways.......56

Intersite Evaluation of Constituents in Runoff from Test Highways and Principal

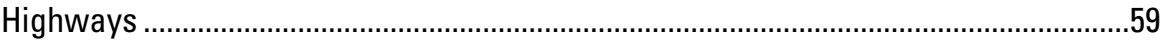

Inter-Site Evaluation of Constituents in Samples of Runoff from the Principal Highways .....65

Relation of Constituents to Annual Average Daily Traffic ..................................................69

Estimated Concentrations of Major Constituents in Road Salt...............................................70

Evaluation of Constituents in Seasonal Samples of Runoff from the Principal Highways .....76

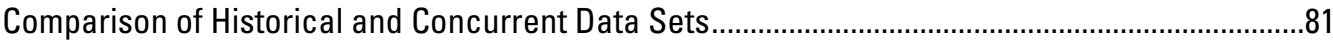

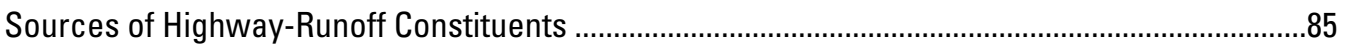

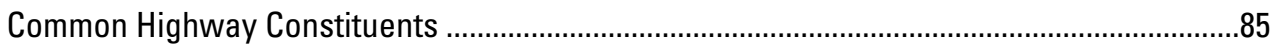

Other Anthropogenic and Natural Organic Compounds .....................................................96

Relations of Concentrations of Selected Elements and Organic Compounds to Suspended

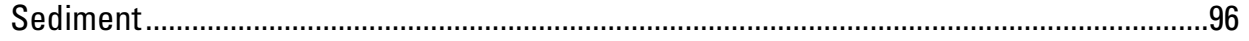

Highway-Runoff Database and Runoff Model Overview ..........................................................101

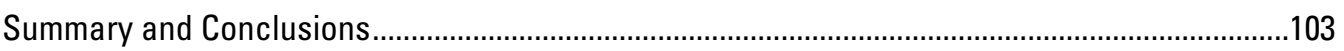

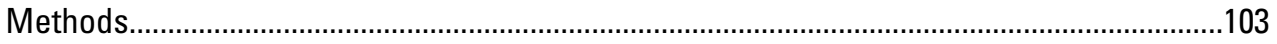

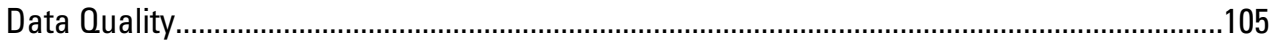

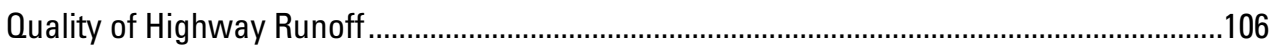

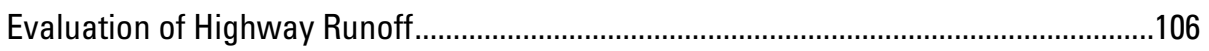

Relation of Constituents to Annual Average Daily Traffic Volume.................................108

Highway Winter Maintenance Materials and Data Seasonality....................................108

Comparison of Historical Data and Concurrent Data Sets ....................................................109

Sources of Highway-Runoff Constituents .......................................................................109

Suspended Sediment as a Surrogate for Highway-Runoff Constituents ..............................110

Highway-Runoff Database .................................................................................................110

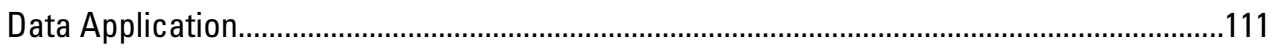

Acknowledgments

References Cited.............................................................................................................111

Appendix 1. Highway-Runoff Database (HRDB Version 1.0.0a).........................................CD-ROM 


\section{Figures}

1. Map of locations of highway-monitoring stations and U.S. Environmental Protection Agency level III ecoregions in Massachusetts ...............................................5

2. Map of locations of highway-monitoring stations and surficial geology of Massachusetts.

3. Photograph showing a catch basin at the highway-monitoring station on Interstate 495 being cleaned by Massachusetts Department of Transportation personnel with a vacuum truck prior to the start of monitoring...

4. Photograph showing a typical highway-monitoring station used to collect measurements of water level, water temperature, air temperature, specific conductance, and rainfall, and composite samples of highway runoff

5. Photograph showing sand debris around a catch basin on Route 2 in Littleton, Massachusetts, that may divert highway runoff to the next downgradient catch basin.

6. Graphs showing $(A)$ percentage of storms for which antecedent dry periods were equaled or exceeded in relation to the antecedent dry periods for storms during which runoff samples were collected from monitoring stations on Route 119, Ashburnham, Massachusetts, 2005-07; $(B)$ percentage of storms for which the event-mean values of specific conductance were calculated from continuous records of flow and specific conductance in relation to specific conductance measured in runoff samples collected from the monitoring stations on Route 119, Ashburnham, Massachusetts, 2005-07 .

7. Graphs showing $(A)$ percentage of storms for which antecedent dry periods were equaled or exceeded in relation to the antecedent dry periods for storms during which runoff samples were collected from monitoring stations on Route 2 in Littleton, Massachusetts, 2005-07; $(B)$ percentage of storms for which the event-mean values of specific conductance were calculated from continuous records of flow and specific conductance in relation to specific conductance measured in runoff samples collected from the monitoring stations on Route 2 in Littleton, Massachusetts, 2005-07.

8. Graphs showing $(A)$ percentage of storms for which antecedent dry periods were equaled or exceeded in relation to the antecedent dry periods for storms during which runoff samples were collected from monitoring stations on Interstate 495 in Boxborough and Bolton, 2005-07; $(B)$ percentage of storms for which the event-mean values of specific conductance were calculated from continuous records of flow and specific conductance in relation to specific conductance measured in runoff samples collected from the monitoring stations on Interstate 495 in Boxborough and Bolton, Massachusetts, 2005-07.

9. Graphs showing $(A)$ percentage of storms for which antecedent dry periods were equaled or exceeded in relation to the antecedent dry periods for storms during which runoff samples were collected from monitoring stations on Interstate 95 in Lexington and Waltham, Massachusetts, 2005-07; (B) percentage of storms for which the event-mean values of specific conductance were calculated from continuous records of flow and specific conductance in relation to specific conductance measured in runoff samples collected from the monitoring stations on Interstate 95 in Lexington and Waltham, Massachusetts, 2005-07.

10. Box plot showing distribution of precipitation totals greater than 0.10 inch recorded by the National Climatic Data Center near Worcester, Massachusetts, and of precipitation totals for storms during which samples were collected at each of the primary highway sites in Massachusetts, 2005-07. 
11. Graph showing results of a statistical resampling experiment indicating uncertainty in the median of event-mean concentrations of suspended sediment using a set of 20 randomly selected sample subpopulations ranging from 3 to 48 samples

12. Photograph showing a static mixer mounted in a cut-out section of 12-inch-diameter plastic pipe

13. Graph showing relation of $(A)$ flow-weighted specific conductance values estimated from continuous records of flow and specific conductance to measured event-mean specific conductance of composite samples of highway runoff collected at 12 monitoring stations on 8 highways for paired events, and $(B)$ relative error between event-mean specific conductance and estimated values of event-mean specific conductance in three ranges.

14. Photographs showing test pipe and sampling equipment (top) where the static mixer assembly was tested; (lower left) looking upstream; and (lower right) turbulence created by the static mixer at the sampler intake location...

15. Bar chart showing sediment particles greater than 0.250 millimeters in diameter collected by an automatic sampler with the intake mounted to a static mixer over a range of artificial flows in relation to the percentage of the total mass of sediment particles greater than 0.250 millimeters in diameter collected at the end of the test pipe.

16. Photograph showing plankton net attached to the outfall of the primary highway-runoff monitoring site on Interstate 495, Boxborough, Massachusetts

17. Photograph showing ruts on the roadway surface running parallel with the road that often caused small flows to bypass the catch basin at the secondary highway-monitoring station on Route 119 in Ashburnham, Massachusetts

18. Boxplots showing distribution of concentrations of selected constituents in samples of soil collected in the vicinity of seven highway-runoff monitoring sites in Massachusetts, 2005-07

19. Graph showing relation of the percentage of impervious area within a 1-mile radius around each of the 12 highway-runoff monitoring sites in Massachusetts to the median concentration of suspended sediment and annual average traffic volumes.....67

20. Boxplots showing concentrations of selected constituents in samples of highway runoff collected at eight highway-monitoring stations in Massachusetts in relation to the annual average daily vehicles per travel lane...

21. Graph showing percentage of event-mean concentrations of chloride estimated from continuous records of specific conductance for 1,381 runoff events from 11 highway-monitoring stations on 7 highways in Massachusetts to measured concentrations of chloride in composite samples of highway runoff...

22. Graph showing probability distribution for loads of chloride estimated from continuous records of specific conductance for 1,381 runoff events from 11 highway-monitoring stations on 7 highways in Massachusetts

23. Photograph showing a snow bank along the guard rail near the highway-monitoring station on Route 119, in Ashburnham, Massachusetts.

24. Bar chart showing concentrations of total-recoverable metals in three particle-size ranges of suspended sediment in samples of highway runoff collected by automatic samplers at the principal highways in Massachusetts, 2005-07 .91

25. Boxplot showing distribution of concentrations of selected constituents measured in samples of berm material from four principal highways and in samples of highway-maintenance sand, and estimated concentrations of berm material derived from samples of suspended-sediment quality and particle size in Massachusetts, 2005-07 
26. Bar chart showing the distribution of concentrations for selected polyaromatic hydrocarbons in two particle-size ranges for suspended sediment in samples of highway runoff collected by automatic samplers at the principal highways in Massachusetts, 2005-07

27. Scatter plot for $(A)$ concentrations of total-recoverable copper in samples of highway runoff collected from eight stations on four highways in Massachusetts in relation to concentrations of total-recoverable copper estimated on the basis of the concentration of total-recoverable copper associated with three particle-size ranges in sediment collected from composite samples of highway runoff and the concentration and particle-size distribution of suspended sediment in the respective samples of highway runoff, and $(B)$ distribution of absolute error between estimated concentrations of total-recoverable copper and measured concentrations of total-recoverable copper in samples of highway runoff, Massachusetts, 2005-07.

28. Pie charts showing the summary of the highway-runoff data including $(A)$ a count of sites, storms, and event-mean concentration values in the database, and the percentage of $(B)$ sites, $(C)$ storm events, and $(D)$ event-mean concentration values in each highway-runoff data set.

29. Scatter plot showing temporal distribution of storm sampling dates for each data set in the highway-runoff database 


\section{Tables}

1. Names, locations, and other highway attributes for U.S. Geological Survey monitoring stations in Massachusetts..

2. Land-use characteristics for a one-half mile radius around each of the 12 highway-monitoring stations in Massachusetts

3. Physical characteristics of, and constituents analyzed in, samples of highway stormwater collected in Massachusetts during 2005-07 with respective long-term method detection limits, analytical techniques, and Chemical Abstract Service numbers.

4. Anthropogenic organic compounds in unfiltered samples of highway runoff determined by solid-phase extraction and capillary-column gas chromatography/mass spectrometry, and respective long-term method detection limits in micrograms per liter and CAS numbers.

5. Theoretical conductance at infinite dilution, regression equation coefficients (equations 4 and 5), the standard error of the estimate, nonparametric coefficients of efficiency, and the median milliequivalent ratio to chloride for major ions in solution measured at highway sites in Massachusetts, 2005-07.

6. Regression equation coefficients and nonparametric coefficients of efficiency for measured specific conductance to concentrations for sodium, calcium, chloride, and sulfate measured in composite samples of highway runoff for 12 sites in Massachusetts, 2005-07

7. Summary for contamination bias expected in 10 percent of samples of highway runoff collected in Massachusetts, 2005-07.

8. Replicate sample statistics for seven organic compounds determined by methylene chloride extraction and gas chromatograph/mass spectrometry analysis and by continuous liquid-liquid extraction and capillary-column gas chromatography/mass spectrometry analysis for 14 samples of highway runoff collected in Massachusetts, 2005-07

9. Recovery statistics for total-recoverable metals, polyaromatic hydrocarbons, and phthalate esters in laboratory-spiked preparation samples, field-spiked samples, and field-replicate-spiked samples and $p$ values for Mann-Whitney tests between laboratory spiked preparation samples and field spiked samples for the study in Massachusetts, 2005-07

10. Recovery statistics for selected natural and anthropogenic organic compounds in laboratory-spiked preparation samples, a single field-spiked sample, and a single replicate field-spiked sample for the study in Massachusetts, 2005-07.

11. Results of field tests of paired samples of suspended sediment greater than $\mathbf{0 . 2 5 0}$ millimeters in diameter in highway runoff collected by a plankton net and an automatic sampler used in conjunction with a static mixer for the total flow-weighted mass of sediment collected at the end of a pipe at the primary station on Interstate 495, in Boxborough, Massachusetts, 2005-07.

12. Concentrations of constituents measured in samples of solids with diameters ranging from 0.250 millimeter to 6.0 millimeters collected from a plankton net at the outfall of the primary station on Interstate 495 in Massachusetts, 2005-07.

13. Means and relative standard deviations for 14 sequential replicate samples analyzed for concentrations of suspended sediment in an experiment to assess the precision of field-splitting methods used in this highway-runoff study in Massachusetts, 2005-07 
14. Median values and relative standard deviations for selected concentrations of total and total-recoverable metals in quality-control samples consisting of National Institute of Standards and Technology standard reference soil.

15. Relative percent differences between 17 replicate pairs for samples of background soils, highway-berm soils, suspended sediment, and other miscellaneous samples collected from and near highways in Massachusetts, 2005-07.

16. Physical properties and concentrations of dissolved major ions, total nutrients, total-recoverable metals, polyaromatic hydrocarbons, phthalate esters, and suspended sediment in stormwater composite samples of highway runoff collected from 12 stations on 8 highways in Massachusetts, 2005-07.

17. Physical properties and concentrations of anthropogenic and natural organic compounds in unfiltered composite samples of highway runoff collected during three storms from five highways in Massachusetts, 2006-07

18. Concentrations of 32 elements and total organic carbon in samples of sieved suspended sediment, highway maintenance sand, road salt, roadside grasses, and dry pine needles collected from four highways in Massachusetts, 2005-07.

19. Distribution of particle sizes and concentrations of 32 elements measured in samples of soil collected near seven highways in Massachusetts, 2005-07

20. Distribution of particle sizes and concentrations of 32 elements measured in samples of berm material collected at the edge of the pavement for four highways in Massachusetts, 2005-07

21. Concentrations of selected polyaromatic hydrocarbons and phthalate compounds in samples of suspended sediment, roadside grasses, and dry pine needles collected from four highways in Massachusetts, 2005-07

22. Resultant $p$ values for Mann-Whitney tests for paired populations of constituent concentrations for highway runoff collected from the primary and secondary stations on four principal highways in Massachusetts, 2005-07

23. Resultant $p$ values for Mann-Whitney tests for paired populations of constituent concentrations in highway runoff collected from three stations on principal highways and four stations on the test highways in Massachusetts, 2005-07

24. Median and interquartile values and resultant $p$ values for Mann-Whitney tests at a 95-percent confidence interval for paired populations of constituent concentrations in highway runoff collected from Interstate 93 in Massachusetts in 1999 through 2000 and 2006 through 2007.

25. Resultant $p$ values for Mann-Whitney tests for paired populations of concentrations of highway-runoff constituents collected from the primary and secondary stations on the four principal highways in Massachusetts, 2005-07

26. Frequency of detection for selected polyaromatic hydrocarbons and phthalate compounds in composite samples of highway runoff collected from the four principal highways at eight sites in Massachusetts, 2005-07

27. Resultant test and $p$ values for Kendall Tau and Spearman Rank correlation tests performed on median values of populations of constituent concentrations in highway runoff and annual average daily traffic volumes for the principal highways in Massachusetts, 2005-07.

28. Selected statistics for populations of concentrations of chloride, sodium, calcium, and sulfate estimated from event-mean values of specific conductance calculated from continuous measurements of flow and specific conductance for the period of record for 11 highway monitoring stations in Massachusetts, 2005-07 
29. The ratio of mean concentrations of total nutrients, total-recoverable metals, and suspended sediment in composite samples of highway runoff collected during winter storms to mean concentrations of the respective constituents in samples collected during non-winter storms for the primary and secondary stations on four principal highways in Massachusetts, 2005-07

30. Resultant $p$ values for single-tail Mann-Whitney tests between paired populations of winter and non-winter concentrations of constituents in highway runoff collected from the primary and secondary stations on the four principal highways in Massachusetts, 2005-07

31. Concentrations of selected constituents measured in a sample of liquid calcium chloride collected at the highway-service depot near Interstate 95, Lexington, Massachusetts and diluted to 3.5 percent by mass and the ratio of the concentration of each constituent to the concentration of chloride..

32. Median of event-mean concentrations and 90-percent confidence interval for selected constituents in samples of highway runoff collected during this study, historical highway studies, and other recent studies for highways with annual average daily traffic volumes of 30,000 to 85,000 vehicles

33. Pearson correlation coefficients for total nutrients, total-recoverable metals, and polyaromatic hydrocarbons in samples of highway runoff collected from Interstate 95 in Lexington and Waltham, Massachusetts, 2005-07.

34. Median ratios between selected polyaromatic hydrocarbons in composites of highway runoff for eight highways in Massachusetts, 2005-07, and ratios for common sources of polyaromatic hydrocarbons found in highway runoff

35. Frequency of detection, frequency of detection greater than or equal to the long-term method detection level, and possible sources of selected anthropogenic and natural organic compounds in 15 composite samples of highway runoff collected at 5 sites in Massachusetts, 2006-07

36. Statistics for concentrations of selected constituents estimated on the basis of the concentration of suspended sediment for three particle-size ranges in 105 samples of highway runoff and for concentrations of the constituents measured in samples of suspended sediment for equivalent particle sizes collected from the principal highways in Massachusetts, and the differences between the estimated concentrations and the measured concentrations in composite samples of highway runoff 


\section{Conversion Factors and Abbreviations}

\begin{tabular}{|c|c|c|}
\hline Multiply & By & To obtain \\
\hline \multicolumn{3}{|c|}{ Length } \\
\hline inch (in.) & 2.54 & centimeter $(\mathrm{cm})$ \\
\hline inch (in.) & 25.4 & millimeter $(\mathrm{mm})$ \\
\hline foot $(\mathrm{ft})$ & 0.3048 & meter $(\mathrm{m})$ \\
\hline mile (mi) & 1.609 & kilometer $(\mathrm{km})$ \\
\hline \multicolumn{3}{|c|}{ Area } \\
\hline square foot $\left(\mathrm{ft}^{2}\right)$ & 929.0 & square centimeter $\left(\mathrm{cm}^{2}\right)$ \\
\hline square foot $\left(\mathrm{ft}^{2}\right)$ & 0.09290 & square meter $\left(\mathrm{m}^{2}\right)$ \\
\hline square inch $\left(\mathrm{in}^{2}\right)$ & 6.452 & square centimeter $\left(\mathrm{cm}^{2}\right)$ \\
\hline square mile $\left(\mathrm{mi}^{2}\right)$ & 259.0 & hectare (ha) \\
\hline square mile $\left(\mathrm{mi}^{2}\right)$ & 2.590 & square kilometer $\left(\mathrm{km}^{2}\right)$ \\
\hline \multicolumn{3}{|c|}{ Volume } \\
\hline gallon (gal) & 3.785 & liter $(\mathrm{L})$ \\
\hline gallon (gal) & 0.003785 & cubic meter $\left(\mathrm{m}^{3}\right)$ \\
\hline gallon (gal) & 3.785 & cubic decimeter $\left(\mathrm{dm}^{3}\right)$ \\
\hline million gallons (Mgal) & 3,785 & cubic meter $\left(\mathrm{m}^{3}\right)$ \\
\hline cubic inch $\left(\right.$ in $\left.^{3}\right)$ & 16.39 & cubic centimeter $\left(\mathrm{cm}^{3}\right)$ \\
\hline cubic inch $\left(\mathrm{in}^{3}\right)$ & 0.01639 & cubic decimeter $\left(\mathrm{dm}^{3}\right)$ \\
\hline cubic inch $\left(\right.$ in $\left.^{3}\right)$ & 0.01639 & liter $(\mathrm{L})$ \\
\hline cubic foot $\left(\mathrm{ft}^{3}\right)$ & 28.32 & cubic decimeter $\left(\mathrm{dm}^{3}\right)$ \\
\hline cubic foot $\left(\mathrm{ft}^{3}\right)$ & 0.02832 & cubic meter $\left(\mathrm{m}^{3}\right)$ \\
\hline \multicolumn{3}{|c|}{ Flow rate } \\
\hline foot per second (ft/s) & 0.3048 & meter per second $(\mathrm{m} / \mathrm{s})$ \\
\hline cubic foot per second $\left(\mathrm{ft}^{3} / \mathrm{s}\right)$ & 0.02832 & cubic meter per second $\left(\mathrm{m}^{3} / \mathrm{s}\right)$ \\
\hline gallon per minute (gal/min) & 0.06309 & liter per second $(\mathrm{L} / \mathrm{s})$ \\
\hline mile per hour $(\mathrm{mi} / \mathrm{h})$ & 1.609 & kilometer per hour $(\mathrm{km} / \mathrm{h})$ \\
\hline \multicolumn{3}{|c|}{ Mass } \\
\hline ounce, avoirdupois (oz) & 28.35 & $\operatorname{gram}(\mathrm{g})$ \\
\hline pound, avoirdupois (lb) & 0.4536 & kilogram $(\mathrm{kg})$ \\
\hline
\end{tabular}

Temperature in degrees Celsius $\left({ }^{\circ} \mathrm{C}\right)$ may be converted to degrees Fahrenheit $\left({ }^{\circ} \mathrm{F}\right)$ as follows:

${ }^{\circ} \mathrm{F}=\left(1.8 x^{\circ} \mathrm{C}\right)+32$

Temperature in degrees Fahrenheit $\left({ }^{\circ} \mathrm{F}\right)$ may be converted to degrees Celsius $\left({ }^{\circ} \mathrm{C}\right)$ as follows:

${ }^{\circ} \mathrm{C}=\left({ }^{\circ} \mathrm{F}-32\right) / 1.8$

Horizontal coordinate information is referenced to the North American Datum of 1983 (NAD 83).

Specific conductance is given in microsiemens per centimeter at 25 degrees Celsius $(\mu \mathrm{S} / \mathrm{cm}$ at $\left.25^{\circ} \mathrm{C}\right)$.

Concentrations of chemical constituents in water are given either in milligrams per liter (mg/L) or micrograms per liter $(\mu \mathrm{g} / \mathrm{L})$. 


$\begin{array}{ll}\text { ABBREVIATIONS AND ACRONYMS } \\ \text { AADT } & \text { Average annual daily traffic } \\ \text { An } & \text { Anthracene } \\ \text { Ba } & \text { Benzo[a]anthracene } \\ \text { Bghi } & \text { Benzo[ghi]perylene } \\ \text { BMP } & \text { Best management practice } \\ \text { Chr } & \text { Chrysene } \\ \text { DOT } & \text { Department of Transportation } \\ \text { EMC } & \text { Event-mean concentration } \\ \text { FI } & \text { Fluoranthene } \\ \text { HRDB } & \text { Highway Runoff Database } \\ \text { Ip } & \text { Indeno[1,2,3-cd]pyrene } \\ \text { LTMDL } & \text { Long-term method detection level } \\ \text { NWOL } & \text { National Water Ouality Laboratory } \\ \text { PAH } & \text { Polyaromatic hydrocarbon } \\ \text { Phe } & \text { Phenanthrene } \\ \text { Py } & \text { Pyrene } \\ \text { RPD } & \text { Relative percent difference } \\ \text { SELDM } & \text { Stochastic Empirical Loading and Dilution Model } \\ \text { SVOC } & \text { Semivolatile organic compound } \\ \text { TOC } & \text { Total organic carbon } \\ \text { USEPA } & \text { U.S. Environmental Protection Agency } \\ \text { USGS } & \text { U.S. Geological Survey } \\ \end{array}$




\title{
Quality of Stormwater Runoff Discharged from Massachusetts Highways, 2005-07
}

\author{
By Kirk P. Smith and Gregory E. Granato
}

\section{Abstract}

The U.S. Geological Survey (USGS), in cooperation with U.S. Department of Transportation Federal Highway Administration and the Massachusetts Department of Transportation, conducted a field study from September 2005 through September 2007 to characterize the quality of highway runoff for a wide range of constituents. The highways studied had annual average daily traffic (AADT) volumes from about 3,000 to more than 190,000 vehicles per day. Highway-monitoring stations were installed at 12 locations in Massachusetts on 8 highways. The 12 monitoring stations were subdivided into 4 primary, 4 secondary, and 4 test stations. Each site contained a 100-percent impervious drainage area that included two or more catch basins sharing a common outflow pipe. Paired primary and secondary stations were located within a few miles of each other on a limited-access section of the same highway. Most of the data were collected at the primary and secondary stations, which were located on four principal highways (Route 119, Route 2, Interstate 495, and Interstate 95). The secondary stations were operated simultaneously with the primary stations for at least a year. Data from the four test stations (Route 8, Interstate 195, Interstate 190, and Interstate 93) were used to determine the transferability of the data collected from the principal highways to other highways characterized by different construction techniques, land use, and geography.

Automatic-monitoring techniques were used to collect composite samples of highway runoff and make continuous measurements of several physical characteristics. Flowweighted samples of highway runoff were collected automatically during approximately 140 rain and mixed rain, sleet, and snowstorms. These samples were analyzed for physical characteristics and concentrations of 6 dissolved major ions, total nutrients, 8 total-recoverable metals, suspended sediment, and 85 semivolatile organic compounds (SVOCs), which include priority polyaromatic hydrocarbons (PAHs), phthalate esters, and other anthropogenic or naturally occurring organic compounds. The distribution of particle size of suspended sediment also was determined for composite samples of highway runoff. Samples of highway runoff were collected year round and under various dry antecedent conditions throughout the 2-year sampling period. In addition to samples of highway runoff, supplemental samples also were collected of sediment in highway runoff, background soils, berm materials, maintenance sands, deicing compounds, and vegetation matter. These additional samples were collected near or on the highways to support data analysis.

There were few statistically significant differences between populations of constituent concentrations in samples from the primary and secondary stations on the same principal highways (Mann-Whitney test, 95-percent confidence level). Similarly, there were few statistically significant differences between populations of constituent concentrations for the four principal highways (data from the paired primary and secondary stations for each principal highway) and populations for test stations with similar AADT volumes. Exceptions to this include several total-recoverable metals for stations on Route 2 and Interstate 195 (highways with moderate AADT volumes), and for stations on Interstate 95 and Interstate 93 (highways with high AADT volumes). Supplemental data collected during this study indicate that many of these differences may be explained by the quantity, as well as the quality, of the sediment in samples of highway runoff.

Nonparametric statistical methods also were used to test for differences between populations of sample constituent concentrations among the four principal highways that differed mainly in traffic volume. These results indicate that there were few statistically significant differences (Mann-Whitney test, 95-percent confidence level) for populations of concentrations of most total-recoverable metals and organic compounds among the stations on the four principal highways. There were significant differences between most populations of concentrations in samples from Route 119 (the highway with the lowest AADT volume) and those from the three principal highways with higher AADT volumes. Nevertheless, the median concentrations and upper interquartile ranges for populations of many total-recoverable metals collected from the 12 stations increased with increasing AADT volume, indicating a positive correlation between the two variables. The frequency of detection for various organic compounds also increased with traffic volume for the four principal highways. Furthermore, results for Kendall's Tau correlation coefficient and Spearman rank correlation coefficient tests indicate that correlations between the median concentrations for total nitrogen $(\mathrm{N})$, total phosphorus $(\mathrm{P})$, all total-recoverable metals, benzo $[a]$ anthracene, 
benzo[b]fluoranthene, fluoranthene, and pyrene to the respective AADT volumes of the eight highways were significantly different at a 95-percent confidence level.

Concentrations of nearly all constituents measured in samples of highway runoff in this study increased substantially during January 2006 through April 2006 and March 2007 through April 2007 compared to the concentrations in samples collected during months without snowfall. Average concentrations of total P, total-recoverable metals, and suspended sediment in samples of highway runoff collected during the winter were about 3 to 11 times the average concentrations observed in samples of non-winter runoff. Results for single-tail MannWhitney tests of nearly all populations of constituents between winter composite samples and non-winter composite samples collected from each principal highway indicate that the winter concentrations were significantly higher at a 99-percent confidence interval. Deicing compounds, which contain trace amounts of total $\mathrm{N}$ and many total-recoverable metals, account for only a small fraction of the difference between winter and non-winter concentrations. Furthermore, results of analyses of 1,381 runoff events indicate that estimated event-mean concentrations (EMCs) of chloride $(\mathrm{Cl})$ in excess of $10,000 \mathrm{mg} / \mathrm{L}$, which would contain relatively marginal amounts of $\mathrm{N}$ and many total-recoverable metals, occurs in less than about 2 percent of the runoff events. Many of the same constituents are associated with sand applied to the highways during the winter. Data from this study indicate that highwaymaintenance sand can account for a substantial amount of the difference between winter and non-winter concentrations of $\mathrm{P}$, iron ( $\mathrm{Fe})$, and manganese ( $\mathrm{Mn})$. For the monitoring stations on Interstate 495, highway maintenance sand was estimated to account for about 94, 38, and 53 percent of the increase in winter EMCs for total $\mathrm{P}, \mathrm{Fe}$, and $\mathrm{Mn}$, respectively.

Results of principal component analysis of all data and data subsets for total-recoverable metals and for PAHs from the principal highways were inconclusive. However, the proportions of most highway constituents originating from likely sources were estimated from the ratios of certain PAH compounds in samples of highway runoff to known ratios of the same PAHs in different matrixes and from ratios of the dominant particulate-associated PAHs to selected elements in exhaust emissions. These analyses indicate that the dominant sources of most PAHs are consistent with automobile emissions. The source for $\mathrm{P}$ and most total-recoverable metals other than copper $(\mathrm{Cu})$ and zinc $(\mathrm{Zn})$ are largely local soils, berm materials, vegetation matter, and maintenance sands, and sources of $\mathrm{Cu}, \mathrm{Zn}$, and many phthalate compounds are likely tire and brake wear. Conservative contributions of $\mathrm{P}, \mathrm{Fe}, \mathrm{Mn}$, nickel $(\mathrm{Ni})$, and lead $(\mathrm{Pb})$ from soils proximate to the highways were estimated to account for on average about 37 percent of the median $P$ concentration, 53 percent of the median Fe concentration, 54 percent of the median Mn concentration, 15 percent of the median Ni concentration, and 44 percent of the median $\mathrm{Pb}$ concentration in samples of highway runoff from the principal highways. Many of the SVOCs that were detected in samples of highway runoff in this study are associated with fuels, lubricants, antifreeze, windshield fluids, and chemical treatments of engine compartments, finish-paint coats, automotive panels, and other vehicle components. However, other SVOCs in the same samples indicate plant materials, tobacco products, wood preservatives, fecal bacteria, and potential leachates from highway litter, including compounds associated with common beverages and personalcare products.

Concentrations of suspended sediment in composite samples of highway runoff were examined as a potential surrogate for concentrations of sediment-affiliated constituents measured in samples of highway runoff. Relations between suspended sediment and total $\mathrm{P}$, and suspended sediment and many total-recoverable metals indicate that it is possible to estimate reasonable planning-level concentrations for many constituents on the basis of the concentration of a constituent affiliated with suspended sediment and from the average gradated concentrations (concentrations that include suspended sediment of specific size ranges) of suspended sediment from the principal highways in this study. For many applications, the average gradated concentrations of suspended sediment from this study may be used in the absence of site-specific data because results of statistical tests of concentrations of suspended sediment among the four principal highways, and between the principal highways and most test highways, were not significantly different, except for Route 119, which had the lowest AADT volume. Relations between gradated concentrations of suspended sediment and concentrations of total $\mathrm{P}$ and many totalrecoverable metals also indicate that a disproportional amount of the concentration for most constituents is associated with fine-grained sediments less than 0.063 millimeters in diameter.

\section{Introduction}

Stormwater discharges from Massachusetts highways can adversely affect the quality of the receiving water and may result in the failure of a water body to meet the Massachusetts surface-water-quality standards. Many studies have shown that stormwater runoff can be a source of suspended solids, nutrients, metals, and polyaromatic hydrocarbons (Kayhanian and others, 2003; Smith, 2002; Breault and Granato, 2000; Davenport, 1990). The variation of contaminants in highway runoff is, however, poorly understood, partly because highway runoff is a complex mix of contaminants from multiple sources, including atmospheric deposition; deposition of local soils and automobile residuals on pavement surfaces, highway-construction residuals, and highway maintenance materials; and other sources. As a result, the quantity of constituents reported and the quality of highway runoff reported in studies may vary by orders of magnitude within a storm and between storms (Smith, 2002; Granato and Smith, 1999; Spangberg and Niemczynowicz, 1992). The wide variation of study results are also caused, at least in part, by inadequate or poorly documented data-collection methods, variation in site characteristics, and limited and out-of-date field data, which can lead to differ- 
ent conclusions about the magnitude of the highway-runoff problem (Transportation Research Board, 1997).

Because little highway-runoff data have been collected in the northeastern United States and because the validity of existing data is questionable (Breault and Granato, 2000), the U.S. Geological Survey (USGS), in cooperation with the Federal Highway Administration and the Massachusetts Department of Transportation, began a study in September 2004 to document the presence of a wide range of constituents in runoff from highways with annual average daily traffic (AADT) volumes ranging from about 3,000 to about 191,000 vehicles per day.

The data presented in this report are integrated in the Highway-Runoff Database (HRDB Version 1.0.0a) (Granato and Cazenas, 2009), which serves as a preprocessor for the Stochastic Empirical Loading and Dilution Model (SELDM) (Granato, 2007). The integration of these data with a technically sound highway-runoff model can be used to guide, substantiate, and support highway planning, design, and maintenance decisions. The study findings may be useful toward meeting total maximum daily load (TMDL) requirements (as outlined by the National Pollutant Discharge Elimination System (NPDES) phase II program) and can aid in the interpretation of local, regional, and national highway-runoff data including flows, concentrations, loads, potential effects on receiving waters, and the potential effectiveness of various best management practices (BMPs).

\section{Purpose and Scope}

This report documents concentrations of selected dissolved major ions, total nitrogen $(\mathrm{N})$ and phosphorus $(\mathrm{P})$, selected total-recoverable metals, suspended sediment, and semivolatile organic compounds (SVOCs) measured in flowweighted composite samples of stormwater collected from typical highway-drainage conveyance structures on eight highways in Massachusetts during a 2-year sampling period. The physiochemical characteristics of samples of highway sediment, highway-berm soil, and local soils adjacent to the highways are described, and the monitoring and sample-collection methods for all data within the report are documented.

The report presents a discussion of the relation between populations of constituent concentration data among the 12 highway-monitoring stations and AADT volumes. The report also presents the methods used to estimate event-mean concentrations (EMCs) of elements used in deicing materials from continuous records of flow and specific conductance, and the methods used to calculate planning-level estimates for various constituents associated with suspended sediment. Concentrations of dissolved major ions, total nutrients, total-recoverable metals and other elements, natural and anthropogenic organic compounds, and suspended sediment in highway runoff, roadside materials, and highway-maintenance materials are presented in tables and illustrations. In addition, an overview is presented of HRDB and SELDM.

\section{Site Selection}

A systematic approach was used to select 12 monitoring locations on 8 highways in Massachusetts. These locations were selected on the basis of published AADT volumes; proximity of sites to each other; similarities in surficial geology, soils, vegetation, and land use as identified by the U.S. Environmental Protection Agency (USEPA) level III ecoregions (U.S. Environmental Protection Agency, 2003); highway and drainage construction; site accessibility and safety; and suitability of sites for hydrologic and meteorologic monitoring, and collection of stormwater samples. The 12 sites were subdivided into 4 primary, 4 secondary, and 4 test sites (table 1). Most of the stormwater samples were collected at the primary and secondary sites, which were located on four principal highways in the eastern region of the State (fig. 1). Paired primary and secondary sites were located within a few miles of each other on a section of highway with limited access to ensure comparable levels of traffic volume and density. Although both the design and operation of the primary and secondary monitoring stations were similar, the monitoring period and number of samples of highway runoff collected at the primary stations were greater than at the secondary stations. Stormwater samples collected at the test sites were used to assess the transferability of the data collected from the principal highways to other highways that have different construction methods, land use, and geography.

The primary- and secondary-monitoring stations were located on Route 119 in Ashburnham (424209071545201 and 42415507154320); Route 2 in Littleton (423027071291301 and 423027071291302); Interstate 495 in Boxborough (422821071332001) and Bolton (422716071343901); and Interstate 95 in Lexington (422620071153301) and Waltham (422420071153302). The monitoring locations on these highways represent relatively low, moderate, high, and very high AADT volumes, respectively (table 1). These sites were chosen in part by analyzing available traffic volumes compiled by the Massachusetts Department of Transportation (DOT) (2007) . Because the EMCs of constituents attributed to vehicular wear and operation are functions of traffic volume, density, and the amount of stormwater, which is directly related to amount of highway-surface area, the number of lanes for each highway also was considered along with the AADT during the site selection. Therefore, normalized AADT volumes (AADT divided by the total number of lanes) that were each incrementally different by about 30 percent or more also were used for site selection.

The proximity of the sampling stations on the principal highways was an additional factor in site selection because the quality of highway runoff can be affected by atmospheric deposition, the composition of soils adjacent to the highways, and land-use characteristics. To determine whether populations of concentrations of highway-related constituents were significantly different between highways with different AADTs, it was important to choose sites that were close enough to 
Table 1. Names, locations, and other highway attributes for U.S. Geological Survey monitoring stations in Massachusetts.

[USGS, U.S. Geological Survey; latitude and longitude: in degrees and decimal minutes; ADT, average daily traffic (values in parenthesis represent year of measurement); MPH, miles per hour; NA, not applicable; MTC, modified top course; T1TC, type one top course; OGFC, open-grade friction course; traffic volume source: Massachusetts Department of Transportation, 2007]

\begin{tabular}{|c|c|c|c|c|c|c|c|c|}
\hline $\begin{array}{l}\text { USGS station } \\
\text { number }\end{array}$ & Highway & Town or city & $\begin{array}{c}\text { Site } \\
\text { designation }\end{array}$ & Annual ADT & $\begin{array}{c}\text { Annual ADT } \\
\text { per lane }\end{array}$ & $\begin{array}{c}\text { Number of } \\
\text { the total } \\
\text { lanes } \\
\text { monitored }\end{array}$ & Latitude & Longitude \\
\hline 424209071545201 & Route 119 & Ashburnham & Primary & $3,000(2004)$ & 1,500 & 2 of 2 & 4242.155 & 7154.867 \\
\hline 423027071291301 & Route 2 & Littleton & Primary & $39,700(2004)$ & 9,923 & 2 of 4 & 4230.448 & 7129.223 \\
\hline 422821071332001 & Interstate 495 & Boxborough & Primary & $81,900(2006)$ & 13,650 & 3 of 6 & 4228.351 & 7133.333 \\
\hline 422620071153301 & Interstate 95 & Lexington & Primary & $154,500(2006)$ & 19,313 & 8 of 8 & 4226.337 & 7115.554 \\
\hline 424155071543201 & Route 119 & Ashburnham & Secondary & 3,000 (2004) & 1,500 & 1 of 2 & 4241.917 & 7154.527 \\
\hline 423027071291302 & Route 2 & Littleton & Secondary & $39,693(2004)$ & 9,923 & 2 of 4 & 4230.448 & 7129.223 \\
\hline 422716071343901 & Interstate 495 & Bolton & Secondary & $81,900(2006)$ & 13,650 & 2 of 4 & 4227.267 & 7134.645 \\
\hline 422420071153302 & Interstate 95 & Waltham & Secondary & $180,600(2000)$ & 22,576 & 2 of 8 & 4224.341 & 7115.553 \\
\hline 424019073062601 & Route 8 & North Adams & Test & $15,532(2006)$ & 3,883 & 4 of 4 & 4240.317 & 7306.433 \\
\hline 414339070462201 & Interstate 195 & Marion & Test & $25,700(2006)$ & 6,425 & 2 of 4 & 4143.65 & 7046.367 \\
\hline 423016071431501 & Interstate 190 & Leominster & Test & $41,168(2004)$ & 10,292 & 2 of 4 & 4230.275 & 7143.250 \\
\hline 421647071024703 & Interstate 93 & Boston & Test & 191,000 (2004) & 23,874 & 8 of 8 & 4216.78 & 7102.78 \\
\hline $\begin{array}{l}\text { USGS Station } \\
\text { number }\end{array}$ & Highway & \multicolumn{2}{|c|}{$\begin{array}{l}\text { Drainage area } \\
\text { (square feet) }\end{array}$} & $\begin{array}{l}\text { osted speed } \\
\text { limit } \\
\text { (MPH) }\end{array}$ & $\begin{array}{l}\text { Paved } \\
\text { median }\end{array}$ & \multicolumn{2}{|c|}{$\begin{array}{l}\text { Age of pavement } \\
\text { at start of study } \\
\text { (years) }\end{array}$} & $\begin{array}{l}\text { avement } \\
\text { type }\end{array}$ \\
\hline 424209071545201 & Route 119 & \multicolumn{2}{|c|}{26,000} & 50 & NA & 15 & & MTC \\
\hline 423027071291301 & Route 2 & \multicolumn{2}{|c|}{11,500} & 55 & Yes & 15 & & MTC \\
\hline 422821071332001 & Interstate 495 & \multicolumn{2}{|c|}{16,600} & 65 & No & 21 & & T1TC \\
\hline 422620071153301 & Interstate 95 & \multicolumn{2}{|c|}{31,500} & 55 & No & \multicolumn{2}{|l|}{5} & OGFC \\
\hline 424155071543201 & Route 119 & \multicolumn{2}{|c|}{13,800} & 50 & NA & 15 & & MTC \\
\hline 423027071291302 & Route 2 & \multicolumn{2}{|c|}{13,590} & 55 & Yes & 15 & & MTC \\
\hline 422716071343901 & Interstate 495 & \multicolumn{2}{|c|}{17,900} & 65 & No & 21 & & T1TC \\
\hline 422420071153302 & Interstate 95 & \multicolumn{2}{|c|}{12,700} & 55 & No & 12 & & MTC \\
\hline 424019073062601 & Route 8 & \multicolumn{2}{|c|}{23,500} & 50 & No & 13 & & T1TC \\
\hline 414339070462201 & Interstate 195 & \multicolumn{2}{|c|}{12,400} & 65 & No & 18 & & T1TC \\
\hline 423016071431501 & Interstate 190 & \multicolumn{2}{|c|}{25,100} & 65 & No & 0 & & OGFC \\
\hline 421647071024703 & Interstate 93 & \multicolumn{2}{|c|}{64,500} & 55 & No & 13 & & OGFC \\
\hline
\end{tabular}




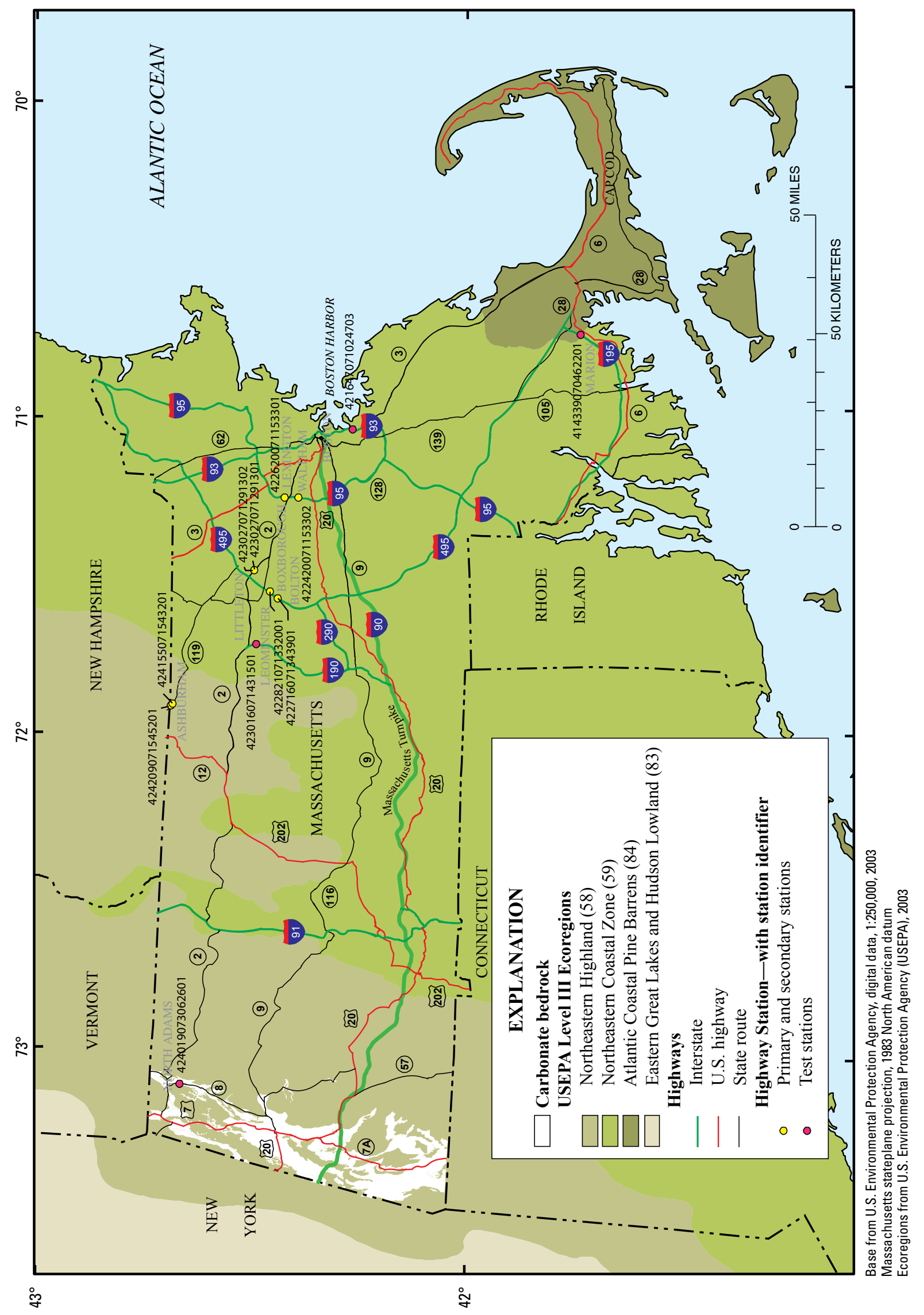

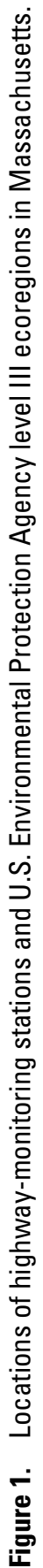


each other that these attributes (atmospheric deposition, soils, and land use) were broadly similar so that a practical level of experimental control could be achieved. As a result, all of the primary and secondary monitoring stations were located within a 38-mi swath in eastern Massachusetts and were located in or near USEPA level III Northeastern Coastal Zone ecoregion 59 (fig. 1) in areas consisting of sand and gravel, till, or bedrock (fig. 2).

USEPA level III ecoregions are areas that are similar in geology, physiography, vegetation, climate, soils, land use, wildlife, and hydrology (Griffith and others, 1999). Massachusetts contains three level III ecoregions. These include ecoregion 58 (Northeastern Highlands), 59 (Northeastern Coastal Zone), and 84 (Atlantic Coastal Pine Barrens) (fig. 1). In general, ecoregion 58 is more mountainous and less populated than ecoregions 59 and 84 . The climate, surficial geology, soils, vegetation, and physiography of ecoregion 84 are much different than those of ecoregions 58 and 59.

The highway attributes for the primary and secondary monitoring stations are relatively similar (table 1). The impervious drainage areas for these sites range from about 13,000 to $31,000 \mathrm{ft}^{2}$. Posted speed limits range from 50 to $65 \mathrm{mi} / \mathrm{h}$. The age of the pavement for the principal highways ranged from 5 to 21 years. The wearing surface for all highways, including the highways where the test sites were located, was constructed of bituminous concrete; however, the type of pavement surface varied among sites. Type I- 1 top course and modified top course are standard wearing surfaces composed of a mix of a specific blend and gradation of aggregates with bituminous cement. The primary difference between the two types of pavement is the gradation of the aggregates used in the mix. The gravel in aggregates used in a modified top course is slightly coarser (95-100 percent of the gravel had a diameter less than or equal to $0.75 \mathrm{in}$.) than the gravel used in a type I-1 course (a diameter of 0.5 in.). Open-grade friction course (OGFC), also referred to as "popcorn pavement," is a more permeable surface than the other types; the macrotexture of the OGFC pavement facilitates the drainage of water from the tire-pavement interface to improve tire contact with the pavement and reduce the potential for hydroplaning (U.S. Department of Transportation Federal Highway Administration, 1990). In general, the dominant land uses surrounding the monitoring stations on the principal highways are forested and residential (table 2). However, the amount of surrounding impervious area increased with the highway AADT because the larger highways are in areas that contain more residential, commercial, industrial, and other transportation-related land uses than highways with lower AADTs.

The tests sites were located on Route 8 in North Adams (424019073062601), Interstate 195 in Marion (414339070462201), Interstate 190 in Leominster (423016071431501), and Interstate 93 in Boston (421647071024703; fig. 1). Some of the characteristics of the test sites were similar to those of the primary and secondary monitoring stations with similar AADTs (tables 1 and 2); however, at least one explanatory variable at each of the test sites differed from that of the corresponding sites on the principal highways. These explanatory variables for a site include one or more of the following categories: pavement age, surficial geology, land use, and climate. The site on Route 8 in western Massachusetts is similar to the sites on Route 119. The site on Route 8 was selected because the chemistry of local soils was often reflected in the runoff chemistry, and a distinguishing feature of this part of western Massachusetts is the carbonate bedrock, which affects the soil characteristics of this area. The test site on Interstate 190 had similar AADT volume, land-use characteristics, and surficial geology to the sites on Route 2 . The Interstate 190 site was selected because this section of Interstate 190 was resurfaced at the start of the study period and, therefore, provided a unique opportunity to compare samples of highway runoff collected from new OGFC pavement to those collected from aged pavement in a similar setting. The third test site was located on Interstate 195 near the coast in southeastern Massachusetts. This site had AADT volume and land-use characteristics similar to those at the sites on Route 2 (tables 1 and 2). This site was selected because the surficial materials there consist largely of sand whereas those at the sites on Route 2 consist mostly of till or bedrock (fig. 2). This location also has a slightly milder climate than elsewhere in Massachusetts, and the quality of precipitation may be affected as a result of the proximity to the coast. A milder climate may affect the level and duration of winter maintenance activities, and coastal precipitation can differ in concentrations of various constituents, including $\mathrm{N}$ and chloride (Cl) (National Atmospheric Deposition Program, 2008). The last test site is on Interstate 93 in Boston. Although this site has an AADT volume similar to those at the sites on Interstate 95, the highway site is located in a highly urbanized area near the Boston Harbor. Thus, the quality of highway runoff also may be affected by differences in precipitation, in addition to differences in land use.

The suitability for hydrologic and meteorologic monitoring and for the collection of water-quality samples was the final factor in the selection of each site. Each site contained a well-defined 100-percent impervious drainage area. At each site, the drainage area encompassed the entire cross section of each highway in one or both directions, with the exception of the secondary site on Interstate 95 . The sites selected in this study do not contain or receive drainage from the median strip, emergency pull-off areas, driveways, or parking lots. These features ultimately reduce chemical and hydrologic bias associated with local soil chemistry and extraneous drainages not characteristic of stormwater runoff from highways. In this study, all samples of stormwater were collected from the outlets of catch basins because these are commonly used along Massachusetts highways, provide a physical means for metering flows during storms, and are often the final discharge points to receiving water bodies. 


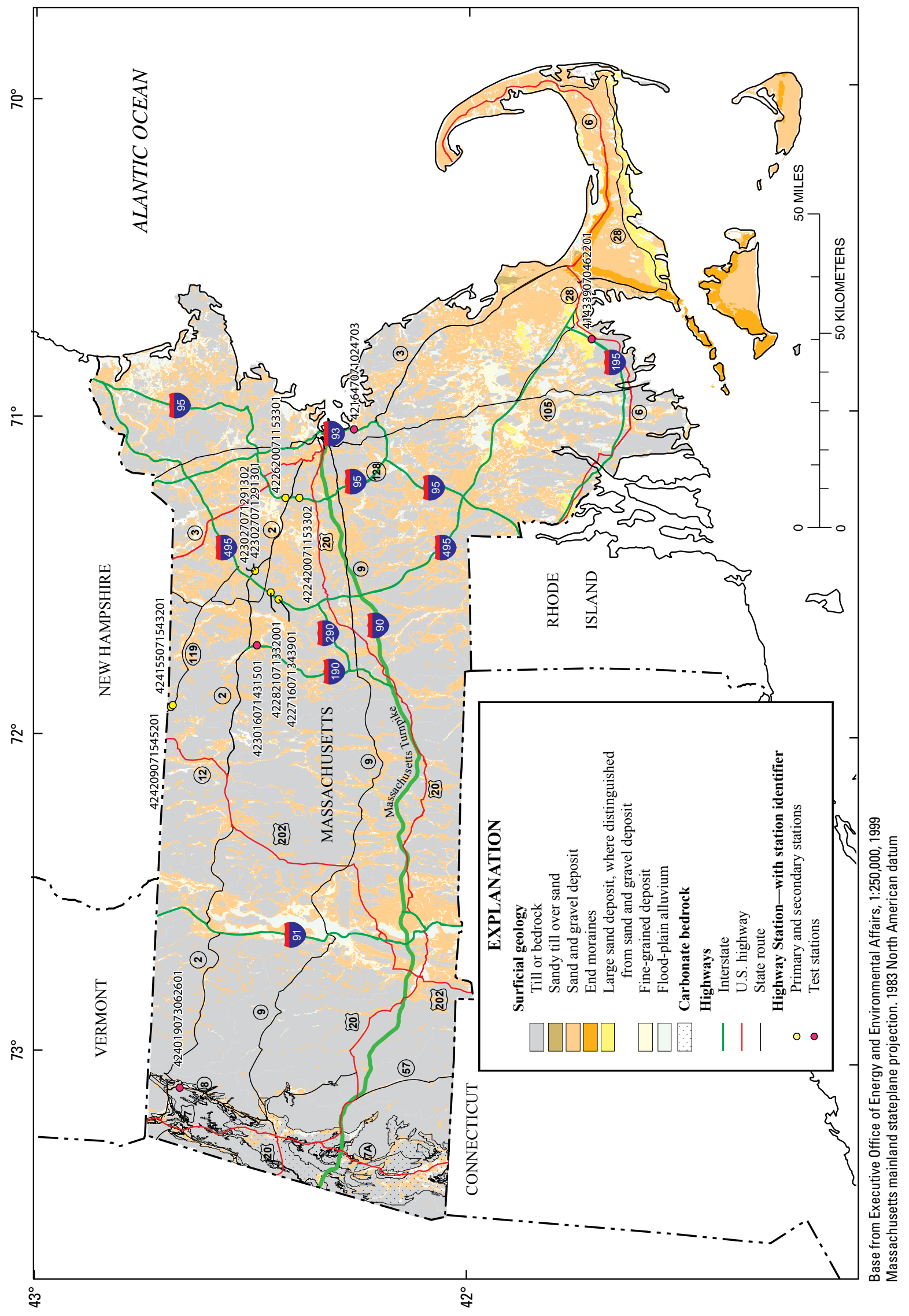

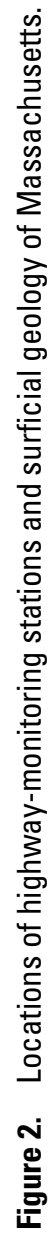


Table 2. Land-use characteristics for a one-half mile radius around each of the 12 highway-monitoring stations in Massachusetts.

[Land use and total impervious area are expressed as percentages of the total area; Data source: Massachusetts GIS Land Use (1951-99) - January 2002 accessed on March 9, 2009, at http://www.mass.gov/mgis/lus.htm]

U.S. Geological Survey station number and highway

\begin{tabular}{|c|c|c|c|c|c|c|}
\hline \multirow[t]{2}{*}{ Surrounding land use } & 424209071545201 & 424155071543201 & 424019073062601 & 423027071291301 & 423027071291302 & 423016071431501 \\
\hline & Route 119 & Route 119 & Route 8 & Route 2 & Route 2 & Interstate 190 \\
\hline Cropland & 0.0 & 0.0 & 20.2 & 4.0 & 4.0 & 0.0 \\
\hline Forest & 85.6 & 91.6 & 44.7 & 69.3 & 69.3 & 64.5 \\
\hline Industrial & 0.0 & 0.0 & 0.0 & 0.0 & 0.0 & 0.0 \\
\hline Open land & 2.7 & 2.1 & 9.2 & 1.0 & 1.0 & 4.2 \\
\hline Other transportation & 0.0 & 0.0 & 0.3 & 4.5 & 4.5 & 8.6 \\
\hline $\begin{array}{l}\text { Parks, cemeteries, vacant } \\
\text { undeveloped land }\end{array}$ & 0.6 & 0.6 & 14.3 & 0.2 & 0.2 & 0.0 \\
\hline Participation recreation & 0.0 & 0.0 & 0.0 & 0.0 & 0.0 & 3.2 \\
\hline Salt wetland & 0.0 & 0.0 & 0.0 & 0.0 & 0.0 & 0.0 \\
\hline Water (fresh and (or) salt) & 4.5 & 0.4 & 1.5 & 0.0 & 0.0 & 1.7 \\
\hline Wetland & 6.1 & 4.4 & 0.0 & 9.3 & 9.3 & 1.2 \\
\hline Total impervious area & 1.1 & 1.1 & 11.2 & 6.0 & 6.0 & 13.1 \\
\hline
\end{tabular}

U.S. Geological Survey station number and highway

\begin{tabular}{|c|c|c|c|c|c|c|}
\hline \multirow[t]{2}{*}{ Surrounding land use } & 414339070462201 & 422821071332001 & 422716071343901 & 422620071153301 & 422420071153302 & 421647071024703 \\
\hline & Interstate 195 & Interstate 495 & Interstate 495 & Interstate 95 & Interstate 95 & Interstate 93 \\
\hline Cropland & 0.0 & 1.5 & 1.4 & 1.2 & 0.0 & 0.0 \\
\hline Forest & 42.3 & 49.1 & 68.7 & 34.7 & 13.2 & 0.5 \\
\hline Industrial & 0.7 & 3.4 & 0.0 & 0.0 & 25.2 & 12.8 \\
\hline Open land & 2.0 & 1.4 & 1.1 & 6.1 & 2.5 & 5.2 \\
\hline Other transportation & 12.5 & 8.1 & 8.0 & 12.4 & 6.0 & 13.8 \\
\hline $\begin{array}{l}\text { Parks, cemeteries, vacant } \\
\text { undeveloped land }\end{array}$ & 0.8 & 0.0 & 2.9 & 0.3 & 0.0 & 6.6 \\
\hline Salt wetland & 0.5 & 0.0 & 0.0 & 0.0 & 0.0 & 12.1 \\
\hline Water (fresh and (or) salt) & 0.0 & 2.1 & 0.0 & 6.7 & 40.5 & 19.9 \\
\hline Wetland & 3.7 & 16.2 & 0.6 & 2.1 & 0.7 & 0.0 \\
\hline Total impervious area & 10.1 & 6.3 & 5.3 & 18.5 & 28.6 & 41.4 \\
\hline
\end{tabular}




\section{Methods}

This section includes a description of the design of each highway-monitoring station and the collection and analysis methods used for samples of highway runoff, sediment transported in highway runoff, background soils, berm soils, and other miscellaneous samples.

\section{Continuous Monitoring of Highway Drainage Systems}

Automatic monitoring equipment was used extensively to make continuous measurements of several physical characteristics and to collect composite samples of highway runoff. The primary monitoring stations and the monitoring station on Interstate 190 were operated from about April 2005 through September 2007, and secondary monitoring stations were operated for a year or more during the same period. The monitoring stations on the remaining three test sites were operated from December 2005 through July 2007. Prior to the monitoring period, the catch basins within the drainage area of each site were drained and cleaned with a vacuum truck (fig. 3). Runoff coefficients were calculated, in part, to determine practical flow thresholds for triggering the automatic samplers. Samples of highway runoff were collected by the automatic samplers on a flow-weighted basis. Finally, continuous records of flow and specific conductance were used to calculate an event-mean value for specific conductance for each storm.

\section{Design of Highway-Drainage Monitoring Systems}

The design of the monitoring stations at the primary and test sites was identical. These sites contained sensors for the measurement of water level, water temperature, specific conductance, air temperature, and rainfall. The secondary monitoring stations were similarly equipped; however, these sites did not contain sensors for measuring air temperature or rainfall. Measurements of water levels were made in order to estimate flow. Water temperature was measured to correct conductivity values to $25^{\circ} \mathrm{C}$. Precipitation was measured to estimate the total runoff for the drainage area of each station. Air temperature was measured to determine whether the precipitation was rain or snow. Prior to the installation of equipment in monitoring shelters, all equipment was tested under controlled conditions at the USGS Massachusetts Water Science Center. Water-level sensors were tested in a stand-pipe assembly where the water level was artificially manipulated in the expected operational range, temperature sensors were tested in a water bath, specific conductance sensors were tested against laboratory standards in the range of 50 to $50,000 \mu \mathrm{S} / \mathrm{cm}$, and rain gages were volumetrically tested.

Monitoring equipment was installed in small shelters, most measuring $2 \times 2 \times 4 \mathrm{ft}$ and located near the highway drainage outfall and along the highway shoulder. The monitoring shelter was used to house the datalogger (the measurement, control, and data-storage module), a digital modem, 12-volt power supply, solar regulator, and the automatic sampler. The assembly of a typically equipped monitoring station is shown in figure 4. Conductivity and water temperature probes were mounted inside each discharge pipe. A submersible water-level probe was mounted below the outlet in the most downstream catch basin or behind a volumetric weir mounted in the catch basin outlet. The submersible water-level probe was mounted within a perforated 3 -in. diameter acrylic tube designed to minimize water-level fluctuations resulting from water falling in the catch basin. The air temperature sensor and tipping-bucket rainfall gage were mounted on a mast attached to the shelter and about 10 to $12 \mathrm{ft}$ above ground surface to reduce bias from vehicular spray.

Each monitoring installation was programmed to record measurements every minute. Baseline data (data that are recorded regardless of the state of runoff), including water level, water temperature, specific conductance, and rainfall, were recorded every 2 hours. Average air temperature was computed from 60 consecutive 1-minute measurements and recorded every hour. Water level, water temperature, specific conductance, and rainfall were recorded on a 1-minute basis whenever the water level exceeded a water-level threshold or when rainfall was measured. Recorded values were retrieved automatically on a daily basis by a computer at the USGS Massachusetts Water Science Center. The telemetry at each site allowed for remote activation of the sampling algorithm and access to measured and recorded values.

\section{Calculation of Discharge}

Discharge from the catch basins was calculated by applying a stage-discharge relation specific to the geometry of the outlet of each catch basin to continuous water-level measurements recorded in the sump of the catch basin. For sites where calibrated weirs were not used, this relation was developed by simultaneously measuring pump flow with in-line flowmeters on as many as three 9,600-gal/h centrifugal pumps and measuring catch-basin-sump level. Paired stage and discharge values were recorded after both pump flow and catch-basin-sump level were stable across a range of pumping rates. This process was repeated until all of the pumps reached their maximum rate of flow. The stage-discharge relations were based on 20 or more discrete discharge measurements and were mathematically extended above the greatest flow rate (about $0.85 \mathrm{ft}^{3} / \mathrm{s}$ ) on the basis of research performed by Lager and others (1977). Depending on the specific site, 80 to 100 percent of the recorded peak discharges were less than $0.85 \mathrm{ft}^{3} / \mathrm{s}$.

\section{Calculation of Runoff Coefficients}

A runoff coefficient is the ratio of the volume of runoff to the volume of rainfall. Runoff coefficients for each event in 


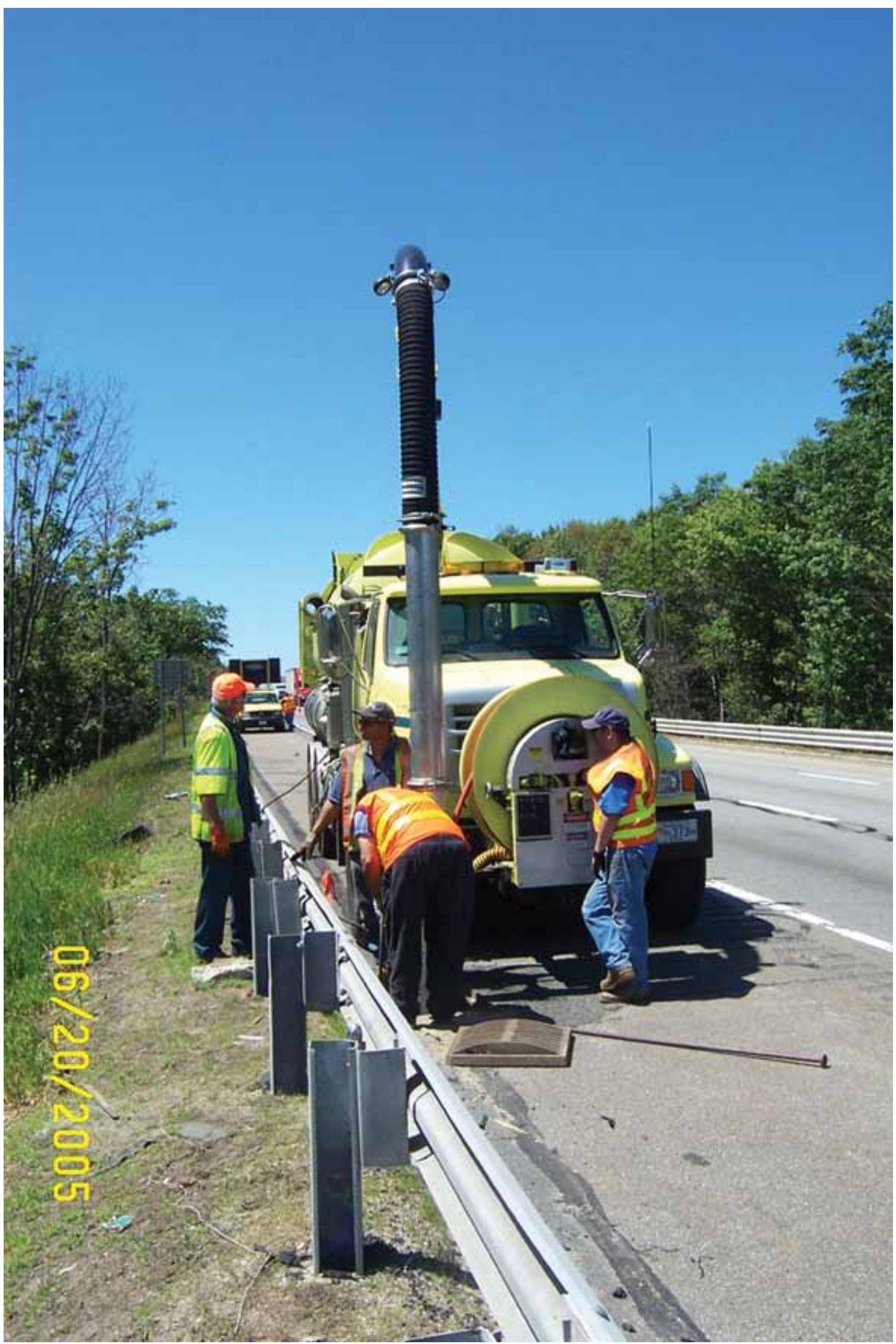

Figure 3. A catch basin at the highway-monitoring station on Interstate 495 being cleaned by Massachusetts Department of Transportation personnel with a vacuum truck prior to the start of monitoring. 


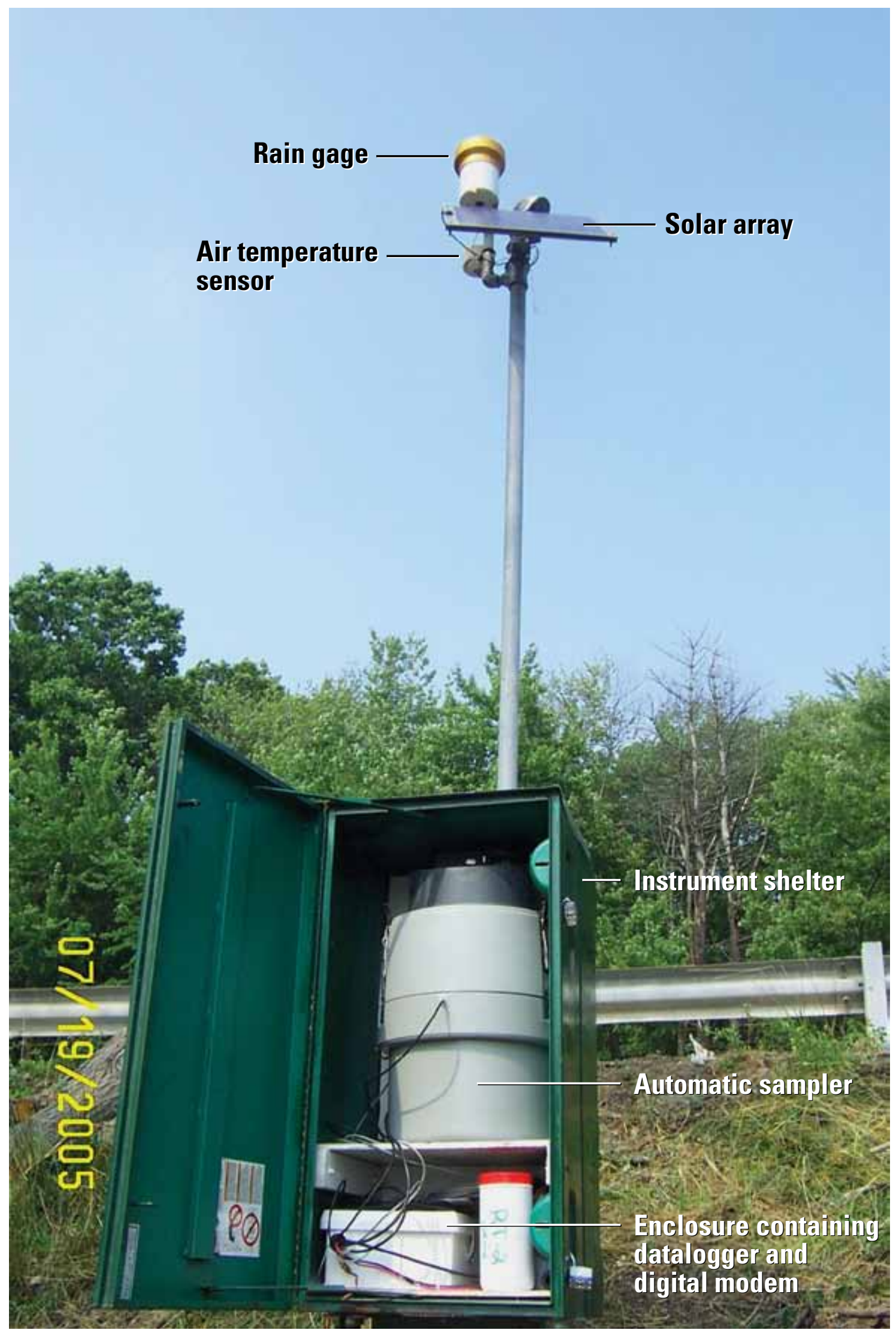

Figure 4. A typical highway-monitoring station used to collect measurements of water level, water temperature, air temperature, specific conductance, and rainfall, and composite samples of highway runoff. 
this study were calculated by dividing the sum of all 1-minute flows with instantaneous discharges greater than $0.009 \mathrm{ft}^{3} / \mathrm{s}$ by the product of the measured rain total and the drainage area for each respective monitoring station. These runoff coefficients were helpful in selecting appropriate flow thresholds for triggering the automatic samplers and identifying potential errors related to measurements of rainfall or water level. Ideally, the ratio of the volume of runoff to the volume of rainfall will range from zero (no runoff) to one (100 percent of the precipitation is measured in the runoff); however, runoff coefficients can exceed a value of one as a result of errors in the measurement of precipitation, flow, and (or) contributing area (Church and others, 1999). Runoff coefficients greater than one also can occur when flow from an upgradient drainage area is diverted into the drainage area of interest. This often results when the inlet of one or more upgradient catch basins is partially blocked by deposits of sand, debris, or slush around the catch-basin grate (fig. 5). In such cases, some or all of the water from a neighboring drainage area can be diverted to a downgradient drainage system. Similarly, obstructions to the inlet of catch basins in the monitored drainage area result in low runoff coefficients. Runoff coefficients also can be decreased when stormwater that leaks from the drainage area as a result of highway curbs that are too low or damaged is not measured. The point in the drainage system where runoff flow is measured also can affect these ratios. In this study, flows were measured at the outlet of the catch basins. Because runoff water leaked from the sump of many catch basins between storms (particularly the sites of Route 2 and Interstate 495), the initial volume of runoff that was required to fill the catch basin to the level of the outlet pipe was not measured. Runoff coefficients can vary more during the winter months on the basis of available snowmelt water. In mixed precipitation events, the removal of snow or slush from plowing operations serves to lower the runoff coefficient.

In large drainage areas, many of these factors tend to average out. For example, flow that bypasses one catch basin often is accounted for in the next downgradient catch basin, resulting in a zero net loss measurement of stormwater volume. However, because the drainage areas in this study are relativity small, a large amount of variability in the runoff coefficients is not unreasonable. While runoff coefficients are an important quality-assurance tool, they are also useful for estimating constituent loads in the absence of flow data. Specifically, flows can be estimated by multiplying the amount of precipitation from a nearby monitoring station by the size of the drainage area of interest, and finally by the runoff coefficient.

\section{Calculation of Event-Mean Values of Specific Conductance}

Specific conductance is the measure of the capacity of water to conduct an electrical current. The measurement is affected by the type and quantity of dissolved solids in water.
Because conductivity sensors are robust and measurements of specific conductance are often relatively accurate under most conditions, continuous records of discharge and specific conductance were used in this study to supplement and expand the number of event-mean measurements of the physical characteristics of samples of highway runoff.

Event-mean specific conductance values were calculated for each highway site on the basis of calculated values of discharge and corresponding measurements of specific conductance. Specifically, for each runoff event (rain, mixed precipitation, and snowmelt) with instantaneous values of discharge greater than $0.009 \mathrm{ft}^{3} / \mathrm{s}$, the event-mean specific conductance was calculated by dividing the sum of flow-weighted 1-minute specific conductance values (that is, the specific conductance multiplied by the instantaneous rate of flow) by the sum of the 1-minute values of flow. For values of discharge less than or equal to $0.009 \mathrm{ft}^{3} / \mathrm{s}$, measurements of specific conductance were often erroneous because the water level at the location of measurement was too low to adequately submerse the sensor. Furthermore, flows less than or equal to $0.009 \mathrm{ft}^{3} / \mathrm{s}$ accounted for little of the total event flow. The accuracy of measurements of specific conductances depend primarily on the rate of sensor drift, sensor fouling, and debris collection. In most cases, corrections for fouling and drift were applied to the data to improve the accuracy (Wagner and others, 2006). These corrections were made on the basis of the performance of the sensor before and after sensor maintenance and by the response of the clean sensor after it was placed in three or more standardized conductance solutions in the field.

\section{Collection and Analysis of Samples}

Samples of highways runoff were collected automatically during storms and analyzed for concentrations of selected dissolved major ions, total $\mathrm{N}$ and $\mathrm{P}$, selected total-recoverable metals, suspended sediment, and SVOCs (tables 3 and 4). Samples of sediment in highway runoff were sieved into specific particle-size ranges, and analyzed for concentrations of 32 total-recoverable elements, total organic carbon (TOC), and selected SVOCs. Samples of soil adjacent to the highways, samples of highway-berm soil, and samples of highway-maintenance materials were collected and analyzed for concentrations of 32 elements. Finally, miscellaneous samples of highway-berm vegetation and catch-basin debris greater than 250 micrometers in diameter were collected and analyzed for concentrations of 32 total-recoverable elements, TOC (catch-basin debris only), and selected SVOCs (highway-berm vegetation only).

\section{Samples of Highway Runoff}

About 140 flow-weighted composite samples of highway runoff were collected automatically throughout the year during rain and mixed precipitation storms from September 2005 to September 2007 at the 12 monitoring stations. 


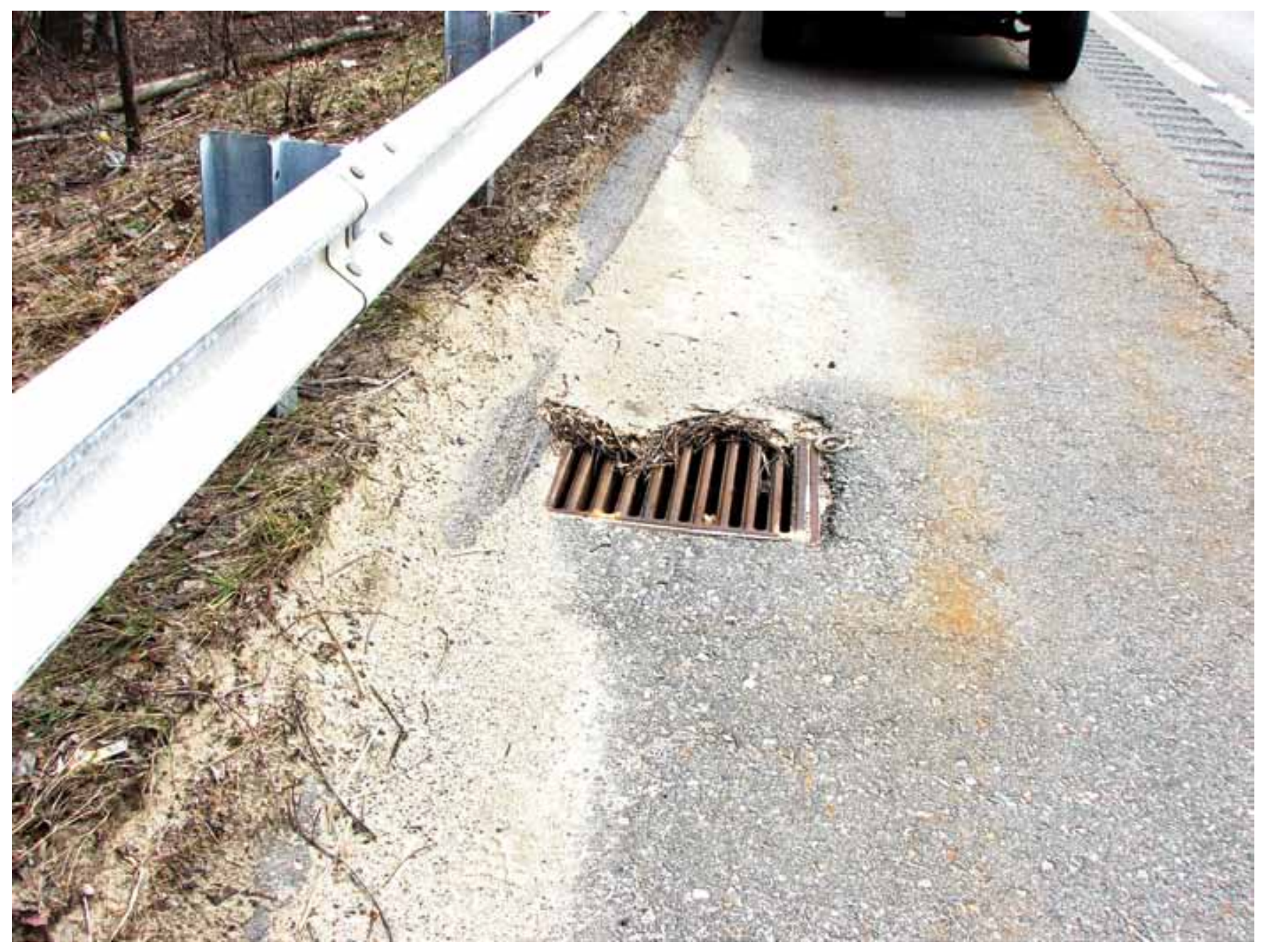

Figure 5. Sand debris around a catch basin on Route 2 in Littleton, Massachusetts, that may divert highway runoff to the next downgradient catch basin. 


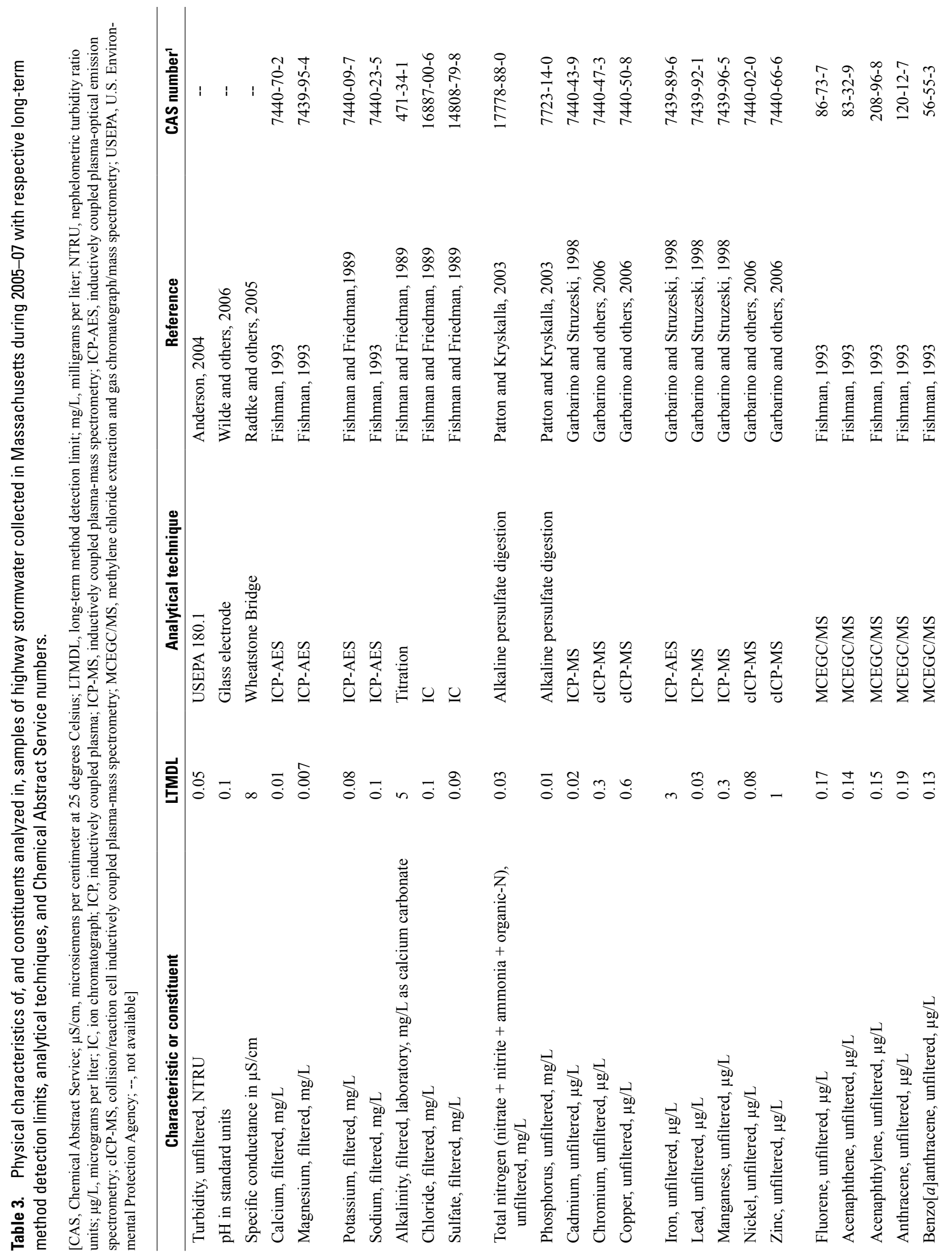




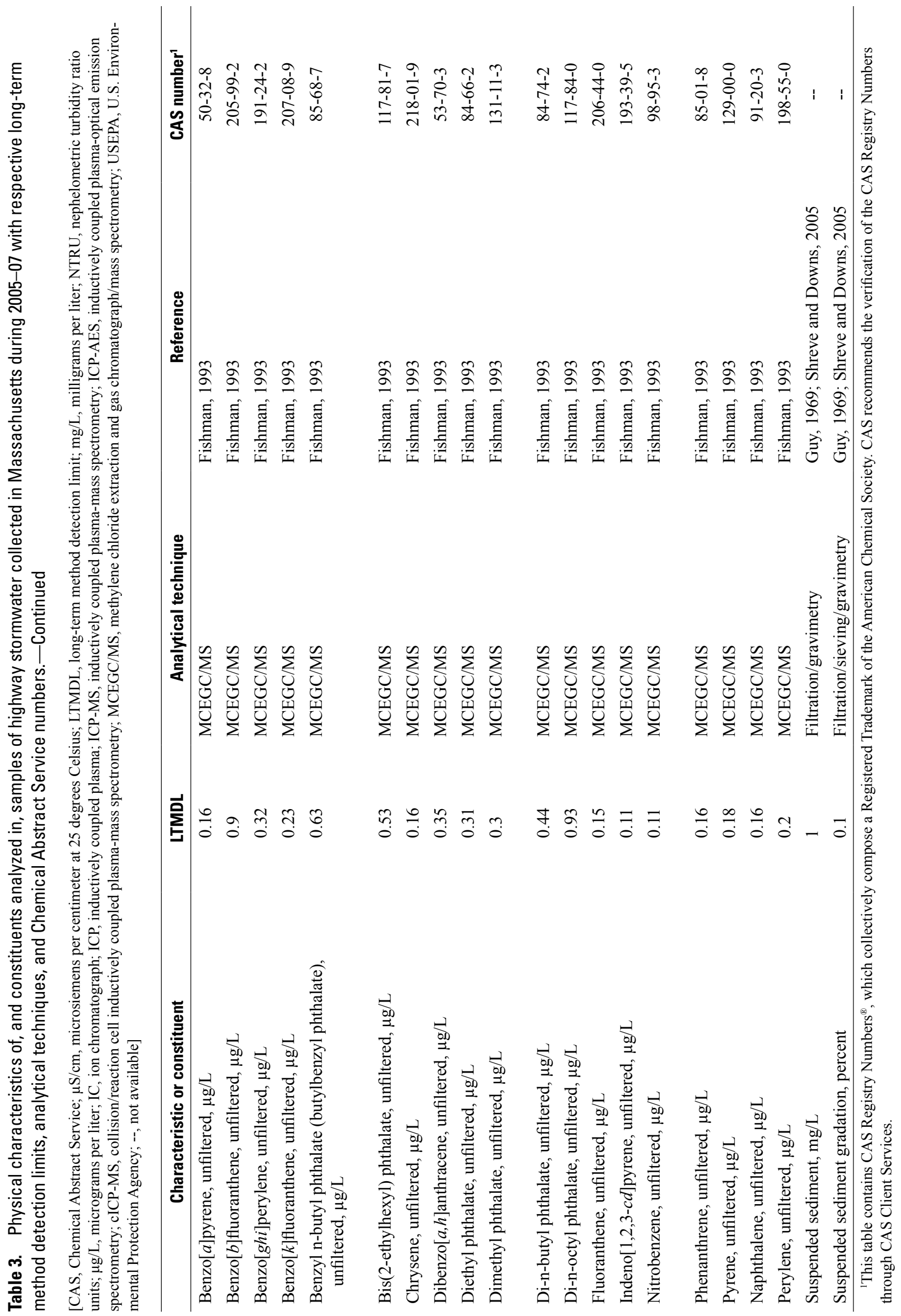


Table 4. Anthropogenic organic compounds in unfiltered samples of highway runoff determined by solid-phase extraction and capillary-column gas chromatography/mass spectrometry, and respective long-term method detection limits in micrograms per liter and CAS numbers.

[CAS, Chemical Abstract Service; LTMDL, long-term method detection limit]

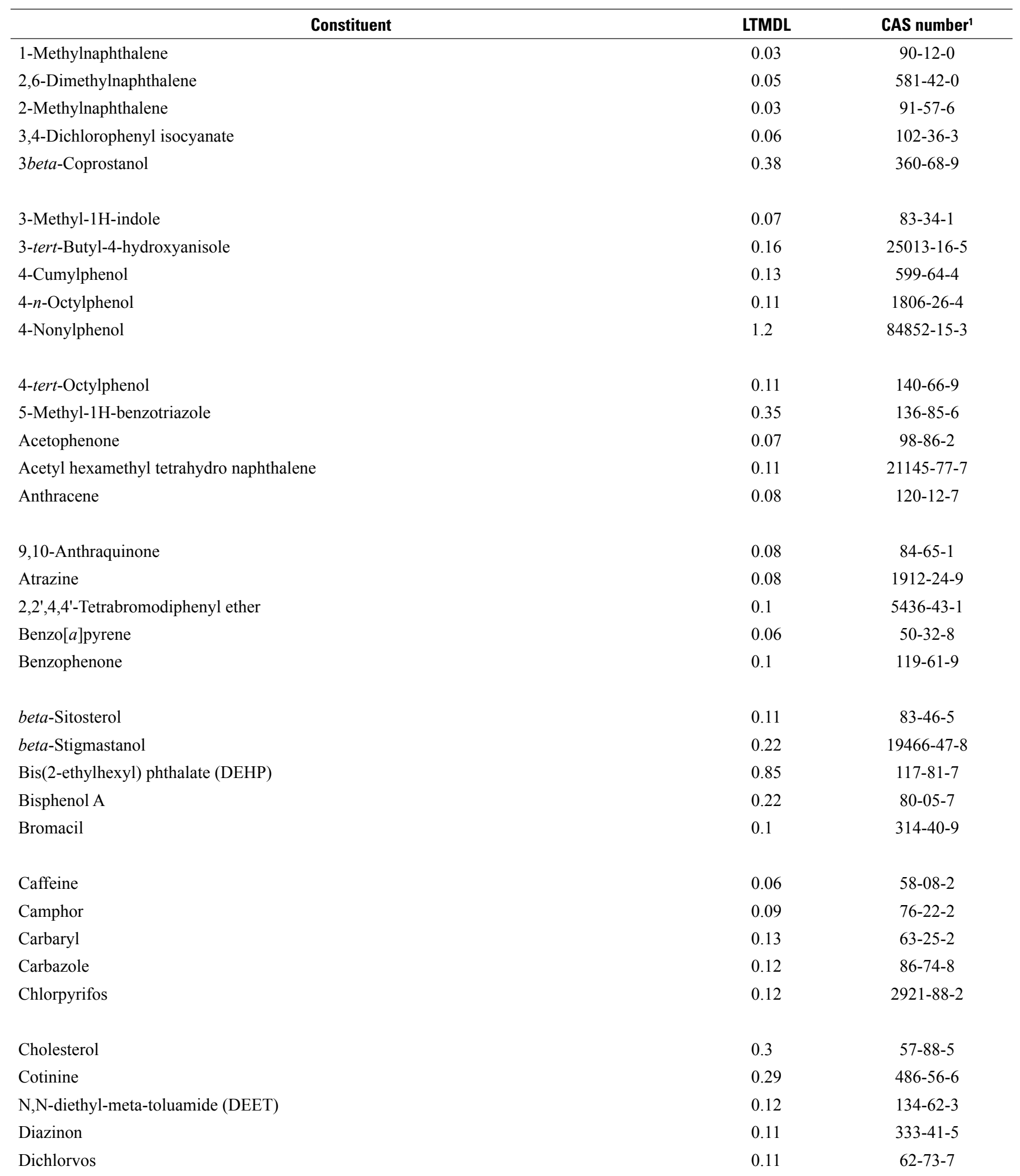


Table 4. Anthropogenic organic compounds in unfiltered samples of highway runoff determined by solid-phase extraction and capillary-column gas chromatography/mass spectrometry, and respective long-term method detection limits in micrograms per liter and CAS numbers.-Continued

[CAS, Chemical Abstract Service; LTMDL, long-term method detection limit]

\begin{tabular}{|c|c|c|}
\hline Constituent & LTMDL & CAS number $^{1}$ \\
\hline Diethoxynonylphenol (4-Nonylphenol diethoxylate; NP2EO) & 1.2 & $26027-38-2$ \\
\hline Diethoxyoctylphenol (4-tert-Octylphenol diethoxylate; OP2EO) & 0.05 & $26636-32-8$ \\
\hline Diethyl phthalate (DEP) & 0.1 & $84-66-2$ \\
\hline$d$-Limonene & 0.02 & $5989-27-5$ \\
\hline Fluoranthene & 0.08 & $206-44-0$ \\
\hline Hexahydrohexamethyl cyclopentabenzopyran (HHCB) & 0.1 & $1222-05-5$ \\
\hline Indole & 0.08 & $120-72-9$ \\
\hline Isoborneol & 0.05 & $124-76-5$ \\
\hline Isophorone & 0.08 & $78-59-1$ \\
\hline Isoquinoline & 0.09 & $119-65-3$ \\
\hline Menthol & 0.05 & $89-78-1$ \\
\hline Metalaxyl & 0.13 & $57837-19-1$ \\
\hline Methyl salicylate & 0.07 & 119-36-8 \\
\hline Metolachlor & 0.12 & $51218-45-2$ \\
\hline Monoethoxynonylphenol (4-Nonylphenol monoethoxylate (sum of all isomers); NP1EO) & 1.35 & $104-35-8$ \\
\hline Monoethoxyoctylphenol (4-tert-Octylphenol monoethoxylate; OP1EO) & 0.5 & $26636-32-8$ \\
\hline$p$-Cresol & 0.08 & $106-44-5$ \\
\hline Pentachlorophenol & 0.33 & $87-86-5$ \\
\hline Phenanthrene & 0.07 & $85-01-8$ \\
\hline Phenol & 0.07 & $108-95-2$ \\
\hline Prometon & 0.08 & $1610-18-0$ \\
\hline Pyrene & 0.08 & $129-00-0$ \\
\hline Tributyl phosphate & 0.11 & $126-73-8$ \\
\hline Triclosan & 0.09 & $3380-34-5$ \\
\hline Triethyl citrate (ethyl citrate) & 0.07 & $77-93-0$ \\
\hline Triphenyl phosphate & 0.1 & $115-86-6$ \\
\hline Tris(2-butoxyethyl) phosphate & 0.05 & $78-51-3$ \\
\hline Tris(2-chloroethyl) phosphate & 0.08 & $115-96-8$ \\
\hline Tris(dichloroisopropyl) phosphate & 0.05 & $13674-87-8$ \\
\hline 1,4-Dichlorobenzene & 0.03 & $106-46-7$ \\
\hline Isopropylbenzene (cumene) & 0.02 & $98-82-8$ \\
\hline Naphthalene & 0.03 & $91-20-3$ \\
\hline Tetrachloroethene & 0.22 & $127-18-4$ \\
\hline Tribromomethane (Bromoform) & 0.03 & $75-25-2$ \\
\hline
\end{tabular}

\footnotetext{
${ }^{1}$ This table contains CAS Registry Numbers ${ }^{\circledR}$, which collectively compose a Registered Trademark of the American Chemical Society. CAS recommends
} the verification of the CAS Registy Numbers through CAS Client Services. 
Composite samples of runoff were collected during storms that represented the range of antecedent dry periods ( $0-45$ days), event-mean specific conductances calculated for individual runoff events (figs. 6-9), and rain totals of 0.1 to 6 in. (fig. 10) throughout the sampling period. Water samples were analyzed for concentrations of selected dissolved major ions, total $\mathrm{N}$ and $\mathrm{P}$, selected total-recoverable metals, suspended sediment, and SVOCs.

\section{Sample Populations}

Composite samples of highway runoff were collected during 16 to 18 storms at the primary monitoring stations, 10 to 11 storms at the secondary monitoring stations, and 5 to 6 storms at the monitoring stations at the test highways over the 2-year sampling period and analyzed for the constituents in table 3. For three storms, composites of highway runoff collected at the four primary sampling stations and at the test station on Interstate 93 also were analyzed for the selected anthropogenic and naturally occurring organic compounds listed in table 4 using the methods described by Zaugg and others (2006a). The size of the anticipated population of storms that would be sampled at sites on the principal highways was determined on the basis of research presented by Thomson and others (1997). Their concept was tested using EMCs of suspended sediment collected during 50 storms from a catch basin on Interstate 93 in Boston (Smith, 2002). Concentrations of suspended sediment from this data set were selected randomly to form 320 discrete populations ranging in size from 3 to 48 samples. This resulted in 20 populations each containing 3 samples, 20 populations each containing 6 samples, 20 populations each containing 9 samples, and so on. Normalized median concentrations of suspended sediment (the median for each discrete population divided by the median of all 50 EMCs) for a randomly generated set of sub-populations are shown in figure 11. These data indicate that the risk of over- and under-estimating suspended-sediment concentrations at a site increases with fewer samples, but the risk of overestimating concentrations increases more rapidly because suspended sediment and constituents affiliated with suspended sediment in highway runoff are lognormally distributed. The range of samples collected from the sites on principal highways in this study should provide reasonable estimates of mean concentrations for many constituents, and the collection of additional samples at these highways may not necessarily provide greater precision. In contrast, the size of the sample population for the test highways is small and less precise, and therefore, analyses between data from the test sites and primary and secondary sites on the principal highways may be improved by collection of additional data.

\section{Selection of Storms}

Storms were selected to reflect seasonal and antecedent dry variations existing throughout the study period. Precipitation totals ranged from about 0.1 to $5.1 \mathrm{in}$. for storms that were sampled at the principal highways. In general, most of the storms that were sampled during this study were within the interquartile range of precipitation totals greater than $0.10 \mathrm{in}$. recorded from 1967 through 2007 by the National Climatic Data Center near Worcester, Massachusetts (Granato, 2007, fig. 10). In this study, storms are defined in terms of measured wet precipitation as one or more measurements of wet precipitation equal to or greater than 0.01 in. (the minimum resolution of the rain gages), separated by a period of 6 hours of antecedent dry time. Because some sites did not contain rain gages and because rain gages are susceptible to plugging from snow and other debris, storms are primarily defined in this study by a function of flow where sequential measurements of discharge greater than or equal to $0.01 \mathrm{ft}^{3} / \mathrm{s}$ are separated by 6 hours or more of discharge less than $0.01 \mathrm{ft}^{3} / \mathrm{s}$. A discharge of $0.01 \mathrm{ft}^{3} / \mathrm{s}$ was chosen as a cutoff because it was the minimum value that was discernable between the presence of flow and no flow on the basis of the resolution of level sensor, the stage-discharge relation for most sites, and reliable concurrent measurements of specific conductance.

\section{Sample Collection}

Samples of highway runoff for the analysis of water chemistry and suspended-sediment concentration were collected in the outlet pipe of a single catch basin or the drainage pipe that received discharge from multiple catch basins, using an automatic sampler controlled by a datalogger. The first sample was collected when flow exceeded $0.009 \mathrm{ft}^{3} / \mathrm{s}$, and subsequent samples were collected at flow-proportional intervals. Approximately 60 samples of stormwater were collected for equivalent runoff of $1 \mathrm{in}$. of rain. Flow-proportional thresholds, at which point the datalogger triggered the automatic water sampler, were fixed at each site throughout the study irrespective of expected storm characteristics; only the volume for each subsample was altered. Generally, a composite of stormwater consisted of multiple 220 -mL aliquots; however, the aliquot volume for the subsamples was reduced for storms with forecasted rain amounts greater than $1.5 \mathrm{in}$. so that the total number of samples could be increased and the 20-L sample bottle would be adequate in size to represent the entire storm. For small storms with forecasted rainfall amounts less than $0.5 \mathrm{in}$., the aliquot volume for each subsample was increased to ensure that sufficient water volume was collected to satisfy analytical requirements. Because the frequency of the collection of the subsamples was a function of a flow threshold derived from an equivalent runoff of 1 in. of rain from each site, the density of subsamples forming the composite of stormwater was comparable from site to site. Various factors were considered during the selection and construction of the sites to ensure the best possible performance of the automatic samplers. Vertical distances from fixed sampling points to the sampler-pump heads were within optimal suction limits (Bent and others, 2001) and for most sites were less than about $5 \mathrm{ft}$, but were as much as $8 \mathrm{ft}$ for the monitoring station on Route 8, Interstate 93, and the primary station on Interstate 95 . All sampler lines were mounted in a sloping 

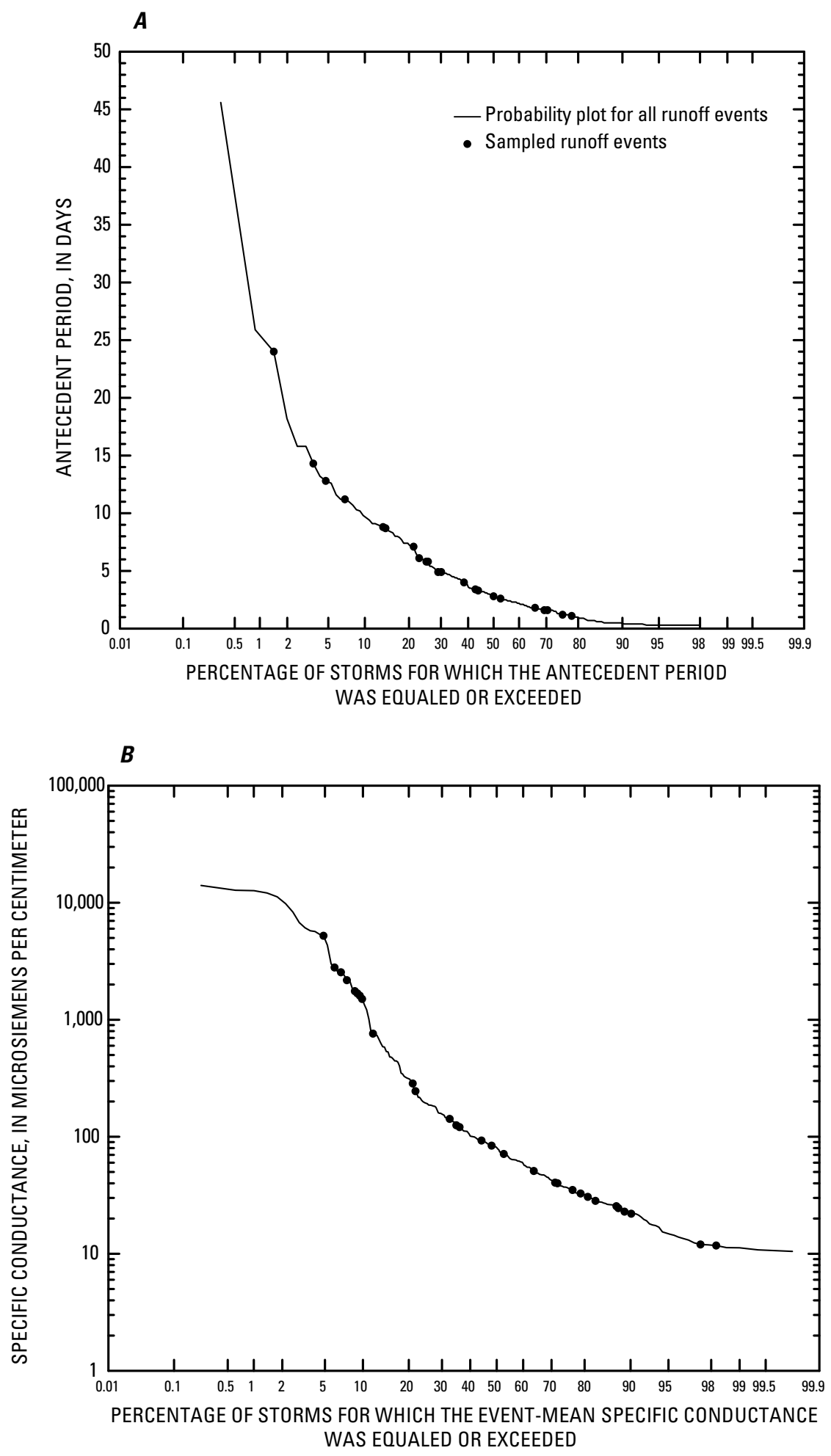

Figure 6. (A) Percentage of storms for which antecedent dry periods were equaled or exceeded in relation to the antecedent dry periods for storms during which runoff samples were collected from monitoring stations on Route 119, Ashburnham, Massachusetts, 2005-07; $(B)$ percentage of storms for which the event-mean values of specific conductance were calculated from continuous records of flow and specific conductance in relation to specific conductance measured in runoff samples collected from the monitoring stations on Route 119, Ashburnham, Massachusetts, 2005-07. 

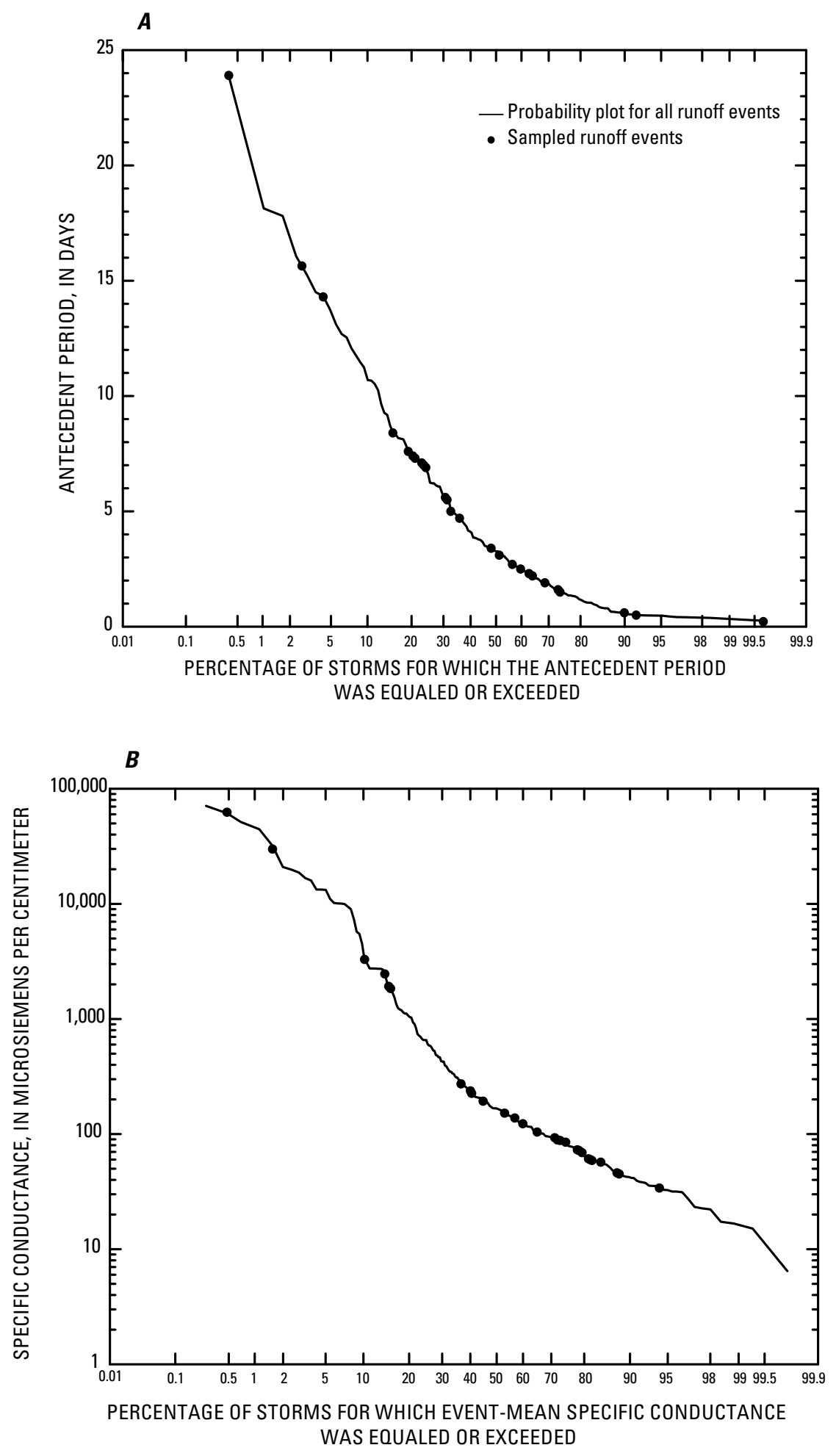

Figure 7. (A) Percentage of storms for which antecedent dry periods were equaled or exceeded in relation to the antecedent dry periods for storms during which runoff samples were collected from monitoring stations on Route 2 in Littleton, Massachusetts, 2005-07; (B) percentage of storms for which the event-mean values of specific conductance were calculated from continuous records of flow and specific conductance in relation to specific conductance measured in runoff samples collected from the monitoring stations on Route 2 in Littleton, Massachusetts, 2005-07. 

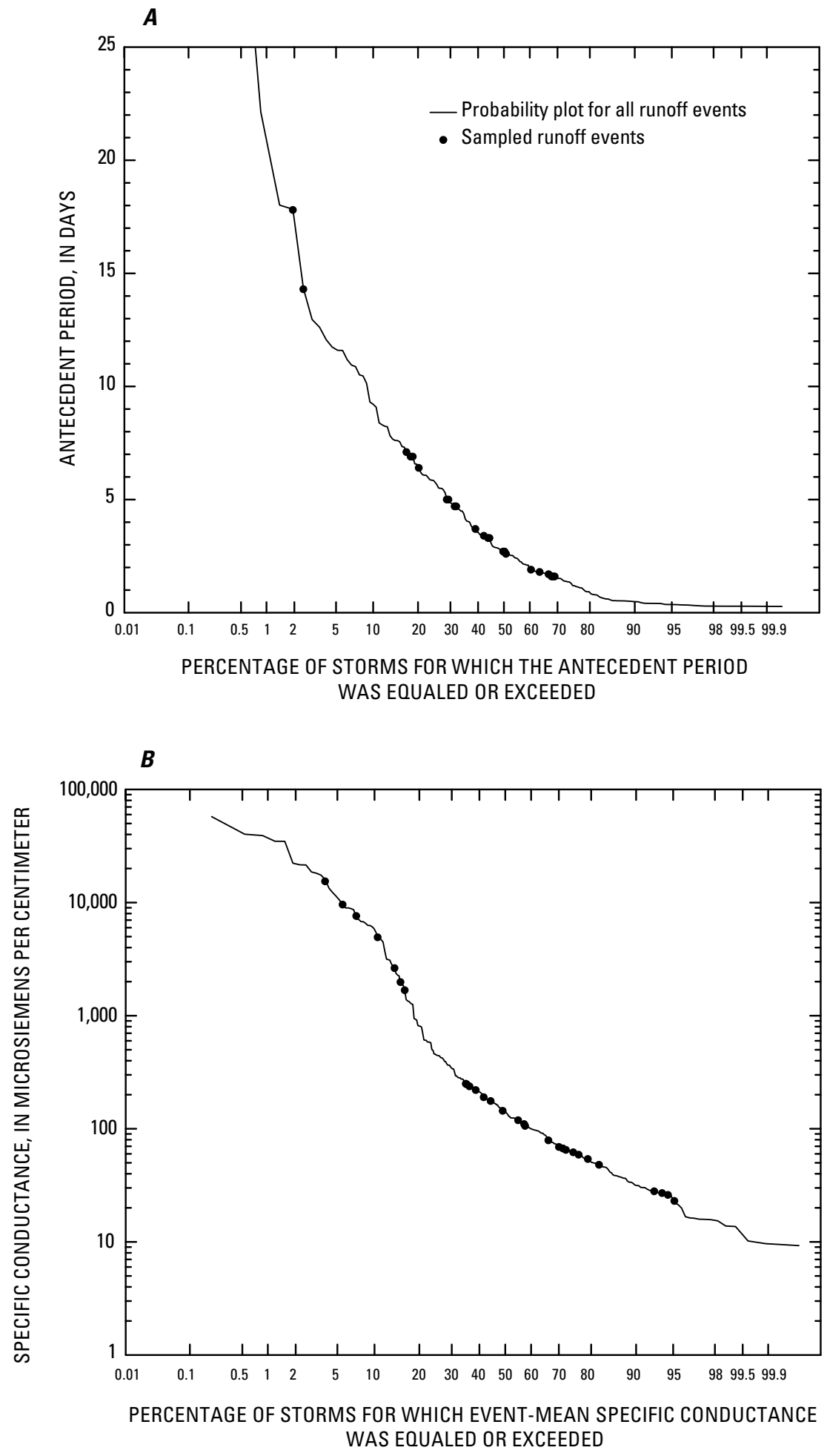

Figure 8. (A) Percentage of storms for which antecedent dry periods were equaled or exceeded in relation to the antecedent dry periods for storms during which runoff samples were collected from monitoring stations on Interstate 495 in Boxborough and Bolton, 2005-07; $(B)$ percentage of storms for which the event-mean values of specific conductance were calculated from continuous records of flow and specific conductance in relation to specific conductance measured in runoff samples collected from the monitoring stations on Interstate 495 in Boxborough and Bolton, Massachusetts, 2005-07. 

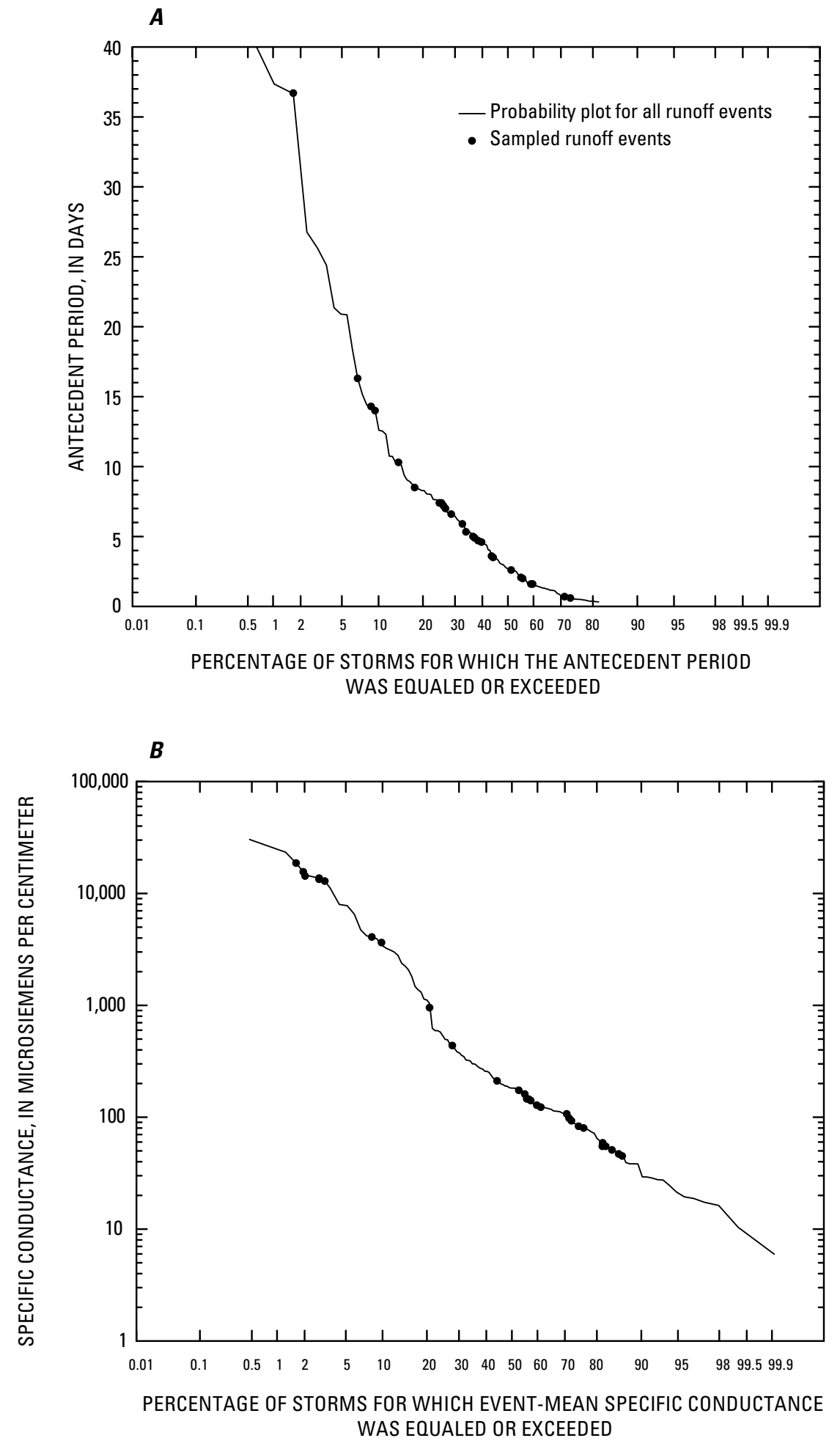

Figure 9. (A) Percentage of storms for which antecedent dry periods were equaled or exceeded in relation to the antecedent dry periods for storms during which runoff samples were collected from monitoring stations on Interstate 95 in Lexington and Waltham, Massachusetts, 2005-07; (B) percentage of storms for which the event-mean values of specific conductance were calculated from continuous records of flow and specific conductance in relation to specific conductance measured in runoff samples collected from the monitoring stations on Interstate 95 in Lexington and Waltham, Massachusetts, 2005-07. 


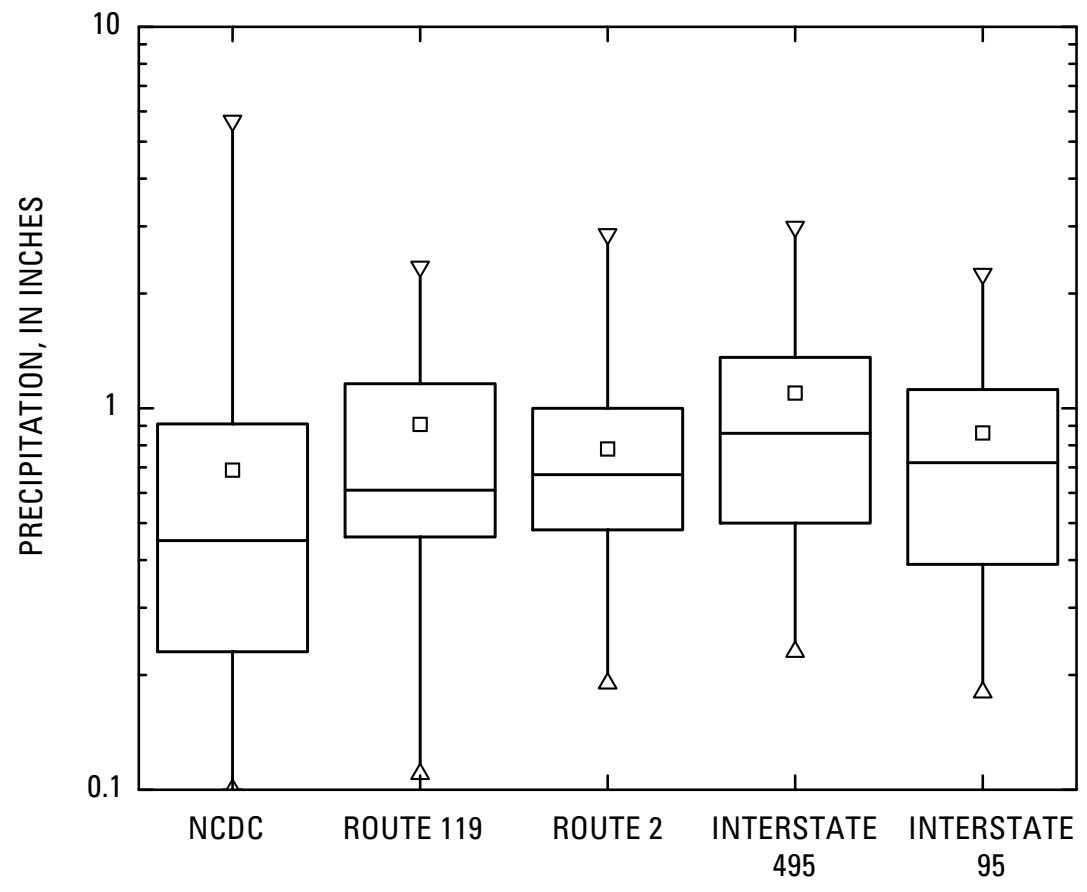

\section{EXPLANATION}

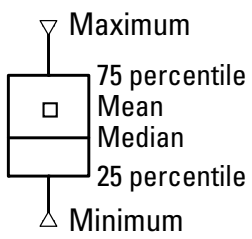

Figure 10. Distribution of precipitation totals greater than 0.10 inch recorded by the National Climatic Data Center near Worcester, Massachusetts, and of precipitation totals for storms during which samples were collected at each of the primary highway sites in Massachusetts, 2005-07.

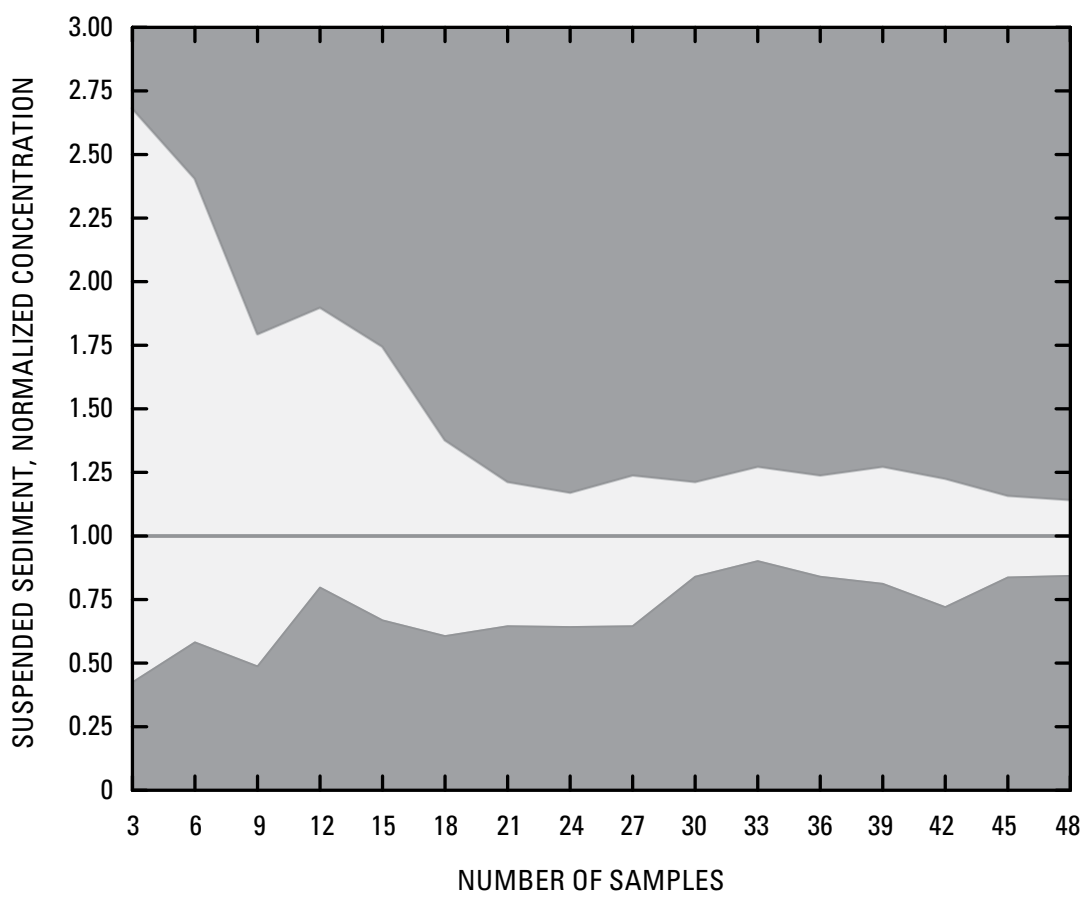

\section{EXPLANATION}

1:1 line for normalized event-mean concentrations

Unshaded area shows the range of the normalized event-mean concentration for samples selected randomly for a given sample population

Figure 11. Results of a statistical resampling experiment indicating uncertainty in the median of event-mean concentrations of suspended sediment using a set of 20 randomly selected sample subpopulations ranging from 3 to 48 samples. Samples were collected along Interstate 93 during 50 storms (Smith, 2002). Subsample concentrations are normalized using the median concentration of suspended sediment for all 50 storms. 
manner to allow for the complete purging and draining of sample water between samples. Sampler intakes were fixed to static mixers (fig. 12) designed specifically for this project at each sampling point for all sampling locations. The static mixer provides a secure and consistent mount for the sampler intake, reduces transport velocity, and provides agitation to produce a sample that represents the average concentration of suspended sediment (Smith, 2002). Sampler intakes were oriented in a horizontal and downstream direction. This configuration minimizes debris accumulation by forming a small eddy that captures sand particles at the intake and thus allows the sampler to collect a more representative sample of the coarse load (Edwards and Glysson, 1999). The static mixers were constructed from a 0.75 -in. low-density polyethylene. The performance of the static mixers was evaluated at a test site prior to, and concurrent with, field sampling at the primary-monitoring station on Interstate 495 . These tests were done to document the effectiveness of using the static mixers in conjunction with the automatic samplers for the collection of coarse particles representative of the distribution of particle sizes expected in the highway runoff.

Pre-cleaned wetted components for the sampling system were installed prior to each sampled storm. Each automatic sampler was configured to hold one 20-L Teflon-lined plastic bottle. The Teflon lining consisted of a double wall Teflon pouch constructed in a clean room without the use of glue or adhesives. The sampler's intake lines consisted of 0.5 -in. Teflon tubing attached to silicon pump-head tubing with a custom made Teflon discharge tube. A multi-step process was used to clean all wetted parts associated with the automatic sampler and the processing equipment before collecting trace-level constituents. The initial cleaning consisted of washing the interior and exterior with a phosphate-free laboratory grade soap and tap water, scrubbing surfaces with a plastic brush, and rinsing with tap water. Circulating the solution through the tubing cleaned the interior of the sampler tubing. Lint-free wipes were forced hydraulically through the tubing to remove internal deposits or films that were difficult to remove by circulating solution alone. After the components dried, they were placed in a large stainless steel pan in a fume hood and immersed in a 1-to-1 hexane-to-acetone solution. A Teflon diaphragm pump was used to circulate the solution through the sampler tubing. The components were allowed to soak, with occasional agitation, for a period of about 6 hours. After appropriately dispensing the waste solution, all components except the tubing were rinsed with a 1-to-1 hexane-to-acetone solution from a Teflon squeeze bottle and air dried in a fume hood overnight. Because the rate of cleaning-solution volatilization was limited within the sampler tubing, the tubing was purged with purified air for approximately 20 minutes. The

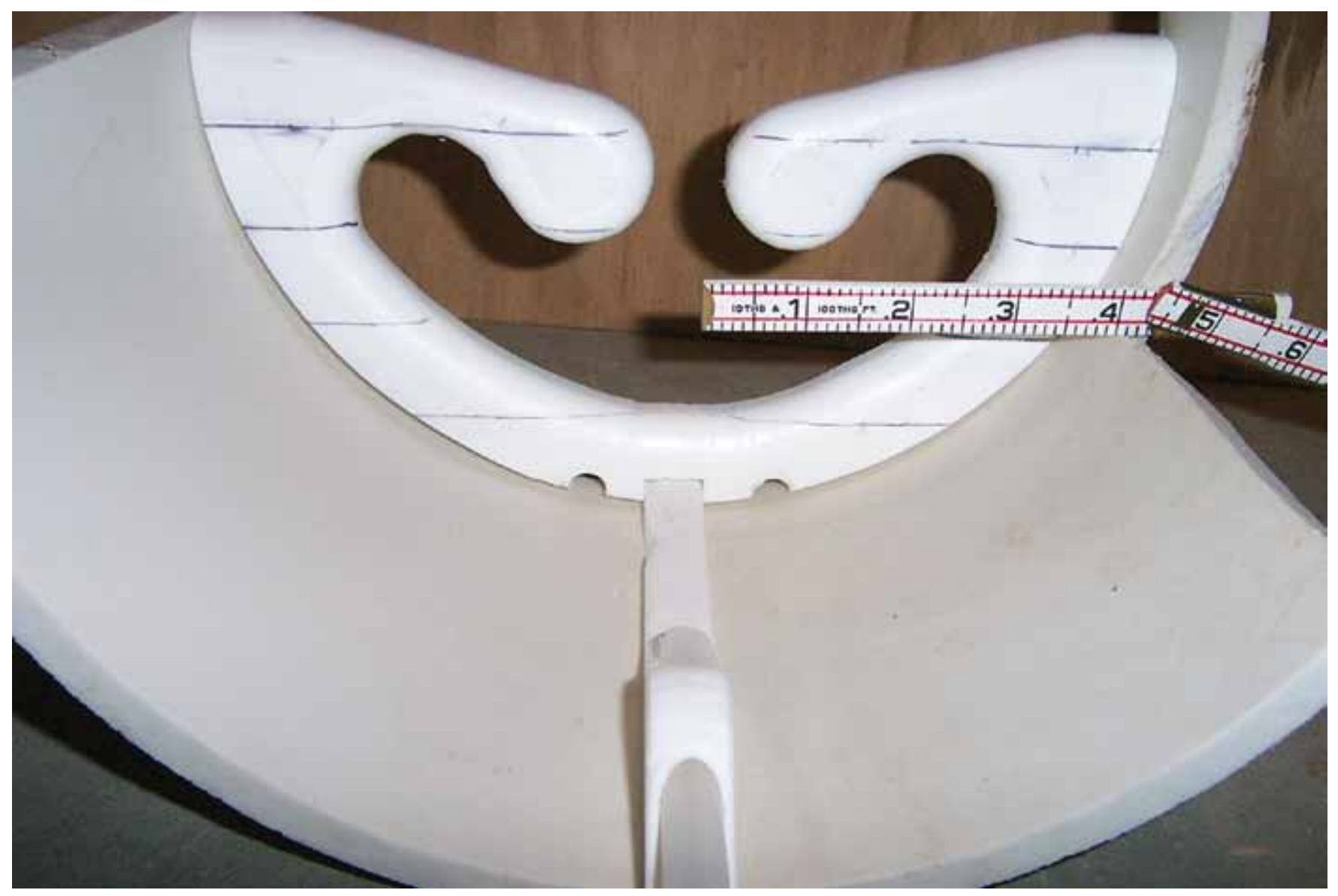

Figure 12. Static mixer mounted in a cut-out section of 12-inch-diameter plastic pipe. 
final steps involved immersing the components in a 5-percent solution of hydrochloric acid for a period of at least 6 hours. The same solution was slowly circulated through each sampler tube for 6 hours or more. All components were thoroughly rinsed with deionized water until the specific conductance of the waste rinse water was less that $1 \mu \mathrm{S} / \mathrm{cm}$.

\section{Sample Processing}

Most samples for chemical analysis were processed within 12 to 24 hours of the completion of each storm in a mobile field unit. Subsamples for the analysis of suspended sediment, nutrients, metals, and SVOCs were split directly from the Teflon-lined bottle into laboratory designated bottles in a positive-pressure hood. This method eliminated sample contact with additional processing equipment and reduced the potential for contamination. Subsamples were dispensed under low pressure directly from the sample bottle with a specialized cap, which included a 6.35-mm (inner diameter) Teflon dispensing tube, a pressure port, and a relief valve. Compressed nitrogen gas applied to the pressure port filled the interior area between the bottle wall and the pouch, compressing the pouch and dispensing the sample. Homogenization of the sample was accomplished by fastening the bottle to a cradle assembly capable of rotating 210 degrees. The sample bottle was rocked the full 210 degrees several times prior to dispensing, and the rocking motion was continued throughout dispensing for all samples except those analyzed for dissolved constituents. Dissolved constituents were filtered through a $600-\mathrm{cm}$ capsule filter with a $0.45-\mu \mathrm{m}$ pore size.

\section{Sample Analysis}

Samples to be analyzed for dissolved cations and totalrecoverable metals were preserved with Optima-grade nitric acid. Samples to be analyzed for total $\mathrm{N}$ and $\mathrm{P}$ were preserved with sulfuric acid. Other samples required no special preservation other than refrigeration. Samples collected for the analysis of major ions, nutrients, total-recoverable metals, and SVOCs were double bagged after processing and stored on ice for overnight delivery to the USGS National Water Quality Laboratory (NWQL) in Denver, Colorado, where they were analyzed. Samples were analyzed for concentrations of suspended sediment and distribution of particle size at the USGS Kentucky Water Science Center Sediment Laboratory.

\section{Samples of Highway-Runoff Sediment}

Suspended sediment, especially fine-grained suspended sediment, is an important transport mechanism for many elements and SVOCs in highway runoff. Several recent studies in Massachusetts have documented the affiliation of various elements and SVOCs with sediment, and the corresponding effect of concentrations with specific particle sizes, in samples of sediment collected from oil-grit separators (Smith 2002), streambeds (Smith 2005), and street sweepings (Breault and others, 2005). In general, sediment surface area and element concentrations tend to increase with a decrease in sediment grain size. To understand these relations, which are important to the selection and implementation of both structural and nonstructural BMPs to improve the quality of water discharged from highways, the relation of sediment quality to particle size is measured.

Samples of suspended sediment for analysis of sediment quality were collected as separate aliquots from the highwayrunoff composite samples that were collected during storms at the sites on the principal highways during the 2-year sampling period. These subsamples, which were separate from samples for the analysis of suspended-sediment concentrations, were wet sieved into specific particle-size ranges, and each size range was analyzed for concentrations of 32 inorganic elements, TOC, and selected SVOCs.

\section{Sample Collection and Processing}

Samples of sediment in highway runoff for analysis of sediment quality were collected during storms from the sites on the principal highways using automatic samplers and methods described earlier. Samples for highway-runoff sediment quality were composited from the flow-weighted composites of highway runoff during two separate 8 and 9 month periods. Thus, the sediment samples represent the quality of suspended sediment in highway runoff during multiple storms. Samples were composited because of the relatively large amounts of sediment required by analytical methods; individual flow-weighted composite samples of highway runoff from individual storms did not contain enough suspended sediment for analysis. Samples of sediment were temporarily frozen until sufficient material was available for analysis. Recent tests indicate that samples of sediment can be stored frozen for up to a year with little degradation of the sample (U.S. Environmental Protection Agency, 2005), thus it is unlikely that the integrity of the samples was affected during the compositing stage.

For analysis of inorganic constituents, water containing sediment and obtained from composite samples of highway stormwater was wet-sieved through pre-cleaned $0.250-\mathrm{mm}$ and 0.062-mm nylon-mesh sieves. The sieves were cleaned by immersing them in a 5-percent solution of hydrochloric acid for a period of about 6 hours and thoroughly rinsing them with deionized water. Sediment from $0.063 \mathrm{~mm}$ to $0.250 \mathrm{~mm}$ in diameter and sediment greater than $0.250 \mathrm{~mm}$ in diameter for each principal highway were set aside in separate clean polyethylene bags. Sediment particles less than $0.063 \mathrm{~mm}$ in diameter were collected in Teflon bags with native water and allowed to settle undisturbed in a laboratory refrigerator in the USGS Massachusetts Water Science Center for several days. After the sediment settled, the supernatant was decanted and discarded, and the sediment was retained for chemical analysis. Composite samples of suspended sediment to be analyzed for elements were collected over an 8-month period during 2006 and 2007. 
The amount of sediment required for the analysis of SVOCs was large, relative to the amount of available sediment in the samples, even after compositing; thus, samples of suspended sediment for analysis of SVOCs were sieved only through a pre-cleaned $0.063-\mathrm{mm}$ stainless-steel sieve. The sieve was cleaned by immersing it in optima-grade methanol and thoroughly rinsing it with deionized water. Sediment greater than or equal to $0.063 \mathrm{~mm}$ in diameter from each principal highway was set aside in a separate pre-cleaned baked glass jar. Sediment particles less than $0.063 \mathrm{~mm}$ in diameter were collected in Teflon bags with native water and allowed to settle undisturbed in a laboratory refrigerator in the USGS Massachusetts Water Science Center for several days. After the sediment settled, the supernatant was decanted and discarded, and the sediment was retained for chemical analysis. Samples of suspended sediment for the analysis of SVOCs were composited over a 9-month period during 2005 and 2006.

\section{Sample Analysis}

Samples of sediment containing particles less than $0.063 \mathrm{~mm}$ in diameter, from $0.063 \mathrm{~mm}$ to $0.250 \mathrm{~mm}$ in diameter, and greater than or equal to $0.250 \mathrm{~mm}$ in diameter were submitted to XRAL Laboratory of Ontario, Canada, for analysis of 32 inorganic elements and TOC. Samples were not milled prior to analysis. Total-recoverable concentrations of inorganic constituents were determined with the use of USEPA method 3050B (U.S. Environmental Protection Agency, 1996) and ICP emission spectroscopy. Concentrations of TOC were determined by infrared spectroscopy. A separate set of sediment samples containing particles less than $0.063 \mathrm{~mm}$ in diameter and particles greater than or equal $0.063 \mathrm{~mm}$, in diameter was submitted to the USGS NWQL in Denver, Colorado, for analysis of organic compounds by accelerated solvent extraction and gas chromatography (Zaugg and others, 2006b).

\section{Samples of Background Soil, Highway-Berm Soil, and Other Miscellaneous Materials}

Samples of background soil, highway-berm soil, and highway-maintenance materials were collected and analyzed for concentrations of 32 inorganic elements. Samples of highway-berm vegetation and catch-basin debris greater than 250 micrometers also were collected and analyzed for concentrations of 32 elements and TOC (except for highway-berm vegetation), and selected SVOCs (except for catch-basin debris).

\section{Sample Collection}

Five samples of background soil were collected at a distance of about $100 \mathrm{ft}$ from each of the principal and test highways in the vicinity of the monitoring stations, except for Interstate 190 where no samples were collected. Samples were collected at a distance of about $30 \mathrm{ft}$ from Interstate 93 in Boston because of the lack of available undeveloped land. Where possible, samples of soil were collected near trees with diameters greater than $1 \mathrm{ft}$ because those trees were presumed to be in areas that were undisturbed for the last several decades. Samples were collected through successive soil horizons to a maximum depth of $1 \mathrm{ft}$ with a stainless-steel soil-recovery probe equipped with a precleaned plastic liner. The plastic liners were cleaned by immersing the tubes in a 5-percent solution of hydrochloric acid for a period of about 6 hours and thoroughly rinsing them with deionized water until the specific conductance of the waste rinse water was less that $1 \mu \mathrm{S} / \mathrm{cm}$.

Samples of surficial highway-berm soil were collected within $1 \mathrm{ft}$ of the highway shoulder and at a depth of about $0.1 \mathrm{ft}$ at five locations along each principal highway in the vicinity of the monitoring stations. Samples were collected with an acid-washed polyethylene scoop and stored in clean polyethylene bags prior to shipment to the laboratory. Two samples of highway maintenance sand also were collected at each of the Massachusetts DOT maintenance depots servicing the principal highways because the materials are procured from different local sources at each depot. In contrast, because the salt used on all Massachusetts highways is from the same source, a single sample of maintenance salt (sodium chloride) and a single sample of liquid calcium chloride were collected from the Massachusetts DOT maintenance depot in Lexington, Massachusetts. The solid-matrix samples were collected with a stainless-steel soil-recovery probe equipped with a precleaned plastic liner. The sample of liquid calcium chloride was dispensed into an acid-cleaned bottle.

Two samples of highway-berm vegetation were collected along Interstate 495 after mowing operations. These samples mainly consisted of roadside grass and weeds. While berm vegetation was available near all the highways sites, it was most plentiful along Interstate 495 in the vicinity of the primary monitoring station. A sample of dry pine needles also was collected along Route 119 because the needles commonly accumulated on the road shoulder and were often found in composite samples of stormwater. Nine samples of catch-basin debris, consisting of particles greater than 250 micrometers, also were collected from a plankton net installed at the outfall of the primary station on Interstate 495.

\section{Sample Processing}

Samples of soil, highway-berm soil, and highway-maintenance materials were processed similarly. For soil samples, the soil from each core was separated from the organic-litter layer and homogenized. The organic litter composed of leaves and twigs was discarded. For highway-berm soils, the soil was homogenized, and the contents were inspected for nonhomologous materials (for example, plastic and foil wrappers) that could bias chemical analysis. Such materials were subsequently removed. Each homogenized sample of soil, highway-berm soil, or highway-maintenance sand was split into a minimum of two subsamples. One subsample was used 
to determine the particle-size distribution of the sample and the other subsample was analyzed for 32 inorganic elements. Samples of roadside vegetation, pine needles, and catch-basin debris were homogenized and reduced to fine particles with an electric chopper consisting of a stainless steel blade and an acrylic housing.

\section{Sample Analysis}

A particle-size gradation and an analysis for inorganic elements were performed for each sample of background soil, highway-berm soil, and highway-maintenance sand. Only an analysis for inorganic elements was performed on the samples of salt. Subsamples of soil, highway-berm soil, and highway-maintenance sand were evaluated for the percentage of particles less than $0.063 \mathrm{~mm}$ in diameter, from $0.063 \mathrm{~mm}$ to $0.250 \mathrm{~mm}$ in diameter, and greater than or equal to $0.250 \mathrm{~mm}$ in diameter at the USGS Kentucky Water Science Center Sediment Laboratory. Samples of soil, highway-berm soil, highway-maintenance sand and salt, roadside vegetation and pine needles, and catch-basin debris were submitted to XRAL Laboratory for analysis of 32 inorganic elements. Samples were not milled prior to analysis. Concentrations of inorganic constituents in solid-matrix samples were determined with the use of USEPA method 3050B (U.S. Environmental Protection Agency, 1996) and ICP emission spectroscopy. The sample of liquid calcium chloride was submitted to the USGS NWQL in Denver, Colorado, for analysis of major ions, total nutrients, and selected total-recoverable metals. Samples of roadside vegetation and pine needles also were submitted to the USGS NWQL for analysis of PAHs. These compounds were determined by accelerated solvent extraction and gas chromatography (Zaugg and others, 2006b).

\section{Estimation of Constituents Contributed to Runoff from Road Salt}

The primary constituents of road salt, sodium $(\mathrm{Na})$, calcium $(\mathrm{Ca})$, and $\mathrm{Cl}$, were measured directly in the composite samples of highway runoff but also were estimated from the more frequent in-situ measurements of specific conductance. The data set includes 129 EMCs for these dissolved ions, specific conductances of the composite samples ranging from 7 to $62,500 \mu \mathrm{S} / \mathrm{cm}$, and $\mathrm{Cl}$ concentrations ranging from less than 1 to $22,600 \mathrm{mg} / \mathrm{L}$. Specific conductance was measured instantaneously for 1,555 runoff events (rain, mixed precipitation, and snowmelt), and estimated event-mean in-situ measurements of specific conductance ranged from about 6 to $105,600 \mu \mathrm{S} / \mathrm{cm}$. (Only four storms had specific conductance values greater than $62,500 \mu \mathrm{S} / \mathrm{cm}$.) Specific conductance measurements, which commonly are used to determine concentrations of dissolved major ions (Hem, 1982, 1992; Miller and others, 1988; Church and others, 1996; Granato and Smith, 1999), were used to estimate concentrations of dissolved $\mathrm{Na}, \mathrm{Ca}, \mathrm{Cl}$, and sulfate $\left(\mathrm{SO}_{4}\right)$ in highway runoff to improve estimates of the populations of concentrations and loads of these constituents in runoff from Massachusetts highways.

Concentrations of dissolved $\mathrm{Na}, \mathrm{Ca}, \mathrm{Cl}$, and $\mathrm{SO}_{4}$ in highway runoff were estimated using the adjusted superposition technique (Granato and Smith, 1999) over the full range of flow-weighted in-situ measurements of specific conductance. The theoretical conductance for each major ionic species in solution is summed to calculate the superposition estimate. Specifically, the theoretical conductance of a solution is the product of each ion in milliequivalents per liter multiplied by the equivalent ionic conductance at infinite dilution (table 5). However, as the concentrations of dissolved constituents increase, superposition will increasingly overestimate the specific conductance measured in a water sample because of interactions among ions in high-ionic strength solutions (Harned and Owen, 1958; Smedley, 1980; Hem, 1982; Miller and others, 1988). The adjusted superposition technique is a semi-empirical method that improves the quantitative relations among estimated and measured specific conductance to account for the attenuating effects of the interactions in high-ionic strength solutions that cannot be adequately quantified using purely theoretical approaches (Granato and Smith, 1999). In this study, nonparametric regression techniques (Granato, 2006) were used to develop an equation using the logarithms of the measured event-mean specific conductance $(C M)$ and the logarithms of the specific conductance estimated by superposition $(C C)$ for the 129 EMCs in the highway runoff data set to account for interionic effects on measured concentrations. This equation, retransformed from log space is

$$
C C=0.829 \times C M^{1.033757},
$$

where $C C$ is the specific conductance (in microsiemens per centimeter) that would be calculated by superposition, and $C M$ is the measured specific conductance (in microsiemens per centimeter). Equation 1 indicates that $C M$ is slightly greater than $C C$ at low concentrations (potentially because the contributions of some ions were not included in the calculation of the superposition values), and CM can be substantially less than $C C$ for measured specific conductance values greater than about $5,000 \mu \mathrm{S} / \mathrm{cm}$. The standard error of this estimate is 0.126 percent, as calculated for all the regression models using the equation

$$
S E=100 \times\left(e^{\left(M S E^{2} \times 5.302\right)}-1\right)^{\left(\frac{1}{2}\right)}
$$

where $S E$ is the standard error of estimate, in percent, and $M S E$ is the mean square error in log (base 10) units (Driver and Tasker, 1990). The nonparametric coefficient of efficiency $E$ (Legates and McCabe, 1999) also indicates the predictive power of a regression equation. The nonparametric coefficient of efficiency is 


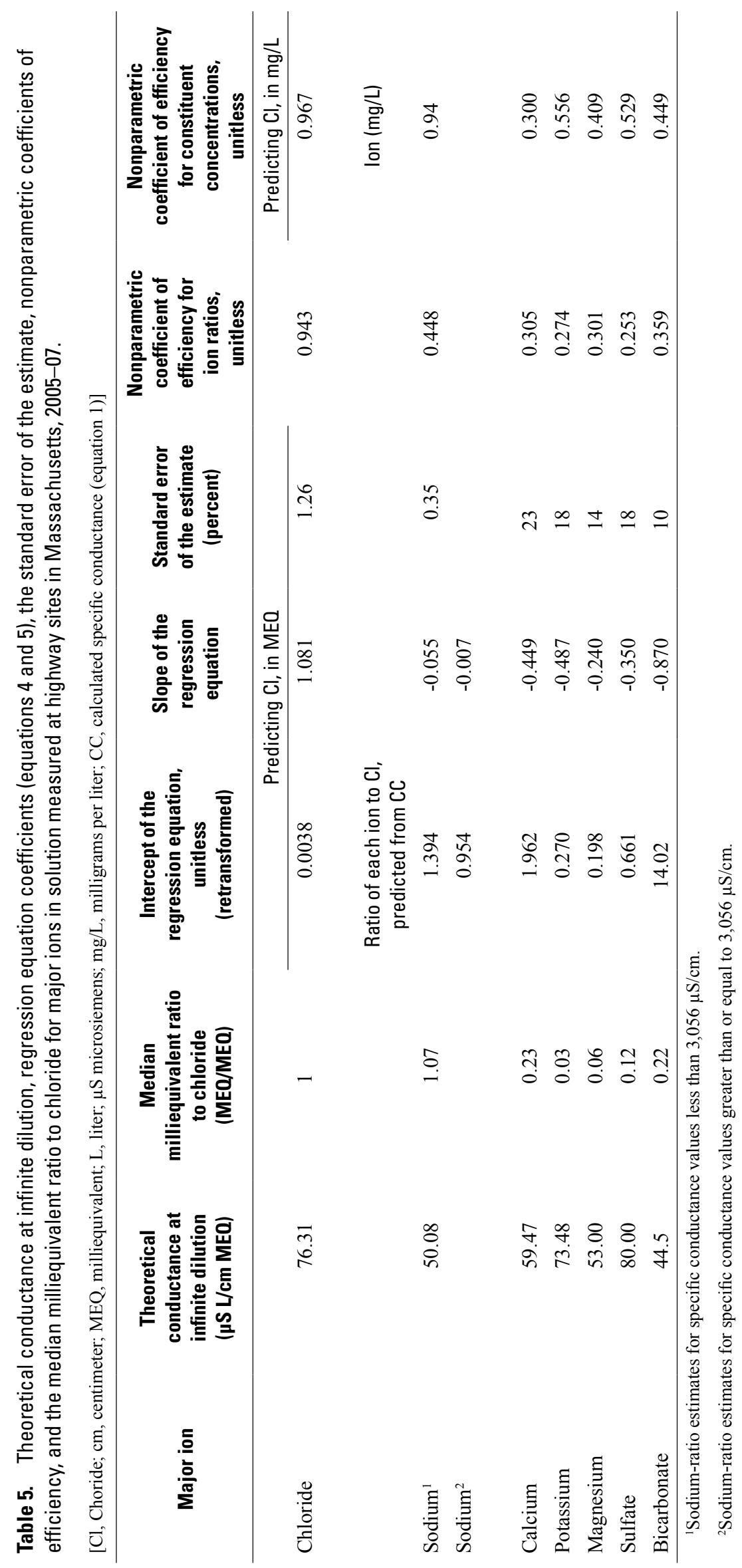




$$
E=1-\frac{\sum_{i=1}^{N}\left|X_{i}-Y_{i}\right|}{\sum_{i=1}^{N}\left|X_{i}-Y_{\text {median }}\right|},
$$

where $X_{i}$ is the $i^{\text {th }}$ measured value, $Y_{i}$ is the predicted value, $N$ is the number of measured values, and $X_{\text {median }}$ is the median of the measured values. The nonparametric coefficient of efficiency $E$ (Legates and McCabe, 1999) for the $C M$ to $C C$ regression equation is 0.95 , indicating that differences between regression estimates and estimates calculated from measured values are about 5 percent of the variability in $C C$ estimates from measured values.

The specific conductance estimated by superposition $(C C)$ from equation 1 may be used with estimates of the predominant ratios among major ions in solution and the theoretical conductance at equivalent dilution to estimate the concentration of $\mathrm{Cl}$ and other ions in solution. The concentrations of constituents in highway runoff should asymptotically converge toward the ratio of constituents in deicing materials as conductance increases because the deicing materials become the dominant source of these ions in solution (Granato, 1996). In eastern Massachusetts, ratios among major ions in highway runoff at low conductances also may approximate ratios of ions present in deicing materials because precipitation in the region is affected by coastal storms that are affected by entrainment of salt spray from the ocean by the storm system (Gay and Melching, 1995). For example for $\mathrm{Na}$ and $\mathrm{Cl}$, maps with isopleths from the National Atmospheric Deposition Program (2008) indicate a substantial effect from coastal storms on precipitation quality for most of Massachusetts (excluding northwestern Massachusetts). Therefore, nonparametric regression techniques were used to develop equations to predict the ratio of each major ion to $\mathrm{Cl}(\mathrm{X} / \mathrm{Cl})$ as a function of the specific conductance estimated by superposition $(C C)$. These equations are in the form

$$
\log \left(\frac{X}{C l}\right)=b+m \times \log (C C),
$$

where $b$ is the intercept and $\mathrm{m}$ is the slope in logarithmic space, and

$$
\frac{X}{C l}=10^{b} \times C C^{m},
$$

when retransformed. Regression coefficients for the equations used to calculate the ratio of $\mathrm{Ca}$, magnesium $(\mathrm{Mg})$, potassium (K), Na, bicarbonate $\left(\mathrm{HCO}_{3}\right)$, and $\mathrm{SO}_{4}$ to $\mathrm{Cl}$ from the specific conductance estimated by superposition $(C C)$ are listed in table 5 with the standard error of the estimate calculated for all the ratios using equation 2 and the coefficients of efficiency calculated using equation 3 .

The concentrations of $\mathrm{Na}, \mathrm{Ca}, \mathrm{SO}_{4}$, and $\mathrm{Cl}$ are of particular interest for analysis of highway-runoff quality because they are the predominant constituents in highway deicing compounds. The regression equations developed to estimate the milliequivalent ratio of each constituent to $\mathrm{Cl}$ can be used to estimate the concentration of these major ions in solution. The equations used to derive $\mathrm{EMC}$ values for $\mathrm{Na}, \mathrm{Ca}, \mathrm{SO}_{4}$, and $\mathrm{Cl}$ are as follows:

$$
\begin{aligned}
& \mathrm{Na}=\mathrm{Rna} \times \mathrm{Cl}, \\
& \mathrm{Ca}=\mathrm{Rca} \times \mathrm{Cl}, \\
& \mathrm{SO}_{4}=\mathrm{RsO} \times \mathrm{Cl},
\end{aligned}
$$

and

$$
\begin{aligned}
& C l=C C \div((R n a \times C n a)+(R c a \times C c a)+ \\
& (R s o \times C s o)+(R k \times C k)+(R m g \times C m g)+ \\
& (\text { Ralk } \times C a l k)+(1 \times C c l)),
\end{aligned}
$$

where

$C C \quad$ is specific conductance calculated by superposition, in microsiemens per centimeter;

$\mathrm{Ca}$ is the milliequivalent concentration of calcium;

$\mathrm{Na}$ is the milliequivalent concentration of sodium;

$\mathrm{Cl}$ is the milliequivalent concentration of chloride;

$\mathrm{SO}_{4} \quad$ is the milliequivalent concentration of sulfate;

Rna is the milliequivalent ratio of sodium to chloride;

Rca is the milliequivalent ratio of calcium to chloride;

Rso is the milliequivalent ratio of sulfate to chloride;

$R k \quad$ is the milliequivalent ratio of potassium to chloride;

Rmg is the milliequivalent ratio of magnesium to chloride;

Ralk is the milliequivalent ratio of carbonate to chloride;

Cna is the equivalent theoretical conductance at infinite dilution of sodium (table 5);

Cca is the equivalent theoretical conductance at infinite dilution of calcium (table 5);

Cso is the equivalent theoretical conductance at infinite dilution of sulfate (table 5);

$C k \quad$ is the equivalent theoretical conductance at infinite dilution of potassium (table 5);

$\mathrm{Cmg}$ is the equivalent theoretical conductance at infinite dilution of magnesium (table 5);

Calk is the equivalent theoretical conductance at infinite dilution for carbonate (table 5); and

$\mathrm{Ccl}$ is the equivalent theoretical conductance at infinite dilution of chloride (table 5). 
These equations provide reasonable estimates of the concentration of $\mathrm{Na}, \mathrm{Ca}, \mathrm{SO}_{4}$, and $\mathrm{Cl}$ from flow-weighted event-mean conductance measurements. The coefficient of efficiency of the modified superposition estimates for $\mathrm{Na}, \mathrm{Ca}$, $\mathrm{SO}_{4}$, and $\mathrm{Cl}$ are about $0.94,0.30,0.53$, and 0.97 , respectively. These results indicate that the concentrations predicted using adjusted superposition are slightly better than the results of regression equations between measured conductance and constituent concentrations (table 6).

\section{Data Quality}

The accuracy and precision of the data collected in this study were ensured by making quality-control measurements at each of the monitoring stations, operating redundant sensors, collecting various types of quality-control samples, and conducting quality-assurance experiments. Quality-control samples include source-solution blanks, field blanks, replicate samples, field-matrix spike samples, and replicate field-matrix spike samples. Quality-control experiments were performed to assess the collection and processing of water samples containing coarse particles greater than $0.250 \mathrm{~mm}$ in diameter. The identification of random error and systematic bias can be achieved through the collection and analysis of quality-control data. These analyses provided the basis for the interpretation of continuous measurements of specific conductance and rainfall, and sediment and chemical data collected in this study.

\section{Continuous Measurements}

Comparative measurements of water level, water temperature, air temperature, and specific conductance were routinely made manually during sampling preparation, sample collection, and routine site visits to ensure the accuracy of the measurements and collection of highway-runoff composite samples. Rain gages also were checked periodically for debris buildup that could plug the device. Manual measurements of water levels were made by measuring the distance between the water surface near the site's sensor and some common reference point. Differences resulting from sensor drift were immediately corrected. The accuracy of water-temperature and air-temperature data was determined by comparing measurements made by the monitoring system with those made by an independent probe calibrated against a National Institute of Standards and Technology traceable thermometer. The accuracy of specific conductance data was obtained by ensuring that the sensor was clean and free from debris, by documenting the performance of the sensor before and after sensor maintenance, and by noting the response of the clean sensor after placing it in several standard solutions. In addition, a redundant rain gage and a redundant specific conductance sensor were installed at the test station on Interstate 190 to determine the potential variability in measurements of rainfall totals and calculated event-mean specific conductance values, respectively.

A comparison of measurements made during site visits at each of the highway-monitoring stations indicated that the continuous measurements were generally accurate and precise. The difference between comparative measurements of water level was often less than about $0.02 \mathrm{ft}$, which was within the combined uncertainty of the measurements of the sensor and the manual comparative measurements. The median errors for raw measurements of specific conductance, which were the combined errors of fouling and drift measurements, ranged from about 5 to 21 percent prior to any improvements made on the basis of field calibration values. Non-winter rainfall totals measured concurrently by the primary and redundant tippingbucket gages at the monitoring station on Interstate 190 also were precise. About 80 percent of the redundant rainfall totals were within $0.01 \mathrm{in}$. of the primary measurements, and about 95 percent of the redundant rainfall totals were with 0.04 in. of the primary measurements. The maximum difference between measurements from the two rain gages was 0.10 in. Larger differences between the amounts of rain measured by each gage could be the result of the physical mounting location of each gage and the direction and speed of wind during the storms.

Event-mean values of specific conductance for each runoff event were calculated on the basis of available continuous records of flow greater than $0.009 \mathrm{ft}^{3} / \mathrm{s}$ and records of in situ specific conductance; results were compared to the respective event-mean specific conductance of flow-weighted composite samples. These comparisons were done, in part, to determine whether the frequency of sample collection within storms was sufficient to accurately characterize the variability of dissolved

Table 6. Regression equation coefficients and nonparametric coefficients of efficiency for measured specific conductance to concentrations for sodium, calcium, chloride, and sulfate measured in composite samples of highway runoff for 12 sites in Massachusetts, 2005-07.

\begin{tabular}{lccc}
\hline Major ion & $\begin{array}{c}\text { Intercept of the } \\
\text { regression equation, } \\
\text { unitless (retransformed) }\end{array}$ & $\begin{array}{c}\text { Slope of the } \\
\text { regression equation }\end{array}$ & $\begin{array}{c}\text { Nonparametric coefficient of } \\
\text { efficiency for constituent } \\
\text { concentrations, unitless }\end{array}$ \\
\hline Chloride & 0.111 & 1.117 & 0.939 \\
Sodium & 0.100 & 1.071 & 0.959 \\
Calcium & 0.144 & 0.677 & 0.263 \\
Sulfate & 0.138 & 0.772 & 0.509 \\
\hline
\end{tabular}


solids and other constituents in runoff. This also was done to determine whether flows calculated from the stage-discharge relation for each monitoring station were reasonable.

Event-mean values for specific conductance also were calculated using data from the redundant sensor at the monitoring station on Interstate 190. The median difference between estimated event-mean values of specific conductance calculated independently from primary and redundant sensor data at the monitoring station on Interstate 190 is about 6 percent. The interquartile range for the respective differences is about 18 percent; differences vary from 2 to 20 percent. Larger differences between data from the primary and redundant sensors generally are the result of the redundant sensor not being adequately submersed because it was mounted slightly higher than the primary sensor.

The agreement between event-mean specific conductance, which was estimated from continuous records of flow and in situ measurements of specific conductance, and specific conductance measured in composite samples tended to have a low bias but generally was reasonable (fig. 13A) despite the sometimes large dissimilarity in runoff coefficients for storms during which the samples of highway runoff were collected. The median difference between estimated event-mean values of specific conductance and respective manual measurements of specific conductance in the same flow-weighted composite samples of highway runoff was about 10 percent for values less than $1,000 \mu \mathrm{S} / \mathrm{cm}$ (fig. 13B). For values of specific conductance greater than $1,000 \mu \mathrm{S} / \mathrm{cm}$ (fig. 13B), the respective difference was about 24 percent. The accuracy of most values of estimated event-mean specific conductance was within the precision of the comparative field measurements ( 5 to 21 percent) and the precision of the estimates made by the redundant sensor at the monitoring station on Interstate 190 (median difference of 6 percent). However, the accuracy of estimated values of event-mean specific conductance greater than $1,000 \mu \mathrm{S} / \mathrm{cm}$ was often less, in part, because the sensors were typically calibrated to a $1,000 \mu \mathrm{S} / \mathrm{cm}$ standard, and as a result, the sensor generally was less accurate at values substantially greater than this value.

\section{Chemical Quality of Water Samples}

Quality-control samples of spiked sample water and blank water were collected to identify potential bias in sampling and processing methods and to identify contamination resulting from the sampling equipment and from the samplecollection, sample-processing, and sample-analysis methods. Other quality-control samples were collected in the field and laboratory to estimate analyte degradation, evaluate method recovery and performance, and determine the presence of interfering agents.

\section{Field Quality-Control Samples}

Quality-control samples collected in the Massachusetts Water Science Center laboratory and in the field include source-solution blanks, field blanks, replicate samples, fieldmatrix spike samples, and replicate field-matrix spike samples.

\section{Field-Blank Samples}

A field blank is used to test for positive bias that can result from contamination at any stage of sample collection, processing, or analysis, as well as from the sampling equipment itself. Source-solution blanks were prepared from deionized water produced by a laboratory-grade water-purification system that uses ion-exchange packs and reverse osmosis. The source-solution water was stored in Teflon-lined bottles until it was used as blank water for the collection of field blanks. The source-solution water was submitted for analysis of all constituents measured in this study at the time of bottling. Field blanks were collected throughout the study period and at every monitoring station. Field blanks were collected by the automatic sampler during preparation for storm sampling. These samples were collected by pumping blank water through the automatic sampler tubing and into the collection bottle, then processing it in a manner consistent with the collection of environmental samples of stormwater. The number of field blanks collected at each site was proportionate with the total number of samples collected at the site.

Over the course of the study period, 18 field blanks were collected and submitted for chemical and sediment analysis. A single bottle to be analyzed for PAHs and phthalates unfortunately was destroyed during shipment to the NWQL, and therefore, only 17 samples were analyzed for most of these analytes. Three field blanks also were collected and analyzed for concentrations of other less frequently measured anthropogenic and natural organic compounds. These samples provided replicate measurements for concentrations of several PAH and phthalate compounds. Measurable concentrations of each constituent in field-blank samples were compared to the long-term method detection limit (LTMDL). The LTMDL is the lowest detectable concentration of an analyte that can be measured and reported with 99 percent confidence that the concentration is greater than zero. The chance of falsely reporting a concentration at or greater than the LTMDL for a sample that does not contain the analyte is predicted to be less than or equal to 1 percent (Childress and others, 1999). For analytes not detected in samples, a concentration equal to twice the LTMDL value (laboratory reporting limit) is reported with a "less than" $(<)$ remark code in all data tables in this report.

A nonparametric statistical method, which focuses on the ranks of concentrations as opposed to the concentrations themselves, was used to determine whether the potential contamination observed in field-blank samples affected the utility of the data. This statistical technique is described in detail by Mueller (1998). In this study, the confidence level for the one-sided upper contamination limit was estimated 


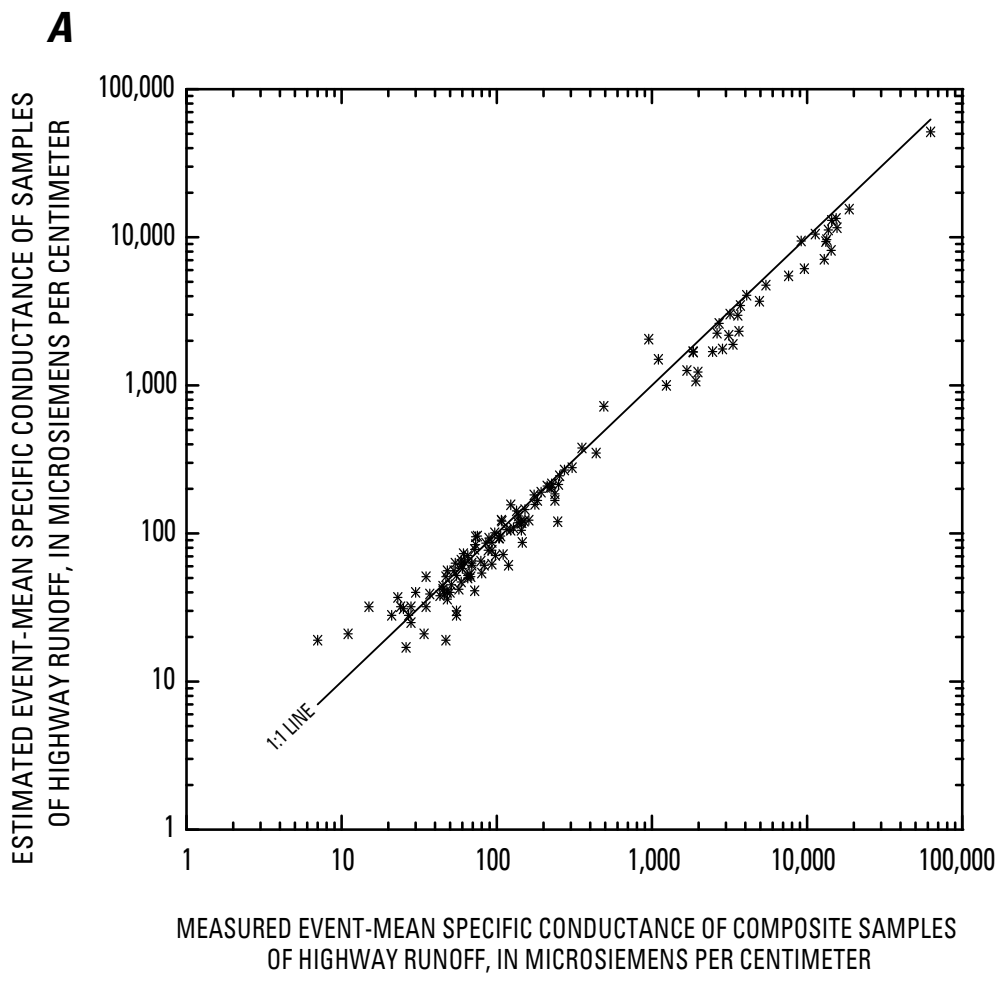

$\boldsymbol{B}$

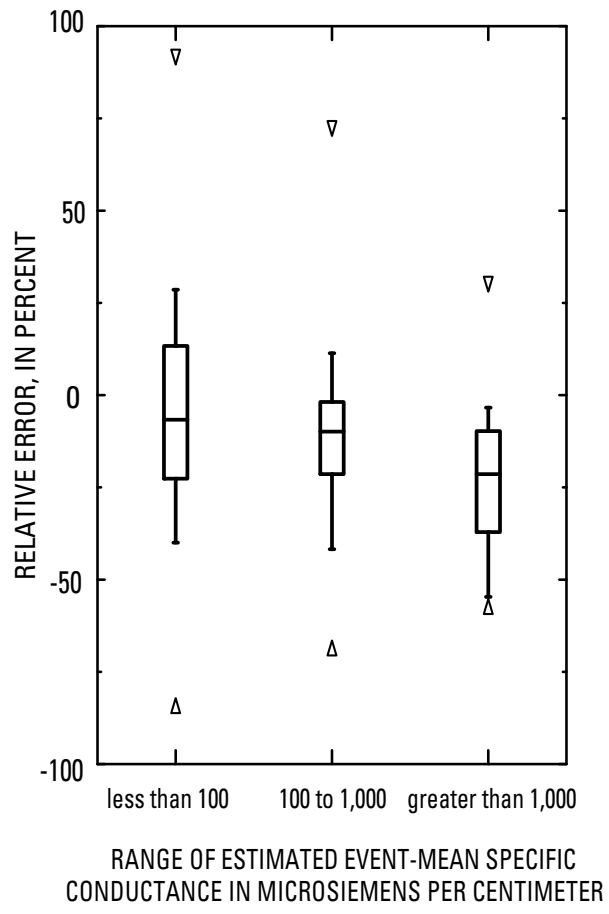

\section{EXPLANATION}

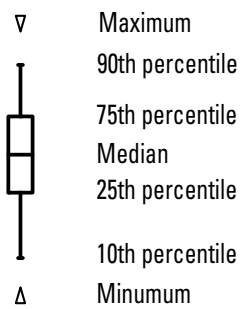

Figure 13. Relation of $(A)$ flow-weighted specific conductance values estimated from continuous records of flow and specific conductance to measured event-mean specific conductance of composite samples of highway runoff collected at 12 monitoring stations on 8 highways for paired events, and $(B)$ relative error between event-mean specific conductance and estimated values of event-mean specific conductance in three ranges. 
for the 90th percentile of highway-runoff concentration data on the basis of the number of field-blank samples and the measured concentration of each constituent in field blank samples in the highest rank. The maximum potential contamination bias for at least 90 percent of all samples was estimated (at various levels of confidence; table 7) to be less than the LTMDL for most of the constituents, except for Ca, total N, P, total-recoverable iron $(\mathrm{Fe})$ and manganese $(\mathrm{Mn})$, anthracene, benzo $[a]$ pyrene, bis(2-ethylhexyl) phthalate, diethyl phthalate, di-n-butyl phthalate, indeno[1,2,3-cd] pyrene, naphthalene, and suspended sediment. The detection of a constituent at a concentration greater than or equal to the LTMDL was rare, limited to three or fewer observations, and the concentrations were often small in comparison to those measured in composite samples of highway runoff.

Low levels of contamination may be acceptable if the level of contamination is within the measurement error of the analytical method or is well below the concentrations of the constituent in the environmental samples. For example, the maximum concentration for $\mathrm{Ca}$ in the field blanks was an order of magnitude lower than the minimum concentration measured in composite samples of highway runoff. However, for other constituents, such as N, P, Fe, Mn, anthracene, benzo[ $a]$ pyrene, bis(2-ethylhexyl) phthalate, diethyl phthalate, di-n-butyl phthalate, indeno[1,2,3-cd] pyrene, naphthalene, and suspended sediment, concentrations in several samples of highway runoff were at or near the LTMDL and similar to the maximum observed concentrations in the field blanks. These cases were generally rare and 90 percent or more of the concentrations of $\mathrm{N}, \mathrm{Fe}, \mathrm{Mn}$, and suspended sediment in samples of highway runoff were at least one order of magnitude greater than the maximum concentration measured in field blanks. Concentrations of $\mathrm{Mn}$ and suspended sediment also were detected in the source water in comparable concentrations, indicating that the water source, analytical containers, or laboratory processes during analysis could have been the source of contaminants. Concentrations of $\mathrm{P}$, anthracene, benzo $[a]$ pyrene, bis(2-ethylhexyl) phthalate, diethyl phthalate, di-n-butyl phthalate, indeno[1,2,3-cd]pyrene, and naphthalene in samples of highway runoff, on the other hand, were generally low, and therefore, the contamination bias is potentially greater. The median $\mathrm{P}$ concentration for all samples of highway runoff in this study was $0.10 \mathrm{mg} / \mathrm{L}$. The precision of the analytical method is about $\pm 0.004 \mathrm{mg} / \mathrm{L}$ at this concentration, and the method precision decreases to $\pm 0.03 \mathrm{mg} / \mathrm{L}$ for higher concentrations (Patton and Kryskalla, 2003). Anthracene and naphthalene were detected in a single blank and exceeded only the lower LTMDL for the secondary analytical method. Benzo $[a]$ pyrene, bis(2-ethylhexyl) phthalate, diethyl phthalate, di-n-butyl phthalate, and indeno[1,2,3-cd]pyrene also were infrequently detected in field blanks (table 7); however, the maximum potential contamination estimated for 90 percent of the field data is similar in magnitude to the median concentrations of individual constituents in all composite samples of highway runoff ( 0.14 to $5.02 \mu \mathrm{g} / \mathrm{L})$. Furthermore, most of the higher concentrations of these constituents, defined by the $95^{\text {th }}$ percentile ( 0.9 to $18 \mu \mathrm{g} / \mathrm{L})$, is less than one order of magnitude greater than the respective median concentration in the highway samples. Thus, the maximum contamination level for 90 percent of these data can potentially account for a substantial amount of the concentration in most samples. Therefore, data for benzo[ $[a]$ pyrene, bis(2-ethylhexyl) phthalate, diethyl phthalate, di-n-butyl phthalate, and indeno[1,2,3-cd] pyrene are to be viewed with caution because the magnitude of potential contamination measured in field blank samples, although rare, is similar to the concentration of each constituent measured in samples of highway runoff.

Contamination bias appeared to be random for all constituents except for naphthalene. Concentrations of naphthalene in field blanks often were equivalent to the concentrations measured in samples of highway runoff. Naphthalene was not detected in the four samples of source water used for field-blank samples; however, these analyses were performed at the time the water was bottled. Analysis of the field-blank concentrations with respect to the holding time of the source water indicates an increasing exponential trend with increased age of the source water. Naphthalene was detected in field blanks where the source water was at least 5 months old, and the concentrations of naphthalene increased with the age of the source water. One possible explanation for the detection of naphthalene in the field blank is that sodium naphthalene is used in the manufacturing of some Teflon products (Benderly, 1962). Because the source water was stored in a bottle lined with a Teflon bag, it is possible that the naphthalene leached from the bag over time. Considering this, it is unlikely that there is any measurable contamination bias for naphthalene in samples of highway runoff.

\section{Replicate Samples}

Replicate samples are samples that are thought to be identical in composition to the environmental samples. Replicate samples provide a measure of bias and variability in the method of sample collection, sample processing (splitting, filtering, and preservation), and laboratory analysis, and in sample changes, such as analyte degradation, that can occur prior to laboratory analysis.

In this study, replicate samples generally were not collected, but analyses were conducted for seven SVOCs using different analytical methods on sample splits of flow-weighted composite samples of highway runoff that provide the same kind of information provided by replicate quality-control samples. Replicate samples were split sequentially from 14 composite samples of highway runoff and analyzed for concentrations of anthracene, benzo[ $[a]$ pyrene, bis(2-ethylhexyl) phthalate, fluoranthene, phenanthrene, pyrene, and naphthalene by two different analytical methods. Most of the data on constituents were determined by an analytical method using methylene chloride extraction and gas chromatograph/ mass spectrometry analysis (Fishman, 1993). The secondary method, which provided measurements for 69 anthropogenic and natural organic compounds, including the seven 


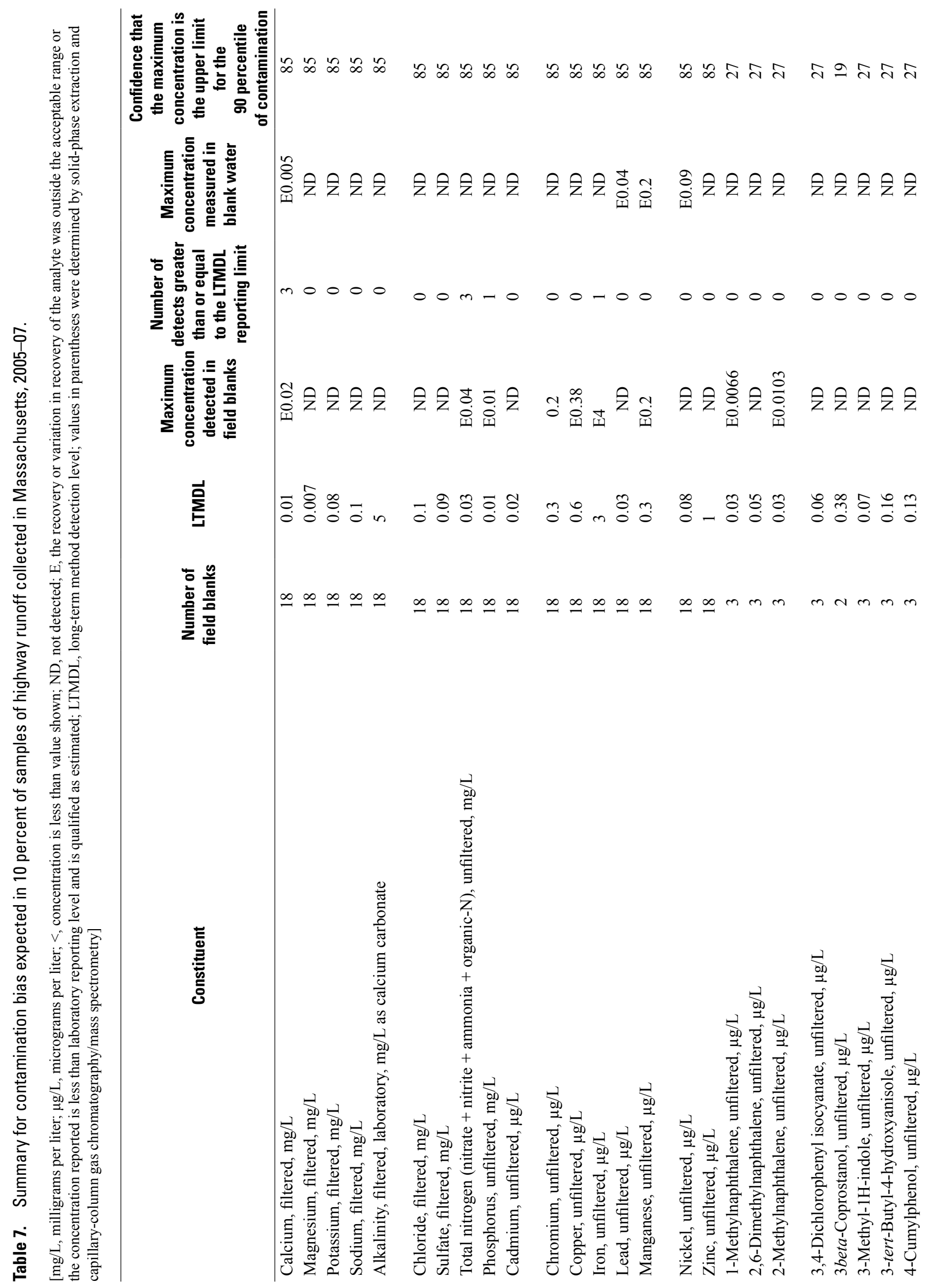




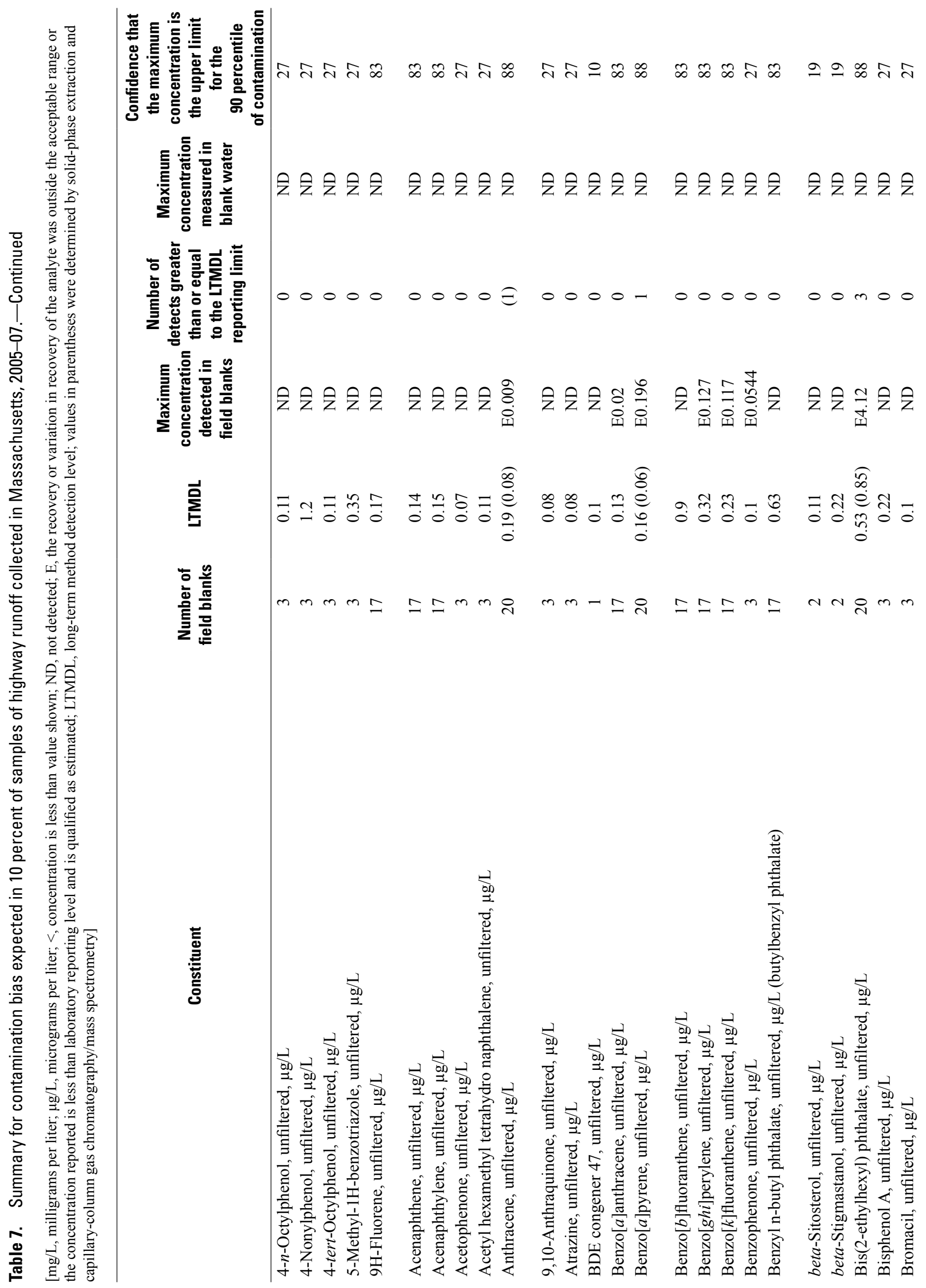




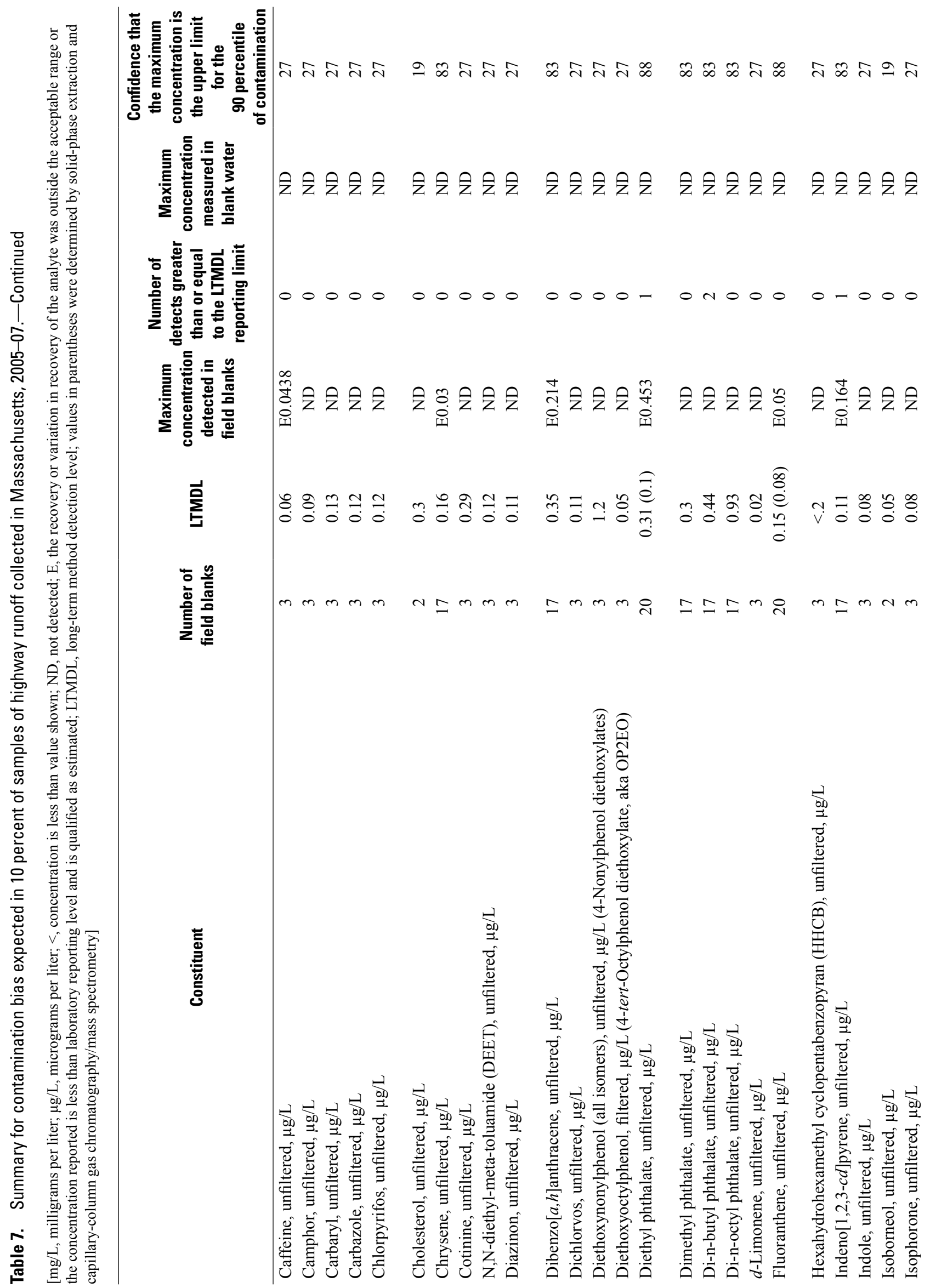




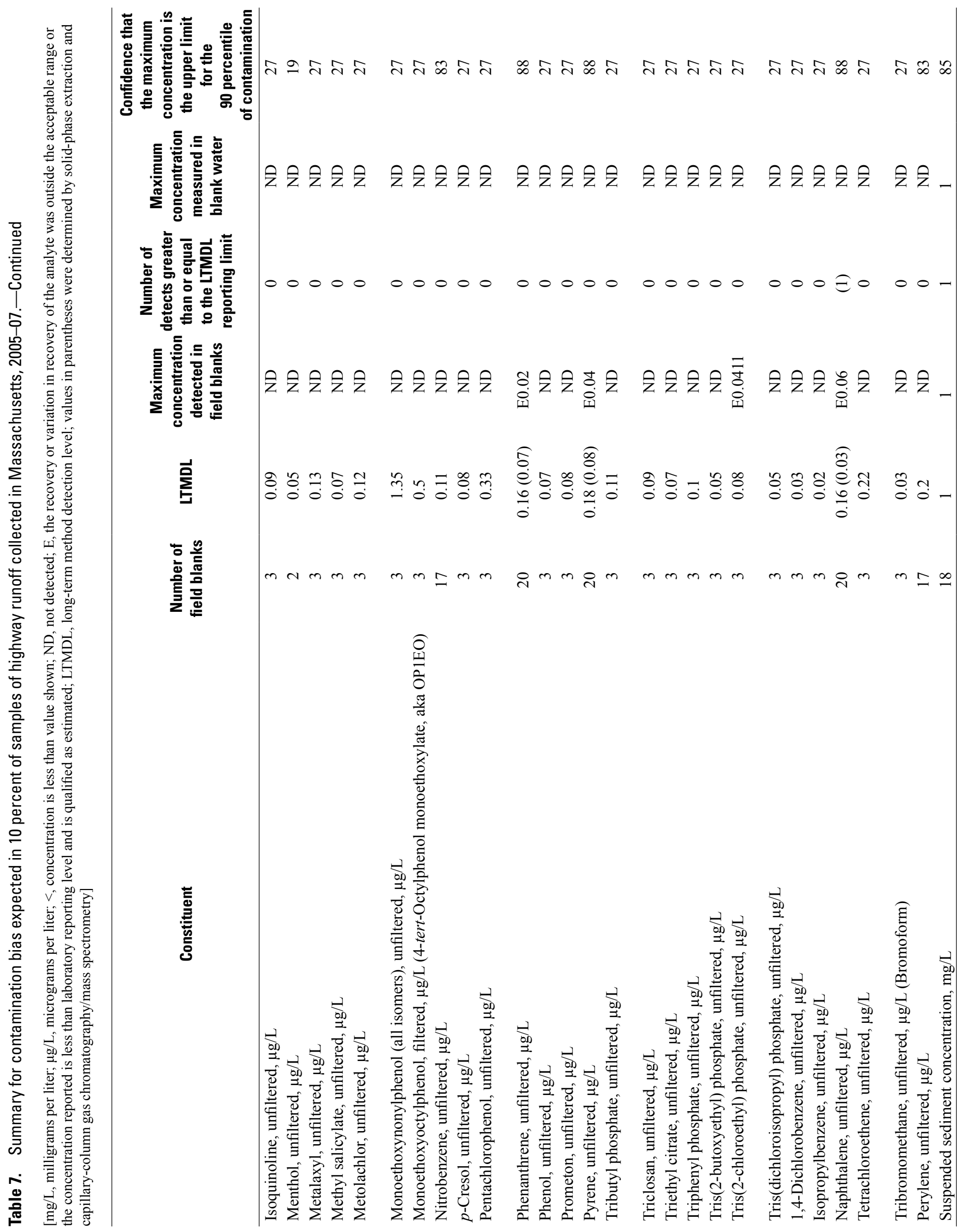


compounds listed immediately above, used continuous liquid-liquid extraction and capillary-column gas chromatography/mass spectrometry analysis (Zaugg and others, 2006a). Replicate sample sets were evaluated by comparing the relative percent differences (RPDs) of the results for each pair of samples where the same analyte was detected in both samples. The average absolute RPD ranged from 12 to 16 percent for five of the seven compounds (table 8). The average RPDs for anthracene and bis(2-ethylhexyl) phthalate were 30 and 35 percent (table 8 ), respectively. The standard deviation for the RPDs indicates the most precise values were determined for benzo $[a]$ pyrene (standard deviation of about 5 percent) and the standard deviation for the other compounds (table 8) ranged from about 11 to 29 percent. The relative concentrations of the target analytes in the water samples did not seem to affect the variability of analyte recovery between samples processed using the different analytical methods.

\section{Field-Spiked and Replicate Field-Spiked Samples}

Field-spiked samples are quality-control samples in which known amounts of target compounds are added to environmental replicate-split samples, which are then measured. The degree of recovery for each target analyte added to the environmental sample is used to determine the bias and variability attributed to the amount of degradation of target analytes during holding and shipment to the laboratory, the analytical method, and interferences contained in the environmental sample that mask or enhance determinations of the target analytes, or matrix effects. Replicate field-spiked samples also were submitted to the NWQL for analysis. Similarly, known amounts of target compounds were added to replicate field-spiked samples. These samples were processed in the same manner as the field-spiked samples, such that the samples were expected to be essentially identical in composition. Comparing the recovery for an analyte in a replicate field-spiked sample to the recovery for an analyte in the paired field-spiked sample provides a measure of the variability attributed to the aforementioned processes that can affect the concentration of each analyte.

Field-spiked samples and replicate field-spiked samples were split sequentially from composites of water collected at most monitoring stations throughout the study period, so comparisons of different matrices and concentrations reveal storm-to-storm and seasonal variations in water chemistry. For two samples, the analytical detection level was raised for bis(2-ethylhexyl) phthalate by the NWQL to a value greater than the fortification amount, and as a result, recoveries for field-spiked samples could not be calculated. The analytical detection level also was raised for benzyl n-butyl phthalate, and a recovery for the field-spiked sample could not be calculated. The average recovery of each compound and the precision of the recoveries, determined on the basis of spiked replicate data, are presented table 9 .

A single field-spiked sample and a single replicate fieldspiked sample also were collected and analyzed for the other anthropogenic and natural compounds that were sampled for less frequently. These data are presented in table 10. The average RPD between analyte recoveries in the field-spiked sample and analyte recoveries in the replicate field-spiked sample for all analytes was about 27 percent. Because only a single fieldspiked sample was collected, broad generalizations for the recovery of concentrations of organic compounds measured in the other 14 samples of highway runoff cannot be made with reasonable certainty.

\section{Laboratory Quality Assurance and Quality- Control Samples}

In addition to the quality-control samples collected during this project, the NWQL routinely analyzes various quality-control samples, including laboratory reagent blanks, interference check solutions, laboratory-control samples, standard-reference materials, laboratory-reagent spiked samples, laboratory-preparation spiked samples, and

Table 8. Replicate sample statistics for seven organic compounds determined by methylene chloride extraction and gas chromatograph/mass spectrometry analysis and by continuous liquid-liquid extraction and capillary-column gas chromatography/ mass spectrometry analysis for 14 samples of highway runoff collected in Massachusetts, 2005-07.

\begin{tabular}{lcccc}
\hline \multirow{2}{*}{ Analyte } & \multicolumn{4}{c}{ Relative percent difference } \\
\cline { 2 - 5 } & Mean & Standard deviation & Minimum & Maximum \\
\hline Anthracene & 30 & 29 & 3 & 94 \\
Benzo[a]pyrene & 12 & 5 & 5 & 22 \\
Bis(2-ethylhexyl) phthalate & 35 & 25 & 3 & 75 \\
Fluoranthene & 16 & 11 & 1 & 41 \\
Phenanthrene & 15 & 14 & 1 & 53 \\
Pyrene & 15 & 13 & 1 & 38 \\
Naphthalene & 14 & 14 & 1 & 34 \\
\hline
\end{tabular}




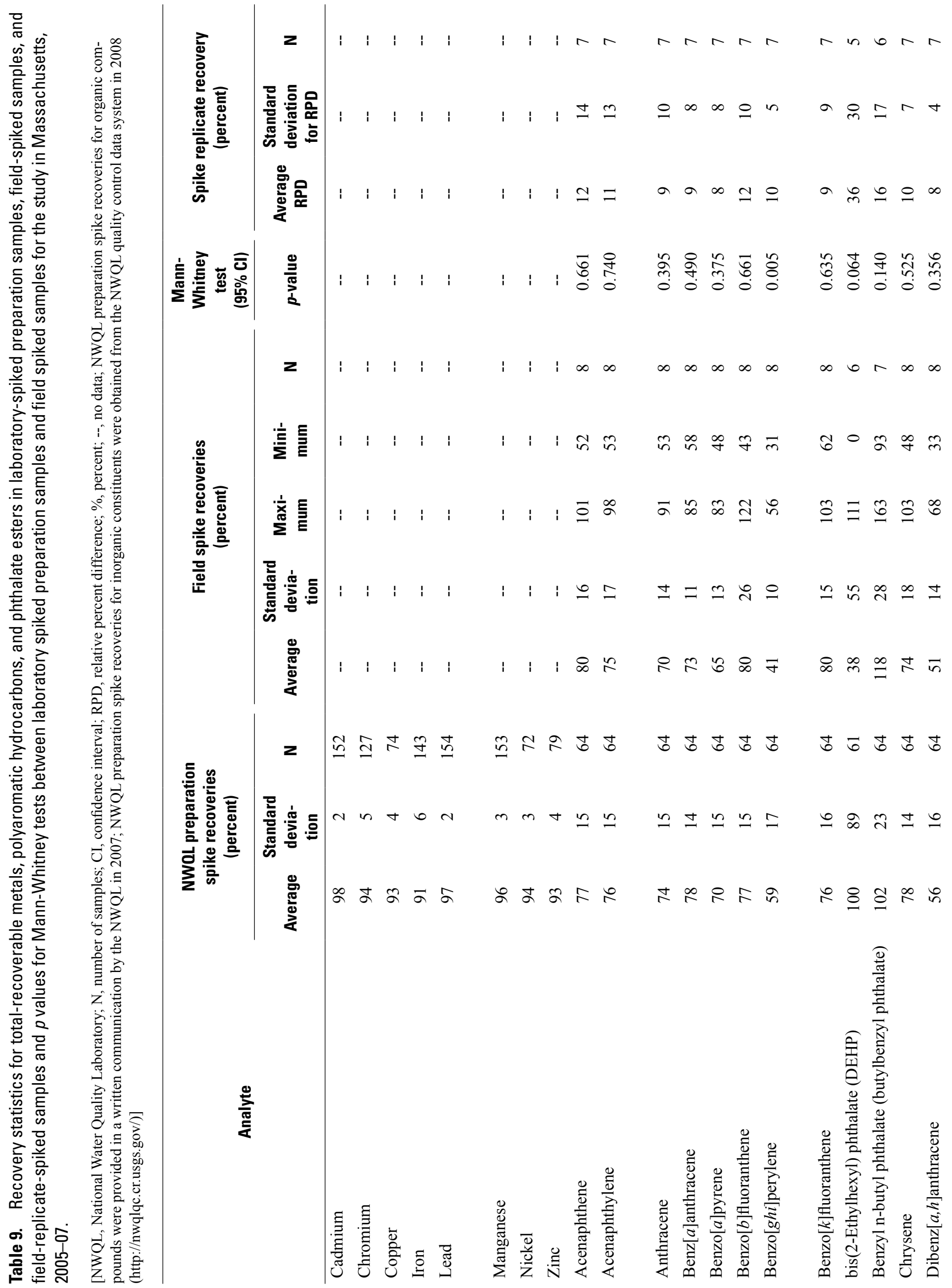




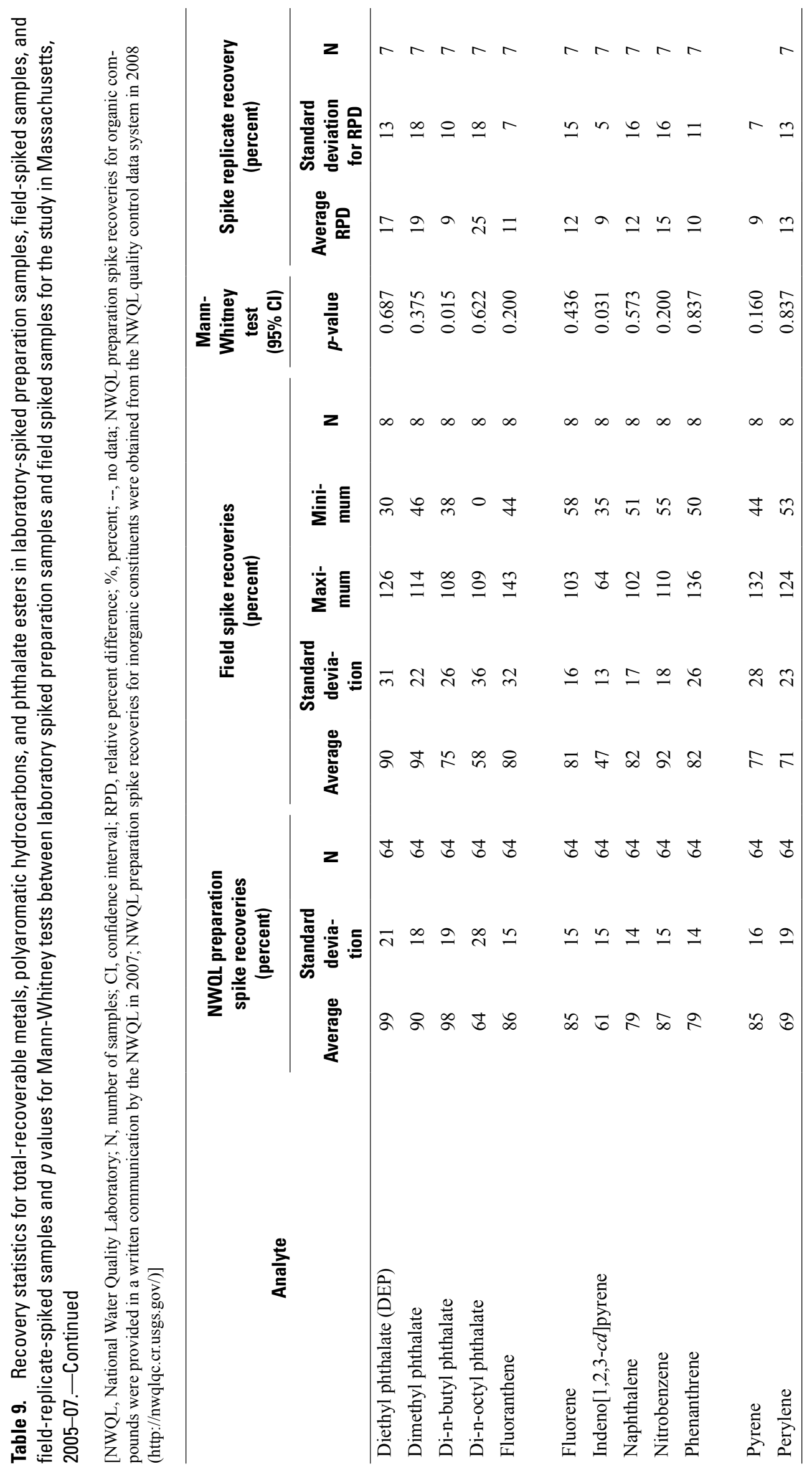


Table 10. Recovery statistics for selected natural and anthropogenic organic compounds in laboratory-spiked preparation samples, a single field-spiked sample, and a single replicate field-spiked sample for the study in Massachusetts, 2005-07.

[NWQL, National Water Quality Laboratory; RPD, relative percent difference; NWQL preparation spike recoveries for inorganic compounds were obtained from the NWQL QC Data system in 2008]

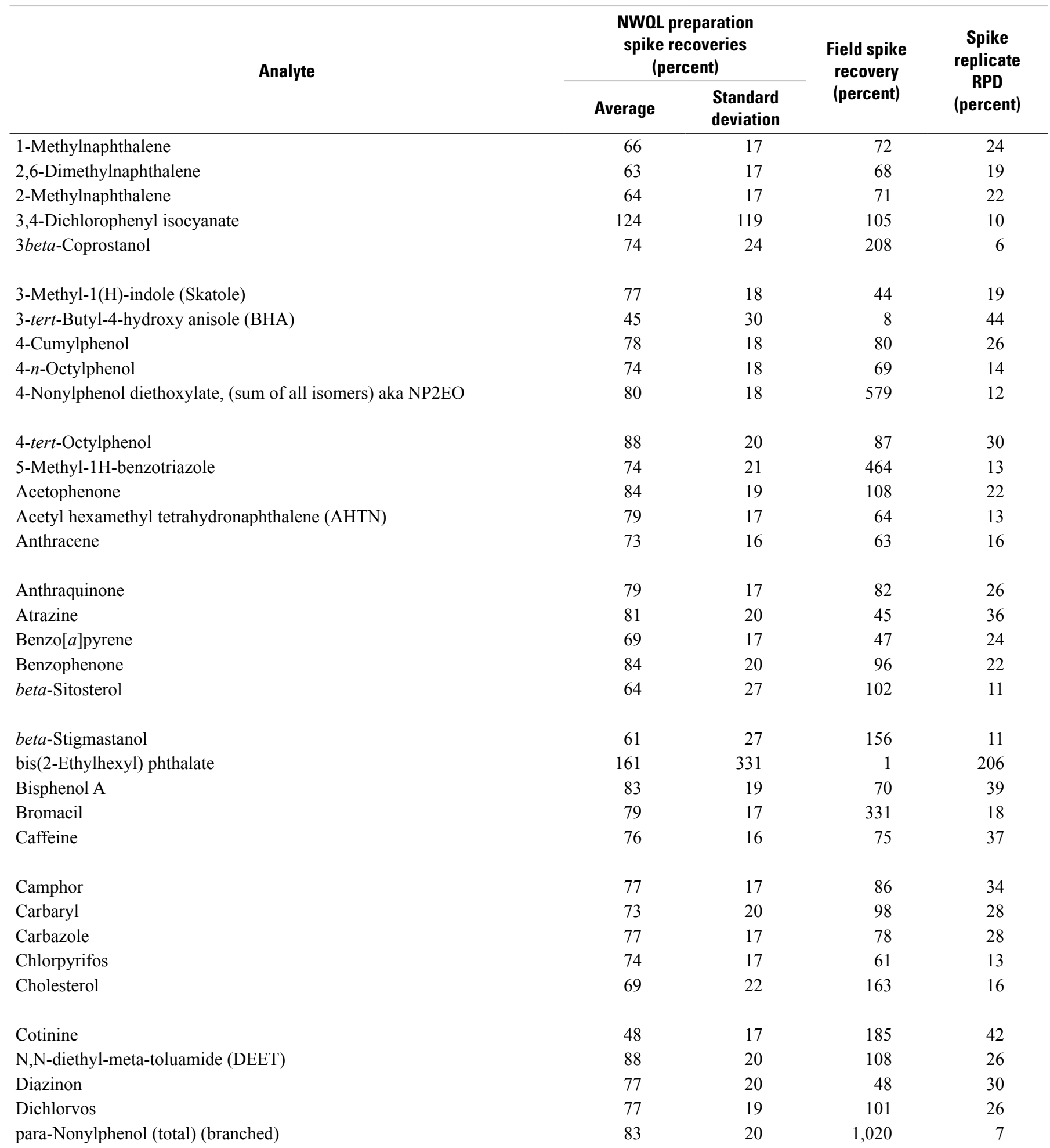


Table 10. Recovery statistics for selected natural and anthropogenic organic compounds in laboratory-spiked preparation samples, a single field-spiked sample, and a single replicate field-spiked sample for the study in Massachusetts, 2005-07.-Continued

[NWQL, National Water Quality Laboratory; RPD, relative percent difference; NWQL preparation spike recoveries for inorganic compounds were obtained from the NWQL QC Data system in 2008]

\begin{tabular}{|c|c|c|c|c|}
\hline \multirow{2}{*}{ Analyte } & \multicolumn{2}{|c|}{$\begin{array}{l}\text { NWOL preparation } \\
\text { spike recoveries } \\
\text { (percent) }\end{array}$} & \multirow{2}{*}{$\begin{array}{l}\text { Field spike } \\
\text { recovery } \\
\text { (percent) }\end{array}$} & \multirow{2}{*}{$\begin{array}{c}\text { Spike } \\
\text { replicate } \\
\text { RPD } \\
\text { (percent) }\end{array}$} \\
\hline & Average & $\begin{array}{l}\text { Standard } \\
\text { deviation }\end{array}$ & & \\
\hline 4-tert-Octylphenol diethoxylate, aka OP2EO & 117 & 117 & 76 & 14 \\
\hline Diethyl phthalate & 90 & 21 & 102 & 26 \\
\hline$d$-Limonene & 29 & 15 & 61 & 22 \\
\hline Fluoranthene & 78 & 17 & 60 & 22 \\
\hline Hexahydrohexamethyl cyclopentabenzopyran (HHCB) & 80 & 17 & 58 & 11 \\
\hline Indole & 78 & 18 & 26 & 16 \\
\hline Isoborneol & 77 & 22 & 87 & 25 \\
\hline Isophorone & 78 & 18 & 97 & 27 \\
\hline Isoquinoline & 76 & 18 & 88 & 48 \\
\hline Menthol & 85 & 29 & 84 & 34 \\
\hline Metalaxyl & 83 & 18 & 89 & 35 \\
\hline Methyl salicylate & 83 & 19 & 69 & 24 \\
\hline Metolachlor & 80 & 16 & 80 & 21 \\
\hline 4-Nonylphenol monoethoxylate, (sum of all isomers) aka NP1EO & 83 & 18 & 557 & 18 \\
\hline 4-tert-Octylphenol monoethoxylate, aka OP1EO & 85 & 19 & 143 & 17 \\
\hline$p$-Cresol & 78 & 18 & 77 & 45 \\
\hline Pentachlorophenol & 65 & 25 & 330 & 38 \\
\hline Phenanthrene & 74 & 16 & 65 & 23 \\
\hline Phenol & 77 & 19 & 63 & 61 \\
\hline Prometon & 79 & 18 & 86 & 33 \\
\hline Pyrene & 74 & 19 & 61 & 24 \\
\hline Tributyl phosphate & 89 & 23 & 84 & 7 \\
\hline Triclosan & 83 & 18 & 102 & 25 \\
\hline Triethyl citrate (ethyl citrate) & 82 & 20 & 97 & 30 \\
\hline Triphenyl phosphate & 76 & 16 & 64 & 13 \\
\hline Tris(2-butoxyethyl)phosphate & 82 & 23 & 95 & 18 \\
\hline Tris(2-chloroethyl)phosphate & 79 & 17 & 80 & 26 \\
\hline Tris(dichlorisopropyl)phosphate & 78 & 17 & 71 & 20 \\
\hline 1,4-Dichlorobenzene & 51 & 20 & 73 & 24 \\
\hline Isopropylbenzene & 36 & 18 & 66 & 25 \\
\hline Naphthalene & 69 & 18 & 81 & 23 \\
\hline Tetrachloroethylene & 24 & 12 & 49 & 28 \\
\hline Bromoform & 62 & 15 & 74 & 23 \\
\hline
\end{tabular}


laboratory-duplicate samples to test and track method performance (Garbarino and others, 2006). The NWQL also adds surrogate compounds to all samples for determinations of SVOCs. Surrogate compounds, such as 2-fluorobiphenyl and p-terphenyl-d14, are expected to perform similarly to the compounds being analyzed for in the laboratory. Because these compounds are not normally found in the environment, the recovery of the surrogate compounds can be used to qualify the performance of the analysis.

\section{Laboratory Spiked Samples}

Laboratory-preparation spiked samples provide a measure of method performance because they are processed and analyzed in the same manner as environmental samples. Laboratory-preparation spiked samples are prepared by adding known concentrations of target analytes to blank water. Average field spike recoveries for PAH compounds were similar to the average laboratory-preparation spike recoveries (table 9), except for benzo[ghi]perylene and indeno[1,2,3-cd]pyrene, which were lower for field-spiked samples. Average spike recoveries for the study period for phthalate compounds also were similar to the average laboratory-preparation spike recoveries for the respective compounds, except for bis(2-ethylhexyl) phthalate and di-n-butyl phthalate (table 9), which were notably lower.

The Mann-Whitney test, also referred to as the rank-sum test, was used to determine whether the independent populations of field-spike values were statistically different than laboratory-preparation spike values to comprehend whether or not the sample collection and field processing potentially affected the concentration of the PAH and phthalates in the composite samples of highway runoff. The Mann-Whitney test is a nonparametric method that makes no assumptions about the distribution of data and is used to determine whether groups of data come from the same population or, alternatively, whether the median values are different (Helsel and Hirsch, 2002). Resultant $p$ values are listed in table 9. These data indicate the populations of field-spike recoveries for benzo[ghi]perylene, indeno[1,2,3-cd]pyrene, and di-n-butyl phthalate are significantly different ( $p$ value less than 0.05 ) than the populations of laboratory-preparation spike recoveries for the respective compounds. The result for bis(2-ethylhexyl) phthalate is significant at a slightly higher confidence interval (table 9). Because the variability of field-spike recoveries for these compounds was similar to the variability of laboratory-preparation spike recoveries, and because the replicate field-spike recoveries for these compounds indicate that the measurements are relatively precise, such differences are likely attributable to the degradation of the compounds prior to laboratory processing or potential matrix effects that masked the compounds. As a result, these data indicate that concentrations of benzo[ghi]perylene, indeno[1,2,3-cd]pyrene, and di-n-butyl phthalate are likely underestimated in samples of highway runoff collected in this study. The recoveries for other analytes that were fortified in samples of highway runoff were similar to the recoveries of the same analytes in laboratory-preparation spike samples, which were prepared from organic-free blank water.

For the less frequently measured natural and anthropogenic compounds (table 4), about 57 and about 84 percent of the spike recoveries in the single composite sample of highway runoff were within one and three standard deviations, respectively, of the average recoveries for the same analytes in laboratory-preparation spiked samples analyzed during the sampling period. Field-spike recoveries of 3 beta-coprostanol, 4-nonylphenol diethoxylate, beta-stigmastanol, bromacil, cholesterol, cotinine, para-nonylphenol, 4-nonylphenol monoethoxylate, 4-tert-octylphenol monoethoxylate, and pentachlorophenol, which were greater than three standard deviations from the average recoveries for the same analytes in laboratory-preparation spiked samples, ranged from 142 to 1,020 percent. Except for the aforementioned compounds, the field and laboratory spike recoveries are similar for this sample of highway runoff (table 10).

Field-spiked samples for major ions and total-recoverable metals were not collected during this study because these constituents do not readily degrade during the short holding periods prior to shipment to the laboratory. However, laboratory-preparation spike recoveries were routinely performed for total-recoverable metals to monitor potential losses during sample digestion. These data indicate that the average recovery for fortified concentrations of total-recoverable metals in laboratory-preparation spiked samples was relatively accurate and precise. Average recoveries for total-recoverable metals processed by the in-bottle digestion method (Garbarino and Hoffman, 1999) ranged from 91 to 98 percent during this study (table 9 ).

\section{Surrogate-Compound Recovery}

Surrogate-compound recoveries provide a measure of method performance for each individual sample. The recoveries of all surrogate compounds are used to evaluate process control of the analytical method. Thus, if the recovery of only one surrogate is outside of acceptable control limits, the sample measurements typically are considered valid. When surrogate recoveries are outside acceptable control limits (usually low) as a result of an identified process failure, the results for the associated analytes are usually flagged by the NWQL as estimated values; if the recovery of the surrogate compounds is poor, the results are deleted. Reporting levels are adjusted upward under some circumstances.

The surrogate compounds 2-fluorobiphenyl and p-terphenyl-d14 were routinely added to samples during the sample preparation at the NWQL for the analysis PAHs and phthalates. The median recovery of these surrogate compounds for all composite samples of highway runoff was about 71 and 52 percent, respectively. Surrogate recoveries of 2 -fluorobiphenyl and p-terphenyl-d14 for about 19 percent and about 12 percent of the samples, respectively, were outside of laboratory control limits of 38 to 90 percent and 27 to 
102 percent, respectively (Duane Wydoski, written commun. 2008). For nine composite samples of highway runoff (about 7 percent of all composite samples analyzed using the primary method), the recovery of both surrogate compounds was outside of control limits. The surrogate compounds caffeine-13C, fluoranthene-d10, bisphenol A-d3, and decafluorobiphenyl were added to samples during the sample preparation at the NWQL for the analysis of other natural and anthropogenic organic compounds. With the exception of a recovery for bisphenol A-d3 in a single sample of highway runoff, recoveries for all surrogate compounds in samples of highway runoff were within acceptable laboratory control limits.

\section{Laboratory-Blind Samples}

The USGS Office of Water Quality Branch of Quality Systems also submits various quality-control samples to ensure that data produced by USGS laboratories, including sediment laboratories, are of a known quality and are sufficient to provide long-term comparability and consistency on a national basis (U.S. Geological Survey, 2008a). Two single-blind sediment-laboratory quality assurance tests were conducted during each year of this study. Single-blind samples were samples of known concentrations and particle-size distribution values that were submitted to the sediment laboratory for analysis and identified as quality-control samples. Laboratory results were compared to the known values to measure the bias and variance of suspended-sediment data.

Analyses of laboratory blind samples indicate that the measurements of concentrations of suspended sediment in water samples collected during this study are accurate and precise. The median absolute difference between known concentrations of sediment in laboratory blind samples and concentrations of suspended sediment reported by the Kentucky Water-Science Center Sediment Laboratory was less than 1 percent for the study period (U.S. Geological Survey, 2008b). Concentrations of suspended sediment in laboratory blind samples ranged from 134 to $10,333 \mathrm{mg} / \mathrm{L}$ in these samples. The absolute median differences for concentrations of suspended sediment less than $0.063 \mathrm{~mm}$ in diameter and greater than or equal to $0.063 \mathrm{~mm}$ in diameter were within about 2.8 and 7.7 percent, respectively (U.S. Geological Survey, 2008c, 2008d). Concentrations of sediment greater than or equal to $0.063 \mathrm{~mm}$ in diameter had higher variability than the concentrations of the total sediment mass and the fine sediment fraction. This is likely because finer material (composed of silts and clays) has a tendency to conglomerate. As a result, the determination of fines is generally biased low, whereas determinations of sands are biased high as a result of the conglomeration of fines. The percent error decreases for samples with high concentrations because the percent errors are exaggerated for analyses of samples with low-concentrations. Loss or reduction in diameter of a few grains of sand-size material during sample processing also can cause errors. About 5 to 15 percent of the sample sediment mass in the laboratory-blind samples was composed of sand-size material, and error may, to some degree, be exaggerated for determinations of these low quantities.

\section{Sampling Methods, Chemical Quality, and Particle Size for Suspended Sediment and Soil Samples}

\section{Effectiveness of Sampling Methods for Suspended Sediment}

Three quality-control experiments were performed to assess the accuracy and bias of automatic-sample collection and manual-processing methods that could affect the distribution of sediment particle size in water samples. The concentration and size distribution of sediment can vary widely in samples of highway runoff. Most of the coarse-grained material in samples of bottom material collected from oilgrit separators on Interstate 93 that receive flow from catch basins (Smith, 2002) ranged from fine sand to gravel less than about $6 \mathrm{~mm}$ in diameter. Quality-assurance data from recent studies indicate that samples of water containing clay- and silt-size particles can be collected with automatic samplers and processed with standard splitting techniques with reasonable precision (Breault and others, 2005; Smith, 2002); however, it is more difficult to collect and split representative samples of water containing large concentrations of sand-size particles (Selbig and others, 2007).

\section{Automated Collection of Samples of Suspended Sediment, Controlled Experiment}

Automatic sampling is a convenient, cost-effective, and systematic method for collecting samples of water that represent the mean quality of stormwater, which would be impractical if performed manually. Nevertheless, all sampling, as well as sample-processing techniques, are subject to bias. The automatic samplers used in this study were basically heavy-duty battery-powered peristaltic pumps under the control of the datalogger. Like most modern automatic samplers, these devices are capable of purging and rinsing the sample lines and dispensing relatively precise amounts of water to the sample-collection bottle (generally within about 5 percent of the programmed volume during calibration tests in the field). The sampler pumps operate at a fixed speed producing a constant intake velocity of about $2 \mathrm{ft} / \mathrm{s}$ and, therefore, are not capable of collecting isokinetic samples (a sample collected with the velocity of water at the intake of the collection device being the same as the velocity of water flowing past the device) under all circumstances. As a result, the distribution of the particle size in sediment in water samples collected by such devices can be affected by the hydraulic characteristics at the point within the pipe where the intake is located. For small diameter pipes, the sampler intakes are often mounted near the floor of the pipe to maximize the allowable range for 
the collection of samples. Consequently, this increases the risk of oversampling coarse particles because vertical gradients of sediment can form with the largest particles concentrating near the floor of the pipe (Bent and others, 2001). In contrast, under environmental conditions where the water velocity is greater than that of the intake velocity of the sampler, the momentum of coarse particles may preclude them from being entrapped by the currents at the sample intake (Edwards and Glysson, 1999). To overcome such shortcomings, a static mixer was developed prior to the field study to reduce the bias associated with the collection of water samples by a pump with a fixed intake velocity over the expected range of field conditions. The static mixer (fig. 12) is a carefully designed baffle, which was mounted in a pipe, produced a hydraulic environment with reduced sediment-transport velocities and provided turbulence that enabled the collection of coarse-grained sediments over a wide range of flows. The design of the static mixer and the relative placement of the sampler intake were modified on a trial and error basis as a result of observations of the behavior of coarse-grain sediments over a range of flows in the test pipe (fig. 14) where the static mixer was mounted and by collection of samples of sediment-laden water. During this time, other tests were conducted with the automatic sampler, but without the static mixer. With the sampler intake oriented downstream and without a static mixer installed, the successful collection of samples of water by the automatic sampler decreased as velocity increased, and visual inspections of the contents of sample collected under high water-velocity conditions indicated that few coarse-grain particles were collected at higher velocities. Mixed results also were noted in tests where the static mixer was not used and the sampler intake was oriented upstream. Occasionally during these tests, the sampler intake was plugged by coarse sand- and small gravel-size particles, and the sampler could not successfully purge and dislodge the particles under high water-velocity conditions.

Previous studies indicate that fine-grained particles are evenly distributed throughout the water column (Smith, 2002; Butler and others, 1996). Therefore, the focus of the experiments in this study was to define the potential limitations of collecting representative samples of water containing a distribution of sediment particles ranging from about $0.250 \mathrm{~mm}$ to about $6 \mathrm{~mm}$ in diameter. During the first experiment, a test structure was designed to simulate flow and sampling conditions in a typical highway drainage pipe (fig. 14). Artificial flows containing low concentrations of suspended sediment (about 3-6 mg/L) were metered into one end of a test pipe, which was $12 \mathrm{in}$. in diameter by $20 \mathrm{ft}$ in length. Flow in the test pipe was generated by as many as three 9,600 -gal $/ \mathrm{h}$ centrifugal pumps. Flow from each pump was measured by an industrial flow sensor. A dry mixture of sand and gravel with particle diameters as large as about $6 \mathrm{~mm}$ was metered by gravity into the flow stream about $4 \mathrm{ft}$ downstream from the point where the flow entered the pipe. The sampler intake, which was fixed $0.1 \mathrm{ft}$ upstream from the static mixer, was mounted about $4 \mathrm{ft}$ from the outlet of the test pipe. Two sets of paired samples were collected at five different flow rates ranging from about 0.10 to $0.85 \mathrm{ft}^{3} / \mathrm{s}$. One $850-\mathrm{mL}$ sample of water was collected by the automatic sampler while a paired sample of sediment was collected concurrently during the forward-pumping cycle of the automatic sampler with a plankton net at the end of the pipe (fig. 14). The plankton net captured the entire mass of sediment greater than $0.250 \mathrm{~mm}$ in diameter during the sampling period of the automatic sampler. The distribution of particle sizes in samples of suspended sediment collected by the automatic sampler and samples of sediment collected from the plankton net were determined by wet-sieving methods.

Particle-size analysis of samples of water collected by an automatic sampler in conjunction with a static mixer indicate that samples of suspended sediment with particle sizes ranging from $0.250 \mathrm{~mm}$ to more than $4.0 \mathrm{~mm}$ can be consistently collected using this method over a range of flows (fig. 15). Results of the experiment indicate that fine-grain sands $(0.250$ to $0.500 \mathrm{~mm}$ ) were consistently undersampled by the automatic sampler. This systemic bias could have resulted from water-surface tension that prevented the powdered sediment, which was metered by gravity through the top of the pipe, from thoroughly mixing with the flowing water in the pipe. As a result, the difference in distributions of the coarser particles also appeared to be systemic. Because these data are expressed as a percentage of the total distribution, the bias in the larger size particles is likely the result of the forward propagation of the systemic bias observed in the 0.250 - to $0.500-\mathrm{mm}$ diameter range. Furthermore, although the samples of suspended sediment were collected concurrently with samples from the autosampler and with the plankton net, the physical segments of water that were sampled were not necessarily identical in concentration because the sampling locations were different; therefore, the concentrations of sediment for each particle-size fraction cannot be compared without error.

\section{Automated Collection of Samples of Suspended Sediment, Field Experiment}

The second experiment was conducted in the field at the primary station on Interstate 495 . For this experiment, samples of stormwater for the evaluation of concentrations of suspended sediment were collected by an automatic sampler and static-mixer assembly concurrently with samples of total sediment greater than $0.250 \mathrm{~mm}$ in diameter collected by a plankton net fastened to the outlet of the drainage pipe (fig. 16). The automatic sampler was triggered to collect samples of highway runoff on a flow proportional basis consistent with the protocols used throughout the study; therefore, only a small fraction of water was collected compared to the amount that flowed through the plankton net. The concentration of suspended sediment greater than $0.250 \mathrm{~mm}$ in diameter in the water samples was determined by dividing the dry mass of sediment by the mass of the water (ASTM, 2002). In most cases, the water samples were not split for other analyses, and the entire sample was processed. Similarly, the concentration of suspended sediment greater than $0.250 \mathrm{~mm}$ in diameter collected 


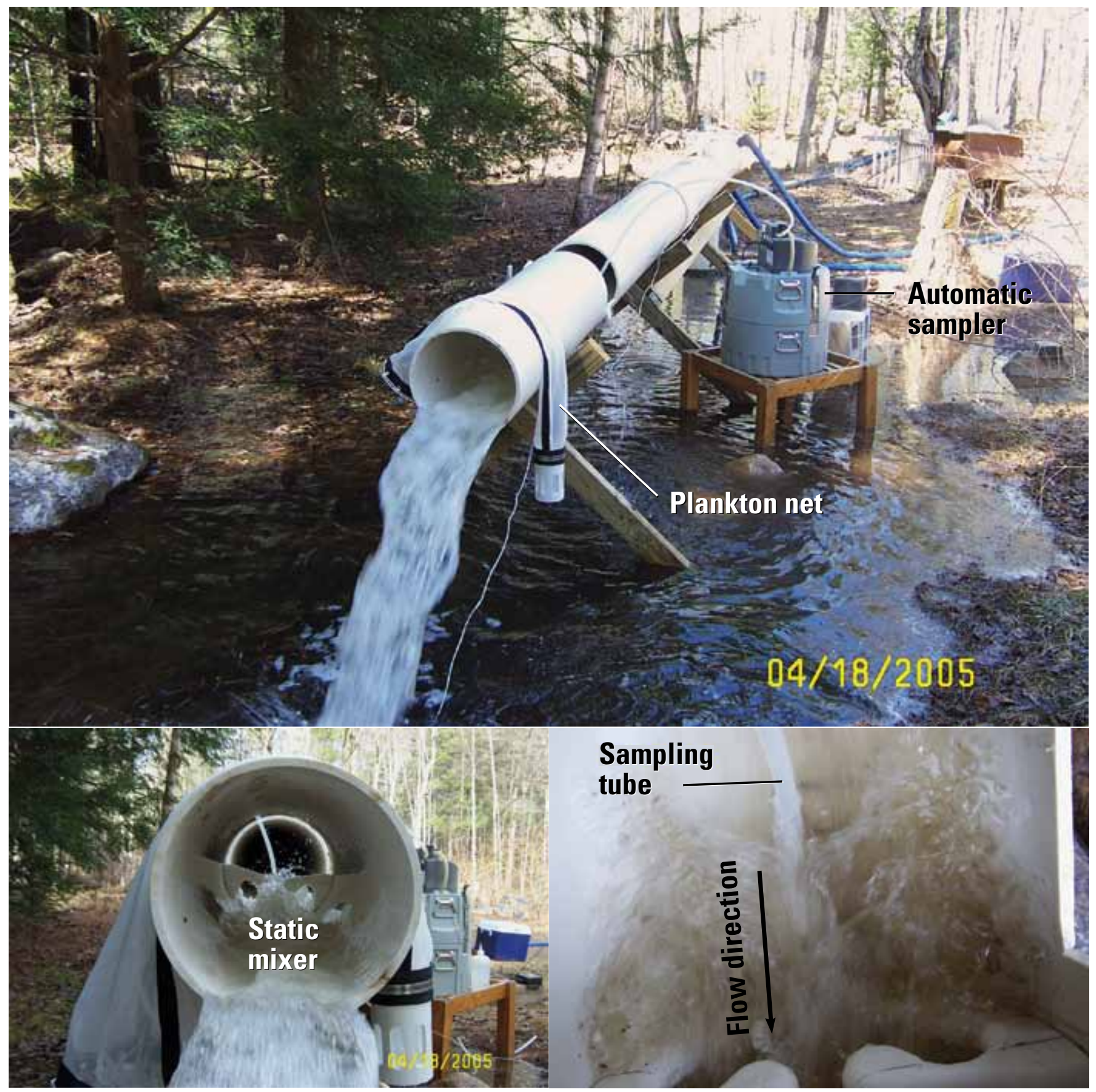

Figure 14. Test pipe and sampling equipment (top) where the static mixer assembly was tested; (lower left) looking upstream; and (lower right) turbulence created by the static mixer at the sampler intake location. The plankton net, which was used to collect the total mass of sediment at the end of the test pipe during the experiment, is draped over the end of the pipe in the photograph. 


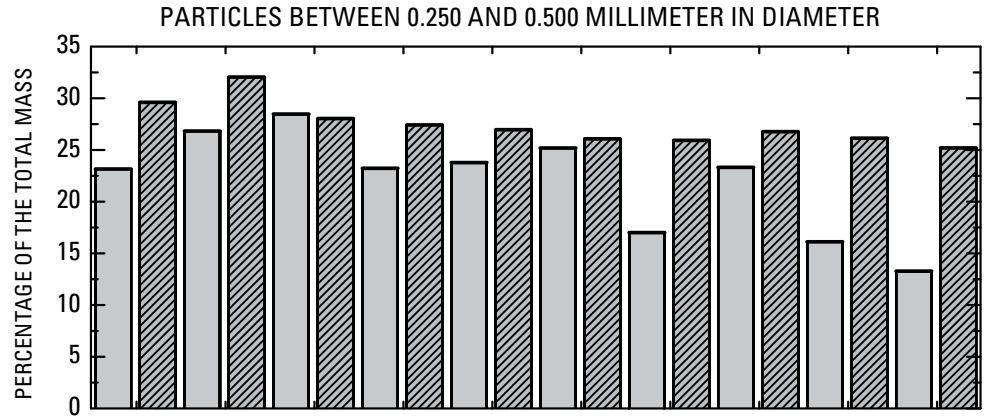

\section{EXPLANATION}
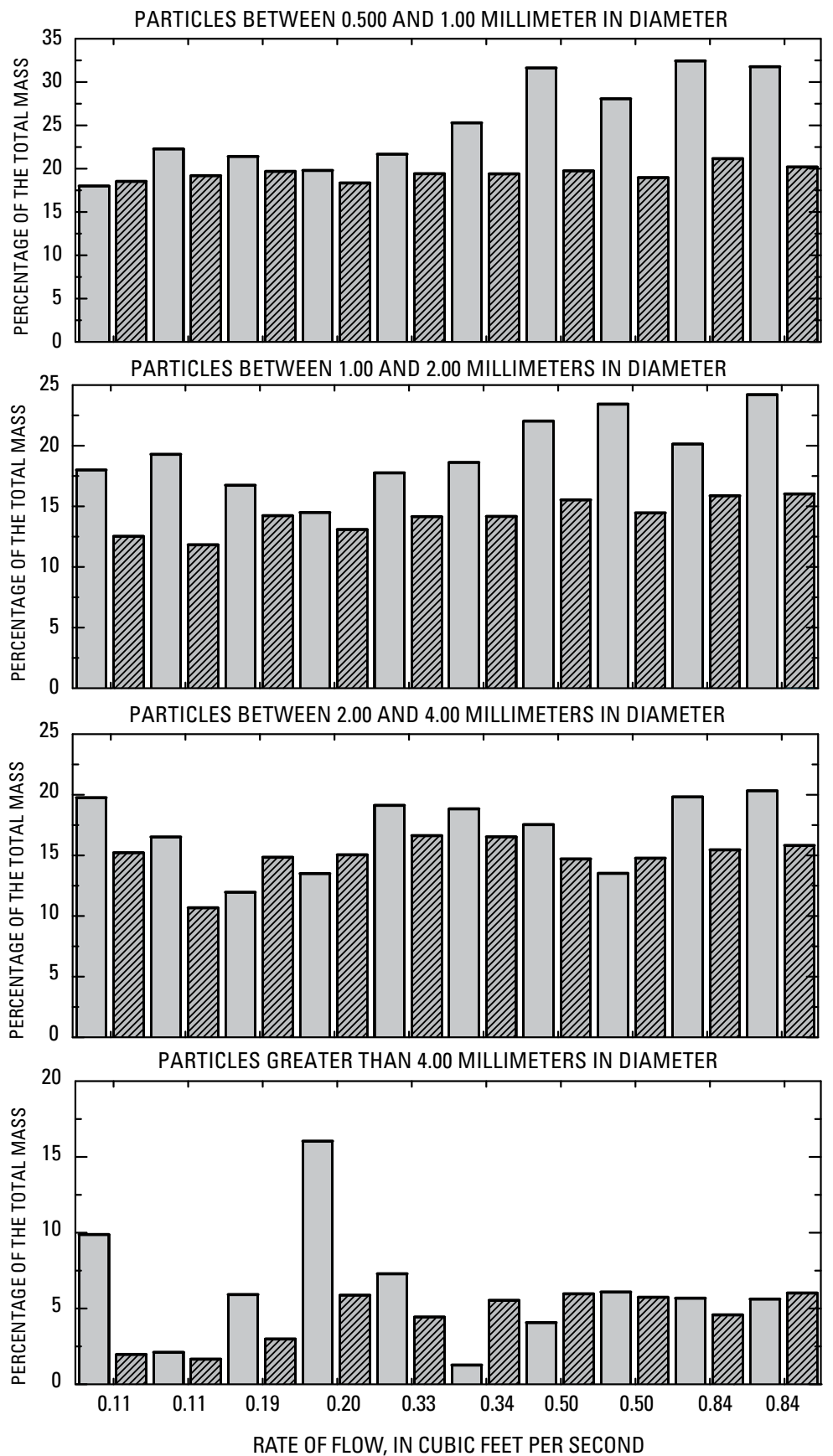

Figure 15. Sediment particles greater than 0.250 millimeters in diameter collected by an automatic sampler with the intake mounted to a static mixer over a range of artificial flows in relation to the percentage of the total mass of sediment particles greater than 0.250 millimeters in diameter collected at the end of the test pipe. 


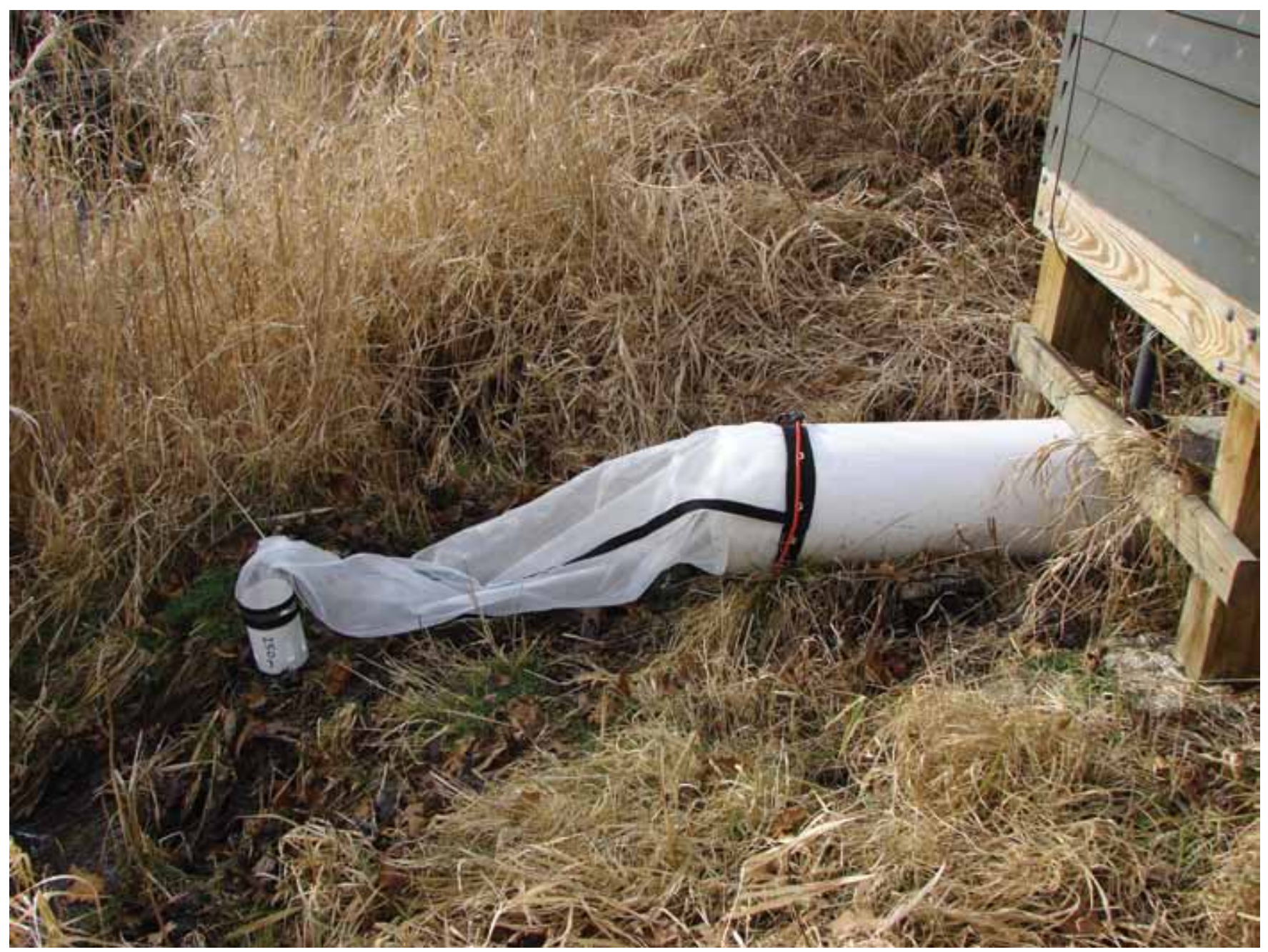

Figure 16. Plankton net attached to the outfall of the primary highway-runoff monitoring site on Interstate 495, Boxborough, Massachusetts. 
by the plankton net was determined by dividing the dry mass of sediment less than $6.0 \mathrm{~mm}$ by the volume of the water calculated for the entire storm. This experiment was conducted for 10 storms from January 2007 through October 2007.

Information from this test indicates that the concentrations of suspended sediment greater than $0.250 \mathrm{~mm}$ in diameter in flow-proportional composite samples of highway runoff were higher than the concentrations estimated for samples collected by a plankton net fixed to the end of the pipe (table 11). The average and relative standard deviation for the differences between paired samples were 187 and 56 percent, respectively. Considering that the amount of water collected by the automatic sampler for each storm was about 0.03 percent of the entire storm volume, the variability in the differences between the concentrations in the paired samples is not unreasonable. However, for samples of highway runoff collected by the automatic sampler, these data potentially indicate that there is a positive bias for the concentration of sediment particles greater than $0.250 \mathrm{~mm}$ in diameter. In contrast, the average TOC content in nine samples of material retained by the plankton net was about 20 percent and ranged as high as 43 percent (table 12). The high TOC content in these samples is attributed to large amounts of natural organic material (grass and leave particles). Because these materials are less dense than mineral sediments, it also is possible that the automatic samplers collected these materials disproportionally. The lack of precision in sampling coarse sediments has only marginal effects on the concentrations of many constituents affiliated with suspended sediment because most metals and hydrophobic organic compounds tend to be concentrated on the particles less than $0.063 \mathrm{~mm}$ in diameter (Smith, 2005; Breault and others, 2005). Similarly, if the positive bias for the concentration of coarse sediment particles is explained by the disproportionate collection of natural organic particles, the effect on the concentrations of many constituents in the water samples may not be large; $\mathrm{P}$ is the exception because it is generally present in high concentrations in vegetation matter compared to the concentrations in soil and sediments. The difference between concentrations of suspended sediment greater than $0.250 \mathrm{~mm}$ in diameter collected by the automatic sampler and that collected by the plankton net can be explained by the previously stated reasons. Nevertheless, the quality-assurance data indicate that potentially there is a positive bias for concentrations of sediment particles greater than $0.250 \mathrm{~mm}$ in diameter, and there could be a bias for concentrations of $\mathrm{P}$ in some samples of highway runoff. Because water samples were collected in a nearly identical manner at all monitoring stations, it also is likely that this same bias may affect the concentrations of coarse sediments and P in water samples collected from other monitoring stations in this study as well.

\section{Sample Splitting}

One of the most often overlooked sources of bias in concentrations of sediment particles, as well as in concentrations of constituents affiliated with such sediments, results from splitting the water sample in the field or in the laboratory prior to analysis (Selbig and others, 2007). The analysis for concentrations of suspended sediment used in this study (ASTM, 2002) did not require that the water sample be split in the laboratory, in contrast to the total suspended solid method (American Public Health Association, American Water

Table 11. Results of field tests of paired samples of suspended sediment greater than 0.250 millimeters in diameter in highway runoff collected by a plankton net and an automatic sampler used in conjunction with a static mixer for the total flow-weighted mass of sediment collected at the end of a pipe at the primary station on Interstate 495, in Boxborough, Massachusetts, 2005-07.

[mm/dd/yyyy, month/day/year; in., inches; mm, millimeter; mg/L, milligrams per liter]

\begin{tabular}{|c|c|c|c|c|c|}
\hline \multirow[b]{2}{*}{ Storm } & \multirow{2}{*}{$\begin{array}{c}\text { Date } \\
\text { (mm/dd/yyyy) }\end{array}$} & \multirow{2}{*}{$\begin{array}{l}\text { Storm total } \\
\quad \text { (in.) }\end{array}$} & \multicolumn{2}{|c|}{$\begin{array}{l}\text { Concentration of suspended sediment } \\
\text { greater than } 0.250 \mathrm{~mm} \text { in diameter }\end{array}$} & \multirow{2}{*}{$\begin{array}{c}\text { Water sample } \\
\text { difference } \\
\text { (percent) }\end{array}$} \\
\hline & & & $\begin{array}{l}\text { Estimated plankton } \\
\text { net sample } \\
(\mathrm{mg} / \mathrm{L})\end{array}$ & $\begin{array}{c}\text { Flow-weighted } \\
\text { composite sample } \\
\text { (mg/L) }\end{array}$ & \\
\hline 1 & $01 / 08 / 2008$ & 0.88 & 0.9 & 2.8 & 301 \\
\hline 2 & $05 / 02 / 2007$ & 0.14 & 3.8 & 12 & 313 \\
\hline 4 & $07 / 11 / 2007$ & 0.19 & 8.2 & 14 & 169 \\
\hline 5 & $07 / 18 / 2007$ & 0.23 & 1.9 & 2.1 & 113 \\
\hline 6 & 08/06/2007 & 0.23 & 15 & 22 & 144 \\
\hline 10 & $10 / 20 / 2007$ & 1.19 & 40 & 88 & 222 \\
\hline
\end{tabular}




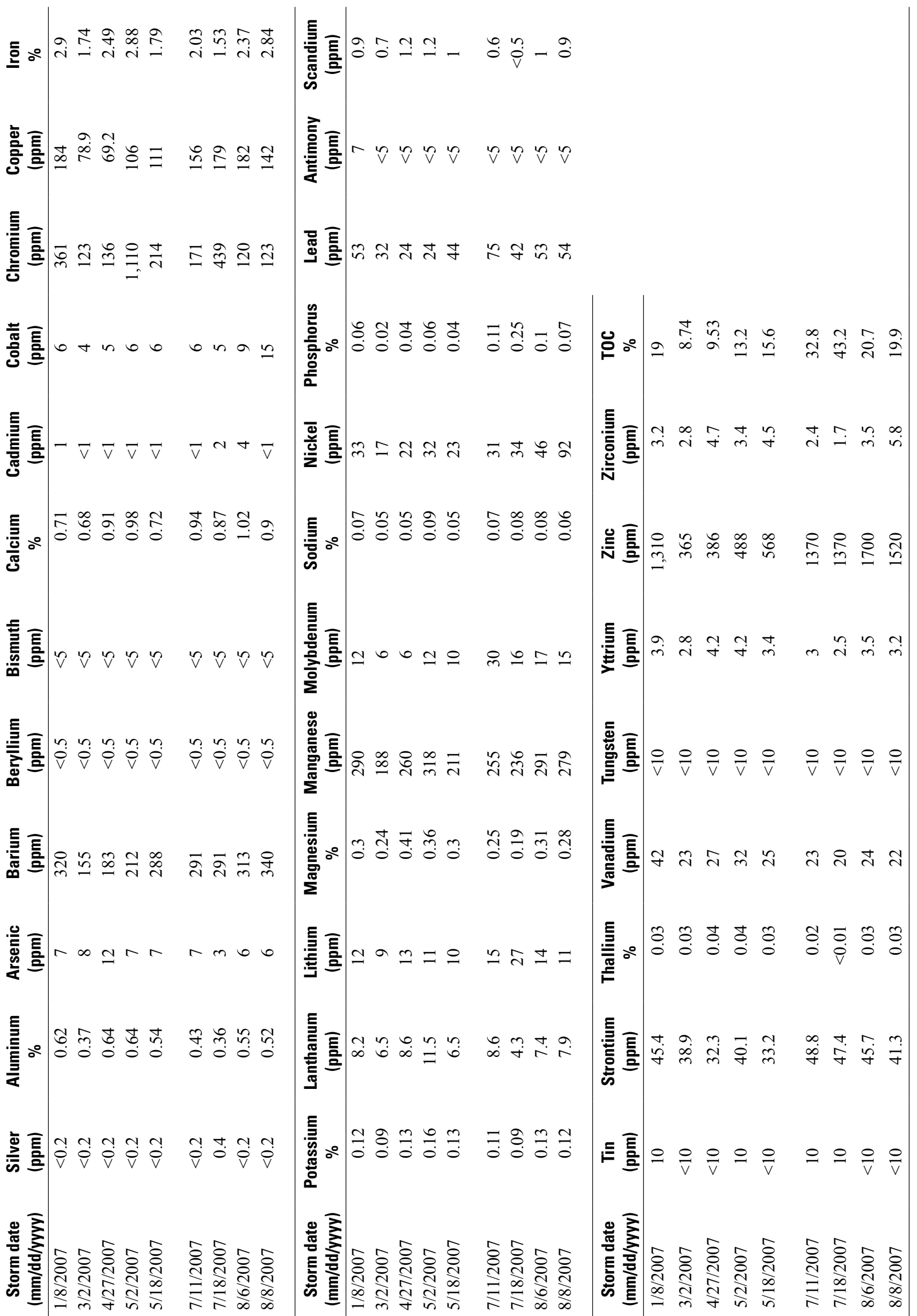


Works Association, and Water Pollution Control Federation, 1995). Furthermore, an in-bottle digestion method (Garbarino and Hoffman, 1999) was used to partially digest unfiltered samples of water prior to analysis for total-recoverable metals at the NWQL. These methods eliminate any potential bias associated with splitting samples containing large amounts of coarse materials in the laboratory. However, when samples of stormwater are analyzed for a wide range of constituents, it is often necessary to split samples of water in the field into representative aliquots to satisfy different analytical methods. In this study, samples of highway runoff were split directly from the Teflon-lined bottle as described earlier. This method eliminated contact of the sample with additional processing equipment and reduced the potential for contamination. To determine the limitations of this method, a mixture of sediment containing five particle-size ranges of known mass was added to $12 \mathrm{~L}$ of deionized water and poured into a typical 20-L Teflon-lined bottle. Samples of the sediment/water mixture of near equal volume were dispensed into 1-L bottles, and the concentration of each particle-size range was determined.

The method used in this study for splitting samples of water containing different size fractions of solids from the automatic sampler bottle into representative aliquots was evaluated under controlled conditions. Using the methods described earlier, 14 sequential replicate samples were collected from a 20 -L bottle with an inner Teflon bag containing $12 \mathrm{~L}$ of water and a sediment concentration of $1,424 \mathrm{mg} / \mathrm{L}$. The total concentration of suspended sediment and the concentrations for five particle-size ranges were determined for each sample. The mean and relative standard deviation for each particle-size range calculated from these data are presented in table 13. Concentrations of suspended-sediment particles less than $0.063 \mathrm{~mm}$ in diameter in samples split from the sediment/ water mixture were both accurate and precise. However, the variability in suspended-sediment concentrations in samples of the sediment/water mixture increased for each size class as the diameter of the sediment particles increased. In part, this decrease in precision is a function of fewer particles being split into a limited number of bottles. These results are not uncommon among splitting devices. Results of experimental tests conducted by the USGS (Capel and Larson, 1996; Capel and nacionales, 1995; Selbig and others, 2007) indicate that concentrations of coarse sediments collected from a churn splitter can deviate from the true concentration by as much as 65 percent, and the relative standard deviation for samples split by a cone splitter range from about 21 to 45 percent. Although the reported results indicate that samples containing coarse sediment may be more precisely collected with a cone splitter, the large and sometimes unpredictable volumes of water collected during storms would require multiple passes through the cone splitter and, because the error is additive, the device may be less effective than the sample splitting method used in this study. Fortunately, the lack of precision in splitting coarse sediments has only marginal effects on the concentrations of many constituents affiliated with suspended sediment because most metals and SVOCs tend to be more concentrated on the particles less than $0.063 \mathrm{~mm}$ in diameter.

\section{Chemical Quality and Particle Size of Suspended Sediment, Soil Samples, and Other Miscellaneous Samples}

Standard reference samples were submitted to laboratories to identify potential contamination bias and to assess analytical method performance. Replicate samples of background soils, highway-berm soils, suspended sediment, and other miscellaneous samples were collected to determine the precision of the data.

\section{Reference Samples}

Five blind samples of standard reference soil (National Institute of Standards and Technology, 2003) from the National Institute of Standards and Technology (NIST)

Table 13. Means and relative standard deviations for 14 sequential replicate samples analyzed for concentrations of suspended sediment in an experiment to assess the precision of field-splitting methods used in this highway-runoff study in Massachusetts, 2005-07.

[mm, millimeter; mg/L, milligrams per liter; $<$, less than]

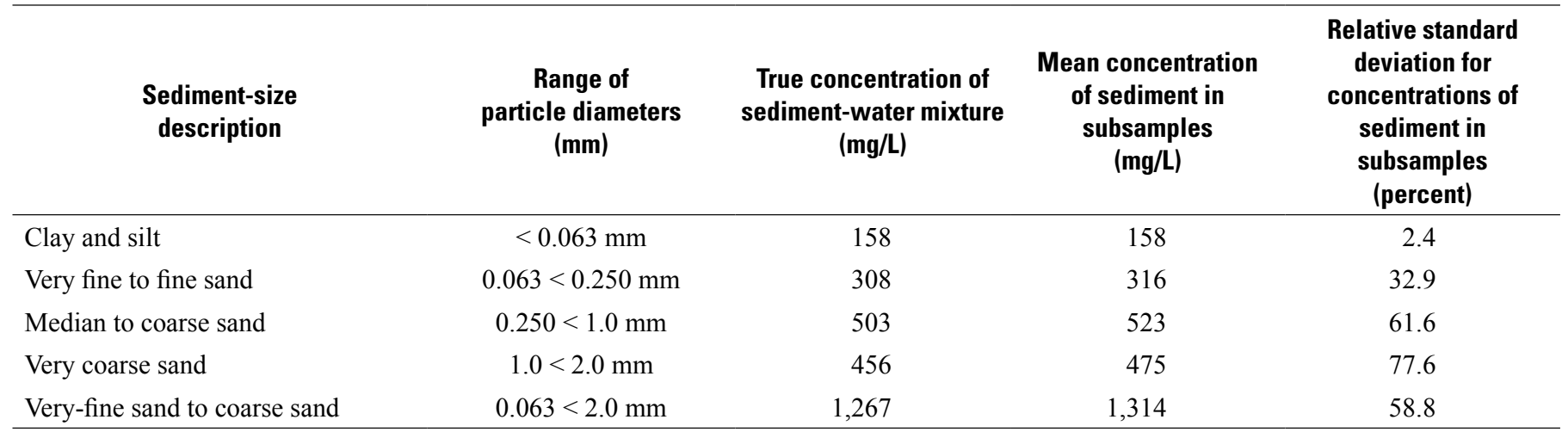


containing high levels of trace elements were submitted simultaneously with samples of background soils, highwayberm soils, highway runoff sediment, and other miscellaneous samples for analysis of elements. Standard reference soil was analyzed to determine both total concentrations and total-recoverable concentrations of 32 elements. Concentrations that are certified by the NIST are based on measurements obtained by two or more independent analytical techniques used by multiple laboratories. Concentrations of total metals, which are measured in samples completely digested by hydrofluoric acid, are certified by the NIST and provide the best estimate of the true concentration. For some elements, noncertified concentration data are provided by the NIST for informational purposes only. Leachable concentrations of the elements also are available for reference material. Concentrations of total-recoverable metals determined under mild leaching conditions that only partially digest the solids are not certified by the NIST but do provide quality-control data for the USEPA digestion method 3050B used predominantly in this study. Results of total-recoverable digestion procedures are generally considered by the USEPA to be an indication of bioavailability of trace elements (U.S. Environmental Protection Agency, 1986).

For about 40 percent of the measured elements for which there were certified concentration values in the standard reference soil, median total concentrations in blind samples were within the certified concentration ranges (table 14). For those elements that were outside the certified concentration ranges, the median total concentrations (except for antimony (Sb)) were within 15 percent of the lower certified concentration ranges. Median concentrations of total aluminum (Al), copper $(\mathrm{Cu}), \mathrm{K}, \mathrm{Mn}$, nickel $(\mathrm{Ni})$, and vanadium $(\mathrm{V})$ fall within about 4 percent of the certified concentrations ranges; median concentrations for lead $(\mathrm{Pb}), \mathrm{Sb}$, titanium $(\mathrm{Ti})$, and zinc $(\mathrm{Zn})$ fall within about 6 to 15 percent from the certified concentration ranges. The relative standard deviations for concentrations in the blind samples range from 1 to 7 percent, indicating that the measurements are relatively precise (table 14). The median concentrations in blind samples with the measured elements for which there are noncertified values generally were less than, but within 20 percent of, the noncertified values. Median concentrations of total cobalt (Co), chromium $(\mathrm{Cr})$, lanthanum $(\mathrm{La})$, tungsten $(\mathrm{W})$, and yttrium $(\mathrm{Y})$ in blind samples were about 14 to 20 percent less than the noncertified total values for the NIST reference material (table 14). The median concentrations of total molybdenum (Mo), scandium $(\mathrm{Sc})$, and strontium $(\mathrm{Sr})$ in blind samples are within 5 percent of the noncertified total values for the NIST reference material (table 14). The relatively close agreement between known values and analytical results from blind samples demonstrates that the analytical methods generally were accurate.

Concentrations for total-recoverable elements in NIST reference material also are presented in table 14 with the associated NIST recovery (or leach) range for each element. Because total-recoverable concentrations are determined using partial digestion methods, the total-recoverable concentration generally is lower than the total concentration; however, the entire concentration can sometimes be recovered even using the weaker digestion method if the element is completely labile. As a result, many of the concentrations of elements that were determined using different digestion methods are similar. The median total-recoverable concentrations for all elements with available reference criteria were within the NIST reported recovery ranges, except for the median total-recoverable concentrations of arsenic (As), K, and P. The median totalrecoverable concentrations for As and $\mathrm{K}$ were about 3 and 8 percent higher than the upper recovery range for the reference material, respectively. However, the variability in recovery of these elements was within the respective recovery range. The median total-recoverable concentration for $\mathrm{P}$ was about 15 percent lower than the lower recovery range for the reference material. These data indicate that the total-recoverable concentrations for this element may exhibit a negative bias.

Inorganic blank water was spiked with known amounts of the NIST reference material to test for differences among total-recoverable concentrations digested using the USEPA method 3050B, the whole-water-in-bottle digestion method (Garbarino and Hoffman, 1999), and the alkaline persulfate digestion method (Patton and Kryskalla, 2003). The latter two methods were used predominantly to determine total-recoverable concentrations for metals and total $\mathrm{P}$, respectively, in samples of highway runoff. Concentrations in parts per million of total-recoverable elements in samples of the sediment/water mixture were calculated on the basis of the mass of blank water and reference material, and the reported concentration for each element in milligrams per liter. Total-recoverable concentrations of $\mathrm{Cu}$ and $\mathrm{Pb}$ in the samples of the sediment/ water mixture were similar to the respective measurements made using USEPA method 3050B; however, the total-recoverable concentrations of the other elements in the samples of the sediment/water mixture were lower than the respective measurements made using USEPA method 3050B (table 14). Total-recoverable concentrations of $\mathrm{Cr}, \mathrm{Fe}, \mathrm{Ni}, \mathrm{P}$, and $\mathrm{Zn}$ in the samples of the sediment/water mixture were lower than the lower recovery range for the reference material. These data do not indicate a process failure in the analytical method because partial digestion methods often provide dissimilar results. The in-bottle digestion method described by Garbarino and Hoffman (1999) partially digests whole-water samples with nitric acid, whereas USEPA method 3050B digests samples with repeated additions of nitric acid and hydrogen peroxide, followed by additions of hydrochloric acid and sample refluxing. Coincidently, USEPA method 3050B is the method by which the ranges of leachable concentrations are determined for the reference material (National Institute of Standards and Technology, 2003). Although the results obtained by nitricacid digestion often are slightly lower than results obtained by the USEPA method, the precision of the in-bottle digestion method is greater because hydrochloric acid can cause spectral inference in the latter method (Garbarino and Hoffman, 1999). The difference between concentrations of $\mathrm{P}$ for each method also can be explained by the different digestion procedures 

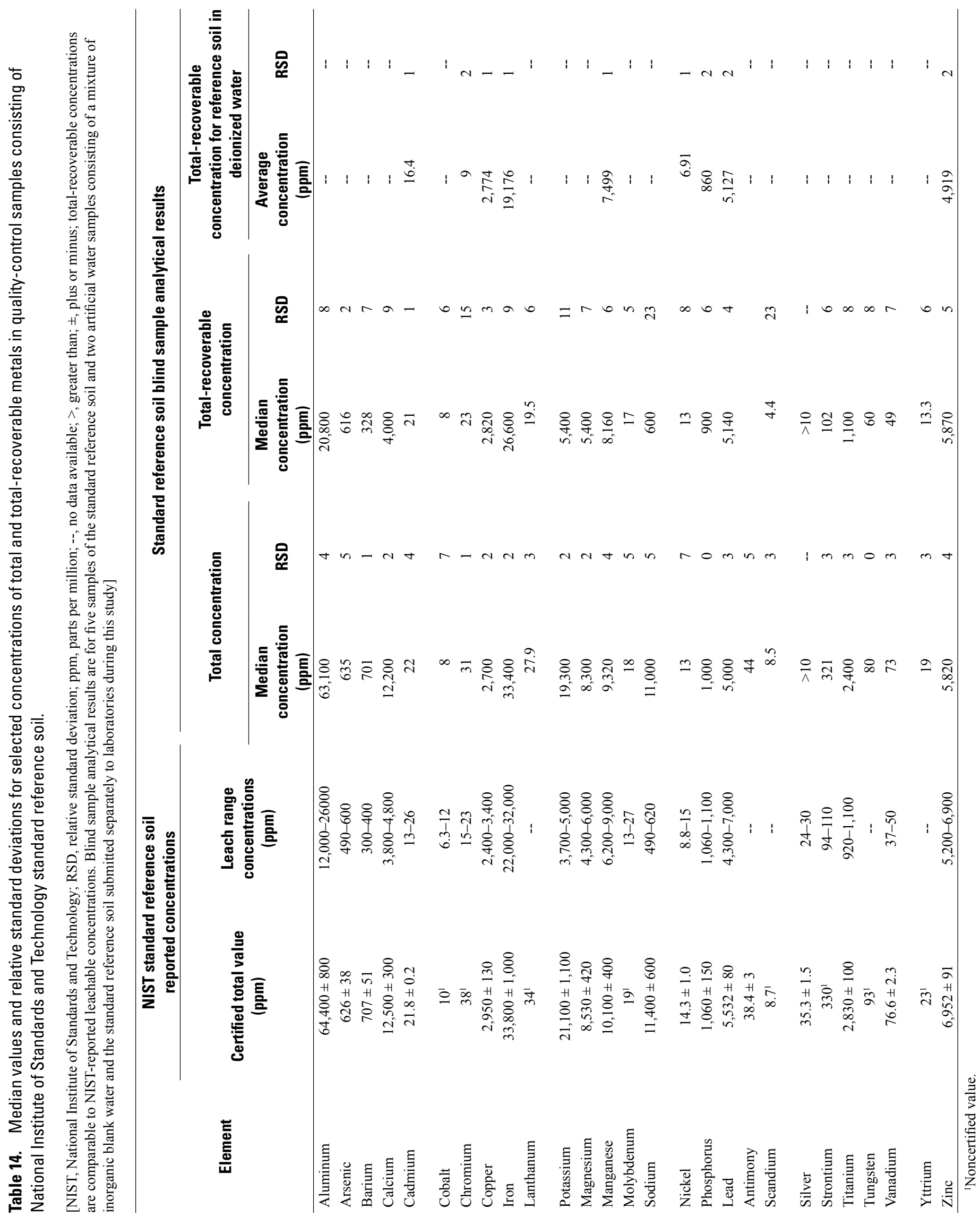
used in the various methods. The alkaline persulfate digestion method (Patton and Kryskalla, 2003), which provides results statistically similar to those for samples digested by Kjeldahl method, is a weaker digestion method. These data indicate that whole-water concentrations of $\mathrm{Cr}, \mathrm{Fe}, \mathrm{Ni}, \mathrm{P}$, and $\mathrm{Zn}$ that are estimated from sediment data will exhibit a positive bias when compared to the whole-water concentrations determined by the in-bottle digestion method, assuming that dissolved concentrations of the elements are ignored.

\section{Replicate Samples}

Replicate samples of background soils, highway-berm soils, suspended sediment, and other miscellaneous materials, including samples of highway-maintenance sand, roadside grass, and solids discharged from the outlet pipe at the primary monitoring station on Interstate 495 were collected to determine the precision of the data. General statistics for the RPDs for 17 pairs of samples are presented in table 15 . The average RPD was less than 10 percent for all elements except As, $\mathrm{Na}$, $\mathrm{Pb}, \mathrm{Sc}$, and Ti. For these elements, the average RPD between replicate pairs ranged from about 11 to 16 percent. The maximum RPDs between replicate pairs for all elements, except for $\mathrm{As}, \mathrm{Co}, \mathrm{Mo}, \mathrm{Pb}, \mathrm{Sc}$, and $\mathrm{Ti}$, were less than 20 percent. The precision of the measurements of environmental samples (table 15) was less than the precision of the measurements of the reference materials (table 14). However, the environmental samples of soil and sediments were not milled prior to laboratory analysis, unlike the NIST reference material, so that comparisons could be made later between concentrations of metals in soils and sediment and concentrations in whole water samples. Because the environmental samples were not milled, greater variability between replicate pairs of samples was expected.

\section{Particle Size}

The variability in the distribution of particles sizes associated with replicate split samples of berm material and some soil samples also was assessed because small changes in the overall content of silt- and clay-size particles that contain disproportional amounts of many elements can affect the elemental concentration in the aggregate. The median RPDs for the amounts of material in particle-size classes less than $0.063 \mathrm{~mm}$ in diameter, from $0.063 \mathrm{~mm}$ to $0.250 \mathrm{~mm}$ in diameter, and greater than $0.250 \mathrm{~mm}$ in diameter for 16 replicate pairs were 7, 8, and 4 percent, respectively. The RPDs between the amounts of material in the particle-size class less than $0.063 \mathrm{~mm}$ in diameter were less than 20 percent for about 90 percent of the replicate pairs. The maximum RPDs between the amounts of material in particle-size classes less than $0.063 \mathrm{~mm}$ in diameter, from $0.063 \mathrm{~mm}$ to $0.250 \mathrm{~mm}$ in diameter, and greater than $0.250 \mathrm{~mm}$ in diameter were 36,19 , and 26 percent. Although these data indicate that the distribution of particle sizes in split samples was generally precise, some of the variability observed in the concentrations of elements in replicate pairs could, in part, result from differences in the distribution of particle sizes in the samples.

\section{Quality of Highway Runoff}

Physical characteristics and concentrations of 6 dissolved major ions, total $\mathrm{N}$, total $\mathrm{P}, 8$ total-recoverable metals, 24 SVOCs (including priority PAHs and phthalate compounds), and suspended sediment in highway runoff samples are presented in table 16 (in the back of the report). Concentrations of 73 organic compounds, including an additional 62 organic compounds, which were measured in fewer samples and include selected organic compounds generally found in urban and industrial wastewater discharges, are presented in table 17 (in the back of the report). These data document the chemistry of runoff from Massachusetts highways during 2005-07, as sampled at the four primary monitoring stations, four secondary monitoring stations, and the four monitoring stations on the test highways. The data also are provided in digital form in the HRBD (appendix A) that was developed by USGS, in cooperation with the Federal Highway Administration (Granato and Cazenas, 2009). Various summary statistics for the highway-runoff data presented in tables 16 and 17 can be generated by use of the database, as described by Granato and Cazenas (2009).

Several types of analyses were conducted with the data to evaluate their suitability for the development of planning-level estimates and other applications. Concentrations of highwayrunoff constituents from primary, secondary, and test stations were compared to determine whether significant differences exist among the stations, or whether data from the multiple stations can be aggregated. Relations of constituent concentrations to traffic volume were investigated. The effects of seasonality on concentrations also were examined. The frequent measurements of specific conductance during storms and relations developed between specific conductance and element concentrations allowed for a detailed characterization of the components of road salt in the highway runoff at the monitoring stations. A probability distribution for concentrations and loads of $\mathrm{Cl}$ in highway runoff and descriptive statistics for the major constituents in road salt were computed on the basis of available continuous records of flow and specific conductance for the entire monitoring period. Potential contributions of highway constituents were estimated on the basis of the chemistry of available soil, berm materials, and highway-maintenance material data, and published source reference data. Finally, the relation of concentrations of selected constituents to suspended sediment was evaluated. In some of the analyses, concentrations of constituents in suspended sediment, constituents in soil samples collected near highways, and other solidphase matrices were used in the interpretation of the highway runoff data. Constituent concentrations in samples of sieved suspended sediments, soils, and highway berms are presented in tables 18 through 21 . 
Table 15. Relative percent differences between 17 replicate pairs for samples of background soils, highway-berm soils, suspended sediment, and other miscellaneous samples collected from and near highways in Massachusetts, 2005-07.

\begin{tabular}{|c|c|c|c|c|c|}
\hline \multirow[b]{2}{*}{ Element } & \multicolumn{5}{|c|}{ Relative percent difference between replicate pairs } \\
\hline & $\begin{array}{c}\text { Minimum } \\
\text { (percent) }\end{array}$ & $\begin{array}{c}\text { Average } \\
\text { (percent) }\end{array}$ & $\begin{array}{c}\text { Median } \\
\text { (percent) }\end{array}$ & $\begin{array}{c}\text { Maximum } \\
\text { (percent) }\end{array}$ & $\begin{array}{l}\text { Relative standard } \\
\text { deviation } \\
\text { (percent) }\end{array}$ \\
\hline Aluminum & 0.0 & 5.6 & 8.2 & 9.9 & 66 \\
\hline Arsenic & 0.0 & 14.7 & 22.2 & 22.2 & 67 \\
\hline Barium & 1.6 & 7.1 & 9.5 & 9.5 & 43 \\
\hline Beryllium & 0.0 & 7.7 & 7.7 & 15.4 & 141 \\
\hline Calcium & 0.0 & 1.5 & 0.0 & 10.5 & 216 \\
\hline Cobalt & 0.0 & 2.9 & 0.0 & 30.8 & 293 \\
\hline Chromium & 0.8 & 3.9 & 3.3 & 12.2 & 73 \\
\hline Copper & 0.6 & 5.2 & 6.0 & 10.0 & 46 \\
\hline Iron & 0.6 & 4.6 & 6.2 & 8.0 & 53 \\
\hline Potassium & 0.0 & 5.6 & 8.0 & 9.5 & 63 \\
\hline Lanthanum & 1.3 & 4.8 & 5.6 & 5.9 & 32 \\
\hline Lithium & 0.0 & 6.8 & 9.5 & 9.5 & 60 \\
\hline Magnesium & 0.0 & 1.3 & 0.0 & 10.5 & 217 \\
\hline Manganese & 0.0 & 6.9 & 10.1 & 10.1 & 56 \\
\hline Molybdenum & 0.0 & 2.9 & 0.0 & 22.2 & 217 \\
\hline Sodium & 0.0 & 11.0 & 18.2 & 18.2 & 80 \\
\hline Nickel & 0.0 & 0.7 & 0.0 & 11.5 & 412 \\
\hline Phosphorus & 0.0 & 0.6 & 0.0 & 9.5 & 412 \\
\hline Lead & 0.0 & 16.1 & 28.6 & 28.6 & 85 \\
\hline Scandium & 0.0 & 12.2 & 12.8 & 46.2 & 82 \\
\hline Strontium & 0.8 & 3.9 & 3.8 & 8.5 & 42 \\
\hline Titanium & 0.0 & 13.3 & 15.4 & 40.0 & 75 \\
\hline Vanadium & 0.0 & 4.7 & 6.1 & 6.1 & 43 \\
\hline Yttrium & 0.0 & 7.8 & 11.1 & 11.4 & 56 \\
\hline Zinc & 0.7 & 3.8 & 3.0 & 15.6 & 94 \\
\hline Zirconium & 3.5 & 9.9 & 10.1 & 14.6 & 28 \\
\hline
\end{tabular}




\section{Intrasite Evaluation of Constituents in Samples of Runoff from the Principal Highways}

The primary and secondary monitoring stations were located along principal highways (table 1). Paired primary and secondary sites were located within a few miles of each other on a section of highway with limited access to ensure comparable levels of traffic volume and density. Although the design and operation of the primary and secondary monitoring stations were similar, the monitoring period and number of samples of highway runoff collected at the primary stations were greater than at the secondary stations. Populations of concentration data for constituents in samples routinely collected at the secondary monitoring stations on each of the principal highways were compared to the populations of concentration data for associated primary monitoring stations to determine whether the variability between the data was significantly different or whether the data could be aggregated. The nonparametric Mann-Whitney test was used to determine whether the independent populations were statistically different ( $p$ value less than 0.05). For constituents whose concentrations either were not detected or were estimated to be less than the LTMDL (censored data), concentrations were set equal to a value less than the respective LTMDL. This approach is appropriate for rank-based nonparametric methods for singly censored data (Helsel, 2005). Analyses for many PAH and phthalate compounds were not performed because they either were not detected in the samples or all of the concentrations were estimated to be less than the LTMDL.

With a few exceptions, results of tests of paired populations of individual constituent concentrations, where sufficient data were available, generally indicate that the populations were not significantly different at a 95 -percent confidence interval for each pair of sites on the principal highways. The resultant $p$ values for each of the principal highways are listed in table 22. Results of tests between paired populations of concentrations of all constituents in samples collected at the monitoring stations on Route 119, except suspended sediment less than $0.063 \mathrm{~mm}$ in diameter, indicate no significant difference (table 22). The difference between the median concentrations of suspended sediment less than $0.063 \mathrm{~mm}$ in diameter for each site is about $19 \mathrm{mg} / \mathrm{L}$ or about 22 percent. The lack of significance observed in the test between paired populations of concentrations of suspended sediment with particles less than $0.063 \mathrm{~mm}$ in diameter may be the result of runoff patterns associated with the secondary monitoring station that differed from those at the primary monitoring station. For example, a pair of parallel ruts in each travel lane on the road surface in the drainage area of the secondary monitoring station (fig. 17) often caused smaller flows to bypass the catch basin; furthermore, frost heaves in the roadway within the drainage area of the secondary monitoring station also diverted water away from the catch basin during the winter when runoff concentrations of suspended sediment are generally high as a result of winter sanding. It is plausible that these factors affected the flow patterns sufficiently to introduce bias into the sample population of sediment concentrations less than $0.063 \mathrm{~mm}$ in diameter at the secondary monitoring station on Route 119. Tests between paired populations of concentrations for all constituents in runoff collected at the monitoring station on Route 2, except for concentrations of total-recoverable $\mathrm{Zn}$, also determined no significant difference (table 22). For this highway, the median concentration of total-recoverable $\mathrm{Zn}$ in composite samples of highway runoff at the primary station $(308 \mathrm{mg} / \mathrm{L})$ was about twice as high as the median concentration measured in composite samples at the adjacent secondary station $(152 \mathrm{mg} / \mathrm{L})$. The significant difference resulting from the test between paired populations of total-recoverable $\mathrm{Zn}$ is not fully explainable with available data. Tests between paired populations of constituent concentrations from the monitoring stations on Interstate 495, except for concentrations of suspended sediment less than $0.063 \mathrm{~mm}$ in diameter, also determined no significant difference (table 22). The difference between the median concentrations of suspended sediment less than $0.063 \mathrm{~mm}$ in diameter for each set of paired sites was about $34 \mathrm{mg} / \mathrm{L}$ or about 41 percent. The significant difference between the paired populations of concentrations of suspended sediment is likely attributable to berm material that eroded onto the roadway surface in the drainage area of the primary monitoring station because the height of the berm along the highway at the secondary monitoring station was lower than the berm at the primary monitoring station and showed little evidence of erosion. Results for all tests between paired populations of constituent concentrations in samples from the monitoring site on Interstate 95 (table 22) indicate that the populations are not significantly different from each other. A greater number of constituents were tested for this highway than for other highways because the frequency of detection for most PAH and phthalate compounds was greater here than at other highways.

In summary, there were few significant differences between constituent concentrations in samples collected at primary and secondary sites on the principal highways. Consequently, in subsequent analyses, data from the primary and secondary monitoring stations were combined to characterize the quality of runoff from the principal highways. For those tests between populations of suspended sediment less than $0.063 \mathrm{~mm}$ in diameter, it was unusual that the concentrations of fine sediment were significantly different between the paired stations on Route 119 and Interstate 495. Yet, concentrations of no other constituents were significantly different between the paired sites for each highway because the concentrations of many elements generally are greater on the fine sediment fraction than on the coarser sand fractions (table 18 in the back of the report). Alternatively, the effects of the distributions of sediment particle size, concentration, and associated sediment chemistry may be small if the dissolved fraction of the total-recoverable metals was high in samples of runoff. Other studies that included analyses for concentrations of filtered composite samples have shown that the concentrations of some dissolved trace elements can account for about 10 to 65 percent of the total concentration (Smith, 2002; 
Table 22. Resultant $p$ values for Mann-Whitney tests for paired populations of constituent concentrations for highway runoff collected from the primary and secondary stations on four principal highways in Massachusetts, 2005-07.

$[<$, Less than value shown; --, insufficient detections to perform test; $\mathrm{mm}$, millimeters in diameter; shaded areas indicate values that are significant at a 95-percent confidence interval]

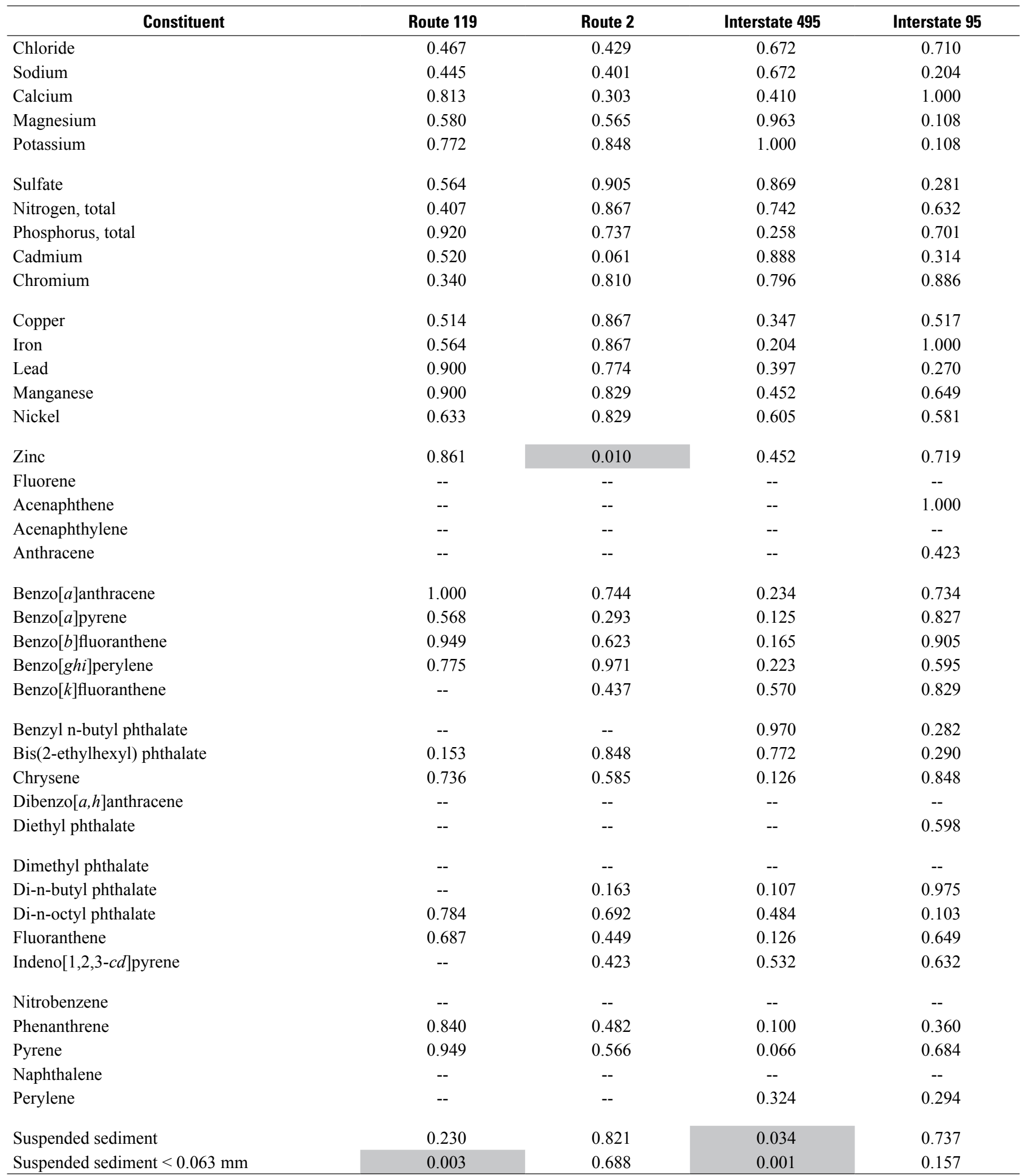




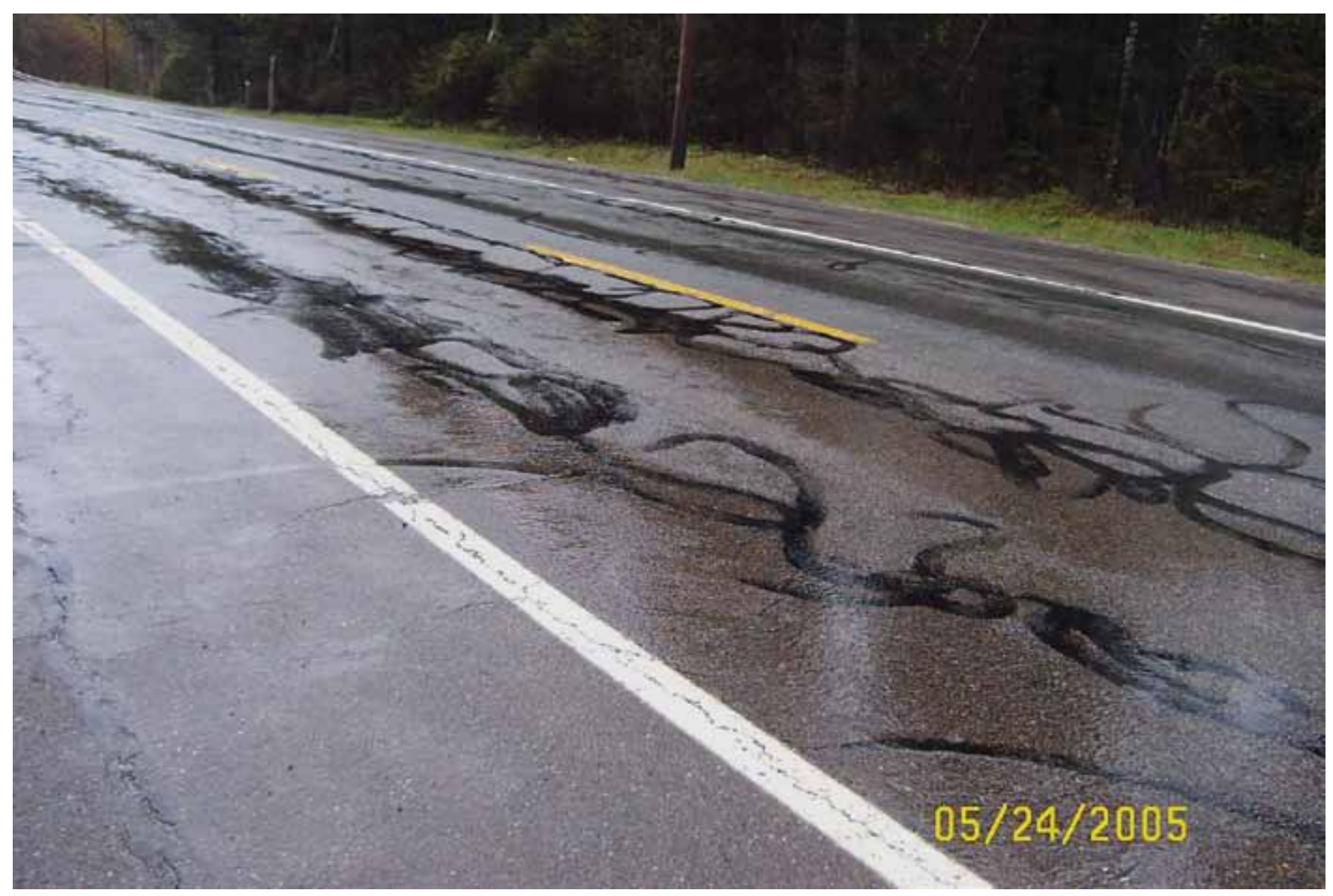

Figure 17. Ruts on the roadway surface running parallel with the road that often caused small flows to bypass the catch basin at the secondary highway-monitoring station on Route 119 in Ashburnham, Massachusetts. 
Breault and Granato, 2000). The partitioning of metals from the dissolved, colloidal, and solid states is poorly understood. Various factors, including $\mathrm{pH}$, ionic strength, temperature, hardness, concentration of anions and suspended sediment, oxidation reduction potential, and in some cases, the presence of other trace elements (Bricker, 1999) can affect the partitioning process in runoff. The duration that the sample remains in the sample bottle prior to processing also can affect the partitioning process as well. Unfortunately, characterization of the dissolved phase of constituents was outside of the scope of this study.

\section{Inter-Site Evaluation of Constituents in Runoff from Test Highways and Principal Highways}

Populations of all concentration data for runoff collected from the test highways were compared to populations of concentration data from the principal highways of similar AADT volumes to determine whether the data were transferable from highway to highway on the basis of AADT volume. Statistically similar sample populations for the primary and secondary stations on the principal highways were combined into one data set. Results of Mann-Whitney tests were used to determine whether the independent populations from the paired highways were statistically different ( $p$ value less than 0.05 ). As previously indicated, censored concentrations of any constituent were set equal to a value less than the LTMDL.

Mann-Whitney tests were performed between populations of constituent concentrations in samples from the monitoring stations on three principal highways and four test highways - Route 119 and Route 8 (low ADDT volume), Route 2 and Interstate 190 (moderate AADT volume), Route 2 and Interstate 195 (moderate AADT volume), and Interstate 95 and Interstate 93 (very high AADT volume). The resulting $p$ values for each of the tests are listed in table 23. Where sufficient concentration data were available for testing, the results showed no significant difference between populations of constituent concentrations collected from the sites on Route 119 and Route 8, and only populations of total-recoverable Zn were significantly different in test results for Route 2 and Interstate 190. Consequently, the significant difference may be attributable to the high total-recoverable $\mathrm{Zn}$ concentrations observed at the primary monitoring station on Route 2 . The test results for populations of total-recoverable $\mathrm{Zn}$ concentrations in samples only from the secondary station on Route 2 and the test station on Interstate 190 indicate that populations were not significantly different ( $p$ value $=0.213$ ). Results for most tests between populations of constituent concentrations in samples collected from the stations on Route 2 and Interstate 195, and for stations on Interstate 95 and Interstate 93, indicate that the populations of several constituents were significantly different. Results of tests between populations of concentrations of dissolved $\mathrm{Ca}$ and $\mathrm{K}$, total $\mathrm{P}$, and total-recoverable $\mathrm{Cd}, \mathrm{Cr}, \mathrm{Cu}, \mathrm{Mn}$, and $\mathrm{Zn}$ in samples from the stations on Route 2 and on Interstate 195 indicate that populations were significantly different. Test results between populations of concentrations of total $\mathrm{N}$; dissolved $\mathrm{Mg}, \mathrm{Na}, \mathrm{Cl}, \mathrm{SO}_{4}$; total-recoverable $\mathrm{Cu}, \mathrm{Fe}, \mathrm{Pb}$, and $\mathrm{Ni}$; suspended sediment; and $\mathrm{PAH}$ and phthalate compounds, where sufficient data were available, indicate populations or concentrations were not significantly different. Because the concentrations of total-recoverable $\mathrm{Zn}$ at the primary monitoring station on Route 2 were significantly higher than at the test monitoring stations, another test was performed between the populations of total-recoverable $\mathrm{Zn}$ concentrations collected from the secondary station on Route 2 and the station on Interstate 195. However, results from this test also indicated that the two populations were significantly different ( $p$ value $=0.017$ ). Because winter-maintenance sanding generally is not practiced on Interstate 195 in the vicinity of the monitoring location (Roy Fierra, Massachusetts Department of Transportation, written commun., 2006), Mann-Whitney tests also were performed on a subset of concentrations of total $\mathrm{P}$ and total-recoverable $\mathrm{Cd}, \mathrm{Cr}, \mathrm{Cu}$, $\mathrm{Mn}$, and $\mathrm{Zn}$ that excluded concentrations in samples collected during winter storms at the Route 2 monitoring locations. These test results indicate that populations of total-recoverable $\mathrm{Cr}, \mathrm{Mn}$, and $\mathrm{Zn}$ collected from the stations on Route 2 and on Interstate 195 remain significantly different at a 95 -percent confidence interval.

The monitoring station on Interstate 195 is located near Cape Cod and USEPA level III ecoregion 84 where the soil and vegetation are different than at the monitoring station on Route 2. Background soils can be deposited on the highway by hydraulic erosion of the roadway berm, or directly deposited on the road by automobiles. As a result of these processes, local soils can be a large part of the suspended sediment in highway runoff (Gupta and others, 1981) and may provide a base concentration for total $\mathrm{P}$ and many metals. Analysis of samples of soil collected along both highways indicate that concentrations of elements were lower near the Interstate 195 station than concentrations near the stations on Route 2 (fig. 18). In fact, concentrations of total $\mathrm{P}$ and totalrecoverable $\mathrm{Cr}, \mathrm{Cu}, \mathrm{Fe}, \mathrm{Ni}, \mathrm{Mn}, \mathrm{Pb}$, and $\mathrm{Zn}$ in samples of soil collected along Interstate 195 were consistently lower than the concentrations of the same constituents collected along six of the other highways (fig. 18) located in Massachusetts. Because concentrations of suspended sediment were not significantly different between the two highways, it is reasonable to conclude that highways with similar anthropogenic-enrichment rates may produce runoff of dissimilar quality, depending on the base quality of the local soils.

These findings indicate that it may be unwise to use descriptive statistics generated by data sets of similar AADT volumes to estimate constituent loads for highways located in the southeastern coastal areas of Massachusetts and USEPA level III ecoregion 84 because the use of the descriptive statistics may result in grossly overestimated loads.

Concentrations of most total-recoverable metals in composite samples of highway runoff collected on Interstate 93 were considerably higher than the concentrations in composite samples from Interstate 95. Results for Mann-Whitney tests 


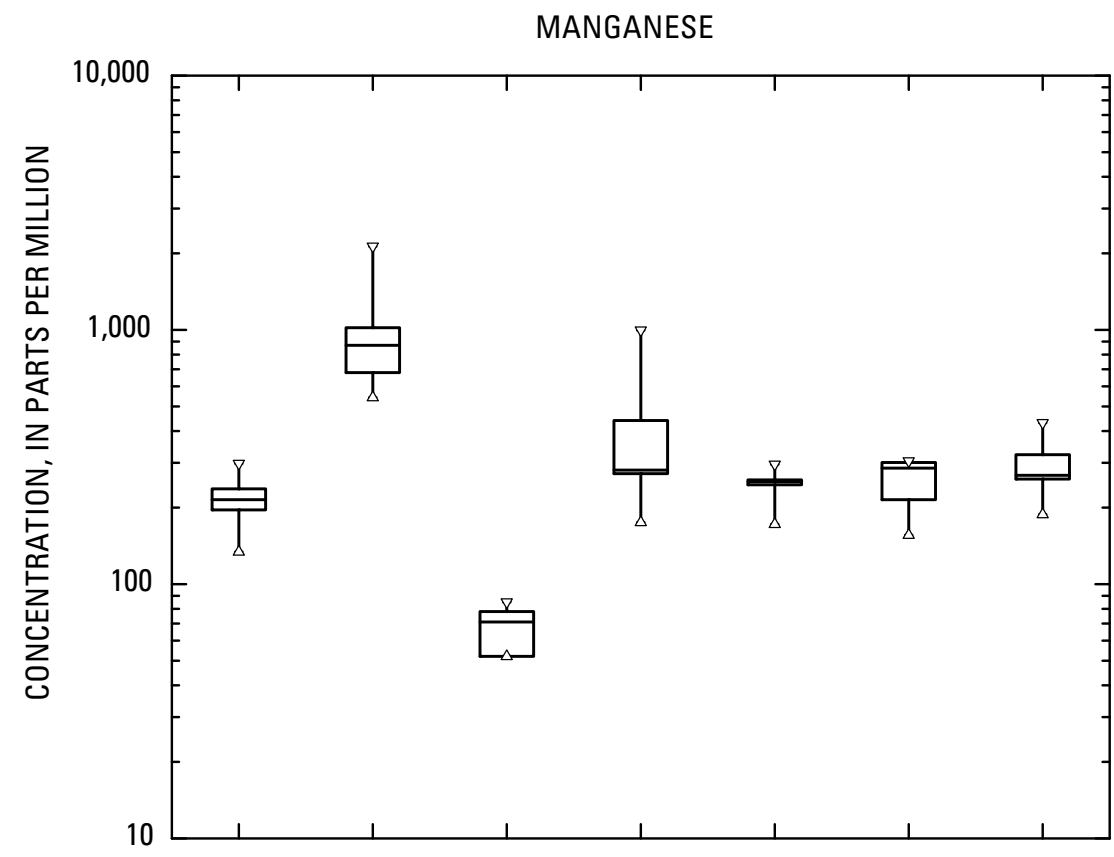

\section{EXPLANATION}
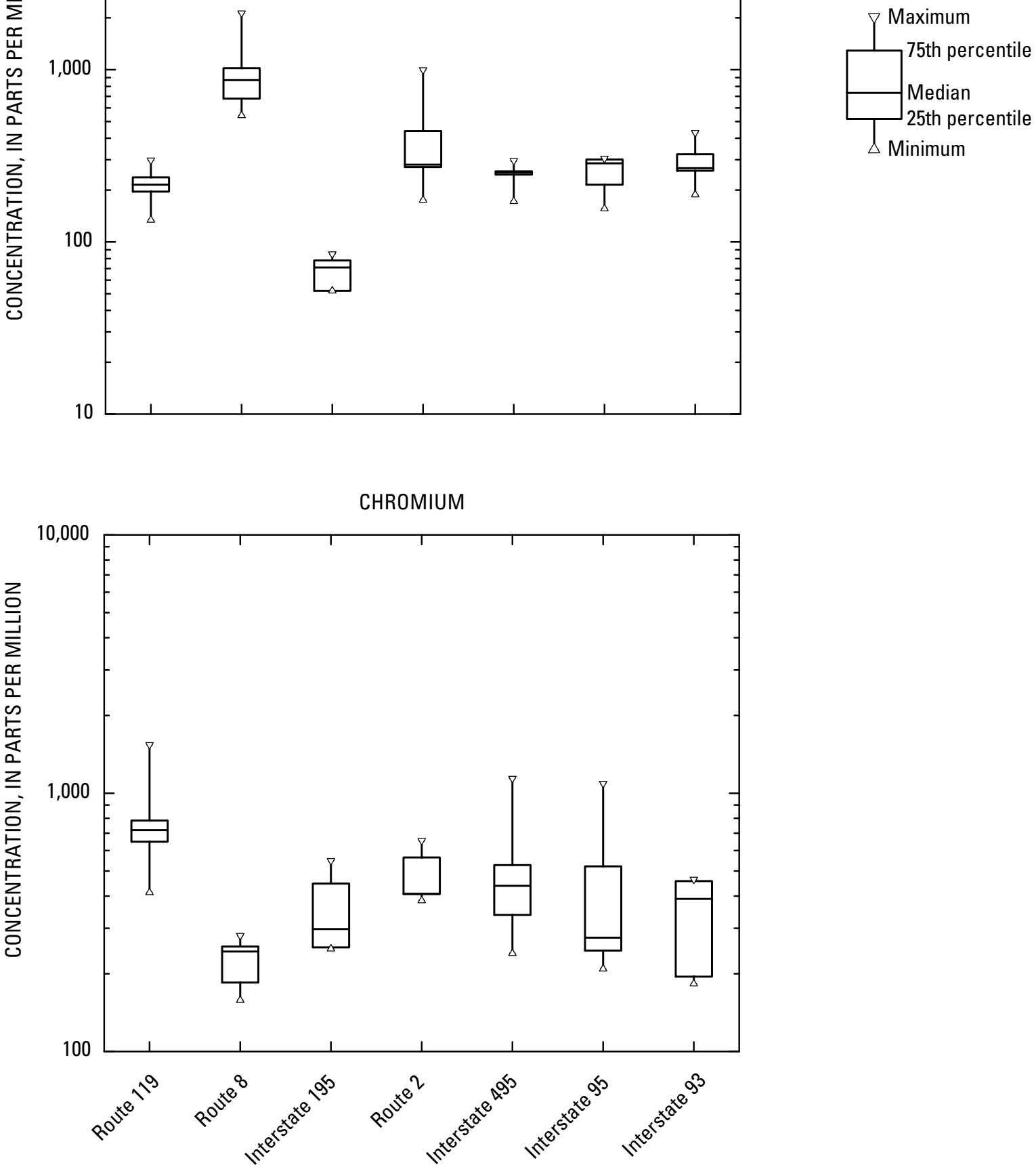

Figure 18. Distribution of concentrations of selected constituents in samples of soil collected in the vicinity of seven highway-runoff monitoring sites in Massachusetts, 2005-07. 


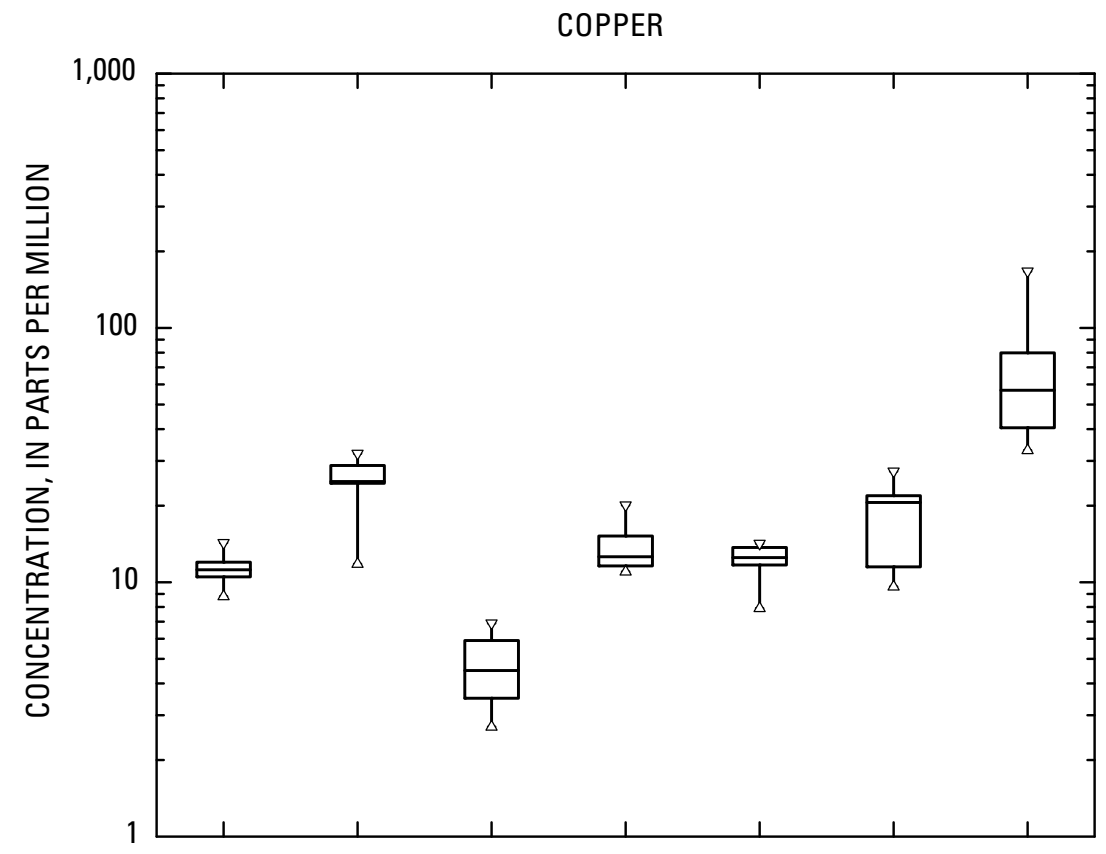

\section{EXPLANATION}

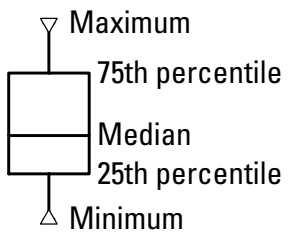

LEAD

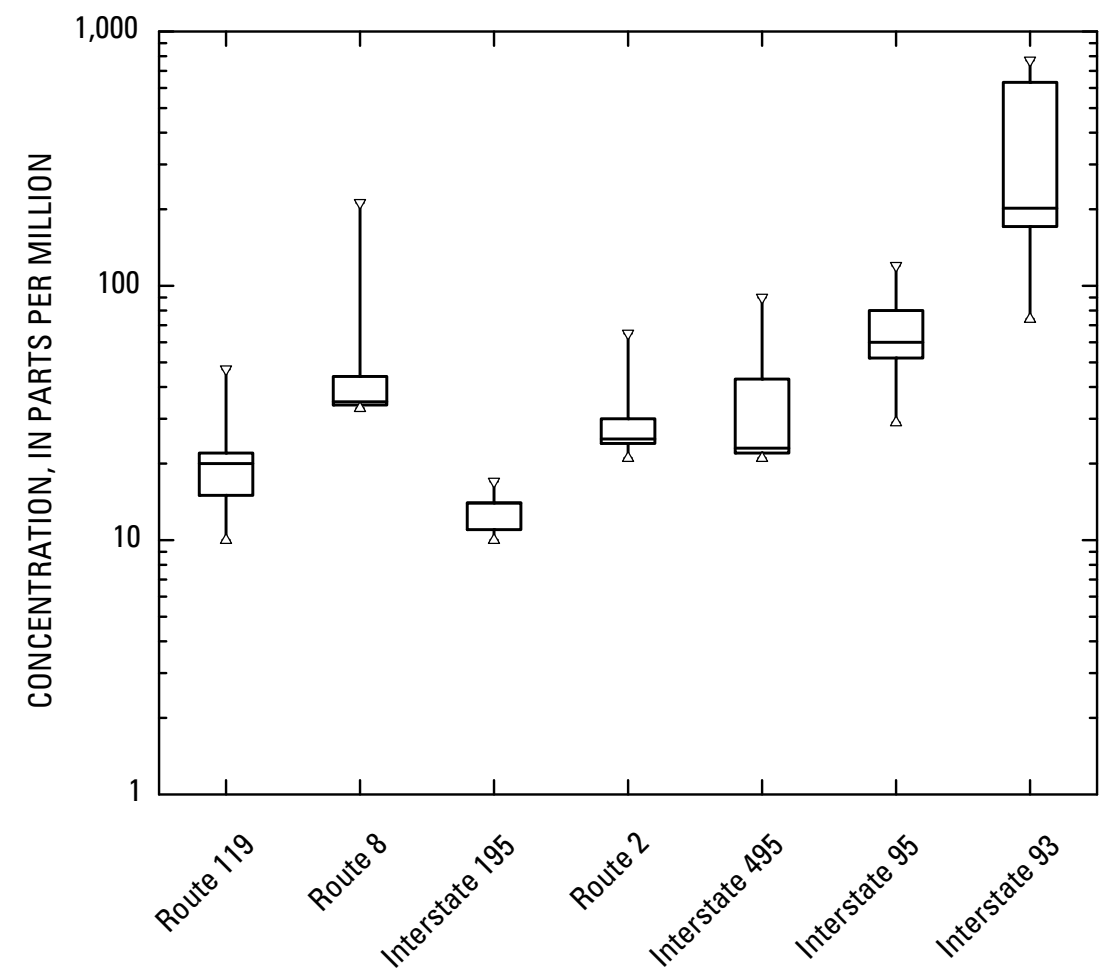

Figure 18. Distribution of concentrations of selected constituents in samples of soil collected in the vicinity of seven highway-runoff monitoring sites in Massachusetts, 2005-07.-Continued 


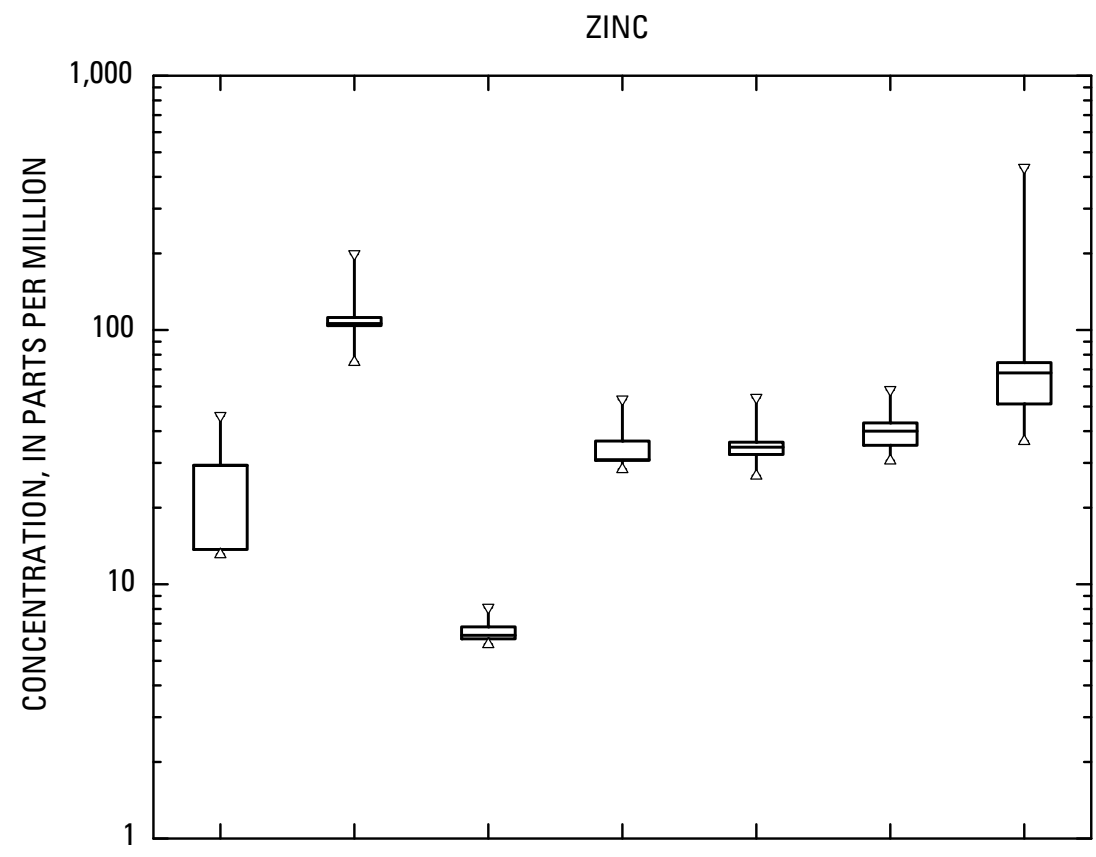

EXPLANATION

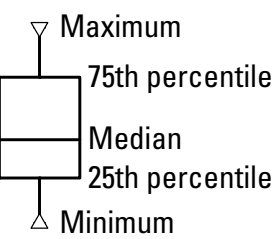

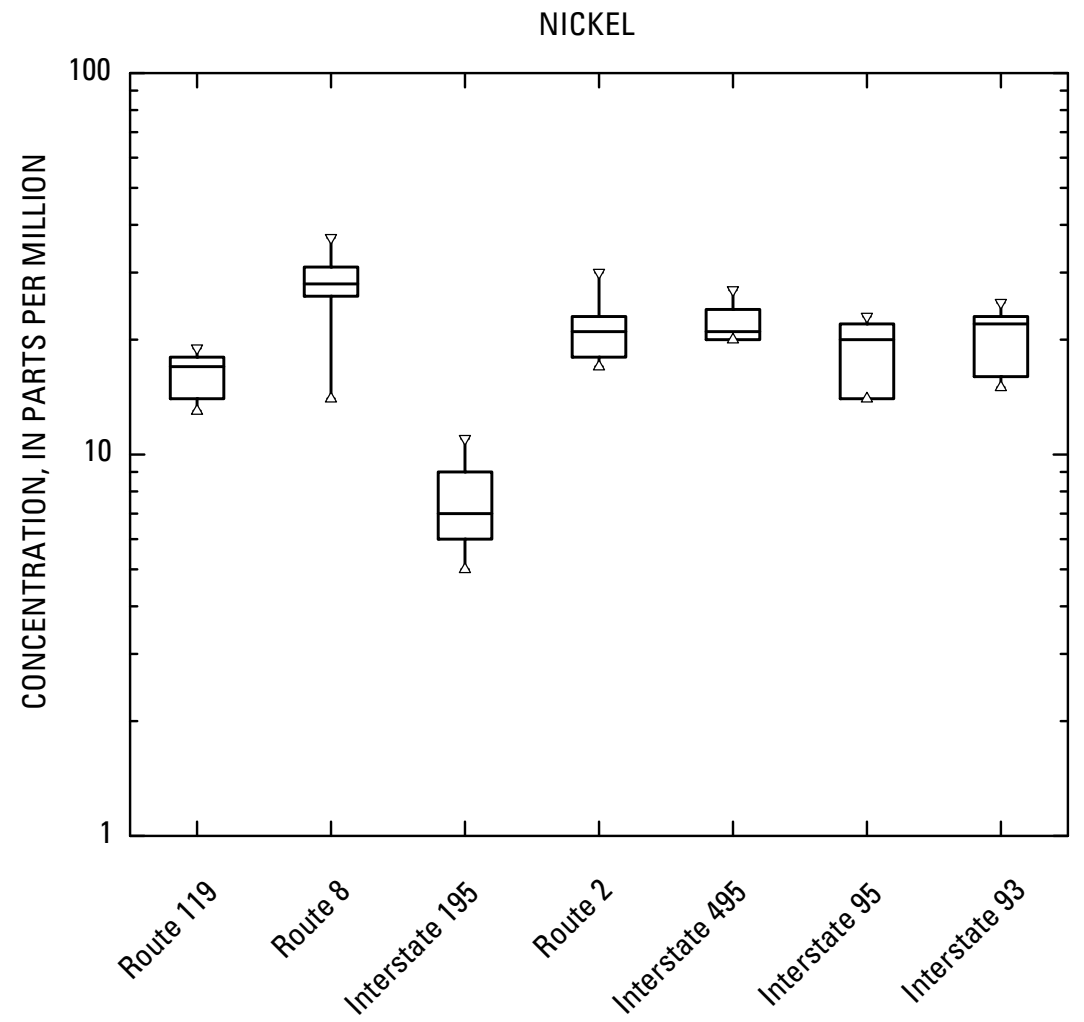

Figure 18. Distribution of concentrations of selected constituents in samples of soil collected in the vicinity of seven highway-runoff monitoring sites in Massachusetts, 2005-07.-Continued 


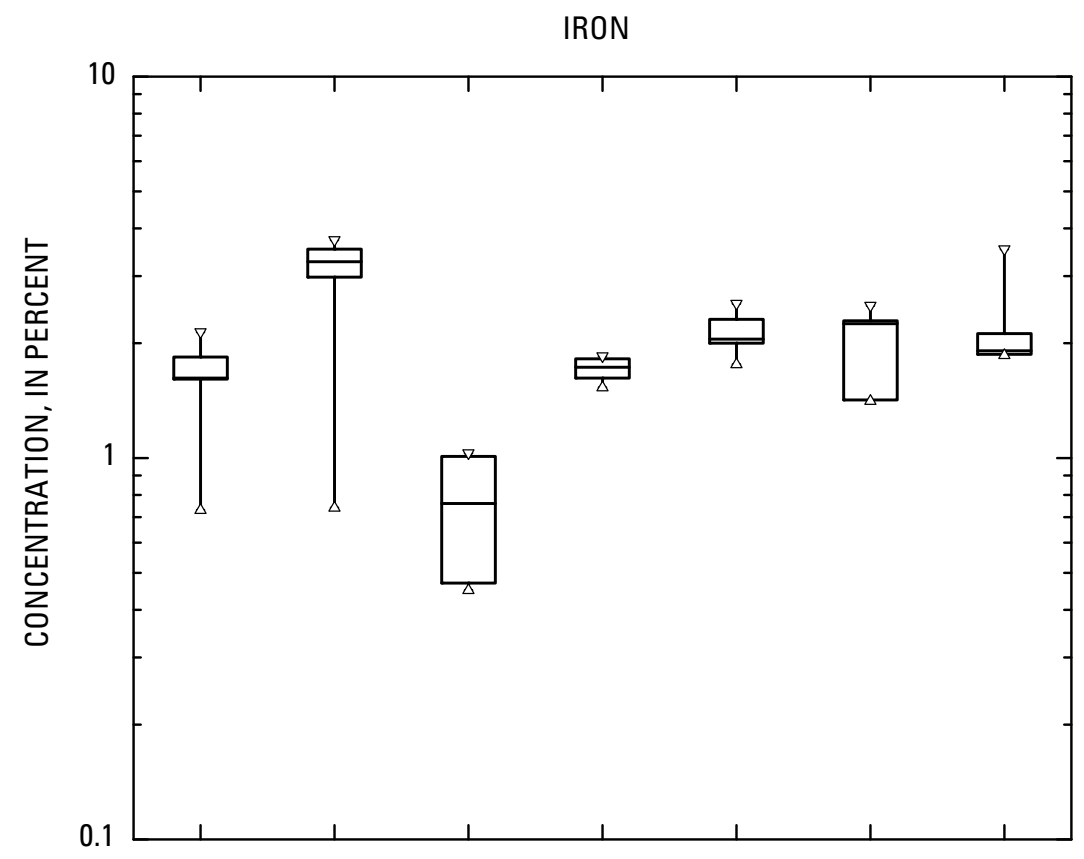

\section{EXPLANATION}

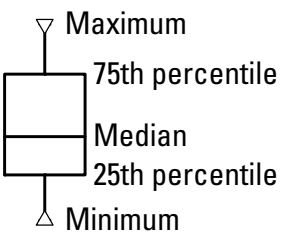

PHOSPHORUS

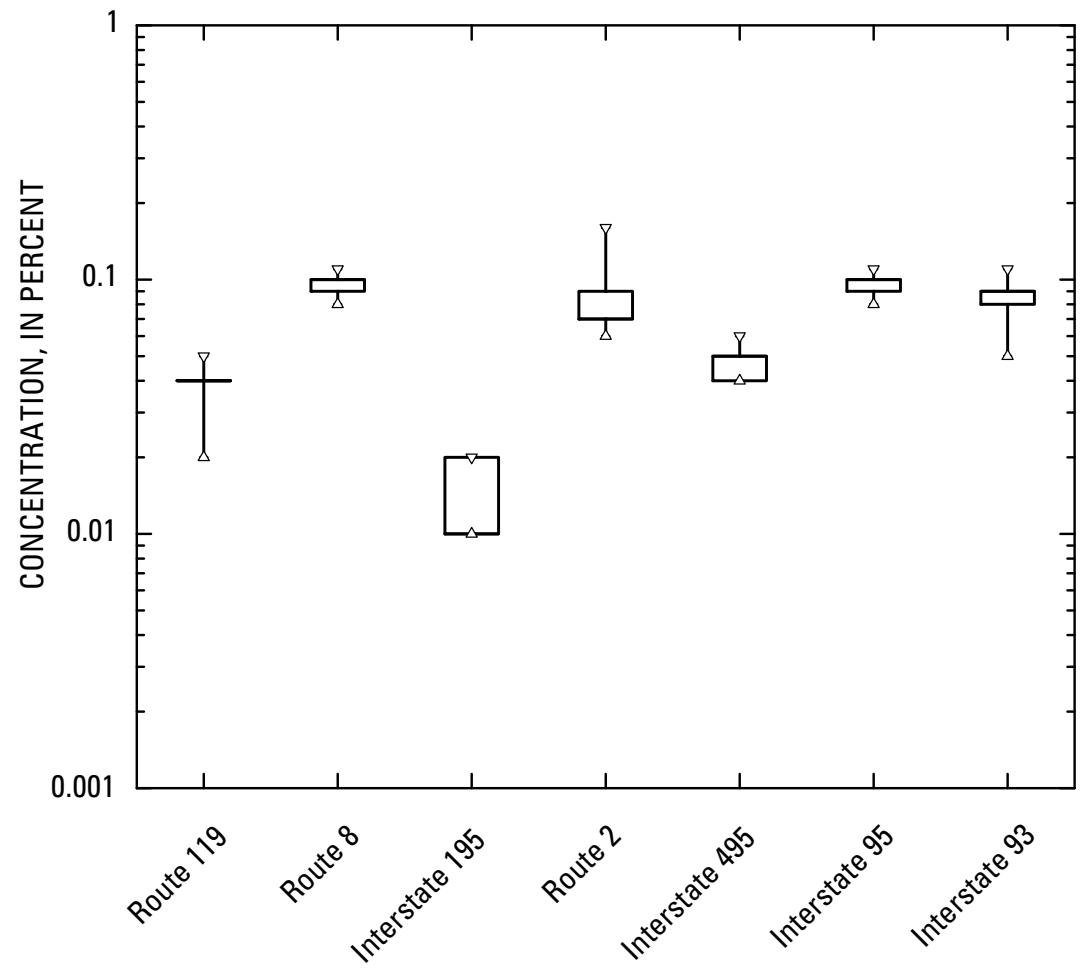

Figure 18. Distribution of concentrations of selected constituents in samples of soil collected in the vicinity of seven highway-runoff monitoring sites in Massachusetts, 2005-07.-Continued 
Table 23. Resultant $p$ values for Mann-Whitney tests for paired populations of constituent concentrations in highway runoff collected from three stations on principal highways and four stations on the test highways in Massachusetts, 2005-07.

$[<$, Less than value shown; --, insufficient detections to perform test; $\mathrm{mm}$, millimeters in diameter; shaded areas indicate values that are significant at a 95-percent confidence interval]

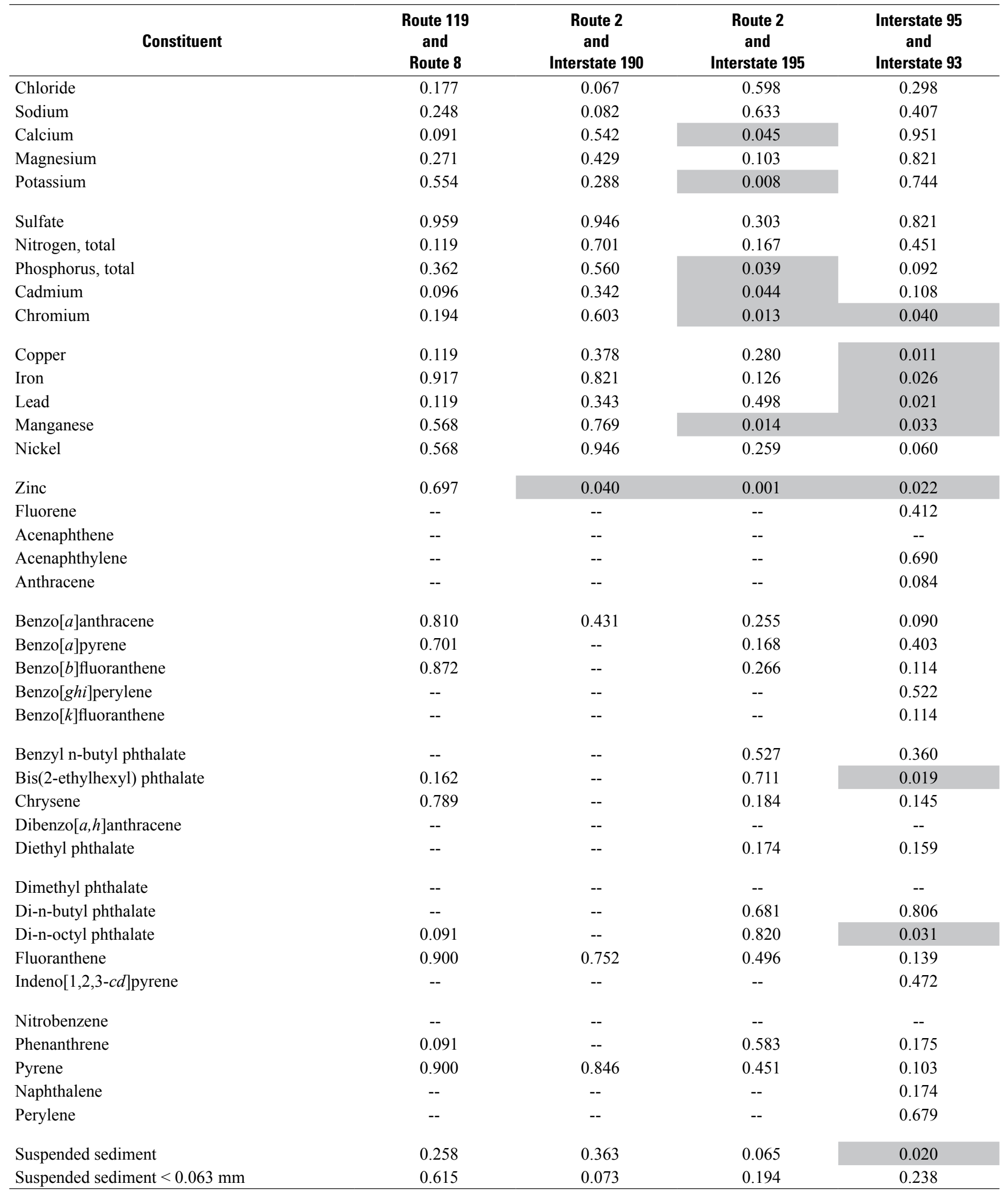


between populations of concentrations of total-recoverable metals, except for $\mathrm{Cd}$ and $\mathrm{Ni}$, and suspended sediment collected from the stations on Interstate 95 and Interstate 93 were significantly different at a 95-percent confidence interval. No significant differences were found between populations of concentrations of total nutrients, major ions, and SVOCs. Concentrations of total-recoverable $\mathrm{Cu}, \mathrm{Pb}$, and $\mathrm{Zn}$ in local soils near the monitoring station on Interstate 93 were greater than the concentrations present in soil samples collected near the monitoring stations on Interstate 95, as well as the other six highways (table 19 in the back of the report and fig. 18). Albeit these soil samples were collected at a distance of about $30 \mathrm{ft}$ from the edge of the highways and samples from other highways were collected at a distance of about $100 \mathrm{ft}$ from the edge of the highways, the concentrations of many metals in soils adjacent to highways have been shown to decay exponentially (Jaradat and Momani, 1999); thus even at about $30 \mathrm{ft}$ from the highway edge, for many metals, concentrations in the soil may approach background concentrations. In part, the higher concentrations of $\mathrm{Cu}, \mathrm{Pb}$, and $\mathrm{Zn}$ in local soils near the monitoring station on Interstate 93 may explain some of the differences between the two populations for these constituents; however, concentrations of the other metals in samples of soil collected near the monitoring station on Interstate 93 were similar to concentrations present in soil samples collected near the monitoring stations on other highways. The concentrations of suspended sediment present in composite samples of highway runoff from the station on Interstate 93 were higher than in composite samples of highway runoff collected at stations on Interstate 95. This is likely the main factor in the significant difference between populations of metals. The median concentration of suspended sediment for the station on Interstate $93(714 \mathrm{mg} / \mathrm{L})$ is nearly an order of magnitude higher than the median concentration for the station on Interstate 95 (87 mg/L).

Although the median concentration of suspended sediment for the monitoring station on Interstate 93 is based on only five measurements, data collected with nearly identical methods at three locations on Interstate 93 in 1999 and 2000 (Smith, 2002) support the high concentrations of suspended sediment observed in this study. In fact, the median concentrations of most constituents in composite samples from the station on Interstate 93 in this study are within the interquartile range of the previous study (table 24); the exceptions are dissolved $\mathrm{Ca}, \mathrm{Cl}$, and $\mathrm{Na}$; total-recoverable $\mathrm{Cd}, \mathrm{Cu}$, and $\mathrm{Fe}$; and a few PAHs. Concentrations of dissolved $\mathrm{Ca}, \mathrm{Cl}$, and $\mathrm{Na}$ were lower than in the previous study likely because, in this study, fewer samples were collected during the winter when deicing compounds are applied than during the prior study when 50 percent of the samples were collected in the months of January and March. Concentrations of PAHs also tend to be higher during the colder months, so a similar bias is applicable. Concentrations of total-recoverable $\mathrm{Cu}$ and $\mathrm{Fe}$ were within about 3 percent of the upper quartile range. Results for Mann-Whitney tests for the respective data sets indicate the populations from the two studies are not statistically different at a 95-percent confidence interval, except for populations of acenaphthylene concentrations (table 24). Acenapthene concentrations were significantly different between the two populations at a slightly higher confidence interval.

The higher concentrations of suspended sediment in samples collected from Interstate 93 may be an artifact of the urban environment. Higher concentrations of airborne sediment build up near highway curbing, guardrails, and other barriers in highly urbanized areas that lack natural vegetation barriers that trap dust fall. Dry-deposition rates are reported to increase substantially from rural areas, which generally have low deposition rates, to urban areas, which have high deposition rates (Colman and others, 2001). In this study, impervious surface area (roofs, paved areas, concrete surfaces) is used in place of generalized land-use indexes to quantify urbanization. Concentration data for stations on highways in this study indicate that the amount of suspended sediment in samples of highway runoff increases with the amount of impervious area surrounding the sampling station on the highway (fig. 19). The amount of impervious area surrounding the Interstate 93 station is about twice that of the areas surrounding the Interstate 95 stations, despite the fact that a substantial amount of land to the east of Interstate 93 consists of park land, river, and embayment. These data indicate that the quantity, as well as the quality, of sediment in highway runoff can be affected by the proximately to highly urbanized areas containing large amounts of impervious area. Thus, information on loads for Interstate 93 within the urbanized area may more accurately be determined from descriptive statistics generated by data collected specifically from Interstate 93 during this study and the previous study (Smith, 2002) than from data sets for other highways with similar AADT volumes.

\section{Intersite Evaluation of Constituents in Samples of Runoff from the Principal Highways}

Populations of all concentration data (table 16) collected from each principal highway (primary and secondary sites) were compared to populations from each of the other principal highways to determine whether the populations were significantly different from highway to highway. Results of the Mann-Whitney tests were used to determine whether the independent populations from each of the principal highways were statistically different ( $p$ value less than 0.05 ). As previously indicated, censored data values were set equal to a value less than the LTMDL for each constituent. For several PAH and phthalate compounds, analysis was limited by the lack of detections in samples of highway runoff. The resultant $p$ values for each of the constituents are listed in table 25 .

Results indicate that, in general, concentrations of most constituents in composite samples collected at the monitoring stations on Route 119, were significantly different from those from the other three principal highways (table 25). Results of paired tests between populations of concentration data from Route 119 and each of the other principal highways show that 
Table 24. Median and interquartile values and resultant $p$ values for Mann-Whitney tests at a 95-percent confidence interval for paired populations of constituent concentrations in highway runoff collected from Interstate 93 in Massachusetts in 1999 through 2000 and 2006 through 2007.

$[\mathrm{mg} / \mathrm{L}$, milligrams per liter; $\mu \mathrm{g} / \mathrm{L}$, micrograms per liter; mm, millimeters in diameter; shaded area indicates values that are significant at a 95 -percent confidence interval]

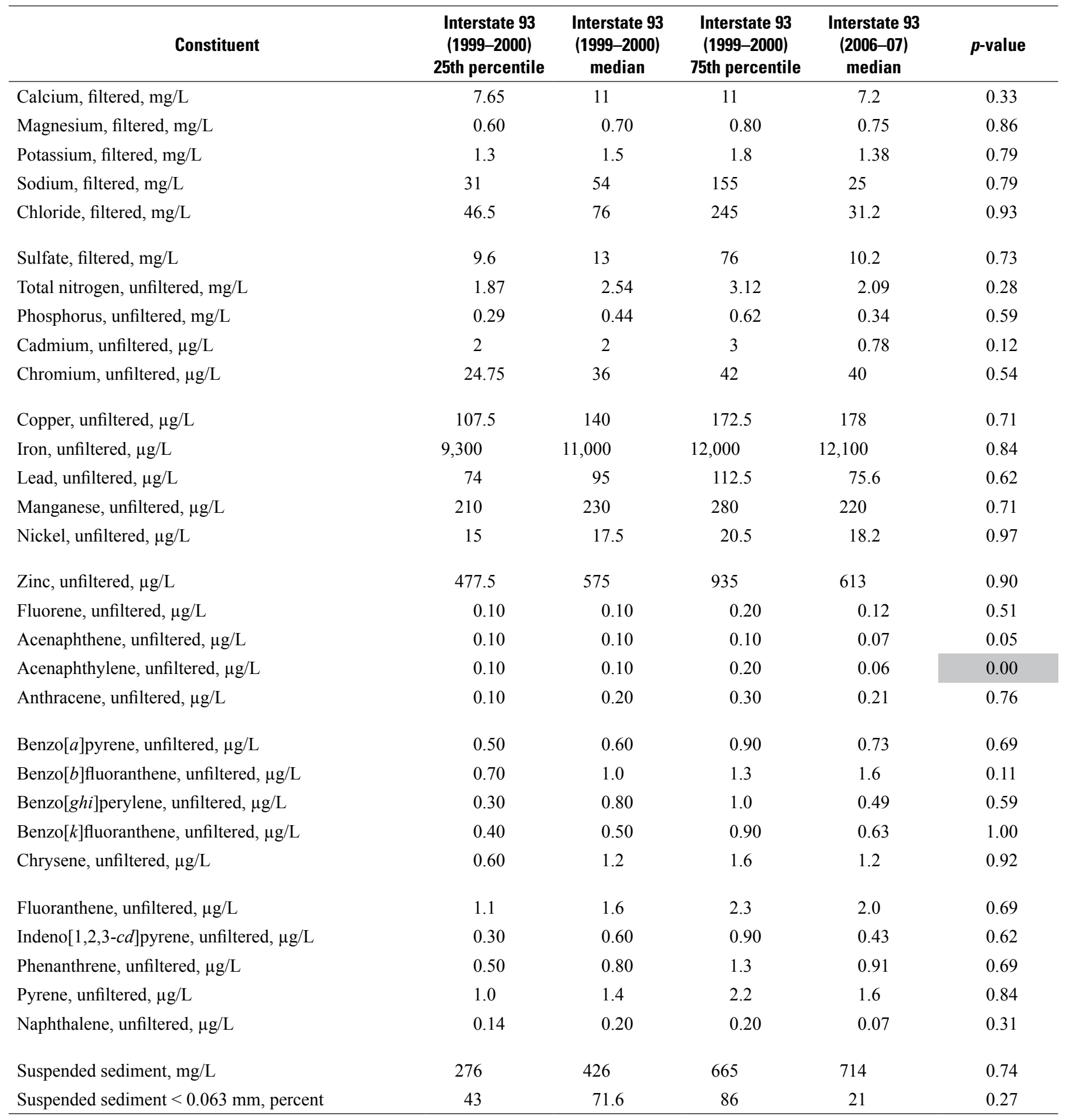




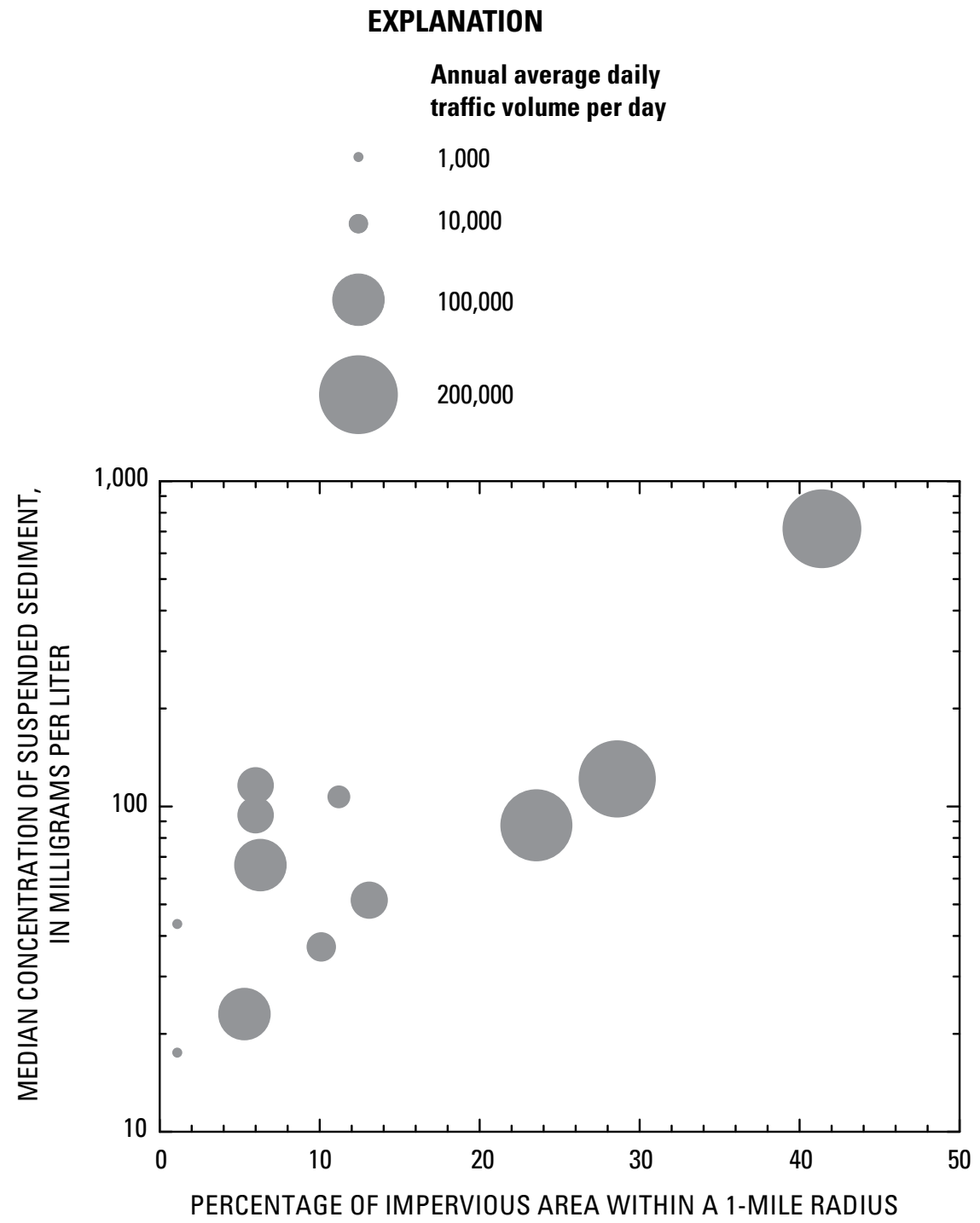

Figure 19. Relation of the percentage of impervious area within a 1-mile radius around each of the 12 highway-runoff monitoring sites in Massachusetts to the median concentration of suspended sediment and annual average traffic volumes. 
Table 25. Resultant $p$ values for Mann-Whitney tests for paired populations of concentrations of highway-runoff constituents collected from the primary and secondary stations on the four principal highways in Massachusetts, $2005-07$.

$[<$, Less than value shown; --, insufficient detections to perform test; $\mathrm{mm}$, millimeters in diameter; shaded areas indicate values that are significant at a 95-percent confidence interval]

\begin{tabular}{|c|c|c|c|c|c|c|}
\hline Constituent & $\begin{array}{c}\text { Route } 119 \\
\text { and } \\
\text { Route } 2\end{array}$ & $\begin{array}{c}\text { Route } 119 \\
\text { and } \\
\text { Interstate } 495\end{array}$ & $\begin{array}{c}\text { Route } 119 \\
\text { and } \\
\text { Interstate } 95\end{array}$ & $\begin{array}{c}\text { Route } 2 \\
\text { and } \\
\text { Interstate } 495\end{array}$ & $\begin{array}{c}\text { Route } 2 \\
\text { and } \\
\text { Interstate } 95\end{array}$ & $\begin{array}{c}\text { Interstate } 495 \\
\text { and } \\
\text { Interstate } 95\end{array}$ \\
\hline Chloride & 0.705 & 0.847 & 0.424 & 0.838 & 0.825 & 0.676 \\
\hline Sodium & 0.829 & 0.986 & 0.411 & 0.812 & 0.572 & 0.466 \\
\hline Calcium & 0.382 & 0.236 & 0.003 & 0.974 & $<0.001$ & 0.001 \\
\hline Magnesium & 0.610 & 0.749 & 0.345 & 0.330 & 0.291 & 0.110 \\
\hline Sulfate & 0.263 & 0.285 & 0.023 & 0.863 & 0.008 & 0.019 \\
\hline Nitrogen, total & 0.000 & 0.001 & $<0.001$ & 0.896 & 0.015 & 0.013 \\
\hline Phosphorus, total & 0.051 & 0.082 & 0.006 & 0.844 & 0.844 & 0.408 \\
\hline Cadmium & $<0.001$ & $<0.001$ & $<0.001$ & 0.600 & 0.658 & 0.980 \\
\hline Chromium & $<0.001$ & $<0.001$ & $<0.001$ & 0.670 & 0.436 & 0.325 \\
\hline Manganese & 0.065 & 0.024 & 0.010 & 0.774 & 0.306 & 0.476 \\
\hline Nickel & 0.040 & 0.007 & 0.003 & 0.572 & 0.210 & 0.346 \\
\hline Zinc & $<0.001$ & $<0.001$ & $<0.001$ & 0.053 & 0.075 & 0.774 \\
\hline Fluorene & -- & -- & -- & -- & -- & 0.954 \\
\hline Acenaphthene & -- & -- & -- & -- & -- & 0.975 \\
\hline Acenaphthylene & -- & -- & -- & -- & -- & -- \\
\hline Anthracene & -- & -- & -- & -- & -- & 0.626 \\
\hline Benzo $[a]$ anthracene & 0.003 & 0.002 & 0.030 & 0.612 & 0.395 & 0.766 \\
\hline Benzo $[a]$ pyrene & $<0.001$ & $<0.001$ & $<0.001$ & 0.808 & 0.162 & 0.295 \\
\hline Dibenzo $[a, h]$ anthracene & -- & -- & -- & -- & -- & -- \\
\hline Diethyl phthalate & $<0.001$ & $<0.001$ & 0.228 & 0.556 & $<0.001$ & $<0.001$ \\
\hline Dimethyl phthalate & -- & -- & -- & -- & -- & -- \\
\hline Di-n-butyl phthalate & 0.893 & 0.876 & 0.316 & 0.911 & 0.239 & 0.340 \\
\hline Di-n-octyl phthalate & 0.001 & 0.003 & 0.001 & 0.365 & 0.532 & 0.142 \\
\hline Fluoranthene & 0.002 & 0.002 & $<0.001$ & 0.967 & 0.148 & 0.244 \\
\hline Indeno $[1,2,3-c d]$ pyrene & 0.044 & 0.007 & 0.001 & 0.362 & 0.029 & 0.210 \\
\hline Nitrobenzene & -- & -- & -- & -- & -- & -- \\
\hline Phenanthrene & 0.095 & 0.060 & 0.005 & 0.685 & 0.159 & 0.367 \\
\hline Pyrene & 0.008 & 0.004 & $<0.001$ & 0.771 & 0.066 & 0.184 \\
\hline Naphthalene & -- & -- & -- & -- & -- & 0.520 \\
\hline Perylene & -- & -- & -- & 0.093 & $<0.001$ & 0.172 \\
\hline Suspended sediment & 0.031 & 0.034 & 0.020 & 0.749 & 0.820 & 0.629 \\
\hline Suspended sediment $<0.063 \mathrm{~mm}$ & 0.002 & 0.550 & 0.079 & 0.049 & 0.183 & 0.403 \\
\hline
\end{tabular}


total $\mathrm{N}$; total-recoverable $\mathrm{Cd}, \mathrm{Cr}, \mathrm{Cu}, \mathrm{Pb}, \mathrm{Ni}$, and $\mathrm{Zn}$; most $\mathrm{PAH}$ and phthalates compounds; and suspended sediment were significantly different at a 95-percent confidence interval.

Paired tests between populations of concentration data from Route 119 and Interstate 95 show that populations of concentrations of dissolved $\mathrm{Ca}, \mathrm{K}$, and $\mathrm{SO}_{4}$; total $\mathrm{P}$; benzo[ghi]perylene; and phenanthrene also were significantly different at a 95-percent confidence interval. Results of paired tests between populations of concentration data from Route 2 and Interstate 495 indicate that these constituents were not significantly different at the respective confidence intervals. Results of paired tests between populations of Fe concentrations indicate that concentrations were significantly different only for Route 119 and Interstate 495, and results of paired tests between populations of Mn concentrations indicate concentrations were significantly different for Route 119 and Interstate 495, and for Route 119 and Interstate 95. Results of paired tests between populations of concentration data from Route 119 and each of the other principal highways indicate that dissolved $\mathrm{Cl}, \mathrm{Na}$, and $\mathrm{Mg}$; benzyl n-butyl phthalate; and di-n-butyl phthalate were not significantly different at the respective confidence intervals. Although results of paired tests of concentrations of suspended sediment indicate a significant difference only for Route 119 (highway with the lowest AADT volume), results of tests were significant for concentrations of suspended sediment less than $0.063 \mathrm{~mm}$ in diameter in samples from Route 119 and Route 2. The significant difference between populations of concentrations of suspended sediment from Route 119 and the other principal highways may, in part, explain the significant difference between the populations of concentrations of sediment-associated constituents from the other principal highways. No significant difference was found for tests between populations of concentration data for Route 2 and Interstate 495, except for concentrations of sediment less than $0.063 \mathrm{~mm}$ in diameter. However, results of paired tests for populations of dissolved $\mathrm{Ca}$ and $\mathrm{SO}_{4}$, total $\mathrm{N}$, total-recoverable $\mathrm{Cu}$, benzo[ghi]perylene, diethyl phthalate, indeno[1,2,3-cd]pyrene, and perylene concentrations between Route 2 and Interstate 95 indicate concentrations were significantly different a 95-percent confidence interval. Results of paired tests between populations of concentration data from Interstate 495 and Interstate 95 indicate concentrations were significantly different at a 95-percent confidence interval only for dissolved $\mathrm{Ca}, \mathrm{K}$, and $\mathrm{SO}_{4}$; total $\mathrm{N}$; and diethyl phthalate. Concentrations of dissolved $\mathrm{Ca}$ were significantly different for all paired tests on data from Interstate 95. The highwaymonitoring stations on Interstate 95 are located in a section of highway designated as a low-salt area because of the proximity to a major drinking-water source area; thus, the significant difference in concentrations of $\mathrm{Ca}$ for Interstate 95 are likely a function of more wide-spread use of liquid calcium chloride on that highway during the winter than on the other highways.

\section{Relation of Constituents to Annual Average Daily Traffic}

Because the principal highways share many similarities in construction, surrounding land use, and local soil composition, and because the samples of highway runoff were collected during similar storm and antecedent conditions, traffic volume was the most prominent factor distinguishing each highway and likely explains much of the observed difference in the data. The significant differences determined between populations of concentrations of data from Route 119, the highway with the lowest traffic volume, and populations of concentrations of data from the other principal highways are similar to findings from previous studies (Driscoll and others, 1990b) where an AADT volume of 30,000 vehicles was a noted breaking point for low and high concentrations of several constituents. Despite the similarities in highway design and land use among the four principal highways, few results of the Mann-Whitney tests between data sets for highways with AADT volumes greater than 30,000 vehicles per day (Route 2, Interstate 495, and Interstate 95) were significantly different at the 95-percent confidence interval.

The lack of test significance between populations of data for the principal highways with moderate or higher volumes of traffic (Route 2 and Interstates 495 and 95) could be a function of the finite capacity of a highway surface to entrain fine particulates as a result of roadway dispersion by vehicle turbulence. In controlled highway turbulence tests, more than 70 percent of marked particles $12 \mu \mathrm{m}$ in diameter were removed from the highway surface within four passes of a passenger vehicle at $40 \mathrm{mi} / \mathrm{h}$ (Nicholson and Branson, 1990), and the percentage of particles removed from the highway surface increased with vehicle speed. The actual distance from the highway where resuspended particles deposit is largely a function of particle size; Gupta and others (1981) report that particles from 5 to $50 \mu \mathrm{m}$ in diameter rapidly deposit near the highway right of way, and smaller particles deposit in places remote from the highway system. Most of the mass of particulate matter emitted in gasoline and diesel exhausts, and created from brake and tire wear, are reported to be less than $20 \mu \mathrm{m}$ in diameter. For example, in two different standardized automotive tests, Cadle and others (2001) found that about 97 and 95 percent of the mass of particles emitted in exhaust from gasoline engines were less than $12.2 \mu \mathrm{m}$ in diameter, and about 92 and 84 percent of the mass of particles were less than $1.2 \mu \mathrm{m}$ in diameter. Councell and others (2004) report that mean tire-wear particles were between 10 and $20 \mu \mathrm{m}$ in diameter, and Garg and others (2000) report that from 63 to 86 percent of airborne particles from brake wear were less than $10 \mu \mathrm{m}$ in diameter. These distributions of source-particle size indicate that a large quantity of the particles potentially are lost entirely from the highway system as a result of vehicle disturbance.

These factors may explain why populations of suspended-sediment concentrations were not significantly different (table 25) among the larger highways. In part, these factors 
also may explain some subtle similarities between concentration data from the principal highways. For example, the median and interquartile concentrations of several constituents (fig. 20) measured in composite samples of stormwater collected at the monitoring stations on Route 2 and Interstate 495 were similar. Although the traffic density at the monitoring stations on Route 2 (about 9,920 vehicles per day per travel lane) was less than the traffic density at the monitoring stations on Interstate 495 (about 13,650 vehicles per day per travel lane), the posted speed limits were similar $(55$ and $65 \mathrm{mi} / \mathrm{h}$, respectively), and traffic at both sites generally was free flowing. Consequently, the constant vehicle turbulence on the highways at these stations may have prevented a significantly dissimilar buildup of anthropogenic particles. In contrast, the differences between concentrations of the same constituents for Route 2 and Interstate 95, and Interstate 495 and Interstate 95, were greater than those between Route 2 and Interstate 495 . Although the posted speed limit for Interstate $95(55 \mathrm{mi} / \mathrm{h})$ was similar to the posted speed limits for the Route 2 and Interstate 495, the traffic density per lane mile was about 94 and 41 percent higher than the traffic density for Route 2 and Interstate 495, respectively. Consequently, Interstate 95 was generally more congested, and traffic movement often was slower, particularly during poor weather.

Although the populations of concentrations of most constituents were not significantly different among the three highways with higher AADT volumes, the median concentrations and upper interquartile ranges for many metals increased with increasing AADT volume (fig. 20), indicating a positive correlation between the two variables. The frequency of detection for various organic compounds also increased with the traffic volume on the principal highways (table 26). To further investigate the relation between concentration data and traffic volume, Kendall's tau correlation coefficient and Spearman rank correlation coefficient tests (SAS Institute, 1998) were performed to evaluate monotonic correlations between the median concentrations of selected constituents that were routinely detected at greater than the LTMDL and the AADT volume for each of the eight highways. Both tests are based on the ranks of the data and, therefore, are resistant to effects caused by outliers and are appropriate for use with censored values (Helsel and Hirsch, 2002). Each method provides results ranging from -1 (negative relation) through 0 (no relation) to +1 (positive relation) (SAS Institute, 1998). Although the results for each test are similar, the test methods differ from each other. For example, differences between data values ranked farther apart are treated the same for Kendall tau test but receive more weight for the Spearman rank correlation coefficient test (Helsel and Hirsch, 2002).

The resultant test statistics and the respective $p$ values for the Kendall's Tau correlation coefficient and Spearman rank correlation coefficient tests are presented in table 27. Test results for one or both methods indicate that correlations of the median concentrations of total N, total P; all total-recoverable metals; benzo $[a]$ anthracene, benzo[ $b]$ fluoranthene, fluoranthene, and pyrene with AADT volumes are significantly different at a 95-percent confidence interval. Spearman rank correlation coefficient test results for benzo $[a]$ anthracene and benzo[ $b]$ fluoranthene were not significantly different at a 95-percent confidence interval; however, correlations between the median concentrations of these constituents and the respective AADT volumes were significantly different at slightly lower confidence intervals. Test results for concentrations of dissolved $\mathrm{Cl}, \mathrm{Na}, \mathrm{Ca}, \mathrm{Mg}, \mathrm{K}$, and $\mathrm{SO}_{4}$; benzo[a]pyrene; bis(2-ethylhexyl) phthalate; chrysene; di-n-octyl phthalate; and suspended sediment were not significantly different at confidence intervals greater than 89 percent for either test; therefore, AADT volumes may be a poor predictor of concentrations of these constituents in the absence of additional data.

\section{Estimated Concentrations of Major Constituents in Road Salt}

Concentrations of $\mathrm{Ca}, \mathrm{Cl}, \mathrm{Na}$, and $\mathrm{SO}_{4}$, which constitute the major constituents of road salt, were estimated on the basis of the superpositioning method and the event-mean values for specific conductance for all available data collected at 11 highway-monitoring stations. Unfortunately, population statistics for the estimated concentrations of these major ions were not computed for runoff events at Route 8 because available data for non-winter storms were insufficient to model the transition from low-ionic strength runoff to runoff dominated by deicing compounds. Although the general statistics for the population of flow-weighted specific-conductance values were similar to that of the other highways sites, estimates for major ions could not accurately be made for 60 to 70 percent of the available data because of the disparity between ratios of $\mathrm{Cl}$ to the other major ions at the Route 8 station. Runoff quality in this area of the state may be different because the chemistry of precipitation in this area is different (National Atmospheric Deposition Program, 2008), and the composition of soils in this area is affected by weathering of limestone bedrock. Data for the other 11 monitoring stations were estimated for 1,381 runoff events that include periods of measurable snowmelt (periods of runoff during the winter months with air temperatures greater than the freezing point and no records of measurable precipitation). These estimated concentration data provide an order of magnitude increase in data density over available water-sample data. Statistics for populations of estimated event-mean concentrations of selected constituents at all highways are listed in table 28 . The median estimated concentrations of $\mathrm{Cl}$ ranged from about 10 to $40 \mathrm{mg} / \mathrm{L}$ for all highway sites, except for the site on Interstate 93 where the median estimated concentration was $79 \mathrm{mg} / \mathrm{L}$. The median estimated concentrations of $\mathrm{Cl}$ were lowest for the monitoring stations on Route 119. Estimated concentrations of $\mathrm{Ca}, \mathrm{Na}$, and $\mathrm{SO}_{4}$, which were derived from estimated concentrations of $\mathrm{Cl}$, followed the same pattern. Estimated average concentrations for each constituent were substantially greater than the median estimated concentrations for each highway (table 28). This is a function of high right skew in the data populations caused by a 

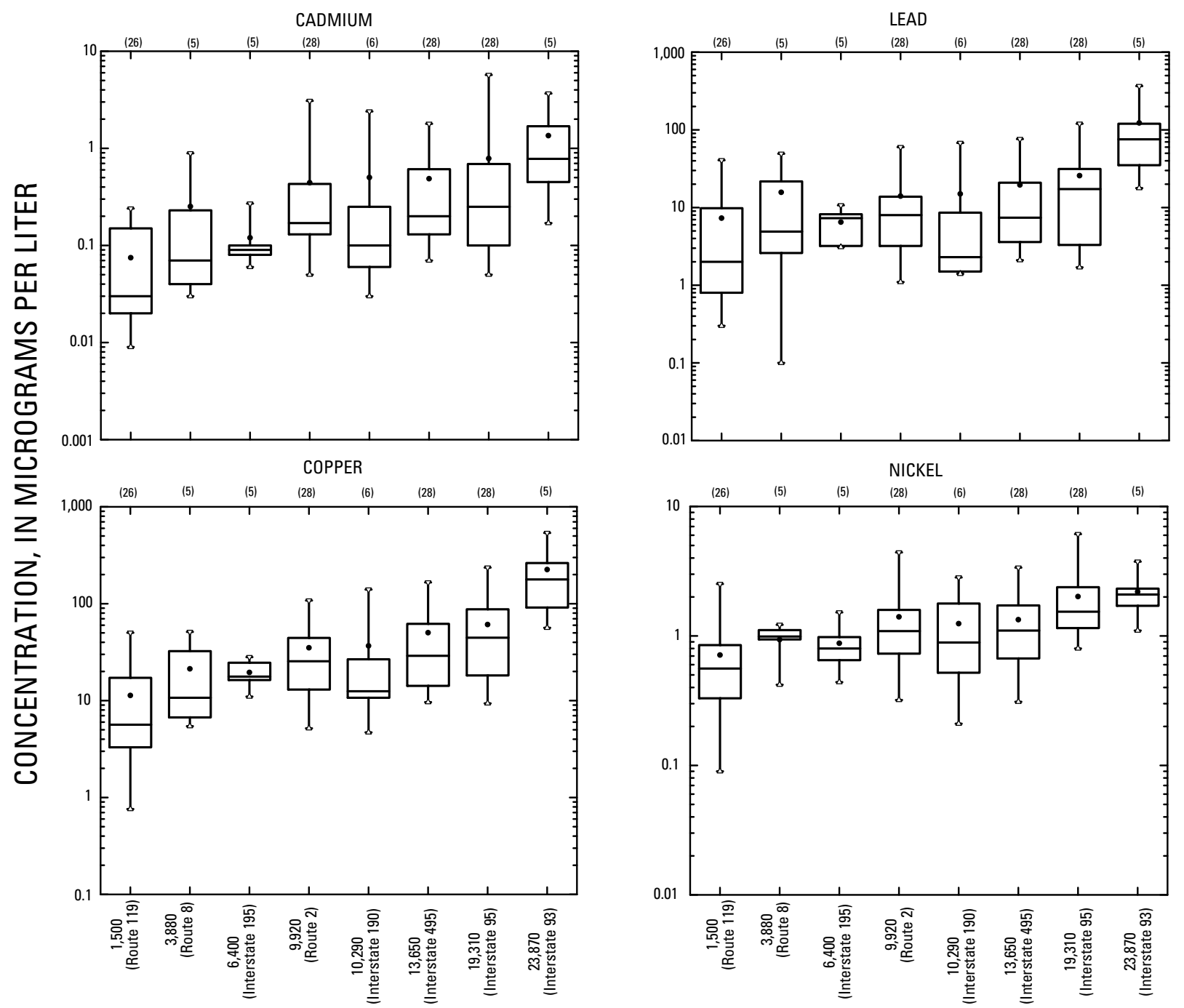

ANNUAL AVERAGE VEHICLES PER DAY PER TRAVEL LANE

\section{EXPLANATION}

(26) Number of observations

Maximum

75 th percentile

- Mean

Median

25th percentile

$\triangle$ Minimum

Figure 20. Concentrations of selected constituents in samples of highway runoff collected at eight highway-monitoring stations in Massachusetts in relation to the annual average daily vehicles per travel lane. 


\section{Quality of Stormwater Runoff Discharged from Massachusetts Highways, 2005-07}

Table 26. Frequency of detection for selected polyaromatic hydrocarbons and phthalate compounds in composite samples of highway runoff collected from the four principal highways at eight sites in Massachusetts, 2005-07.

[LTMDL, long-term method detection level; $\geq$, greater than or equal to LTMDL]

\begin{tabular}{|c|c|c|c|c|c|c|c|c|}
\hline \multirow[b]{2}{*}{ Compound } & \multicolumn{4}{|c|}{ Frequency of detection (percent) } & \multicolumn{4}{|c|}{ Frequency of detection (percent $\geq$ LTMDL) } \\
\hline & Route 119 & Route 2 & $\begin{array}{c}\text { Interstate } \\
495\end{array}$ & $\begin{array}{c}\text { Interstate } \\
95\end{array}$ & Route 119 & Route 2 & $\begin{array}{c}\text { Interstate } \\
495\end{array}$ & $\begin{array}{c}\text { Interstate } \\
95\end{array}$ \\
\hline Fluorene & 38 & 67 & 68 & 46 & 0 & 0 & 7 & 7 \\
\hline Acenaphthene & 27 & 44 & 50 & 43 & 0 & 0 & 11 & 11 \\
\hline Acenaphthylene & 31 & 48 & 50 & 46 & 0 & 0 & 4 & 0 \\
\hline Anthracene & 35 & 59 & 86 & 86 & 0 & 0 & 11 & 21 \\
\hline $\operatorname{Benzo}[a]$ anthracene & 38 & 85 & 96 & 96 & 12 & 52 & 54 & 71 \\
\hline Benzo $[a]$ pyrene & 62 & 89 & 93 & 100 & 23 & 56 & 50 & 68 \\
\hline Benzo $[b]$ fluoranthene & 69 & 96 & 100 & 100 & 31 & 70 & 68 & 82 \\
\hline Benzo[ghi]perylene & 77 & 85 & 89 & 93 & 8 & 19 & 29 & 43 \\
\hline Benzo $[k]$ fluoranthene & 50 & 89 & 96 & 100 & 4 & 30 & 32 & 46 \\
\hline Benzyl n-butyl phthalate & 8 & 19 & 18 & 32 & 8 & 11 & 14 & 25 \\
\hline Bis(2-ethylhexyl) phthalate (DEHP) & 50 & 85 & 79 & 82 & 50 & 85 & 79 & 82 \\
\hline Chrysene & 62 & 85 & 100 & 100 & 27 & 59 & 61 & 75 \\
\hline Dibenzo $[a, h]$ anthracene & 4 & 22 & 32 & 36 & 0 & 0 & 0 & 4 \\
\hline Diethyl phthalate (DEP) & 19 & 19 & 7 & 21 & 4 & 4 & 4 & 14 \\
\hline Dimethyl phthalate & 12 & 22 & 18 & 25 & 0 & 0 & 0 & 0 \\
\hline Di-n-butyl phthalate & 27 & 41 & 39 & 36 & 15 & 15 & 21 & 29 \\
\hline Di-n-octyl phthalate & 54 & 93 & 75 & 86 & 19 & 74 & 61 & 75 \\
\hline Fluoranthene & 88 & 100 & 100 & 100 & 38 & 81 & 82 & 86 \\
\hline Indeno[1,2,3-cd]pyrene & 69 & 93 & 89 & 93 & 4 & 22 & 32 & 43 \\
\hline Nitrobenzene & 4 & 7 & 14 & 0 & 0 & 0 & 0 & 0 \\
\hline Phenanthrene & 85 & 96 & 100 & 96 & 23 & 52 & 46 & 61 \\
\hline Pyrene & 88 & 100 & 100 & 100 & 31 & 70 & 71 & 82 \\
\hline Naphthalene & 19 & 44 & 39 & 54 & 0 & 0 & 7 & 4 \\
\hline Perylene & 12 & 67 & 64 & 68 & 0 & 0 & 18 & 35 \\
\hline
\end{tabular}


Table 27. Resultant test and $p$ values for Kendall Tau and Spearman Rank correlation tests performed on median values of populations of constituent concentrations in highway runoff and annual average daily traffic volumes for the principal highways in Massachusetts, 2005-07.

[Shaded areas indicate values that are significant at a 95-percent confidence interval]

\begin{tabular}{lcccc}
\hline \multicolumn{1}{c}{ Constituent } & Kendall Tau value & Kendall Tau $\boldsymbol{p}$ value & Spearman Rho value & Spearman Rho $\boldsymbol{p}$ value \\
\hline Chloride & 0.357 & 0.216 & 0.405 & 0.284 \\
Sodium & 0.429 & 0.138 & 0.429 & 0.257 \\
Calcium & 0.286 & 0.322 & 0.238 & 0.529 \\
Magnesium & 0.429 & 0.138 & 0.310 & 0.413 \\
Potassium & 0.429 & 0.138 & 0.595 & 0.115 \\
Sulfate & & & & 0.115 \\
Nitrogen, total & 0.500 & 0.083 & 0.595 & 0.012 \\
Phosphorus, total & 0.857 & 0.003 & 0.952 & 0.023 \\
Cadmium & 0.714 & 0.013 & 0.857 & 0.010 \\
Chromium & 0.929 & 0.001 & 0.976 & 0.020 \\
Copper & 0.714 & 0.013 & 0.881 & 0.010 \\
Iron & & & 0.976 & 0.023 \\
Lead & 0.929 & 0.001 & 0.857 & 0.020 \\
Manganese & 0.786 & 0.007 & 0.881 & 0.017 \\
Nickel & 0.786 & 0.007 & 0.804 & 0.023 \\
Zinc & 0.679 & 0.019 & 0.905 & 0.083 \\
Benzo[a]anthracene & 0.786 & 0.007 & 0.857 & 0.166 \\
Benzo[a]pyrene & & & 1.000 & 0.072 \\
Benzo[b]fluoranthene & 0.786 & 0.007 & 0.800 & 0.277 \\
Bis(2-ethylhexyl) phthalate & 1.000 & 0.042 & 0.900 & 0.166 \\
Chrysene & 0.667 & 0.174 & 0.486 & 0.115 \\
Di-n-octyl phthalate & 0.800 & 0.050 & 0.800 & 0.035 \\
Fluoranthene & 0.333 & 0.348 & 0.643 & 0.035 \\
Pyrene & & & 0.943 & 0.208 \\
Suspended sediment & 0.667 & 0.174 & 0.943 & 0.476 \\
\hline
\end{tabular}




\section{Quality of Stormwater Runoff Discharged from Massachusetts Highways, 2005-07}

Table 28. Selected statistics for populations of concentrations of chloride, sodium, calcium, and sulfate estimated from event-mean values of specific conductance calculated from continuous measurements of flow and specific conductance for the period of record for 11 highway monitoring stations in Massachusetts, 2005-07.

[USGS, U.S. Geological Survey]

\begin{tabular}{|c|c|c|c|c|c|c|c|}
\hline $\begin{array}{l}\text { USGS station } \\
\text { number }\end{array}$ & Highway & $\begin{array}{c}\text { Number of } \\
\text { events }\end{array}$ & Statistic & Chloride & Sodium & Calcium & Sulfate \\
\hline \multirow[t]{6}{*}{424209071545201} & Route 119 & 149 & Maximum & 4,500 & 2,600 & 65 & 140 \\
\hline & & & Median & 18 & 13 & 2.7 & 3.4 \\
\hline & & & Average & 285 & 168 & 7.8 & 14 \\
\hline & & & Standard deviation & 818 & 473 & 13 & 28 \\
\hline & & & Skew & 3.76 & 3.76 & 2.86 & 3.10 \\
\hline & & & Minimum & 1.1 & 0.87 & 0.44 & 0.45 \\
\hline \multirow[t]{6}{*}{424155071543201} & Route 119 & 105 & Maximum & 3,100 & 1,800 & 53 & 110 \\
\hline & & & Median & 10 & 7.6 & 1.9 & 2.3 \\
\hline & & & Average & 96 & 58 & 4.2 & 6.6 \\
\hline & & & Standard deviation & 359 & 208 & 7.3 & 14 \\
\hline & & & Skew & 6.72 & 6.72 & 4.29 & 4.99 \\
\hline & & & Minimum & 1.1 & 0.91 & 0.45 & 0.46 \\
\hline \multirow[t]{6}{*}{423027071291301} & Route 2 & 148 & Maximum & 11,000 & 6,100 & 100 & 240 \\
\hline & & & Median & 36 & 25 & 4.0 & 5.4 \\
\hline & & & Average & 542 & 315 & 11 & 21 \\
\hline & & & Standard deviation & 1,510 & 860 & 19 & 41 \\
\hline & & & Skew & 3.98 & 3.87 & 2.67 & 2.96 \\
\hline & & & Minimum & 1.8 & 1.4 & 0.62 & 0.65 \\
\hline \multirow[t]{6}{*}{423027071291302} & Route 2 & 72 & Maximum & 25,000 & 14,000 & 170 & 420 \\
\hline & & & Median & 32 & 22 & 3.8 & 5.0 \\
\hline & & & Average & 1,070 & 612 & 14 & 28 \\
\hline & & & Standard deviation & 4,040 & 2,276 & 31 & 74 \\
\hline & & & Skew & 4.69 & 4.65 & 3.80 & 4.05 \\
\hline & & & Minimum & 3.2 & 2.5 & 0.90 & 0.99 \\
\hline \multirow{6}{*}{422821071332001} & Interstate 495 & 178 & Maximum & 20,000 & 11,000 & 150 & 360 \\
\hline & & & Median & 29 & 20 & 3.6 & 4.7 \\
\hline & & & Average & 543 & 315 & 11 & 20 \\
\hline & & & Standard deviation & 2,000 & 1,130 & 20 & 44 \\
\hline & & & Skew & 7.08 & 6.86 & 3.91 & 4.56 \\
\hline & & & Minimum & 1.6 & 1.3 & 0.57 & 0.59 \\
\hline \multirow[t]{6}{*}{422716071343901} & Interstate 495 & 115 & Maximum & 14,000 & 7,800 & 120 & 280 \\
\hline & & & Median & 37 & 25 & 4.1 & 5.5 \\
\hline & & & Average & 834 & 478 & 14 & 27 \\
\hline & & & Standard deviation & 2,400 & 1,350 & 25 & 56 \\
\hline & & & Skew & 3.83 & 3.76 & 2.73 & 2.98 \\
\hline & & & Minimum & 0.58 & 0.48 & 0.29 & 0.28 \\
\hline
\end{tabular}


Table 28. Selected statistics for populations of concentrations of chloride, sodium, calcium, and sulfate estimated from event-mean values of specific conductance calculated from continuous measurements of flow and specific conductance for the period of record for 11 highway monitoring stations in Massachusetts, 2005-07.-Continued

[USGS, U.S. Geological Survey]

\begin{tabular}{|c|c|c|c|c|c|c|c|}
\hline $\begin{array}{l}\text { USGS station } \\
\text { number }\end{array}$ & Highway & $\begin{array}{c}\text { Number of } \\
\text { events }\end{array}$ & Statistic & Chloride & Sodium & Calcium & Sulfate \\
\hline \multirow[t]{6}{*}{422620071153301} & Interstate 95 & 126 & Maximum & 10,000 & 5,800 & 100 & 230 \\
\hline & & & Median & 40 & 27 & 4.3 & 5.9 \\
\hline & & & Average & 441 & 258 & 11 & 19 \\
\hline & & & Standard deviation & 1,320 & 761 & 17 & 36 \\
\hline & & & Skew & 5.07 & 5.09 & 3.14 & 3.62 \\
\hline & & & Minimum & 0.48 & 0.40 & 0.25 & 0.24 \\
\hline \multirow[t]{6}{*}{422420071153302} & Interstate 95 & 103 & Maximum & 12,000 & 6,900 & 110 & 260 \\
\hline & & & Median & 26 & 18 & 3.3 & 4.3 \\
\hline & & & Average & 526 & 306 & 11 & 20 \\
\hline & & & Standard deviation & 1,630 & 935 & 19 & 42 \\
\hline & & & Skew & 4.69 & 4.69 & 3.03 & 3.40 \\
\hline & & & Minimum & 0.58 & 0.48 & 0.29 & 0.28 \\
\hline \multirow[t]{6}{*}{423016071431501} & Interstate 190 & 138 & Maximum & 22,000 & 13,000 & 160 & 390 \\
\hline & & & Median & 24 & 17 & 3.1 & 4.1 \\
\hline & & & Average & 1,340 & 778 & 18 & 37 \\
\hline & & & Standard deviation & 3,710 & 2,150 & 32 & 76 \\
\hline & & & Skew & 3.57 & 3.60 & 2.59 & 2.85 \\
\hline & & & Minimum & 1.2 & 0.99 & 0.48 & 0.49 \\
\hline \multirow[t]{6}{*}{414339070462201} & Interstate 195 & 125 & Maximum & 8,500 & 4,900 & 92 & 210 \\
\hline & & & Median & 22 & 15 & 3.0 & 3.8 \\
\hline & & & Average & 478 & 278 & 11 & 20 \\
\hline & & & Standard deviation & 1,280 & 732 & 18 & 37 \\
\hline & & & Skew & 3.85 & 3.87 & 2.55 & 2.86 \\
\hline & & & Minimum & 1.6 & 1.2 & 0.57 & 0.59 \\
\hline \multirow[t]{6}{*}{421647071024703} & Interstate 93 & 122 & Maximum & 21,000 & 12,000 & 150 & 380 \\
\hline & & & Median & 79 & 52 & 6.4 & 9.3 \\
\hline & & & Average & 897 & 521 & 16 & 31 \\
\hline & & & Standard deviation & 2,510 & 1,430 & 24 & 55 \\
\hline & & & Skew & 5.43 & 5.40 & 2.86 & 3.46 \\
\hline & & & Minimum & 7.4 & 5.5 & 1.5 & 1.8 \\
\hline \multirow[t]{6}{*}{ All sites } & -- & 1381 & Maximum & 25,000 & 14,000 & 170 & 420 \\
\hline & & & Median & 29 & 20 & 3.5 & 4.7 \\
\hline & & & Average & 627 & 364 & 12 & 22 \\
\hline & & & Standard deviation & 2,160 & 1,240 & 21 & 49 \\
\hline & & & Skew & 6.06 & 6.02 & 3.50 & 4.05 \\
\hline & & & Minimum & 0.5 & 0.4 & 0.3 & 0.2 \\
\hline
\end{tabular}


relatively small number of high estimated concentrations. For example, the percentage for all estimated concentrations of $\mathrm{Cl}$ greater than $10,000 \mathrm{mg} / \mathrm{L}$ was less than 2 percent (fig. 21), and the percentage for all estimated concentrations of $\mathrm{Cl}$ greater than $230 \mathrm{mg} / \mathrm{L}$ (the USEPA national recommended freshwaterquality criteria; U.S. Environmental Protection Agency, 2009) was about 20 percent (fig. 21). The highest EMCs of deicing compounds were typically measured for mixed precipitation storms, which usually generate only small flows, for small rain storms that occur subsequent to applications of deicing compounds, and for relatively small amounts of snowmelt water. Thus, $\mathrm{Cl}$ yields per lane mile may be more useful for estimating the potential effects on receiving water quality. The frequency at which a given yield of $\mathrm{Cl}$ per lane mile was equaled or exceeded is illustrated in figure 22. If the average background in-storm concentration of $\mathrm{Cl}$ and volume of flow corresponding to the runoff event for the receiving water body are known, and the area of highway draining directly to the water body can be calculated, the data illustrated in figure 22 can be used to determine the potential risk for exceeding some threshold concentration of $\mathrm{Cl}$ in the receiving water body during the runoff event.

\section{Evaluation of Constituents in Seasonal Samples of Runoff from the Principal Highways}

The concentrations of constituents in samples of highway runoff varied considerably from storm to storm, as well as from station to station. However, concentrations of nearly all constituents measured in composite samples of highway runoff collected after the first snowfall in January 2006 through April 2006, and March 2007 through April 2007, increased substantially during the winter months. The average concentrations of total P, total-recoverable metals, and suspended sediment in samples of highway runoff collected during the winter were about 3 to 11 times the average concentrations observed in samples of non-winter runoff (table 29). Concentrations of suspended sediment and majors ions are expected to increase during the winter season in Massachusetts as a result of the application of deicing compounds and maintenance sands to the highway surface; however, virtually all populations of winter and non-winter concentrations of metals, PAH compounds, and phthalates also increased substantially. Changes in ambient temperature, differences in driving methods, snow-removal operations, and the presence of snow embankments along the highways also affect the winter concentrations of metals and

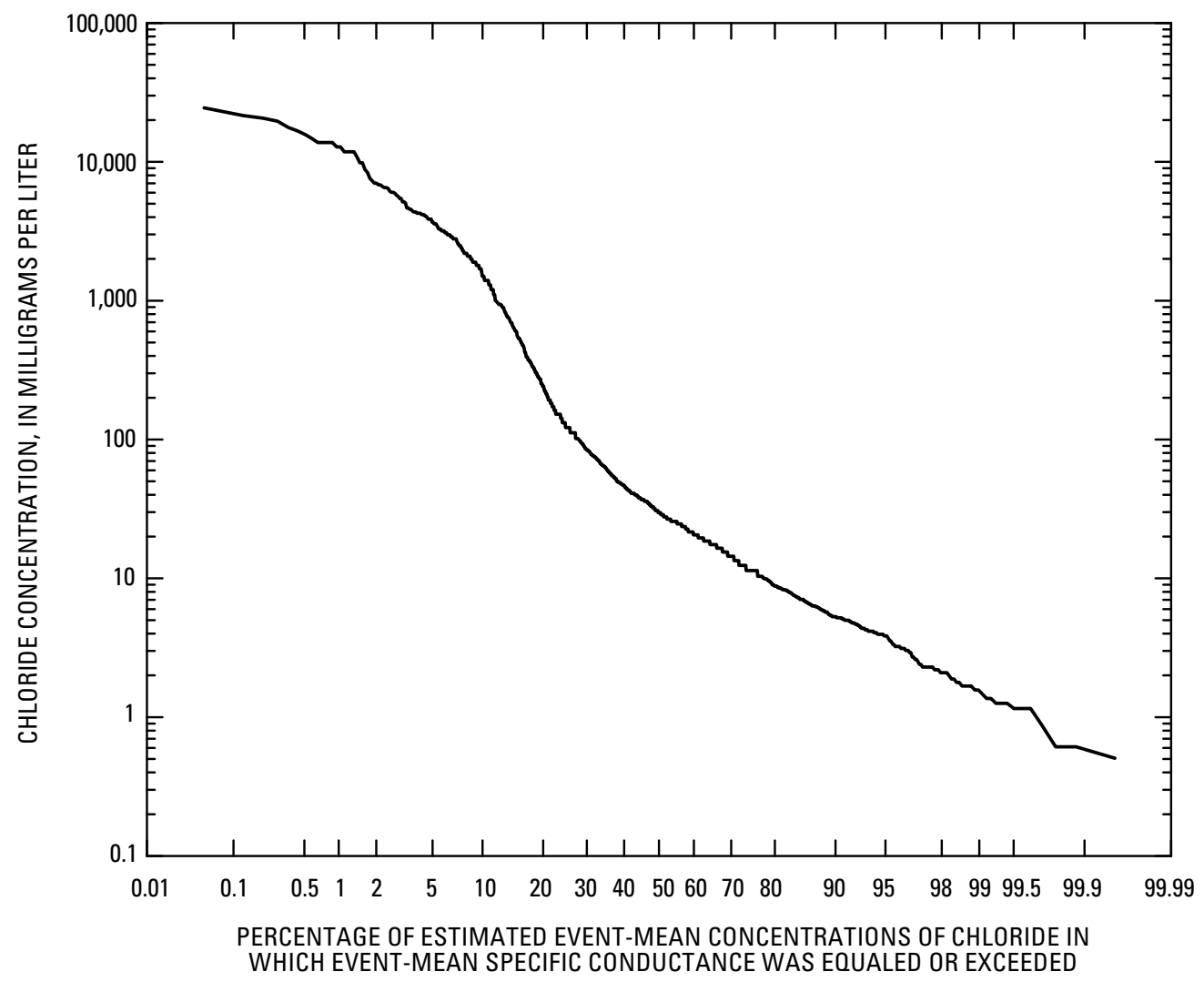

Figure 21. Percentage of event-mean concentrations of chloride estimated from continuous records of specific conductance for 1,381 runoff events from 11 highway-monitoring stations on 7 highways in Massachusetts to measured concentrations of chloride in composite samples of highway runoff. 


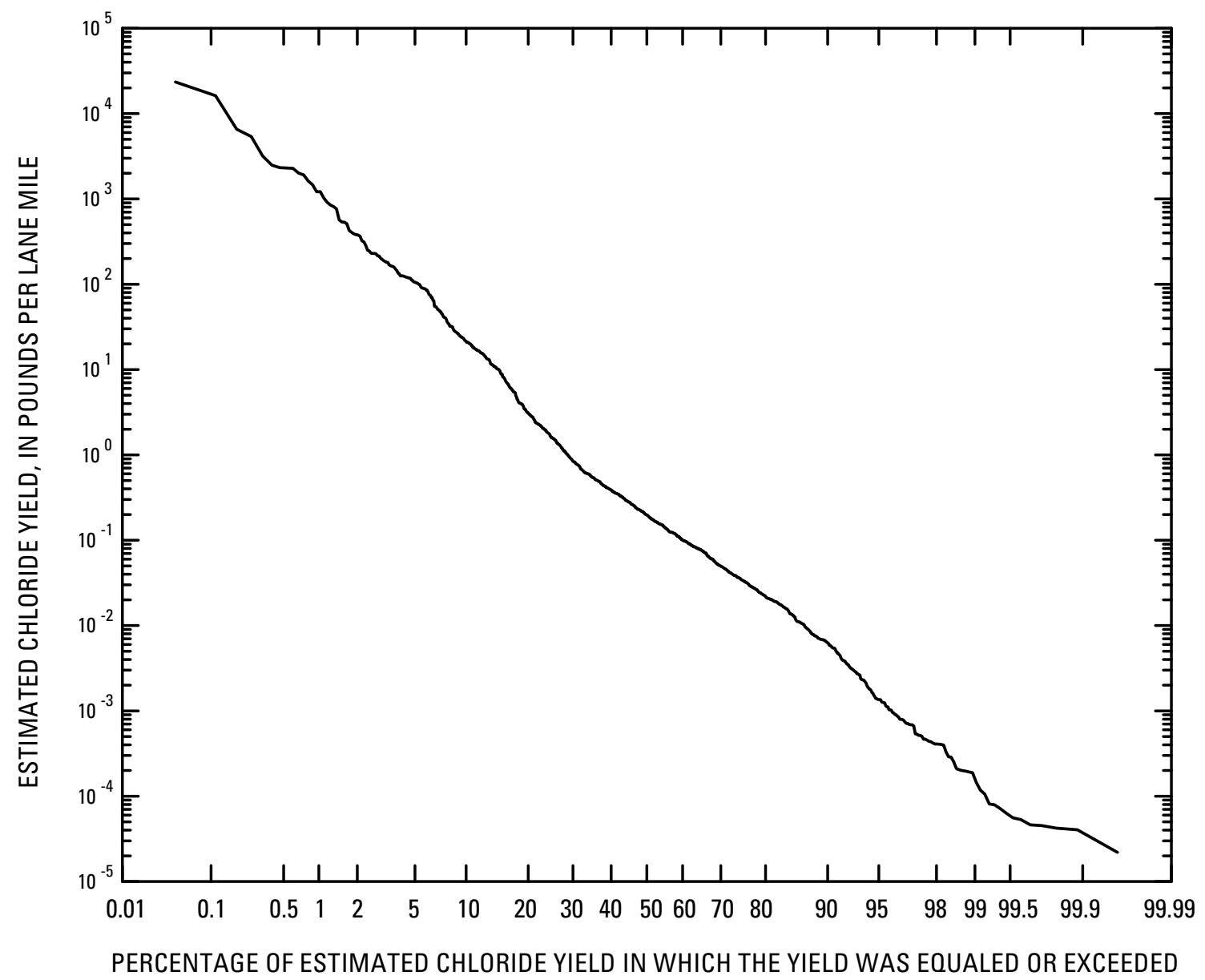

Figure 22. Probability distribution for loads of chloride estimated from continuous records of specific conductance for 1,381 runoff events from 11 highway-monitoring stations on 7 highways in Massachusetts.

Table 29. The ratio of mean concentrations of total nutrients, total-recoverable metals, and suspended sediment in composite samples of highway runoff collected during winter storms to mean concentrations of the respective constituents in samples collected during non-winter storms for the primary and secondary stations on four principal highways in Massachusetts, 2005-07.

\begin{tabular}{|c|c|c|c|c|c|c|}
\hline Highway & Nitrogen & Phosphorus & Cadmium & Chromium & Copper & Iron \\
\hline Route 119 & 1.5 & 3.9 & 5.0 & 5.8 & 4.4 & 14.4 \\
\hline Route 2 & 1.1 & 2.4 & 6.6 & 2.9 & 3.1 & 6.8 \\
\hline Interstate 495 & 1.4 & 3.7 & 6.3 & 4.0 & 4.0 & 8.2 \\
\hline Interstate 95 & 1.6 & 2.4 & 11.4 & 3.5 & 3.3 & 6.9 \\
\hline Highway & Lead & Manganese & Nickel & Zinc & $\begin{array}{c}\text { Suspended } \\
\text { sediment }\end{array}$ & \\
\hline Route 119 & 11.4 & 6.6 & 6.9 & 6.0 & 11.6 & \\
\hline Route 2 & 5.5 & 4.9 & 7.1 & 3.8 & 3.1 & \\
\hline Interstate 495 & 7.9 & 6.4 & 6.1 & 4.3 & 9.1 & \\
\hline Interstate 95 & 4.2 & 6.0 & 5.4 & 4.3 & 5.8 & \\
\hline
\end{tabular}


organic compounds measured in this study. Results of singletail Mann-Whitney tests indicate that the concentrations of nearly all constituents measured in samples of highway runoff collected during the winter and after the first snowfall from each principal highway were significantly greater at a 99-percent confidence interval ( $p$ value less than 0.01 ; table 30 ).

Deicing compounds are not entirely pure and thus contain trace amounts of elements typically associated with highway runoff; however, the trace amounts of total $\mathrm{N}$ and total-recoverable metals in highway deicing compounds do not fully explain the significant differences in concentrations observed during winter. Ratios for concentrations of nitrate and totalrecoverable $\mathrm{Cr}, \mathrm{Cu}, \mathrm{Fe}, \mathrm{Pb}$, and $\mathrm{Ni}$ to concentrations of $\mathrm{Cl}$ in samples of Massachusetts road salt reported by Granato (1996) and in a sample of liquid calcium chloride (table 31) collected at the Lexington, Massachusetts, DOT maintenance depot ranged from $10^{-5}$ to $10^{-6}$. At a ratio of $10^{-5}$ for nitrate and $\mathrm{Fe}$ to $\mathrm{Cl}$, the estimated increase in the EMC for these constituents, resulting from the addition of deicing compounds at a $\mathrm{Cl}$ concentration of $10,000 \mathrm{mg} / \mathrm{L}$ (which occurred in less than 2 percent of all of the runoff events during the 2.5-year monitoring period; fig. 21), is about $0.1 \mathrm{mg} / \mathrm{L}$. In contrast, the difference between the mean non-winter and mean winter concentrations of nitrate and $\mathrm{Fe}$ in composite samples of runoff was many times larger. For example, the differences between the mean non-winter and winter concentrations for total $\mathrm{N}$ and total-recoverable $\mathrm{Fe}$ in composites of highway runoff collected at the monitoring stations on Interstate 495 are about 0.45 and $14.4 \mathrm{mg} / \mathrm{L}$, respectively. For the same $\mathrm{EMC}$ of $\mathrm{Cl}$ and using a ratio of $10^{-6}$ for total-recoverable $\mathrm{Cr}$, $\mathrm{Cu}$, and $\mathrm{Pb}$ to $\mathrm{Cl}$, the estimated increase in the $\mathrm{EMC}$, resulting from the addition of deicing compounds, is about $10 \mu \mathrm{g} / \mathrm{L}$. In contrast, the differences between the mean non-winter and winter concentrations for these same constituents in composite samples of runoff collected at the monitoring stations on Interstate 495 are about $27.8,85.4$, and $49.4 \mu \mathrm{g} / \mathrm{L}$, respectively. At more typical $\mathrm{Cl}$ concentrations of about $1,000 \mathrm{mg} / \mathrm{L}$ (which occurred in less than 12 percent of all of the storms during the 2.5-year monitoring period; fig. 21), the concentrations of nitrate and the total-recoverable metals would decrease by an order of magnitude. These levels represent less than 4 percent of the mean increase in EMCs for the respective constituents measured in composite samples of highway runoff collected during the winter at the monitoring stations on Interstate 495. Although the ratios of winter to non-winter concentrations of total-recoverable $\mathrm{Cr}, \mathrm{Cu}$, and $\mathrm{Pb}$ are somewhat similar from highway to highway (table 29), road salt could account, in part, for the larger increases in concentrations of the respective elements during winter for smaller highways, such as Route 119, because the non-winter concentrations of the metals are lower than the non-winter concentrations for the other principal highways. For example, the differences between the mean non-winter and winter concentrations of total-recoverable $\mathrm{Cr}, \mathrm{Cu}$, and $\mathrm{Pb}$ at the monitoring stations on Route 119 are about $11.9,18$, and $17 \mu \mathrm{g} / \mathrm{L}$, respectively. At $\mathrm{Cl}$ concentrations of about $1,000 \mathrm{mg} / \mathrm{L}$, the concentration of the three total-recoverable metals associated with the deicing compounds represent about 8 to 6 percent, respectively, of the mean increase in the EMC for the respective constituents measured in composite samples of highway runoff collected at the Route 119 monitoring stations.

The increase in concentrations of total $\mathrm{P}$ and total-recoverable metals during winter also are associated with the application of maintenance sand. Highway maintenance sand is a hard material, free of organic material, with no melting capabilities. Winter maintenance sands are applied to the highway to increase tire traction on the pavement. Maintenance sand, like soils, contains trace amounts of total $\mathrm{P}$ and total-recoverable metals. Although the concentrations of these constituents in the sand are small, the amount of sand applied to the highways during the winter can increase the concentration of suspended sediment by as much as an order of magnitude. For example, the ratios of mean non-winter EMCs of suspended sediment to mean winter EMCs in samples collected at the monitoring stations on the principal highways ranged from 3.1 to 11.6 (table 29). An approximate contribution of total P and total-recoverable metals from the application of maintenance sand was estimated on the basis of the average change in the concentration of suspended sediment during winter storms and on the basis of the mean concentrations of the associated constituents in samples of highway maintenance sand (table 18 in the back of the report). For example, the average increase in the EMC of suspended sediment in composite samples of runoff collected during winter storms at the monitoring stations on Interstate 495 was about $637 \mathrm{mg} / \mathrm{L}$. Assuming that the increase in the concentration of suspended sediment is exclusively accounted for by the addition of maintenance sand, the estimated concentrations for total $\mathrm{P}$, and total-recoverable $\mathrm{Cu}, \mathrm{Fe}, \mathrm{Mn}, \mathrm{Ni}, \mathrm{Pb}$, and $\mathrm{Zn}$ associated with the sand are about $0.24 \mathrm{mg} / \mathrm{L}$ and 5.7, 7, 640, 134, 5.3, 4.3, and $10.1 \mu \mathrm{g} / \mathrm{L}$, respectively. After further adjusting the estimated concentrations of $\mathrm{P}, \mathrm{Fe}, \mathrm{Ni}$, and $\mathrm{Zn}$ on the basis of the performance of the different analytical digestion methods discussed earlier, highway maintenance sand would account for about 94, 7, 38, 53, 15, 9, and 2 percent of the increase in winter EMCs for $\mathrm{P}, \mathrm{Cu}, \mathrm{Fe}, \mathrm{Mn}, \mathrm{Ni}, \mathrm{Pb}$, and $\mathrm{Zn}$, respectively. As noted earlier, the differences between winter and non-winter EMCs for P, $\mathrm{Cu}, \mathrm{Fe}, \mathrm{Mn}, \mathrm{Ni}, \mathrm{Pb}$, and $\mathrm{Zn}$ are greater for smaller highways because those highways have lower non-winter EMCs for these constituents (table 29).

The Mass DOT typically uses salt alone, but also applies maintenance sand to the highway as a 1-to-1 sand-to-salt premix at low temperatures and on roadway sections with steep grades, ramp sections, sharp curves, and at intersections (Massachusetts Department of Transportation, 2006). Routine application of maintenance sand is limited to reduced salt zones, such as Interstate 95 in this study (Massachusetts Department of Transportation, 2008). However, Mass DOT records indicate that maintenance sand was applied to a greater extent on Massachusetts highways during this study (Paul Brown, Massachusetts Department of Transportation, written commun., 2010). As a result, concentrations for 
Table 30. Resultant $p$ values for single-tail Mann-Whitney tests between paired populations of winter and non-winter concentrations of constituents in highway runoff collected from the primary and secondary stations on the four principal highways in Massachusetts, 2005-07.

$[<$, Less than value shown; --, insufficient detections to perform test; mm, millimeters in diameter; shaded areas indicate values that are significant at a 99-percent confidence interval]

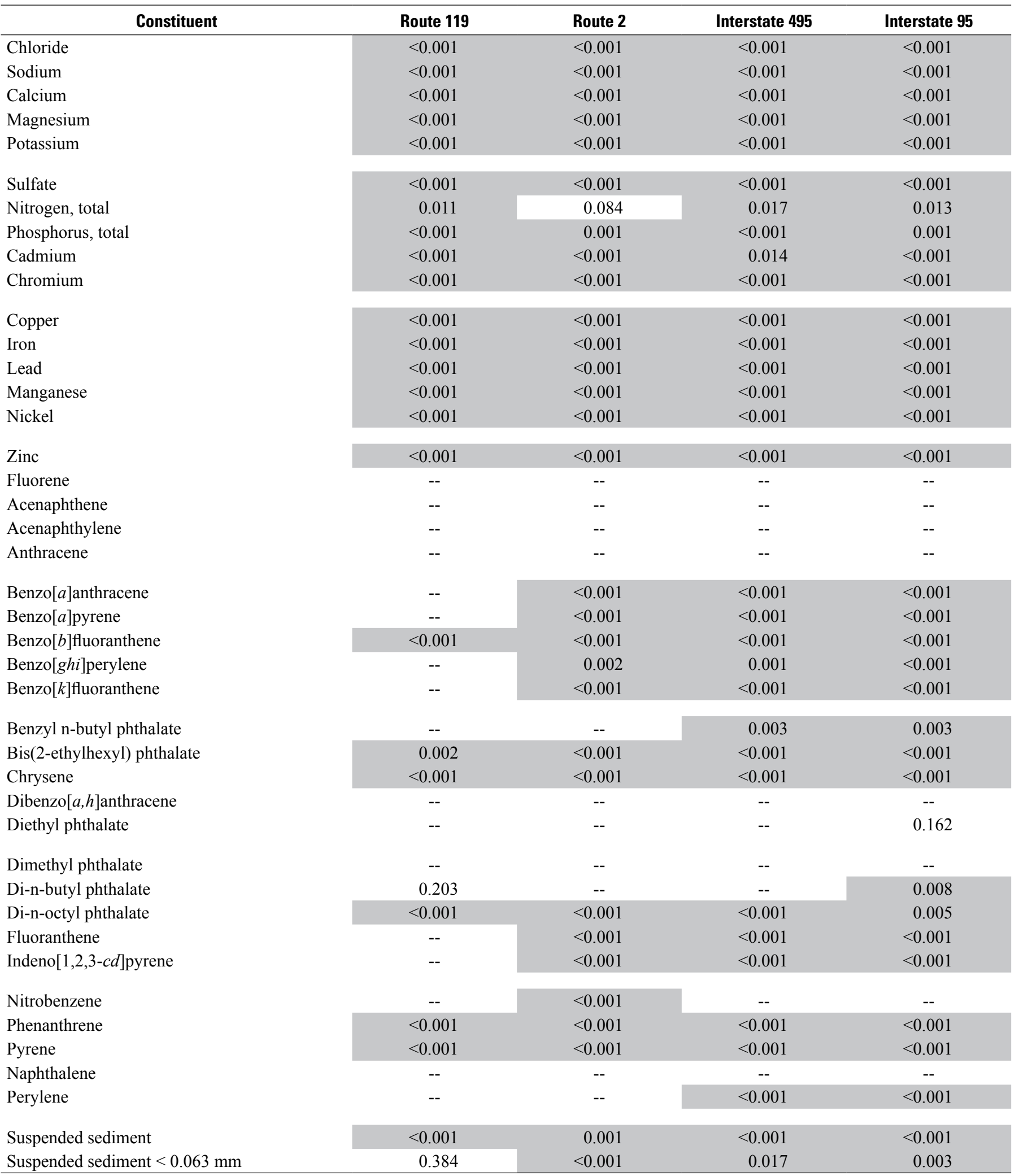


Table 31. Concentrations of selected constituents measured in a sample of liquid calcium chloride collected at the highwayservice depot near Interstate 95, Lexington, Massachusetts and diluted to 3.5 percent by mass and the ratio of the concentration of each constituent to the concentration of chloride.

$[\mu \mathrm{S} / \mathrm{cm}$, microsiemens per centimeter at 25 degrees Celsius; $\mathrm{mg} / \mathrm{L}$, milligrams per liter; $\mu \mathrm{g} / \mathrm{L}$, micrograms per liter; $<$, concentration is less than value shown; E, the concentration reported is less than laboratory reporting level and is qualified as estimated; --, no information]

\begin{tabular}{|c|c|c|}
\hline Constituent & $\begin{array}{c}\text { Concentration or } \\
\text { measurement }\end{array}$ & $\begin{array}{c}\text { Ratio of } \\
\text { constituent concentration to } \\
\text { chloride concentration }\end{array}$ \\
\hline $\mathrm{pH}$ in standard units & 10.0 & -- \\
\hline Specific conductance in $\mu \mathrm{S} / \mathrm{cm}$ & 19,600 & -- \\
\hline Calcium, filtered, $\mathrm{mg} / \mathrm{L}$ & 3,640 & $4.98 \times 10^{-1}$ \\
\hline Magnesium, filtered, $\mathrm{mg} / \mathrm{L}$ & 0.26 & $3.56 \times 10^{-5}$ \\
\hline Potassium, filtered, $\mathrm{mg} / \mathrm{L}$ & 150 & $2.05 \times 10^{-2}$ \\
\hline Sodium, filtered, $\mathrm{mg} / \mathrm{L}$ & 85.9 & $1.18 \times 10^{-2}$ \\
\hline Alkalinity, filtered, laboratory, $\mathrm{mg} / \mathrm{L}$ as calcium carbonate & 28 & -- \\
\hline Chloride, filtered, $\mathrm{mg} / \mathrm{L}$ & 7,310 & 1.00 \\
\hline Sulfate, filtered, $\mathrm{mg} / \mathrm{L}$ & $<4.5$ & $<6.16 \times 10^{-4}$ \\
\hline Total nitrogen $($ nitrate + nitrite + ammonia + organic- $-\mathrm{N}$ ), unfiltered, $\mathrm{mg} / \mathrm{L}$ & 0.17 & $2.33 \times 10^{-5}$ \\
\hline Phosphorus, unfiltered, mg/L & $<.02$ & $<2.74 \times 10^{-6}$ \\
\hline Arsenic, unfiltered, $\mathrm{mg} / \mathrm{L}$ & E2.5 & $3.42 \times 10^{-4}$ \\
\hline Barium, unfiltered, $\mu \mathrm{g} / \mathrm{L}$ & 210 & $2.78 \times 10^{-2}$ \\
\hline Cadmium, unfiltered, $\mu \mathrm{g} / \mathrm{L}$ & E0.11 & $1.50 \times 10^{-5}$ \\
\hline Chromium, unfiltered, $\mu \mathrm{g} / \mathrm{L}$ & $<3.2$ & $<4.38 \times 10^{-4}$ \\
\hline Copper, unfiltered, $\mu \mathrm{g} / \mathrm{L}$ & $<9.6$ & $<1.31 \times 10^{-3}$ \\
\hline Iron, unfiltered, $\mu \mathrm{g} / \mathrm{L}$ & E84 & $1.15 \times 10^{-2}$ \\
\hline Lead, unfiltered, $\mu \mathrm{g} / \mathrm{L}$ & 0.3 & $4.10 \times 10^{-5}$ \\
\hline Manganese, unfiltered, $\mu \mathrm{g} / \mathrm{L}$ & $<6.4$ & $<8.76 \times 10^{-4}$ \\
\hline Nickel, unfiltered, $\mu \mathrm{g} / \mathrm{L}$ & 0.96 & $1.31 \times 10^{-4}$ \\
\hline Selenium, unfiltered, $\mu \mathrm{g} / \mathrm{L}$ & $<0.6$ & $<8.21 \times 10^{-5}$ \\
\hline Zinc, unfiltered, $\mu \mathrm{g} / \mathrm{L}$ & 16 & $2.19 \times 10^{-3}$ \\
\hline Total organic carbon, $\mathrm{mg} / \mathrm{L}$ & $<0.4$ & $<5.47 \times 10^{-5}$ \\
\hline
\end{tabular}


suspended sediment and other constituents associated with highway maintenance sands in composite samples collected during winter storms in this study (except for samples collected at the primary and secondary stations of Interstate 95 and the test station on Interstate 195) may represent higher values in regard to the 2008 sanding policy.

Changes in ambient temperature affect the rate of emissions for both gasoline and diesel engines. In controlled tests, Westerholm and Egebäck (1994) reported that the mean emission rates for particulate matter and oxides of nitrogen for five gasoline-powered vehicles increased by a factor of two between tests conducted at 22 and $-10^{\circ} \mathrm{C}$, and total PAHs increased by about a factor of five. In a larger scale test, Cadle and others (2001) noted that particulate matter increased by a factor of 2.5 between tests conducted at mean temperatures of 15.5 and $3.3^{\circ} \mathrm{C}$. Increases in the rate of emissions from diesel vehicles during winter operation also have been reported (Kuusimaki, 2003). The rate of vehicle emission, as well as brake and tire wear, can increase during poor winter driving conditions when vehicle speeds are slower and less constant. Inconsistent regulation of the engine speed results in temporary fuel enrichment that potentially increases emission rates. Colder winter temperatures also affect the rate of volatilization and bacterial degradation for PAHs and phthalates (Lopes and Dionne, 1998). These factors also contribute to the increase in concentrations of total $\mathrm{N}$, total-recoverable metals (except for Mn, which may have a greater association with sanding or road wear), PAHs, and phthalates observed in samples collected during winter.

One final factor that could explain, in part, the increase in concentrations of total $\mathrm{P}$, total-recoverable metals, $\mathrm{PAH}$, and phthalates between winter and non-winter samples is the effect of snow removal from the roadway. Snow is generally removed from the highway with heavy trucks equipped with plows, and in some cases, tire chains. This results in contact wear of both the equipment and the roadway surface. Snowplows and tire chains are constructed predominantly from $\mathrm{Fe}$ or Fe alloys. In contrast, $\mathrm{Mn}$ and $\mathrm{Zn}$ are the dominant metals found in asphalt with lesser amounts of $\mathrm{Cr}, \mathrm{Fe}, \mathrm{Pb}$, and Ni (Breault and others, 2005). Asphalt also contains several PAH compounds, such as benzo[ $b]$ fluoranthene, chrysene, and phenanthrene. Increases in concentrations of $\mathrm{Fe}, \mathrm{Mn}, \mathrm{Zn}$, and the above PAHs during winter could result, in part, from the wear of these contact surfaces. Another effect of snow plowing is the tendency for snow to pack into the openings of highway guardrails. Such snow packs effectively form large curbs that can be as high as or higher than the guardrails (fig. 23). In such cases, not only do solids build up near the base of the pack, but the snow pack itself absorbs large amounts of particulates that subsequently are deposited on or near the highway shoulder after the snow melts. Glenn and Sansalone (2002) found that various highway-related constituents accumulated in fresh snow banks quickly during the first 12 hours after plowing, and Reinosdotter and others (2006) report that in snow surveys done perpendicular to highways, most of the highway-related metals were present in the first few horizontal feet of highway snow banks. Because most of the monitoring stations in the study have guardrails within the highway-drainage areas, deposition of particulates near or on the highway shoulder from melting snow packs also is an important factor that may explain some of the significant differences in concentrations of the constituents measured in this study between non-winter and winter storms.

\section{Comparison of Historical and Concurrent Data Sets}

Highway managers and other data analysts need current data to accurately estimate loads of various constituents discharged from highways and to determine the effects of these loads on receiving water bodies. The accuracy of information on constituent loads is ensured, in part, by periodically collecting new data. Comparisons of the data collected in this study with other subsequent data can provide useful information for identifying compositional differences and trends in highway runoff. Such differences can result over time from changes in anthropogenic sources, sampling methods, and laboratory analytical methods. Differences in the composition of highway runoff also are affected by local materials that are deposited on the highways in different geographic areas. Populations of constituent concentrations, separated by either time or space, that are similar can be combined to form a robust data set. In contrast, it is inappropriate to combine populations of constituents that exhibit large but potentially explainable differences, and at best, the data sets are periodically updated to monitor trends in the concentrations so that future analyses will be accurate.

From 1985 to 2009, automobile technology, tire and brake-pad formulations, fuel additives, construction materials, and highway maintenance practices have changed. Methods used for sample collection, handling, and analysis of environmental samples have improved since the early 1980s. As a result, the laboratory analytical techniques have improved the accuracy and precision of analysis and the detection of contaminants in stormwater runoff (Van Loon, 1985; Thompson and Walsh, 1989; Garbarino and Struzeski, 1998). To determine the potential effect of these changes, the median concentrations of dissolved $\mathrm{Cl}$, total $\mathrm{N}$ and $\mathrm{P}$, and total-recoverable $\mathrm{Cd}, \mathrm{Cr}, \mathrm{Cu}, \mathrm{Fe}, \mathrm{Pb}$, and $\mathrm{Zn}$ in all data sets collected for Interstate 190, Interstate 195, Interstate 495, and Route 2 were compared to the median concentrations recorded in historical highway-runoff data sets (Driscoll and others, 1990a) collected by eight other states from 1976 to 1984 at highway sites with similar AADT volumes of 30,000 to 85,000 vehicles per day (table 32). The 90-percent confidence interval was computed for the median value of each constituent using the methods described by McGill and others (1978). With the exception of dissolved $\mathrm{Cl}$, the median concentrations of the nutrients and metals in this study were less than the median concentrations in the historical data. Furthermore, the median 


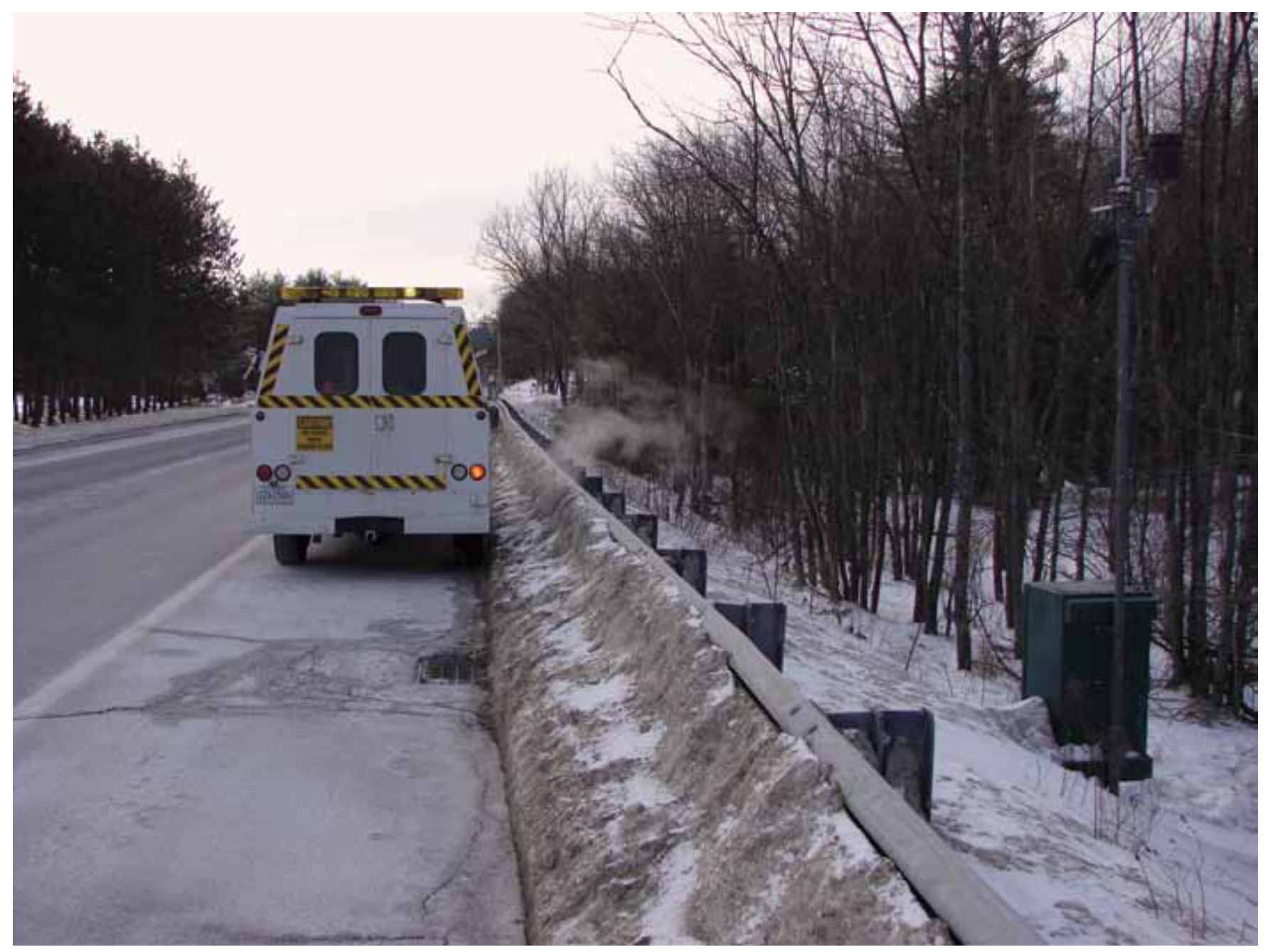

Figure 23. A snow bank along the guard rail near the highway-monitoring station on Route 119, in Ashburnham, Massachusetts. 
Table 32. Median of event-mean concentrations and 90-percent confidence interval for selected constituents in samples of highway runoff collected during this study, historical highway studies, and other recent studies for highways with annual average daily traffic volumes of 30,000 to 85,000 vehicles.

[CI, 90-percent confidence interval for median; mg/L, milligrams per liter; $\mu \mathrm{g} / \mathrm{L}$, micrograms per liter; AR, Arizona; CA, California; MA; Massachusetts; MN, Minnesota; NC, North Carolina; PA, Pennsylvania; TN, Tennessee; TX, Texas; WA, Washington; WI, Wisconsin; --, no data]

\begin{tabular}{|c|c|c|c|c|c|c|c|}
\hline \multirow[b]{2}{*}{$\begin{array}{c}\text { State where data } \\
\text { were } \\
\text { collected }\end{array}$} & \multirow[b]{2}{*}{$\begin{array}{l}\text { Data } \\
\text { collection } \\
\text { period } \\
\text { (years) }\end{array}$} & \multirow[b]{2}{*}{ Statistic } & \multicolumn{5}{|c|}{ Constituent } \\
\hline & & & $\begin{array}{c}\text { Chloride } \\
\text { (mg/L) }\end{array}$ & $\begin{array}{c}\text { Total } \\
\text { nitrogen } \\
\text { (mg/L) }\end{array}$ & $\begin{array}{c}\text { Total } \\
\text { Phosphorus } \\
\text { (mg/L) }\end{array}$ & $\begin{array}{c}\text { Total } \\
\text { recoverable } \\
\text { cadmium } \\
(\mu \mathrm{g} / \mathrm{L})\end{array}$ & $\begin{array}{c}\text { Total } \\
\text { recoverable } \\
\text { chromium } \\
(\mu \mathrm{g} / \mathrm{L})\end{array}$ \\
\hline \multirow[t]{3}{*}{ MA } & $2005-07$ & Median & 17.6 & 1.09 & 0.11 & 0.175 & 11 \\
\hline & & $\mathrm{CI}$ & 10.8 & 0.21 & 0.03 & 0.07 & 2.4 \\
\hline & & Sites & 4 & 4 & 4 & 4 & 4 \\
\hline \multirow{2}{*}{$\begin{array}{l}\text { AR, CA, MN, } \\
\text { NC, PA, TN, } \\
\text { WA, WI }\end{array}$} & $1976-84$ & Median & 17.5 & 2.64 & 0.37 & 20 & 20 \\
\hline & & CI & 8.37 & 0.63 & 0.06 & 5.06 & 6.8 \\
\hline \multirow[t]{4}{*}{$\mathrm{CA}$} & 1999-2003 & Median & 490 & -- & 0.22 & 0.45 & 5.5 \\
\hline & & CI & 55 & -- & 0.03 & 0.07 & 0.74 \\
\hline & & Samples & 17 & -- & 242 & 225 & 225 \\
\hline & & Sites & 1 & -- & 14 & 13 & 14 \\
\hline \multirow[t]{4}{*}{ WA } & 1994-97 & Median & -- & -- & 0.11 & 0.46 & -- \\
\hline & & CI & -- & -- & 0.03 & 0.23 & -- \\
\hline & & Samples & -- & -- & 57 & 31 & -- \\
\hline & & Sites & -- & -- & 4 & 4 & -- \\
\hline
\end{tabular}


Table 32. Median of event-mean concentrations and 90-percent confidence interval for selected constituents in samples of highway runoff collected during this study, historical highway studies, and other recent studies for highways with annual average daily traffic volumes of 30,000 to 85,000 vehicles.-Continued

[CI, 90-percent confidence interval for median; mg/L, milligrams per liter; $\mu \mathrm{g} / \mathrm{L}$, micrograms per liter; AR, Arizona; CA, California; MA; Massachusetts; MN, Minnesota; NC, North Carolina; PA, Pennsylvania; TN, Tennessee; TX, Texas; WA, Washington; WI, Wisconsin; --, no data]

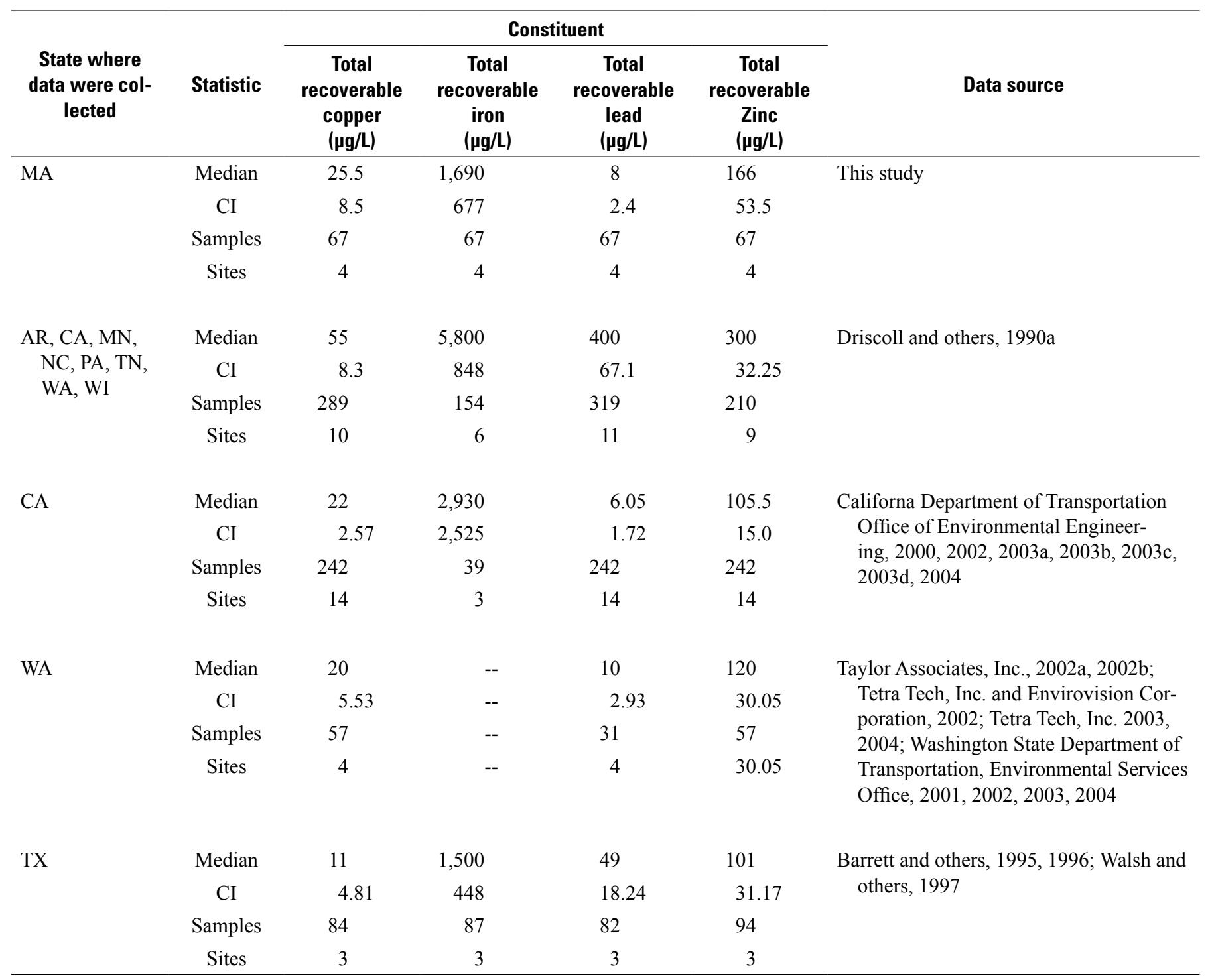


historical concentrations for these constituents were outside the 90-percent confidence interval determined for this study, indicating there is a significant difference between data sets. Although the median concentrations for dissolved $\mathrm{Cl}$ were quite similar between the study and historical data sets, the differences for other constituents were often substantial. For example, the median concentrations for total-recoverable $\mathrm{Cd}$ and $\mathrm{Pb}$ for this study were 114 and 50 times lower, respectively, than the historical median concentrations. These data indicate that concentrations of nutrients and metals in highway runoff, particularly $\mathrm{Cd}$ and $\mathrm{Pb}$, are substantially lower in this study than in the 1970s and 1980s, despite the fact that total vehicle miles have increased (Colman and others, 2001; Breault and Granato, 2000). These differences are likely attributable, at least in part, to improvements in fuel formulations, emission control systems, and tire life.

As discussed earlier, large differences in the composition of wash-on materials (adjacent soils and berm materials) and differences in the amount of impervious area surrounding the highway can potentially cause significant differences between the data populations. However, it is not logistically or economically feasible to collect data for every storm and on every highway. As a result, population statistics are limited by the number of samples, and data are often extrapolated to highways that do not necessarily share all of the characteristics of the highway where the data were originally collected. With this in mind, it is often beneficial to systematically combine smaller data sets to form more robust data populations. The median concentrations of dissolved $\mathrm{Cl}$, total $\mathrm{P}$, and total-recoverable $\mathrm{Cd}, \mathrm{Cr}, \mathrm{Cu}, \mathrm{Fe}, \mathrm{Pb}$, and $\mathrm{Zn}$ from all data collected from Interstate 190, Interstate 195, Interstate 495, and Route 2 were compared to available median concentrations of the respective constituents for highway with AADT volumes of 30,000 to 85,000 vehicles per day to determine whether data collected in other recent studies are similar to the data presented in this study (table 32). The previous studies were conducted between 1994 and 2003 in California, Texas, and Washington. Concentration data for $\mathrm{Cl}$ was available for only one station near Lake Tahoe in California, and most of the samples were collected during the winter months (California Department of Transportation, Office of Environmental Engineering, 2003a-d), thus explaining the larger median concentration of $\mathrm{Cl}$ compared to the median concentration in this study. The median concentration of $0.11 \mathrm{mg} / \mathrm{L}$ for total $\mathrm{P}$ in this study is identical to the median concentration reported for the state of Washington but is about half of the median concentration for the California and Texas studies (table 32). The median concentration of $\mathrm{Cr}$ for this study is higher than the median concentration for the California data set, and the 90-percent confidence intervals do not overlap. Median concentrations for $\mathrm{Cu}$ and $\mathrm{Pb}$ for this study are similar to the median concentrations in the California and Washington studies, but the 90-percent confidence intervals for this study and the Texas data set do not overlap. The 90-percent confidence intervals for the median concentrations of Fe and $\mathrm{Zn}$ overlap for all four studies. The similarities in many of these populations selected on the basis of AADT volumes indicate that some recent data collected in states other than Massachusetts could supplement the data collected in this study.

\section{Sources of Highway-Runoff Constituents}

Highway runoff is a complex mix of contaminants from multiple sources that include automobile and highway residuals, atmospheric deposition, local soils, highway-berm soil, highway-maintenance materials, and other sources. Antecedent conditions, traffic volume, climate, storm characteristics, and other factors also can affect the quality of highway runoff. Identification of individual sources of specific constituents is difficult because many highway-related constituents are found in a wide variety of natural and anthropogenic materials deposited on highways. For example, $\mathrm{Zn}$ is found in soil (table 19 in the back of the report), berm materials (table 20 in the back of the report), highway guardrails, automobile components, automobile emissions, tire particles, brake dust, automobile lubricants, and atmospheric deposition. Accurate assessments of yields of specific constituents are further complicated by differences in exhaust emissions rates, and brake and tire wear rates, which are a function of road conditions and traffic density.

\section{Common Highway Constituents}

Principal component analysis was used for dimensional reduction of the data. In general, principal component techniques are used to identify underlying data structures by establishing linear combinations of the $\mathrm{p}$ original variables, which form new sets of variables or axes that are uncorrelated with one another (Helsel and Hirsch, 2002). Results of principal component analysis of all data and data subsets for total-recoverable metals and for SVOCs from the principal highways indicate that 80 to 95 percent of the variance is explained by a single variable. This likely stems from the high degree of correlation between most of the constituents. For example, the average Pearson correlation coefficient for totalrecoverable metals and SVOCs in samples of runoff collected from the principal highway, Interstate 95 , was about 0.83 (table 33). The Pearson product moment correlation coefficient measures the degree of linear relation between two variables. The correlation coefficient ranges from -1 to +1 . A negative coefficient indicates that one variable tends to increase as the other decreases, and a positive coefficient indicates that the two variables tend to increase together. Unfortunately, the high degree of correlation between most of the constituents makes it difficult to identify individual source patterns.

Further research indicates that the use of ratios between certain PAH compounds, and ratios of the dominant particulate-associated PAHs to $\mathrm{P}$ and to selected metals, may provide 


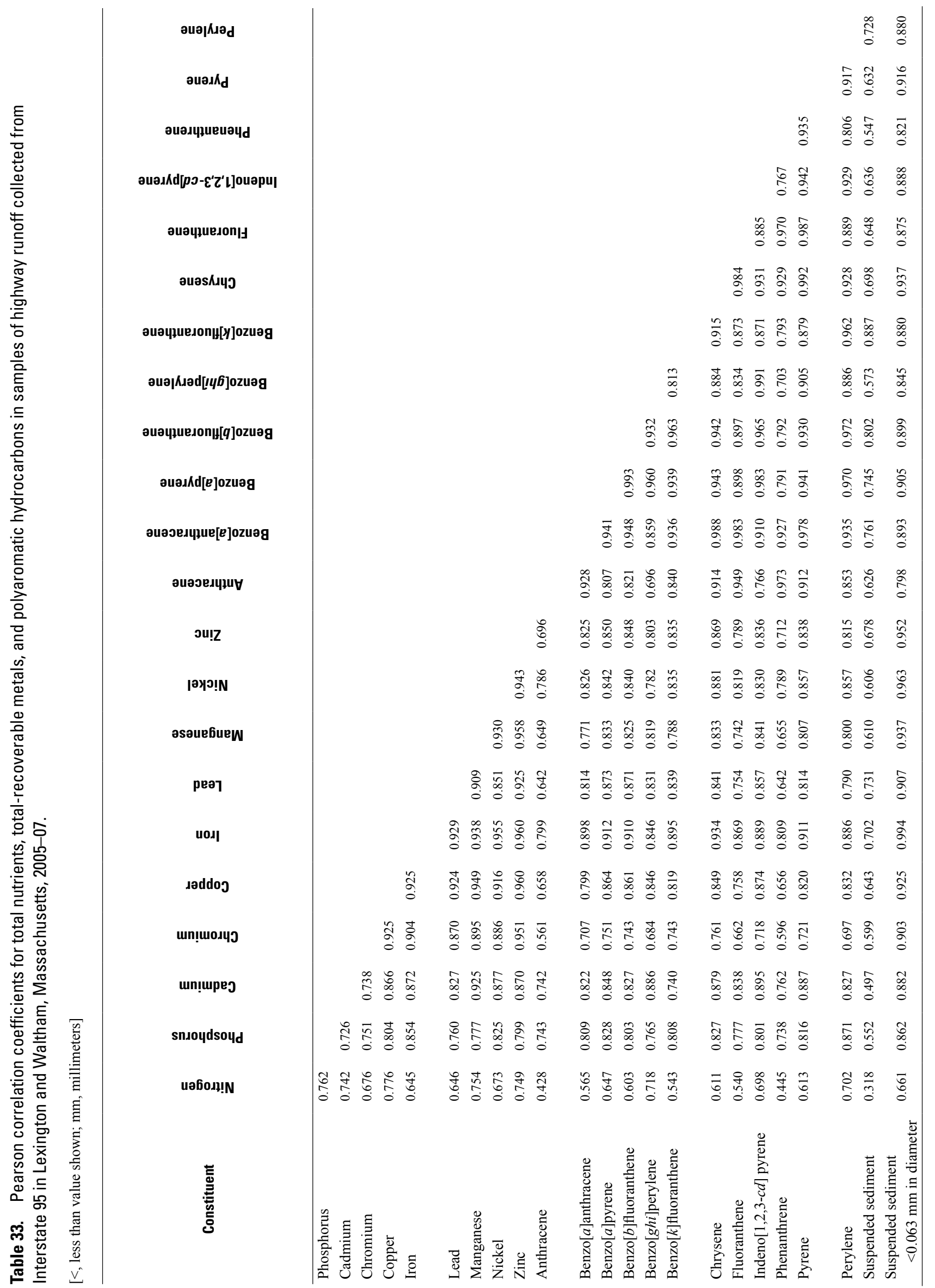


qualitative estimates of the proportion of most highway-runoff constituents attributable to likely sources. Comparisons of ratios of $\mathrm{PAH}$ compounds in environmental samples to $\mathrm{PAH}$ ratios from known sources are commonly used to determine potential sources (Breault and other, 2005; Lima and others, 2005; Yunker and others, 2002; Dickhut and others, 2000). Ratios are derived for PAH compounds of the same molecular mass to avoid differences in volatility, water solubility, and absorption (Yunker and others, 2002).

For this study, ratios for anthracene to anthracene plus phenanthrene (An/(An+Phe)), fluoranthene to fluoranthene plus pyrene $(\mathrm{Fl} /(\mathrm{Fl}+\mathrm{Py}))$, benzo $[a]$ anthracene to benzo[ $a]$ anthracene plus chrysene $(\mathrm{Ba} /(\mathrm{Ba}+\mathrm{Chr}))$, and indeno[1,2,3-cd]pyrene to indeno[1,2,3-cd]pyrene plus benzo[ghi]perylene (Ip/(Ip+Bghi)) were computed from sample pairs for each highway. The median ratios for these PAH compounds in composite samples of highway runoff for each highway in this study are listed with ratios related to potential sources of highway PAHs reported in the literature in table 34. Ratios for $\mathrm{An} /(\mathrm{An}+\mathrm{Phe})$ greater than 0.1 generally indicate combustion sources, and ratios less than 0.1 indicate petroleum sources (Yunker and others 2002). The median ratios for $\mathrm{An} /(\mathrm{An}+\mathrm{Phe})$ in this study ranged from about 0.13 to 0.24 , and most of these ratios are within the range of ratios for gasoline-engine exhaust emissions (table 34). The median ratios for $\mathrm{An} /(\mathrm{An}+\mathrm{Phe})$ in composite samples of highway runoff during, or shortly after, winter plowing operations (runoff events in January, February, March, and April 2006, and March and April 2007) on the principal highways were closer to 0.08 . This lower ratio indicates that the dominant source of individual PAHs could shift from gasoline-engine exhaust emissions to asphalt wear during the winter, possibly as the result of contact wear of the asphalt surface during snow plowing. Transition breaks between sources of combustion and petroleum are less certain for ratios for $\mathrm{Fl} /(\mathrm{Fl}+\mathrm{Py}$ ) (Yunker and others, 2002). The median ratios for $\mathrm{Fl} /(\mathrm{Fl}+\mathrm{Py})$ in this study ranged from about 0.53 to 0.57 (table 34 ), which were slightly higher than ratios for $\mathrm{Fl} /(\mathrm{Fl}+\mathrm{Py})$ in automobile exhaust generated from gasoline engines (Cadle and others, 2001) but within the rather large range of ratios for diesel-exhaust emissions (Westerholm and Egebäck, 1994; Strandell and others, 1994; Rogge and others, 1993). However, it is unlikely that these ratios result from diesel-exhaust emissions because of the low inter-highway variability and the dissimilar heavy truck traffic on the different highways. Furthermore, the range of ratios for $\mathrm{Fl} /(\mathrm{Fl}+\mathrm{Py})$ calculated by Miguel and others (1998) is more precise for diesel-exhaust emissions than for gasoline-exhaust emissions, and the ratios are lower than those calculated for exhaust from gasoline engines. The median environmental PAH ratios for the highways in this study also might be higher than those in the literature as a result of further improvements in engine technology and fuel formulations since the test data were reported. Differences in the age of engines, emission controls, vehicle speed, fuel formulations, and engine operational procedures affect the assemblage of PAHs, thus, potentially affecting the final ratios (Lima and others, 2005).
For example, ratios for $\mathrm{Fl} /(\mathrm{Fl}+\mathrm{Py})$ derived from emission samples from older catalyst-equipped automobiles (Rogge and others, 1993) are lower than ratios from tests conducted with newer model vehicles (Cadle and others, 2001), and although the research by Marr and others (1999) indicated that fuel was not the only source of the PAHs in exhaust, they reported that particle-phase emission factors correlated well for most $\mathrm{PAH}$ compounds in gasoline. The median ratios for $\mathrm{Ba} /(\mathrm{Ba}+\mathrm{Chr})$ in composites of highway runoff in this study ranged from about 0.30 to 0.46 (table 34 ), which are within the range of ratios for automobile exhaust generated by gasoline engines (Cadle and others, 2001). The higher ratios for $\mathrm{Ba} /(\mathrm{Ba}+\mathrm{Chr})$ for some of the highways may have been affected by larger amounts of diesel-exhaust emissions from heavy trucks. The presence of benzo[ $a]$ athracene and the absence of chrysene in diesel exhaust results in an increased $\mathrm{Ba} /(\mathrm{Ba}+\mathrm{Chr})$ ratio. The median ratios for Ip/(Ip+Bghi) in composite samples of highway runoff in this study ranged from about 0.44 to 0.48 (table 34 ); this range is greater than the range of ratios for gasoline and diesel exhaust emissions. These ratios likely reflect a blend of different potential sources that include gasoline and diesel exhaust emissions, and asphalt and tire wear. Ratios for $\mathrm{Fl} /(\mathrm{Fl}+\mathrm{Py}), \mathrm{Ba} /(\mathrm{Ba}+\mathrm{Chr})$, and (Ip/(Ip+Bghi), calculated on the basis of available concentration data for samples of suspended sediment (table 21 in the back of the report), are similar to the median ratios calculated from the concentration data for the composite samples of highway runoff. Ratios for $\mathrm{An} /(\mathrm{An}+\mathrm{Phe}), \mathrm{Fl} /(\mathrm{Fl}+\mathrm{Py})$, and (Ip/(Ip+Bghi) also are similar to ratios for precipitation calculated on the basis of the mean concentration of the above PAHs reported for precipitation in Narragansett Bay, Rhode Island (Latimer, 1997). However, these similarities more likely indicate that automobile emissions are the source of the PAHs in the atmosphere rather than wet deposition is the source of PAHs in highway runoff.

In this study, the median concentrations of total $\mathrm{P}$ and most metals measured in samples of highway runoff from each principal highway were compared to the concentrations expected from automobile emissions. Average emission rates for $\mathrm{Cr}, \mathrm{Cu}, \mathrm{Ni}$, and $\mathrm{Pb}$ in oxygenated fuel, using different standardized-test procedures and different automobiles, are similar to the emission rates for major particulate-associated PAHs (chrysene and indeno[1,2,3-cd]pyrene), but the emission rates for $\mathrm{P}, \mathrm{Fe}$, and $\mathrm{Zn}$ are reported to be about 6 to 38 times greater than the emission rates for the respective PAHs (Cadle and others, 2001). Concentrations of each element in automobile exhaust were estimated on the basis of the average ratio for the emission rate of the individual element to the emission rates for chrysene and indeno[1,2,3-cd]pyrene in exhaust, which were obtained from the literature (Cadle and others, 2001). Assuming the dispersion for both metals and PAHs associated with exhaust particles is similar, exhaust emissions account for only a small fraction of metals measured in samples of highway runoff. For example, ratios for median concentrations of total $\mathrm{P}$ and total-recoverable $\mathrm{Cu}$ and $\mathrm{Fe}$ to the concentration of the respective elements estimated from the median concentrations of chrysene and indeno[1,2,3-cd]pyrene in samples of 


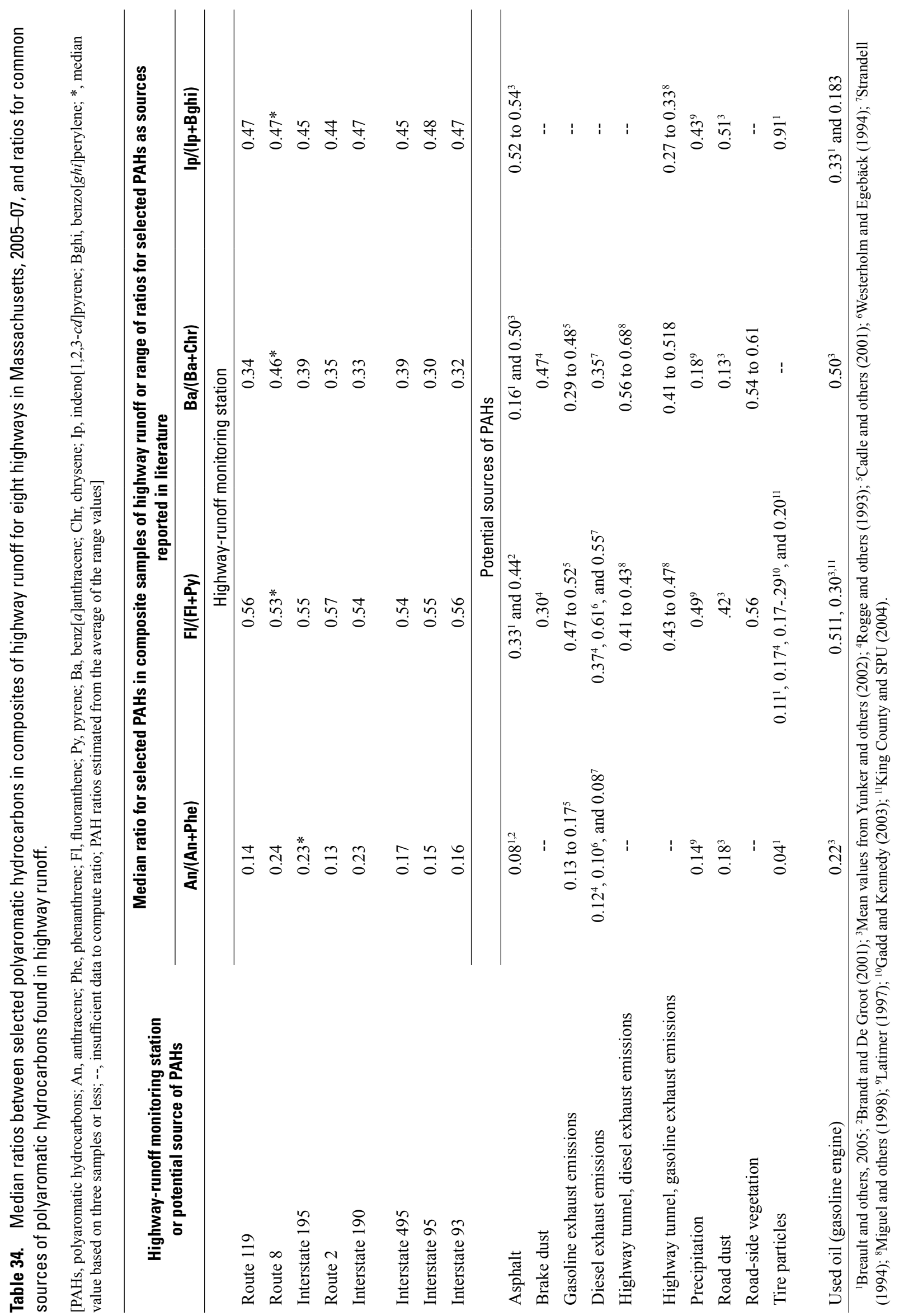


highway runoff collected at the principal highways indicate that less than 3 percent of the constituents are accounted for by exhaust emissions from gasoline engines, whereas ratios for median concentrations for total-recoverable $\mathrm{Cr}, \mathrm{Mn}, \mathrm{Ni}$, $\mathrm{Pb}$, and $\mathrm{Zn}$ to the concentration of the respective elements estimated from the median concentrations of chrysene and indeno[1,2,3-cd] pyrene indicate that from about 4 to 13 percent of the of the constituents are accounted for by exhaust emissions from gasoline engines.

Atmospheric deposition also can affect the quality of highway runoff. Atmospheric deposition of constituents measured in samples of highway runoff occurs in the form of dry and wet deposition. Dry deposition includes settleable particulates, aerosols, gases, and vapors. The deposition of these particles is dependent on the size, surface area, and mass of the particle (Legge, 1990). Larger airborne particles, greater than a few micrometers in diameter, result from natural sources of mechanical abrasion and wind erosion, and are subject to gravitational settling, whereas smaller particles are removed from the atmosphere by precipitation scavenging (Colman and others, 2001). Available data for dry deposition rates are sparse, and particle chemistry and deposition rates are subject to local conditions. However, concentration data on ammonia, nitrate, and most major ions, which are available from the National Atmospheric Deposition Program/National Trends Network (NADP/NTN), are more common. Concentrations of total $\mathrm{P}$ were unavailable; however, concentrations of $\mathrm{P}$ in precipitation generally are too low to be measured accurately (Colman and others, 2001). Concentrations of major ions in precipitation do not constitute a large fraction of the major ions in samples of highway runoff, except for $\mathrm{Mg}$ and $\mathrm{SO}_{4}$. Comparisons of annual precipitation weighted-mean concentrations (concentration for each storm is weighted by the respective volume) of major ions other than $\mathrm{Mg}$ and $\mathrm{SO}_{4}$ in 2005 and 2006 for NADP/NTN site MA13 in Lexington, Massachusetts (NADP/NTN, 2008), to mean concentrations for the same constituents in composite samples of highway runoff from non-winter storms (where the effect of addition of deicing compounds is eliminated) for the principal highway Interstate 95 in parts of Lexington and Waltham, Massachusetts, indicate that less than about 4 percent of the concentrations of the respective major ions is explained by atmospheric deposition in the non-winter months. In contrast, weightedmean concentrations of $\mathrm{Mg}$ and $\mathrm{SO}_{4}$ in precipitation may account for about 10 and 21 percent, respectively, of the mean concentrations in non-winter highway runoff. Weighted-mean concentrations of $\mathrm{NH}_{4}$ and $\mathrm{NO}_{3}$ in precipitation may account for about 55 percent of the mean concentrations of total $\mathrm{N}$ in all samples (winter and non-winter) collected at Interstate 95 in this study. Concentrations of total $\mathrm{N}$ in precipitation likely constitute a greater percentage of total $\mathrm{N}$ in highway runoff at the other principal highways because the concentrations of total $\mathrm{N}$ in samples of highway runoff at those sites were significantly different (table 22). Data on concentrations of metals in precipitation in the Massachusetts area could not be located; however, concentrations of metals measured in wet precipitation in Michigan, Illinois, and Indiana (Coleman and others, 2001) are low and likely represent only a small fraction of the metal content measured in samples of highway runoff in Massachusetts.

Local soils and highway-berm soil can represent much of the suspended sediment entrained in highway runoff (Gupta and others, 1981). As a result, background soil adjacent to each highway can affect the composition and concentrations of many constituents in highway runoff. Soils often are washed onto the roadway surface during stormflows or are directly deposited on the road by automobiles (for example, vehicles that have come into contact with adjacent unpaved shoulders).

Soil is natural material occupying the portion of the earth mainly composed of mineral and organic materials and develops from surficial material that unless otherwise specified can include any unconsolidated deposits down to bedrock. Geologic processes, such as weathering and erosion, break bedrock down into small particles of sediment. Sediments such as clay, silt, sand, gravel, and other loose deposits that lie on top of bedrock are grouped together in the general category of surficial materials. These materials are not soils, but are the deeper earth materials that lie between the soil zone and the underlying bedrock. Soils commonly develop by weathering of the uppermost part of these materials. Differences in weathering as a function of climate, presence of salt, and topography also can affect the development of soils (Ritter and others, 1995). This may explain in part the difference between the composition of soil in samples collected in southeastern Massachusetts, USEPA level III ecoregion 84 on and near Cape Cod, and samples collected elsewhere in Massachusetts in areas with similar surficial materials (table 19 in the back of the report).

The extent to which background soils contribute to the concentrations of $\mathrm{P}, \mathrm{Cr}, \mathrm{Cu}, \mathrm{Fe}, \mathrm{Mn}, \mathrm{Ni}, \mathrm{Pb}$, and $\mathrm{Zn}$ in highway runoff was estimated on the basis of the median concentrations of suspended sediment in composite samples of highway runoff (table 16 in the back of the report) and the median concentrations of each of these constituents in background samples of soils from each of the principal highways (table 19 in the back of the report). The median concentrations for $\mathrm{P}, \mathrm{Cr}, \mathrm{Fe}, \mathrm{Mn}, \mathrm{Ni}$, and $\mathrm{Zn}$ in soil were adjusted on the basis of quality-control data to account for differences between the digestion techniques used in the analytical methods for the soil and whole-water samples. These initial estimates indicate that background soils account for on average about 37 percent of the median $\mathrm{P}$ concentration, 100 percent of the median $\mathrm{Cr}$ concentration, 4 percent of the median $\mathrm{Cu}$ concentration, 53 percent of the median Fe concentration, 54 percent of the median Mn concentration, 15 percent of the median $\mathrm{Ni}$ concentration, 44 percent of the median $\mathrm{Pb}$ concentration, and 2 percent of the median $\mathrm{Zn}$ concentration in samples of highway runoff from the principal highways. Except for $\mathrm{Cr}$, these values are likely conservative because the values were estimated without regard to the distribution of the particle sizes for the two media - soil and sediment. The distribution of particle sizes in samples of soil or sediment can have great 
effects on the concentrations of many constituents. The disproportionate differences in concentrations of inorganic constituents relative to grain size are well documented (table 18 in the back of the report; fig. 24; Breault and others, 2005; Smith, 2002, 2005; Horowitz, 1991; Horowitz and Elrick, 1987; Forstner and Wittmann, 1981; Salomons and Forstner, 1984). In general, surface area and trace-element concentrations tend to increase with a decrease in particle-grain size. Furthermore, the silt- and clay-sized particle group contains more clay minerals, which typically have higher sorptive capacities, than other groups. In contrast, concentrations of $\mathrm{Cr}$ typically are greater in the coarse fractions of sediment (table 18 in the back of the report; fig. 24; Breault and others, 2005; Smith, 2002, 2005); therefore, the contribution of $\mathrm{Cr}$ from local soils, which contain a higher proportion of coarse particles than highway sediments, results in an overestimation of $\mathrm{Cr}$ in highway sediments.

Highway-berm soils often are composed of soil excavated from nearby locations during highway construction. The concentrations of many metals in berm soils become enriched over time through the deposition of small particulates emitted from automobiles and pavement wear. Winter sanding of pavement surfaces also contributes to the buildup of berm soils near the highway shoulder. As a result, the median concentrations and upper ranges of concentrations of most constituents, except $P$, in samples of highway-berm soils increase with the AADT volume of the highways (fig. 25). Moreover, the chemical composition of these berm soils often is comparable to the chemical composition of samples of suspended sediment in highway runoff. This is further illustrated by normalizing data collected in this study on the basis of the particle-size distribution to reduce the disproportionate differences between concentrations of constituents that are affiliated with sediment relative to grain size. Specifically, concentrations of $\mathrm{Cu}$, $\mathrm{Cr}, \mathrm{Fe}, \mathrm{Mn}, \mathrm{Ni}, \mathrm{P}, \mathrm{Pb}$, and $\mathrm{Zn}$ in suspended sediment for each principal highway (fig. 25) were estimated on the basis of the concentrations of the respective constituents affiliated with the three particle-size fractions in sieved samples of suspended sediment to reflect the particle-size distribution of the five respective berm samples (table 20 in the back of the report) for each principal highway. The distributions of concentrations of the selected elements in highway berm and the distributions of normalized concentrations measured in suspended sediment were most similar for $\mathrm{P}$ and $\mathrm{Zn}$, with few exceptions. In several cases, the ranges of concentrations of $\mathrm{Cu}, \mathrm{Fe}, \mathrm{Pb}, \mathrm{Mn}$, and $\mathrm{Ni}$ in samples of highway berm soil overlapped the ranges of the estimated concentrations in suspended sediment. These data indicate that erosion or mechanical transport of highwayberm soils onto the paved surface is potentially a large source for $\mathrm{P}$ and other metals. Furthermore, although the concentrations of most constituents (except for $\mathrm{Cr}$ and $\mathrm{P}$ ) in wintermaintenance sand were relatively low compared to concentrations measured in samples of highway berm (fig. 25), high concentrations of maintenance sand, which contain $\mathrm{Cu}, \mathrm{Cr}, \mathrm{Fe}$, $\mathrm{Pb}, \mathrm{Mn}$, and $\mathrm{Ni}$, and $\mathrm{Zn}$ in samples of winter runoff can cause large increases in concentrations of these constituents and, as discussed earlier, may account for most of the P concentration.

Thus far, much of the concentrations of PAHs, major ions, and metals can be accounted for by exhaust emissions, road wear, atmospheric deposition, local and berm soils, and highway maintenance materials. However, these potential sources do not fully account for concentrations of $\mathrm{Cu}, \mathrm{Zn}$, and phthalates measured in samples of highway runoff. Sources reported to contribute substantial amounts of $\mathrm{Cu}$ and $\mathrm{Zn}$ in highway and urban runoff are brake and tire wear (Hjortenkrans and others, 2007; Hulskotte and others, 2006; Councell and others, 2004; Gadd and Kennedy, 2000). The composition of individual brake pads can vary widely from manufacturer to manufacturer, and the composition also can vary between front and rear brakes (Hjortenkrans and others, 2007). Garg and others (2000) report that 19 different elements were found in the analysis of 7 different brake pads, and the analysis of most brakes indicated that $\mathrm{Fe}, \mathrm{Cu}, \mathrm{Ba}$, and $\mathrm{S}$ were the major elements associated with particle matter emitted during brake wear. As discussed earlier, the size of the emission particle can have a large effect on where the particles are deposited. Laboratory brake-wear tests indicated that 3 to 30 percent of the break debris falls on the road surface, 16 to 22 percent is retained on the wheel, and 8 to 25 percent is retained on the vehicle steering and suspension equipment (Sanders and others, 2003). The latter two depositional areas are likely subject to wash-off during rainstorms. Emission rates for break wear depend strongly on traffic conditions and brake temperature, but Garg and others (2000) report that emission rates for Fe and $\mathrm{Cu}$ in brake wear are 2.21 and $0.70 \mathrm{mg} / \mathrm{mi}$, respectively, which are more than an order of magnitude greater than emission rates reported for exhaust emissions from gasoline engines. Given these emission rates, brake wear as a source of $\mathrm{Cu}$ can easily account for the mass closure in concentrations measured in samples of highway runoff. Similarly, phthalate esters, including bis(2-ethylhexyl) phthalate, di-n-butyl phthalate, di-n-octyl phthalate, and diethyl phthalate, are reported to be used in brake-pad construction (King County and SPU, 2004); this may explain much of the observed concentrations in composite samples of highway runoff.

In contrast, anthropogenic sources of $\mathrm{Zn}$ have largely been linked to tire emissions. $\mathrm{Zn}$ is used to facilitate vulcanization of the rubber in the manufacturing process for tires (Councell and others, 2004), and as a result, $\mathrm{Zn}$ can account for about 1 percent of the mass of the tread particles (Hjortenkrans and others, 2007; Breault and others, 2005; Councell and others, 2004). To determine the relative magnitude of $\mathrm{Zn}$ loading to the highway surface as a function of tire wear, the load of $\mathrm{Zn}$ for a single day was estimated for each of the principal highways on the basis of an average tire-tread wear rate of about $0.08 \mathrm{~g} / \mathrm{mi} /$ tire (Councell and others, 2004), a tread-wear composition consisting of 1-percent Zn, the AADT volumes (assuming four wheels per vehicle) for each principal highway (table 1), and an average linear distance of about $300 \mathrm{ft}$ for the sites on the principal highways. These simple estimates indicate that for a 0.5 -in. rainstorm, the estimated 

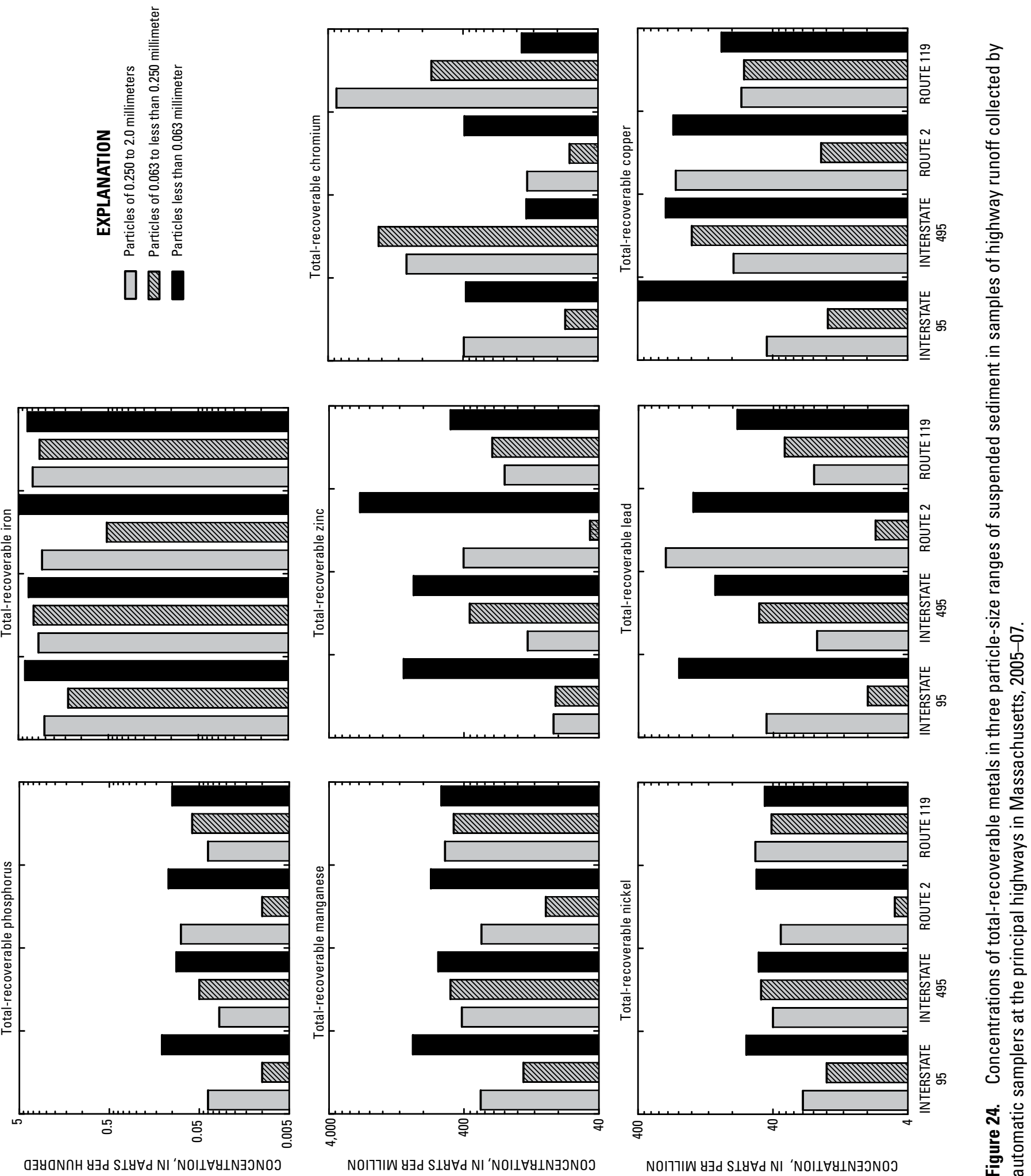

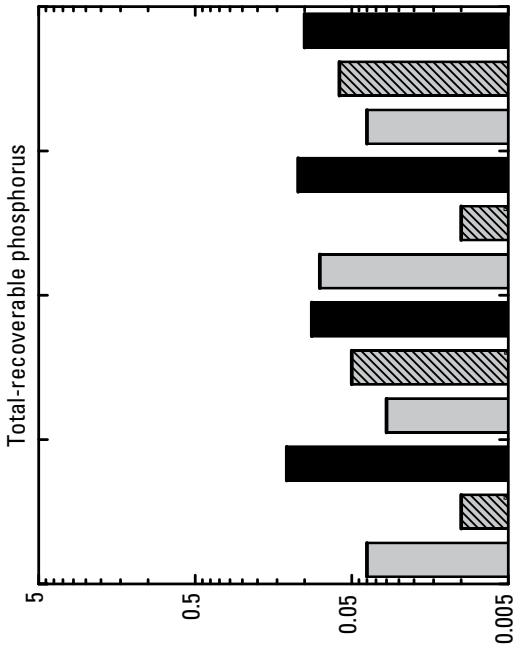

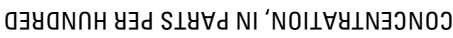

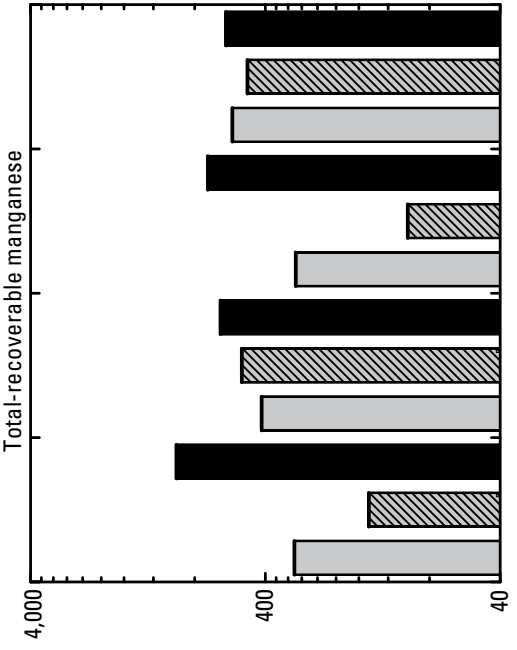

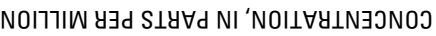

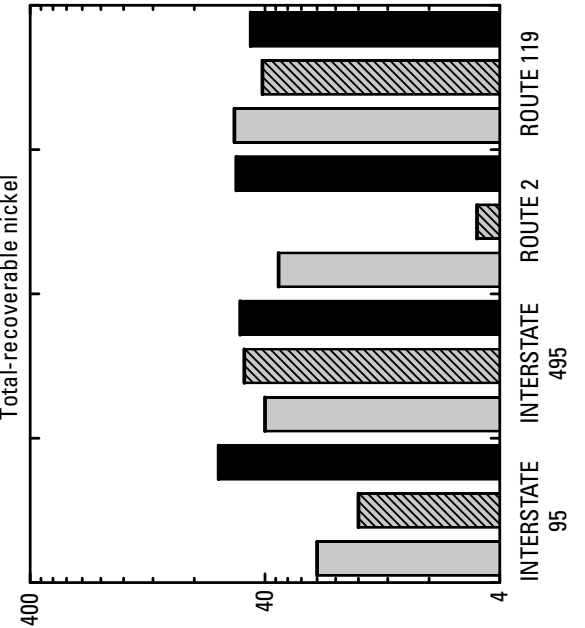

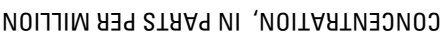




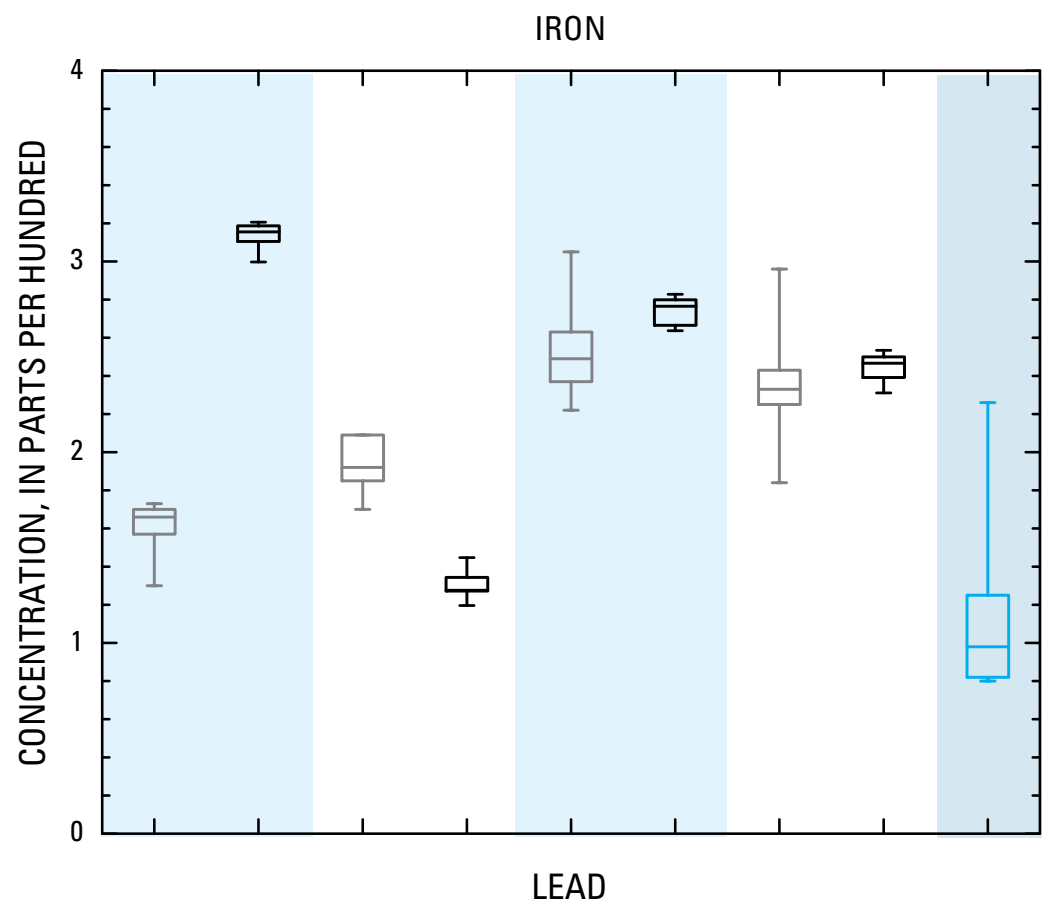

\section{EXPLANATION}
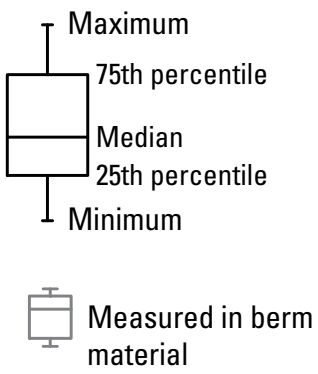
$\mp$ Estimated in berm

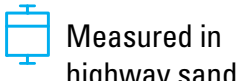
highway sand

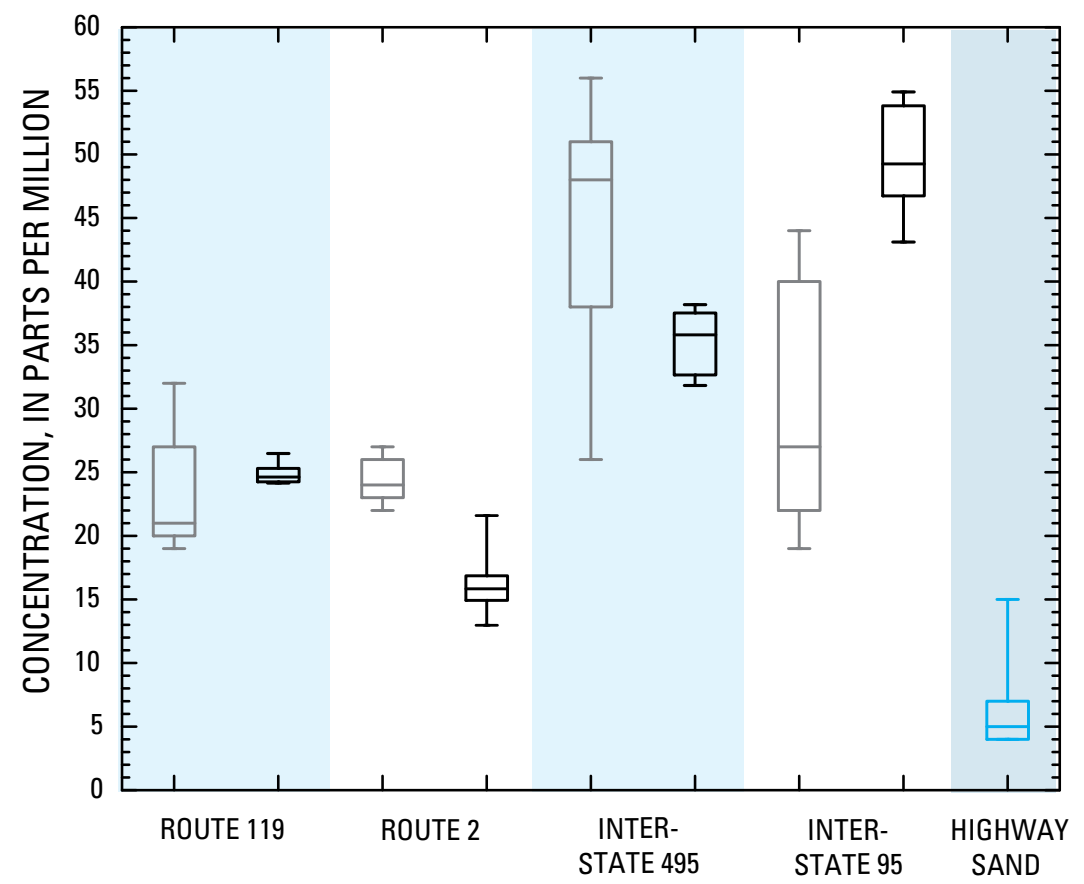

Figure 25. Distribution of concentrations of selected constituents measured in samples of berm material from four principal highways and in samples of highway-maintenance sand, and estimated concentrations of berm material derived from samples of suspended-sediment quality and particle size in Massachusetts, 2005-07. Five samples of highway-berm material were collected within 1 foot of the edge of the pavement in the vicinity of each of eight highway-monitoring stations. Eight samples of highway-maintenance sand were collected. 


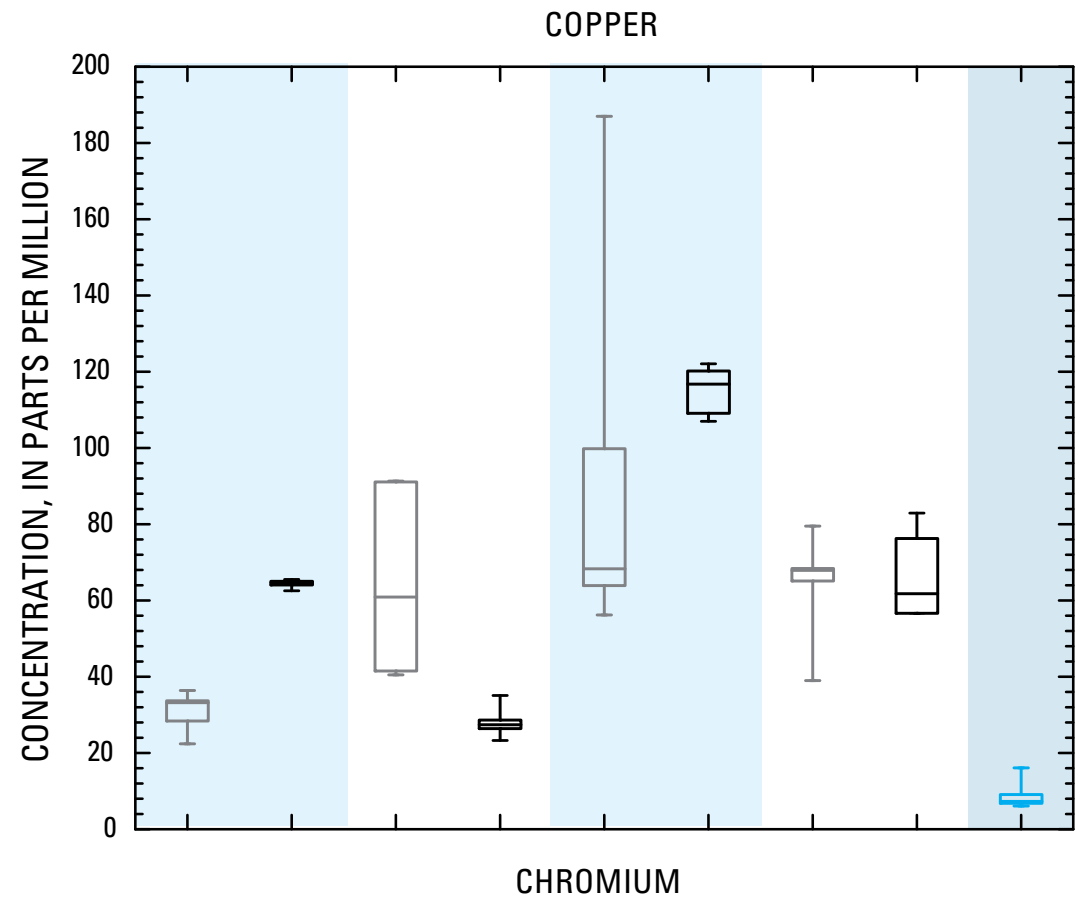

\section{EXPLANATION}

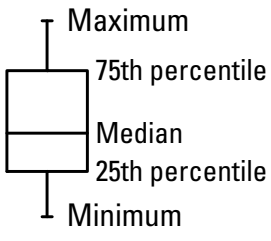

$\mp$ Measured in berm

Estimated in berm material

Measured in highway sand

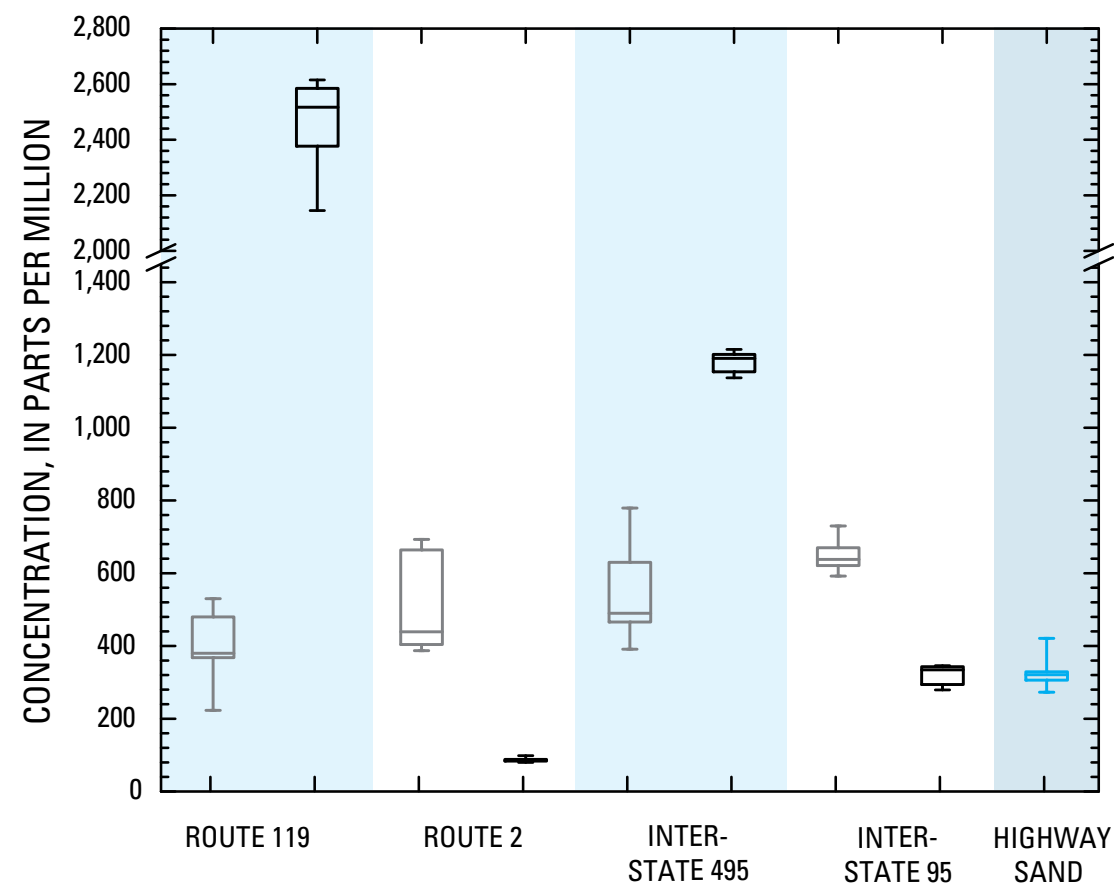

Figure 25. Distribution of concentrations of selected constituents measured in samples of berm material from four principal highways and in samples of highway-maintenance sand, and estimated concentrations of berm material derived from samples of suspended-sediment quality and particle size in Massachusetts, 2005-07. Five samples of highway-berm material were collected within 1 foot of the edge of the pavement in the vicinity of each of eight highway-monitoring stations. Eight samples of highway-maintenance sand were collected.-Continued 


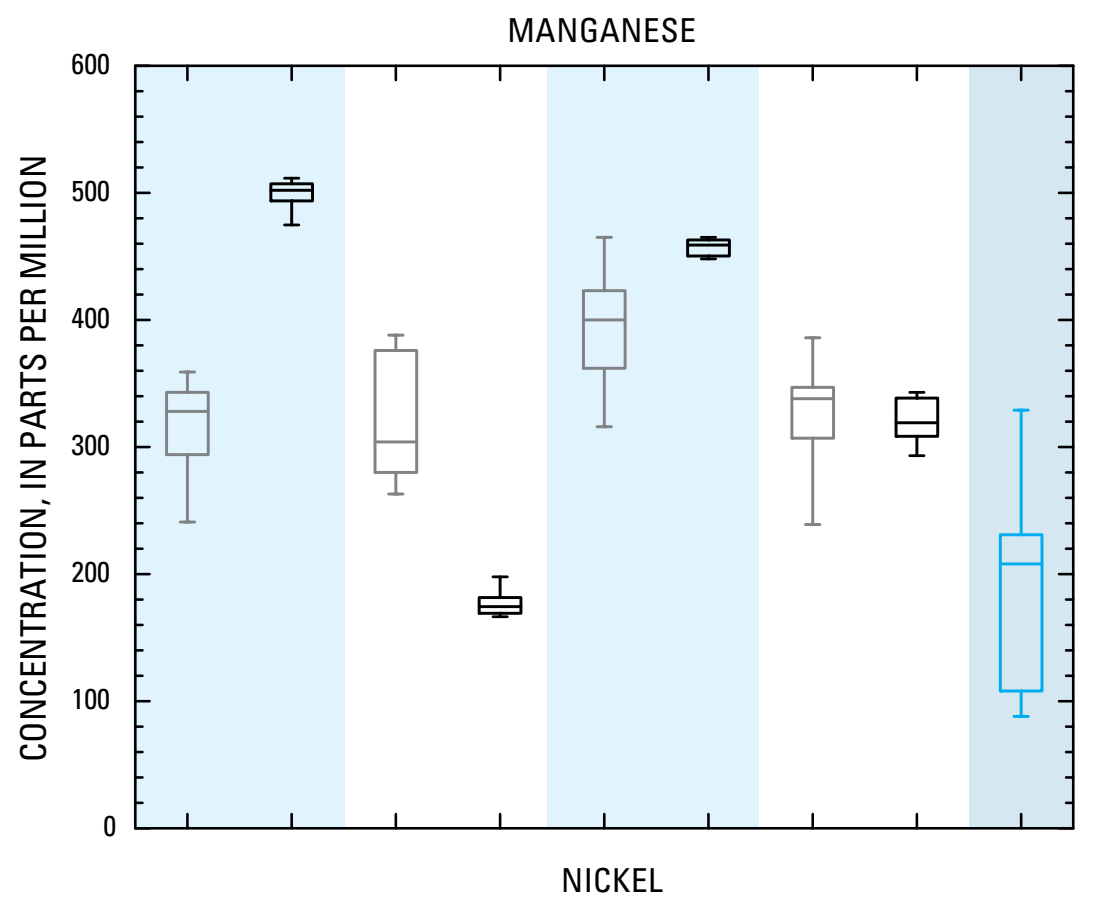

\section{EXPLANATION}

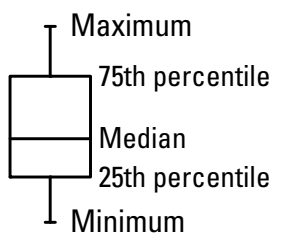
$\square$ Measured in berm material

$\mp$ Estimated in berm material

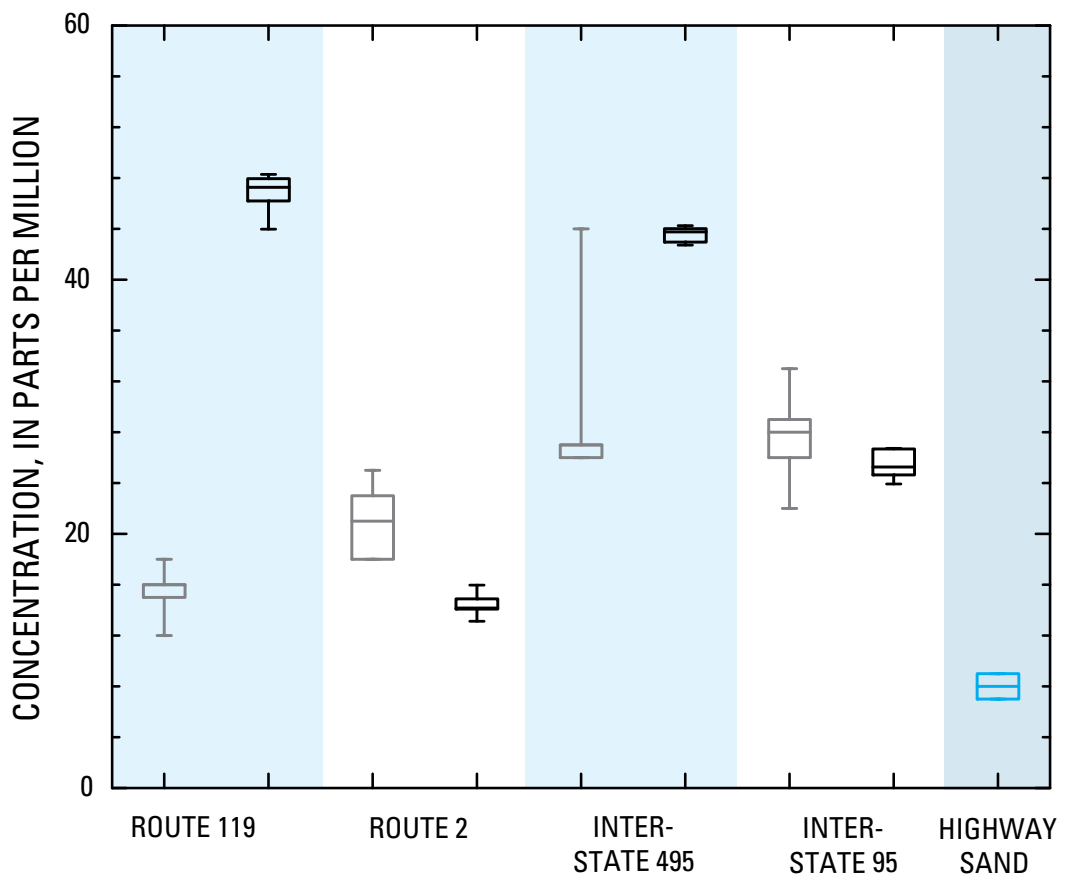

Figure 25. Distribution of concentrations of selected constituents measured in samples of berm material from four principal highways and in samples of highway-maintenance sand, and estimated concentrations of berm material derived from samples of suspended-sediment quality and particle size in Massachusetts, 2005-07. Five samples of highway-berm material were collected within 1 foot of the edge of the pavement in the vicinity of each of eight highway-monitoring stations. Eight samples of highway-maintenance sand were collected.-Continued 


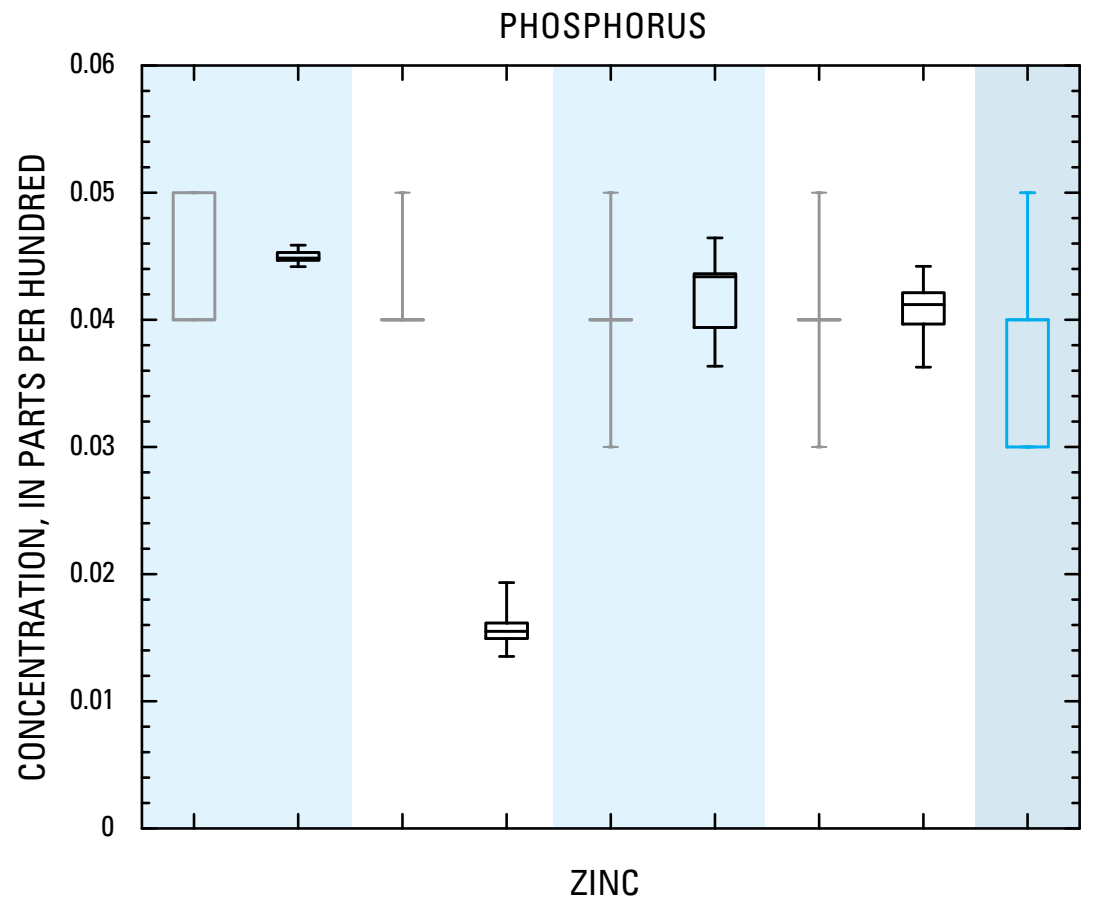

EXPLANATION

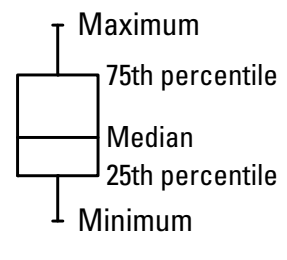
$\square$ Measured in berm material

$\mp$ Estimated in berm material

$\mp$ Measured in

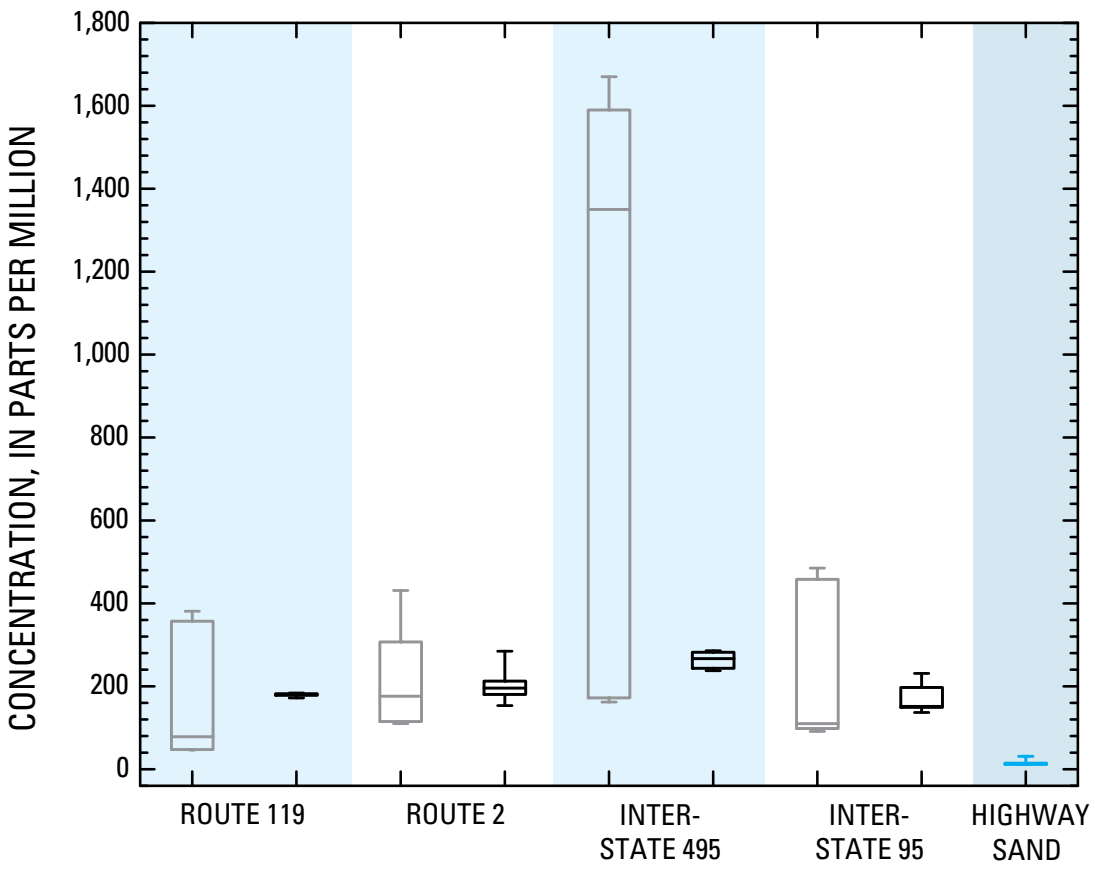

Figure 25. Distribution of concentrations of selected constituents measured in samples of berm material from four principal highways and in samples of highway-maintenance sand, and estimated concentrations of berm material derived from samples of suspended-sediment quality and particle size in Massachusetts, 2005-07. Five samples of highway-berm material were collected within 1 foot of the edge of the pavement in the vicinity of each of eight highway-monitoring stations. Eight samples of highway-maintenance sand were collected.-Continued 
concentration of $\mathrm{Zn}$ emitted from tire wear was about 1.5 to 6 times greater than the median non-winter concentrations of $\mathrm{Zn}$ for the principal highways. For the estimates, it was assumed that all of the tire particles are retained on the highway, which is highly unlikely given the small diameter of the tire particles. In one study (Rogge and others, 1993), 30 percent of the mass of tire-wear particles measured near the street surface was found in air-quality samples at more than $200 \mathrm{ft}$ above the street. Accurate load estimates for $\mathrm{Zn}$ as a function of tire wear are difficult to make because tire-emission rates vary widely depending on tire construction, vehicle weight, and pavement and driving conditions. Although Councell and others (2004) suggest that about $0.08 \mathrm{~g} / \mathrm{mi} /$ tire is a reasonable rate for average driving conditions, they also report emission rates ranging from about 0.002 to about $40 \mathrm{~g} / \mathrm{mi} /$ tire. Nevertheless, the evidence indicates that tire-wear is a substantial source for $\mathrm{Zn}$ in highway runoff, and other material testing indicates that some tires also may be a source of bis(2-ethylhexyl)phthalate (King County and SPU, 2004).

\section{Other Anthropogenic and Natural Organic Compounds}

The vast majority of highway-runoff data documents the concentrations of major ions, nutrients, metals, PAHs, and suspended sediments; however, few data sets document the concentration or detection for some of the lesser-known anthropogenic and natural organic compounds that have recently been detected in surface water and groundwater throughout the Nation (Zaugg, and others, 2006a). In this study, a subset of samples of highway runoff were collected at the primary sites on the principal highways and on Interstate 93 and analyzed for an additional 62 organic compounds (table 17 in the back of the report). These analyses include many compounds that typically are associated with industrial and household wastewater (Paxéus and others, 1992), such as nonionic surfactants, caffeine, indicators of plant sterols, indicators of fecal bacteria, flame retardants, wood preservatives, gasoline and diesel compounds, antioxidants, and personal care products.

In 15 samples of highway runoff, 45 of the 62 compounds were detected at least once, and 23 compounds were detected at concentrations greater than the LTMDL (table 35). Anthraquinone, bisphenol A, camphor, and cholesterol were the most frequently detected compounds. Although some compounds were detected less frequently in samples of highway runoff collected on Route 119, the frequency of detection for most compounds generally was similar among the other highways. About one-third of the compounds that were detected are likely attributable to vehicle fuels, lubricants, antifreeze, windshield fluids, chemical treatments of the engine compartments, finish-paint coats, automotive panels, and other vehicle components. Beta-sitosterol and cholesterol can originate from plant sources; 3beta-coprostanol and beta-stimastanol are indicators of fecal bacteria (Zaugg, and others, 2006a). The sources for many of the remaining compounds may be leachates from highway litter. These compounds consist of caffeine, cotinine, and various flavor enhancers used in beverages, cigarettes, and ointments commonly found in food wrappers, containers, and other litter along the edge of the highway.

\section{Relations of Concentrations of Selected Elements and Organic Compounds to Suspended Sediment}

Suspended sediment in runoff often can cause degradation in the receiving waters by affecting the clarity of the water and through large-scale depositions. Many trace elements and hydrophobic-organic compounds are associated with sediments (Breault and others, 2005; Smith, 2002, 2005; Lopes and Dionne, 1998; Horowitz, 1991; Gupta and others, 1981). Suspended sediment can represent a major transport mechanism for many constituents in highway runoff. Results of laboratory analysis for sieved samples of suspended sediment collected in highway runoff for this study indicate that highway suspended sediment contains high concentrations of $\mathrm{P}$, trace elements, PAHs, and phthalates (tables 18 and 21). Results also indicate that in many cases, the fine fraction of sediment less than $0.063 \mathrm{~mm}$ in diameter was more enriched compared to the coarser sediment fractions (figs. 24 and 26).

Concentrations of suspended sediment measured in samples of highway runoff were examined as a potential surrogate for concentrations of sediment-affiliated constituents. Results of statistical tests between concentrations of suspended sediment and concentrations of total $\mathrm{P}$, total-recoverable metals, and PAH compounds in samples collected at Interstate 95 indicate a positive relation between the test pairs (table 33). Furthermore, correlations are stronger between concentrations of suspended sediment less than $0.063 \mathrm{~mm}$ in diameter and concentrations of total $\mathrm{P}$, total-recoverable metals, and PAH compounds (table 33) than for concentrations of total suspended sediment. Pearson correlation coefficients for total $\mathrm{P}$, total-recoverable metals, and PAH compounds are 0.86 , 0.88 to 0.99 , and 0.80 to 0.94 , respectively (calculated from data presented in table 33). These data further demonstrate that the distribution of grain size in suspended sediment may have an effect on the concentration of the various constituents in samples of highway runoff. Regression techniques may provide reasonable estimates for many of these constituents on the basis of concentrations of suspended sediment; however, such methods may not be transferable to other locations without additional measurements of highway runoff, which often require substantial capital and time. Instead, planninglevel estimates of concentrations of many total-recoverable elements can be made directly from the respective constituent concentrations in samples of sieved suspended sediment and from the concentrations of specific particle classes of suspended sediment in samples of highway runoff. To demonstrate the applicability of this method, EMCs of $\mathrm{Cu}$ were 

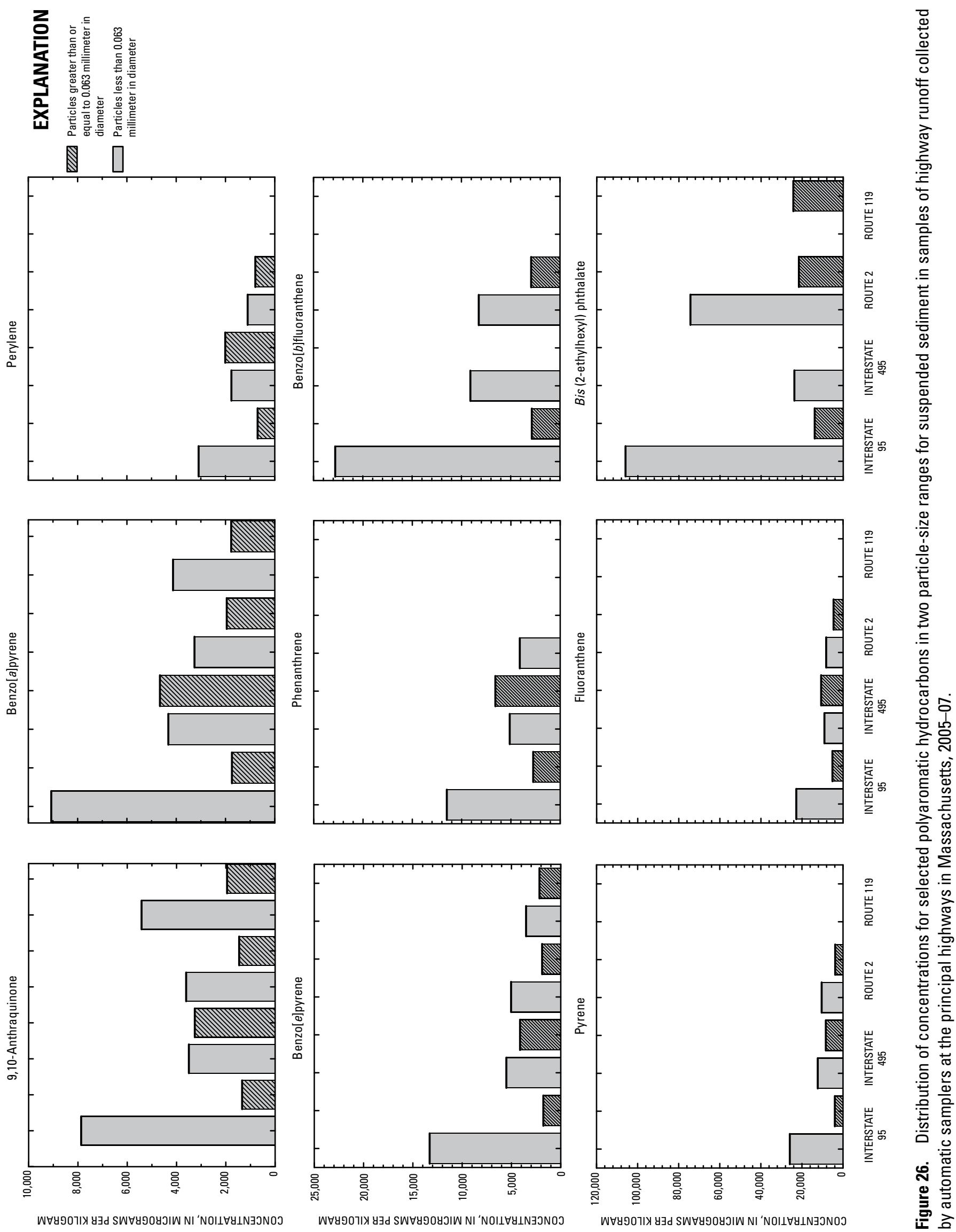


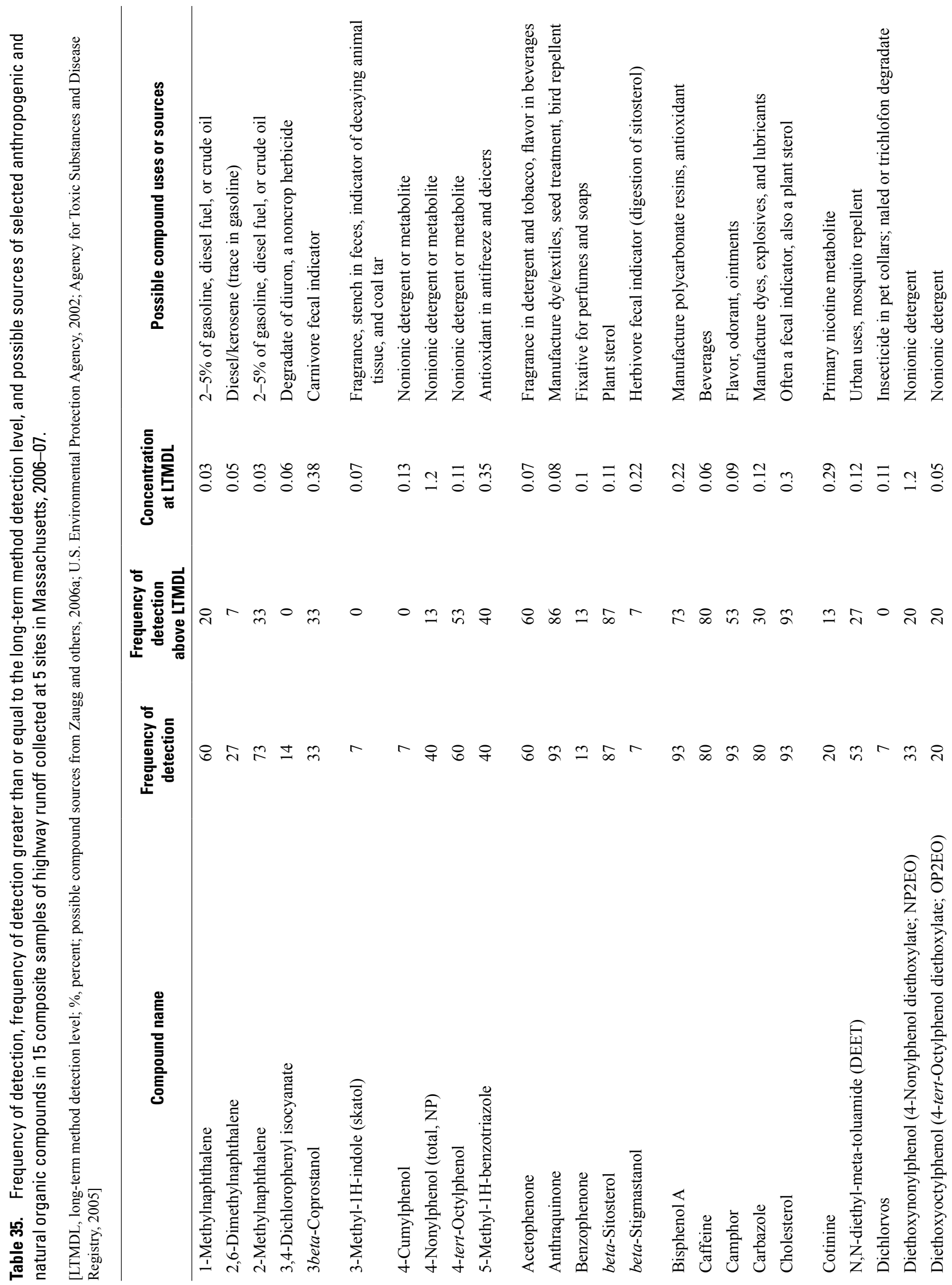




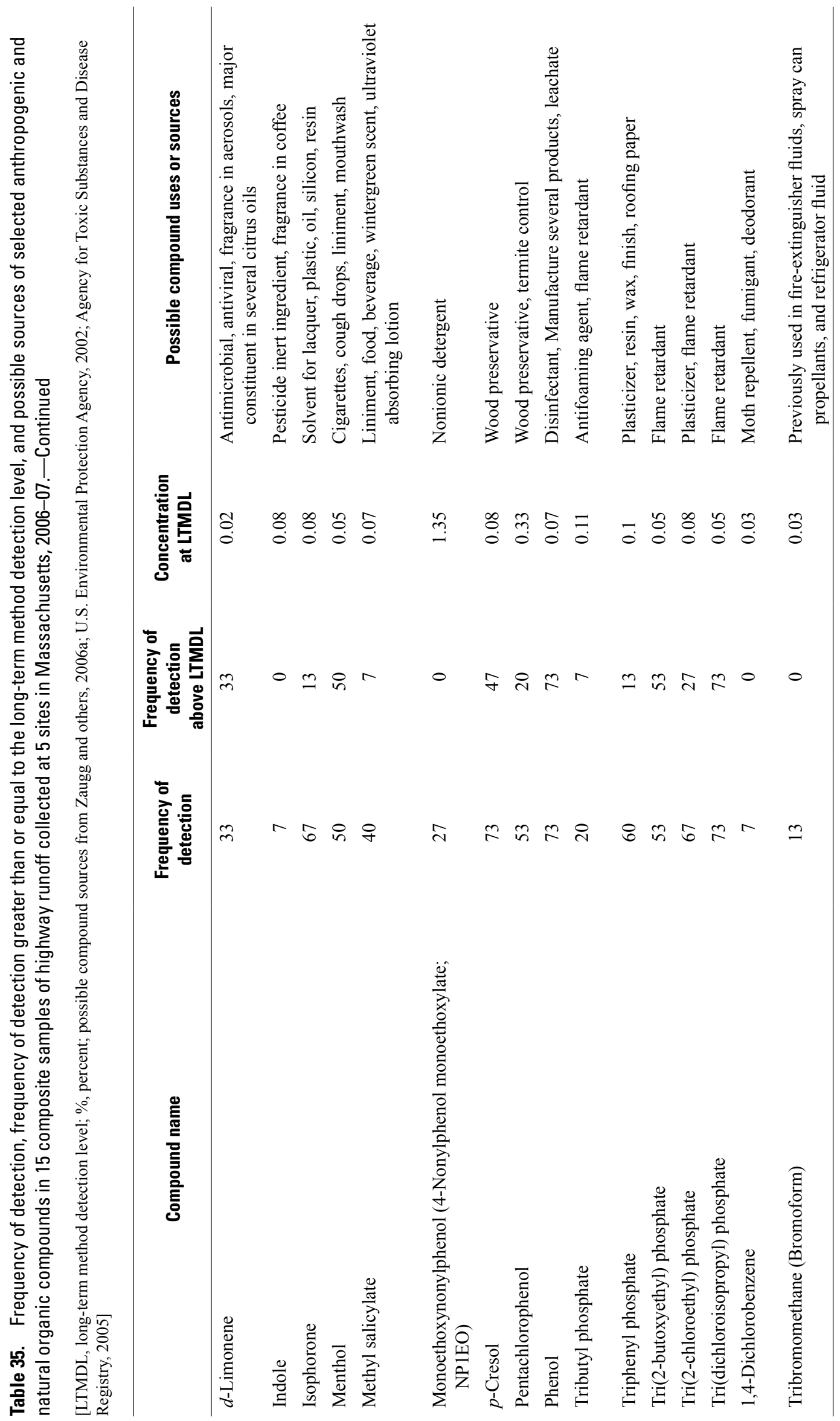


A

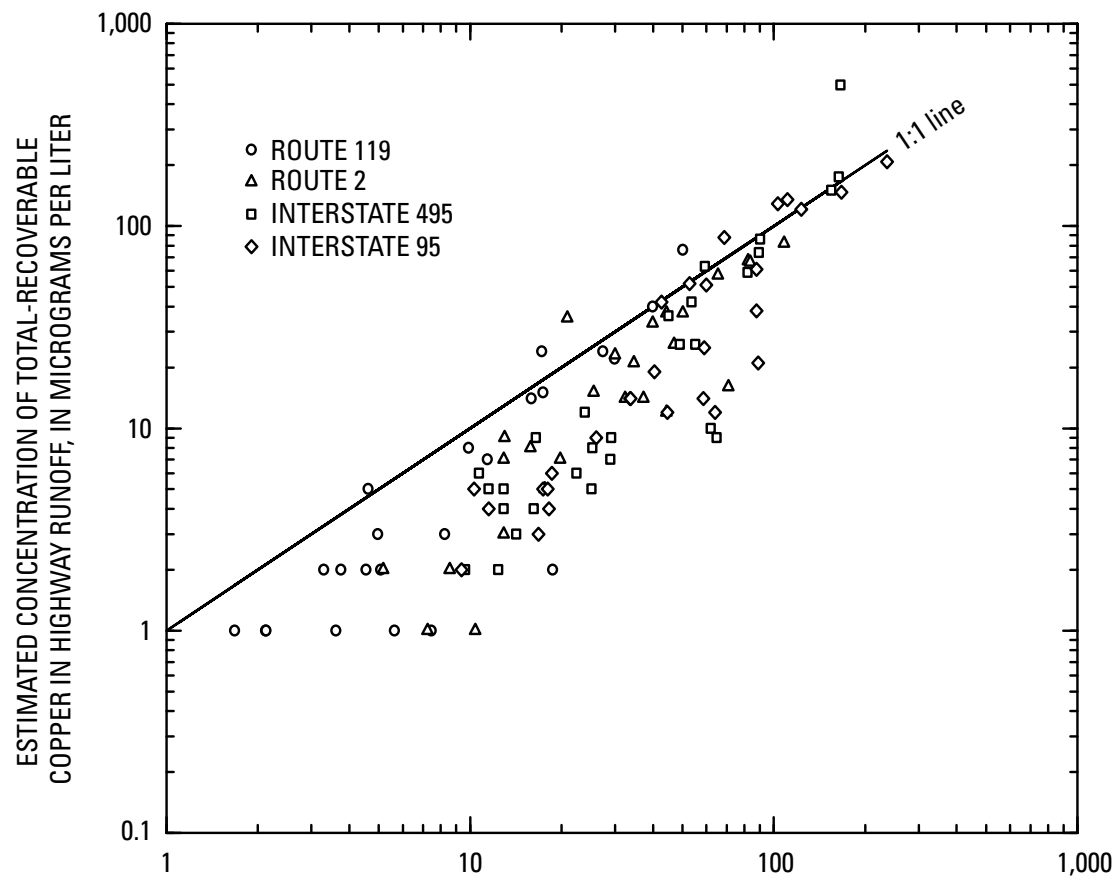

B

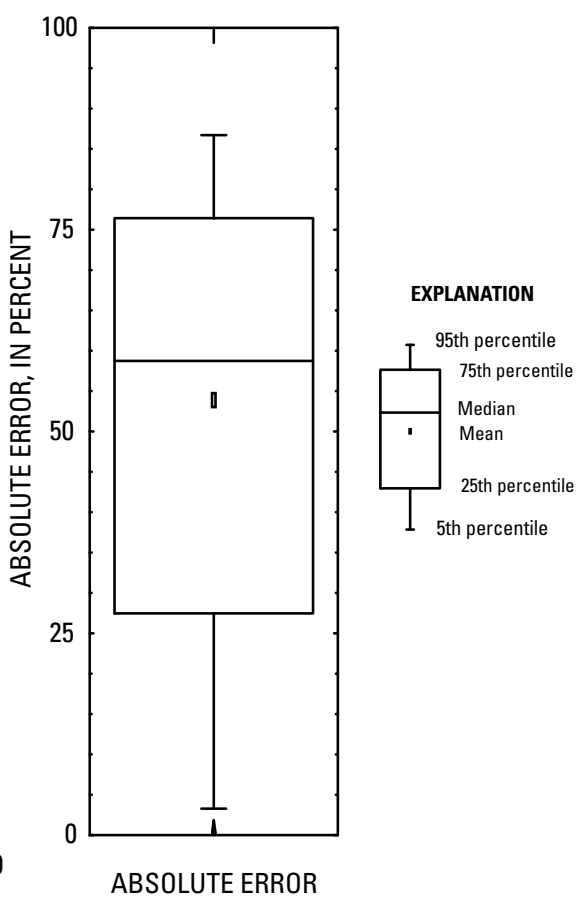

MEASURED CONCENTRATION OF TOTAL-RECOVERABLE COPPER IN HIGHWAY RUNOFF, IN MICROGRAMS PER LITER

Figure 27. (A) Concentrations of total-recoverable copper in samples of highway runoff collected from eight stations on four highways in Massachusetts in relation to concentrations of total-recoverable copper estimated on the basis of the concentration of total-recoverable copper associated with three particle-size ranges in sediment collected from composite samples of highway runoff and the concentration and particle-size distribution of suspended sediment in the respective samples of highway runoff, and $(B)$ distribution of absolute error between estimated concentrations of total-recoverable copper and measured concentrations of total-recoverable copper in samples of highway runoff, Massachusetts, $2005-07$. 
estimated for each principal highway (fig. 27) on the basis of the EMCs for the three respective particle-size classes of suspended sediment in the composite samples (table 16) and the concentration of $\mathrm{Cu}$ for the respective particle-size classes in samples of sieved suspended sediment for each highway (table 18 in the back of the report). The absolute difference between measured concentrations of $\mathrm{Cu}$ and estimated concentrations of $\mathrm{Cu}$ for about 95 percent of the samples were within 87 percent of the measured total-recoverable $\mathrm{Cu}$ values (fig. 27). In general, estimated concentrations of $\mathrm{Cu}$ less than about $90 \mu \mathrm{g} / \mathrm{L}$ tended to be underestimated, particularly for highways other than Route 119. This bias is predictable because the whole-water concentrations of $\mathrm{Cu}$ estimated from the concentrations of $\mathrm{Cu}$ in samples of sieved suspended sediment do not account for the dissolved fraction of $\mathrm{Cu}$ in the whole-water samples. In contrast, the difference between the estimated concentration of $\mathrm{Cu}$ and the measured concentration of $\mathrm{Cu}$ in composite samples decreases as the concentration of suspended sediment increases. This indicates that most of the $\mathrm{Cu}$ is partitioned to the solid phase in composite samples with high concentrations of suspended sediment. Similar results were found for $\mathrm{P}$ and most of the total-recoverable metals, except for $\mathrm{Cr}$ (table 36). These data also indicate that the vast majority of sediment-associated concentrations of $\mathrm{P}$ and metals are associated with sediment particles less than $0.063 \mathrm{~mm}$ in diameter. Such information is important for choosing appropriate BMPs.

Reasonable planning-level estimates for many constituents can be derived from known concentrations of specific constituents affiliated with sediments and from the average gradated concentrations of suspended sediment in the composite samples collected in this study. For many applications, the average gradated concentrations of suspended sediment measured in composite samples of highway runoff in this study can be used in the absence of site-specific concentration data for suspended sediment because most results of statistical tests between populations of concentrations of suspended sediment among the highways and results for median concentrations of suspended sediment with AADT volume were not significantly different ( $p$ value $>0.05$ ). If the concentrations of sedimentaffiliated constituents presented in this study (tables 18 and 21) are used to estimate planning-level EMCs or loads of constituents, the appropriate step is to select data with regard to the AADT volume of the principal highways and degree of urbanization. Ideally, site-specific samples of suspended sediment would be collected and analyzed for the constituents of interest. In theory, gradated samples of road dust, street sweepings, catch-basin-sump sediments, and highway sediments from other structural features could be practical substitutes for highway suspended sediment, although such testing was outside the scope of this study. Use of this method may have broad application and provide useful information for stormwater-monitoring applications.

\section{Highway-Runoff Database and Runoff Model Overview}

The data from this study were entered into the HRBD (appendix A) that was developed by the USGS, in cooperation with the Federal Highway Administration (FHWA) (Granato and Cazenas, 2009). The HRDB was designed to serve as a data warehouse for current and future highway-runoff data sets. The HRDB application also was developed to serve as a data preprocessor for the SELDM (Granato, 2007). SELDM is a water-quality model designed to facilitate the estimation of runoff flows, and constituent concentrations and loads in highway runoff and in receiving waters at unmonitored sites, using site characteristics as a basis for the estimates. Runoff coefficients and EMC statistics are used with SELDM to generate random populations of runoff volumes, and constituent concentrations and loads, from regional precipitation statistics and site characteristics by use of Monte Carlo simulation methods. This information can be used to estimate runoff quantity and quality based on site characteristics, and to predict potential effects of highway runoff on receiving waters. Proper application of such a model, however, requires technically sound statistical estimates of the quality and quantity of runoff and receiving waters upstream from the highway outfall. Such statistical estimates require technically sound and well-documented data and statistically valid estimation methods appropriate for the data. As SELDM was developed, it was realized that use of the model, as well as other analyses and applications of highway-runoff data, would be greatly facilitated by a database for complete and comprehensive storage, retrieval, and analysis of these data in a consistent format. Thus, the HRDB warehouse was created to document data and information from available highway-runoff monitoring studies. The HRDB application, which is the graphical user interface and associated computer code, can be used to facilitate estimation of statistical properties of runoff coefficients, runoff-quality statistics, and relations between water-quality variables in highway runoff from the available data.

Entering data into version 1.0.0a of the HRDB database is an important step in meeting the State and national data needs. The need for available, consistent, and technically sound runoff-monitoring data was highlighted by the findings of the FHWA National Highway Runoff Data and Methodology Synthesis (NDAMS) (Granato and others, 1998; Granato, 2009). Results of the NDAMS study indicate that knowledge of the details of highway-runoff studies is not persistent or pervasive and that detailed data and documentation for studies more than 5 years old often are unobtainable because of changes in personnel and computer systems (Granato, 2009). Similarly, a recent study by the National Cooperative Highway Research Program (NCHRP) concluded that a national highway-runoff database, available in the public domain, was needed to document the results of monitoring efforts to characterize the quality of runoff from operating highways (Venner and others, 2004). Data from the current study, an earlier 
Table 36. Statistics for concentrations of selected constituents estimated on the basis of the concentration of suspended sediment for three particle-size ranges in 105 samples of highway runoff and for concentrations of the constituents measured in samples of suspended sediment for equivalent particle sizes collected from the principal highways in Massachusetts, and the differences between the estimated concentrations and the measured concentrations in composite samples of highway runoff.

$[<$, less than the value shown; $>$, greater than the value shown; $\mathrm{mm}$, millimeters in diameter]

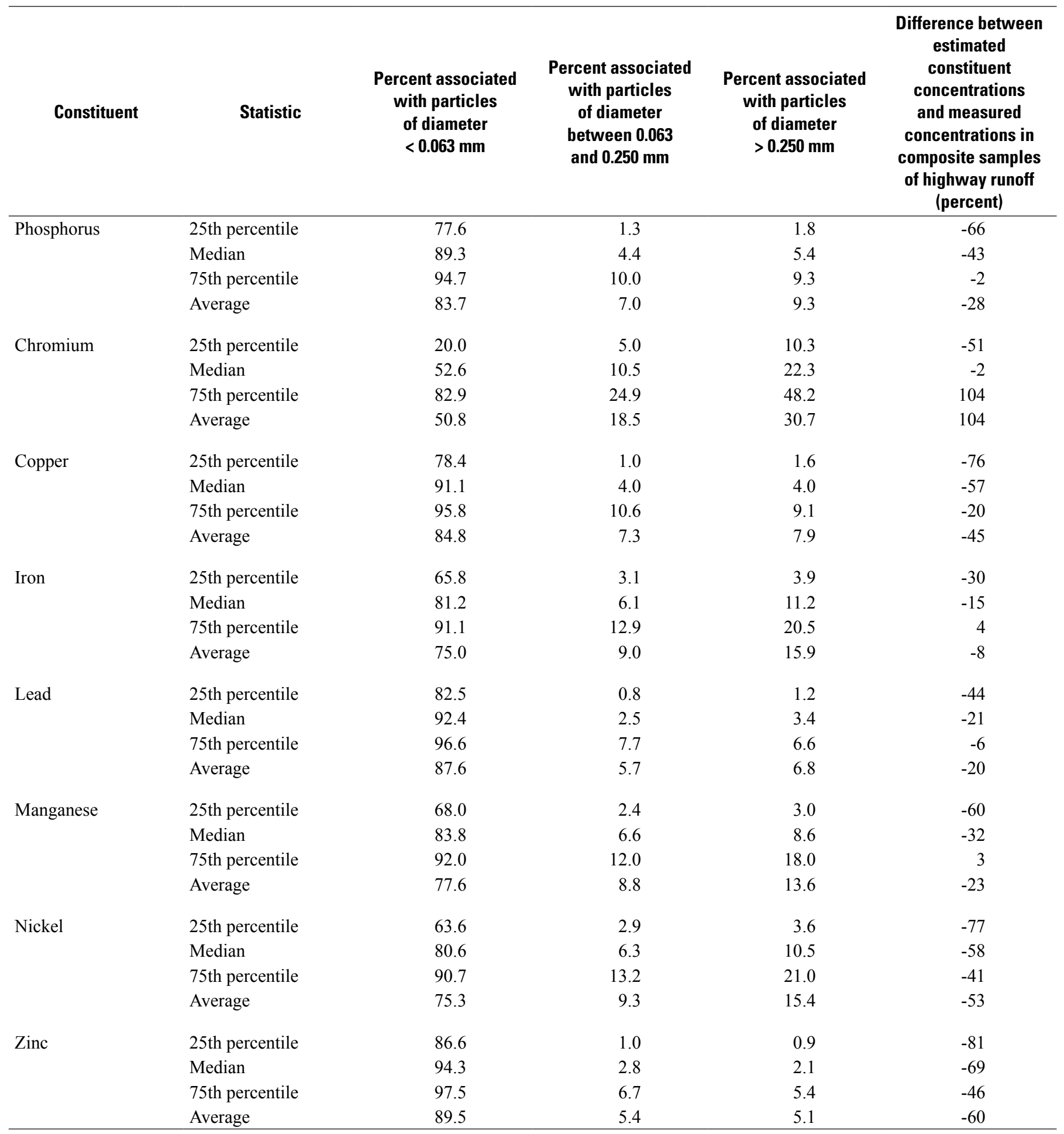


Massachusetts highway-runoff study (Smith, 2002), and other highway-runoff studies (for example, Hardee and others, 1978; Harned, 1988; Waschbusch, 2003) are available from the USGS National Water Information System Web (NWIS Web). The NWIS Web format, however, does not facilitate use of the data with the SELDM model, and the NWIS Web database does not include data collected by organizations other than the USGS. As such, Version 1.0.0a of the HRDB database will be archived with this report at the USGS Publications Warehouse (available on the web at: http://pubs.usgs.gov) to document currently available highway-runoff data in a format that facilitates use of the data with SELDM. A copy of the HRDB documentation, the data dictionary, and the database design plate (Granato and Cazenas, 2009) are on the CD-ROM accompanying this report to facilitate use of the HRDB.

The summary in figure 28 provides an overview of the complete HRDB version 1.0.0a data set that is currently available for analysis of highway-runoff quality. Currently, the database includes data from 9 highway-runoff data sets with 117 stations, 4,186 storms, and 54,383 individual stormwaterquality measurements. Data from the 1990 FHWA runoff-quality model "working database," which represents a compilation of previous studies (Driscoll and others, 1990a; b), are included to supplement and to provide a basis for comparison with newer data sets. The California data set (CA 2003) currently is one of the largest highway-runoff data sets collected, processed, analyzed, and recorded in a robust and consistent data-quality system (California Department of Transportation, Office of Environmental Engineering, 2000, 2002, 2003a, 2003b, 2003c, 2003d, 2004). Highway-runoff data from Massachusetts represent results from this investigation (MA 2009) and the BMP characterization study (MA 2002). The Michigan Department of Transportation data (MI 1998) are results from a highway stormwater-runoff characterization study $(\mathrm{CH} 2 \mathrm{M}-$ Hill, Inc., 1998). The Ohio data (OH 1997) are results from a small highway stormwater-runoff characterization study in Cincinnati, Ohio (Sansalone and Buchberger, 1997; Sansalone and others, 1997). The Texas data set represents results from a characterization study (Barrett and others, 1995, 1996) and a BMP study (Walsh and others, 1997). The Washington State data sets include highway runoff characterization data for NPDES permits (Tetra Tech, Inc., 2002, 2003, 2004; Washington State Department of Transportation, Environmental Services Office, 2001, 2002, 2003, 2004) and BMP monitoring data (Taylor Associates, Inc., 2002a, 2002b). The Wisconsin study (Waschbusch, 2003) documents highway-runoff quality with and without street sweeping. The current data set (MA 2009) represents about 11 percent of the sites, 36 percent of the storm events, and about 27 percent of the EMC values in version 1.0.0a of the HRDB (fig 28). Combined, the two Massachusetts studies (MA 2002 and MA 2009) represent about 14 percent of the sites, 43 percent of the storm events, and 29 percent of the EMC values in the database. The storm events in the highway-runoff database span a period of more than three decades from 1975 to 2007 (fig. 29). The two Mas- sachusetts studies (MA 2002 and MA 2009) represent current conditions in Massachusetts.

\section{Summary and Conclusions}

The USGS, in cooperation with FHWA and the Massachusetts DOT, began a study in September 2004 to characterize the quality of highway runoff for a wide range of constituents for selected highways in Massachusetts with AADT volumes ranging from about 3,000 to more than 190,000 vehicles per day. Highway-monitoring stations were installed at 12 locations on 8 highways throughout the State of Massachusetts. The highway-monitoring stations were selected on the basis of published AADT volumes; proximity to each other; similarities in surficial geology, soils, vegetation, and land use as a function of USEPA level III ecoregions; highway and drainage construction; site accessibility and safety; and suitability for hydrologic and meteorologic monitoring and collection of stormwater samples. The 12 stations were subdivided into four primary, four secondary, and four test stations. Paired primary and secondary stations were located within a few miles of each other on a limited-access section of the same highway to ensure comparable levels of traffic volume and density. Although both the design and operation of the primary and secondary monitoring stations were similar, the monitoring period and number of samples of highway runoff collected at the primary station were greater than at the secondary stations. Most of the stormwater samples were collected at the primary and secondary stations, which were located on four principal highways in the eastern region of the State. Samples of stormwater collected at the test stations were used to assess the transferability of the data collected from the principal highways to other highways with characteristics that differ in construction, land use, and geography from the principal highways.

\section{Methods}

Automatic-monitoring techniques were used extensively to collect continuous measurements of water level, water temperature, specific conductance, air temperature, and rainfall, and to collect composite samples of highway runoff. Runoff coefficients were computed on the basis of the drainage areas, and flow and rainfall records for each storm for which data were available. Event-mean specific conductance values were calculated for each highway site on the basis of calculated values of discharge greater than $0.009 \mathrm{ft}^{3} / \mathrm{s}$ and corresponding measurements of specific conductance to supplement and expand the number of event-mean values of specific conductance. Additionally, EMCs for dissolved $\mathrm{Ca}, \mathrm{Cl}, \mathrm{Na}$, and $\mathrm{SO}_{4}$ were estimated on the basis of the event-mean specific conductance values with the adjusted superpositioning technique for most monitoring stations. 
A Count of sites, storm events, and event-mean concentration values

\begin{tabular}{lrrr} 
Highway-Runoff & \multicolumn{3}{c}{ Count of } \\
\cline { 2 - 4 } Data Set & Sites & Storms & EMC \\
\hline Federal: & & & \\
FHWA 1990 & 24 & 937 & 8,428 \\
& & & \\
State: & & & \\
CA 2003 & 52 & 981 & 26,104 \\
MA 2002 & 4 & 285 & 1,236 \\
MA 2009 & 13 & 1,523 & 14,563 \\
MI 1998 & 3 & 9 & 198 \\
OH 1997 & 1 & 13 & 169 \\
TX 1997 & 6 & 187 & 1,925 \\
WA 2005 & 12 & 155 & 1,486 \\
WI 2000 & 2 & 96 & 725 \\
\hline Sum & 117 & 4,186 & 54,384
\end{tabular}

C Percentage of storm events in each data set

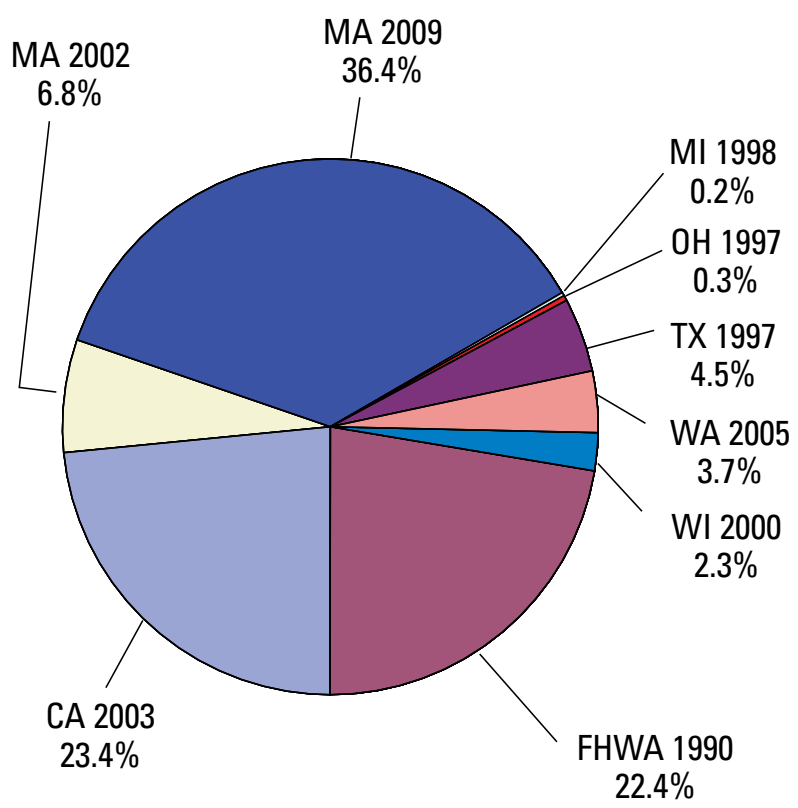

$\boldsymbol{B}$ Percentage of sites in each data set

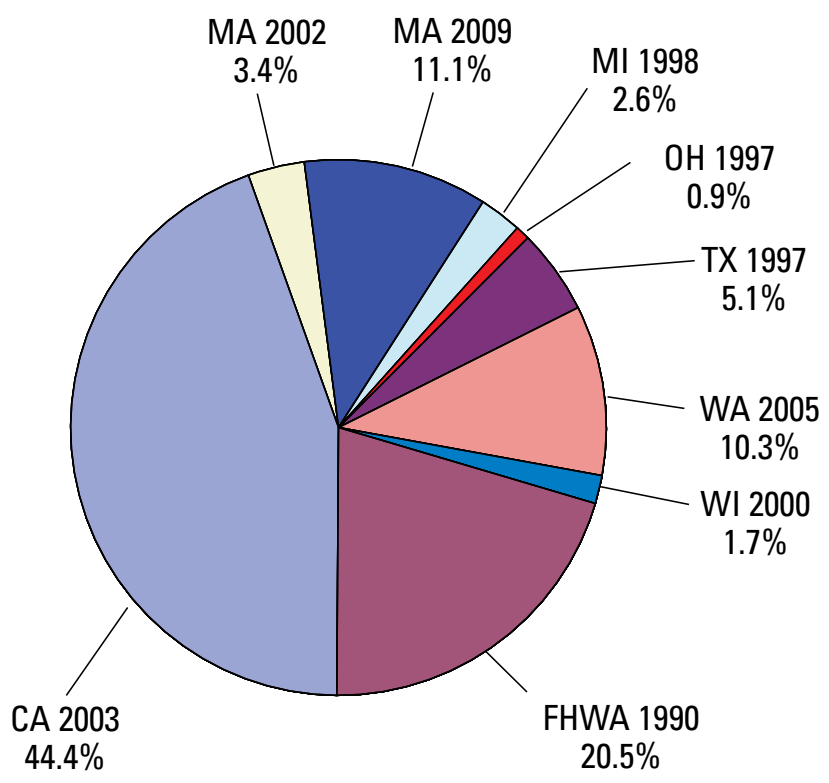

D Percentage of event-mean concentration values in each data set

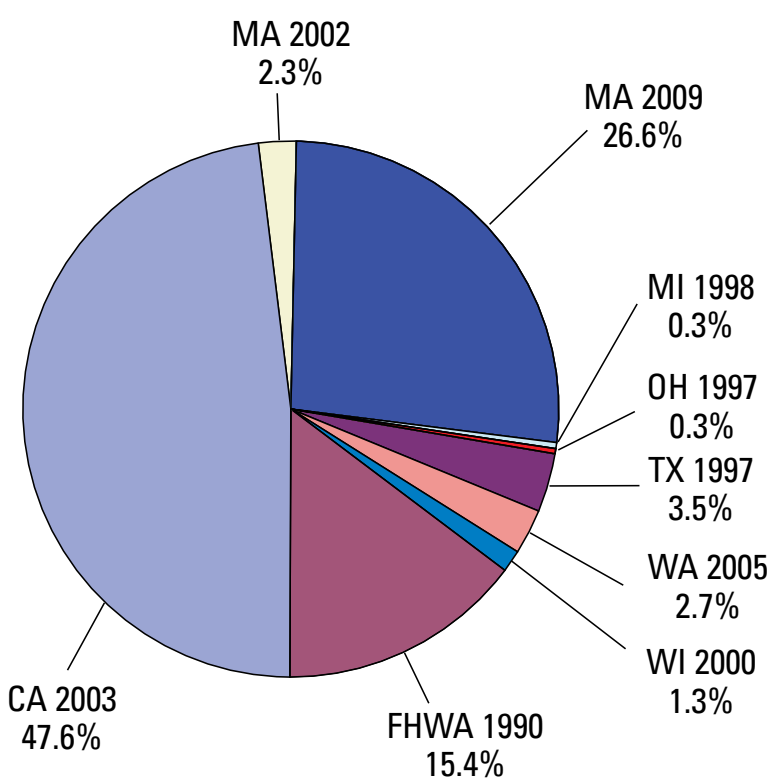

Figure 28. Summary of the highway-runoff data including $(A)$ a count of sites, storms, and event-mean concentration values in the database, and the percentage of $(B)$ sites, $(C)$ storm events, and $(D)$ event-mean concentration values in each highway-runoff data set. (FHWA, Federal Highway Administration) 


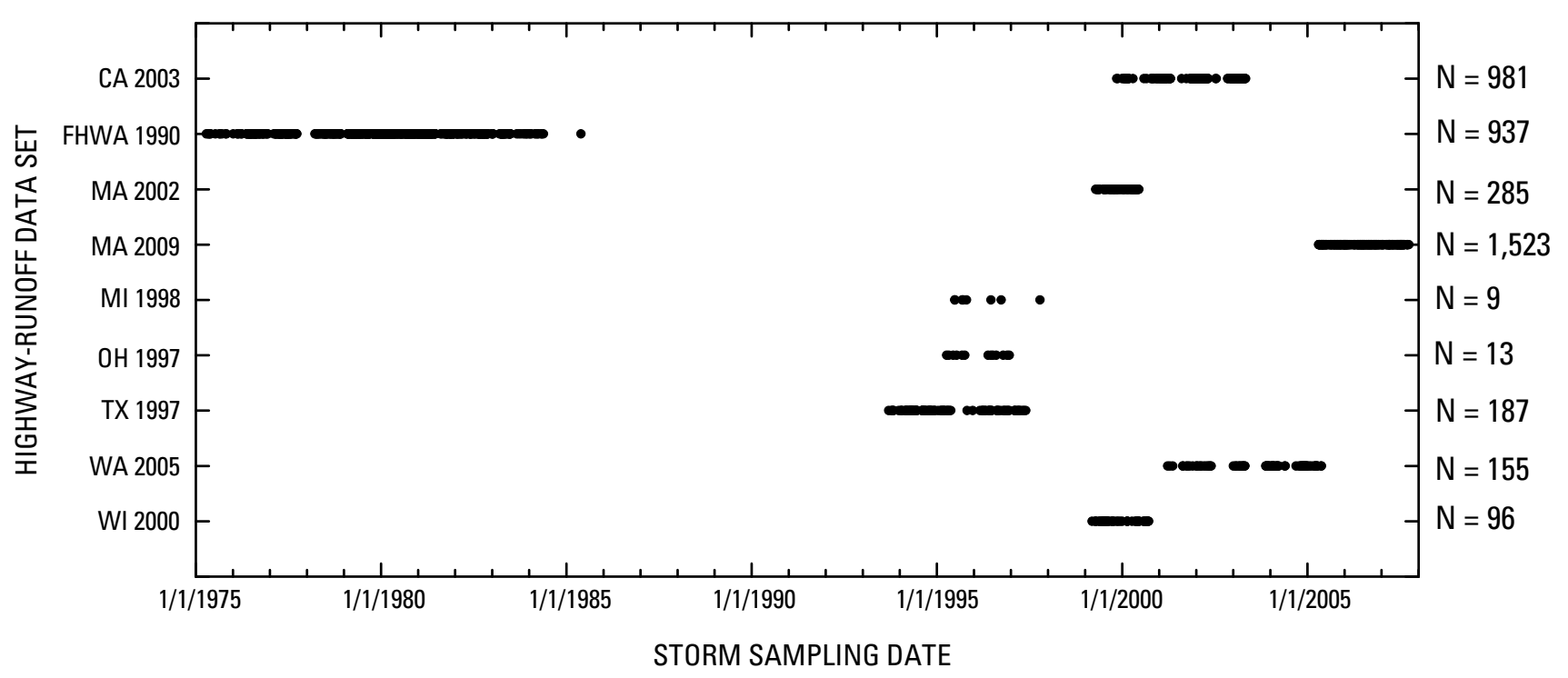

\section{EXPLANATION}

- Storm event

$\mathrm{N}$ Number of observations

Figure 29. Temporal distribution of storm sampling dates for each data set in the highway-runoff database.

Approximately 140 flow-weighted samples were collected automatically during rain and mixed precipitation storms at the 12 monitoring stations from September 2005 through September 2007 and analyzed for concentrations of selected dissolved major ions, total $\mathrm{N}$ and $\mathrm{P}$, selected total-recoverable metals, suspended sediment, and SVOCs. Samples of highway runoff were collected year-round during storms with various antecedent dry periods throughout the 2 -year sampling period. The distribution of the duration of dry antecedent periods, as well as the distribution of event-mean specific conductance values, for storms during which samples were collected at each of the principal highways was similar to the distribution of both of these conditions during the monitoring period. Precipitation totals ranged from about 0.1 to $5.1 \mathrm{in}$. for storms that were sampled at the principal highways and most precipitation totals for sampled storms were within the interquartile range of precipitation totals greater than $0.10 \mathrm{in}$. recorded from 1967 through 2007 by the National Climatic Data Center near Worcester, Massachusetts.

In addition to the collection of samples of highway runoff, samples of other media were collected to supplement the data set and support data analysis. These media include sieved highway-runoff sediment from the principal highways, and background soils, berm materials, maintenance sands, deicing compounds, and vegetation matter collected near or on the highway. Most of these samples were analyzed for 32 elements. Samples of sieved highway-runoff sediment and vegetation matter also were analyzed for selected PAHs and TOC.

\section{Data Quality}

The accuracy and precision of the data collected in this study were ensured by making quality-control measurements at each of the monitoring stations, operating redundant sensors, conducting quality-assurance experiments, and collecting various types of quality-control samples. Quality-control samples of artificial and blank water were collected to identify potential bias in sampling and processing methods and contamination resulting from the sampling equipment and from the sample collection, processing, and analysis. Other qualitycontrol samples were collected in the field and laboratory to estimate analyte degradation, analytical-method recovery and performance, and presence of interfering agents.

Comparative measurements made during site visits at each of the highway-monitoring stations indicate that the continuous measurements of water level, water temperature, and specific conductance recorded by the monitoring stations were generally accurate and precise. Despite the sometimes large variability in runoff coefficients, the agreement between values of event-mean specific conductance estimated from continuous records of flow and specific conductance, and the measured specific conductance of flow-weighted water samples indicate that flows calculated from a stage-discharge relation for each monitoring station were reasonable. This also indicates that the frequency of sample collection within storms was sufficient to accurately characterize the variability of the quality of runoff during the storms. Experimental results indicate that concentrations of suspended sediment with diameters ranging from $0.250 \mathrm{~mm}$ to about $6.0 \mathrm{~mm}$ in water samples 
collected by an automatic sampler in conjunction with the static-mixer assembly reasonably represent the distribution of particle sizes in an artificial flow stream over a range of flows. However, a comparison of measurements of suspended sediment greater than $0.250 \mathrm{~mm}$ in diameter collected at the end of the highway discharge pipe and in flow-weighted composite samples of runoff from one of the primary monitoring stations indicates that there is a potential positive bias associated with concentrations of coarse particles in samples of water collected using automatic-sampling methods in this study. The bias observed for the environmental samples could, in part, result from the automatic sampler disproportionally collecting natural organic materials, which are less dense than mineral sediments and relatively abundant. Considering that the concentration of $\mathrm{P}$ in natural organic matter is high compared to the concentration of metals, the concentrations for P also may be elevated in samples of highway runoff, particularly during the growing season.

Results of analyses of sample volumes reduced through splitting indicate that concentrations of suspended-sediment particles less than $0.063 \mathrm{~mm}$ in diameter in the subsamples of the sediment/water mixture were both accurate and precise. Analysis of field-blank data indicates that the cleaning and preparation of sampling equipment, sample processing, and respective analytical methods were not a source of contamination bias for most constituents. With the exception of naphthalene, contamination bias appeared to be random for all constituents. Low-level measurements for naphthalene in field blanks are believed to be from contaminated source water.

Analysis of replicate samples for selected PAH and phthalate compounds and spike recoveries in fortified environmental samples analyzed for $\mathrm{PAH}$, phthalate, and other anthropogenic organic and natural organic compounds indicate that the measured concentrations for most of these constituents are reasonably precise and that field and laboratory processing, analytical method performance, and sample matrix effects for the constituents are not a large source of bias for most constituents. The average spike recoveries for both PAH and phthalate compounds were similar to the average laboratory-preparation spike recoveries for the respective compounds for the study period, except for benzo[ghi]perylene, indeno[1,2,3-cd] pyrene, bis(2-ethylhexyl) phthalate, and di-n-butyl phthalate, which were notably lower. Because the variability of field-spike recoveries for these compounds was similar to the variability of the respective laboratory preparation-spike recoveries and because the replicate field-spike recoveries for these compounds were relatively precise, such differences are likely attributable to degradation of the compounds prior to laboratory processing or matrix effects that mask the respective compounds. As a result, these data indicate that concentrations of these four compounds are likely underestimated for samples of highway runoff collected in this study.

Standard-reference samples were submitted to laboratories to identify potential contamination bias and to assess analytical method performance. Samples were analyzed for both total and total-recoverable concentrations, in part, because reference materials are certified only for total concentrations. Concentrations of $\mathrm{P}$ and selected metals also were determined in reference-material water mixtures. Median total concentrations in blind samples for about 40 percent of the measured elements, for which there were certified concentration values for standard reference soil, were within the certified concentration ranges. The median concentrations for blind samples of the measured elements, for which there were noncertified values, were generally less than, but within 20 percent of, the noncertified values. The median total-recoverable concentrations of elements in NIST reference material samples were within the reported range of recovery, except those for As, La, and P. Total-recoverable concentrations of selected elements, except $\mathrm{Cu}$ and $\mathrm{Pb}$, measured in artificial samples of water were lower than the respective measurements made by the USEPA method 3050B in samples of solid media. Concentrations of total-recoverable $\mathrm{Cr}, \mathrm{Fe}, \mathrm{Ni}, \mathrm{P}$, and $\mathrm{Zn}$ in the artificial water samples were lower than the lower recovery limit of the reference material. These quality-control data were used as a basis to adjust the concentrations of constituents in solid media when comparisons were made with whole-water concentration data.

Replicate samples of background soils, highway-berm soils, suspended sediment, and other miscellaneous samples were collected to determine the precision of the data. The average absolute RPD was less than 10 percent for all elements, except for $\mathrm{As}, \mathrm{Na}, \mathrm{Pb}, \mathrm{Sc}$, and Ti. For these elements, the average absolute RPD between replicate pairs ranged from about 11 to 16 percent. The variability observed in the concentrations of elements in replicate pairs could be, in part, a result of differences in the distribution of particle sizes in the samples. The median RPD between the amount of material in particle-size classes less than $0.063 \mathrm{~mm}$ in diameter, between $0.063 \mathrm{~mm}$ and $0.250 \mathrm{~mm}$ in diameter, and greater than $0.250 \mathrm{~mm}$ in diameter for 16 replicate pairs was 7,8 , and 4 percent, respectively.

\section{Quality of Highway Runoff}

The data presented in this report represents the quality of stormwater runoff from highways with AADT volumes ranging from about 3,000 to more than 190,000 vehicles per day at 12 locations on 8 highways throughout the State of Massachusetts. These data were analyzed to determine the appropriate aggregation for individual data sets to estimate planning-level highway contributions for the constituents presented in this study for other highways in Massachusetts.

\section{Evaluation of Highway Runoff}

Highway-runoff data, including populations of concentrations of selected dissolved major ions, total nutrients, total-recoverable metals, PAHs, phthalates, and suspended sediments (including particle size) were evaluated using the 
nonparametric Mann-Whitney test. Mann-Whitney tests were used to determine significant differences between sample populations collected from the same highways, but at different locations, and to determine significant differences between sample populations collected from different highways, but with similar AADT volumes. Similar statistical methods also were used to test for differences between the populations of sample concentrations among the four principal highways that differed mainly by traffic volume. Sample concentrations that were not detected or were estimated to be below the LTMDL were set equal to a value less than the LTMDL for each constituent evaluated. Analyses for many PAH and phthalate compounds were not performed because these compounds were consistently undetected in samples or because all of the concentrations were estimated to be below the LTMDL.

With a few exceptions, test results between paired populations (that is, data from the primary and secondary stations on each principal highway) show that concentration data generally are not statistically different at a 95 -percent confidence interval, indicating similarities between populations. Results of tests between populations of concentrations of suspended sediment and (or) concentrations of suspended sediment less than $0.063 \mathrm{~mm}$ in diameter show that populations of concentrations are significantly different for the stations on Route 119 and Interstate 495. These differences are believed to be the result of runoff patterns and berm conditions associated with the secondary monitoring station that differed from the primary monitoring station for each highway. Also, results of tests between populations of concentrations of total-recoverable $\mathrm{Zn}$ for the stations on Route 2 show that populations of concentrations are significantly different ( $p$ value less than 0.05 ). Unfortunately, this difference is not fully explainable with available data.

Concentration data collected from the test highways were compared to concentration data collected from the principal highways of similar AADT volumes to determine whether the data were transferable from highway to highway on the basis of AADT volume. Where sufficient concentration data were available for testing, no significant differences were found between populations of concentrations of selected dissolved major ions, total nutrients, total-recoverable metals, PAHs, phthalates, and suspended sediments (including particle size) in composite samples of highway runoff collected from the stations on Route 119 and Route 8 (highways with the lowest AADT volumes), and the only significant difference observed in test results between populations of constituent concentrations for the stations on Route 2 and Interstate 190 (highways with moderate AADT volumes) was for total-recoverable $\mathrm{Zn}$. As previously discussed, the significant difference between the populations of total-recoverable $\mathrm{Zn}$ concentrations may be attributable to the high concentrations (median value of $308 \mu \mathrm{g} / \mathrm{L}$ ) determined for the primary monitoring station on Route 2. In contrast, results of many tests between populations of constituent concentrations collected from the sites on Route 2 and Interstate 195 (highways with moderate AADT volumes) were significant at a 95-percent confidence interval.
Test results between populations of dissolved concentrations of $\mathrm{Ca}$ and $\mathrm{K}$; concentrations of total $\mathrm{P}$; and total-recoverable concentrations of $\mathrm{Cd}, \mathrm{Cr}, \mathrm{Cu}, \mathrm{Mn}$, and $\mathrm{Zn}$ from Route 2 and Interstate 195 were significant at a 95-percent confidence interval. Test results between populations of concentrations of total $\mathrm{N}$; dissolved $\mathrm{Mg}, \mathrm{Na}, \mathrm{Cl}$, and $\mathrm{SO}_{4}$; total-recoverable $\mathrm{Cu}$, $\mathrm{Fe}, \mathrm{Pb}$, and $\mathrm{Ni}$; suspended sediment; and $\mathrm{PAH}$ and phthalate compounds, where sufficient data were available, were not significant at a 95-percent confidence interval. Results of many tests between populations of constituent concentrations in composite samples of highway runoff collected from stations on Interstate 95 and Interstate 93 (highways with very high AADT volumes) also were significant. Concentrations of most total-recoverable metals in samples of highway runoff collected from Interstate 93 were considerably higher than the respective concentrations measured in samples from Interstate 95. Results for Mann-Whitney tests between populations of concentrations of total-recoverable metals, except for $\mathrm{Cd}$ and $\mathrm{Ni}$, and suspended sediment collected from the stations on Interstate 95 and on Interstate 93 were significant at the 95 -percent confidence interval. No significant differences were found between populations of concentrations of total nutrients, major ions, and $\mathrm{PAH}$ and phthalate compounds.

The significant differences between many of the populations of metal concentrations for Route 2 and Interstate 195, and for Interstate 95 and Interstate 93, in part, could be due to the effect of local soil deposition on the highway surfaces. The concentrations of many metals in samples of soil collected near Interstate 195 were substantially lower than the concentrations of those metals in samples of soil collected near Route 2. Likewise, the concentrations of many metals in samples of soil collected near Interstate 93 were substantially higher than the concentrations of the same constituents collected in samples of soil near Interstate 95. The differences in the test results are, in part, a function of the local soil chemistry near each of the highways, given the dissimilar enrichment of metal concentrations measured in the samples of soil. However, though this may help to explain the higher concentrations of $\mathrm{Cu}, \mathrm{Pb}$, and $\mathrm{Zn}$ in samples of highway runoff collected from Interstate 93, concentrations of other metals in soil samples collected near Interstate 93 were similar to the concentrations in soil samples collected near the other highways. The nearly order-of-magnitude higher concentration of suspended sediment measured in samples of highway runoff collected at Interstate 93 is likely the main factor in the difference between the populations of concentration data for many of the totalrecoverable metals for the two highways. High rates of dry deposition, which are commonly reported for urbanized areas containing large impervious areas, also could explain the significant difference between concentrations of suspended sediment measured for Interstate 93. These data indicate that the quantity, as well as the quality, of sediment in highway runoff can be affected by the proximity of the site to highly urbanized areas containing large amounts of impervious area.

Populations of concentration data collected for each principal highway were compared to the populations of 
concentration data collected for each of the other principal highways to determine whether the populations are significantly different from highway to highway. Most of the MannWhitney test results indicate that the data collected for the principal highway on Route 119, which had the lowest AADT volume, are significantly different at a 95-percent confidence interval from data collected for the other three principal highways. Results for paired tests between populations of concentrations of dissolved $\mathrm{Cl}, \mathrm{Na}$, and $\mathrm{Mg}$; benzyl n-butyl phthalate; and di-n-butyl phthalate for Route 119 and each of the other principal highways are not significant at the respective confidence interval. Results for paired tests for concentrations of suspended sediment were not significant for any of the principal highways other than Route 119. Only a handful of test results indicate a significant difference between populations of constituent concentrations among the three larger highways. Concentrations of dissolved $\mathrm{Ca}$ were significantly different for all paired tests of data from Interstate 95 . The highway-monitoring stations on Interstate 95 were located in a section of highway designated as a low-salt area because of its proximity to a major drinking-water-source area; thus, the significant difference between concentrations of $\mathrm{Ca}$ for Interstate 95 and the other highways is likely a function of the more widespread use of liquid calcium chloride for winter highway maintenance on Interstate 95.

\section{Relation of Constituents to Annual Average Daily Traffic Volume}

Although the populations of concentrations of most constituents were not significantly different among the three larger highways, the median concentrations and upper interquartile ranges for many total-recoverable metals collected from the 12 monitoring stations increased with increasing AADT volumes, indicating a positive correlation between the two variables. The frequency of detection for various organic compounds also increased with traffic volume for the four principal highways. Results for Kendal's Tau correlation coefficient and Spearman rank correlation coefficient tests for all highways indicate that correlations between the median concentrations of total $\mathrm{N}$, total $\mathrm{P}$, all total-recoverable metals, benzo $[a]$ anthracene, benzo $[b]$ fluoranthene, fluoranthene, and pyrene and AADT volumes are significantly different at a 95-percent confidence interval. Spearman rank correlation coefficient test results for benzo $[a]$ anthracene and benzo[b]fluoranthene are not significant at a 95 -percent confidence interval; however, correlations between the median concentrations of these constituents and the AADT volumes are significantly different at slightly lower confidence intervals. Test results for concentrations of dissolved $\mathrm{Cl}, \mathrm{Na}, \mathrm{Ca}$, $\mathrm{Mg}, \mathrm{K}$, and $\mathrm{SO}_{4}$; benzo[a]pyrene; Bis(2-ethylhexyl) phthalate; chrysene; di-n-octyl phthalate; and suspended sediment are not significant at confidence intervals greater than 89 percent for either test; therefore, AADT volumes may be a poor pre- dictor for concentrations of these constituents in the absence of additional data.

\section{Highway Winter Maintenance Materials and Data Seasonality}

Concentrations of $\mathrm{Ca}, \mathrm{Cl}, \mathrm{Na}$, and $\mathrm{SO}_{4}$, which are the major constituents of road salt, were estimated using the adjusted superposition technique over the full range of flow-weighted measurements of specific conductance for all available data, including snowmelt events, collected at 11 highway-monitoring stations. These 1,381 estimated concentrations provide a nearly order of magnitude increase in data density over water-sample data collected during this study. The estimated data from this study indicate that less than about 2 percent of the event-mean concentrations of $\mathrm{Cl}$ exceed $10,000 \mathrm{mg} / \mathrm{L}$, and about 20 percent of the event-mean concentrations exceed $230 \mathrm{mg} / \mathrm{L}$ (the USEPA freshwater aquatic life criteria).

Concentrations of nearly all constituents measured in samples of highway runoff in this study increased substantially in composite samples collected during the winter months compared to the concentrations in non-winter composite samples. Average concentrations of total P, total-recoverable metals, and suspended sediment in samples of highway runoff collected from the principal highways during the winter were about 3 to 11 times greater than the average concentrations in samples of non-winter runoff. Changes in ambient temperature, differences in driving methods, snow removal operations, and the presence of snow embankments along the highways potentially affect winter concentrations of metals and organic compounds measured in this study. Results of the single-tail Mann-Whitney test indicate that the concentrations of nearly all constituents measured in composite samples collected during the winter were significantly higher at a 99 -percent confidence interval than the concentrations of constituents measured in composite samples collected during the nonwinter months. The use of deicing compounds, which contain trace amounts of $\mathrm{N}$ and total-recoverable metals, does not fully explain the significant differences observed between winter and non-winter concentrations of each of the constituents. Ratios for nitrate and total-recoverable metals associated with road salt and calcium chloride to $\mathrm{Cl}$ are estimated to account for only a small fraction of the increase in overall concentrations from non-winter levels. However, many of the same constituents were measured in samples of winter maintenance sands, and although the concentrations of these constituents in the sand were small, the amount of sand applied to the highways during the winter increased the concentrations of suspended sediment by as much as an order of magnitude. The contribution of $\mathrm{P}$ and total-recoverable metals from the application of maintenance sand was estimated on the basis of the average increase in the concentration of suspended sediment during winter storms and on the basis of the average concentrations of $\mathrm{P}$ and total-recoverable metals in samples of 
highway-maintenance sand. Data on concentrations of several elements estimated on the basis of stormwater EMCs in samples collected on Interstate 495 and highway-maintenance sand indicate that highway-maintenance sand accounts for about $94,7,38,53,15,9$, and 2 percent of the increase in the winter concentrations of $\mathrm{P}, \mathrm{Cu}, \mathrm{Fe}, \mathrm{Mn}, \mathrm{Ni}, \mathrm{Pb}$, and $\mathrm{Zn}$, respectively. The increase in the difference between winter and non-winter concentrations of these constituents is likely greater for smaller highways, such as Route 119, because such highways have similar levels of winter maintenance and lower non-winter stormwater concentrations of the same constituents. Other winter conditions have the potential to increase concentrations of many constituents in runoff. Low ambient temperatures can affect volatilization rates for SVOCs and increase engine emission rates. Poor winter driving conditions affect vehicle operations and can increase the rate of wear for vehicle components as well as the highway surface, and snow banks can entrain large amounts of highway-related particles near the shoulder that subsequently can wash onto the highway surface.

\section{Comparison of Historical Data and Concurrent Data Sets}

Comparisons of data collected during this study with data in other published data sets can provide useful information for identifying compositional differences and trends in concentrations of highway-related constituents in highway runoff. In this study, the median concentrations of dissolved $\mathrm{Cl}$, total $\mathrm{N}$, and total-recoverable $\mathrm{P}, \mathrm{Cd}, \mathrm{Cr}, \mathrm{Cu}, \mathrm{Fe}, \mathrm{Pb}$, and $\mathrm{Zn}$ in samples collected from highway sites with AADT volumes of 30,000 to 85,000 vehicles (Interstate 190, Interstate 195, Interstate 495, and Route 2) were compared to median concentrations in other published data sets containing data collected from highways of similar AADT volume. With the exception of dissolved $\mathrm{Cl}$, the median concentrations of nutrients and total-recoverable metals in this study were much lower than the respective median concentrations in the historical data collected by the FHWA from 1976 to 1984. These data indicate that concentrations of total P and many total-recoverable metals in highway runoff, particularly $\mathrm{Cd}$ and $\mathrm{Pb}$, are substantially lower than the historical concentrations from the 1970s and 1980s, despite the fact that total vehicle miles have increased. Favorable comparisons with more recent studies indicate that some concentration data collected in other states could be used to supplement the data collected in this study.

\section{Sources of Highway-Runoff Constituents}

Identification of individual sources of specific constituents is difficult because many highway-related constituents coexist in a wide variety of both natural and anthropogenic materials deposited on highways. The proportions of most highway constituents attributable to likely sources were estimated from ratios of certain $\mathrm{PAH}$ compounds and from ratios of the dominant particulate-associated PAHs to selected elements. For example, the median ratios for all concentrations of $\mathrm{An} /(\mathrm{An}+\mathrm{Phe})$ in composites of runoff from each highway in this study are synonymous with the ratios reported for gasoline-engine emissions. In contrast, the median ratios for winter concentrations of $\mathrm{An} /(\mathrm{An}+\mathrm{Phe})$ in composites of highway runoff during, or shortly after, winter plowing operations of the principal highways decreased, likely indicating that the dominant source of the PAHs shifted from gasolineengine emissions to asphalt wear. The median ratios for concentrations of $\mathrm{Fl} /(\mathrm{Fl}+\mathrm{Py})$ and $\mathrm{Ba} /(\mathrm{Ba}+\mathrm{Chr})$ in composites of highway runoff in this study also were similar to ratios for emissions from gasoline and diesel engines.

The median concentrations of total $\mathrm{P}$ and most trace elements measured in composite samples of highway runoff from each principal highway were compared to estimated concentrations expected from automobile emissions. Concentrations of the above constituents in exhaust were estimated on the basis of the average ratio of the reported emission rates for each constituent to the emission rates for chrysene and indeno[1,2,3-cd]pyrene. Assuming the dispersion of both trace metals and PAHs associated with exhaust particles is similar, exhaust emissions account for only a small fraction of metals measured in samples of highway runoff. Ratios of median EMCs of $\mathrm{P}$ and total-recoverable $\mathrm{Cu}$, and $\mathrm{Fe}$ to average metal concentrations associated with concentrations of chrysene and indeno[1,2,3-cd] pyrene indicate that less than 3 percent of the constituents are accounted for by exhaust emissions from gasoline engines. Similar ratios for median concentrations for total-recoverable $\mathrm{Cr}, \mathrm{Mn}, \mathrm{Ni}, \mathrm{Pb}$, and $\mathrm{Zn}$ indicate that about 4 to 13 percent of the respective constituents are accounted for by exhaust emissions from gasoline engines.

Atmospheric deposition also can affect the quality of highway runoff. Concentrations of major ions in precipitation do not constitute a large fraction of the major ions in samples of highway runoff in Massachusetts, except for $\mathrm{Mg}$ and $\mathrm{SO}_{4}$. Concentrations of $\mathrm{Mg}$ and $\mathrm{SO}_{4}$ in precipitation account for about 10 and 21 percent, respectively, of the mean concentrations in non-winter highway runoff for Interstate 95, and concentrations of $\mathrm{NH}_{4}$ and $\mathrm{NO}_{3}$ in precipitation account for about 55 percent of the mean concentrations of total $\mathrm{N}$ in all samples collected on Interstate 95 in this study. Concentrations of total $\mathrm{N}$ in precipitation potentially constitute a greater percentage of the concentrations in highway runoff from the other principal highways because the concentrations of total $\mathrm{N}$ in samples of highway runoff from those sites were lower.

Local soils and highway-berm soil can contribute much of the suspended sediment entrained in highway runoff. As discussed earlier, adjacent soils deposited on the surface of the highway can affect the composition of, and concentrations of many elements in, highway runoff. Contributions of many of the total-recoverable metals in background soils were estimated on the basis of the median concentration of suspended sediment in composite samples of highway runoff from the principal highways along with median concentrations of the same total-recoverable metals in samples of local 
soil collected near the primary highway-monitoring stations. These estimates indicate that background soils account for on average about 37 percent of the median $\mathrm{P}$ concentration, 100 percent of the median $\mathrm{Cr}$ concentration, 4 percent of the median $\mathrm{Cu}$ concentration, 53 percent of the median Fe concentration, 54 percent of the median Mn concentration, 15 percent of the median Ni concentration, 44 percent of the median $\mathrm{Pb}$ concentration, and 2 percent of the median $\mathrm{Zn}$ concentration in samples of runoff from the principal highways. The contributions of the elements to concentrations in whole water samples are likely conservative, excluding $\mathrm{Cr}$ which is overestimated, because the values were estimated without regard to the distribution of the particle sizes for background soils and total concentrations of suspended sediment. The concentrations of many elements in berm materials composed of native soils, winter maintenance materials, and other anthropogenic particles also can affect the quality of highway runoff. Data from this study indicate that the distributions for concentrations of $\mathrm{Cu}, \mathrm{Fe}, \mathrm{Mn}, \mathrm{Ni}, \mathrm{P}, \mathrm{Pb}$, and $\mathrm{Zn}$ in highway-berm soils and for normalized concentrations of these constituents in suspended sediment often overlap. These data indicate that erosion or mechanical transport of highway-berm soils onto the paved surface could be a large source of $\mathrm{P}$ and several total-recoverable metals in samples of highway runoff.

The mass of $\mathrm{Cu}, \mathrm{Zn}$, and phthalate compounds measured in samples of highway runoff is only partially, if at all, accounted for by the application of deicing compounds, exhaust emissions, soils, and berm materials. Tire and brake wear appears to be the dominant source of these constituents on the basis of the composition and wear rates for these items reported elsewhere in the literature.

For 15 samples of highway runoff collected from the principal highways and from Interstate 93, an additional 62 organic compounds that include nonionic surfactants, caffeine, plant sterols, flame retardants, trace compounds associated with fecal bacteria, wood preservatives, gasoline and diesel fuels, antioxidants, and personal care products were included in the sample analysis. For these 15 samples, 45 of the 62 compounds were detected at least once, and 23 compounds were detected at concentrations greater than the laboratory LTMDL. Anthraquinone, bisphenol A, camphor, and cholesterol were the most frequently detected compounds. Although most compounds were detected less frequently in samples of highway runoff collected on Route 119 (the most rural highway with the lowest AADT volume) than in other samples, the frequency of detection generally was similar among highways. About one-third of the compounds that were detected are likely attributable to fuels, lubricants, antifreeze, windshield fluids, chemical treatments of the engine compartments, finish coats, panels, and other vehicle components. Other compounds detected in samples of highway runoff indicate the presence of plant materials, fecal bacteria, and potential leachates from highway litter.

\section{Suspended Sediment as a Surrogate for Highway-Runoff Constituents}

Suspended sediment can be a major transport mechanism for many constituents in highway runoff. Data collected in this study indicate that highway suspended sediment contains relatively high concentrations of $\mathrm{P}$, trace elements, PAHs, and phthalates. These analyses also indicate that, in many cases, the fine fraction of sediment less than $0.063 \mathrm{~mm}$ in diameter often is more enriched in these constituents than the coarser sediment fractions. Concentrations of suspended sediment for three particle-size ranges were examined as potential surrogates for concentrations of sediment-affiliated constituents measured in samples of highway runoff.

Planning-level estimates for concentrations of total P and total-recoverable metals were made directly from the constituent concentrations in samples of sieved suspended sediment and from the concentrations of the three particle-size grades of suspended sediment in samples of highway runoff. Comparisons of these estimated $\mathrm{P}$ and total-recoverable metal concentrations with concentrations in whole-water samples indicate that it is possible to estimate reasonable planning-level loads for many constituents discharged from highways. For many applications, the average concentration for gradated concentrations of suspended sediment measured in composite samples of highway runoff in this study may be used in the absence of site-specific data because tests between most populations of concentrations of suspended sediment among the highways in this study, and tests between median concentrations of suspended sediment with AADT volume were not significantly different. Use of this method could have broad application and may provide useful information for the selection of BMP and for stormwater-monitoring applications.

\section{Highway-Runoff Database}

Data from this study are stored in Version 1.0.0a of the HRDB database, which is presented in the appendix of this report. The HRDB warehouse was created to document data and information from available highway-runoff monitoring studies. Version 1.0.0a of the HRDB database also contains data from an earlier Massachusetts highway-runoff study, and other highway-runoff studies conducted across the Nation since 1978. The HRDB application, which is the graphical user interface and associated computer code, can be used to facilitate estimation of statistical properties of runoff coefficients, runoff-quality statistics, and relations between waterquality variables in highway runoff from the available data. Thus, the HRDB application can serve as a data preprocessor for the Stochastic Empirical Loading and Dilution Model, which is designed to facilitate the estimation of runoff flows, concentrations of constituents, and loads of constituents from highways and in receiving waters at unmonitored sites on the basis of site characteristics. 


\section{Data Application}

In general, concentrations of many total-recoverable metals, PAHs, and phthalate compounds increase with increasing AADT volume and amount of urbanization or surrounding impervious area. Concentrations of all constituents measured in samples of highway runoff in this study increased significantly during the winter months. Increases in concentrations of total $\mathrm{P}$ and many total-recoverable metals in this study were specifically attributed to maintenance sands applied to the highways. Therefore, information on use and application rate for maintenance sands may be important to include in future studies of the quality of highway runoff. The geographic location of a given highway under study is important because the level of highway maintenance during the winter is different across Massachusetts because the climate away from the coast generally is cooler, and the highway grades tend to be steeper. Ancillary data, collected as part of this study, also indicate that soil chemistry can affect the base concentration of total $\mathrm{P}$ and many total-recoverable metals in samples of highway runoff. As a result, the quality of highway runoff can differ within the natural features of the State. Mobilization of these soils, either from vehicles that track materials onto the road surface or from erosion of adjacent highway shoulders, can cause large increases in constituent concentrations. The data presented in this report represent the typical quality of highway runoff discharged through catch basins for eight Massachusetts highways over a large range of AADT volumes. Concentrations in highway runoff for the constituents reported in this study may be different for other highways within the State that have different levels of winter maintenance activity, or additional BMPs within the drainage system, or that have site characteristics that were previously identified to affect runoff quality.

\section{Acknowledgments}

The author expresses his gratitude to Henry L. Barbaro of the Massachusetts DOT, Environmental Services Division; Larry Salvatore and Mark J. Moore, Massachusetts DOT District 1; Paul Hoey and Ann Sullivan, Massachusetts DOT District 3; Brett Loosian, Massachusetts DOT District 4; and Roy Fierra, Massachusetts DOT District 5 for providing logistical support, including site selection, highway-site maintenance and repair, and periodic traffic control.

\section{References Cited}

Agency for Toxic Substances and Disease Registry (ATSDR), 2005, Toxicological profile for bromoform and chlorodibromomethane: Atlanta, GA, U.S. Department of Health and Human Services, Public Health Service, accessed on August 06, 2008, at http://www.atsdr.cdc.gov/toxprofiles/tp130c1-b.pdf.

American Public Health Association, American Water Works Association, and Water Pollution Control Federation, 1995, Standard methods for the examination of water and wastewater (19th ed.): Washington, D.C., American Public Health Association, variously paged.

Anderson, C.W., 2004, Turbidity, in Wilde, F.D., and Radtke, D.B., eds., Field measurements ( $2 \mathrm{~d}$ ed.): U.S. Geological Survey Techniques of Water-Resources Investigations, book 9, chap. A6.7, 64 p., accessed June 16, 2008, at http://water. usgs.gov/owq/FieldManual/Chapter6/6.7_contents.html.

ASTM, 2002, Standard test method for determining sediment concentration in water samples: ASTM Designation D 3977-97, p. 395-400.

Barrett, M.E., Malina, J.F., Jr., Charbeneau, R.J., and Ward, G.H., 1995, Characterization of highway runoff in the Austin, Texas area: Austin, TX, University of Texas at Austin, Bureau of Engineering Research, Center for Research in Water Resources Report CRWR 263, 35 p.

Barrett, M.E., Malina, J.F., Jr., Charbeneau, R.J., and Ward, G.H., 1996, Characterization of highway runoff in the Austin, Texas area: Austin, TX, Texas Department of Transportation Report FHWA/TX-96/1943-4, 38 p.

Benderly, A.A., 1962, Treatment of Teflon to promote bondability: Journal of Applied Polymer Science, v. 6, no. 20, p. 221-225.

Bent, G.C., Gray, J.R., Smith, K.P., and Glysson, G.D., 2001, A synopsis of technical issues for monitoring sediment in highway and urban runoff: U.S. Geological Survey OpenFile Report 00-497, $51 \mathrm{p}$.

Brandt, H.C.A., and De Groot, P.C., 2001, Aqueous leaching of polycyclic aromatic hydrocarbons from bitumen and asphalt: Water Resource, v. 35, no. 17, p. 4200-4207.

Breault, R.F., and Granato, G.E., 2000, A synopsis of technical issues for monitoring trace elements in highway and urban runoff: U.S. Geological Survey Open-File Report 00-422, $67 \mathrm{p}$. 
Breault, R.F., Smith, K.P., and Sorenson, J.R., 2005, Residential street-dirt accumulation rates and chemical composition, and removal efficiencies by mechanical- and vacuum-type sweepers, New Bedford, Massachusetts, 2003-04: U.S. Geological Survey Scientific Investigations Report 2005$5184,27 \mathrm{p}$.

Bricker, O.P., 1999, An overview of the factors involved in evaluating the geochemical effects of highway runoff on the environment: U.S. Geological Survey Open-File Report 98-630, $28 \mathrm{p}$.

Butler, D., May, R.W.O., and Ackers, J.C., 1996, Sediment transport in sewers Part 1-Background: Proceedings of the Institution of Civil Engineers-Water Maritime and Energy, v. 118, no. 2, p. 103-112.

Cadle, S.H., Mulawa, P., Groblicki, P., Laroo, C., Ragazzi, R.A., Nelson, K.., Gallagher, G., and Zielinska, B., 2001, In-use light-duty gasoline vehicle particulate matter emissions on three driving cycles: Environmental Science \& Technology, v. 35, no. 1, p. 26-32.

California Department of Transportation, Office of Environmental Engineering, 2000, Guidance manual-Stormwater monitoring protocols ( $2 \mathrm{~d}$ ed.): Sacramento, CA, California Department of Transportation Report CTSW-RT-00-005, $303 \mathrm{p}$.

California Department of Transportation, Office of Environmental Engineering, 2002, CALTRANS statewide stormwater runoff characterization study--Monitoring season 20012002 final report: Sacramento, CA, California Department of Transportation, Report CTSW-RT-02-022, 583 p.

California Department of Transportation, Office of Environmental Engineering, 2003a, Storm water monitoring and research program preliminary report of discharge characterization studies: Sacramento, CA, California Department of Transportation Report CTSW-RT-03-023, 42 p.

California Department of Transportation, Office of Environmental Engineering, 2003b, CALTRANS Tahoe highway runoff characterization and sand trap effectiveness studies 2000-03 monitoring report: Sacramento, CA, California Department of Transportation Report CTSW-RT-03-054.36.02, 895 p.

California Department of Transportation, Office of Environmental Engineering, 2003c, Storm water monitoring and data management discharge characterization study report: Sacramento, CA, California Department of Transportation Report CTSW-RT-03-065.51.42, 93 p.

California Department of Transportation, Office of Environmental Engineering, 2003d, Storm water monitoring and data management 2002-2003 annual data summary report: Sacramento, CA, California Department of Transportation Report CTSW-RT-03-069.51.42, 1859 p.
California Department of Transportation, Office of Environmental Engineering, 2004, Storm water monitoring and BMP development status report: Sacramento, CA, California Department of Transportation Report CTSW-RT-03-069.51.42, $111 \mathrm{p}$.

Capel, P.D., and Larson, S.J., 1996. Evaluation of selected information on splitting devices for water samples: U.S. Geological Survey Water-Resources Investigation Report 95-4141, 103 p.

Capel, P.D., and Nacionales, F., 1995, Precision of a splitting device for water samples: U.S. Geological Survey OpenFile Report 95-293, 23 p.

CH2MHill Inc., 1998, Highway stormwater runoff study: Lansing, MI, Michigan Department of Transportation Report MDOT-MS4-91946-7, variously paged.

Childress, C.J.O., Foreman, W.T., Connor, B.F., and Maloney, T.J., 1999, New reporting procedures based on long-term method detection levels and some considerations for interpretations of water-quality data provided by the U.S. Geological Survey National Water Quality Laboratory: U.S. Geological Survey Open-File Report 99-193, p. 19.

Church, P.E., Armstrong, D.S., Granato, G.E., Stone, V.J., Smith, K.P., and Provencher, P.L., 1996, Effectiveness of highway-drainage systems in preventing contamination of ground water by road salt, Route 25, southeastern Massachusetts - Description of study area, data collection programs, and methodology: U.S. Geological Survey OpenFile Report 96-317, 72 p.

Church, P.E., Granato, G.E., and Owens, D.W., 1999, Basic requirements for collecting, documenting, and reporting precipitation and stormwater-flow measurements: U.S. Geological Survey Open-File Report 99-255, 30 p.

Colman, J.A., Rice, K.C., and Willoughby, T.C., 2001, Methodology and significance of studies of atmospheric deposition in highway runoff: U.S. Geological Survey Open-File Report 01-259, $63 \mathrm{p}$.

Councell, T.B., Suckenfield, K.U., Landa, E.R., and Callender, E., 2004, Tire-wear particles as a source of zinc to the environment: Environmental Science \& Technology, v. 38, no. 15 , p. 4206-4214.

Davenport, T.E., 1990, Urban targeting and BMP selection project, in Jennings, M.E., ed., Symposium prodeedings on urban hydrology, Denver, Colo., November 4-8, 1990: American Water Resource Association, p. 273-281. 
Dickhut, R.M., Canuel, E.A., Gustafson, K.E., Liu, K., Arzayus, K.M., Walker, S.E., Edgecombe, G., Gaylor, M.O., and MacDonald, E.H., 2000, Automotive sources of carcinogenic polycyclic aromatic hydrocarbons associated with particulate matter in the Chesapeake Bay region: Environmental Science \& Technology, v. 34, p. 4635-4640.

Driscoll, E.D., Shelley, P.E., and Strecker, E.W., 1990a, Pollutant loadings and impacts from highway stormwater runoff volume IV--Research report data appendix: Federal Highway Administration Final Report FHWA-RD-88-009, 143 p.

Driscoll, E.D., Shelley, P.E., and Strecker, E.W., 1990b, Pollutant loadings and impacts from highway stormwater runoff, v. III-Analytical investigation and research report: Washington, D.C., Federal Highway Administration Final Report FHWA-RD-88-008, $160 \mathrm{p}$.

Driver, N.E., and Tasker, G.D., 1990, Techniques for estimation of storm-runoff loads, volumes and selected constituent concentrations in urban watersheds in the United States: U.S. Geological Survey Water-Supply Paper 2363, 44 p.

Edwards, T.K., and Glysson, G.D., 1999, Field methods for measurement of fluvial sediment: U.S. Geological Survey Techniques of Water-Resources Investigations, book 3 , chap. C2, 89 p.

Executive Office of Transportation Massachusetts Highway Department, 2007, Traffic volume counts: accessed August 10, 2007, at http://www.mhd.state.ma.us/default. asp?pgid=content/traffic $01 \&$ sid=about.

Fishman, M.J., ed., 1993, Methods of analysis by the U.S. Geological Survey National Water Quality LaboratoryDetermination of inorganic and organic constituents in water and fluvial sediments: U.S. Geological Survey OpenFile Report 93-125, 217 p.

Fishman, M.J., and Friedman, L.C., 1989, Methods for determination of inorganic substances in water and fluvial sediments: U.S. Geological Survey Techniques of WaterResources Investigations, book 5, chap. A1, 545 p.

Forstner, U., and Wittmann, G.T.W., 1981, Metal pollution in the aquatic environment: New York, Springer-Verlag, $486 \mathrm{p}$.

Gadd, J., and Kennedy, P., 2003, Preliminary examination of organic compounds present in tyres, brake pads and road bitumen in New Zealand: Prepared for the Ministry of Transport by Kingett Mitchell Limited, 23 p.

Garbarino, J.R., and Hoffman, G.L., 1999, Methods of analysis by the U.S. Geological Survey National Water Quality Laboratory-Comparison of a nitric acid in-bottle digestion procedure to other whole-water digestion procedures: U.S. Geological Survey Open-File Report 99-094, 21 p.
Garbarino, J.R., Kanagy, L.K., and Cree, M.E., 2006, Determination of elements in natural-water, biota, sediment, and soil samples using collision/reaction cell inductively coupled plasma-mass spectrometry: U.S. Geological Survey Techniques and Methods, book 5, sec. B, chap. 1, 88 p.

Garbarino, J.R., and Struzeski, T.M., 1998, Methods of analysis by the USGS National Water Quality LaboratoryDetermination of elements in whole-water digests using inductively coupled plasma-optical emission spectrometry and inductively coupled plasma-mass spectrometry: U.S. Geological Survey Open-File Report 98-165, 101 p.

Garg, B.D., Cale, S.H., Mulawa, P.A., and Groblicki, P.J., 2000, Brake wear particulate matter emissions: Environmental Science \& Technology, v. 34, p. 4463-4469.

Gay, F.B., and Melching, C.S., 1995, Relation of precipitation quality to storm type, and constituent loads in Massachusetts, 1983-85: U.S. Geological Survey Water-Resources Investigations Report 94-4224, 82 p.

Glenn, D.W., III, and Sansalone, J.J., 2002, Accretion and partitioning of heavy metals associated with snow exposed to urban traffic and winter storm maintenance activities: Journal of Environmental Engineering, v. 128, no. 2, p. 151-166.

Granato, G.E., 1996, Deicing chemicals as a source of constituents in highway runoff: Washington, D.C., Transportation Research Board, National Research Council, Transportation Research Record 1533, p. 50-58.

Granato, G.E., 2006, Kendall-Theil Robust Line (KTRLineversion 1.0) - A visual basic program for calculating and graphing robust nonparametric estimates of linear-regression coefficients between two continuous variables: Techniques and Methods of the U.S. Geological Survey, book 4, chap. A7, $31 \mathrm{p}$.

Granato, G.E., 2007, Stochastic Empirical Loading and Dilution Model (SELDM): accessed on April, 16, 2009, at http://ma.water.usgs.gov/FHWA/SELDM.htm.

Granato, G.E., 2009, Methods for development of planninglevel estimates of stormflow at unmonitored stream sites in the conterminous United States: Washington, D.C., U.S. Department of Transportation, Federal Highway Administration, Office of Natural and Human Evnironment, FHWAHEP-09-005, CD-ROM.

Granato, G.E., Bank, F.G., and Cazenas, P.A., 1998, Data quality objectives and criteria for basic information, acceptable uncertainty, and quality-assurance and quality-control documentation: U.S. Geological Survey Open-File Report 98-394, 17 p. 
Granato, G.E., and Cazenas, P.A., 2009, Highway-runoff database (HRDB Version 1.0) -A data warehouse and preprocessor for the stochastic empirical loading and dilution model: Washington, D.C., U.S. Department of Transportation, Federal Highway Administration FHWA-HEP-09-004, $57 \mathrm{p}$.

Granato, G.E., and Smith, K.P., 1999, Estimating concentrations of road-salt constituents in highway runoff from measurements of specific conductance: U.S. Geological Survey Water-Resources Investigations Report 99-4077, 22 p.

Griffith, G.E., Omernik, J.M., Pierson, S.M., and Kiilsgaard, C.W., 1999, Level III and IV Ecoregions of Massachusetts, Rhode Island, and Connecticut: U.S. Environmental Protection Agency accessed May 5, 2005, at ftp://ftp.epa.gov/wed/ ecoregions/ma_ct_ri/ma_ct_ri_eco.pdf.

Gupta, M.K., Agnew, R.W., and Kobriger, N.P., 1981, Constituents of highway runoff, v. I, State-of-the-art report: Federal Highway Administration Report no. FHWA/ RD-81/042, $111 \mathrm{p}$.

Guy, H.P., 1969, Laboratory theory and methods for sediment analysis: U.S. Geological Survey Techniques of Water-Resources Investigations, book 5, chap. C1, 58 p.

Hardee, Jack, Miller, R.A., and Mattraw, H.C., Jr., 1978, Stormwater runoff data for a highway area, Broward County, Florida: U.S. Geological Survey Open-File Report 78-612, $180 \mathrm{p}$.

Harned, D.A., 1988, Effects of highway runoff on streamflow and water quality in the Sevenmile Creek Basin, a rural area in the Piedmont Province of North Carolina, July 1981 to July 1982: U.S. Geological Survey Water-Supply Paper 2329, $105 \mathrm{p}$.

Harned, H.S., and Owen, B.B., 1958, The physical chemistry of electrolytic solutions (3d ed.): New York, Reinhold Publishing Corporation, $803 \mathrm{p}$.

Hem, J.D., 1982, Conductance-A collective measure of dissolved ions, in Minear, R.A., and Keith, L.A., eds., Water Analysis, v. 1, Inorganic species, Part 1: New York, Academic Press, p. 137-161.Helsel, D.R., 2005, Nondetects and data analysis-Statistics for censored environmental data: New York, John Wiley and Sons, $250 \mathrm{p}$.

Hem, J.D., 1992, Study and interpretation of the chemical characteristics of natural water ( $3 \mathrm{~d}$ ed): U.S. Geological Survey Water-Supply Paper 2254, 263 p.

Helsel, D.R., 2005, Nondetects and data analysis-Statistics for censored environmental data: New York, John Wiley and Sons, $250 \mathrm{p}$.
Helsel, D.R., and Hirsch, R.M., 2002, Statistical methods in water resources-Hydrologic analysis and interpretation: U.S. Geological Survey Techniques of Water-Resources Investigations, chap. A3, book 4, $510 \mathrm{p}$.

Hjortenkrans, S.T.D., Bergbäck, G.B., and Häggerud, A.V., 2007, Metal emissions from brake linings and tires-Case studies of Stockholm, Sweden 1995/1998 and 2005: Environmental Science \& Technology, v. 41, no. 15, p. 5224-5230.

Hoffman, G.L., Fishman, M.J., and Garbarino, J.R., 1996, Methods of analysis by the U.S. Geological Survey National Water Quality Laboratory-In-bottle acid digestion of whole-water samples: U.S. Geological Survey Open-File Report 96-225, 28 p.

Horowitz, A.J., 1991, A primer on sediment-trace element chemistry, (2d ed.): Ann Arbor, Mich., Lewis Publishing Company, $136 \mathrm{p}$.

Horowitz, A.J., and Elrick, K.A., 1987, The relation of stream sediment surface area, grain size, and composition to trace element chemistry: Applied Geochemistry, v. 2, p. $437-451$.

Hulskotte, J.H.J., Schaap, M., and Visschedijk, A.J.H., 2006, Brake wear from vehicles as an important source of diffuse copper pollution, in $10^{\text {th }}$ International specialized conference on diffuse pollution and sustainable basin management, September 18-22, 2006: International Water Association, 10 p., accessed September 16, 2008, at http://www.tno.nl/downloads/W_211_Jan_Hulskotte.pdf.

Jaradat, Q.M., and Momani, K.A., 1999, Contamination of roadside soil, plants, and air with heavy metals in Jordan, A comparative study: Turkish Journal of Chemistry, v. 23, p. 209-220.

Kayhanian, M., Singh, A., Suverkropp, C., and Borroum, S., 2003, Impact of annual average daily traffic on highway runoff pollutant concentrations: Journal of Environmental Engineering, v. 129, no. 11, p. 975-990.

King County and SPU, 2004, King County and Seattle Public Utilities source control program for the Lower Duwamish Waterway, June 2004 Progress Report: King County Industrial Waste and Seattle Public Utilities, accessed January 16, 2008, at http://dnr.metrokc.gov/wlr/indwaste/docs/ LDW-SC-June04/progress_report_06-04_no-figs.pdf.

Kuusimaki, L., 2003, Analysis of particle and vapour phase PAHs from the personal air samples of bus garage workers exposed to diesel exhaust: Annals of Occupational Hygiene, v. 47, no. 5, p. 389-398. 
Lager, J.A., Smith, W.G., and Tchobanoglous, G., 1977, Catchbasin technology overview and assessment: U.S. Environmental Protection Agency Final Report, EPA-600/2-77-051, 128 p.

Latimer J.S., 1997, The significance of atmospheric deposition as a source of PCBs and PAHs to Narragansett Bay, in Baker, J.E., and Baker, J.E.S., 1997, Atmospheric deposition of contaminants to the Great Lakes and Coastal Waters: SETAC Press, p. 227-243.

Legates D.R., and McCabe, G.J., Jr., 1999, Evaluating the use of "goodness-of fit" measures in hydrologic and hydroclimatic model validation: Water Resources Research, v. 35, no. 1 , p. 233-241.

Legge, A.H., 1990, Sulphur and nitrogen in the atmosphere, in Legge, A.H., and Krupa, S.V., Acidic deposition-Sulphur and nitrogen oxides: Chelsea, Mich., Lewis Publishers, $659 \mathrm{p}$.

Lima, Ana Lúcia C., Farrington, J.W. and Reddy, C.M., 2005, Combustion-derived polycyclic aromatic hydrocarbons in the environment-A Review: Environmental Forensics, v. 6 , no. 2 , p. 109-131.

Lopes, T.J., and Dionne, S.G., 1998, A review of semivolatile and volatile organic compounds in highway runoff and urban stormwater: U.S. Geological Survey Open-File Report 98-409, 67 p.

Marr, L.C., Kirchstetter, T.W., Harly, R.A., Miguel, A.H., Hering, S.V., and Hammond, K.S., 1999, Characterization of polycyclic aromatic hydrocarbons in motor vehicle fuels and exhaust emissions: Environmental Science \& Technology, v. 33, p. 3091-3099.

Massachusetts Department of Transportation, 2006, Snow and ice control generic environmental impact report: accessed January 10, 2010, at http://www.mhd.state.ma.us/ downloads/projDev/geir06.pdf.

Massachusetts Department of Transportation, 2007, Traffic volume counts: accessed November 16, 2009, at http://www.mhd.state.ma.us//default.asp?pgid=content/ traffic01\&sid=about.

Massachusetts Department of Transportation, 2008, Policy for reduced salt areas in the vicinity of water supplies: accessed January 10, 2010, at http://www.mhd.state.ma.us/downloads/snowIce/saltpolicy/ salt_policy.pdf.

McGill, R., Tukey, J.W., and Larsen, W.A., 1978, Variations of box plots: The American Statistician, v. 32, no. 1, p 12-16.
Miguel, A.H., Kirchstetter, T.W., Harley, R.A., and Hering, S.V., 1998, On-road emissions of particulate polycyclic aromatic hydrocarbons and black carbon from gasoline and diesel vehicles: Environmental Science \& Technology, v. 32 , p. $450-455$.

Miller, R.L., Bradford, W.L., and Peters, N.E., 1988, Specific conductance-Theoretical considerations and application to analytical quality control: U.S. Geological Survey WaterSupply Paper 2311, 16 p.

Mueller, D.K., 1998, Quality of nutrient data from streams and ground water sampled during 1993-95-National WaterQuality Assessment Program: U.S. Geological Survey Open-File Report 98-276, 25 p.

National Atmospheric Deposition Program, 2008, 2007 Isopleth Maps: accessed August 26, 2007, at http://nadp.sws.uiuc.edu/isopleths/maps2007/.

National Atmospheric Deposition Program, NADP/NTN monitoring location MA13, 2008, 2006 annual \& seasonal data summary for Site MA13: accessed August 26, 2007, at http://nadp.sws.uiuc.edu/sites/siteinfo. asp?net=NTN\&id=MA13.

National Institute of Standards and Technology, 2003, Certificate of analysis for standard reference material ${ }^{\circledR} 2710$, Montana soil, highly elevated trace element concentrations: accessed July 24, 2008, at https://srmors.nist.gov/certificates $/ 2710$.pdf?CFID $=16331926 \&$ CFTOKEN $=$ dc6f3b $23 \mathrm{bd}$ c39a5b-556E38E8-D77F-D549-6D926FB94DE8B3DA\&js essionid=b43098afc34e39184f6b.

Nicholson, K.W., and Branson, J.R., 1990, Factors affecting resuspension by road traffic: The Science of the Total Environment, v. 93, p. 349-358.

Patton, C.J., and Kryskalla, J.R., 2003, Methods of analysis by the U.S. Geological Survey National Water Quality Laboratory-Evaluation of alkaline persulfate digestion as an alternative to Kjeldahl digestion for determination of total and dissolved nitrogen and phosphorus in water: U.S. Geological Survey Water-Resources Investigations Report 03-4174, 33 p.

Paxéus, N., Robinson, P., and Balmér, P., 1992, Study of organic pollutants in municipal wastewater in Göteborg, Sweden: Water Science Technology, v. 25, no. 11, p. 245-256.

Radtke, D.B., Davis, J.V., and Wilde, F.D., eds, 2005, Specific electrical conductance (Ver. 1.2): U.S. Geological Survey Techniques of Water-Resources Investigations, book 9, chap. A6, section 6.3 revised 2005. 
Reinosdotter, K., Viklander, M, and Maimqvist, P.A., 2006, Polycyclic aromatic hydrocarbons and metals in snow along a highway: Water Science and Technology, v. 54, no. 6-7, p. 195-203.

Ritter, D.F., Kochel, R.C., and Miller, J.R., 1995, Process geomorphology (3rd ed.): Dubuque, IA, Wm. C. Brown, 545 p.

Rogge, W.F., Hildemann, L.M., Mazurek, M.A., and Cass, G.R., 1993, Sources of fine organic aerosol. 2. noncatalyst and catalyst-equipped automobiles and heavy-duty diesel trucks: Environmental Science \& Technology, v. 27, p. 636-651.

Salomons, W., and Forstner, U., 1984, Metals in the hydrocycle: New York, Springer-Verlag, $349 \mathrm{p}$.

Sanders, P.G., Xu, N., Dalka, T.M., and Maricq, M., 2003, Airborne brake wear debris, size distributions, composition, and a comparison of dynamometer and vehicle tests: Environmental Science \& Technology, v. 37, p. 4060-4069.

Sansalone, J.J., and Buchberger, S.G., 1997, Partitioning and first flush of metals in urban roadway storm water: Journal of Environmental Engineering, v. 123, no. 2, p. 134-143.

Sansalone, J.J., Koran, J.M., Smithson, J.A., and Buchberger, S.G., 1997, Physical characteristics of urban roadway solids transported during rain events: Journal of Environmental Engineering, v. 124 , no. 5 , p. $427-440$.

SAS Institute, 1998, Statview Reference, 2nd ed.: Cary, N.C., Sas Institute, Inc., 528 p.

Selbig, W.R., Bannerman, Roger, and Bowman, George, 2007, Improving the accuracy of sediment-associated constituent concentrations in whole stormwater samples by wet-sieving: Journal of Environmental Quality, v. 36, no. 1, 7 p.

Shreve, E.A., and Downs, A.C., 2005, Quality-assurance plan for the analysis of fluvial sediment by the U.S. Geological Survey Kentucky Water Science Center Sediment Laboratory: U.S. Geological Survey Open-File Report 2005-1230, $28 \mathrm{p}$.

Smedley, S.I., 1980, The interpretation of ionic conductivity in liquids: New York, Plenum Press, 195 p.

Smith, K.P., 2002, Effectiveness of three best management practices for highway-runoff quality along the Southeast Expressway, Boston Massachusetts: U.S. Geological Survey Water-Resource Investigation Report 02-4059, 62 p.

Smith, K.P., 2005, Hydrologic, water-quality, bed-sediment, soil-chemistry, and statistical summaries of data for the Cambridge, Massachusetts, drinking-water source area, water year 2004: U.S. Geological Survey Open-File Report 2005-1383, $110 \mathrm{p}$.
Spangberg, A., and Niemczynowicz, J., 1992, High resolution measurements of pollution wash-off from an asphalt surface: Nordic Hydrology, v. 23, p. 245-256.

Strandell, M., Zakrisson, S., Alsberg, T., Westerholm, R.,Winquist, L., and Rannug, U., 1994, Chemical analysis and biological testing of a polar fraction of ambient air, diesel engine, and gasoline engine particulate extracts, environmental health perspectives, v. 102, Supplement 4: Risk Assessment of Urban Air: Emissions, Exposure, Risk Identification, and Risk Quantitation, p. 85-92.

Taylor Associates, Inc., 2002a, SR 167 Ecology embankment water quality monitoring project final report: Olympia, WA, Washington State Department of Transportation, $28 \mathrm{p}$.

Taylor Associates, Inc., 2002b, SR 405 Vortechs water quality monitoring project final report: Olympia, WA, Washington State Department of Transportation, $267 \mathrm{p}$.

Tetra Tech, Inc., 2003, Washington State Department of Transportation stormwater characterization/water quality management effectiveness monitoring 2003/2005 sampling season (rev. October 2003): Olympia, Washington, Washington State Department of Transportation, $31 \mathrm{p}$.

Tetra Tech, Inc., 2004, Washington State Department of Transportation stormwater characterization/water quality management effectiveness monitoring, addendum for 2004/2005 sampling season: Olympia, Washington, Washington State Department of Transportation, $16 \mathrm{p}$.

Tetra Tech, Inc. and Envirovision Corporation, 2002, National pollutant discharge elimination system Washington State Department of Transportation stormwater characterization monitoring quality assurance project plan 2001/2003 Biennium: Olympia, Washington, Washington State Department of Transportation, $19 \mathrm{p}$.

Thomson, N.R., McBean, E.A., Snodgrass, W., and Mostrenko, I., 1997, Sample size needs for characterizing pollutant concentrations in highway runoff: Journal of Environmental Engineering, v. 123, no. 10, p. 1061-1065.

Thompson, M., and Walsh, J.N., 1989, Handbook of inductively coupled plasma spectrometry, $(2 \mathrm{~d}$ ed.): New York, Chapman and Hall, p. 1-15, 238-269.

Transportation Research Board, 1997, Environmental research needs in transportation: Transportation Research Board, National Research Council, Washington, D.C., Circular, no. $469,98 \mathrm{p}$.

U.S. Department of Transportation Federal Highway Administration, 1990, Open graded friction courses, T 5040.31: accessed June 16, 2008, at http://www.fhwa.dot.gov/ legsregs/directives/techadvs/t504031.htm. 
U.S. Environmental Protection Agency, 1986, Quality Criteria for Water 1986: U.S. Environmental Protection Agency, EPA 440/5-86-001, variously paged.

U.S. Environmental Protection Agency, 1996, Method 3050B: Acid digestion of sediments, sludges, and soils, Revision 2; accessed May 20, 2005, at http://www.epa.gov/epaoswer/ hazwaste/test/pdfs/3050b.pdf.

U.S. Environmental Protection Agency, 2002, Integrated risk information system for $d$-Limonene (CASRN 5989-27-5), accessed on August 6, 2008, at http://www.epa.gov/iris/ subst/0682.htm.

U.S. Environmental Protection Agency, 2003, Level III ecoregions of the continental Unites States: accessed November 11, 2005, at ftp://ftp.epa.gov/wed/ecoregions/us/ useco_pg.pdf.

U.S. Environmental Protection Agency, 2005, Sample holding time reevaluation, EPA/600/R-05/124, 329 p.

U.S. Environmental Protection Agency, 2009, National recommended water quality criteria: accessed November 17 , 2009, at http://www.epa.gov/waterscience/criteria/wqctable/ nrwqc-2009.pdf.

U.S. Geological Survey, 2008a, Home page: accessed June 2, 2008, at http://bqs.usgs.gov/.

U.S. Geological Survey, 2008b, Sediment Laboratory Quality Assurance Project, USGS Kentucky Laboratory, Suspended sediment concentration: accessed June 2, 2008, at http://bqs.usgs.gov/slqa/ky_web_ssc.htm.

U.S. Geological Survey, 2008c, Sediment Laboratory Quality Assurance Project, USGS Kentucky Laboratory, Fine sediment separation results: accessed June 2, 2008, at http://bqs.usgs.gov/slqa/ky_web_fine.htm.

U.S. Geological Survey, 2008d, Sediment Laboratory Quality Assurance Project, USGS Kentucky Laboratory, Sand separation results: accessed June 2, 2008, at http://bqs.usgs.gov/slqa/ky_web_sand.htm.

Van Loon, J.C., 1985, Selected methods of trace metal analysis-Biological and environmental samples: New York, John Wiley \& Sons, p. 1-52.

Venner, Marie, Leisenring, Marc, Pankani, Dan, and Strecker, Eric, 2004, Identification of research needs related to highway runoff management: Washington, D.C., Transportation Research Board, National Cooperative Highway Research Program NCHRP Report 521, 175 p.
Wagner, R.J., Boulger, R.W., Jr., Oblinger, C.J., and Smith, B.A., 2006, Guidelines and standard procedures for continuous water-quality monitors - Station operation, record computation, and data reporting: U.S. Geological Survey Techniques and Methods 1-D3, 51 p. +8 attachments; accessed April 10, 2006, at http://pubs.water.usgs.gov/tm1d3.

Walsh, P.M., Barrett, M.E., Malina, J.F., Jr., and Charbeneau, R.J., 1997, Use of vegetative controls for treatment of highway runoff: Austin, TX, University of Texas at Austin, Bureau of Engineering Research, Center for Research in Water Resources Online Report 97-5, 125 p.

Waschbusch, R.J., 2003, Data and methods of a 1999-2000 street sweeping study on an urban freeway in Milwaukee County, Wisconsin: U.S. Geological Survey Open-File Report 03-93, $41 \mathrm{p}$.

Washington State Department of Transportation, Environmental Services Office, 2001, 2001 NPDES progress report Cedar-Green, Island-Snohomish, and South Puget Sound water quality management areas, national pollutant discharge elimination system MS4 permits WASM10001, WASM20001, AND WASM30001: Olympia, Washington, Washington State Department of Transportation, $47 \mathrm{p}$.

Washington State Department of Transportation, Environmental Services Office, 2002, 2002 NPDES progress report Cedar-Green, Island-Snohomish, and South Puget Sound water quality management areas, national pollutant discharge elimination system MS4 permits WASM10001, WASM20001, AND WASM30001: Olympia, Washington, Washington State Department of Transportation, $57 \mathrm{p}$.

Washington State Department of Transportation, Environmental Services Office, 2003, 2003 NPDES progress report Cedar-Green, Island-Snohomish, and South Puget Sound water quality management areas, national pollutant discharge elimination system MS4 permits WASM10001, WASM20001, AND WASM30001: Olympia, Washington, Washington State Department of Transportation, $50 \mathrm{p}$.

Washington State Department of Transportation, Environmental Services Office, 2004, 2004 NPDES progress report Cedar-Green, Island-Snohomish, and South Puget Sound water quality management areas, national pollutant discharge elimination system MS4 permits WASM10001, WASM20001, AND WASM30001: Olympia, Washington, Washington State Department of Transportation, $797 \mathrm{p}$.

Westerholm, R., and Egebäck, K., 1994, Exhaust emissions from light- and heavy-duty vehicles: Chemical Composition, Impact of Exhaust after Treatment, and Fuel Parameters, Environmental Health Perspectives, p. 13-33. 
Wilde, F.D., Busenberg, Eurybiades, and Radtke, D.B., eds., 2006, National field manual for the collection of water-quality data, Field measurements, $\mathrm{pH}$ (v. 1.3): U.S. Geological Survey Techniques of Water-Resources Investigation, book 9, chap. A6, section 6.4, revised 2006.

Yunker, M.B., Macdonald, R.W., Vingarzan, R., Mitchell, R.H., Goyette, D., and Sylvestre, S., 2002, PAHs in the Fraser river basin-A critical appraisal of PAH ratios as indicators of PAH source and composition: Organic Geochemistry, v. 33, p. 489-515.
Zaugg, S.D., Smith, S.G., and Schroeder, M.P., 2006a, Determination of wastewater compounds in whole water by continuous liquid-liquid extraction and capillary-column gas chromatography/mass spectrometry: U.S. Geological Survey Techniques and Methods, book 5, chap. B4, 30 p.

Zaugg, S.D., Burkhardt, M.R., Burbank, T.L., Olson, M.C., Iverson, J.L., and Schroeder, M.P., 2006b, Determination of semivolatile organic compounds and polycyclic aromatic hydrocarbons in solids by gas chromatography/mass spectrometry: U.S. Geological Survey Techniques and Methods, book 5, chap. B3, $44 \mathrm{p}$. 
Table 16. Physical properties and concentrations of dissolved major ions, total nutrients, total-recoverable metals, polyaromatic hydrocarbons, phthalate esters, and suspended sediment in stormwater composite samples of highway runoff collected from 12 stations on 8 highways in Massachusetts, 2005-07.

[USGS, U.S. Geological Survey; -P, primary monitoring station; -S, secondary monitoring station; -T, monitoring station on test highway; mm/dd/yyyy, month, day, year; hrmn, hour minute; NTRU, nephelometric turbidity ratio units; mg/L, milligrams per liter; $\mu \mathrm{g} / \mathrm{L}$, micrograms per liter; $\mu \mathrm{S} / \mathrm{cm}$, microsiemens per centimeter at 25 degrees Celsius; mm, millimeter; <, concentration is less than the laboratory reporting limit; --, no data; E, the recovery or variation in recovery of the analyte was outside the acceptable range or the concentration reported is less than laboratory reporting level and is qualified as estimated; blue-shaded values are associated with the secondary monitoring sites for each principal highway; gray-shaded values are associated with the monitoring sites for each test highway]

\begin{tabular}{|c|c|c|c|c|c|c|c|}
\hline lia & $\begin{array}{l}\text { US } \\
\text { station }\end{array}$ & $\underset{(\mathrm{mm}}{\mathrm{Be}}$ & $\begin{array}{l}\text { me } \\
\text { ) }\end{array}$ & $\begin{array}{r}\text { Enc } \\
\text { (mm/ }\end{array}$ & & $\begin{array}{c}\text { Total } \\
\text { precipitation } \\
\text { (inches) }\end{array}$ & $\begin{array}{c}\text { Total storm } \\
\text { volume } \\
\text { (cubic feet) }\end{array}$ \\
\hline
\end{tabular}

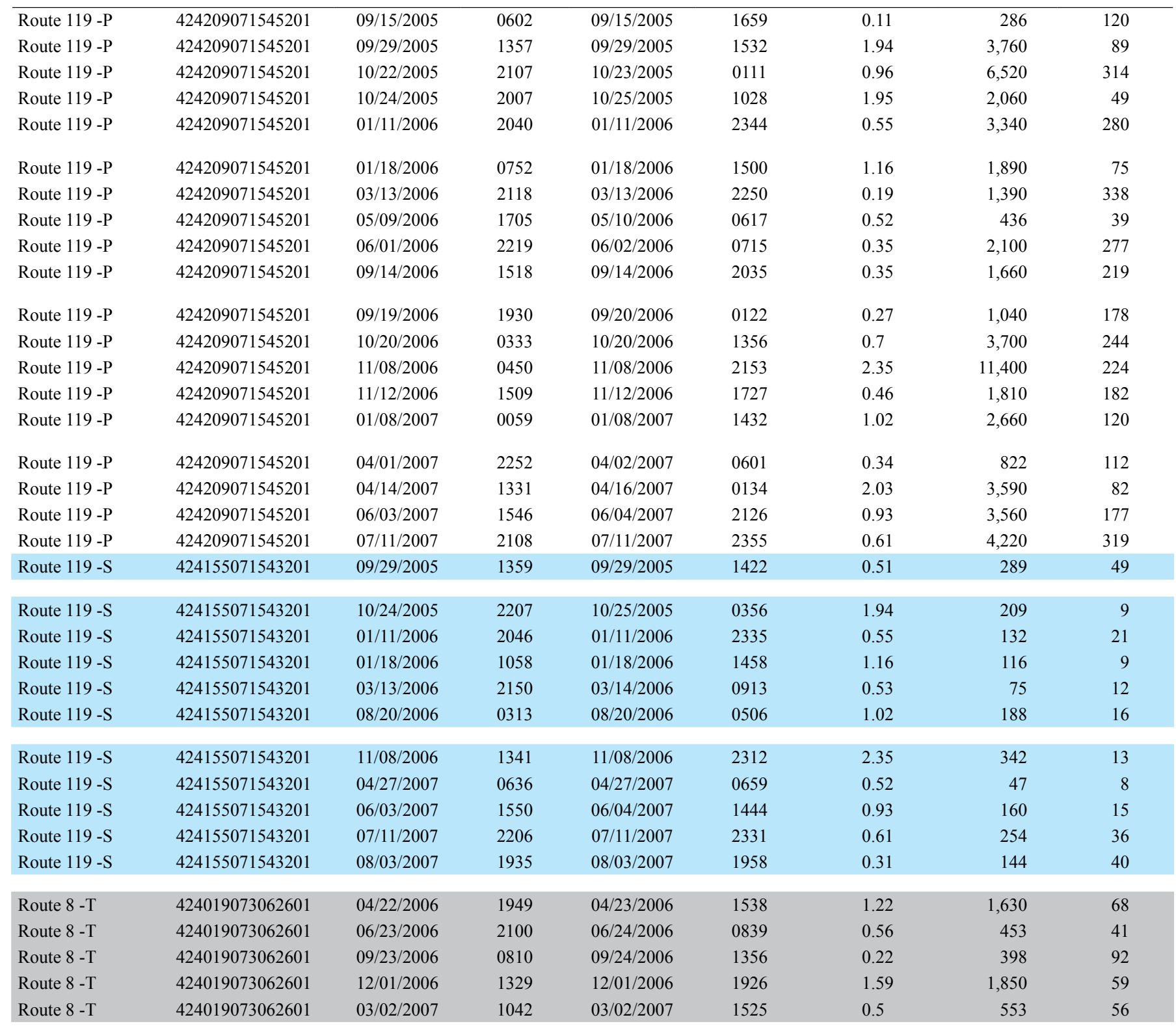


Table 16. Physical properties and concentrations of dissolved major ions, total nutrients, total-recoverable metals, polyaromatic hydrocarbons, phthalate esters, and suspended sediment in stormwater composite samples of highway runoff collected from 12 stations on 8 highways in Massachusetts, 2005-07.-Continued

[USGS, U.S. Geological Survey; -P, primary monitoring station; -S, secondary monitoring station; -T, monitoring station on test highway; mm/dd/yyyy, month, day, year; hrmn, hour minute; NTRU, nephelometric turbidity ratio units; mg/L, milligrams per liter; $\mu \mathrm{g} / \mathrm{L}$, micrograms per liter; $\mu \mathrm{S} / \mathrm{cm}$, microsiemens per centimeter at 25 degrees Celsius; mm, millimeter; <, concentration is less than the laboratory reporting limit; --, no data; E, the recovery or variation in recovery of the analyte was outside the acceptable range or the concentration reported is less than laboratory reporting level and is qualified as estimated; blue-shaded values are associated with the secondary monitoring sites for each principal highway; gray-shaded values are associated with the monitoring sites for each test highway]

\begin{tabular}{|c|c|c|c|c|c|c|c|c|}
\hline $\begin{array}{l}\text { Highway and } \\
\text { designation }\end{array}$ & $\begin{array}{c}\text { USGS } \\
\text { station number }\end{array}$ & $\begin{array}{c}\text { Begin date } \\
\text { (mm/dd/yyyy) }\end{array}$ & $\begin{array}{l}\text { Begin time } \\
\text { (hrmn) }\end{array}$ & $\begin{array}{c}\text { End date } \\
\text { (mm/dd/yyyy) }\end{array}$ & $\begin{array}{l}\text { End time } \\
\text { (hrmn) }\end{array}$ & $\begin{array}{c}\text { Total } \\
\text { precipitation } \\
\text { (inches) }\end{array}$ & $\begin{array}{c}\text { Total storm } \\
\text { volume } \\
\text { (cubic feet) }\end{array}$ & $\begin{array}{c}\text { Runoff } \\
\text { coefficient } \\
\text { (percent) }\end{array}$ \\
\hline
\end{tabular}

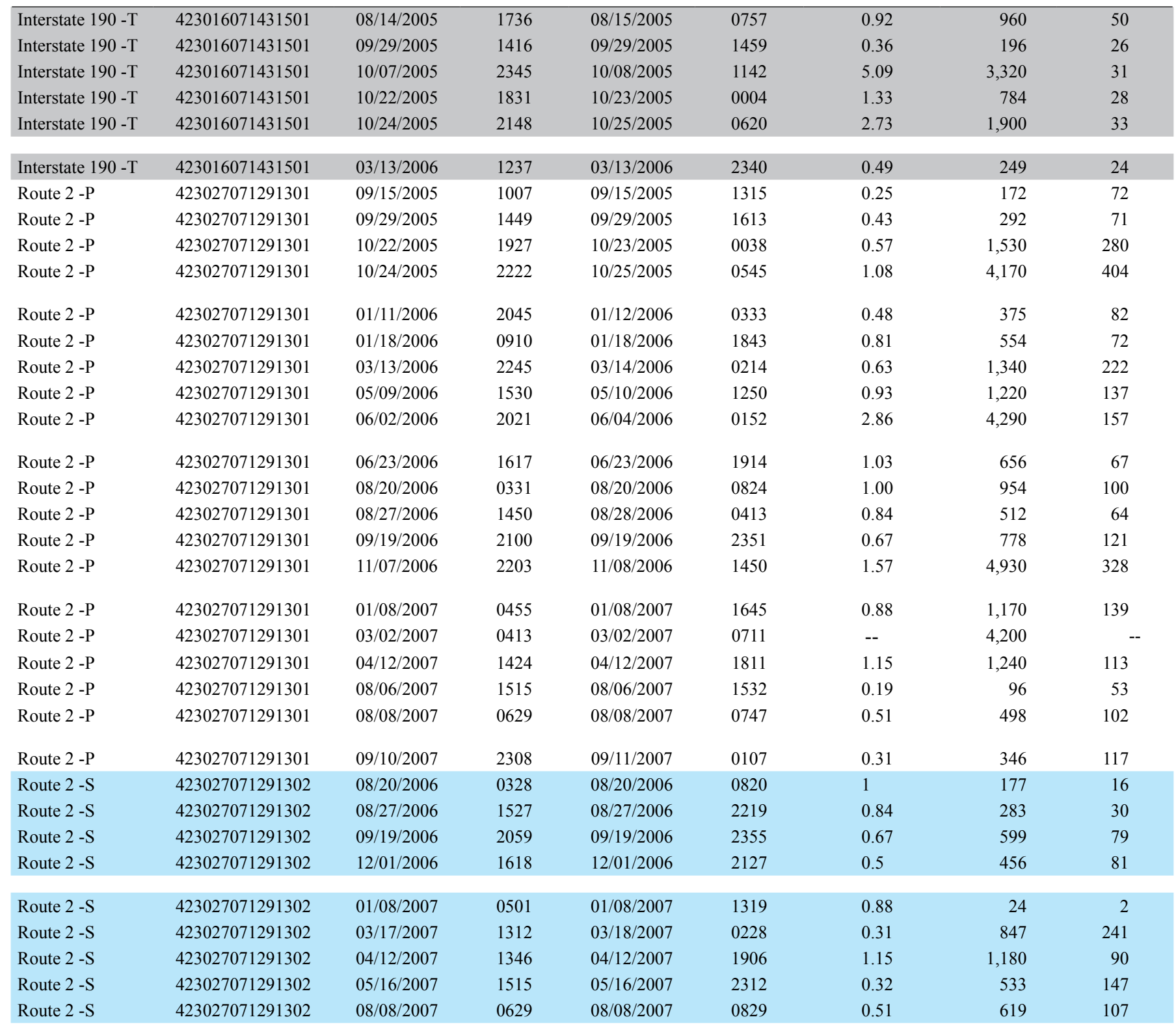


Table 16. Physical properties and concentrations of dissolved major ions, total nutrients, total-recoverable metals, polyaromatic hydrocarbons, phthalate esters, and suspended sediment in stormwater composite samples of highway runoff collected from 12 stations on 8 highways in Massachusetts, 2005-07.-Continued

[USGS, U.S. Geological Survey; -P, primary monitoring station; -S, secondary monitoring station; -T, monitoring station on test highway; mm/dd/yyyy, month, day, year; hrmn, hour minute; NTRU, nephelometric turbidity ratio units; mg/L, milligrams per liter; $\mu \mathrm{g} / \mathrm{L}$, micrograms per liter; $\mu \mathrm{S} / \mathrm{cm}$, microsiemens per centimeter at 25 degrees Celsius; mm, millimeter; <, concentration is less than the laboratory reporting limit; --, no data; E, the recovery or variation in recovery of the analyte was outside the acceptable range or the concentration reported is less than laboratory reporting level and is qualified as estimated; blue-shaded values are associated with the secondary monitoring sites for each principal highway; gray-shaded values are associated with the monitoring sites for each test highway]

\begin{tabular}{|c|c|c|c|c|c|c|c|}
\hline $\begin{array}{l}\text { Higl } \\
\text { des }\end{array}$ & $\begin{array}{c}\text { USGS } \\
\text { station number }\end{array}$ & $\begin{array}{c}\text { Bes } \\
(\mathrm{mm})\end{array}$ & $\begin{array}{r}\text { Beg } \\
\text { (h }\end{array}$ & $\begin{array}{c}\text { En } \\
(\mathrm{mm} /\end{array}$ & & $\begin{array}{l}\text { Total } \\
\text { precipitation } \\
\text { (inches) }\end{array}$ & $\begin{array}{c}\text { Total storm } \\
\text { volume } \\
\text { (cubic feet) }\end{array}$ \\
\hline
\end{tabular}

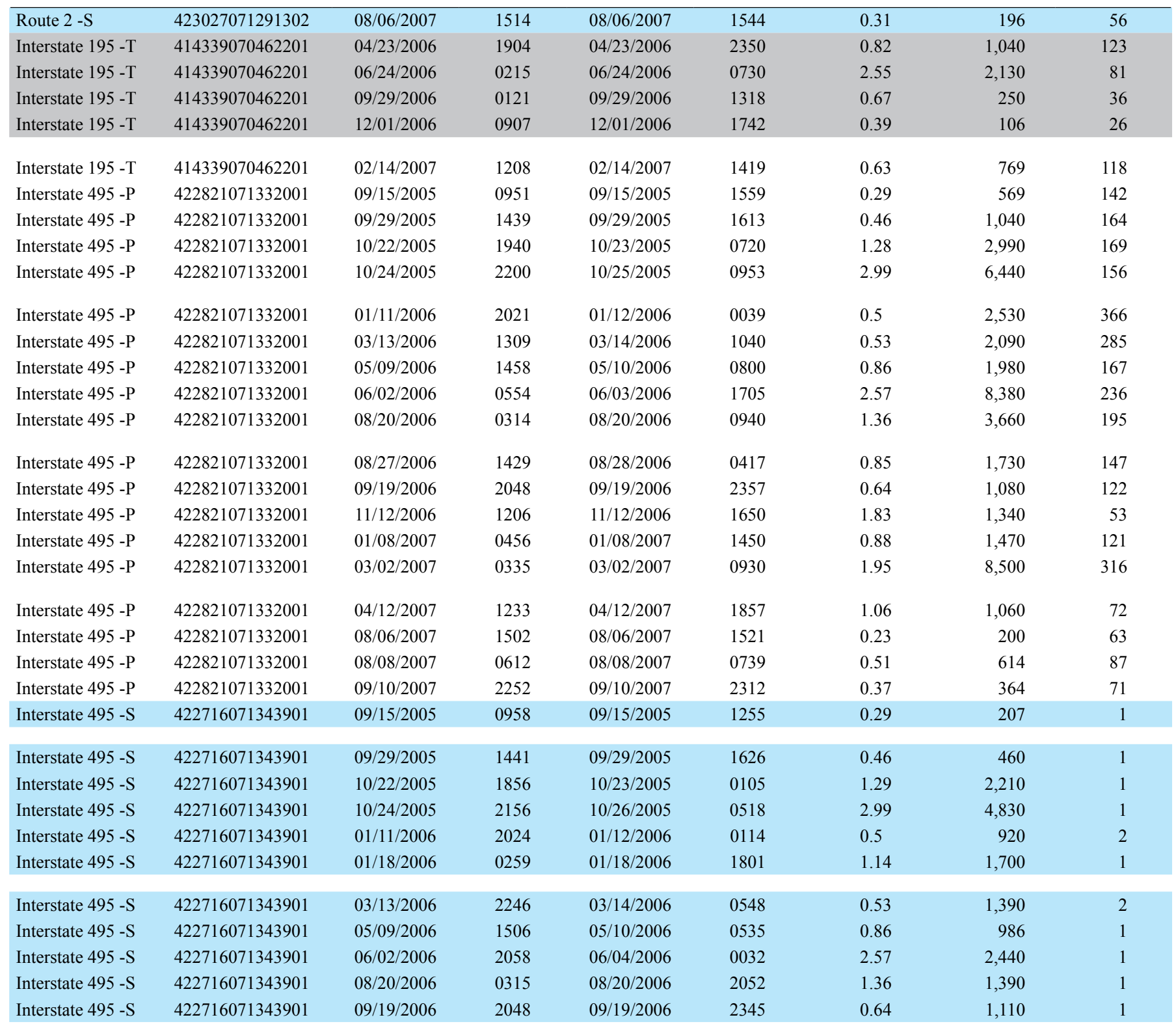


Table 16. Physical properties and concentrations of dissolved major ions, total nutrients, total-recoverable metals, polyaromatic hydrocarbons, phthalate esters, and suspended sediment in stormwater composite samples of highway runoff collected from 12 stations on 8 highways in Massachusetts, 2005-07.-Continued

[USGS, U.S. Geological Survey; -P, primary monitoring station; -S, secondary monitoring station; -T, monitoring station on test highway; mm/dd/yyyy, month, day, year; hrmn, hour minute; NTRU, nephelometric turbidity ratio units; mg/L, milligrams per liter; $\mu \mathrm{g} / \mathrm{L}$, micrograms per liter; $\mu \mathrm{S} / \mathrm{cm}$, microsiemens per centimeter at 25 degrees Celsius; mm, millimeter; <, concentration is less than the laboratory reporting limit; --, no data; E, the recovery or variation in recovery of the analyte was outside the acceptable range or the concentration reported is less than laboratory reporting level and is qualified as estimated; blue-shaded values are associated with the secondary monitoring sites for each principal highway; gray-shaded values are associated with the monitoring sites for each test highway]

\begin{tabular}{|c|c|c|c|c|c|c|c|c|}
\hline $\begin{array}{l}\text { Highway and } \\
\text { designation }\end{array}$ & $\begin{array}{c}\text { USGS } \\
\text { station number }\end{array}$ & $\begin{array}{c}\text { Begin date } \\
\text { (mm/dd/yyyy) }\end{array}$ & $\begin{array}{l}\text { Begin time } \\
\text { (hrmn) }\end{array}$ & $\begin{array}{c}\text { End date } \\
\text { (mm/dd/yyyy) }\end{array}$ & $\begin{array}{l}\text { End time } \\
\text { (hrmn) }\end{array}$ & $\begin{array}{c}\text { Total } \\
\text { precipitation } \\
\text { (inches) }\end{array}$ & $\begin{array}{c}\text { Total storm } \\
\text { volume } \\
\text { (cubic feet) }\end{array}$ & $\begin{array}{c}\text { Runoff } \\
\text { coefficient } \\
\text { (percent) }\end{array}$ \\
\hline
\end{tabular}

\begin{tabular}{|c|c|c|c|c|c|c|c|c|}
\hline Interstate $95-\mathrm{P}$ & 422620071153301 & $09 / 15 / 2005$ & 1007 & $09 / 15 / 2005$ & 1620 & 0.96 & 1,760 & 70 \\
\hline Interstate $95-\mathrm{P}$ & 422620071153301 & $09 / 29 / 2005$ & 1518 & $09 / 29 / 2005$ & 1630 & 0.39 & 548 & 54 \\
\hline Interstate $95-\mathrm{P}$ & 422620071153301 & $10 / 22 / 2005$ & 2356 & $10 / 23 / 2005$ & 0045 & 0.99 & 842 & 32 \\
\hline Interstate $95-\mathrm{P}$ & 422620071153301 & $11 / 16 / 2005$ & 2056 & $11 / 17 / 2005$ & 0221 & 0.6 & 713 & 45 \\
\hline Interstate $95-\mathrm{P}$ & 422620071153301 & $01 / 12 / 2006$ & 0026 & $01 / 12 / 2006$ & 0106 & 0.28 & 230 & 31 \\
\hline Interstate $95-\mathrm{P}$ & 422620071153301 & $01 / 18 / 2006$ & 1311 & $01 / 18 / 2006$ & 1535 & 0.72 & 1,150 & 61 \\
\hline Interstate $95-\mathrm{P}$ & 422620071153301 & $03 / 13 / 2006$ & 2311 & $03 / 13 / 2006$ & 2343 & 0.52 & 625 & 46 \\
\hline Interstate $95-\mathrm{P}$ & 422620071153301 & $05 / 09 / 2006$ & 1456 & $05 / 09 / 2006$ & 2010 & 1.12 & 1,540 & 52 \\
\hline Interstate $95-\mathrm{P}$ & 422620071153301 & $06 / 02 / 2006$ & 0356 & $06 / 03 / 2006$ & 1517 & 0.18 & 9,880 & 149 \\
\hline Interstate $95-\mathrm{P}$ & 422620071153301 & $08 / 20 / 2006$ & 0429 & $08 / 20 / 2006$ & 0652 & 0.49 & 2,590 & 97 \\
\hline Interstate $95-\mathrm{P}$ & 422620071153301 & $08 / 27 / 2006$ & 1636 & $08 / 27 / 2006$ & 2300 & 0.72 & 2,230 & 118 \\
\hline Interstate $95-\mathrm{P}$ & 422620071153301 & $09 / 19 / 2006$ & 2136 & $09 / 20 / 2006$ & 0000 & 0.71 & 3,330 & 179 \\
\hline Interstate $95-\mathrm{P}$ & 422620071153301 & $10 / 20 / 2006$ & 1601 & $10 / 20 / 2006$ & 1812 & 0.59 & 837 & 54 \\
\hline Interstate $95-\mathrm{P}$ & 422620071153301 & $10 / 28 / 2006$ & 0551 & $10 / 28 / 2006$ & 1440 & 1.92 & 2,700 & 54 \\
\hline Interstate $95-\mathrm{P}$ & 422620071153301 & $11 / 07 / 2006$ & 2306 & $11 / 08 / 2006$ & 2331 & 1.54 & 2,350 & 58 \\
\hline Interstate $95-\mathrm{P}$ & 422620071153301 & 03/11/2007 & 0320 & $03 / 11 / 2007$ & 0508 & 0.23 & 195 & 32 \\
\hline Interstate $95-\mathrm{P}$ & 422620071153301 & $03 / 17 / 2007$ & 0311 & $03 / 17 / 2007$ & 1017 & 1.86 & 235 & 5 \\
\hline Interstate $95-\mathrm{P}$ & 422620071153301 & $04 / 12 / 2007$ & 1403 & $04 / 12 / 2007$ & 1726 & 1.06 & 1,060 & 38 \\
\hline Interstate $95-\mathrm{P}$ & 422620071153301 & 08/06/2007 & 1538 & $08 / 06 / 2007$ & 1605 & E0.28 & 35 & -- \\
\hline Interstate $95-\mathrm{P}$ & 422620071153301 & $08 / 08 / 2007$ & 0722 & $08 / 08 / 2007$ & 0859 & E0.19 & 113 & -- \\
\hline Interstate $95-\mathrm{S}$ & 422420071153302 & $08 / 20 / 2006$ & 0334 & $08 / 20 / 2006$ & 0654 & 0.81 & 654 & 76 \\
\hline Interstate $95-\mathrm{S}$ & 422420071153302 & $08 / 27 / 2006$ & 1556 & $08 / 28 / 2006$ & 0133 & 0.72 & 443 & 58 \\
\hline Interstate $95-\mathrm{S}$ & 422420071153302 & 09/19/2006 & 2028 & $09 / 20 / 2006$ & 0005 & 0.71 & 542 & 72 \\
\hline Interstate $95-\mathrm{S}$ & 422420071153302 & $11 / 07 / 2006$ & 2138 & $11 / 09 / 2006$ & 0104 & 1.28 & 856 & 63 \\
\hline Interstate $95-\mathrm{S}$ & 422420071153302 & $03 / 02 / 2007$ & 0257 & $03 / 02 / 2007$ & 1019 & 1.81 & 1,840 & 96 \\
\hline Interstate $95-\mathrm{S}$ & 422420071153302 & $03 / 17 / 2007$ & 0226 & $03 / 17 / 2007$ & 0900 & 2.25 & 731 & 31 \\
\hline Interstate $95-\mathrm{S}$ & 422420071153302 & $04 / 12 / 2007$ & 1353 & $04 / 12 / 2007$ & 1817 & 1.03 & 553 & 51 \\
\hline Interstate $95-\mathrm{S}$ & 422420071153302 & $05 / 16 / 2007$ & 1532 & $05 / 16 / 2007$ & 1831 & 1.41 & 811 & 54 \\
\hline Interstate $95-\mathrm{S}$ & 422420071153302 & $08 / 06 / 2007$ & 1541 & $08 / 06 / 2007$ & 1601 & 0.28 & 91 & 31 \\
\hline Interstate $95-\mathrm{S}$ & 422420071153302 & $08 / 08 / 2007$ & 0726 & $08 / 08 / 2007$ & 0753 & 0.19 & 60 & 30 \\
\hline Interstate $93-\mathrm{T}$ & 421647071024703 & $04 / 23 / 2006$ & 1444 & $04 / 24 / 2006$ & 0423 & 0.64 & 2,320 & 67 \\
\hline Interstate $93-\mathrm{T}$ & 421647071024703 & $06 / 23 / 2006$ & 1427 & $06 / 23 / 2006$ & 1847 & 1.6 & 6,100 & 71 \\
\hline Interstate $93-\mathrm{T}$ & 421647071024703 & $09 / 19 / 2006$ & 2235 & $09 / 20 / 2006$ & 0321 & 0.61 & 2,600 & 79 \\
\hline Interstate $93-\mathrm{T}$ & 421647071024703 & $12 / 01 / 2006$ & 1634 & $12 / 01 / 2006$ & 2217 & 0.26 & 829 & 59 \\
\hline Interstate $93-\mathrm{T}$ & 421647071024703 & $02 / 14 / 2007$ & 1108 & $02 / 14 / 2007$ & 1436 & 2 & 8,690 & 94 \\
\hline
\end{tabular}


Table 16. Physical properties and concentrations of dissolved major ions, total nutrients, total-recoverable metals, polyaromatic hydrocarbons, phthalate esters, and suspended sediment in stormwater composite samples of highway runoff collected from 12 stations on 8 highways in Massachusetts, 2005-07.-Continued

[USGS, U.S. Geological Survey; -P, primary monitoring station; -S, secondary monitoring station; -T, monitoring station on test highway; mm/dd/yyyy, month, day, year; hrmn, hour minute; NTRU, nephelometric turbidity ratio units; mg/L, milligrams per liter; $\mu \mathrm{g} / \mathrm{L}$, micrograms per liter; $\mu \mathrm{S} / \mathrm{cm}$, microsiemens per centimeter at 25 degrees Celsius; mm, millimeter; <, concentration is less than the laboratory reporting limit; --, no data; E, the recovery

or variation in recovery of the analyte was outside the acceptable range or the concentration reported is less than laboratory reporting level and is qualified as estimated; blue-shaded values are associated with the secondary monitoring sites for each principal highway; gray-shaded values are associated with the monitoring sites for each test highway]

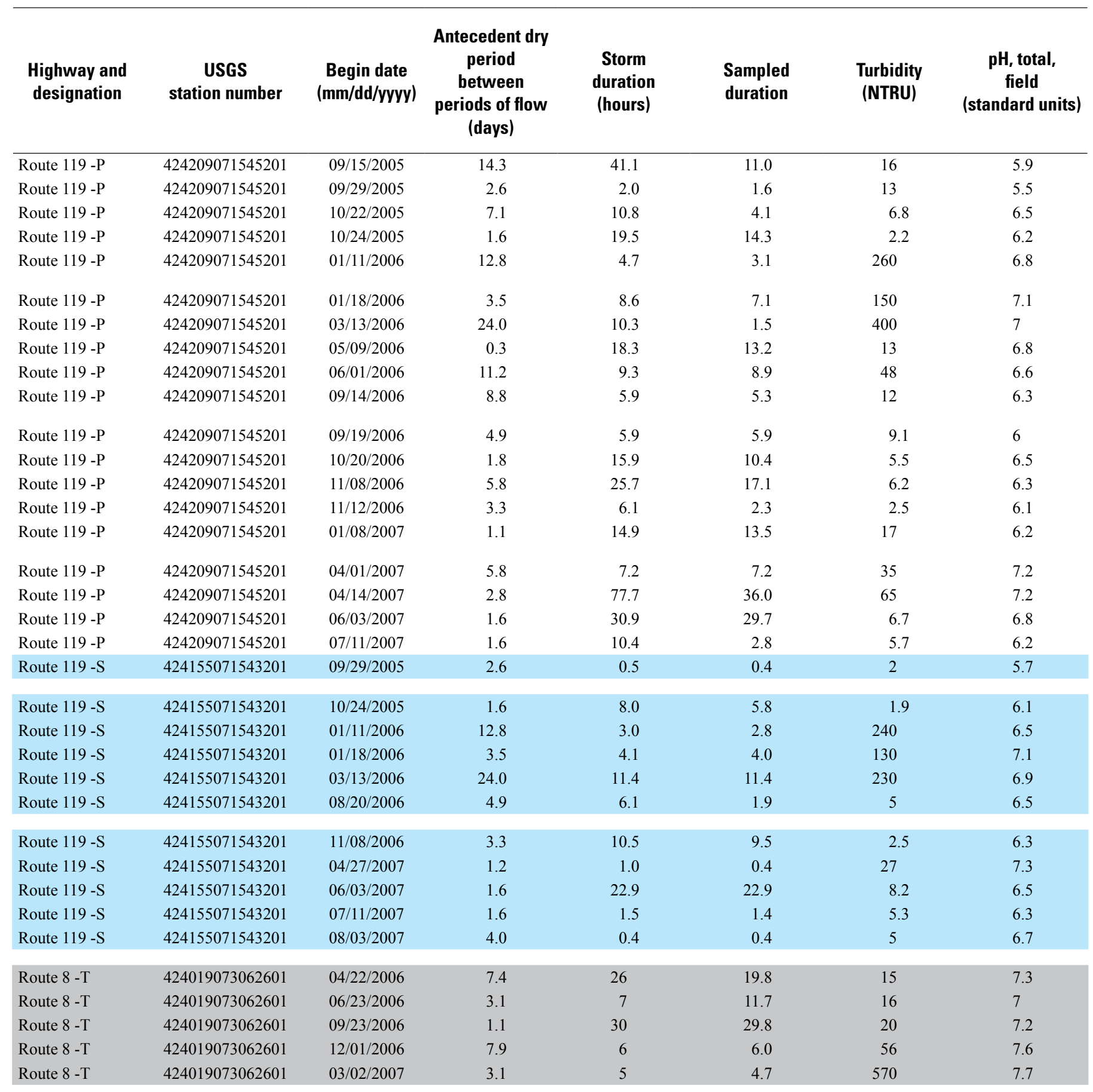


Table 16. Physical properties and concentrations of dissolved major ions, total nutrients, total-recoverable metals, polyaromatic hydrocarbons, phthalate esters, and suspended sediment in stormwater composite samples of highway runoff collected from 12 stations on 8 highways in Massachusetts, 2005-07.-Continued

[USGS, U.S. Geological Survey; -P, primary monitoring station; -S, secondary monitoring station; -T, monitoring station on test highway; mm/dd/yyyy, month, day, year; hrmn, hour minute; NTRU, nephelometric turbidity ratio units; mg/L, milligrams per liter; $\mu \mathrm{g} / \mathrm{L}$, micrograms per liter; $\mu \mathrm{S} / \mathrm{cm}$, microsiemens per centimeter at 25 degrees Celsius; $\mathrm{mm}$, millimeter; <, concentration is less than the laboratory reporting limit; --, no data; E, the recovery

or variation in recovery of the analyte was outside the acceptable range or the concentration reported is less than laboratory reporting level and is qualified as estimated; blue-shaded values are associated with the secondary monitoring sites for each principal highway; gray-shaded values are associated with the monitoring sites for each test highway]

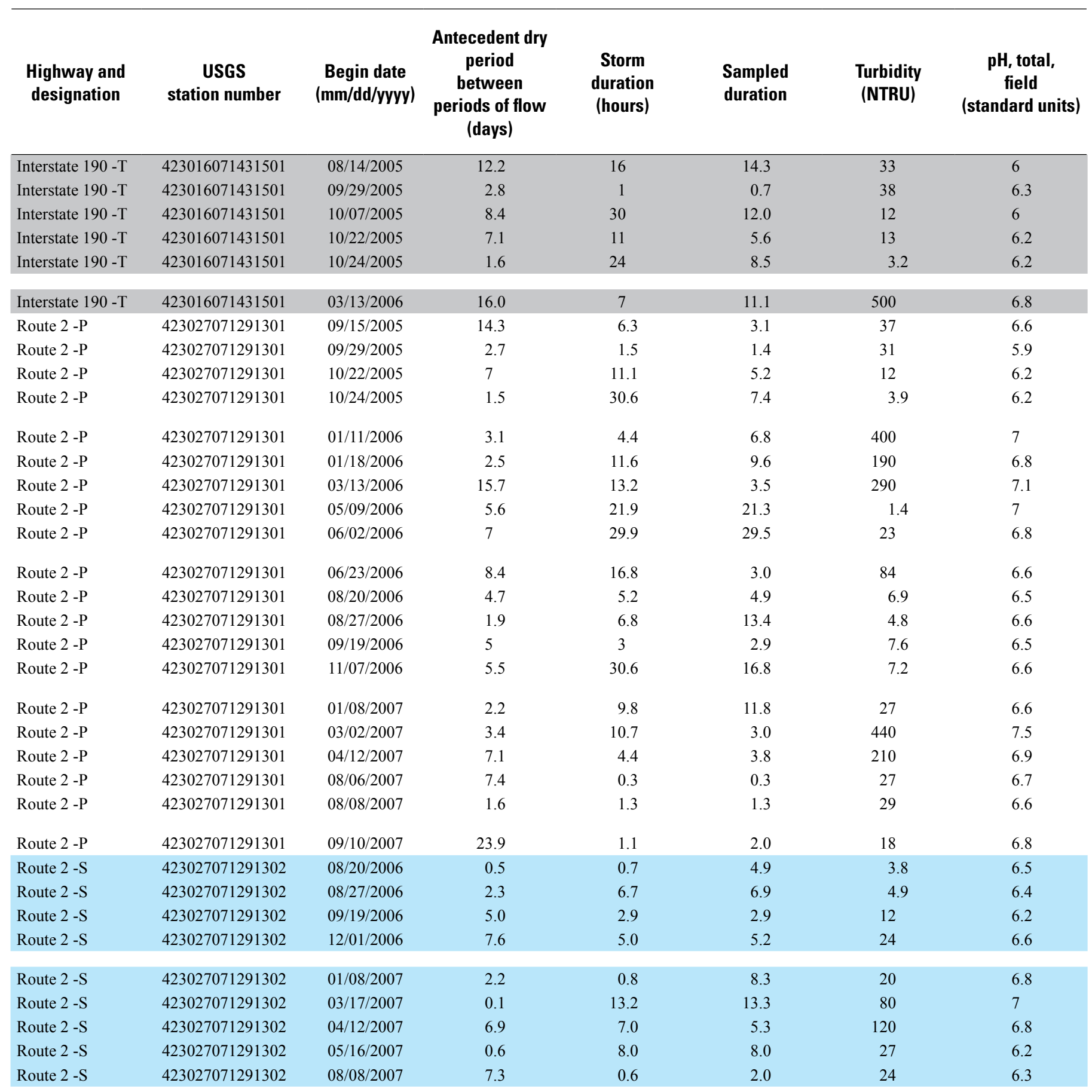


Table 16. Physical properties and concentrations of dissolved major ions, total nutrients, total-recoverable metals, polyaromatic hydrocarbons, phthalate esters, and suspended sediment in stormwater composite samples of highway runoff collected from 12 stations on 8 highways in Massachusetts, 2005-07.-Continued

[USGS, U.S. Geological Survey; -P, primary monitoring station; -S, secondary monitoring station; -T, monitoring station on test highway; mm/dd/yyyy, month, day, year; hrmn, hour minute; NTRU, nephelometric turbidity ratio units; mg/L, milligrams per liter; $\mu \mathrm{g} / \mathrm{L}$, micrograms per liter; $\mu \mathrm{S} / \mathrm{cm}$, microsiemens per centimeter at 25 degrees Celsius; $\mathrm{mm}$, millimeter; <, concentration is less than the laboratory reporting limit; --, no data; E, the recovery

or variation in recovery of the analyte was outside the acceptable range or the concentration reported is less than laboratory reporting level and is qualified as estimated; blue-shaded values are associated with the secondary monitoring sites for each principal highway; gray-shaded values are associated with the monitoring sites for each test highway]

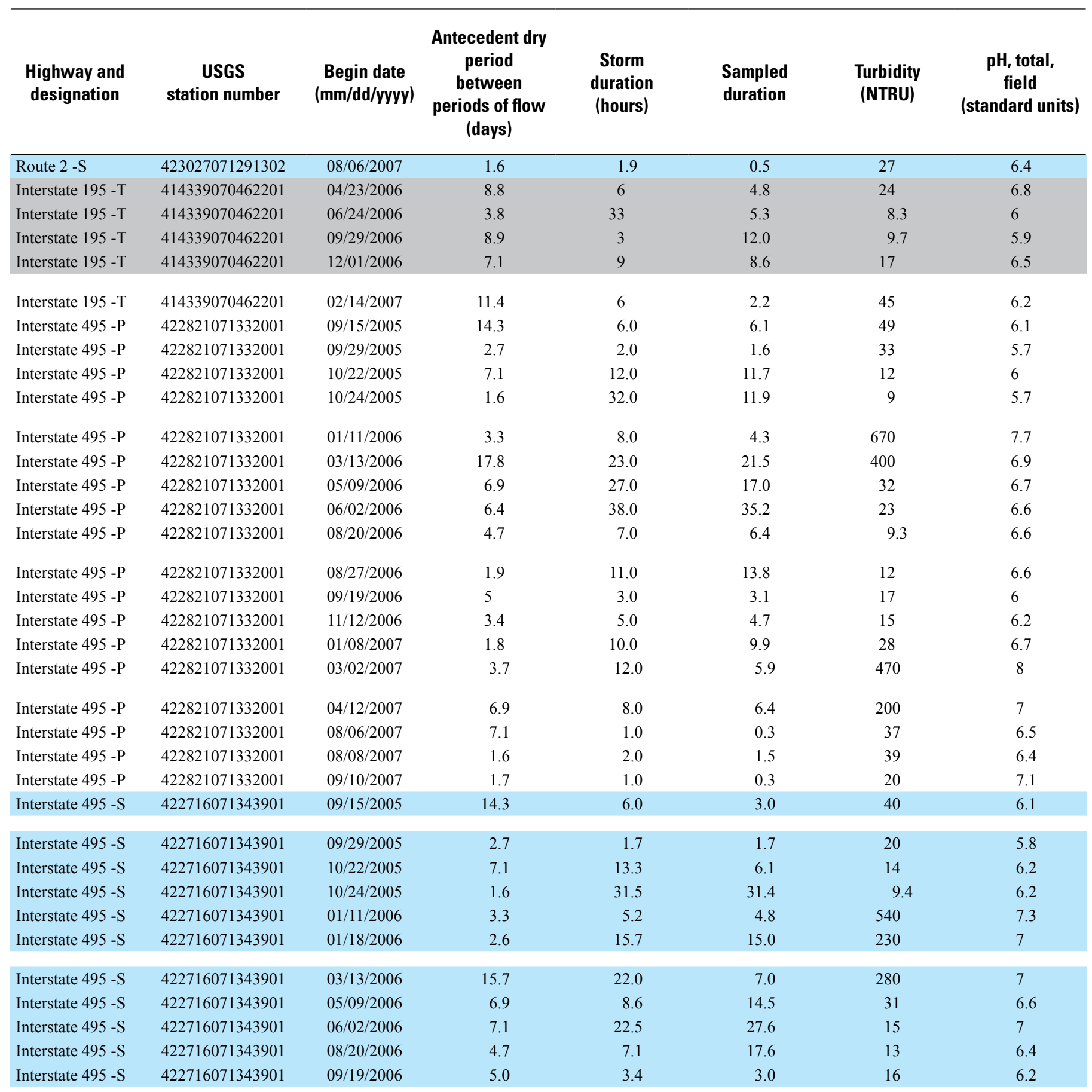


Table 16. Physical properties and concentrations of dissolved major ions, total nutrients, total-recoverable metals, polyaromatic hydrocarbons, phthalate esters, and suspended sediment in stormwater composite samples of highway runoff collected from 12 stations on 8 highways in Massachusetts, 2005-07.-Continued

[USGS, U.S. Geological Survey; -P, primary monitoring station; -S, secondary monitoring station; -T, monitoring station on test highway; mm/dd/yyyy, month, day, year; hrmn, hour minute; NTRU, nephelometric turbidity ratio units; $\mathrm{mg} / \mathrm{L}$, milligrams per liter; $\mu \mathrm{g} / \mathrm{L}$, micrograms per liter; $\mu \mathrm{S} / \mathrm{cm}$, microsiemens per centimeter at 25 degrees Celsius; mm, millimeter; <, concentration is less than the laboratory reporting limit; --, no data; E, the recovery

or variation in recovery of the analyte was outside the acceptable range or the concentration reported is less than laboratory reporting level and is qualified as estimated; blue-shaded values are associated with the secondary monitoring sites for each principal highway; gray-shaded values are associated with the monitoring sites for each test highway]

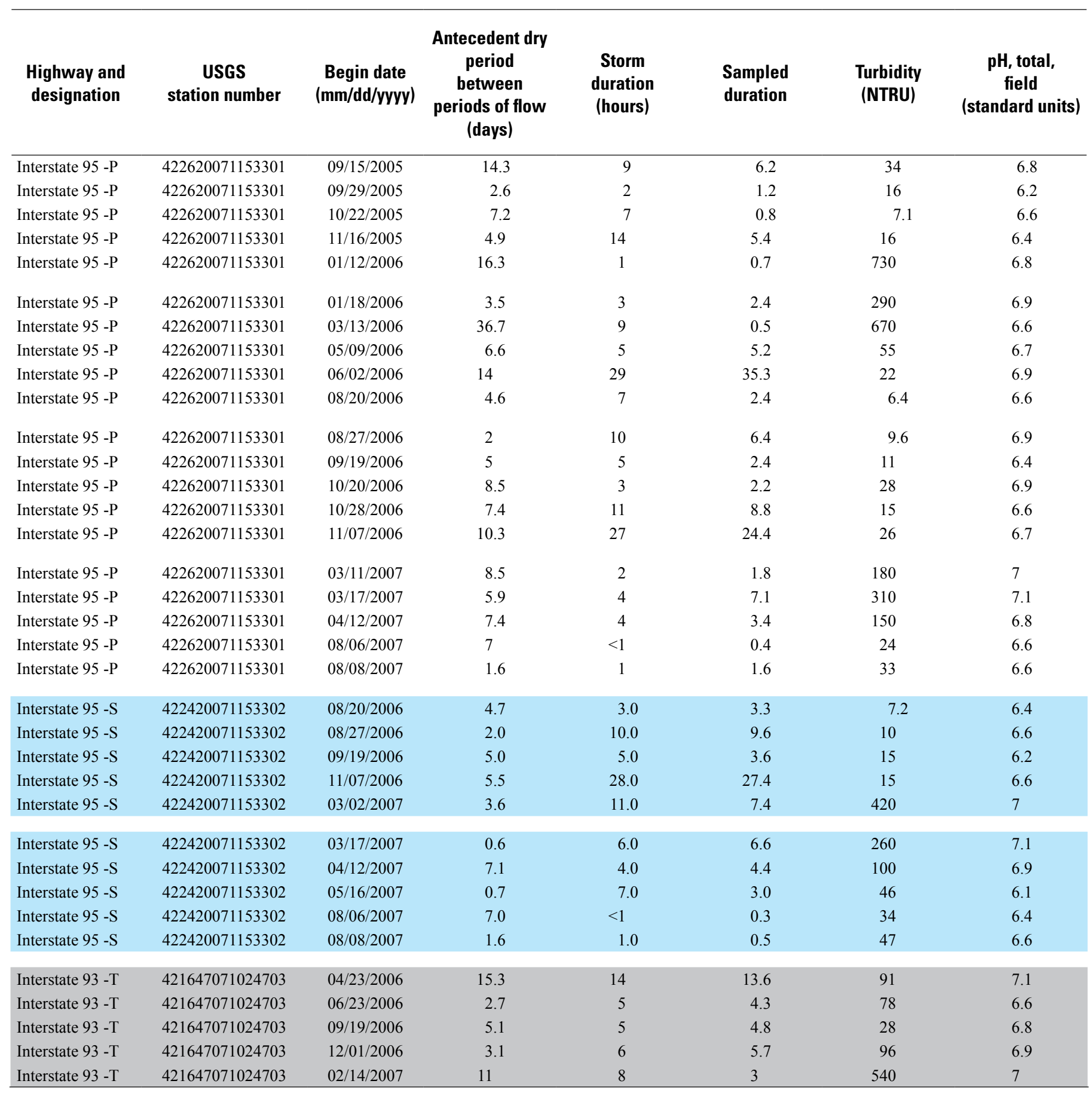


Table 16. Physical properties and concentrations of dissolved major ions, total nutrients, total-recoverable metals, polyaromatic hydrocarbons, phthalate esters, and suspended sediment in stormwater composite samples of highway runoff collected from 12 stations on 8 highways in Massachusetts, 2005-07.-Continued

[USGS, U.S. Geological Survey; -P, primary monitoring station; -S, secondary monitoring station; -T, monitoring station on test highway; mm/dd/yyyy, month, day, year; hrmn, hour minute; NTRU, nephelometric turbidity ratio units; mg/L, milligrams per liter; $\mu \mathrm{g} / \mathrm{L}$, micrograms per liter; $\mu \mathrm{S} / \mathrm{cm}$, microsiemens per centimeter at 25 degrees Celsius; mm, millimeter; <, concentration is less than the laboratory reporting limit; --, no data; E, the recovery or variation in recovery of the analyte was outside the acceptable range or the concentration reported is less than laboratory reporting level and is qualified as estimated; blue-shaded values are associated with the secondary monitoring sites for each principal highway; gray-shaded values are associated with the monitoring sites for each test highway]

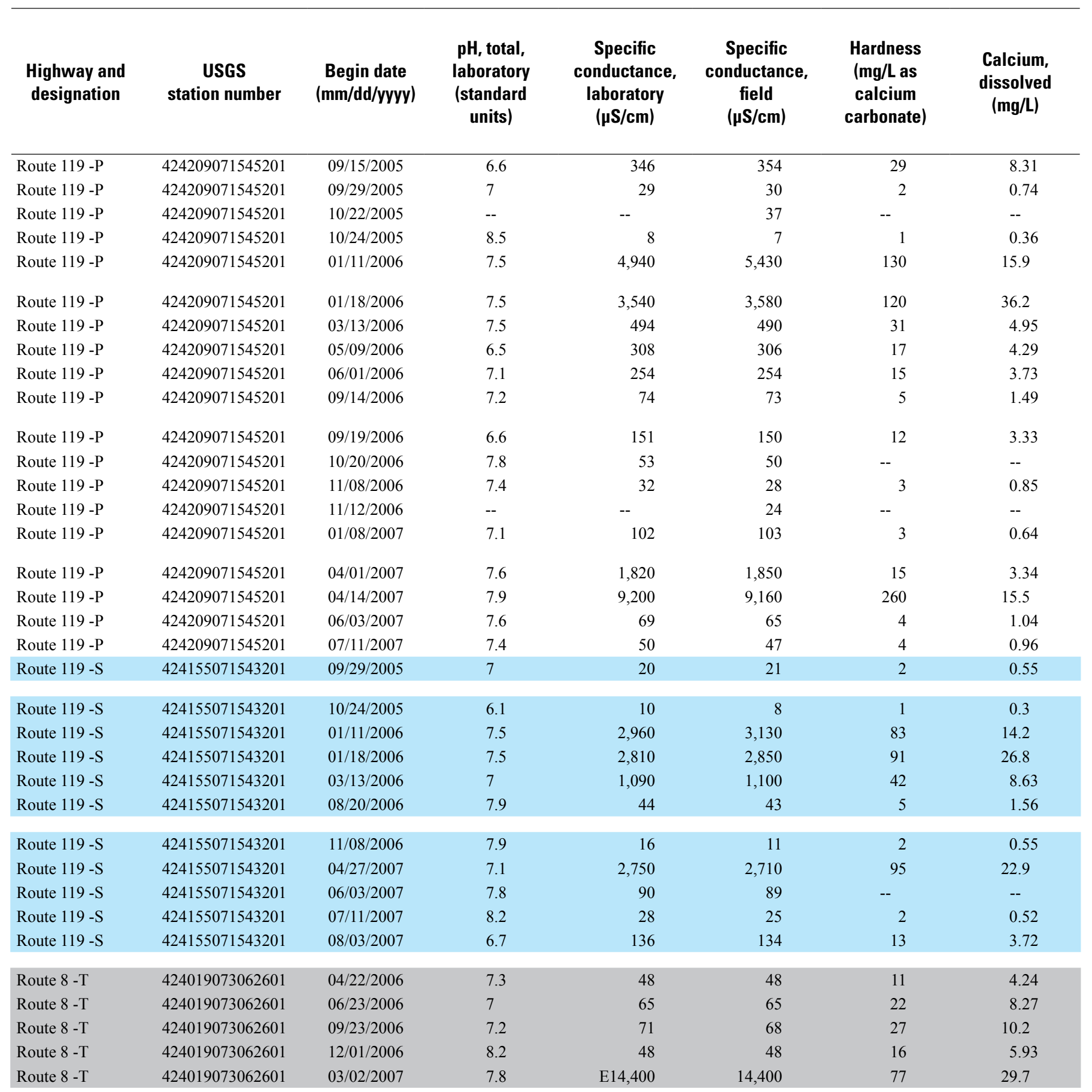


Table 16. Physical properties and concentrations of dissolved major ions, total nutrients, total-recoverable metals, polyaromatic hydrocarbons, phthalate esters, and suspended sediment in stormwater composite samples of highway runoff collected from 12 stations on 8 highways in Massachusetts, 2005-07.-Continued

[USGS, U.S. Geological Survey; -P, primary monitoring station; -S, secondary monitoring station; -T, monitoring station on test highway; mm/dd/yyyy, month, day, year; hrmn, hour minute; NTRU, nephelometric turbidity ratio units; mg/L, milligrams per liter; $\mu \mathrm{g} / \mathrm{L}$, micrograms per liter; $\mu \mathrm{S} / \mathrm{cm}$, microsiemens per centimeter at 25 degrees Celsius; mm, millimeter; <, concentration is less than the laboratory reporting limit; --, no data; E, the recovery or variation in recovery of the analyte was outside the acceptable range or the concentration reported is less than laboratory reporting level and is qualified as estimated; blue-shaded values are associated with the secondary monitoring sites for each principal highway; gray-shaded values are associated with the monitoring sites for each test highway]

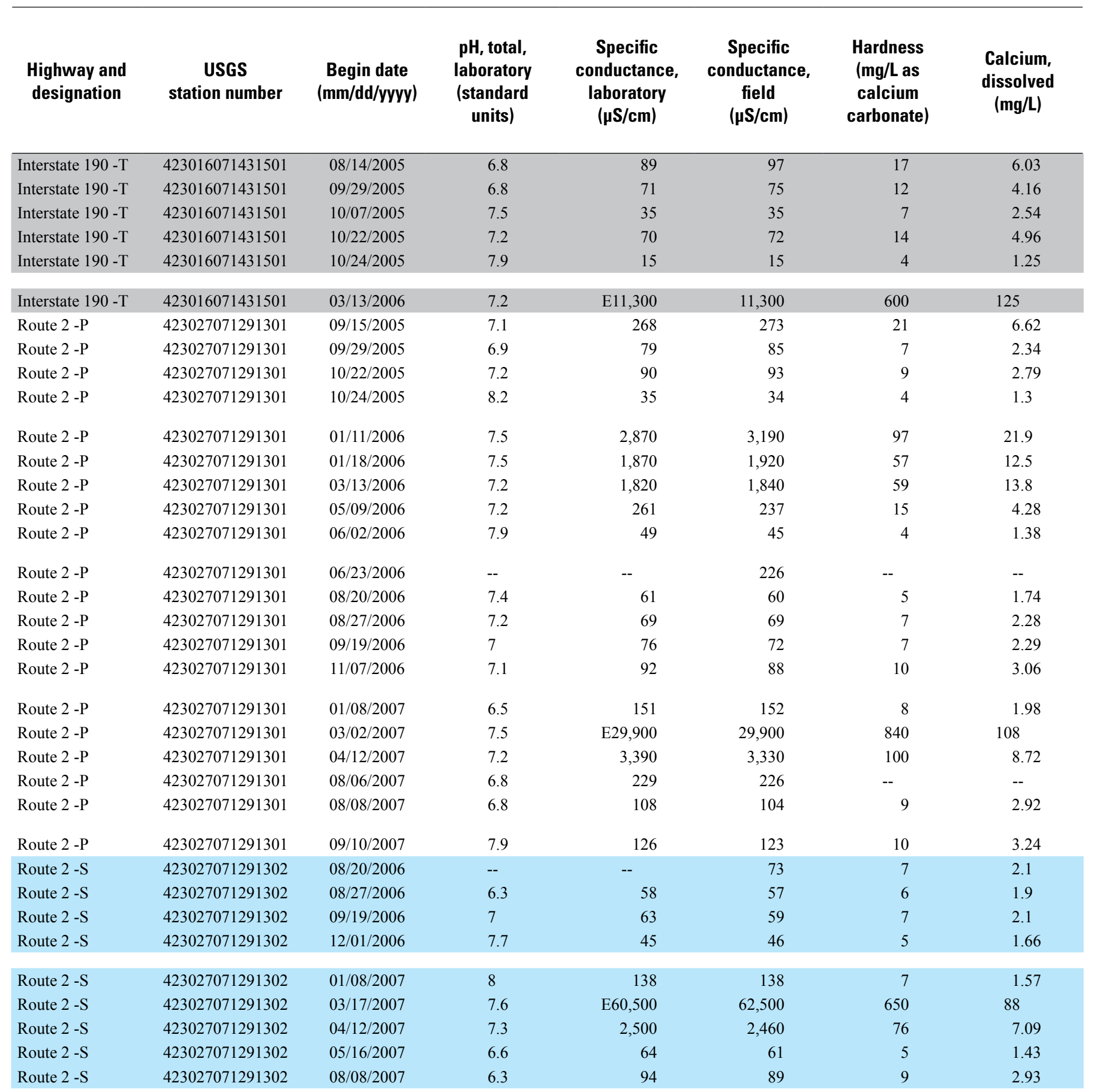


Table 16. Physical properties and concentrations of dissolved major ions, total nutrients, total-recoverable metals, polyaromatic hydrocarbons, phthalate esters, and suspended sediment in stormwater composite samples of highway runoff collected from 12 stations on 8 highways in Massachusetts, 2005-07.-Continued

[USGS, U.S. Geological Survey; -P, primary monitoring station; -S, secondary monitoring station; -T, monitoring station on test highway; mm/dd/yyyy, month, day, year; hrmn, hour minute; NTRU, nephelometric turbidity ratio units; mg/L, milligrams per liter; $\mu \mathrm{g} / \mathrm{L}$, micrograms per liter; $\mu \mathrm{S} / \mathrm{cm}$, microsiemens per centimeter at 25 degrees Celsius; $\mathrm{mm}$, millimeter; <, concentration is less than the laboratory reporting limit; --, no data; E, the recovery or variation in recovery of the analyte was outside the acceptable range or the concentration reported is less than laboratory reporting level and is qualified as estimated; blue-shaded values are associated with the secondary monitoring sites for each principal highway; gray-shaded values are associated with the monitoring sites for each test highway]

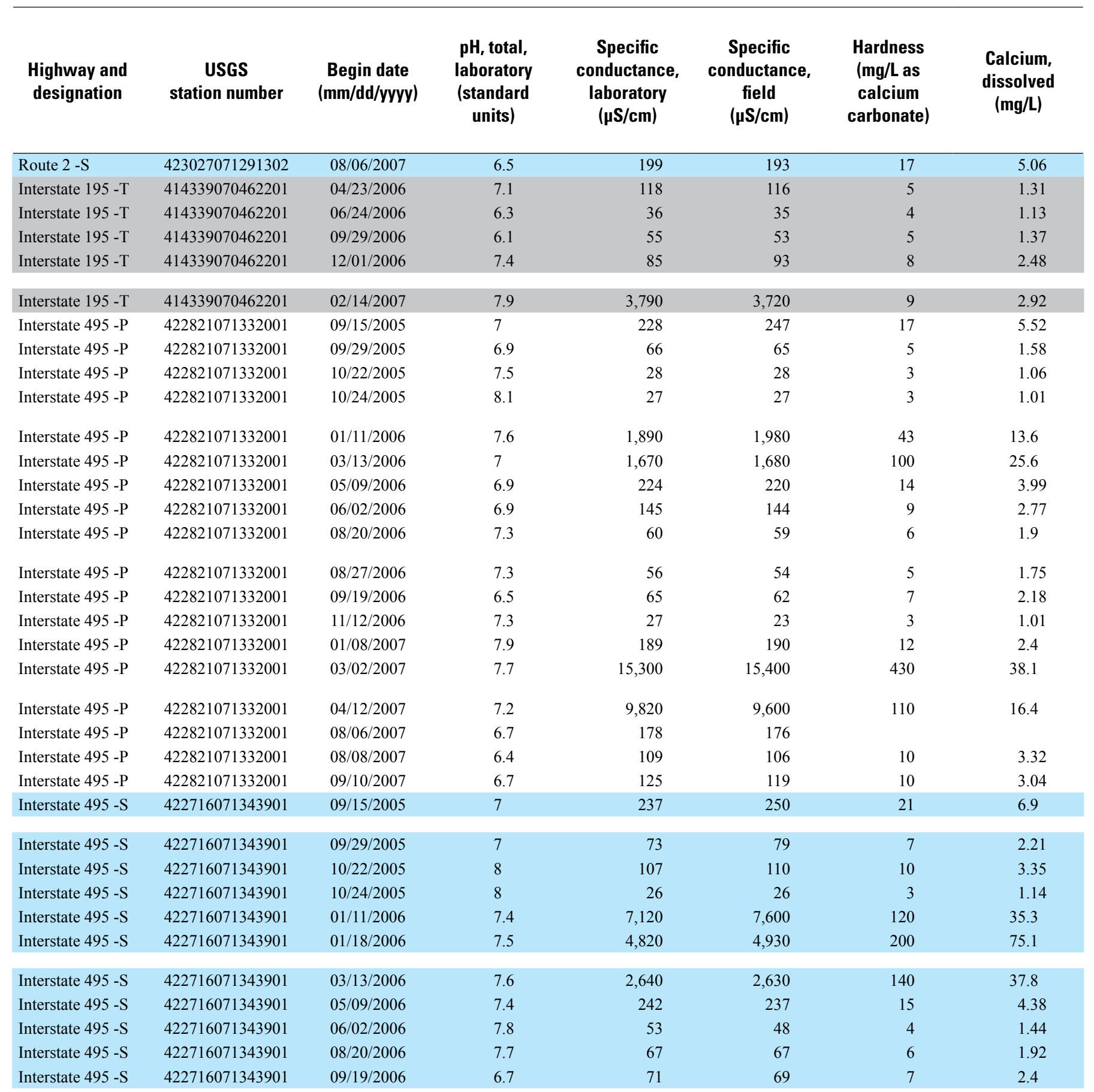


Table 16. Physical properties and concentrations of dissolved major ions, total nutrients, total-recoverable metals, polyaromatic hydrocarbons, phthalate esters, and suspended sediment in stormwater composite samples of highway runoff collected from 12 stations on 8 highways in Massachusetts, 2005-07.-Continued

[USGS, U.S. Geological Survey; -P, primary monitoring station; -S, secondary monitoring station; -T, monitoring station on test highway; mm/dd/yyyy, month, day, year; hrmn, hour minute; NTRU, nephelometric turbidity ratio units; mg/L, milligrams per liter; $\mu \mathrm{g} / \mathrm{L}$, micrograms per liter; $\mu \mathrm{S} / \mathrm{cm}$, microsiemens per centimeter at 25 degrees Celsius; mm, millimeter; <, concentration is less than the laboratory reporting limit; --, no data; E, the recovery or variation in recovery of the analyte was outside the acceptable range or the concentration reported is less than laboratory reporting level and is qualified as estimated; blue-shaded values are associated with the secondary monitoring sites for each principal highway; gray-shaded values are associated with the monitoring sites for each test highway]

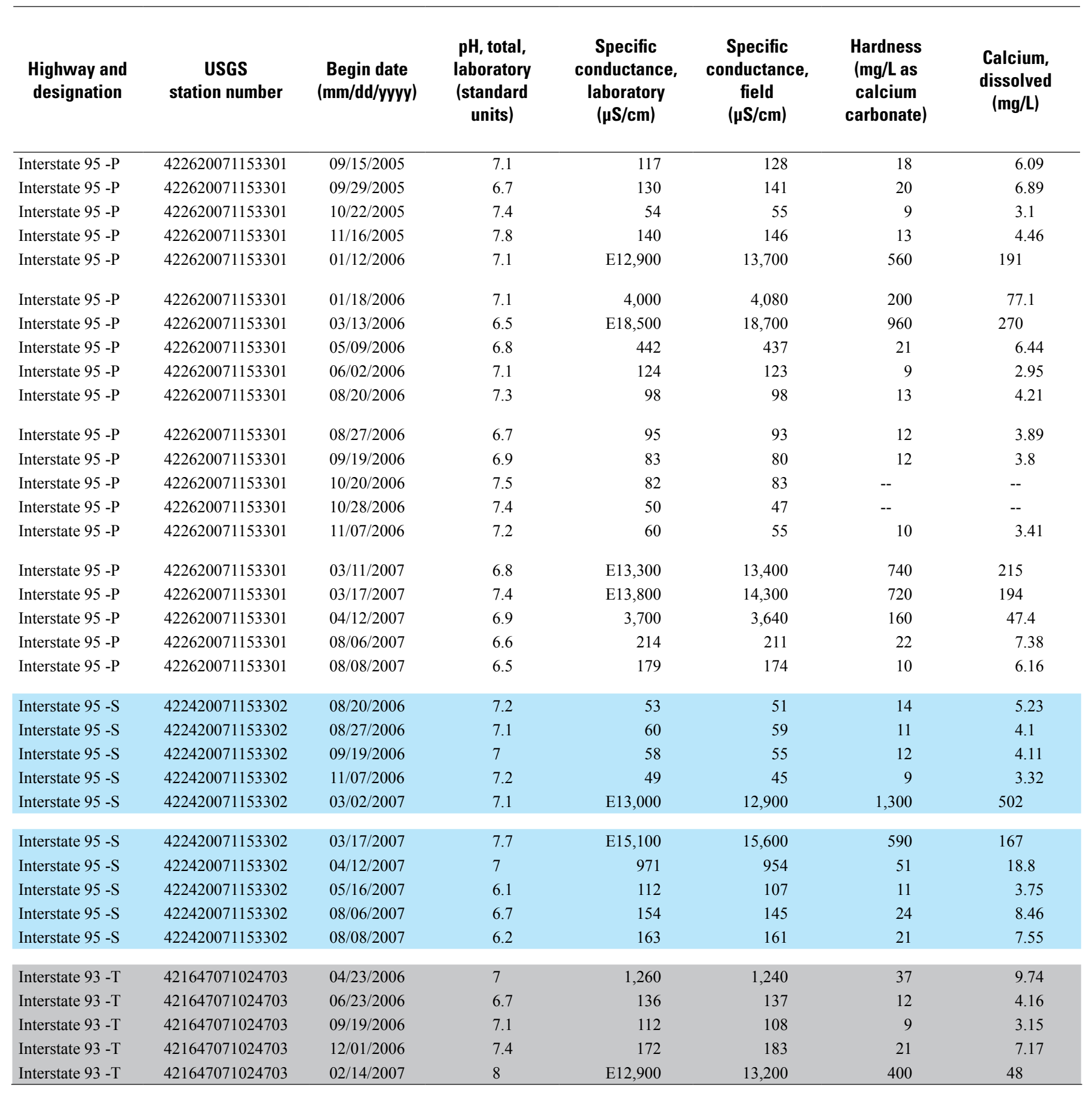


Table 16. Physical properties and concentrations of dissolved major ions, total nutrients, total-recoverable metals, polyaromatic hydrocarbons, phthalate esters, and suspended sediment in stormwater composite samples of highway runoff collected from 12 stations on 8 highways in Massachusetts, 2005-07.-Continued

[USGS, U.S. Geological Survey; -P, primary monitoring station; -S, secondary monitoring station; -T, monitoring station on test highway; mm/dd/yyyy, month, day, year; hrmn, hour minute; NTRU, nephelometric turbidity ratio units; mg/L, milligrams per liter; $\mu \mathrm{g} / \mathrm{L}$, micrograms per liter; $\mu \mathrm{S} / \mathrm{cm}$, microsiemens per centimeter at 25 degrees Celsius; $\mathrm{mm}$, millimeter; <, concentration is less than the laboratory reporting limit; --, no data; E, the recovery or variation in recovery of the analyte was outside the acceptable range or the concentration reported is less than laboratory reporting level and is qualified as estimated; blue-shaded values are associated with the secondary monitoring sites for each principal highway; gray-shaded values are associated with the monitoring sites for each test highway]

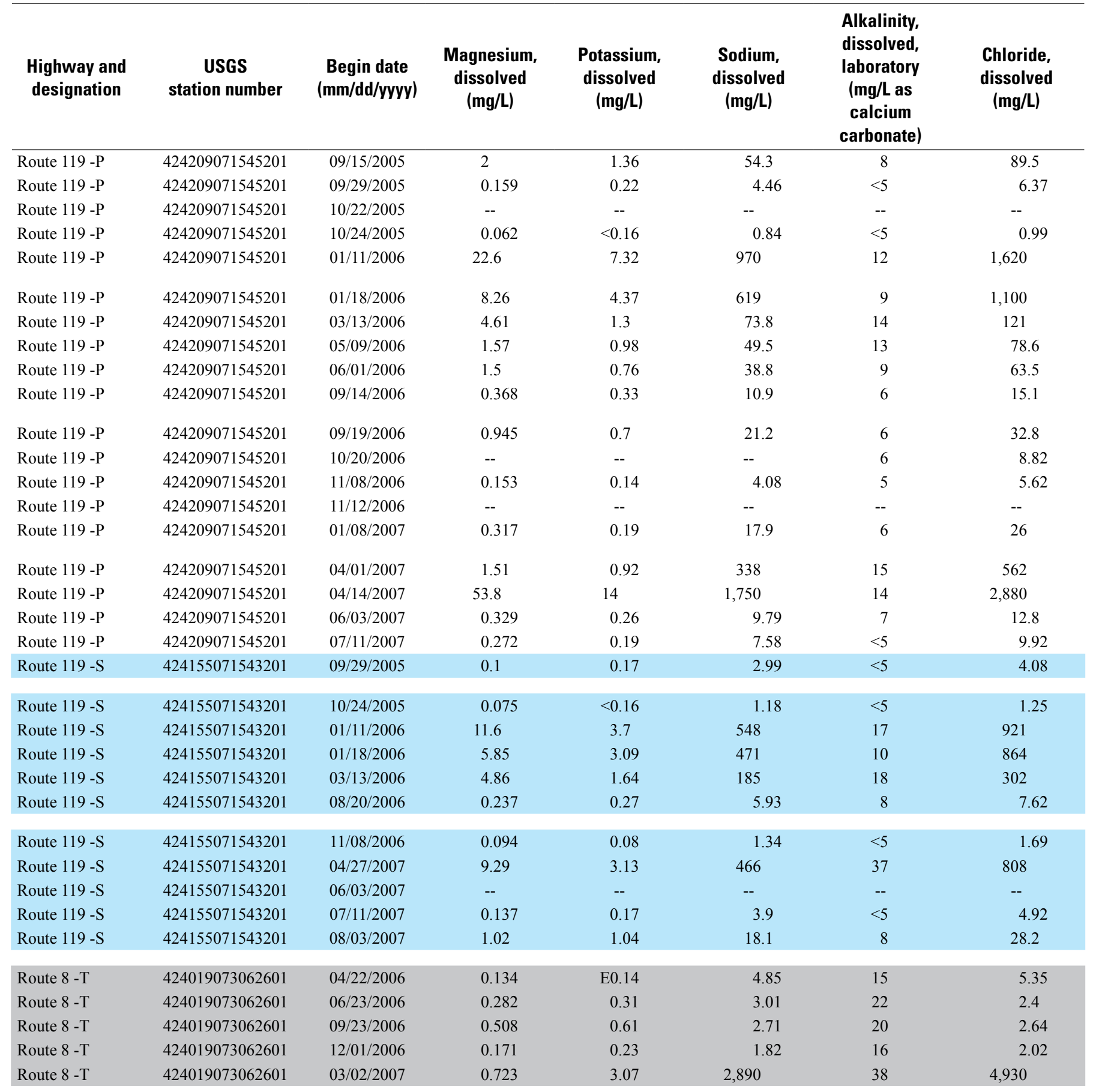


Table 16. Physical properties and concentrations of dissolved major ions, total nutrients, total-recoverable metals, polyaromatic hydrocarbons, phthalate esters, and suspended sediment in stormwater composite samples of highway runoff collected from 12 stations on 8 highways in Massachusetts, 2005-07.-Continued

[USGS, U.S. Geological Survey; -P, primary monitoring station; -S, secondary monitoring station; -T, monitoring station on test highway; mm/dd/yyyy, month, day, year; hrmn, hour minute; NTRU, nephelometric turbidity ratio units; mg/L, milligrams per liter; $\mu \mathrm{g} / \mathrm{L}$, micrograms per liter; $\mu \mathrm{S} / \mathrm{cm}$, microsiemens per centimeter at 25 degrees Celsius; mm, millimeter; <, concentration is less than the laboratory reporting limit; --, no data; E, the recovery or variation in recovery of the analyte was outside the acceptable range or the concentration reported is less than laboratory reporting level and is qualified as estimated; blue-shaded values are associated with the secondary monitoring sites for each principal highway; gray-shaded values are associated with the monitoring sites for each test highway]

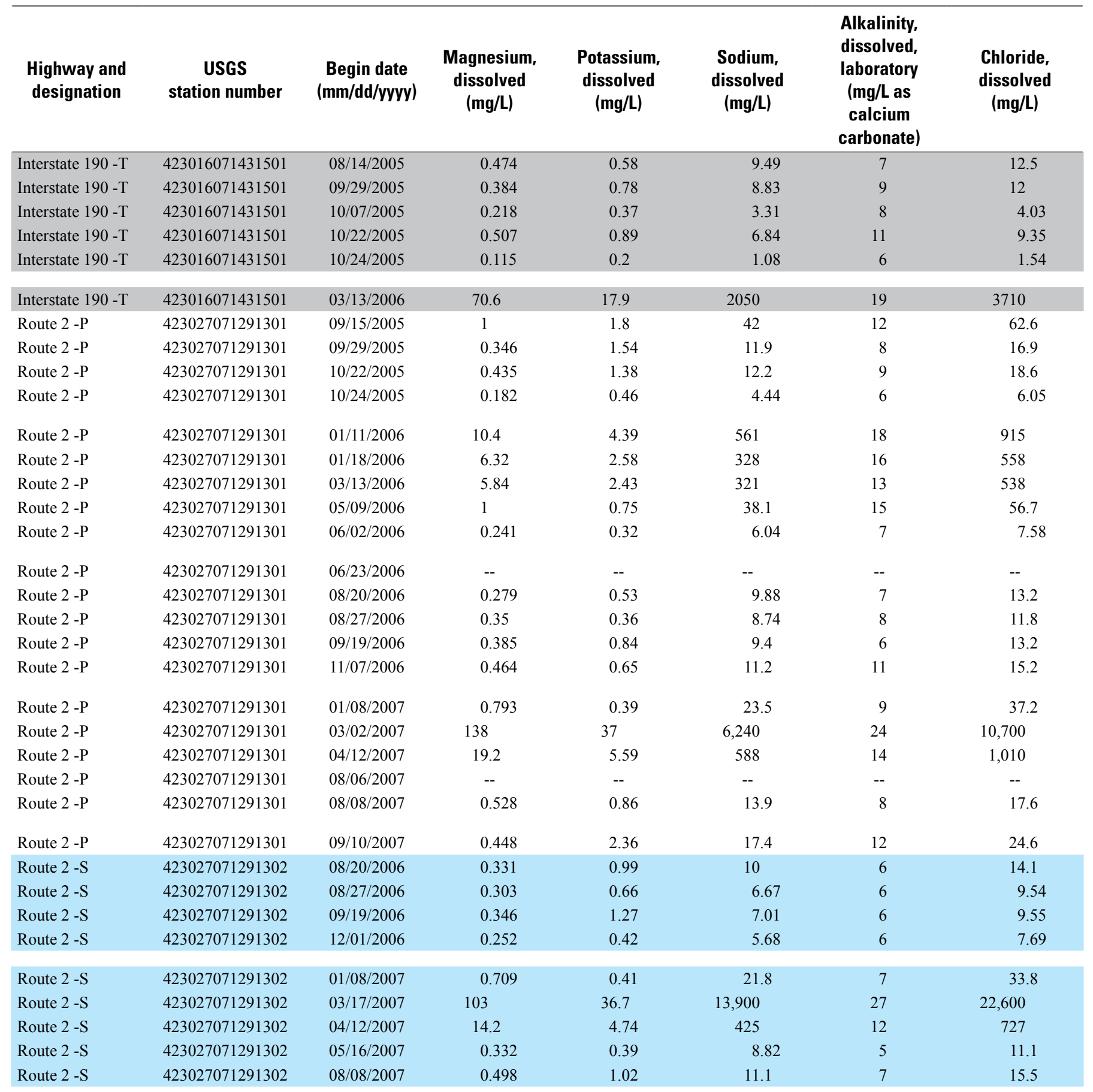


Table 16. Physical properties and concentrations of dissolved major ions, total nutrients, total-recoverable metals, polyaromatic hydrocarbons, phthalate esters, and suspended sediment in stormwater composite samples of highway runoff collected from 12 stations on 8 highways in Massachusetts, 2005-07.-Continued

[USGS, U.S. Geological Survey; -P, primary monitoring station; -S, secondary monitoring station; -T, monitoring station on test highway; mm/dd/yyyy, month, day, year; hrmn, hour minute; NTRU, nephelometric turbidity ratio units; mg/L, milligrams per liter; $\mu \mathrm{g} / \mathrm{L}$, micrograms per liter; $\mu \mathrm{S} / \mathrm{cm}$, microsiemens per centimeter at 25 degrees Celsius; $\mathrm{mm}$, millimeter; <, concentration is less than the laboratory reporting limit; --, no data; E, the recovery or variation in recovery of the analyte was outside the acceptable range or the concentration reported is less than laboratory reporting level and is qualified as estimated; blue-shaded values are associated with the secondary monitoring sites for each principal highway; gray-shaded values are associated with the monitoring sites for each test highway]

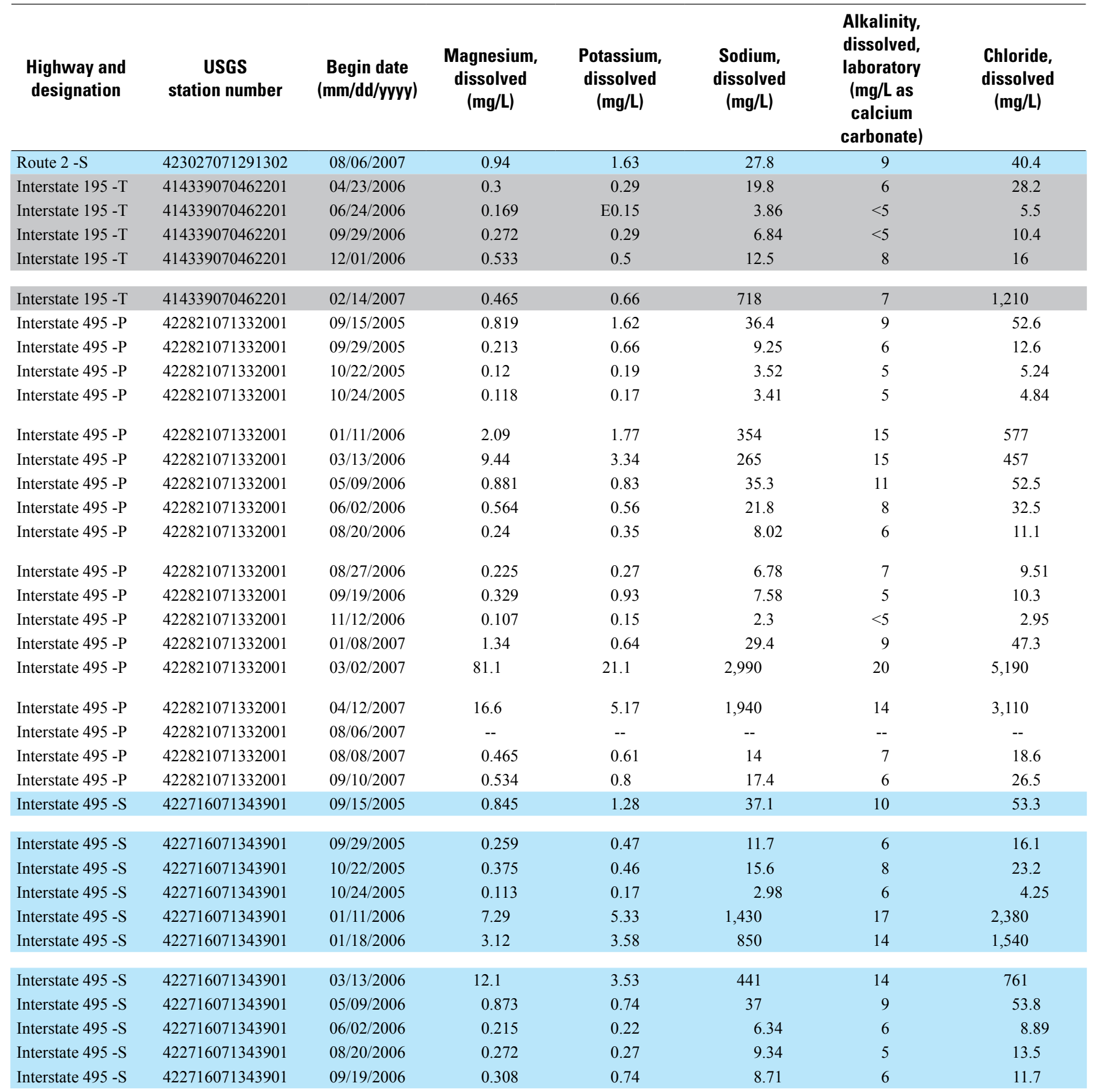


Table 16. Physical properties and concentrations of dissolved major ions, total nutrients, total-recoverable metals, polyaromatic hydrocarbons, phthalate esters, and suspended sediment in stormwater composite samples of highway runoff collected from 12 stations on 8 highways in Massachusetts, 2005-07.-Continued

[USGS, U.S. Geological Survey; -P, primary monitoring station; -S, secondary monitoring station; -T, monitoring station on test highway; mm/dd/yyyy, month, day, year; hrmn, hour minute; NTRU, nephelometric turbidity ratio units; mg/L, milligrams per liter; $\mu \mathrm{g} / \mathrm{L}$, micrograms per liter; $\mu \mathrm{S} / \mathrm{cm}$, microsiemens per centimeter at 25 degrees Celsius; mm, millimeter; <, concentration is less than the laboratory reporting limit; --, no data; E, the recovery or variation in recovery of the analyte was outside the acceptable range or the concentration reported is less than laboratory reporting level and is qualified as estimated; blue-shaded values are associated with the secondary monitoring sites for each principal highway; gray-shaded values are associated with the monitoring sites for each test highway]

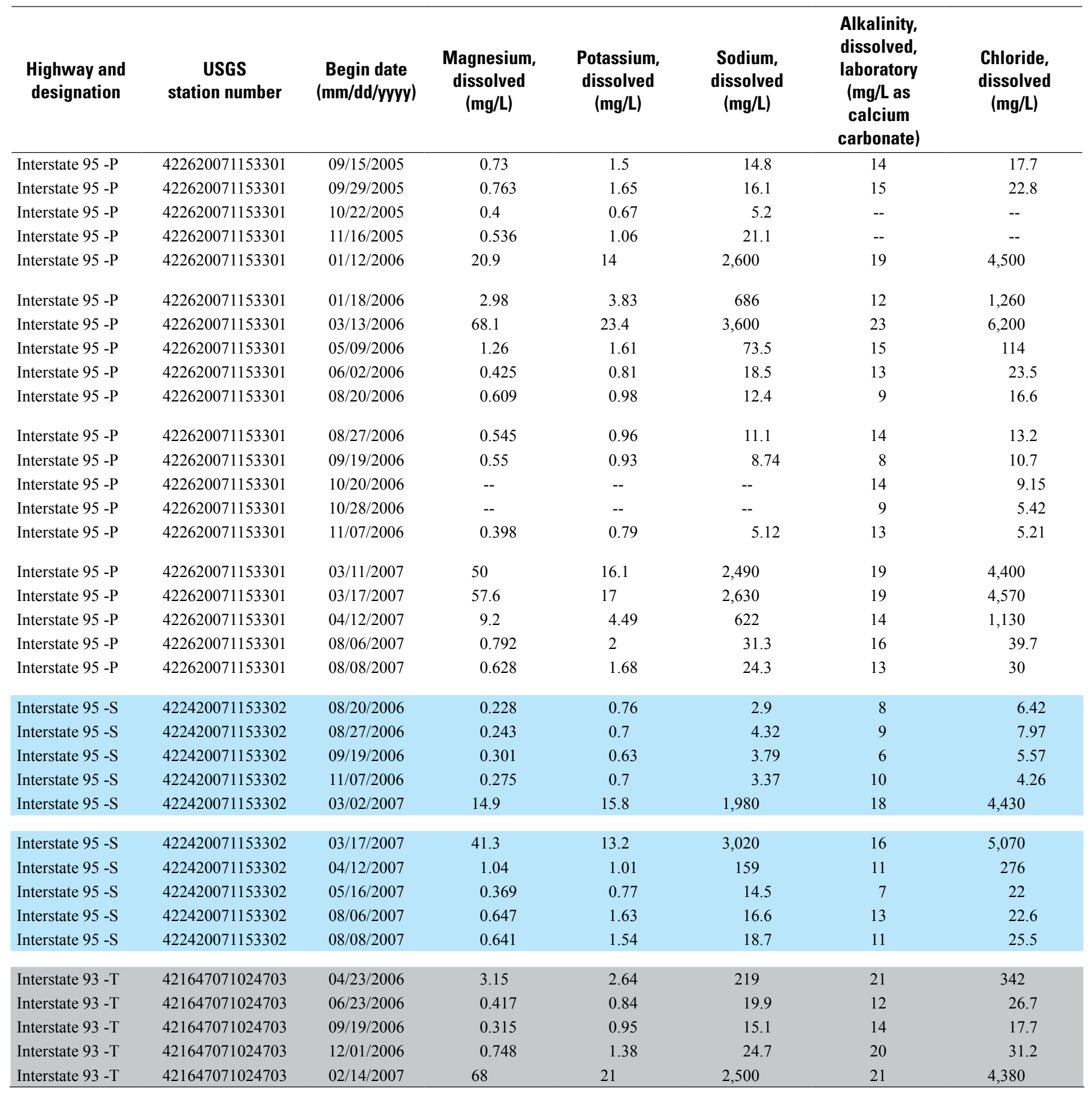


Table 16. Physical properties and concentrations of dissolved major ions, total nutrients, total-recoverable metals, polyaromatic hydrocarbons, phthalate esters, and suspended sediment in stormwater composite samples of highway runoff collected from 12 stations on 8 highways in Massachusetts, 2005-07.-Continued

[USGS, U.S. Geological Survey; -P, primary monitoring station; -S, secondary monitoring station; -T, monitoring station on test highway; mm/dd/yyyy, month, day, year; hrmn, hour minute; NTRU, nephelometric turbidity ratio units; mg/L, milligrams per liter; $\mu \mathrm{g} / \mathrm{L}$, micrograms per liter; $\mu \mathrm{S} / \mathrm{cm}$, microsiemens per centimeter at 25 degrees Celsius; mm, millimeter; <, concentration is less than the laboratory reporting limit; --, no data; E, the recovery or variation in recovery of the analyte was outside the acceptable range or the concentration reported is less than laboratory reporting level and is qualified as estimated; blue-shaded values are associated with the secondary monitoring sites for each principal highway; gray-shaded values are associated with the monitoring sites for each test highway]

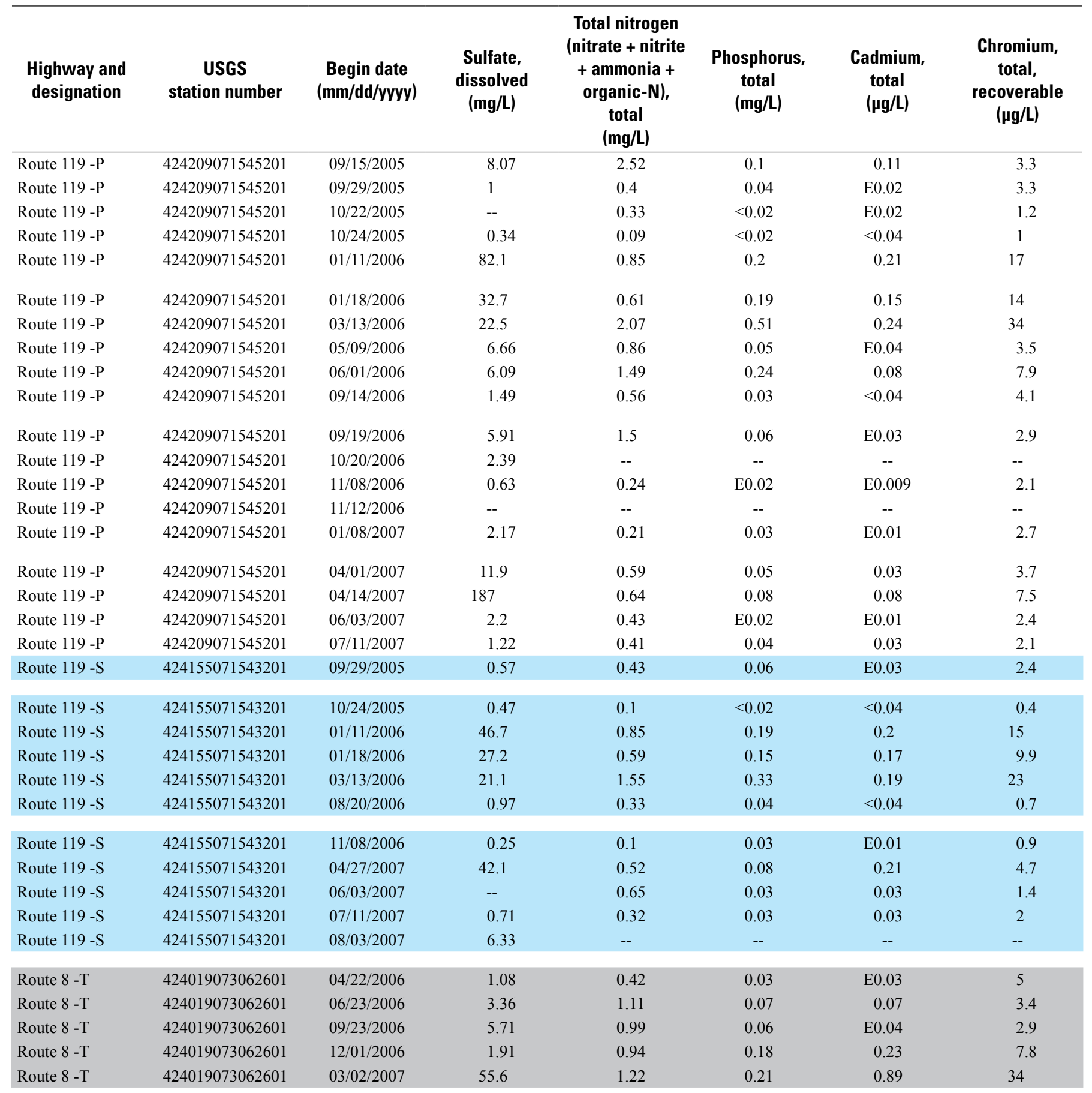


Table 16. Physical properties and concentrations of dissolved major ions, total nutrients, total-recoverable metals, polyaromatic hydrocarbons, phthalate esters, and suspended sediment in stormwater composite samples of highway runoff collected from 12 stations on 8 highways in Massachusetts, 2005-07.-Continued

[USGS, U.S. Geological Survey; -P, primary monitoring station; -S, secondary monitoring station; -T, monitoring station on test highway; mm/dd/yyyy, month, day, year; hrmn, hour minute; NTRU, nephelometric turbidity ratio units; mg/L, milligrams per liter; $\mu \mathrm{g} / \mathrm{L}$, micrograms per liter; $\mu \mathrm{S} / \mathrm{cm}$, microsiemens per centimeter at 25 degrees Celsius; mm, millimeter; <, concentration is less than the laboratory reporting limit; --, no data; E, the recovery or variation in recovery of the analyte was outside the acceptable range or the concentration reported is less than laboratory reporting level and is qualified as estimated; blue-shaded values are associated with the secondary monitoring sites for each principal highway; gray-shaded values are associated with the monitoring sites for each test highway]

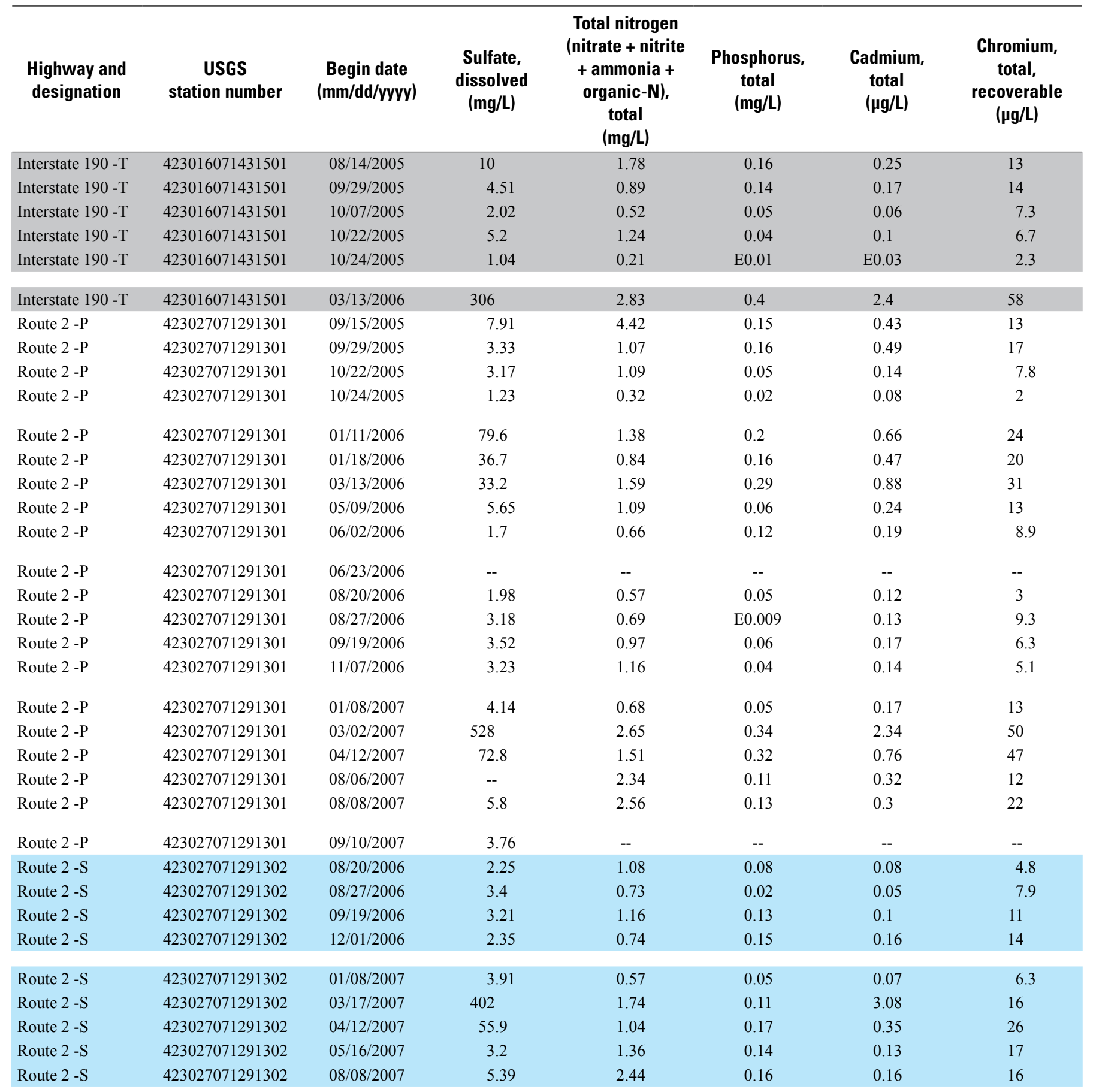


Table 16. Physical properties and concentrations of dissolved major ions, total nutrients, total-recoverable metals, polyaromatic hydrocarbons, phthalate esters, and suspended sediment in stormwater composite samples of highway runoff collected from 12 stations on 8 highways in Massachusetts, 2005-07.-Continued

[USGS, U.S. Geological Survey; -P, primary monitoring station; -S, secondary monitoring station; -T, monitoring station on test highway; mm/dd/yyyy, month, day, year; hrmn, hour minute; NTRU, nephelometric turbidity ratio units; mg/L, milligrams per liter; $\mu \mathrm{g} / \mathrm{L}$, micrograms per liter; $\mu \mathrm{S} / \mathrm{cm}$, microsiemens per centimeter at 25 degrees Celsius; $\mathrm{mm}$, millimeter; <, concentration is less than the laboratory reporting limit; --, no data; E, the recovery or variation in recovery of the analyte was outside the acceptable range or the concentration reported is less than laboratory reporting level and is qualified as estimated; blue-shaded values are associated with the secondary monitoring sites for each principal highway; gray-shaded values are associated with the monitoring sites for each test highway]

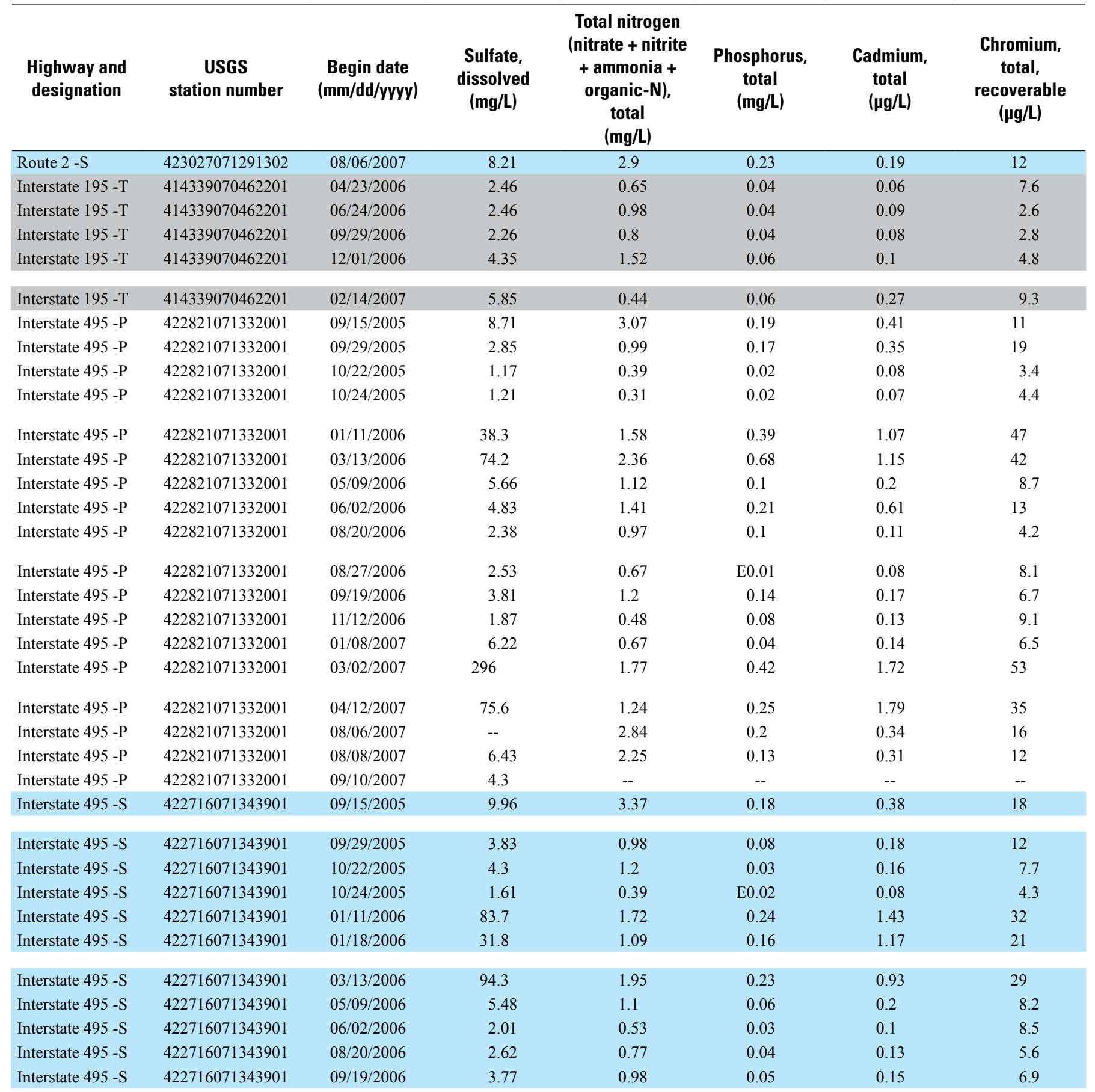


Table 16. Physical properties and concentrations of dissolved major ions, total nutrients, total-recoverable metals, polyaromatic hydrocarbons, phthalate esters, and suspended sediment in stormwater composite samples of highway runoff collected from 12 stations on 8 highways in Massachusetts, 2005-07.-Continued

[USGS, U.S. Geological Survey; -P, primary monitoring station; -S, secondary monitoring station; -T, monitoring station on test highway; mm/dd/yyyy, month, day, year; hrmn, hour minute; NTRU, nephelometric turbidity ratio units; mg/L, milligrams per liter; $\mu \mathrm{g} / \mathrm{L}$, micrograms per liter; $\mu \mathrm{S} / \mathrm{cm}$, microsiemens per centimeter at 25 degrees Celsius; mm, millimeter; <, concentration is less than the laboratory reporting limit; --, no data; E, the recovery or variation in recovery of the analyte was outside the acceptable range or the concentration reported is less than laboratory reporting level and is qualified as estimated; blue-shaded values are associated with the secondary monitoring sites for each principal highway; gray-shaded values are associated with the monitoring sites for each test highway]

\begin{tabular}{|c|c|c|c|c|c|c|c|}
\hline $\begin{array}{l}\text { Highway and } \\
\text { designation }\end{array}$ & $\begin{array}{c}\text { USGS } \\
\text { station number }\end{array}$ & $\begin{array}{c}\text { Begin date } \\
\text { (mm/dd/yyyy) }\end{array}$ & $\begin{array}{l}\text { Sulfate, } \\
\text { dissolved } \\
\text { (mg/L) }\end{array}$ & $\begin{array}{c}\text { Total nitrogen } \\
\text { (nitrate + nitrite } \\
\text { + ammonia + } \\
\text { organic-N), } \\
\text { total } \\
\text { (mg/L) }\end{array}$ & $\begin{array}{c}\text { Phosphorus, } \\
\text { total } \\
\text { (mg/L) }\end{array}$ & $\begin{array}{c}\text { Cadmium, } \\
\text { total } \\
(\mu \mathrm{g} / \mathrm{L})\end{array}$ & $\begin{array}{c}\text { Chromium, } \\
\text { total, } \\
\text { recoverable } \\
(\mu \mathrm{g} / \mathrm{L})\end{array}$ \\
\hline Interstate $95-\mathrm{P}$ & 422620071153301 & $09 / 15 / 2005$ & 8.62 & 1.54 & 0.13 & 0.25 & 24 \\
\hline Interstate $95-\mathrm{P}$ & 422620071153301 & $11 / 16 / 2005$ & -- & 1.19 & 0.05 & 0.08 & 4.9 \\
\hline Interstate $95-\mathrm{P}$ & 422620071153301 & $01 / 12 / 2006$ & 125 & 3.74 & 0.31 & 2.4 & 89 \\
\hline Interstate $95-\mathrm{P}$ & 422620071153301 & $01 / 18 / 2006$ & 19.8 & 1.58 & 0.23 & 1.03 & 39 \\
\hline Interstate $95-\mathrm{P}$ & 422620071153301 & $03 / 13 / 2006$ & 468 & 6.12 & 0.54 & 5.7 & 73 \\
\hline Interstate $95-\mathrm{P}$ & 422620071153301 & $05 / 09 / 2006$ & 9.18 & 1.52 & 0.13 & 0.16 & 21 \\
\hline Interstate $95-\mathrm{P}$ & 422620071153301 & $09 / 19 / 2006$ & 6.87 & 1.12 & 0.07 & 0.11 & 9.9 \\
\hline Interstate $95-\mathrm{P}$ & 422620071153301 & $10 / 20 / 2006$ & 6.28 & -- & -- & -- & -- \\
\hline Interstate $95-\mathrm{P}$ & 422620071153301 & $10 / 28 / 2006$ & 3.25 & -- & -- & -- & -- \\
\hline Interstate $95-\mathrm{P}$ & 422620071153301 & $11 / 07 / 2006$ & 3.8 & 1.25 & 0.1 & 0.37 & 9.7 \\
\hline Interstate $95-\mathrm{P}$ & 422620071153301 & 03/11/2007 & 364 & 3.32 & 0.15 & 2.63 & 16 \\
\hline Interstate $95-\mathrm{P}$ & 422620071153301 & $03 / 17 / 2007$ & 214 & 1.75 & 0.38 & 1.31 & 47 \\
\hline Interstate $95-\mathrm{P}$ & 422620071153301 & $04 / 12 / 2007$ & 43.6 & 2.05 & 0.2 & 0.69 & 29 \\
\hline Interstate $95-\mathrm{P}$ & 422620071153301 & $08 / 06 / 2007$ & 12.4 & 2.32 & 0.21 & 0.08 & 11 \\
\hline Interstate $95-\mathrm{P}$ & 422620071153301 & 08/08/2007 & 13.1 & 2.38 & 0.16 & 0.1 & 8.3 \\
\hline Interstate $95-\mathrm{S}$ & 422420071153302 & $05 / 16 / 2007$ & 4.35 & 2.8 & 0.33 & 0.3 & 27 \\
\hline Interstate $95-\mathrm{S}$ & 422420071153302 & $08 / 06 / 2007$ & 9.82 & 4.07 & 0.41 & 0.53 & 16 \\
\hline Interstate $95-\mathrm{S}$ & 422420071153302 & $08 / 08 / 2007$ & 10.9 & 3.89 & 0.15 & 0.28 & 39 \\
\hline Interstate $93-\mathrm{T}$ & 421647071024703 & $04 / 23 / 2006$ & 17.4 & 1.71 & 0.13 & 0.45 & 26 \\
\hline Interstate $93-\mathrm{T}$ & 421647071024703 & $06 / 23 / 2006$ & 5.13 & 2.09 & 0.71 & 1.69 & 100 \\
\hline Interstate $93-\mathrm{T}$ & 421647071024703 & $09 / 19 / 2006$ & 4.84 & 1.1 & 0.11 & 0.17 & 13 \\
\hline Interstate $93-\mathrm{T}$ & 421647071024703 & $12 / 01 / 2006$ & 10.2 & 2.32 & 0.34 & 0.78 & 40 \\
\hline Interstate $93-\mathrm{T}$ & 421647071024703 & $02 / 14 / 2007$ & 257 & 4 & 1 & 4 & 110 \\
\hline
\end{tabular}


Table 16. Physical properties and concentrations of dissolved major ions, total nutrients, total-recoverable metals, polyaromatic hydrocarbons, phthalate esters, and suspended sediment in stormwater composite samples of highway runoff collected from 12 stations on 8 highways in Massachusetts, 2005-07.-Continued

[USGS, U.S. Geological Survey; -P, primary monitoring station; -S, secondary monitoring station; -T, monitoring station on test highway; mm/dd/yyyy, month, day, year; hrmn, hour minute; NTRU, nephelometric turbidity ratio units; mg/L, milligrams per liter; $\mu \mathrm{g} / \mathrm{L}$, micrograms per liter; $\mu \mathrm{S} / \mathrm{cm}$, microsiemens per centimeter at 25 degrees Celsius; mm, millimeter; <, concentration is less than the laboratory reporting limit; --, no data; E, the recovery or variation in recovery of the analyte was outside the acceptable range or the concentration reported is less than laboratory reporting level and is qualified as estimated; blue-shaded values are associated with the secondary monitoring sites for each principal highway; gray-shaded values are associated with the monitoring sites for each test highway]

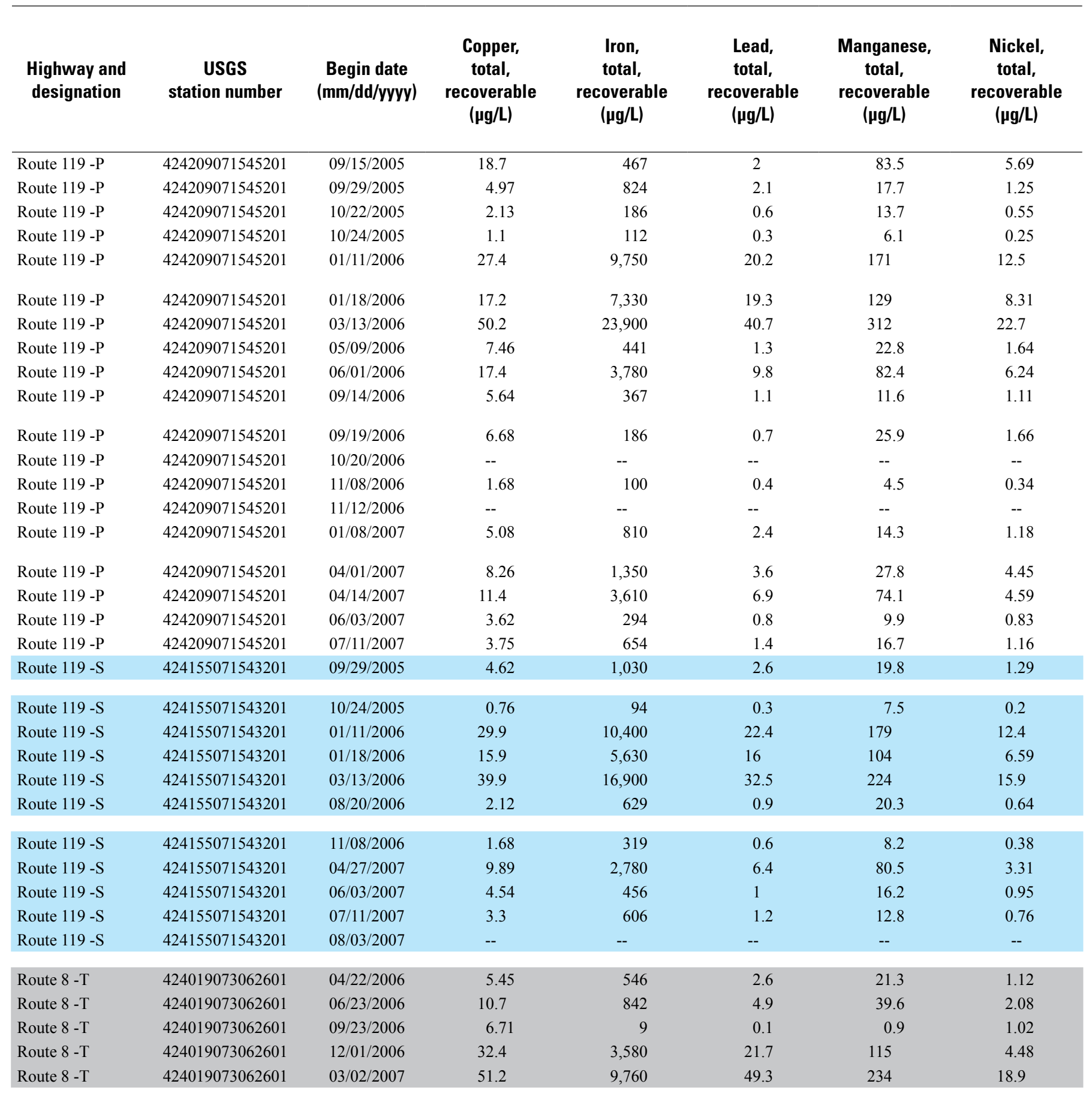


Table 16. Physical properties and concentrations of dissolved major ions, total nutrients, total-recoverable metals, polyaromatic hydrocarbons, phthalate esters, and suspended sediment in stormwater composite samples of highway runoff collected from 12 stations on 8 highways in Massachusetts, 2005-07.-Continued

[USGS, U.S. Geological Survey; -P, primary monitoring station; -S, secondary monitoring station; -T, monitoring station on test highway; mm/dd/yyyy, month, day, year; hrmn, hour minute; NTRU, nephelometric turbidity ratio units; mg/L, milligrams per liter; $\mu \mathrm{g} / \mathrm{L}$, micrograms per liter; $\mu \mathrm{S} / \mathrm{cm}$, microsiemens per centimeter at 25 degrees Celsius; $\mathrm{mm}$, millimeter; <, concentration is less than the laboratory reporting limit; --, no data; E, the recovery or variation in recovery of the analyte was outside the acceptable range or the concentration reported is less than laboratory reporting level and is qualified as estimated; blue-shaded values are associated with the secondary monitoring sites for each principal highway; gray-shaded values are associated with the monitoring sites for each test highway]

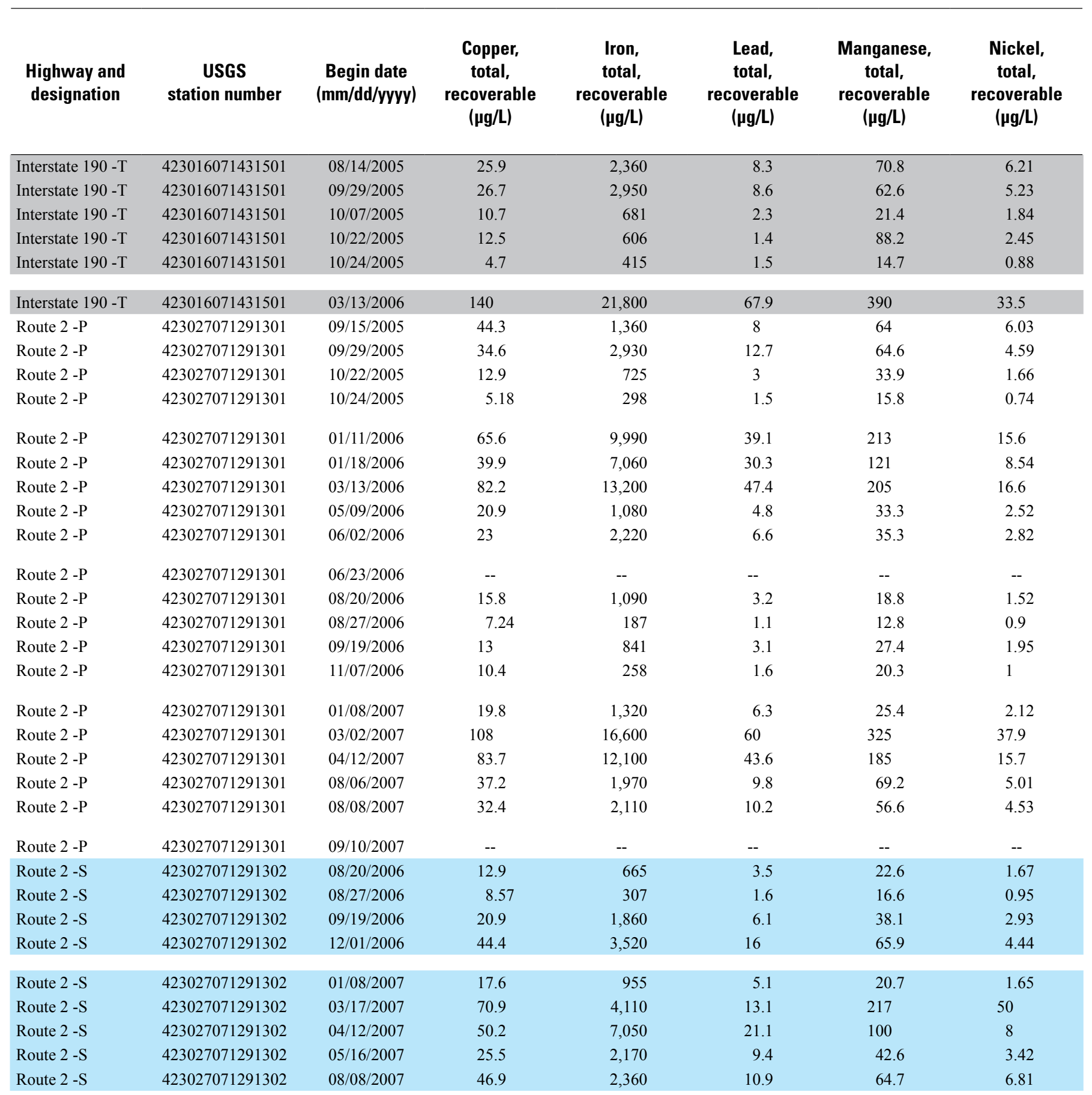


Table 16. Physical properties and concentrations of dissolved major ions, total nutrients, total-recoverable metals, polyaromatic hydrocarbons, phthalate esters, and suspended sediment in stormwater composite samples of highway runoff collected from 12 stations on 8 highways in Massachusetts, 2005-07.-Continued

[USGS, U.S. Geological Survey; -P, primary monitoring station; -S, secondary monitoring station; -T, monitoring station on test highway; mm/dd/yyyy, month, day, year; hrmn, hour minute; NTRU, nephelometric turbidity ratio units; mg/L, milligrams per liter; $\mu \mathrm{g} / \mathrm{L}$, micrograms per liter; $\mu \mathrm{S} / \mathrm{cm}$, microsiemens per centimeter at 25 degrees Celsius; $\mathrm{mm}$, millimeter; <, concentration is less than the laboratory reporting limit; --, no data; E, the recovery or variation in recovery of the analyte was outside the acceptable range or the concentration reported is less than laboratory reporting level and is qualified as estimated; blue-shaded values are associated with the secondary monitoring sites for each principal highway; gray-shaded values are associated with the monitoring sites for each test highway]

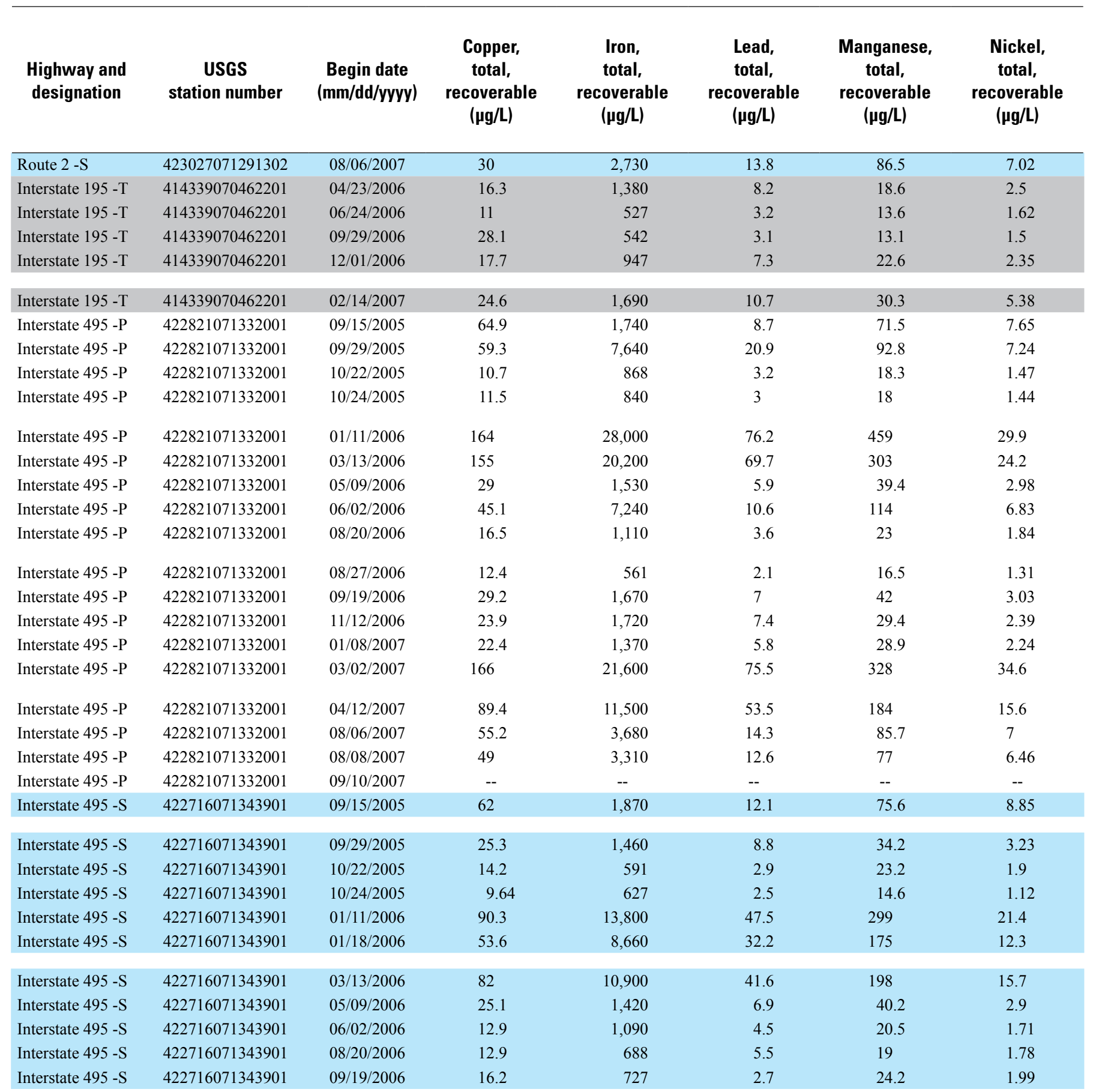


Table 16. Physical properties and concentrations of dissolved major ions, total nutrients, total-recoverable metals, polyaromatic hydrocarbons, phthalate esters, and suspended sediment in stormwater composite samples of highway runoff collected from 12 stations on 8 highways in Massachusetts, 2005-07.-Continued

[USGS, U.S. Geological Survey; -P, primary monitoring station; -S, secondary monitoring station; -T, monitoring station on test highway; mm/dd/yyyy, month, day, year; hrmn, hour minute; NTRU, nephelometric turbidity ratio units; mg/L, milligrams per liter; $\mu \mathrm{g} / \mathrm{L}$, micrograms per liter; $\mu \mathrm{S} / \mathrm{cm}$, microsiemens per centimeter at 25 degrees Celsius; $\mathrm{mm}$, millimeter; <, concentration is less than the laboratory reporting limit; --, no data; E, the recovery or variation in recovery of the analyte was outside the acceptable range or the concentration reported is less than laboratory reporting level and is qualified as estimated; blue-shaded values are associated with the secondary monitoring sites for each principal highway; gray-shaded values are associated with the monitoring sites for each test highway]

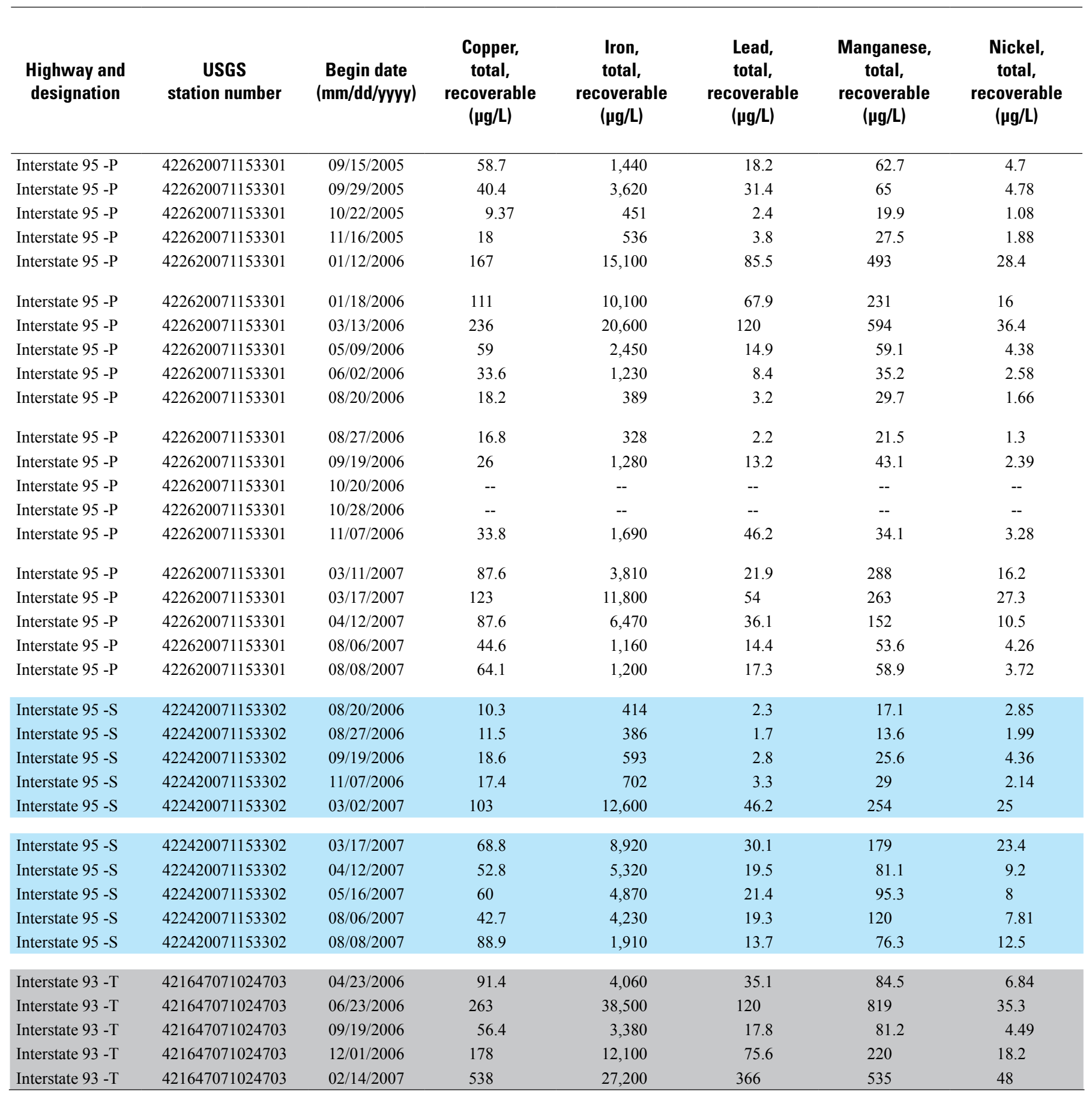


Table 16. Physical properties and concentrations of dissolved major ions, total nutrients, total-recoverable metals, polyaromatic hydrocarbons, phthalate esters, and suspended sediment in stormwater composite samples of highway runoff collected from 12 stations on 8 highways in Massachusetts, 2005-07.-Continued

[USGS, U.S. Geological Survey; -P, primary monitoring station; -S, secondary monitoring station; -T, monitoring station on test highway; mm/dd/yyyy, month, day, year; hrmn, hour minute; NTRU, nephelometric turbidity ratio units; mg/L, milligrams per liter; $\mu \mathrm{g} / \mathrm{L}$, micrograms per liter; $\mu \mathrm{S} / \mathrm{cm}$, microsiemens per centimeter at 25 degrees Celsius; $\mathrm{mm}$, millimeter; <, concentration is less than the laboratory reporting limit; --, no data; E, the recovery

or variation in recovery of the analyte was outside the acceptable range or the concentration reported is less than laboratory reporting level and is qualified as estimated; blue-shaded values are associated with the secondary monitoring sites for each principal highway; gray-shaded values are associated with the monitoring sites for each test highway]

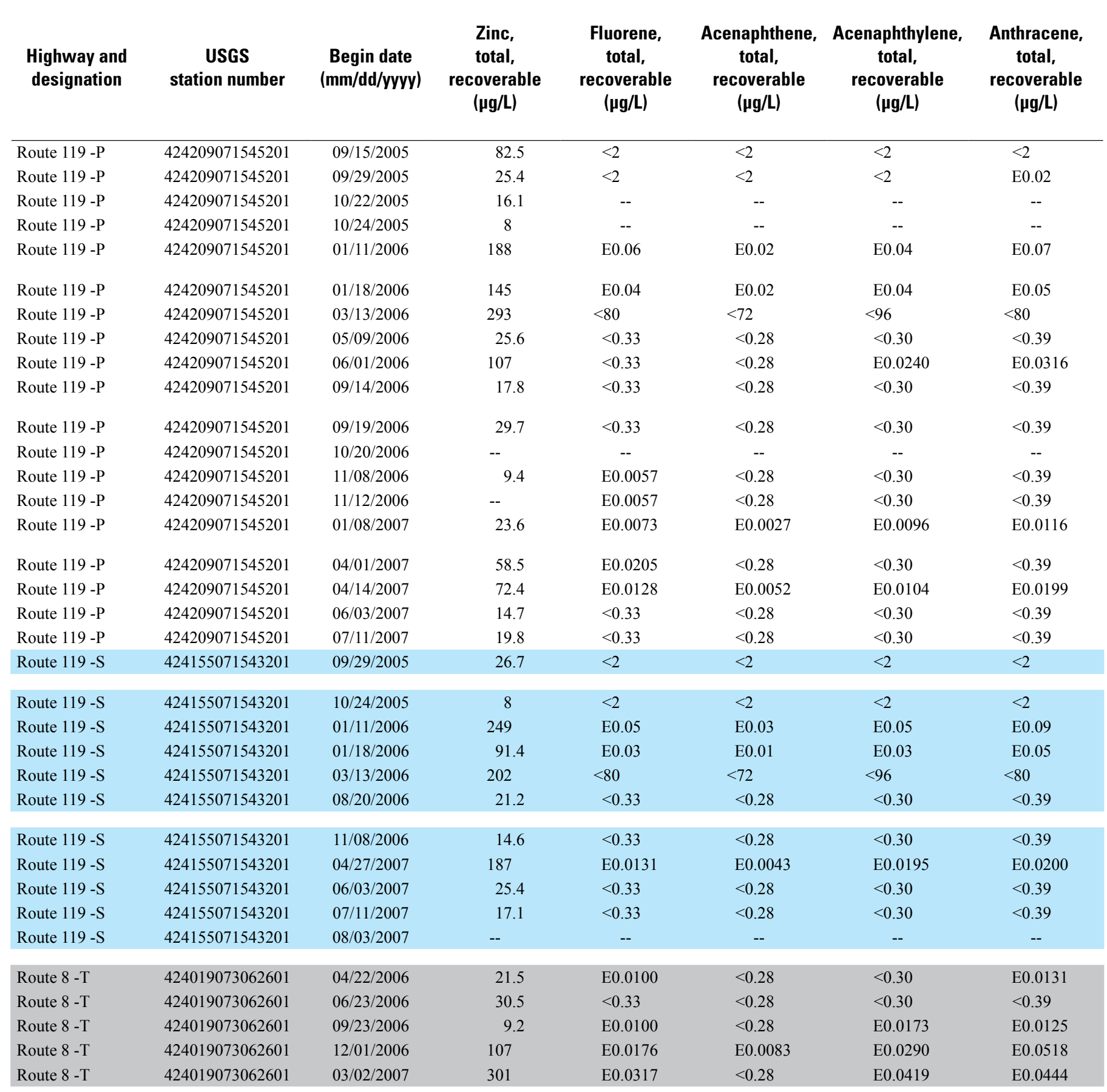


Table 16. Physical properties and concentrations of dissolved major ions, total nutrients, total-recoverable metals, polyaromatic hydrocarbons, phthalate esters, and suspended sediment in stormwater composite samples of highway runoff collected from 12 stations on 8 highways in Massachusetts, 2005-07.-Continued

[USGS, U.S. Geological Survey; -P, primary monitoring station; -S, secondary monitoring station; -T, monitoring station on test highway; mm/dd/yyyy, month, day, year; hrmn, hour minute; NTRU, nephelometric turbidity ratio units; mg/L, milligrams per liter; $\mu \mathrm{g} / \mathrm{L}$, micrograms per liter; $\mu \mathrm{S} / \mathrm{cm}$, microsiemens per centimeter at 25 degrees Celsius; $\mathrm{mm}$, millimeter; <, concentration is less than the laboratory reporting limit; --, no data; E, the recovery

or variation in recovery of the analyte was outside the acceptable range or the concentration reported is less than laboratory reporting level and is qualified as estimated; blue-shaded values are associated with the secondary monitoring sites for each principal highway; gray-shaded values are associated with the monitoring sites for each test highway]

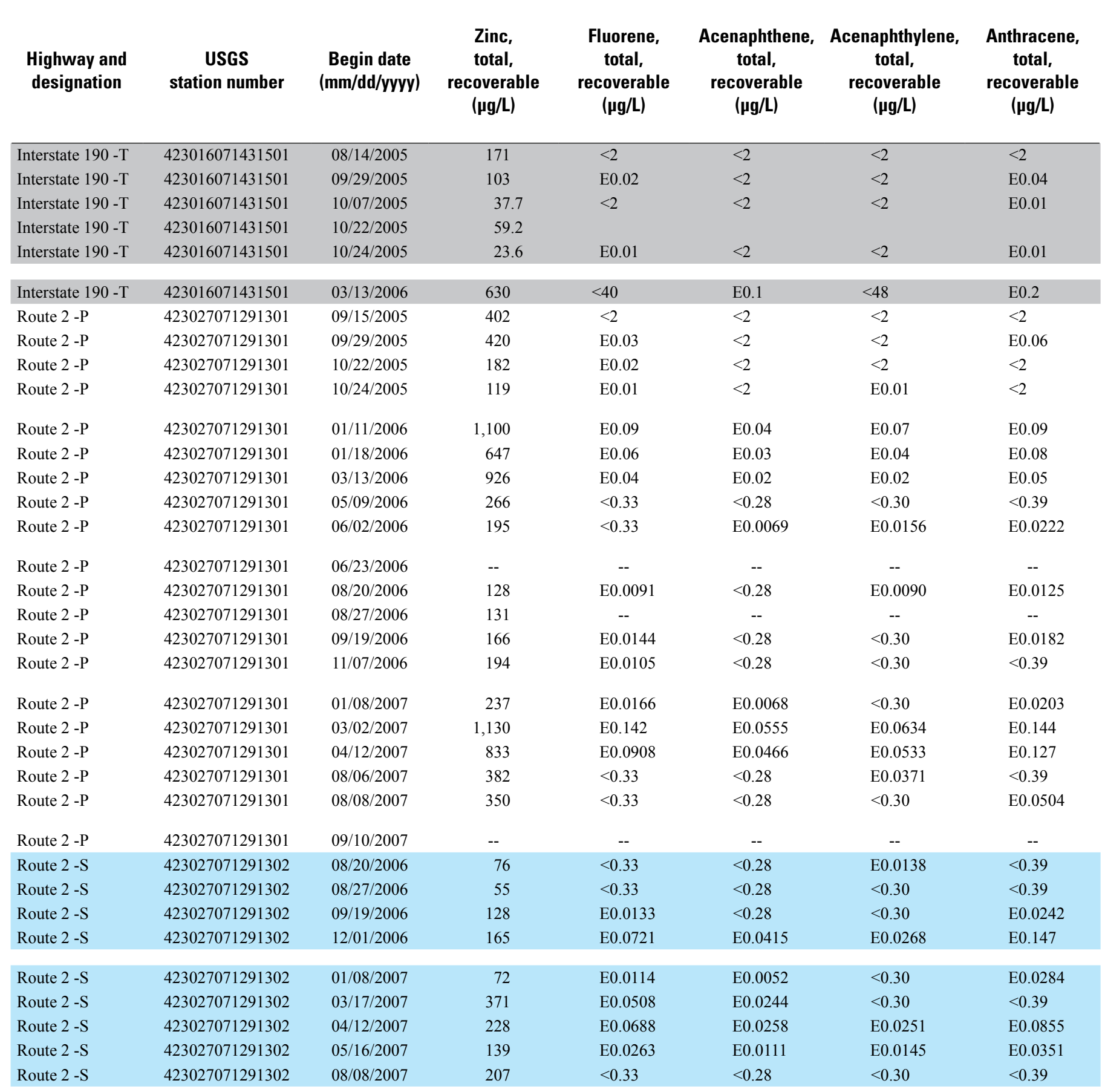


Table 16. Physical properties and concentrations of dissolved major ions, total nutrients, total-recoverable metals, polyaromatic hydrocarbons, phthalate esters, and suspended sediment in stormwater composite samples of highway runoff collected from 12 stations on 8 highways in Massachusetts, 2005-07.-Continued

[USGS, U.S. Geological Survey; -P, primary monitoring station; -S, secondary monitoring station; -T, monitoring station on test highway; mm/dd/yyyy, month, day, year; hrmn, hour minute; NTRU, nephelometric turbidity ratio units; mg/L, milligrams per liter; $\mu \mathrm{g} / \mathrm{L}$, micrograms per liter; $\mu \mathrm{S} / \mathrm{cm}$, microsiemens per centimeter at 25 degrees Celsius; mm, millimeter; <, concentration is less than the laboratory reporting limit; --, no data; E, the recovery

or variation in recovery of the analyte was outside the acceptable range or the concentration reported is less than laboratory reporting level and is qualified as estimated; blue-shaded values are associated with the secondary monitoring sites for each principal highway; gray-shaded values are associated with the monitoring sites for each test highway]

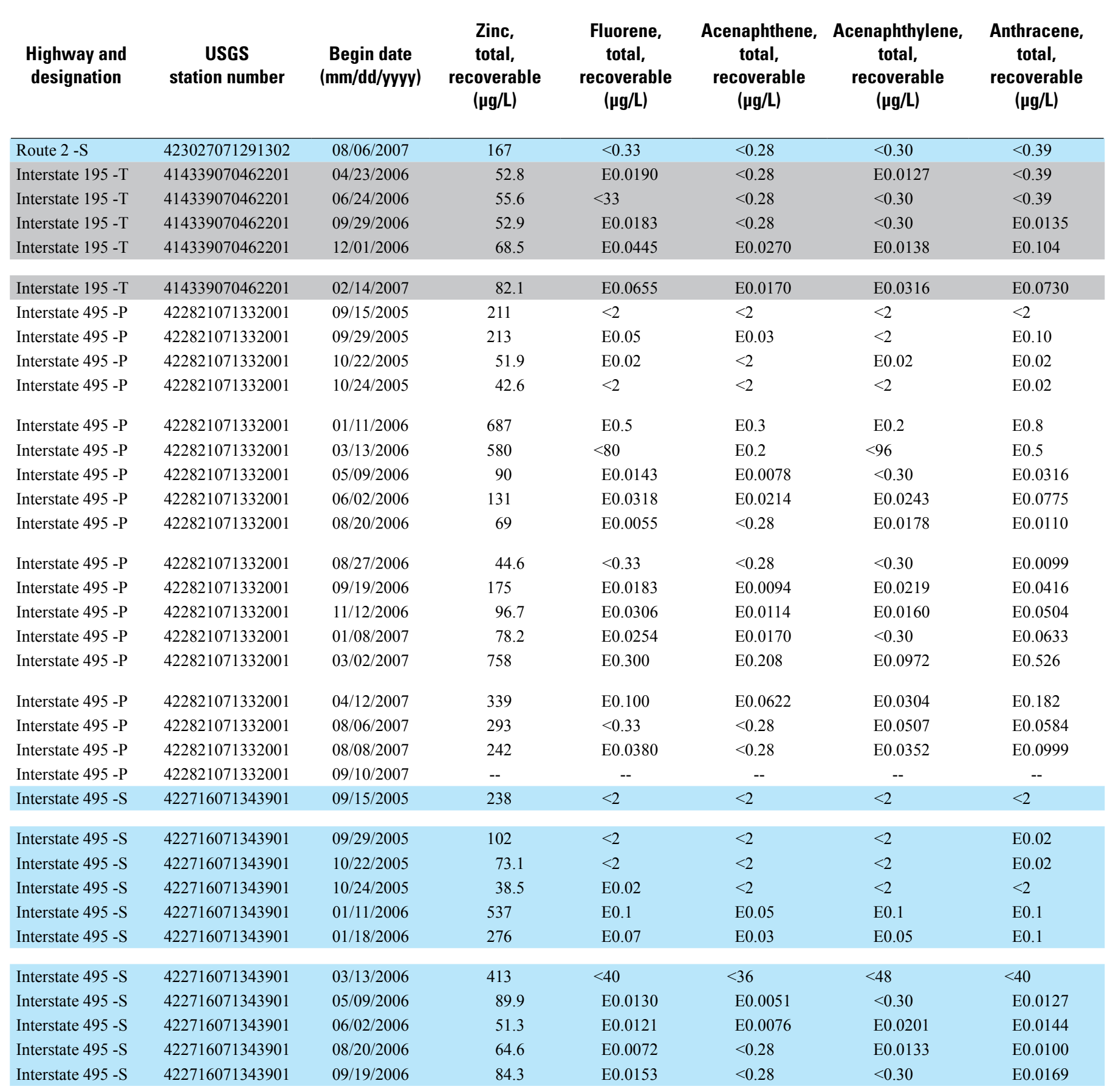


Table 16. Physical properties and concentrations of dissolved major ions, total nutrients, total-recoverable metals, polyaromatic hydrocarbons, phthalate esters, and suspended sediment in stormwater composite samples of highway runoff collected from 12 stations on 8 highways in Massachusetts, 2005-07.-Continued

[USGS, U.S. Geological Survey; -P, primary monitoring station; -S, secondary monitoring station; -T, monitoring station on test highway; mm/dd/yyyy, month, day, year; hrmn, hour minute; NTRU, nephelometric turbidity ratio units; mg/L, milligrams per liter; $\mu \mathrm{g} / \mathrm{L}$, micrograms per liter; $\mu \mathrm{S} / \mathrm{cm}$, microsiemens per centimeter at 25 degrees Celsius; $\mathrm{mm}$, millimeter; <, concentration is less than the laboratory reporting limit; --, no data; E, the recovery

or variation in recovery of the analyte was outside the acceptable range or the concentration reported is less than laboratory reporting level and is qualified as estimated; blue-shaded values are associated with the secondary monitoring sites for each principal highway; gray-shaded values are associated with the monitoring sites for each test highway]

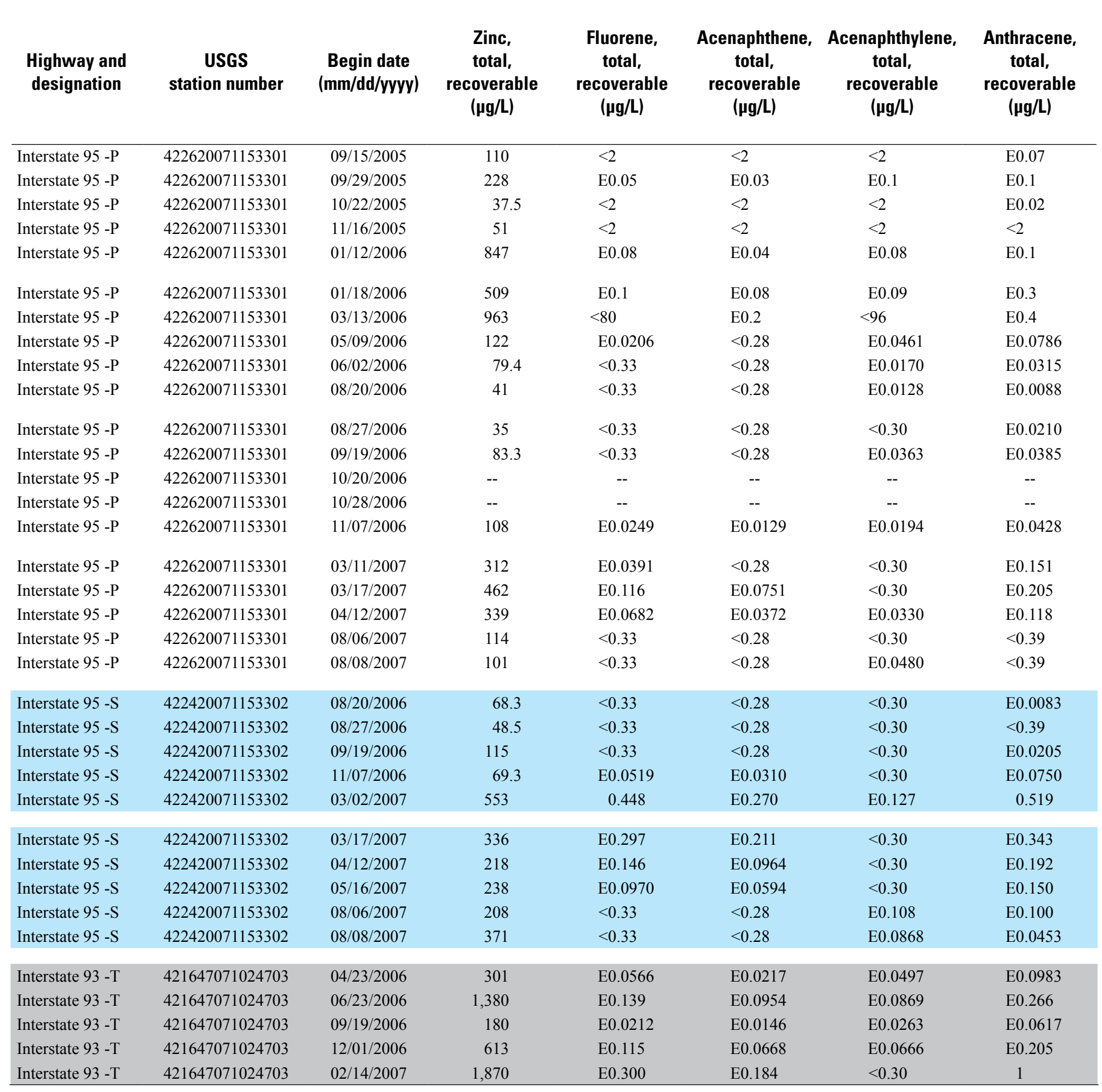


Table 16. Physical properties and concentrations of dissolved major ions, total nutrients, total-recoverable metals, polyaromatic hydrocarbons, phthalate esters, and suspended sediment in stormwater composite samples of highway runoff collected from 12 stations on 8 highways in Massachusetts, 2005-07.-Continued

[USGS, U.S. Geological Survey; -P, primary monitoring station; -S, secondary monitoring station; -T, monitoring station on test highway; mm/dd/yyyy, month, day, year; hrmn, hour minute; NTRU, nephelometric turbidity ratio units; mg/L, milligrams per liter; $\mu \mathrm{g} / \mathrm{L}$, micrograms per liter; $\mu \mathrm{S} / \mathrm{cm}$, microsiemens per centimeter at 25 degrees Celsius; $\mathrm{mm}$, millimeter; <, concentration is less than the laboratory reporting limit; --, no data; E, the recovery or variation in recovery of the analyte was outside the acceptable range or the concentration reported is less than laboratory reporting level and is qualified as estimated; blue-shaded values are associated with the secondary monitoring sites for each principal highway; gray-shaded values are associated with the monitoring sites for each test highway]

\begin{tabular}{|c|c|c|c|c|c|c|c|}
\hline $\begin{array}{l}\text { Highway and } \\
\text { designation }\end{array}$ & $\begin{array}{c}\text { USGS } \\
\text { station number }\end{array}$ & $\begin{array}{c}\text { Begin date } \\
\text { (mm/dd/yyyy) }\end{array}$ & $\begin{array}{c}\text { Benzo[a]- } \\
\text { anthracene, } \\
\text { total, } \\
\text { recoverable } \\
(\mu \mathrm{g} / \mathrm{L})\end{array}$ & $\begin{array}{c}\text { Benzo[a]- } \\
\text { pyrene, } \\
\text { total, } \\
\text { recoverable } \\
\text { ( } \mu \mathrm{g} / \mathrm{L})\end{array}$ & $\begin{array}{l}\text { Benzo[b]fluor- } \\
\text { anthene, } \\
\text { total, } \\
\text { recoverable } \\
(\mu \mathrm{g} / \mathrm{L})\end{array}$ & $\begin{array}{l}\text { Benzo[ghi]- } \\
\text { perylene, } \\
\text { total, } \\
\text { recoverable } \\
\text { ( } \mu \mathrm{g} / \mathrm{L})\end{array}$ & $\begin{array}{c}\text { Benzo }[k]- \\
\text { fluoranthene, } \\
\text { total, } \\
\text { recoverable } \\
(\mu \mathrm{g} / \mathrm{L})\end{array}$ \\
\hline Route 119 -P & 424209071545201 & $09 / 15 / 2005$ & $<2$ & $<1$ & $<2$ & E0.03 & $<2$ \\
\hline Route 119 -P & 424209071545201 & $09 / 29 / 2005$ & E0.04 & E0.07 & E0.1 & E0.05 & $<2$ \\
\hline Route 119 -P & 424209071545201 & $10 / 24 / 2005$ & -- & -- & -- & -- & -- \\
\hline Route 119 -P & 424209071545201 & $01 / 11 / 2006$ & E0.2 & E0.3 & E0.7 & E0.2 & E0.2 \\
\hline Route 119 -P & 424209071545201 & $01 / 18 / 2006$ & $\mathrm{E} 0.2$ & E0.3 & E0.6 & E0.1 & $\mathrm{E} 0.2$ \\
\hline Route 119 -P & 424209071545201 & $03 / 13 / 2006$ & $<96$ & E0.5 & E0.6 & E0.4 & $\mathrm{E} 0.2$ \\
\hline Route 119 -P & 424209071545201 & $05 / 09 / 2006$ & $<0.26$ & $<0.33$ & $<0.40$ & E0.0209 & $<0.45$ \\
\hline Route 119 -P & 424209071545201 & $10 / 20 / 2006$ & -- & -- & -- & -- & -- \\
\hline Route 119 -P & 424209071545201 & $11 / 08 / 2006$ & $<0.26$ & $<0.33$ & $<0.40$ & $<0.64$ & $<0.45$ \\
\hline Route 119 -P & 424209071545201 & $11 / 12 / 2006$ & $<0.26$ & E0.0380 & E0.0600 & E0.0387 & $<0.45$ \\
\hline Route 119 -P & 424209071545201 & $01 / 08 / 2007$ & E0.0336 & E0.0417 & E0.0764 & E0.0461 & E0.0246 \\
\hline Route 119 -P & 424209071545201 & $04 / 01 / 2007$ & $<0.26$ & E0.0695 & E0.149 & E0.0899 & E0.0597 \\
\hline Route 119 -P & 424209071545201 & $04 / 14 / 2007$ & E0.0606 & E0.0970 & E0.218 & E0.0705 & E0.0782 \\
\hline Route 119 -P & 424209071545201 & $06 / 03 / 2007$ & $<0.26$ & $<0.33$ & $<0.40$ & $<0.64$ & $<0.45$ \\
\hline Route 119 -P & 424209071545201 & $07 / 11 / 2007$ & $<0.26$ & $<0.33$ & E0.0440 & E0.0256 & $<0.45$ \\
\hline Route 119 -S & 424155071543201 & $09 / 29 / 2005$ & E0.05 & E0.08 & E0.1 & E0.06 & $<2$ \\
\hline Route 119 -S & 424155071543201 & $06 / 03 / 2007$ & $<0.26$ & $<0.33$ & $<0.40$ & $<0.64$ & $<0.45$ \\
\hline Route 119 -S & 424155071543201 & $07 / 11 / 2007$ & $<0.26$ & $<0.33$ & E0.0433 & E0.0302 & E0.0142 \\
\hline Route 119 -S & 424155071543201 & $08 / 03 / 2007$ & -- & -- & -- & -- & -- \\
\hline Route 8 -T & 424019073062601 & $04 / 22 / 2006$ & $<0.26$ & E0.0366 & E0.0564 & E0.0329 & E0.0223 \\
\hline Route 8 -T & 424019073062601 & $06 / 23 / 2006$ & $<0.26$ & $<0.33$ & $<0.40$ & E0.0572 & $<0.45$ \\
\hline Route 8 -T & 424019073062601 & $09 / 23 / 2006$ & E0.0406 & E0.0770 & E0.114 & E0.0682 & E0.0461 \\
\hline Route 8 - $\mathrm{T}$ & 424019073062601 & $12 / 01 / 2006$ & E0.160 & E0.218 & E0.356 & E0.125 & E0.144 \\
\hline Route 8 -T & 424019073062601 & $03 / 02 / 2007$ & $<0.26$ & E0.176 & E0.586 & E0.163 & $<0.45$ \\
\hline
\end{tabular}


Table 16. Physical properties and concentrations of dissolved major ions, total nutrients, total-recoverable metals, polyaromatic hydrocarbons, phthalate esters, and suspended sediment in stormwater composite samples of highway runoff collected from 12 stations on 8 highways in Massachusetts, 2005-07.-Continued

[USGS, U.S. Geological Survey; -P, primary monitoring station; -S, secondary monitoring station; -T, monitoring station on test highway; mm/dd/yyyy, month, day, year; hrmn, hour minute; NTRU, nephelometric turbidity ratio units; mg/L, milligrams per liter; $\mu \mathrm{g} / \mathrm{L}$, micrograms per liter; $\mu \mathrm{S} / \mathrm{cm}$, microsiemens per centimeter at 25 degrees Celsius; $\mathrm{mm}$, millimeter; <, concentration is less than the laboratory reporting limit; --, no data; E, the recovery or variation in recovery of the analyte was outside the acceptable range or the concentration reported is less than laboratory reporting level and is qualified as estimated; blue-shaded values are associated with the secondary monitoring sites for each principal highway; gray-shaded values are associated with the monitoring sites for each test highway]

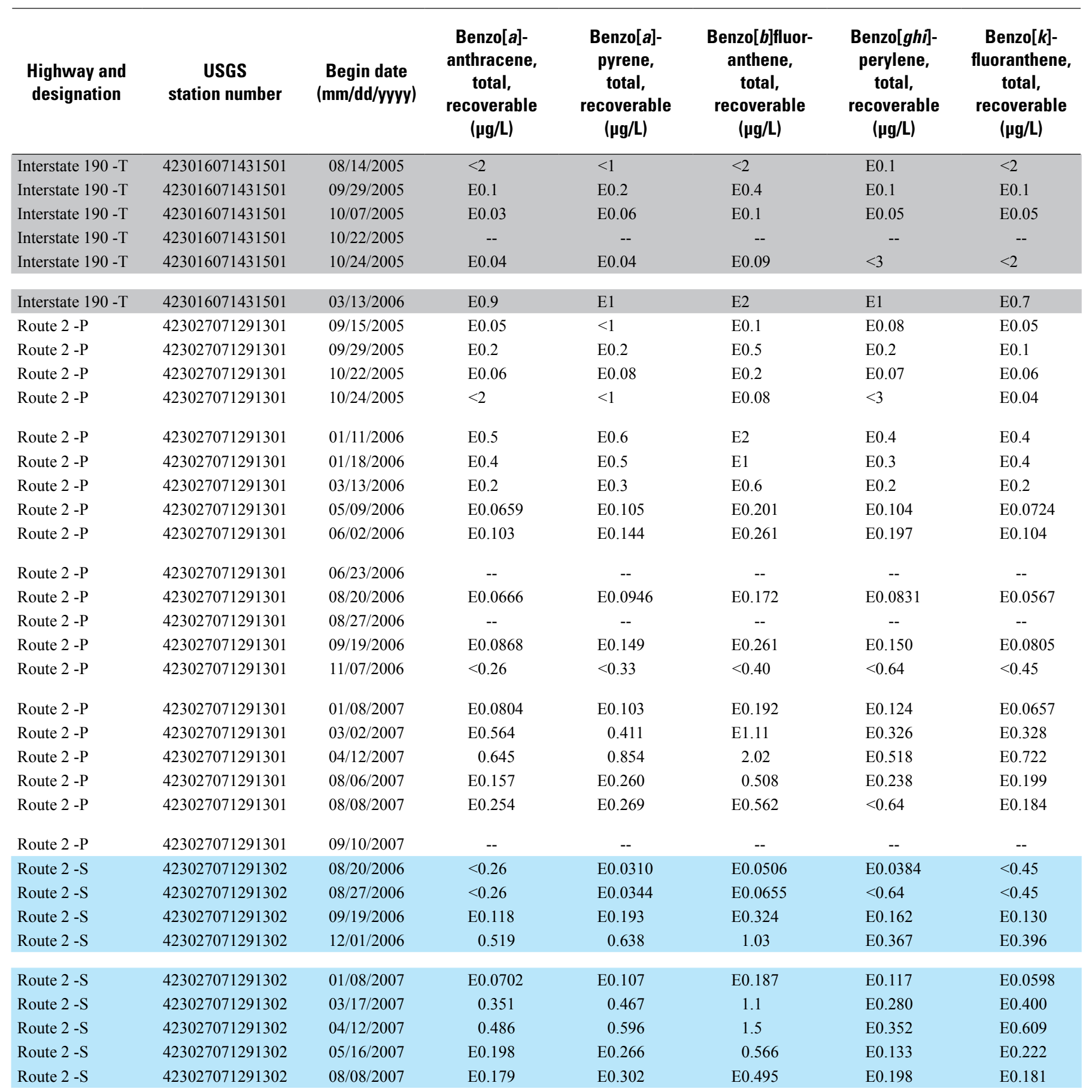


Table 16. Physical properties and concentrations of dissolved major ions, total nutrients, total-recoverable metals, polyaromatic hydrocarbons, phthalate esters, and suspended sediment in stormwater composite samples of highway runoff collected from 12 stations on 8 highways in Massachusetts, 2005-07.-Continued

[USGS, U.S. Geological Survey; -P, primary monitoring station; -S, secondary monitoring station; -T, monitoring station on test highway; mm/dd/yyyy, month, day, year; hrmn, hour minute; NTRU, nephelometric turbidity ratio units; mg/L, milligrams per liter; $\mu \mathrm{g} / \mathrm{L}$, micrograms per liter; $\mu \mathrm{S} / \mathrm{cm}$, microsiemens per centimeter at 25 degrees Celsius; mm, millimeter; <, concentration is less than the laboratory reporting limit; --, no data; E, the recovery or variation in recovery of the analyte was outside the acceptable range or the concentration reported is less than laboratory reporting level and is qualified as estimated; blue-shaded values are associated with the secondary monitoring sites for each principal highway; gray-shaded values are associated with the monitoring sites for each test highway]

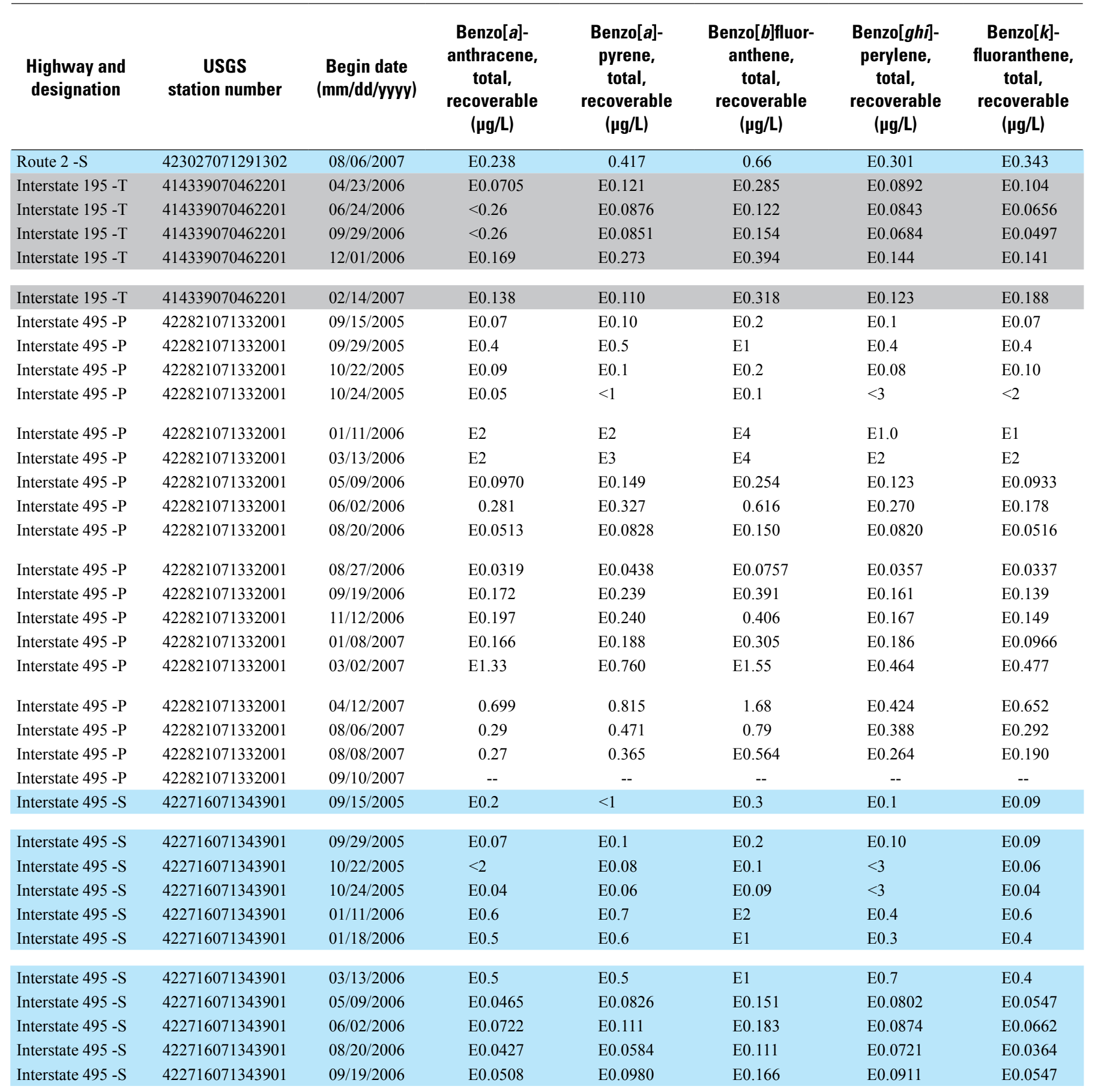


Table 16. Physical properties and concentrations of dissolved major ions, total nutrients, total-recoverable metals, polyaromatic hydrocarbons, phthalate esters, and suspended sediment in stormwater composite samples of highway runoff collected from 12 stations on 8 highways in Massachusetts, 2005-07.-Continued

[USGS, U.S. Geological Survey; -P, primary monitoring station; -S, secondary monitoring station; -T, monitoring station on test highway; mm/dd/yyyy, month, day, year; hrmn, hour minute; NTRU, nephelometric turbidity ratio units; mg/L, milligrams per liter; $\mu \mathrm{g} / \mathrm{L}$, micrograms per liter; $\mu \mathrm{S} / \mathrm{cm}$, microsiemens per centimeter at 25 degrees Celsius; $\mathrm{mm}$, millimeter; <, concentration is less than the laboratory reporting limit; --, no data; E, the recovery or variation in recovery of the analyte was outside the acceptable range or the concentration reported is less than laboratory reporting level and is qualified as estimated; blue-shaded values are associated with the secondary monitoring sites for each principal highway; gray-shaded values are associated with the monitoring sites for each test highway]

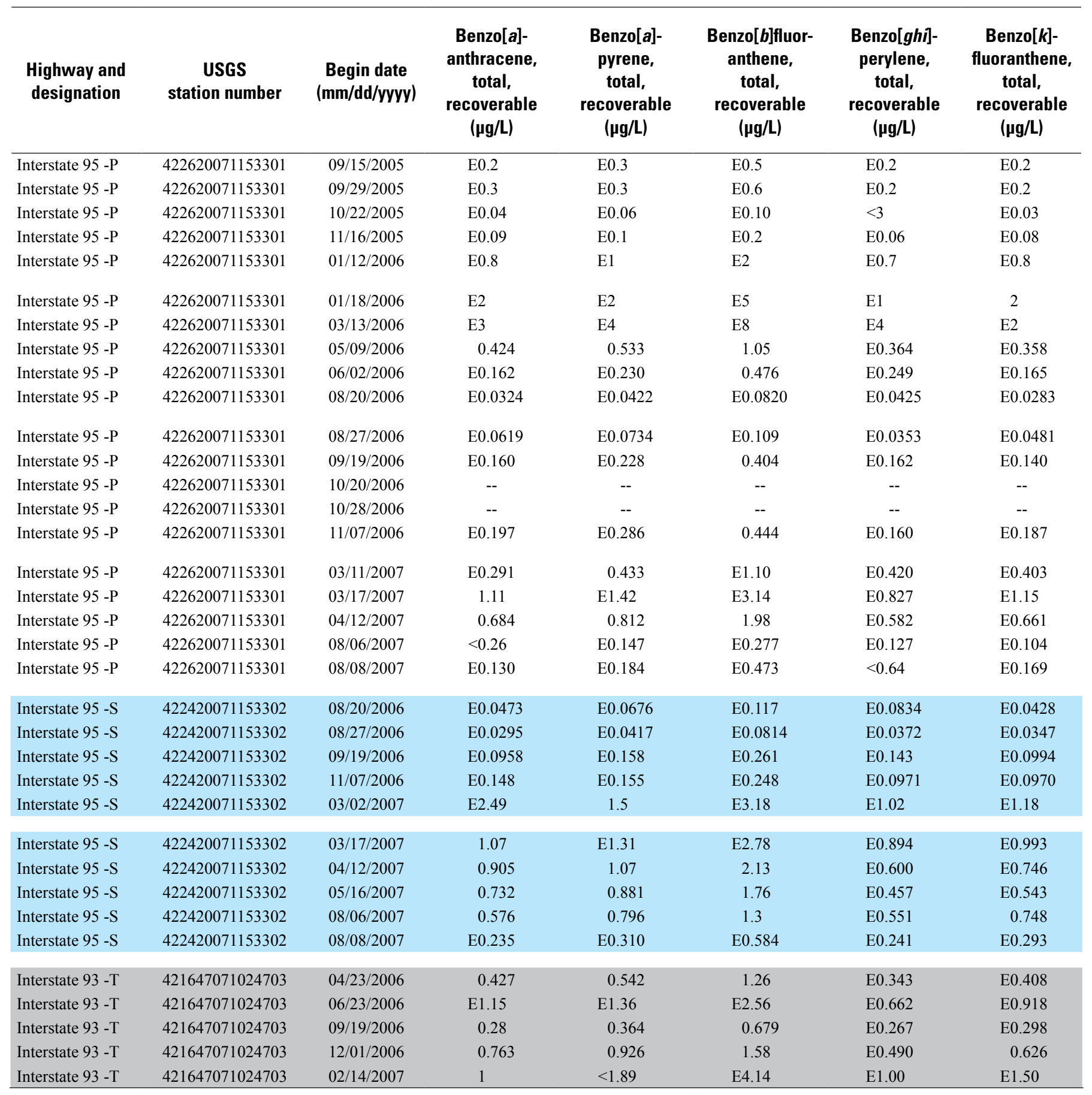


Table 16. Physical properties and concentrations of dissolved major ions, total nutrients, total-recoverable metals, polyaromatic hydrocarbons, phthalate esters, and suspended sediment in stormwater composite samples of highway runoff collected from 12 stations on 8 highways in Massachusetts, 2005-07.-Continued

[USGS, U.S. Geological Survey; -P, primary monitoring station; -S, secondary monitoring station; -T, monitoring station on test highway; mm/dd/yyyy, month, day, year; hrmn, hour minute; NTRU, nephelometric turbidity ratio units; mg/L, milligrams per liter; $\mu \mathrm{g} / \mathrm{L}$, micrograms per liter; $\mu \mathrm{S} / \mathrm{cm}$, microsiemens per centimeter at 25 degrees Celsius; $\mathrm{mm}$, millimeter; <, concentration is less than the laboratory reporting limit; --, no data; E, the recovery or variation in recovery of the analyte was outside the acceptable range or the concentration reported is less than laboratory reporting level and is qualified as estimated; blue-shaded values are associated with the secondary monitoring sites for each principal highway; gray-shaded values are associated with the monitoring sites for each test highway]

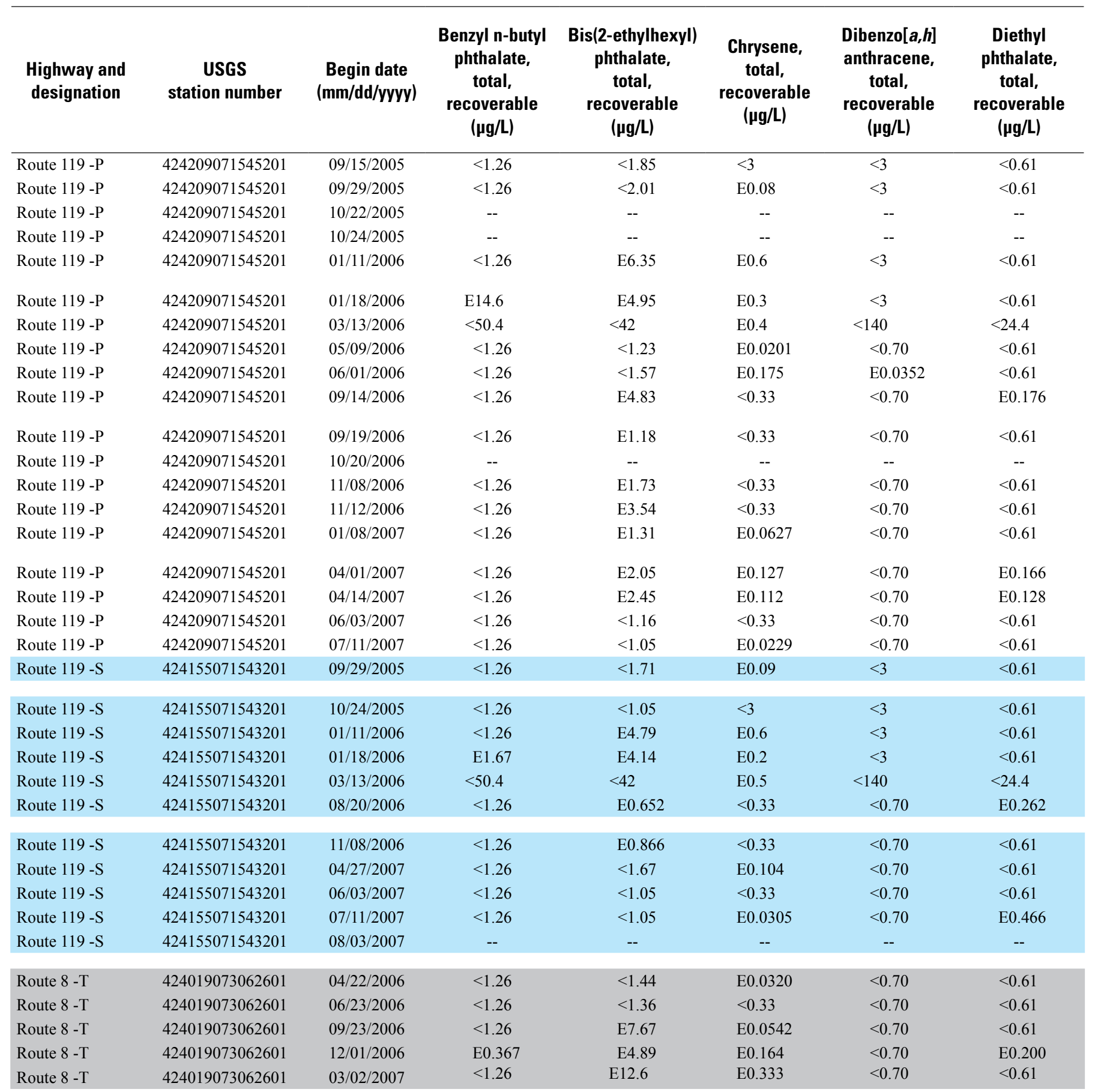


Table 16. Physical properties and concentrations of dissolved major ions, total nutrients, total-recoverable metals, polyaromatic hydrocarbons, phthalate esters, and suspended sediment in stormwater composite samples of highway runoff collected from 12 stations on 8 highways in Massachusetts, 2005-07.-Continued

[USGS, U.S. Geological Survey; -P, primary monitoring station; -S, secondary monitoring station; -T, monitoring station on test highway; mm/dd/yyyy, month, day, year; hrmn, hour minute; NTRU, nephelometric turbidity ratio units; mg/L, milligrams per liter; $\mu \mathrm{g} / \mathrm{L}$, micrograms per liter; $\mu \mathrm{S} / \mathrm{cm}$, microsiemens per centimeter at 25 degrees Celsius; mm, millimeter; <, concentration is less than the laboratory reporting limit; --, no data; E, the recovery or variation in recovery of the analyte was outside the acceptable range or the concentration reported is less than laboratory reporting level and is qualified as estimated; blue-shaded values are associated with the secondary monitoring sites for each principal highway; gray-shaded values are associated with the monitoring sites for each test highway]

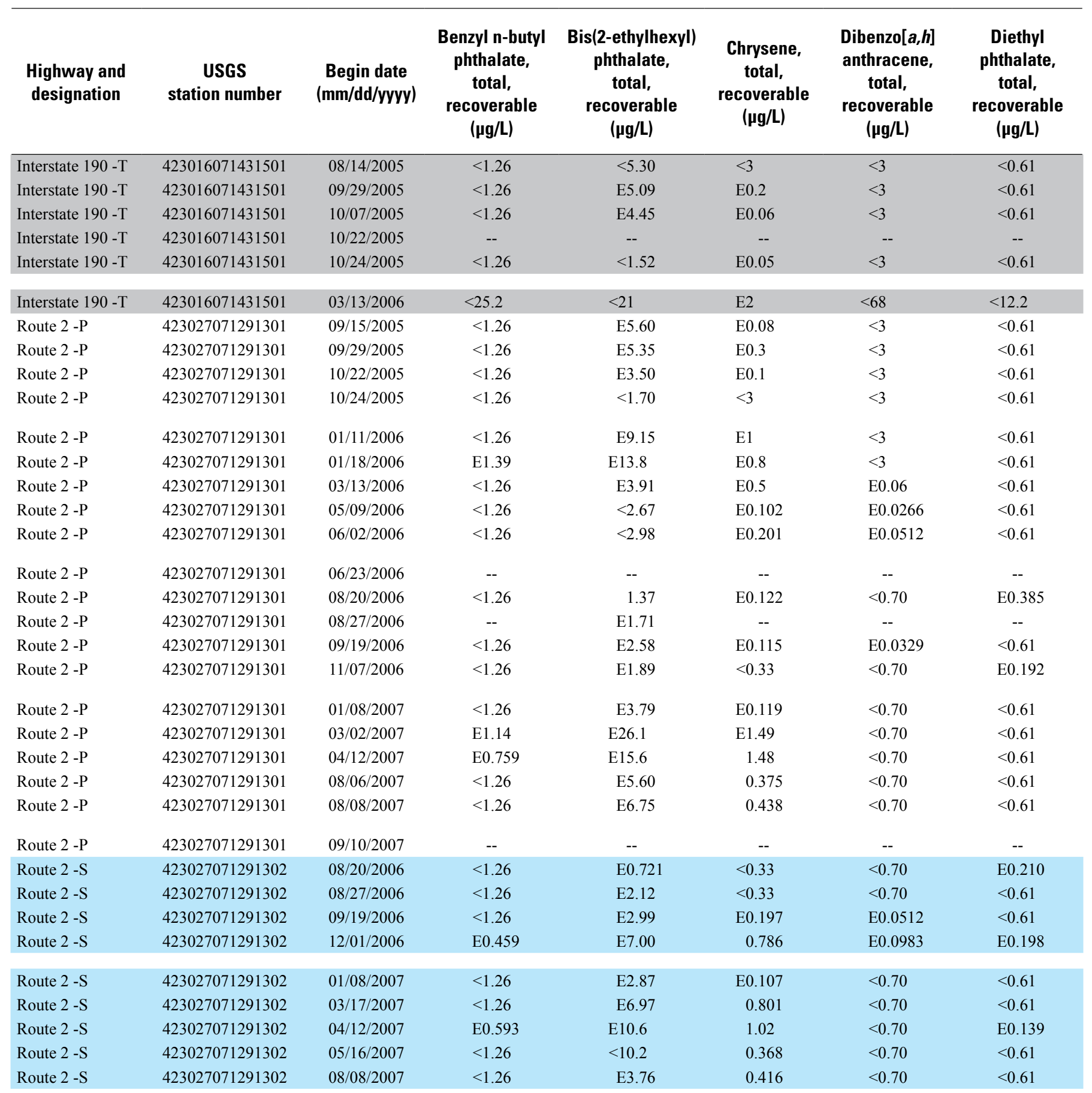


Table 16. Physical properties and concentrations of dissolved major ions, total nutrients, total-recoverable metals, polyaromatic hydrocarbons, phthalate esters, and suspended sediment in stormwater composite samples of highway runoff collected from 12 stations on 8 highways in Massachusetts, 2005-07.-Continued

[USGS, U.S. Geological Survey; -P, primary monitoring station; -S, secondary monitoring station; -T, monitoring station on test highway; mm/dd/yyyy, month, day, year; hrmn, hour minute; NTRU, nephelometric turbidity ratio units; mg/L, milligrams per liter; $\mu \mathrm{g} / \mathrm{L}$, micrograms per liter; $\mu \mathrm{S} / \mathrm{cm}$, microsiemens per centimeter at 25 degrees Celsius; $\mathrm{mm}$, millimeter; <, concentration is less than the laboratory reporting limit; --, no data; E, the recovery or variation in recovery of the analyte was outside the acceptable range or the concentration reported is less than laboratory reporting level and is qualified as estimated; blue-shaded values are associated with the secondary monitoring sites for each principal highway; gray-shaded values are associated with the monitoring sites for each test highway]

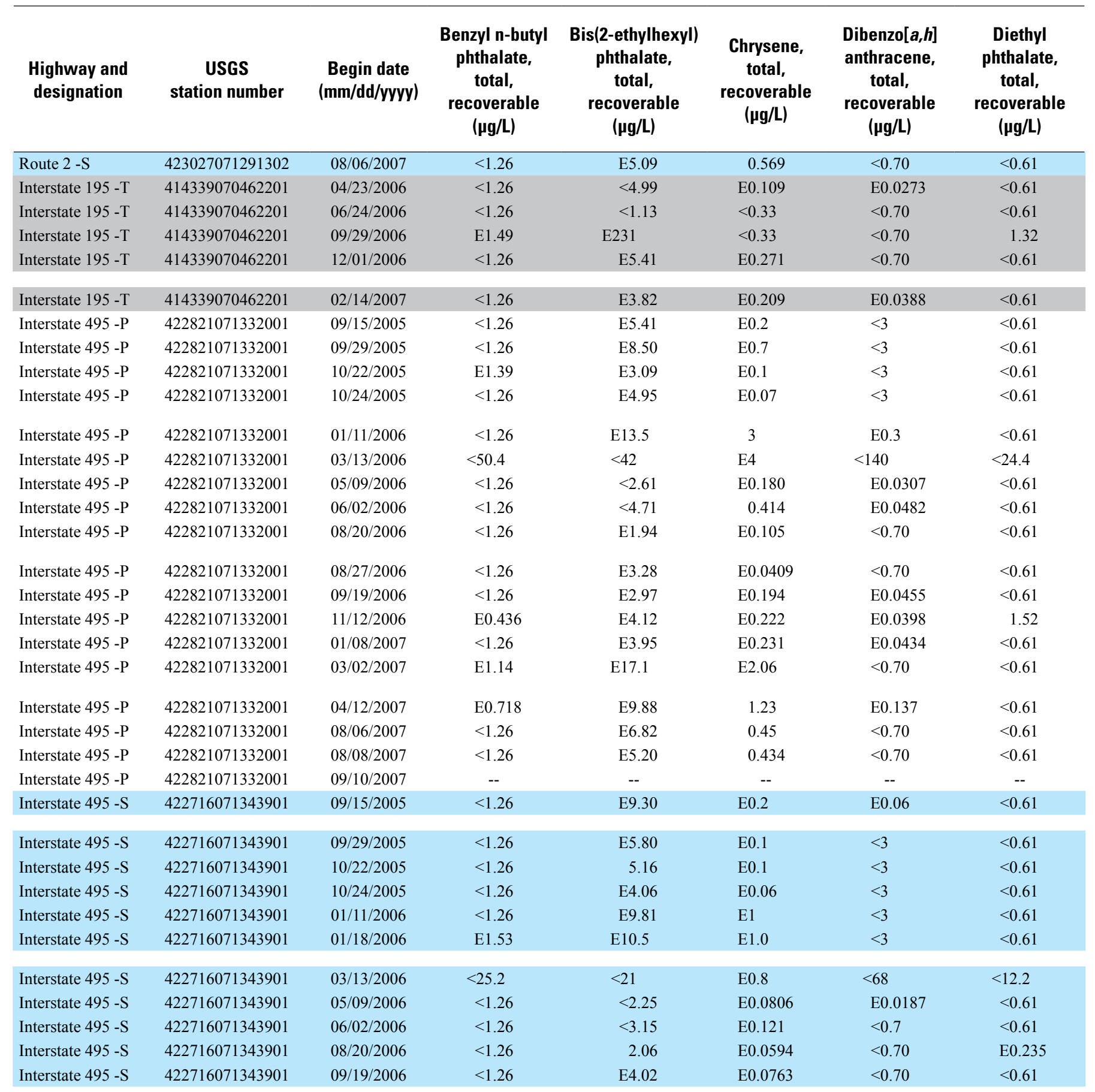


Table 16. Physical properties and concentrations of dissolved major ions, total nutrients, total-recoverable metals, polyaromatic hydrocarbons, phthalate esters, and suspended sediment in stormwater composite samples of highway runoff collected from 12 stations on 8 highways in Massachusetts, 2005-07.-Continued

[USGS, U.S. Geological Survey; -P, primary monitoring station; -S, secondary monitoring station; -T, monitoring station on test highway; mm/dd/yyyy, month, day, year; hrmn, hour minute; NTRU, nephelometric turbidity ratio units; mg/L, milligrams per liter; $\mu \mathrm{g} / \mathrm{L}$, micrograms per liter; $\mu \mathrm{S} / \mathrm{cm}$, microsiemens per centimeter at 25 degrees Celsius; mm, millimeter; <, concentration is less than the laboratory reporting limit; --, no data; E, the recovery or variation in recovery of the analyte was outside the acceptable range or the concentration reported is less than laboratory reporting level and is qualified as estimated; blue-shaded values are associated with the secondary monitoring sites for each principal highway; gray-shaded values are associated with the monitoring sites for each test highway]

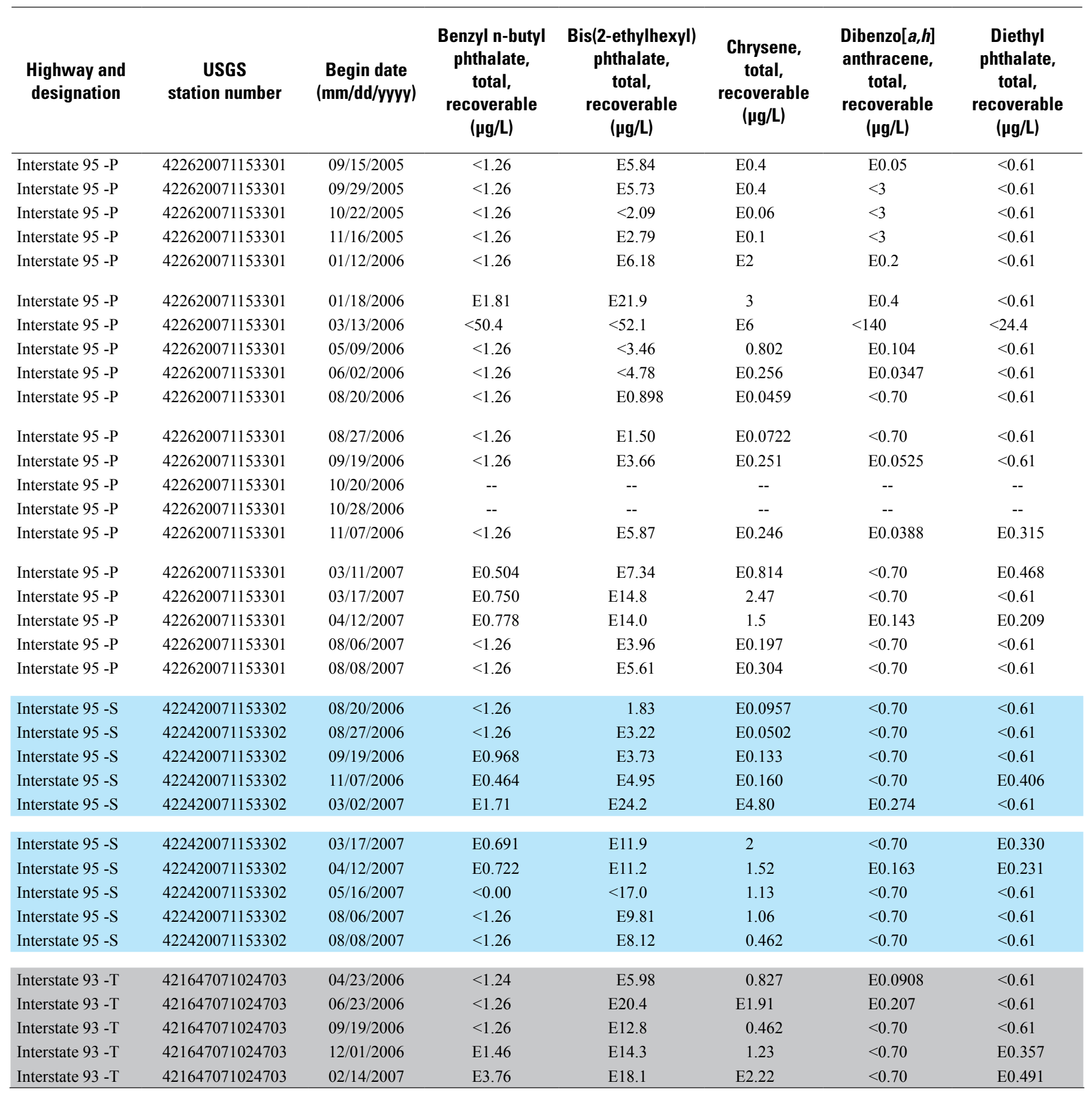


Table 16. Physical properties and concentrations of dissolved major ions, total nutrients, total-recoverable metals, polyaromatic hydrocarbons, phthalate esters, and suspended sediment in stormwater composite samples of highway runoff collected from 12 stations on 8 highways in Massachusetts, 2005-07.-Continued

[USGS, U.S. Geological Survey; -P, primary monitoring station; -S, secondary monitoring station; -T, monitoring station on test highway; mm/dd/yyyy, month, day, year; hrmn, hour minute; NTRU, nephelometric turbidity ratio units; mg/L, milligrams per liter; $\mu \mathrm{g} / \mathrm{L}$, micrograms per liter; $\mu \mathrm{S} / \mathrm{cm}$, microsiemens per centimeter at 25 degrees Celsius; mm, millimeter; <, concentration is less than the laboratory reporting limit; --, no data; E, the recovery or variation in recovery of the analyte was outside the acceptable range or the concentration reported is less than laboratory reporting level and is qualified as estimated; blue-shaded values are associated with the secondary monitoring sites for each principal highway; gray-shaded values are associated with the monitoring sites for each test highway]

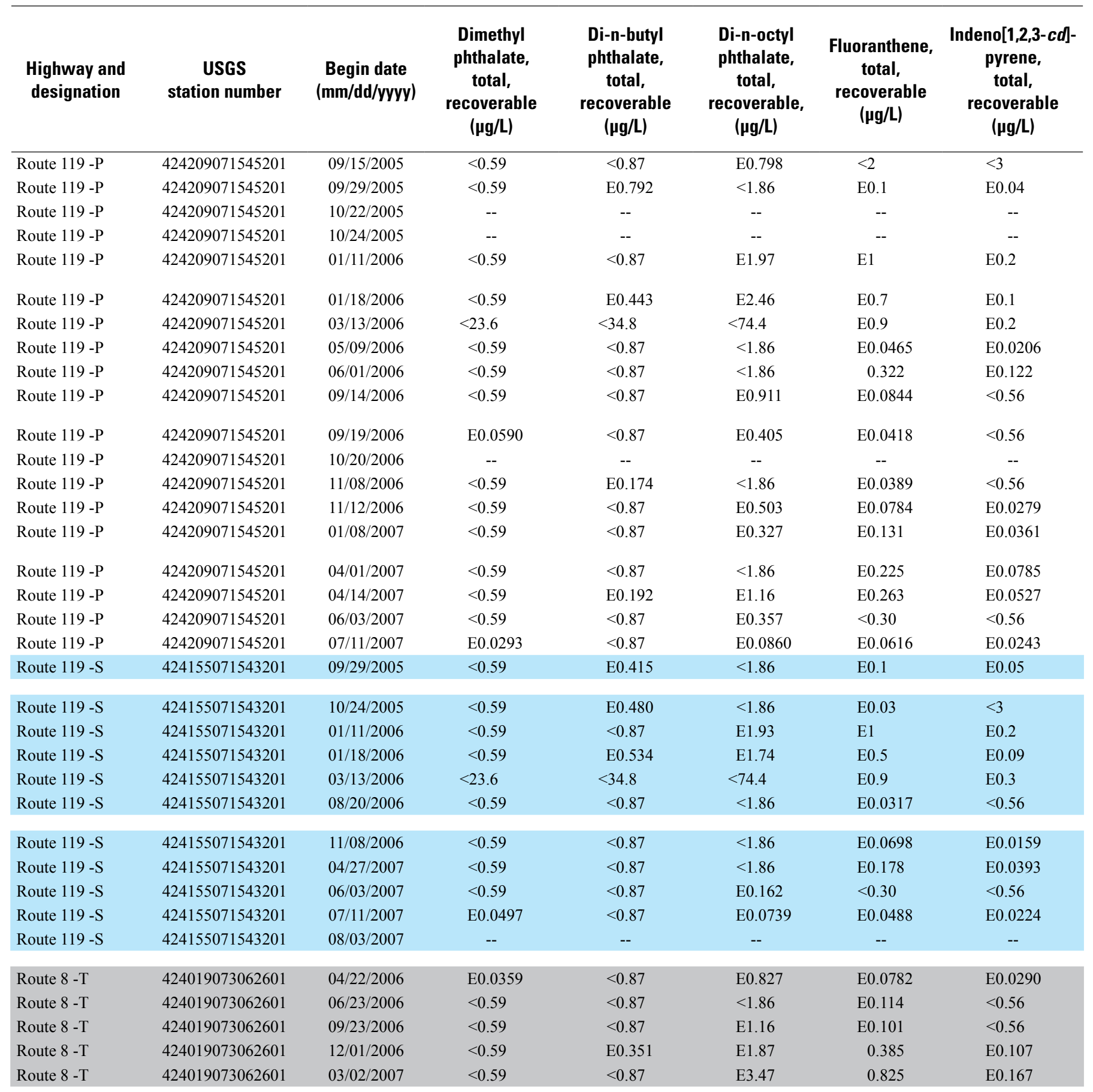


Table 16. Physical properties and concentrations of dissolved major ions, total nutrients, total-recoverable metals, polyaromatic hydrocarbons, phthalate esters, and suspended sediment in stormwater composite samples of highway runoff collected from 12 stations on 8 highways in Massachusetts, 2005-07.-Continued

[USGS, U.S. Geological Survey; -P, primary monitoring station; -S, secondary monitoring station; -T, monitoring station on test highway; mm/dd/yyyy, month, day, year; hrmn, hour minute; NTRU, nephelometric turbidity ratio units; mg/L, milligrams per liter; $\mu \mathrm{g} / \mathrm{L}$, micrograms per liter; $\mu \mathrm{S} / \mathrm{cm}$, microsiemens per centimeter at 25 degrees Celsius; $\mathrm{mm}$, millimeter; <, concentration is less than the laboratory reporting limit; --, no data; E, the recovery or variation in recovery of the analyte was outside the acceptable range or the concentration reported is less than laboratory reporting level and is qualified as estimated; blue-shaded values are associated with the secondary monitoring sites for each principal highway; gray-shaded values are associated with the monitoring sites for each test highway]

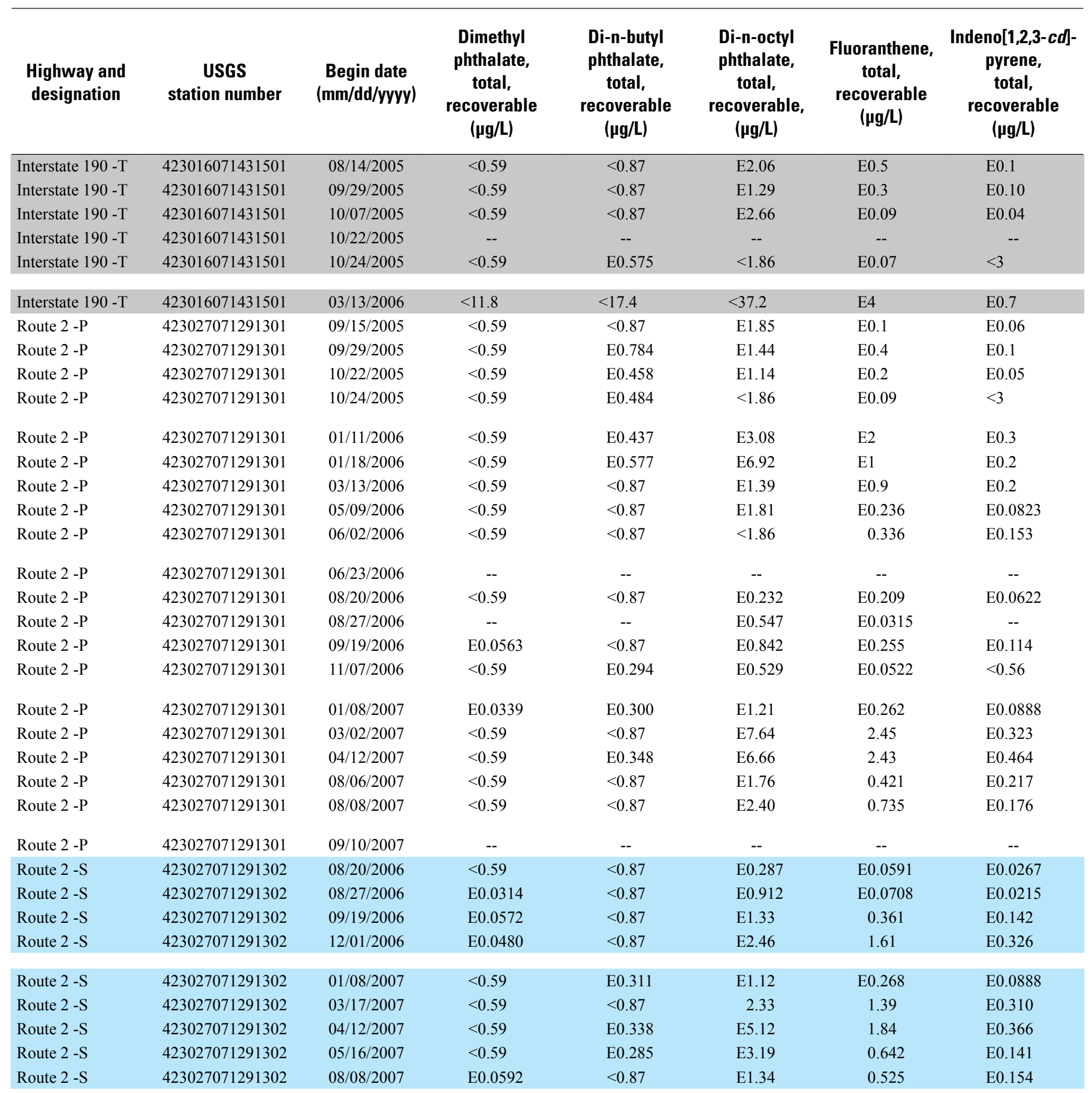


Table 16. Physical properties and concentrations of dissolved major ions, total nutrients, total-recoverable metals, polyaromatic hydrocarbons, phthalate esters, and suspended sediment in stormwater composite samples of highway runoff collected from 12 stations on 8 highways in Massachusetts, 2005-07.-Continued

[USGS, U.S. Geological Survey; -P, primary monitoring station; -S, secondary monitoring station; -T, monitoring station on test highway; mm/dd/yyyy, month, day, year; hrmn, hour minute; NTRU, nephelometric turbidity ratio units; mg/L, milligrams per liter; $\mu \mathrm{g} / \mathrm{L}$, micrograms per liter; $\mu \mathrm{S} / \mathrm{cm}$, microsiemens per centimeter at 25 degrees Celsius; $\mathrm{mm}$, millimeter; <, concentration is less than the laboratory reporting limit; --, no data; E, the recovery or variation in recovery of the analyte was outside the acceptable range or the concentration reported is less than laboratory reporting level and is qualified as estimated; blue-shaded values are associated with the secondary monitoring sites for each principal highway; gray-shaded values are associated with the monitoring sites for each test highway]

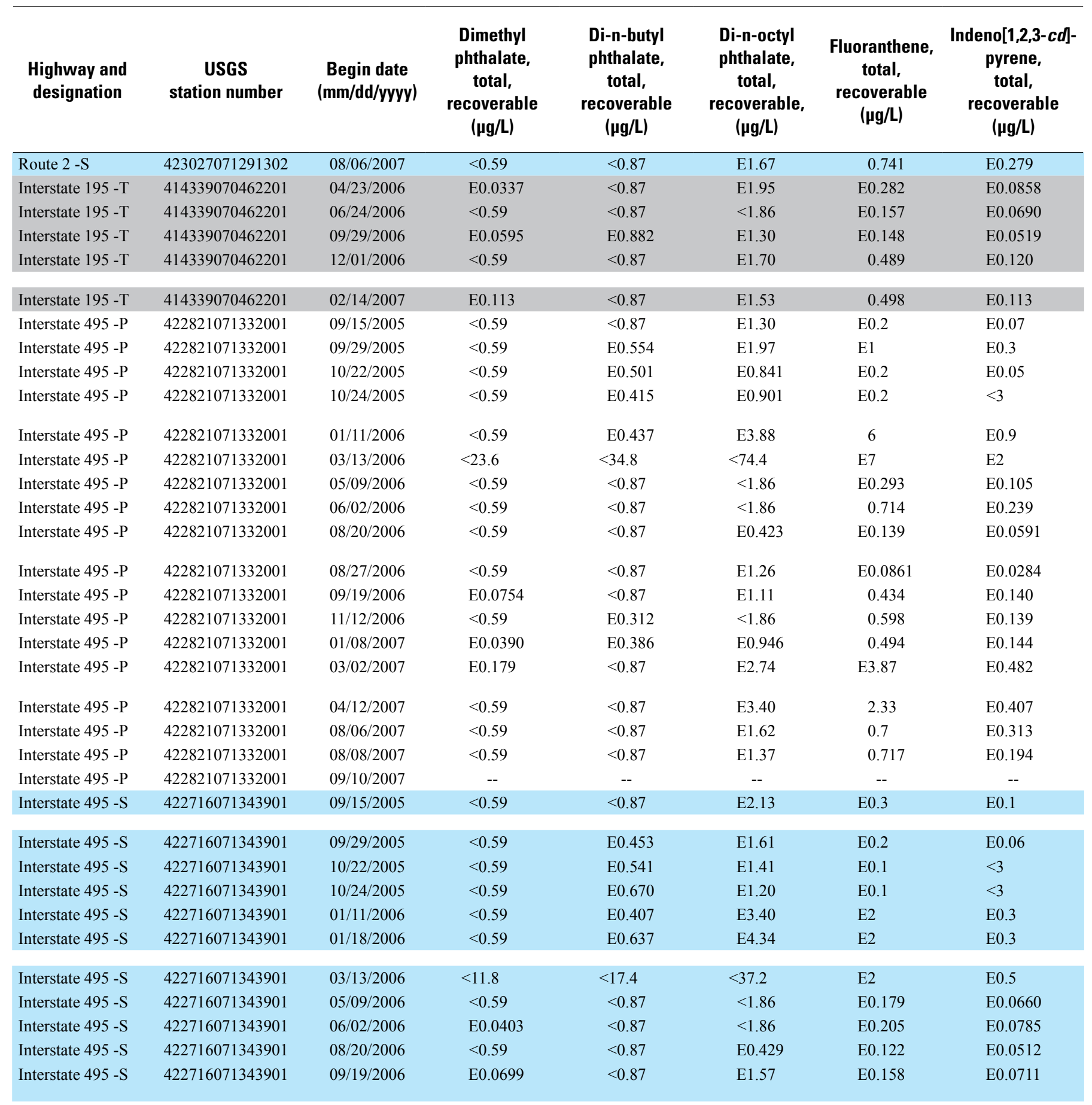


Table 16. Physical properties and concentrations of dissolved major ions, total nutrients, total-recoverable metals, polyaromatic hydrocarbons, phthalate esters, and suspended sediment in stormwater composite samples of highway runoff collected from 12 stations on 8 highways in Massachusetts, 2005-07.-Continued

[USGS, U.S. Geological Survey; -P, primary monitoring station; -S, secondary monitoring station; -T, monitoring station on test highway; mm/dd/yyyy, month, day, year; hrmn, hour minute; NTRU, nephelometric turbidity ratio units; mg/L, milligrams per liter; $\mu \mathrm{g} / \mathrm{L}$, micrograms per liter; $\mu \mathrm{S} / \mathrm{cm}$, microsiemens per centimeter at 25 degrees Celsius; $\mathrm{mm}$, millimeter; <, concentration is less than the laboratory reporting limit; --, no data; E, the recovery or variation in recovery of the analyte was outside the acceptable range or the concentration reported is less than laboratory reporting level and is qualified as estimated; blue-shaded values are associated with the secondary monitoring sites for each principal highway; gray-shaded values are associated with the monitoring sites for each test highway]

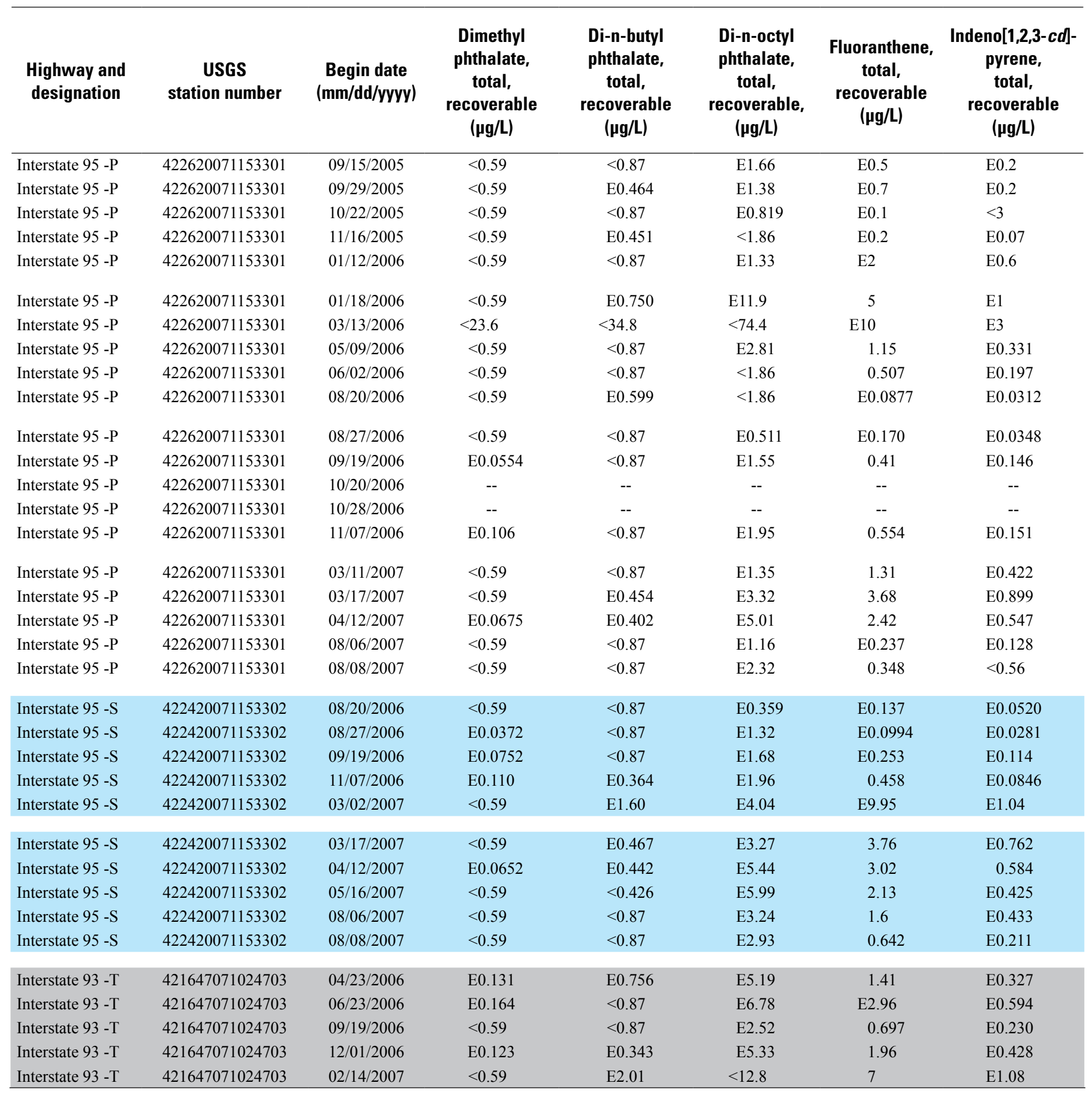


Table 16. Physical properties and concentrations of dissolved major ions, total nutrients, total-recoverable metals, polyaromatic hydrocarbons, phthalate esters, and suspended sediment in stormwater composite samples of highway runoff collected from 12 stations on 8 highways in Massachusetts, 2005-07.-Continued

[USGS, U.S. Geological Survey; -P, primary monitoring station; -S, secondary monitoring station; -T, monitoring station on test highway; mm/dd/yyyy, month, day, year; hrmn, hour minute; NTRU, nephelometric turbidity ratio units; mg/L, milligrams per liter; $\mu \mathrm{g} / \mathrm{L}$, micrograms per liter; $\mu \mathrm{S} / \mathrm{cm}$, microsiemens per centimeter at 25 degrees Celsius; mm, millimeter; <, concentration is less than the laboratory reporting limit; --, no data; E, the recovery or variation in recovery of the analyte was outside the acceptable range or the concentration reported is less than laboratory reporting level and is qualified as estimated; blue-shaded values are associated with the secondary monitoring sites for each principal highway; gray-shaded values are associated with the monitoring sites for each test highway]

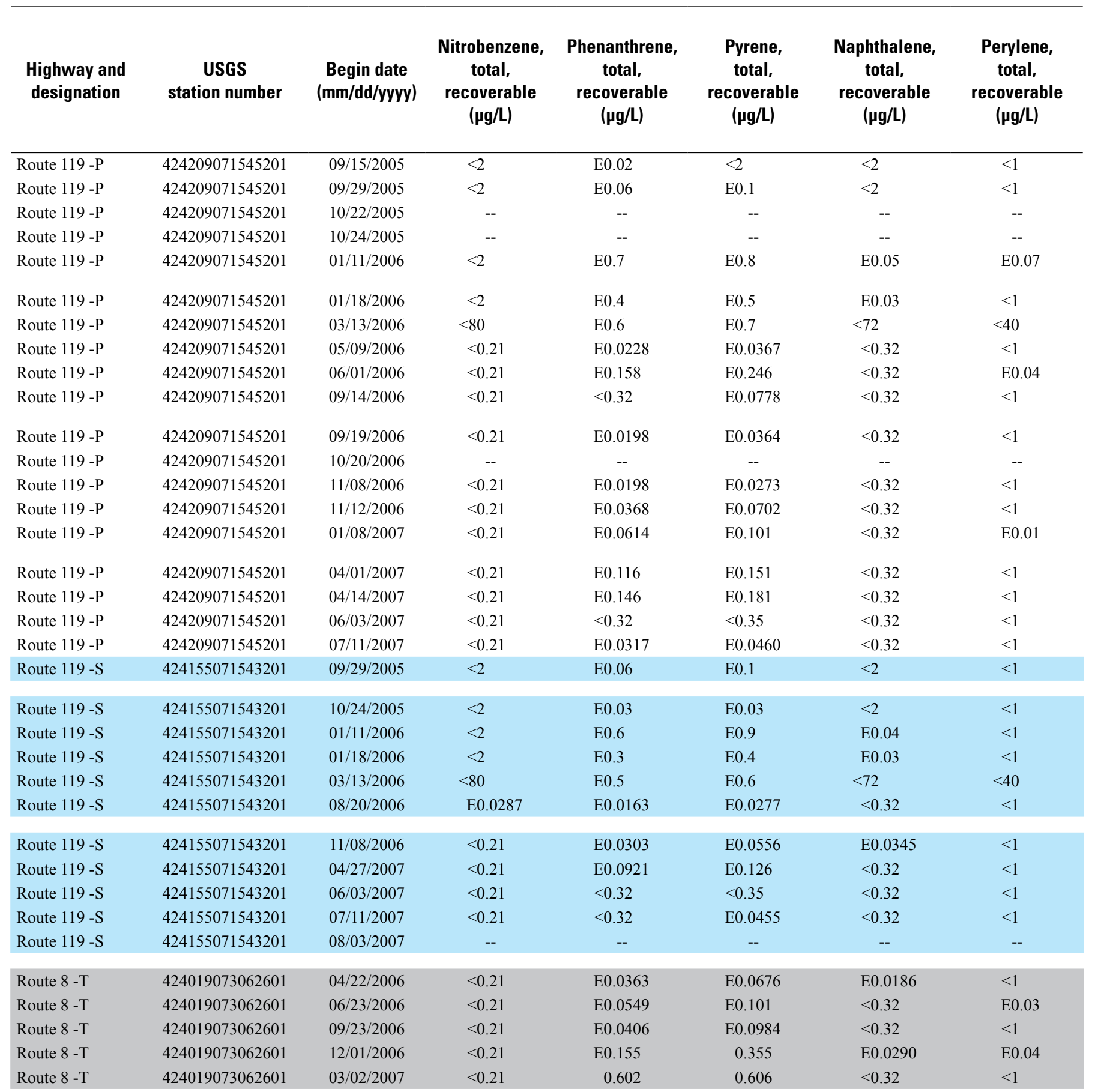


Table 16. Physical properties and concentrations of dissolved major ions, total nutrients, total-recoverable metals, polyaromatic hydrocarbons, phthalate esters, and suspended sediment in stormwater composite samples of highway runoff collected from 12 stations on 8 highways in Massachusetts, 2005-07.-Continued

[USGS, U.S. Geological Survey; -P, primary monitoring station; -S, secondary monitoring station; -T, monitoring station on test highway; mm/dd/yyyy, month, day, year; hrmn, hour minute; NTRU, nephelometric turbidity ratio units; mg/L, milligrams per liter; $\mu \mathrm{g} / \mathrm{L}$, micrograms per liter; $\mu \mathrm{S} / \mathrm{cm}$, microsiemens per centimeter at 25 degrees Celsius; $\mathrm{mm}$, millimeter; $<$, concentration is less than the laboratory reporting limit; --, no data; E, the recovery or variation in recovery of the analyte was outside the acceptable range or the concentration reported is less than laboratory reporting level and is qualified as estimated; blue-shaded values are associated with the secondary monitoring sites for each principal highway; gray-shaded values are associated with the monitoring sites for each test highway]

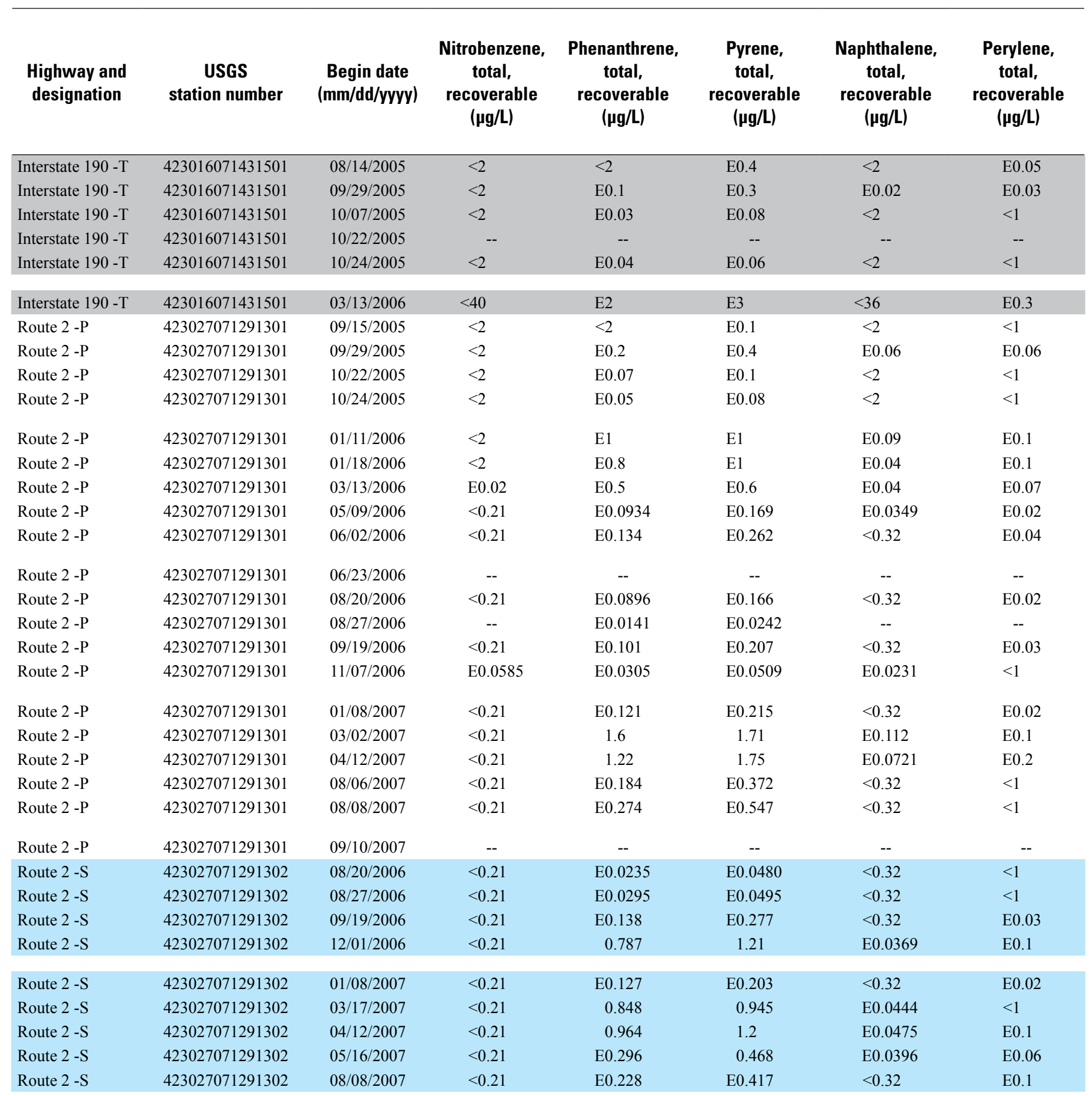


Table 16. Physical properties and concentrations of dissolved major ions, total nutrients, total-recoverable metals, polyaromatic hydrocarbons, phthalate esters, and suspended sediment in stormwater composite samples of highway runoff collected from 12 stations on 8 highways in Massachusetts, 2005-07.-Continued

[USGS, U.S. Geological Survey; -P, primary monitoring station; -S, secondary monitoring station; -T, monitoring station on test highway; mm/dd/yyyy, month, day, year; hrmn, hour minute; NTRU, nephelometric turbidity ratio units; mg/L, milligrams per liter; $\mu \mathrm{g} / \mathrm{L}$, micrograms per liter; $\mu \mathrm{S} / \mathrm{cm}$, microsiemens per centimeter at 25 degrees Celsius; $\mathrm{mm}$, millimeter; <, concentration is less than the laboratory reporting limit; --, no data; E, the recovery or variation in recovery of the analyte was outside the acceptable range or the concentration reported is less than laboratory reporting level and is qualified as estimated; blue-shaded values are associated with the secondary monitoring sites for each principal highway; gray-shaded values are associated with the monitoring sites for each test highway]

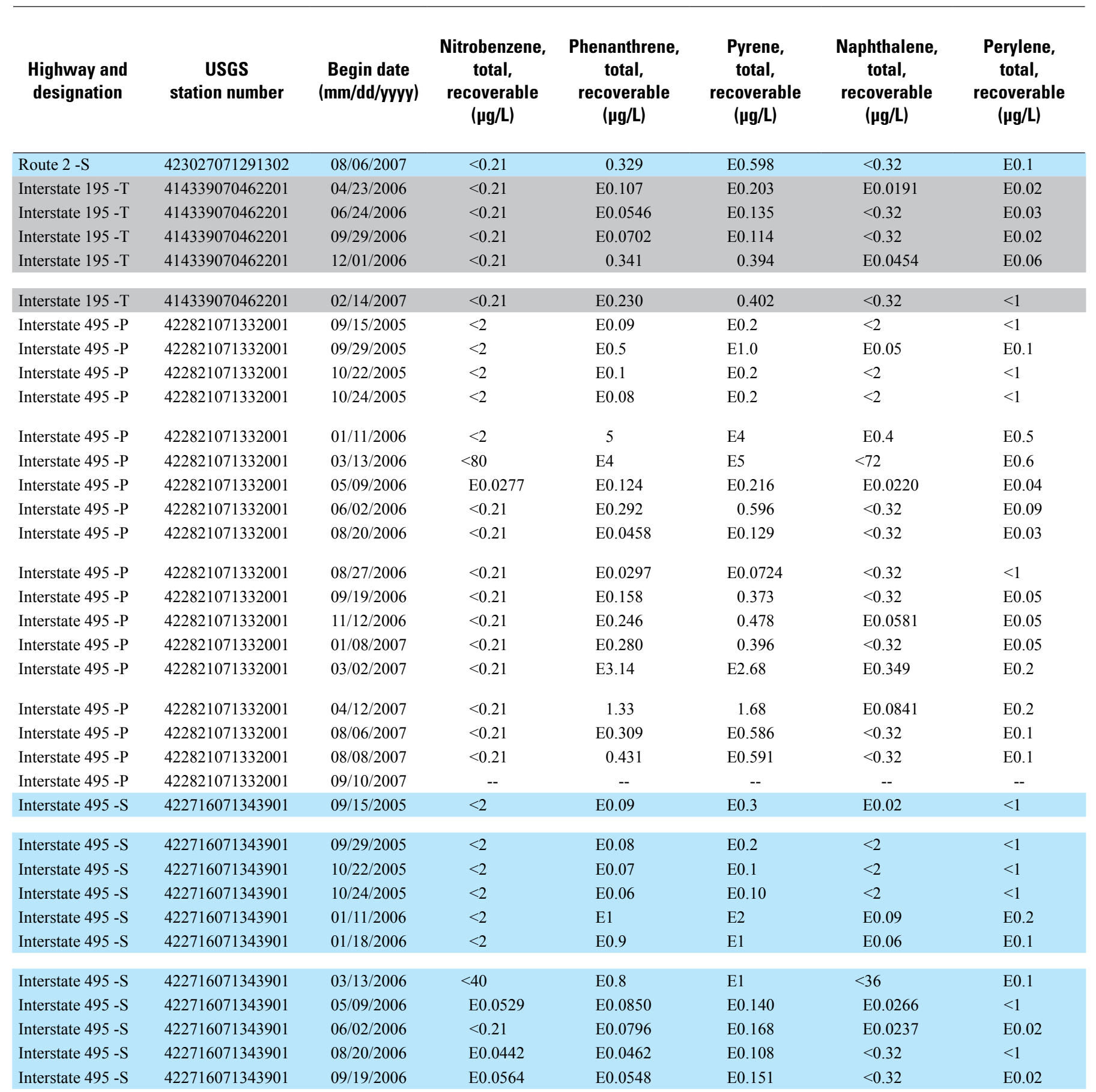


Table 16. Physical properties and concentrations of dissolved major ions, total nutrients, total-recoverable metals, polyaromatic hydrocarbons, phthalate esters, and suspended sediment in stormwater composite samples of highway runoff collected from 12 stations on 8 highways in Massachusetts, 2005-07.-Continued

[USGS, U.S. Geological Survey; -P, primary monitoring station; -S, secondary monitoring station; -T, monitoring station on test highway; mm/dd/yyyy, month, day, year; hrmn, hour minute; NTRU, nephelometric turbidity ratio units; mg/L, milligrams per liter; $\mu \mathrm{g} / \mathrm{L}$, micrograms per liter; $\mu \mathrm{S} / \mathrm{cm}$, microsiemens per centimeter at 25 degrees Celsius; mm, millimeter; <, concentration is less than the laboratory reporting limit; --, no data; E, the recovery or variation in recovery of the analyte was outside the acceptable range or the concentration reported is less than laboratory reporting level and is qualified as estimated; blue-shaded values are associated with the secondary monitoring sites for each principal highway; gray-shaded values are associated with the monitoring sites for each test highway]

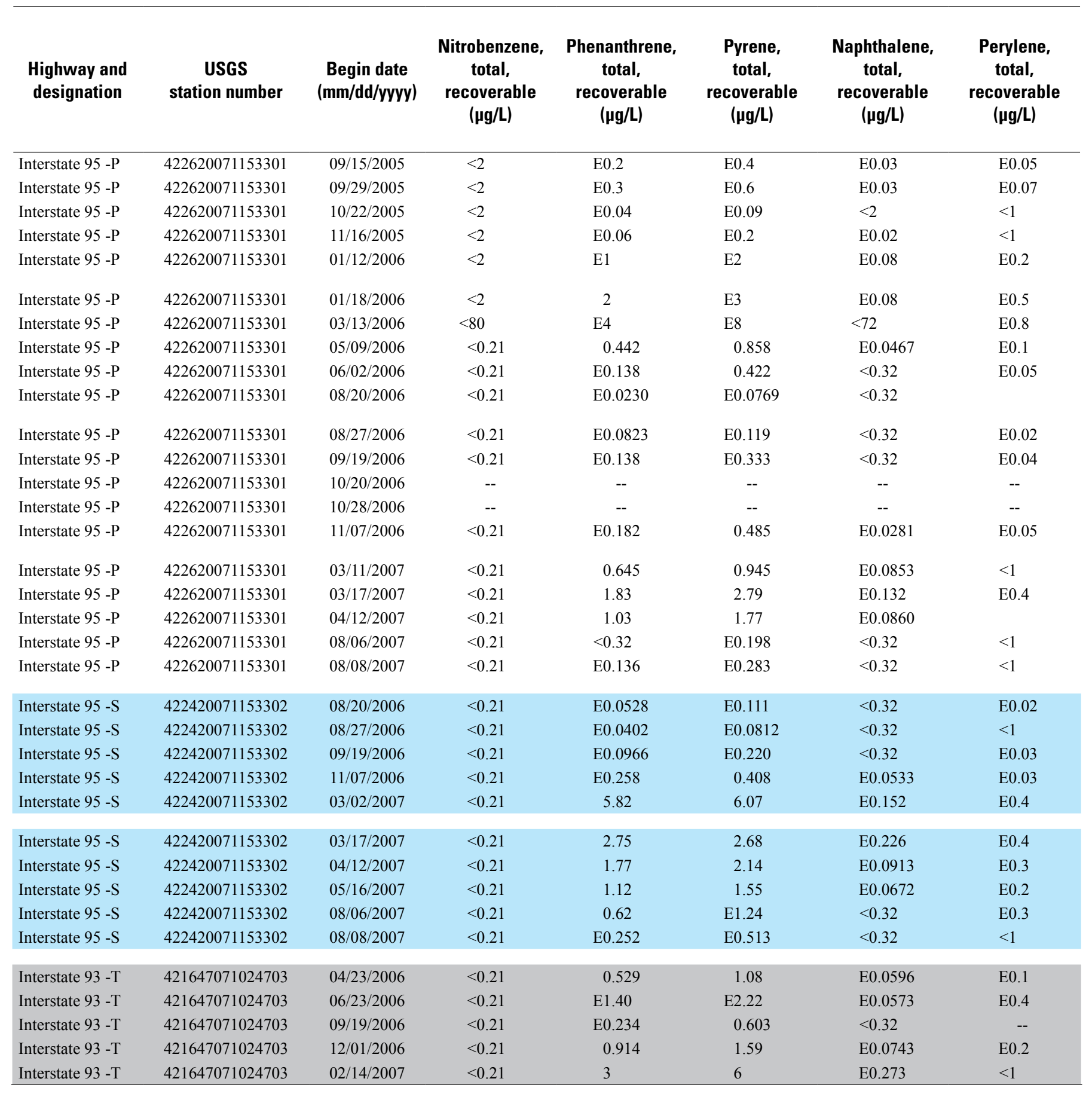


Table 16. Physical properties and concentrations of dissolved major ions, total nutrients, total-recoverable metals, polyaromatic hydrocarbons, phthalate esters, and suspended sediment in stormwater composite samples of highway runoff collected from 12 stations on 8 highways in Massachusetts, 2005-07.-Continued

[USGS, U.S. Geological Survey; -P, primary monitoring station; -S, secondary monitoring station; -T, monitoring station on test highway; mm/dd/yyyy, month, day, year; hrmn, hour minute; NTRU, nephelometric turbidity ratio units; mg/L, milligrams per liter; $\mu \mathrm{g} / \mathrm{L}$, micrograms per liter; $\mu \mathrm{S} / \mathrm{cm}$, microsiemens per centimeter at 25 degrees Celsius; $\mathrm{mm}$, millimeter; <, concentration is less than the laboratory reporting limit; --, no data; E, the recovery or variation in recovery of the analyte was outside the acceptable range or the concentration reported is less than laboratory reporting level and is qualified as estimated; blue-shaded values are associated with the secondary monitoring sites for each principal highway; gray-shaded values are associated with the monitoring sites for each test highway]

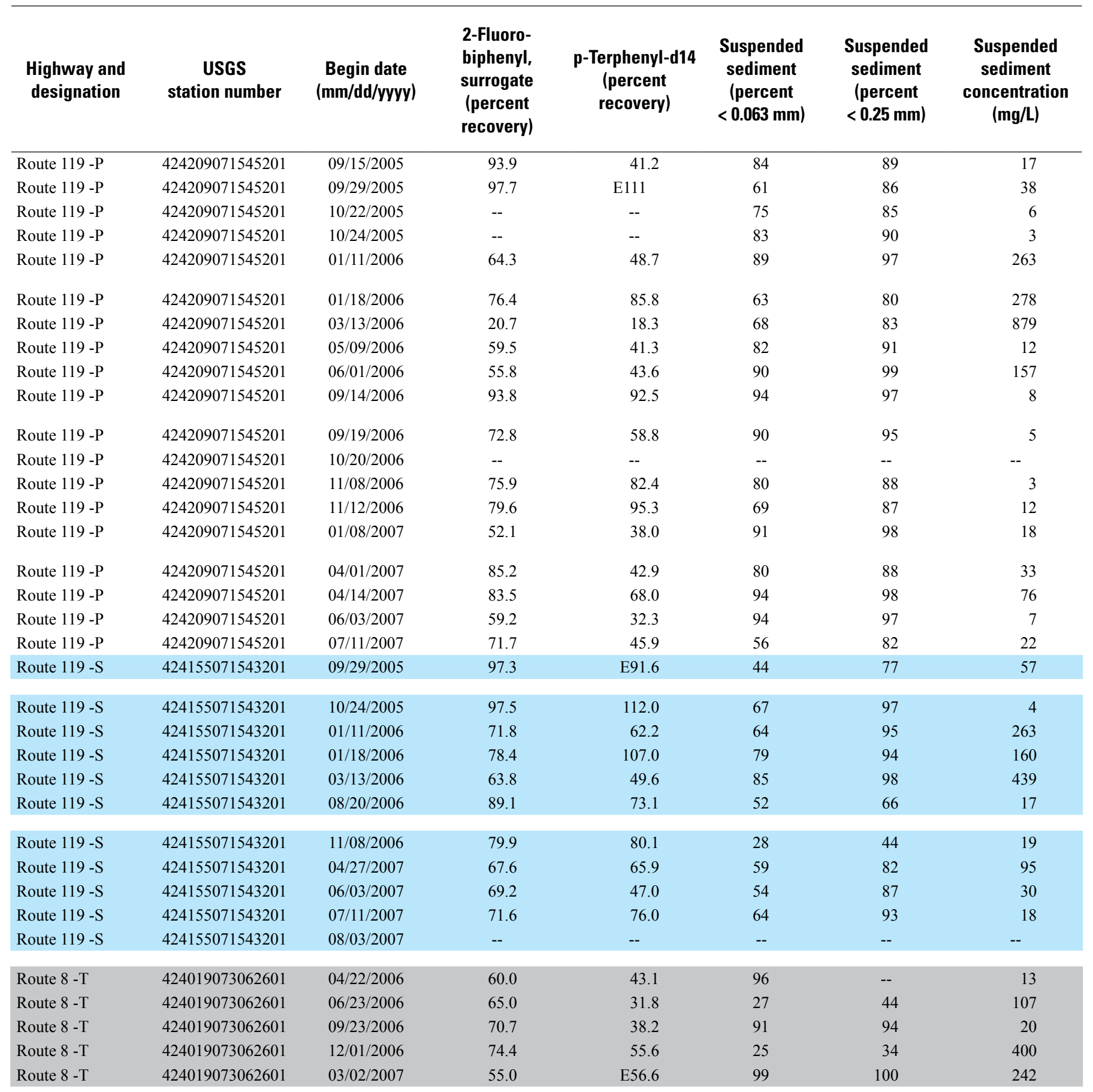


Table 16. Physical properties and concentrations of dissolved major ions, total nutrients, total-recoverable metals, polyaromatic hydrocarbons, phthalate esters, and suspended sediment in stormwater composite samples of highway runoff collected from 12 stations on 8 highways in Massachusetts, 2005-07.-Continued

[USGS, U.S. Geological Survey; -P, primary monitoring station; -S, secondary monitoring station; -T, monitoring station on test highway; mm/dd/yyyy, month, day, year; hrmn, hour minute; NTRU, nephelometric turbidity ratio units; mg/L, milligrams per liter; $\mu \mathrm{g} / \mathrm{L}$, micrograms per liter; $\mu \mathrm{S} / \mathrm{cm}$, microsiemens per centimeter at 25 degrees Celsius; $\mathrm{mm}$, millimeter; <, concentration is less than the laboratory reporting limit; --, no data; E, the recovery or variation in recovery of the analyte was outside the acceptable range or the concentration reported is less than laboratory reporting level and is qualified as estimated; blue-shaded values are associated with the secondary monitoring sites for each principal highway; gray-shaded values are associated with the monitoring sites for each test highway]

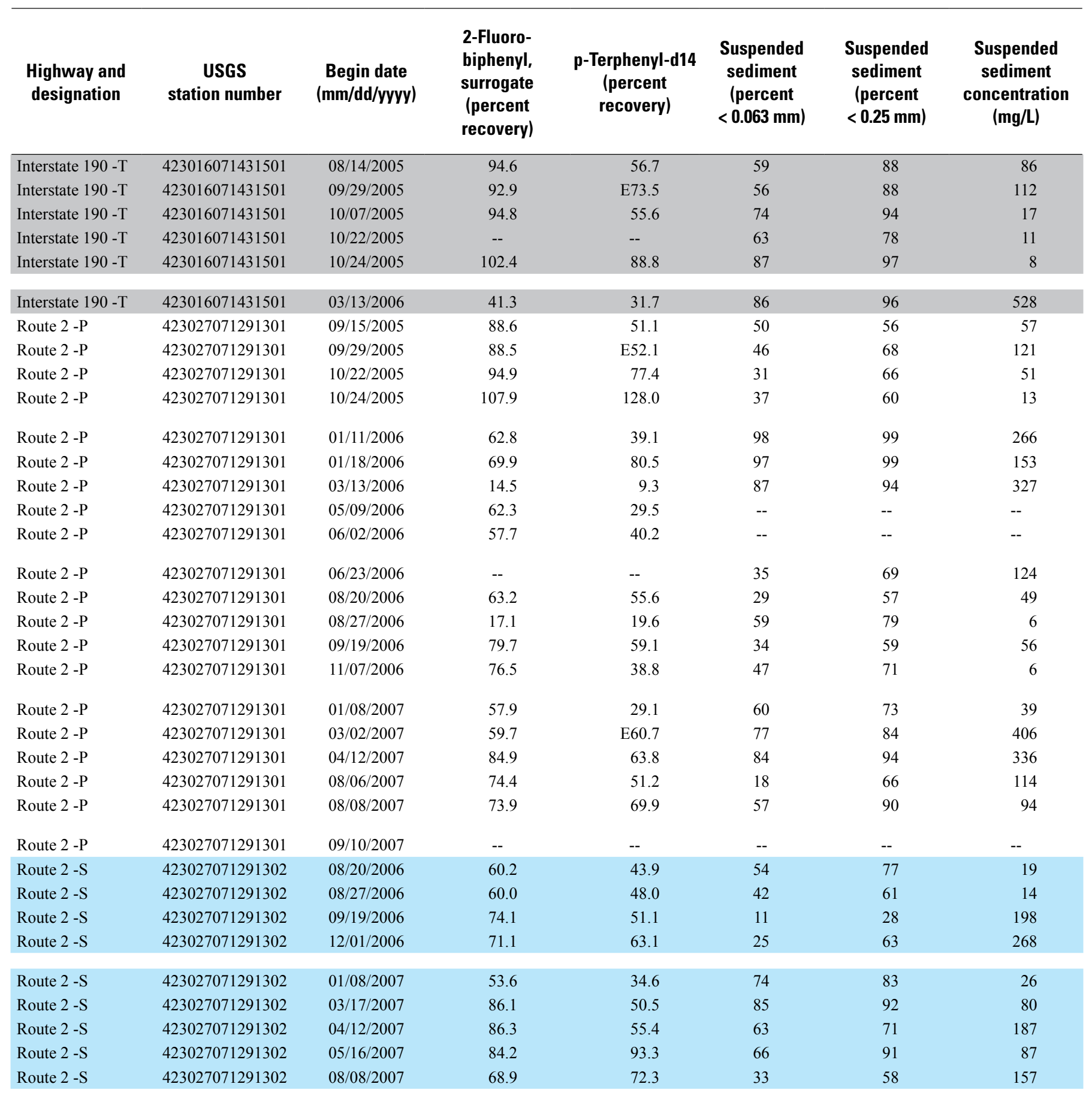


Table 16. Physical properties and concentrations of dissolved major ions, total nutrients, total-recoverable metals, polyaromatic hydrocarbons, phthalate esters, and suspended sediment in stormwater composite samples of highway runoff collected from 12 stations on 8 highways in Massachusetts, 2005-07.-Continued

[USGS, U.S. Geological Survey; -P, primary monitoring station; -S, secondary monitoring station; -T, monitoring station on test highway; mm/dd/yyyy, month, day, year; hrmn, hour minute; NTRU, nephelometric turbidity ratio units; mg/L, milligrams per liter; $\mu \mathrm{g} / \mathrm{L}$, micrograms per liter; $\mu \mathrm{S} / \mathrm{cm}$, microsiemens per centimeter at 25 degrees Celsius; $\mathrm{mm}$, millimeter; <, concentration is less than the laboratory reporting limit; --, no data; E, the recovery or variation in recovery of the analyte was outside the acceptable range or the concentration reported is less than laboratory reporting level and is qualified as estimated; blue-shaded values are associated with the secondary monitoring sites for each principal highway; gray-shaded values are associated with the monitoring sites for each test highway]

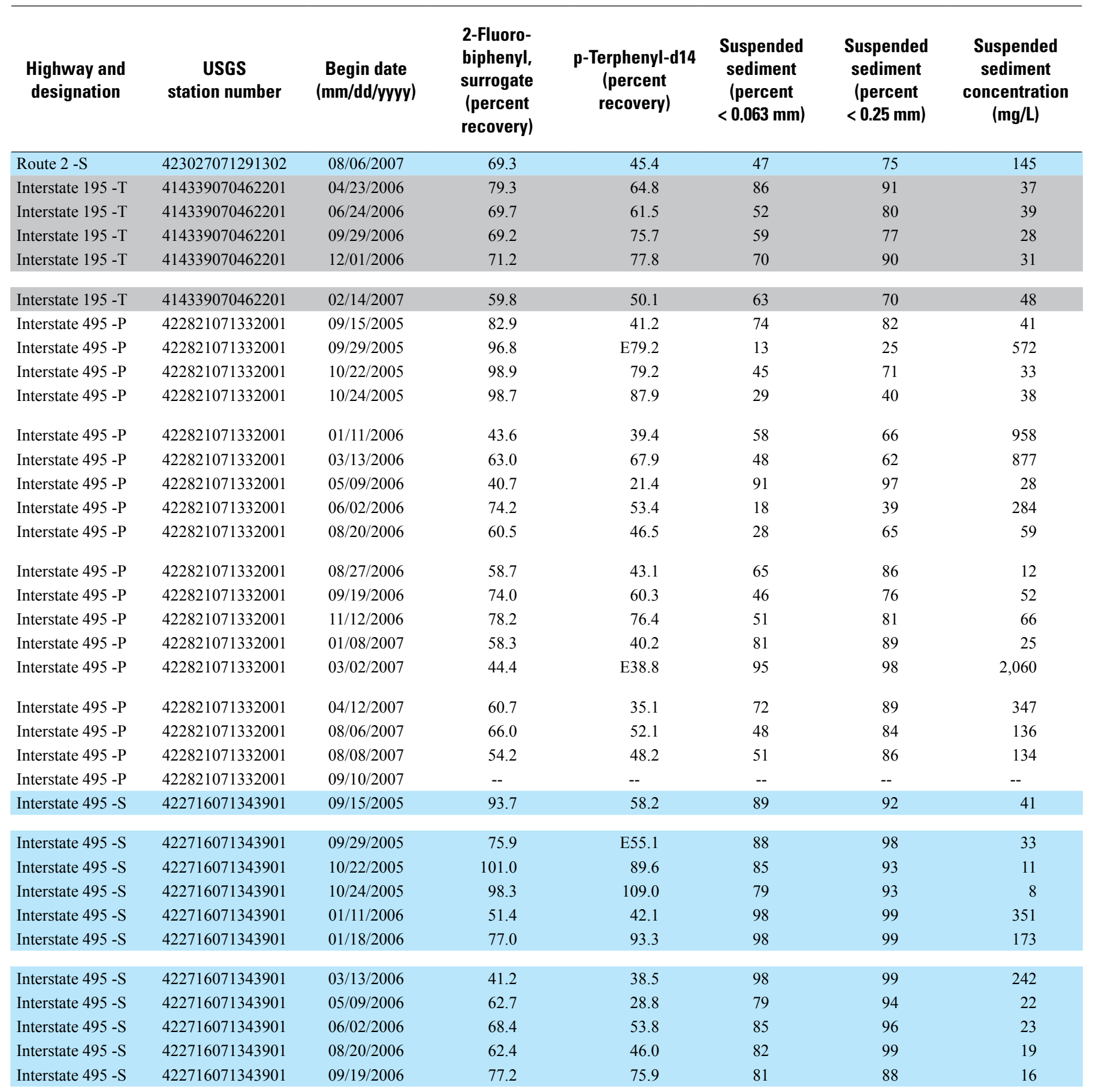


Table 16. Physical properties and concentrations of dissolved major ions, total nutrients, total-recoverable metals, polyaromatic hydrocarbons, phthalate esters, and suspended sediment in stormwater composite samples of highway runoff collected from 12 stations on 8 highways in Massachusetts, 2005-07.-Continued

[USGS, U.S. Geological Survey; -P, primary monitoring station; -S, secondary monitoring station; -T, monitoring station on test highway; mm/dd/yyyy, month, day, year; hrmn, hour minute; NTRU, nephelometric turbidity ratio units; mg/L, milligrams per liter; $\mu \mathrm{g} / \mathrm{L}$, micrograms per liter; $\mu \mathrm{S} / \mathrm{cm}$, microsiemens per centimeter at 25 degrees Celsius; $\mathrm{mm}$, millimeter; <, concentration is less than the laboratory reporting limit; --, no data; E, the recovery or variation in recovery of the analyte was outside the acceptable range or the concentration reported is less than laboratory reporting level and is qualified as estimated; blue-shaded values are associated with the secondary monitoring sites for each principal highway; gray-shaded values are associated with the monitoring sites for each test highway]

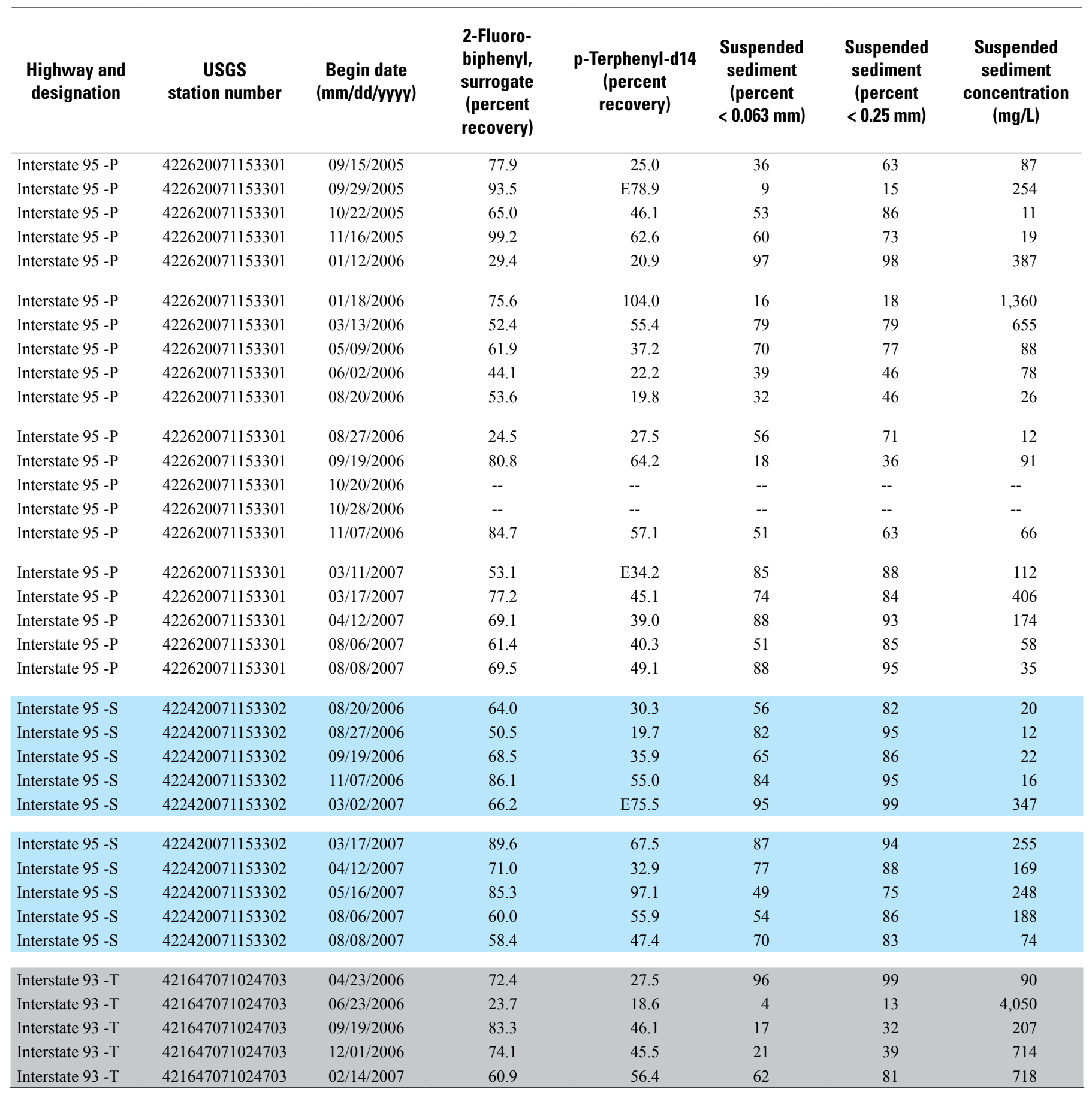




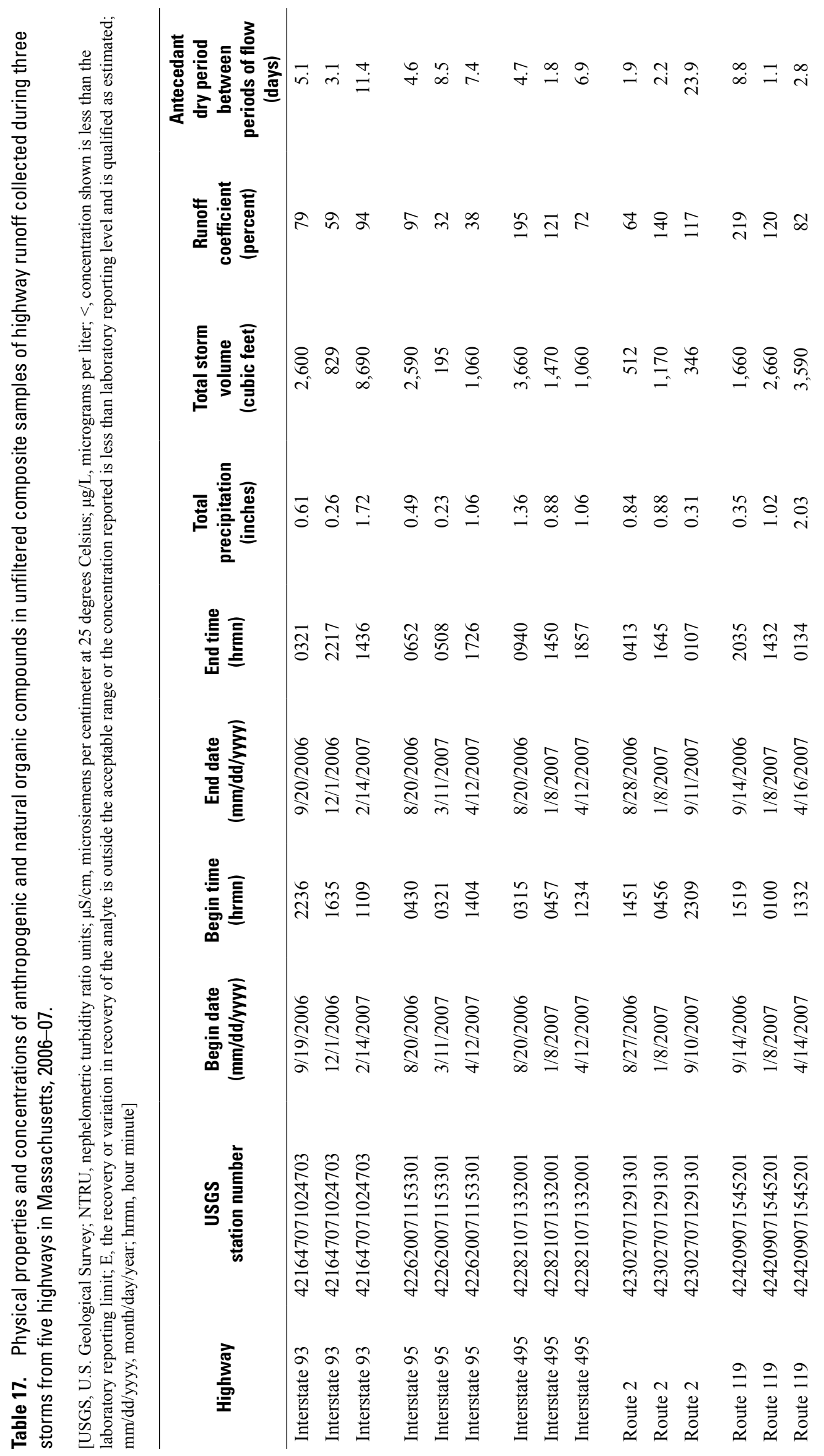




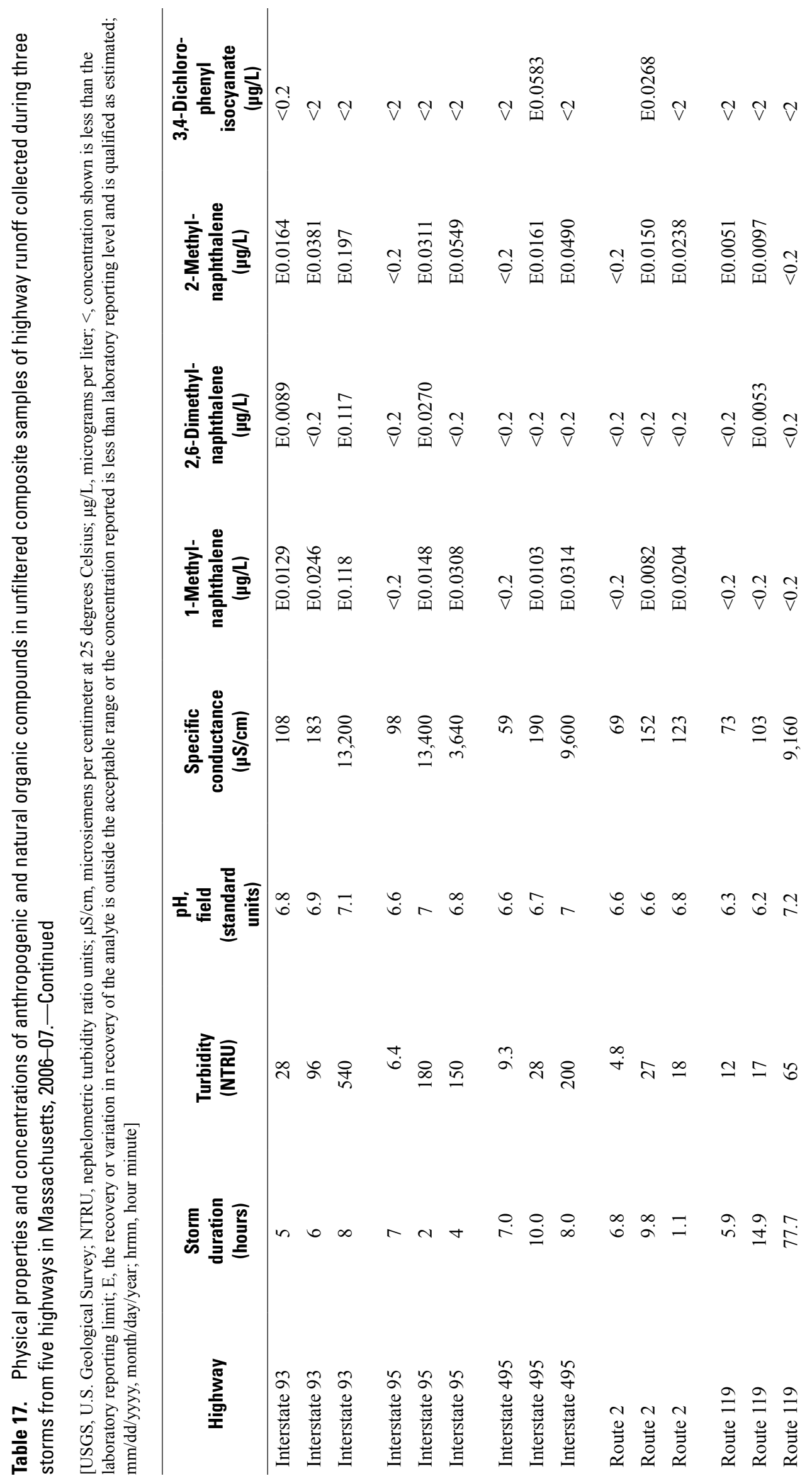




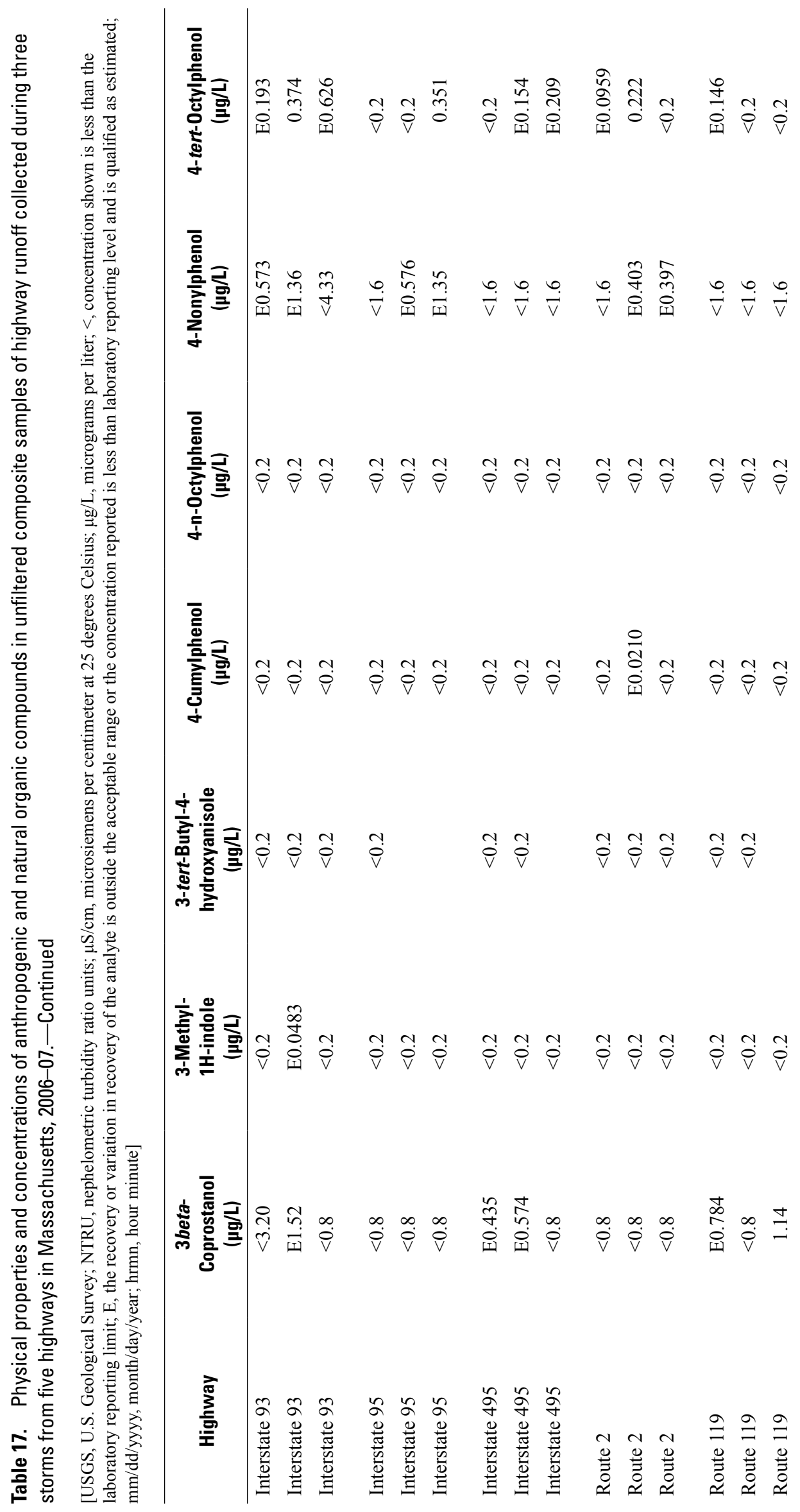




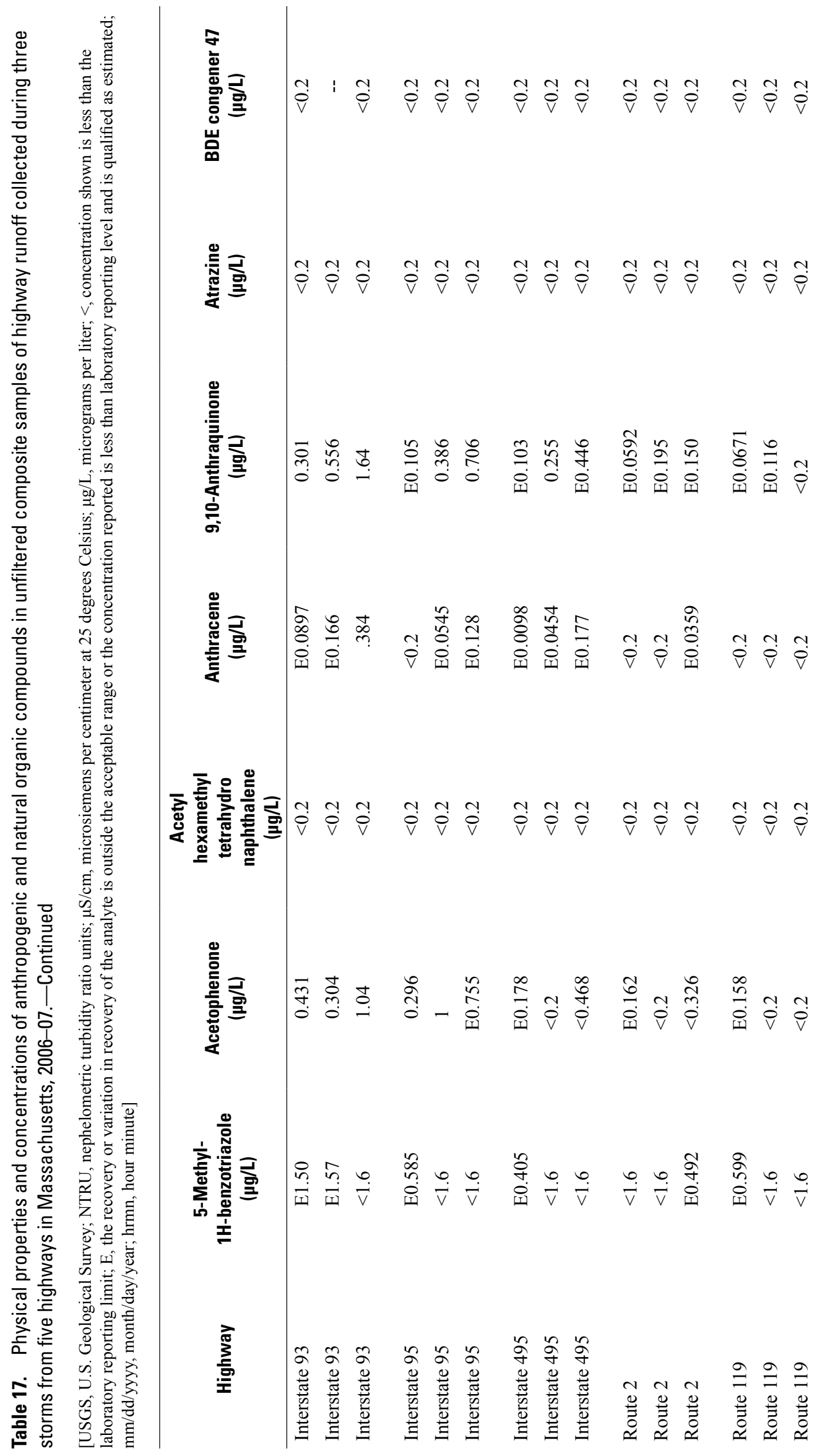




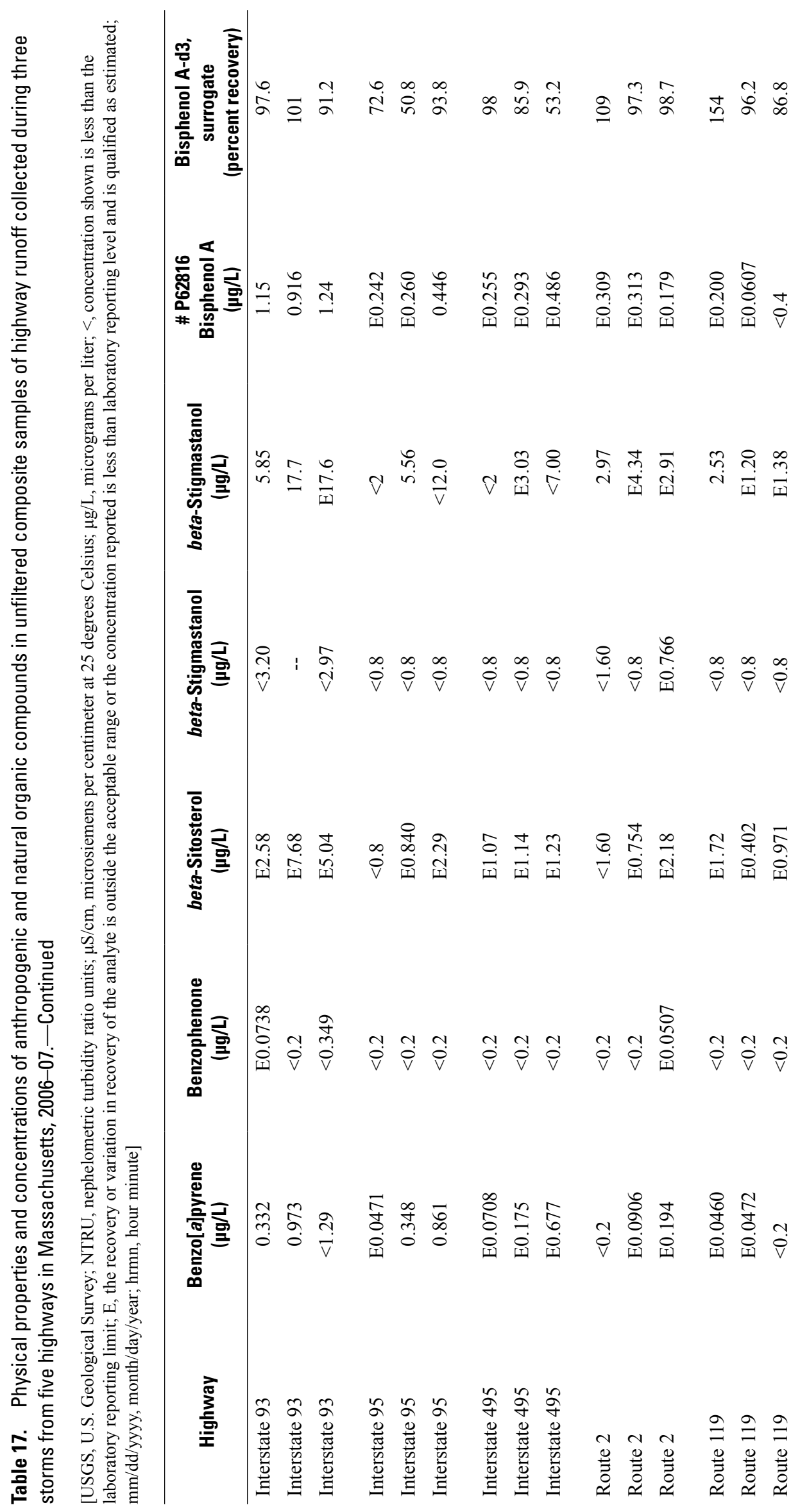




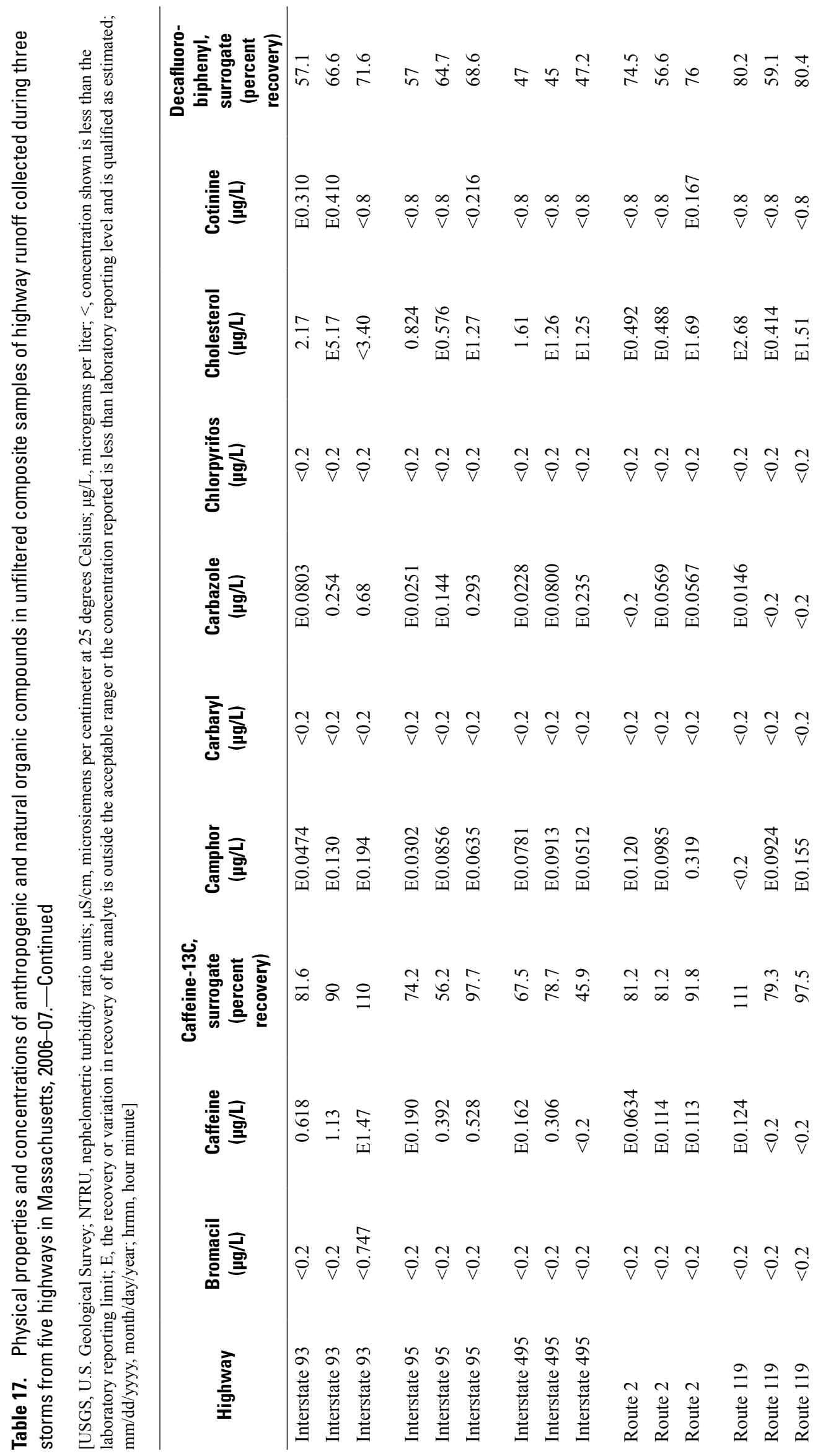




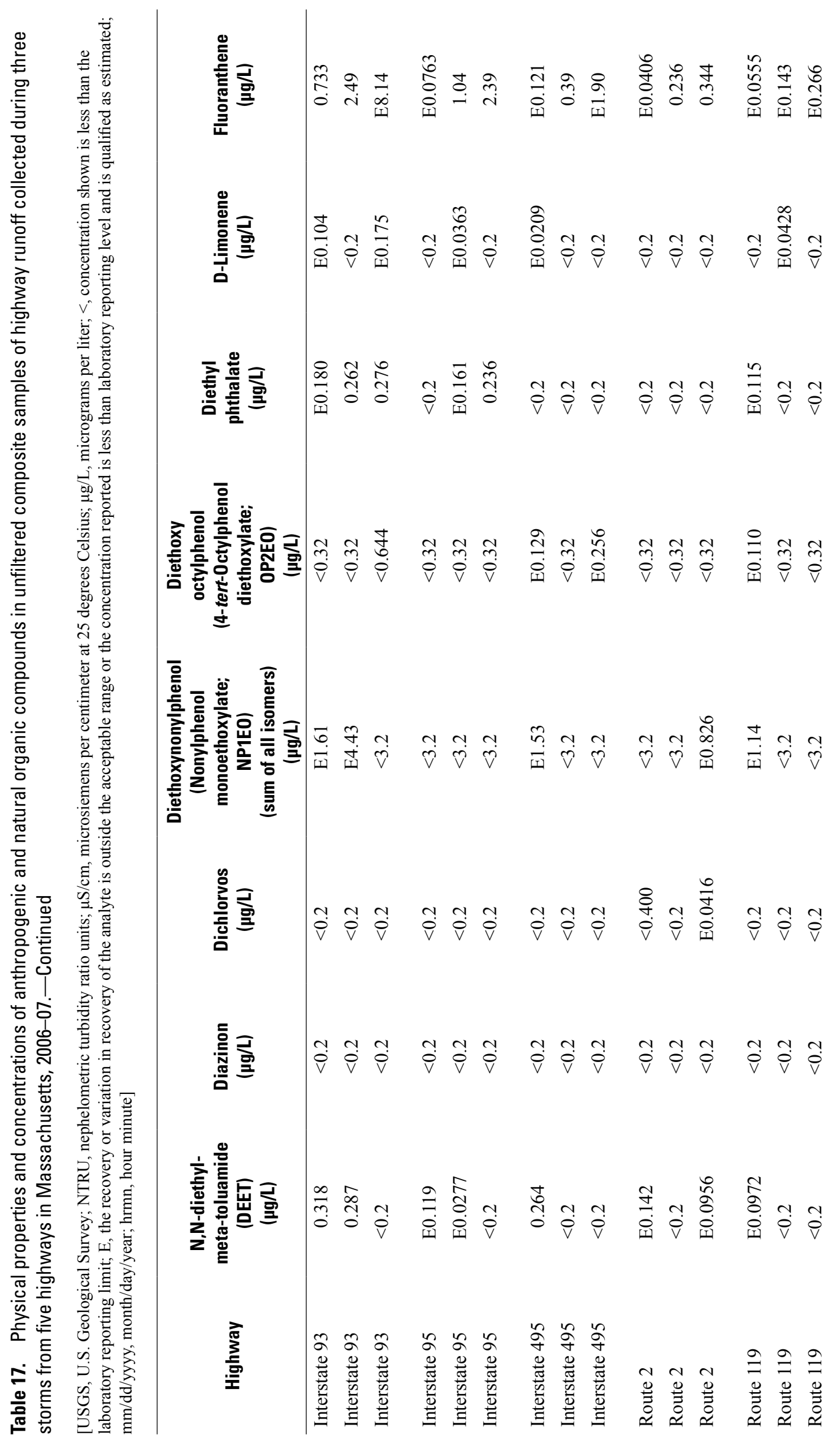




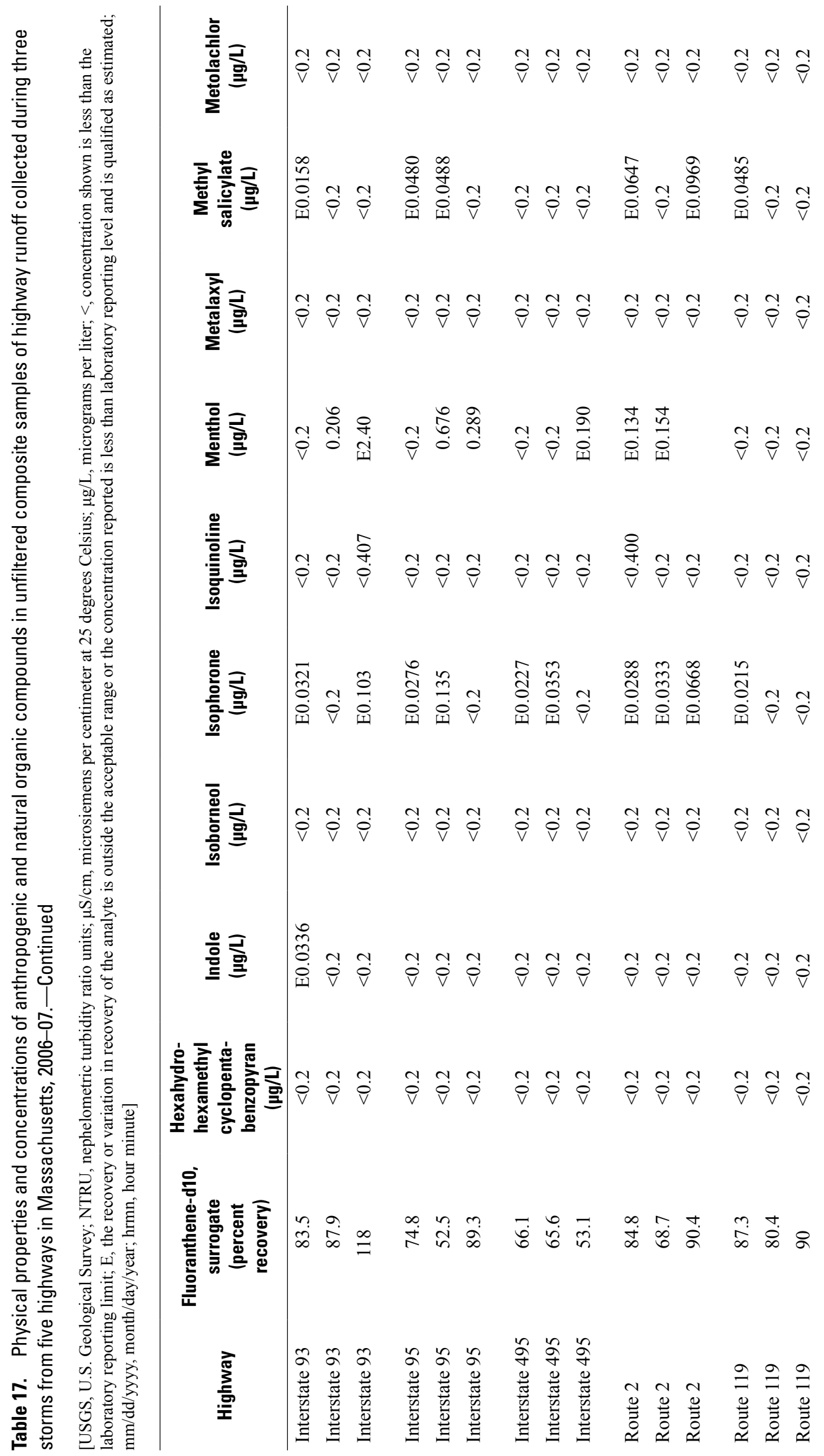




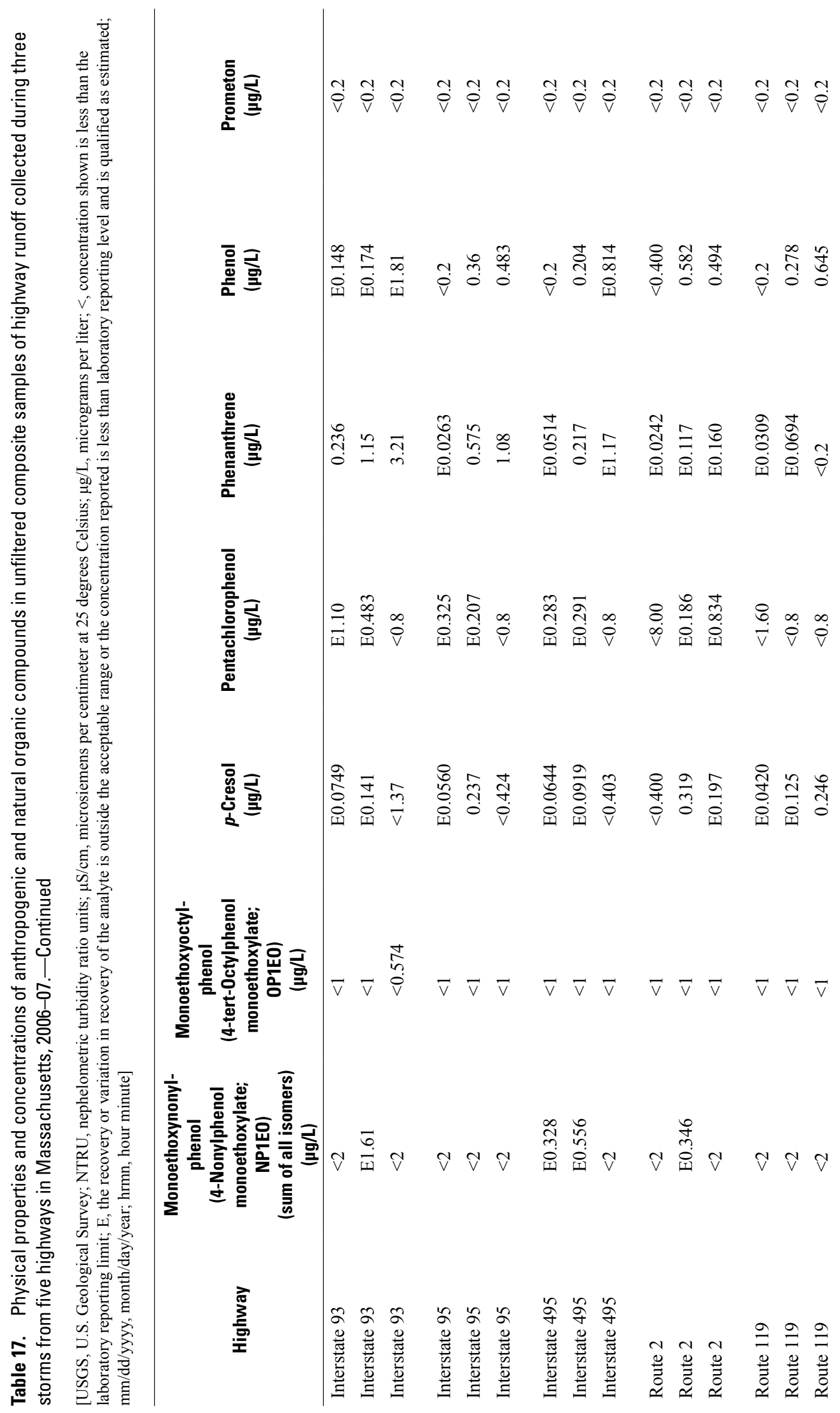




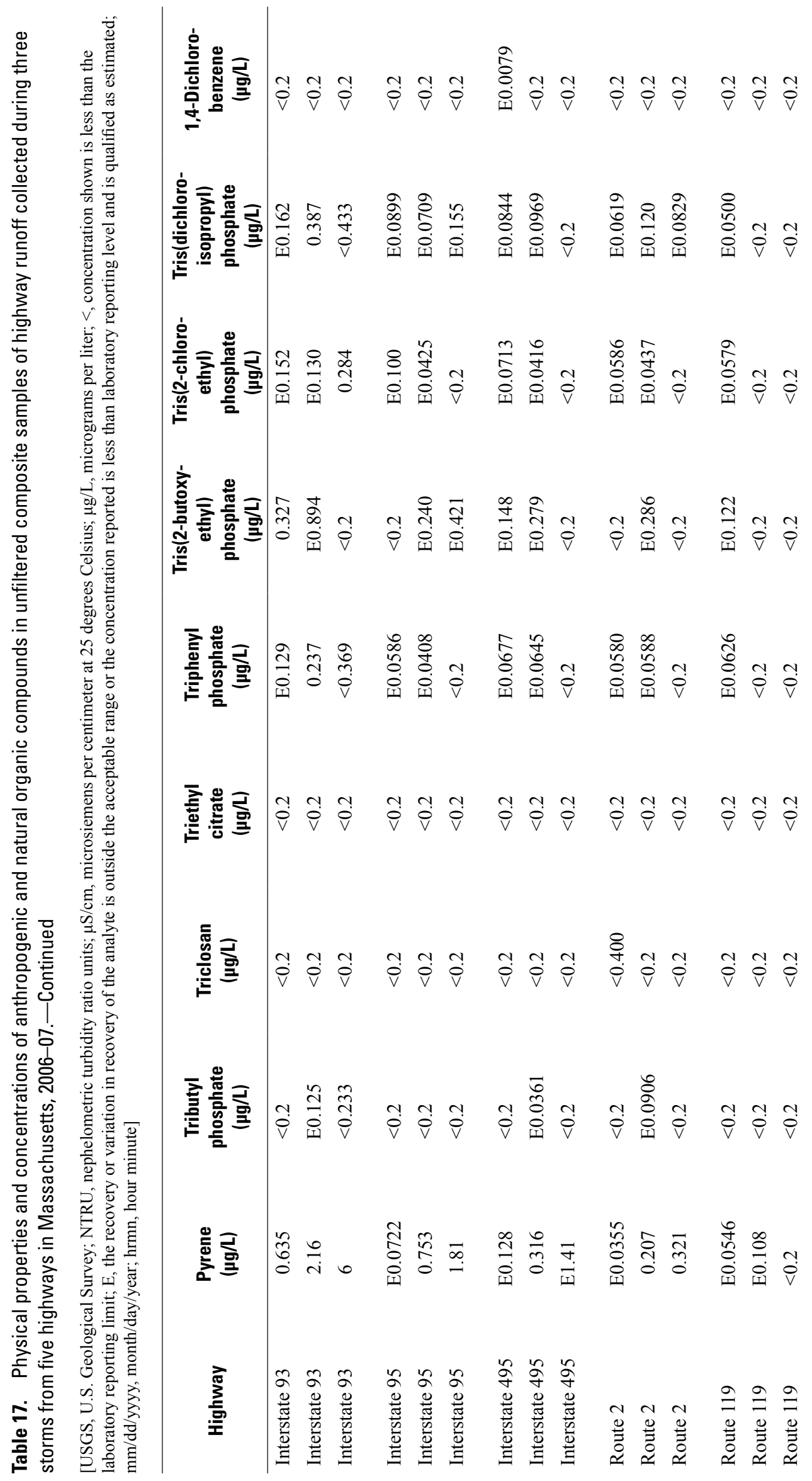



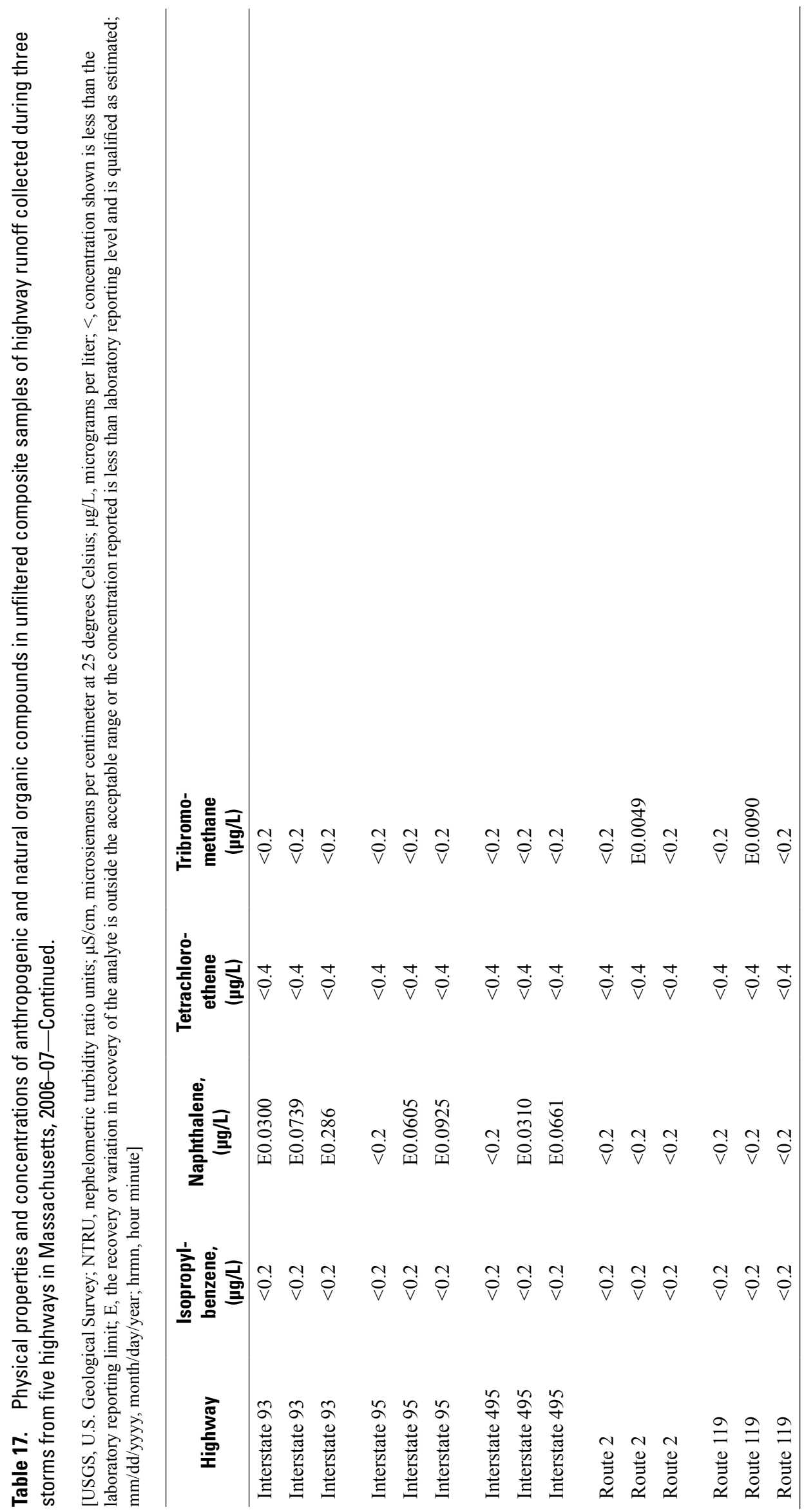
Table 18. Concentrations of 32 elements and total organic carbon in samples of sieved suspended sediment, highway maintenance sand, road salt, roadside grasses, and dry pine needles collected from four highways in Massachusetts, 2005-07.

$[<$, Less than the value shown; $\geq$, greater than or equal to the value shown; $\leq$, less than or equal to the value shown; mm, millimeters in diameter; W, whole sample; --, no data; ppm, parts per million; \%, parts per hundred; TOC, total organic carbon]

\begin{tabular}{|c|c|c|c|c|c|c|c|}
\hline Highway & Sample type & $\begin{array}{l}\text { Particle-size } \\
\text { fraction }\end{array}$ & $\begin{array}{c}\text { Antimony } \\
(\mathrm{ppm})\end{array}$ & $\begin{array}{c}\text { Aluminum } \\
(\%)\end{array}$ & $\begin{array}{c}\text { Arsenic } \\
\text { (ppm) }\end{array}$ & $\begin{array}{l}\text { Barium } \\
\text { (ppm) }\end{array}$ & $\begin{array}{c}\text { Beryllium } \\
\text { (ppm) }\end{array}$ \\
\hline Route 119 & Suspended sediment & $<0.063 \mathrm{~mm}$ & $<5$ & 1.91 & 39 & 79 & 0.8 \\
\hline Route 119 & Suspended sediment & $0.063 \leq 0.250 \mathrm{~mm}$ & $<5$ & 1.59 & 19 & 87 & 0.5 \\
\hline Route 119 & Suspended sediment & $\geq 0.250 \mathrm{~mm}$ & $<5$ & 0.89 & 22 & 55 & $<0.5$ \\
\hline Route 2 & Suspended sediment & $<0.063 \mathrm{~mm}$ & 9 & 2.81 & 29 & 157 & 1.1 \\
\hline Route 2 & Suspended sediment & $0.063 \leq 0.250 \mathrm{~mm}$ & $<5$ & 0.15 & 3 & 19 & $<0.5$ \\
\hline Route 2 & Suspended sediment & $\geq 0.250 \mathrm{~mm}$ & $<5$ & 0.27 & 3 & 27 & $<0.5$ \\
\hline Interstate 495 & Suspended sediment & $<0.063 \mathrm{~mm}$ & 7 & 2.32 & 21 & 615 & 0.9 \\
\hline Interstate 495 & Suspended sediment & $0.063 \leq 0.250 \mathrm{~mm}$ & $<5$ & 1.36 & 17 & 314 & 0.6 \\
\hline Interstate 495 & Suspended sediment & $\geq 0.250 \mathrm{~mm}$ & $<5$ & 0.77 & 13 & 101 & $<0.5$ \\
\hline Interstate 95 & Suspended sediment & $<0.063 \mathrm{~mm}$ & 10 & 2.03 & 20 & 268 & 0.9 \\
\hline Interstate 95 & Suspended sediment & $0.063 \leq 0.250 \mathrm{~mm}$ & $<5$ & 0.99 & 9 & 109 & $<0.5$ \\
\hline Interstate 95 & Suspended sediment & $\geq 0.250 \mathrm{~mm}$ & $<5$ & 0.75 & 6 & 47 & $<0.5$ \\
\hline Route 119 & Maintenance sand & $\mathrm{W}$ & $<5$ & 0.74 & 5 & 46 & $<0.5$ \\
\hline Route 119 & Maintenance sand & $\mathrm{W}$ & $<5$ & 0.82 & 5 & 50 & $<0.5$ \\
\hline Route 2 & Maintenance sand & $\mathrm{W}$ & $<5$ & 0.49 & $<3$ & 30 & $<0.5$ \\
\hline Route 2 & Maintenance sand & $\mathrm{W}$ & $<5$ & 0.63 & $<3$ & 38 & $<0.5$ \\
\hline Interstate 495 & Maintenance sand & $\mathrm{W}$ & $<5$ & 0.57 & $<3$ & 37 & $<0.5$ \\
\hline Interstate 495 & Maintenance sand & $\mathrm{W}$ & $<5$ & 0.54 & $<3$ & 33 & $<0.5$ \\
\hline Interstate 95 & Maintenance sand & $\mathrm{W}$ & $<5$ & 0.3 & 11 & 19 & $<0.5$ \\
\hline Interstate 95 & Maintenance sand & $\mathrm{W}$ & $<5$ & 0.27 & 15 & 15 & $<0.5$ \\
\hline Interstate 95 & Road salt (sodium chloride) & $\mathrm{W}$ & $<5$ & 0.02 & $<3$ & 3 & $<0.5$ \\
\hline Interstate 495 & Roadside grasses & $\mathrm{W}$ & $<5$ & 0.2 & 4 & 33 & $<0.5$ \\
\hline Interstate 495 & Roadside grasses & $\mathrm{W}$ & $<5$ & 0.18 & $<3$ & 31 & $<0.5$ \\
\hline Route 119 & Pine needles & W & $<5$ & 0.05 & $<3$ & 26 & $<0.5$ \\
\hline
\end{tabular}


Table 18. Concentrations of 32 elements and total organic carbon in samples of sieved suspended sediment, highway maintenance sand, road salt, roadside grasses, and dry pine needles collected from four highways in Massachusetts, 2005-07.-Continued

$[<$, Less than the value shown; $\geq$, greater than or equal to the value shown; $\leq$, less than or equal to the value shown; mm, millimeters in diameter; W, whole sample; --, no data; ppm, parts per million; \%, parts per hundred; TOC, total organic carbon]

\begin{tabular}{|c|c|c|c|c|c|c|c|}
\hline Highway & Sample type & $\begin{array}{l}\text { Particle-size } \\
\text { fraction }\end{array}$ & $\begin{array}{c}\text { Bismuth } \\
\text { (ppm) }\end{array}$ & $\begin{array}{l}\text { Calcium } \\
(\%)\end{array}$ & $\begin{array}{c}\text { Cadmium } \\
\text { (ppm) }\end{array}$ & $\begin{array}{l}\text { Cobalt } \\
\text { (ppm) }\end{array}$ & $\begin{array}{c}\text { Chromium } \\
\text { (ppm) }\end{array}$ \\
\hline Route 119 & Suspended sediment & $<0.063 \mathrm{~mm}$ & $<5$ & 0.25 & $<1$ & 19 & 147 \\
\hline Route 119 & Suspended sediment & $0.063 \leq 0.250 \mathrm{~mm}$ & $<5$ & 0.27 & $<1$ & 13 & 687 \\
\hline Route 119 & Suspended sediment & $\geq 0.250 \mathrm{~mm}$ & $<5$ & 0.33 & $<1$ & 11 & 3,470 \\
\hline Route 2 & Suspended sediment & $<0.063 \mathrm{~mm}$ & $<5$ & 0.35 & 1 & 15 & 391 \\
\hline Route 2 & Suspended sediment & $0.063 \leq 0.250 \mathrm{~mm}$ & $<5$ & 0.1 & $<1$ & $<1$ & 65 \\
\hline Route 2 & Suspended sediment & $\geq 0.250 \mathrm{~mm}$ & $<5$ & 0.22 & $<1$ & 2 & 70 \\
\hline Interstate 495 & Suspended sediment & $<0.063 \mathrm{~mm}$ & $<5$ & 0.34 & 1 & 14 & 136 \\
\hline Interstate 495 & Suspended sediment & $0.063 \leq 0.250 \mathrm{~mm}$ & $<5$ & 0.39 & $<1$ & 10 & 1,690 \\
\hline Interstate 495 & Suspended sediment & $\geq 0.250 \mathrm{~mm}$ & $<5$ & 0.3 & $<1$ & 6 & 1,050 \\
\hline Interstate 95 & Suspended sediment & $<0.063 \mathrm{~mm}$ & $<5$ & 0.51 & 2 & 15 & 381 \\
\hline Interstate 95 & Suspended sediment & $0.063 \leq 0.250 \mathrm{~mm}$ & $<5$ & 0.62 & $<1$ & 7 & 134 \\
\hline Interstate 95 & Suspended sediment & $\geq 0.250 \mathrm{~mm}$ & $<5$ & 0.5 & $<1$ & 5 & 395 \\
\hline Route 119 & Maintenance sand & $\mathrm{W}$ & $<5$ & 0.11 & $<1$ & 3 & 325 \\
\hline Route 119 & Maintenance sand & $\mathrm{W}$ & $<5$ & 0.12 & $<1$ & 3 & 361 \\
\hline Route 2 & Maintenance sand & $\mathrm{W}$ & $<5$ & 0.07 & $<1$ & 1 & 273 \\
\hline Route 2 & Maintenance sand & $\mathrm{W}$ & $<5$ & 0.08 & $<1$ & 2 & 308 \\
\hline Interstate 495 & Maintenance sand & $\mathrm{W}$ & $<5$ & 0.12 & $<1$ & 2 & 306 \\
\hline Interstate 495 & Maintenance sand & $\mathrm{W}$ & $<5$ & 0.13 & $<1$ & 2 & 321 \\
\hline Interstate 95 & Maintenance sand & $\mathrm{W}$ & $<5$ & 0.04 & $<1$ & 2 & 421 \\
\hline Interstate 95 & Maintenance sand & $\mathrm{W}$ & $<5$ & 0.03 & $<1$ & 2 & 329 \\
\hline Interstate 95 & Road salt (sodium chloride) & $\mathrm{W}$ & $<5$ & 0.26 & $<1$ & $<1$ & 12 \\
\hline Interstate 495 & Roadside grasses & $\mathrm{W}$ & $<5$ & 0.33 & $<1$ & 2 & 483 \\
\hline Interstate 495 & Roadside grasses & $\mathrm{W}$ & $<5$ & 0.25 & $<1$ & 1 & 227 \\
\hline Route 119 & Pine needles & $\mathrm{W}$ & $<5$ & 0.47 & $<1$ & $<1$ & 34 \\
\hline
\end{tabular}


Table 18. Concentrations of 32 elements and total organic carbon in samples of sieved suspended sediment, highway maintenance sand, road salt, roadside grasses, and dry pine needles collected from four highways in Massachusetts, 2005-07.-Continued

$[<$, Less than the value shown; $\geq$, greater than or equal to the value shown; $\leq$, less than or equal to the value shown; mm, millimeters in diameter; W, whole sample; --, no data; ppm, parts per million; \%, parts per hundred; TOC, total organic carbon]

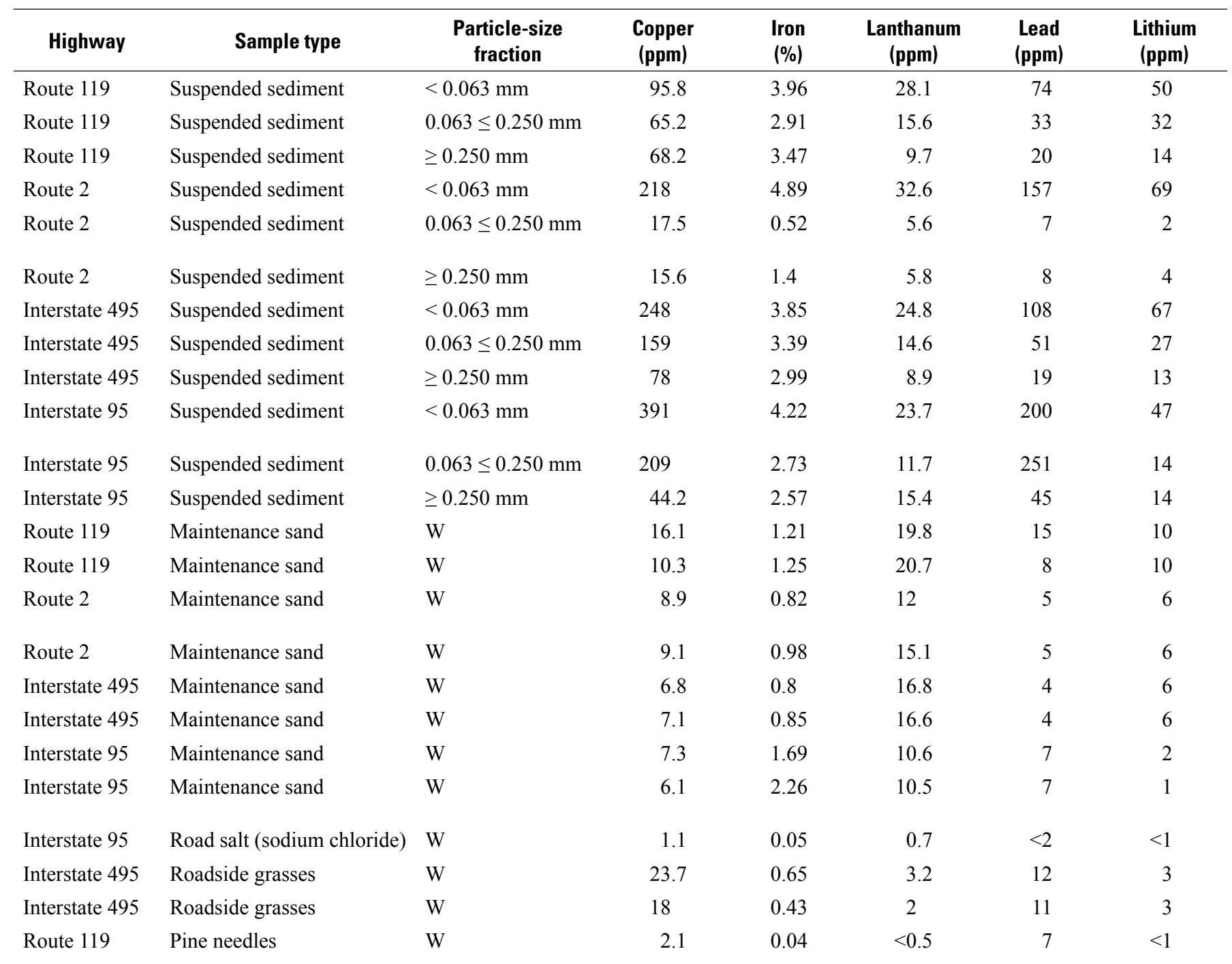


Table 18. Concentrations of 32 elements and total organic carbon in samples of sieved suspended sediment, highway maintenance sand, road salt, roadside grasses, and dry pine needles collected from four highways in Massachusetts, 2005-07.-Continued

$[<$, Less than the value shown; $\geq$, greater than or equal to the value shown; $\leq$, less than or equal to the value shown; mm, millimeters in diameter; W, whole sample; --, no data; ppm, parts per million; \%, parts per hundred; TOC, total organic carbon]

\begin{tabular}{|c|c|c|c|c|c|c|c|}
\hline Highway & Sample type & $\begin{array}{l}\text { Particle-size } \\
\text { fraction }\end{array}$ & $\begin{array}{l}\text { Magnesium } \\
(\%)\end{array}$ & $\begin{array}{l}\text { Manganese } \\
\quad(\mathrm{ppm})\end{array}$ & $\begin{array}{c}\text { Molyb- } \\
\text { denum } \\
\text { (ppm) }\end{array}$ & $\begin{array}{l}\text { Nickel } \\
\text { (ppm) }\end{array}$ & $\begin{array}{c}\text { Phosphorus } \\
(\%)\end{array}$ \\
\hline Route 119 & Suspended sediment & $<0.063 \mathrm{~mm}$ & 1.24 & 589 & 5 & 46 & 0.1 \\
\hline Route 119 & Suspended sediment & $0.063 \leq 0.250 \mathrm{~mm}$ & 0.72 & 477 & 7 & 41 & 0.06 \\
\hline Route 119 & Suspended sediment & $\geq 0.250 \mathrm{~mm}$ & 0.29 & 553 & 12 & 54 & 0.04 \\
\hline Route 2 & Suspended sediment & $<0.063 \mathrm{~mm}$ & 1.92 & 703 & 11 & 53 & 0.11 \\
\hline Route 2 & Suspended sediment & $0.063 \leq 0.250 \mathrm{~mm}$ & 0.06 & 99 & 1 & 5 & 0.01 \\
\hline Route 2 & Suspended sediment & $\geq 0.250 \mathrm{~mm}$ & 0.13 & 145 & 2 & 16 & 0.01 \\
\hline Interstate 495 & Suspended sediment & $<0.063 \mathrm{~mm}$ & 1.88 & 621 & 11 & 51 & 0.09 \\
\hline Interstate 495 & Suspended sediment & $0.063 \leq 0.250 \mathrm{~mm}$ & 0.67 & 504 & 13 & 49 & 0.05 \\
\hline Interstate 495 & Suspended sediment & $\geq 0.250 \mathrm{~mm}$ & 0.3 & 415 & 11 & 40 & 0.03 \\
\hline Interstate 95 & Suspended sediment & $<0.063 \mathrm{~mm}$ & 1.14 & 957 & 17 & 63 & 0.13 \\
\hline Interstate 95 & Suspended sediment & $0.063 \leq 0.250 \mathrm{~mm}$ & 0.46 & 297 & 7 & 35 & 0.08 \\
\hline Interstate 95 & Suspended sediment & $\geq 0.250 \mathrm{~mm}$ & 0.35 & 301 & 6 & 24 & 0.04 \\
\hline Route 119 & Maintenance sand & $\mathrm{W}$ & 0.21 & 304 & 6 & 9 & 0.04 \\
\hline Route 119 & Maintenance sand & W & 0.2 & 329 & 6 & 9 & 0.04 \\
\hline Route 2 & Maintenance sand & W & 0.1 & 198 & 2 & 8 & 0.03 \\
\hline Route 2 & Maintenance sand & $\mathrm{W}$ & 0.14 & 220 & 2 & 7 & 0.03 \\
\hline Interstate 495 & Maintenance sand & W & 0.12 & 208 & 5 & 7 & 0.04 \\
\hline Interstate 495 & Maintenance sand & $\mathrm{W}$ & 0.12 & 231 & 13 & 8 & 0.04 \\
\hline Interstate 95 & Maintenance sand & W & 0.06 & 108 & 2 & 9 & 0.03 \\
\hline Interstate 95 & Maintenance sand & $\mathrm{W}$ & 0.07 & 88 & 3 & 9 & 0.05 \\
\hline Interstate 95 & Road salt (sodium chloride) & W & 1.56 & 15 & $<1$ & $<1$ & $<0.01$ \\
\hline Interstate 495 & Roadside grasses & $\mathrm{W}$ & 0.27 & 265 & 4 & 14 & 0.27 \\
\hline Interstate 495 & Roadside grasses & W & 0.23 & 246 & 2 & 7 & 0.22 \\
\hline Route 119 & Pine needles & W & 0.05 & 1,150 & $<1$ & 2 & 0.04 \\
\hline
\end{tabular}


Table 18. Concentrations of 32 elements and total organic carbon in samples of sieved suspended sediment, highway maintenance sand, road salt, roadside grasses, and dry pine needles collected from four highways in Massachusetts, 2005-07.-Continued

$[<$, Less than the value shown; $\geq$, greater than or equal to the value shown; $\leq$, less than or equal to the value shown; mm, millimeters in diameter; W, whole sample; --, no data; ppm, parts per million; \%, parts per hundred; TOC, total organic carbon]

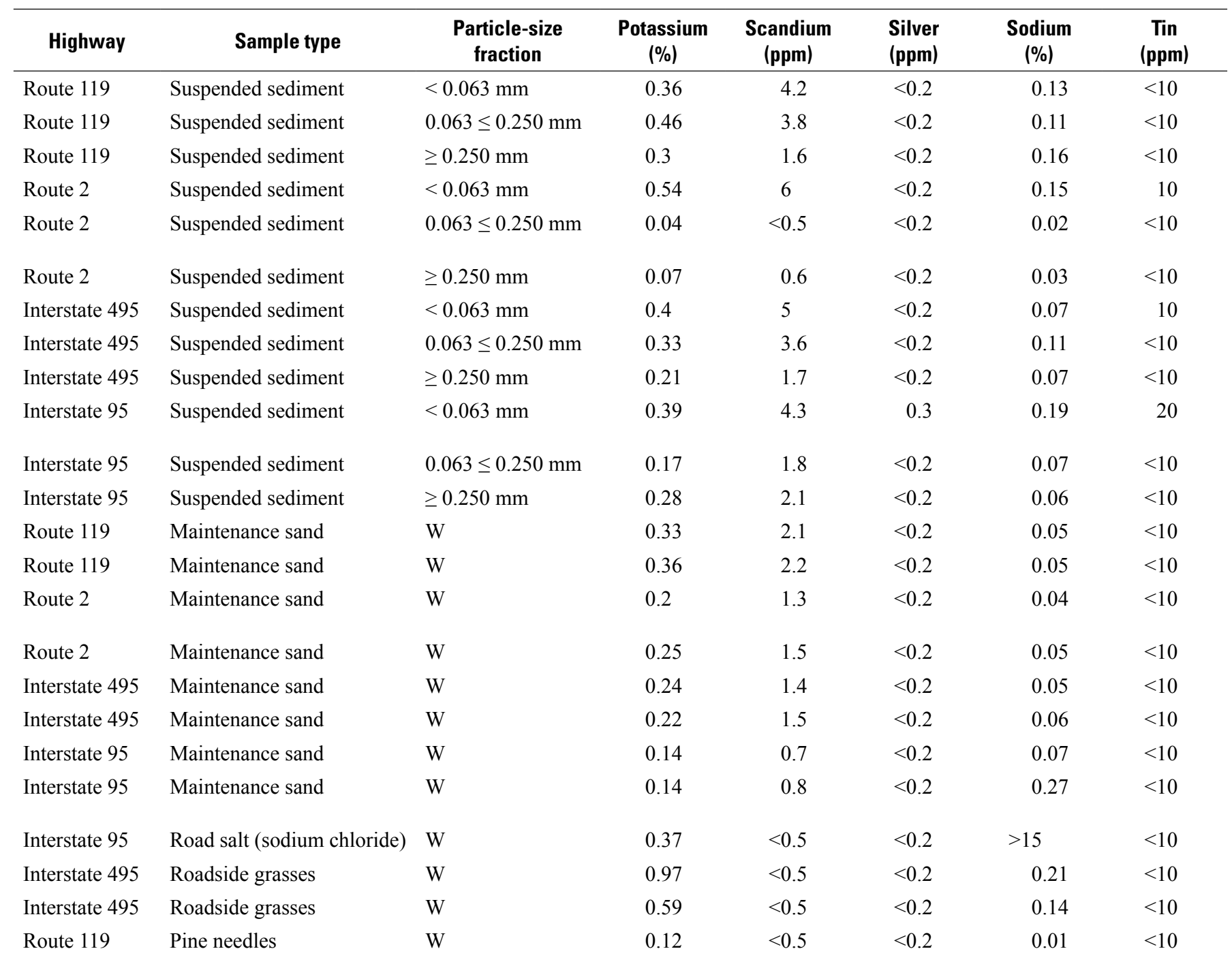


Table 18. Concentrations of 32 elements and total organic carbon in samples of sieved suspended sediment, highway maintenance sand, road salt, roadside grasses, and dry pine needles collected from four highways in Massachusetts, 2005-07.-Continued

$[<$, Less than the value shown; $\geq$, greater than or equal to the value shown; $\leq$, less than or equal to the value shown; mm, millimeters in diameter; W, whole sample; --, no data; ppm, parts per million; \%, parts per hundred; TOC, total organic carbon]

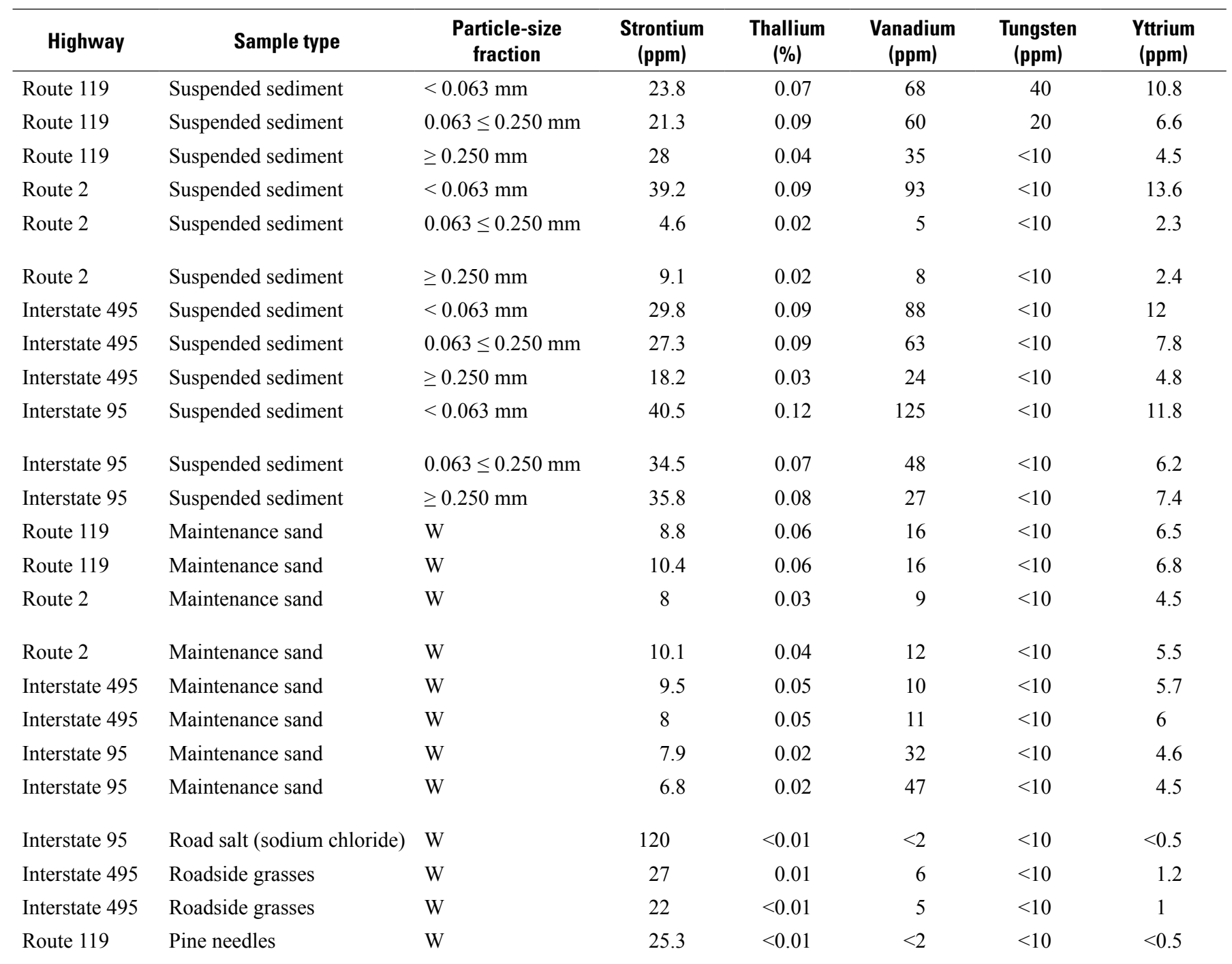


Table 18. Concentrations of 32 elements and total organic carbon in samples of sieved suspended sediment, highway maintenance sand, road salt, roadside grasses, and dry pine needles collected from four highways in Massachusetts, 2005-07.-Continued

$[<$, Less than the value shown; $\geq$, greater than or equal to the value shown; $\leq$, less than or equal to the value shown; mm, millimeters in diameter; W, whole sample; --, no data; ppm, parts per million; \%, parts per hundred; TOC, total organic carbon]

\begin{tabular}{|c|c|c|c|c|c|}
\hline Highway & Sample type & $\begin{array}{l}\text { Particle-size } \\
\text { fraction }\end{array}$ & $\begin{array}{l}\text { Zinc } \\
\text { (ppm) }\end{array}$ & $\begin{array}{c}\text { Zirconium } \\
\text { (ppm) }\end{array}$ & $\begin{array}{l}\text { TOC } \\
(\%)\end{array}$ \\
\hline Route 119 & Suspended sediment & $<0.063 \mathrm{~mm}$ & 503 & 10.4 & 7.86 \\
\hline Route 119 & Suspended sediment & $0.063 \leq 0.250 \mathrm{~mm}$ & 247 & 6.8 & 7.56 \\
\hline Route 119 & Suspended sediment & $\geq 0.250 \mathrm{~mm}$ & 200 & 5.3 & 10.2 \\
\hline Route 2 & Suspended sediment & $<0.063 \mathrm{~mm}$ & 2,360 & 15.2 & 11.7 \\
\hline Route 2 & Suspended sediment & $0.063 \leq 0.250 \mathrm{~mm}$ & 46.6 & 1.8 & 12.3 \\
\hline Route 2 & Suspended sediment & $\geq 0.250 \mathrm{~mm}$ & 83.9 & 3.4 & 12.2 \\
\hline Interstate 495 & Suspended sediment & $<0.063 \mathrm{~mm}$ & 945 & 12.6 & 11.7 \\
\hline Interstate 495 & Suspended sediment & $0.063 \leq 0.250 \mathrm{~mm}$ & 363 & 8.2 & 7.69 \\
\hline Interstate 495 & Suspended sediment & $\geq 0.250 \mathrm{~mm}$ & 135 & 6.7 & 2.78 \\
\hline Interstate 95 & Suspended sediment & $<0.063 \mathrm{~mm}$ & 1,120 & 16.6 & 17.5 \\
\hline Interstate 95 & Suspended sediment & $0.063 \leq 0.250 \mathrm{~mm}$ & 403 & 6.1 & 17.1 \\
\hline Interstate 95 & Suspended sediment & $\geq 0.250 \mathrm{~mm}$ & 86.8 & 11.3 & 1.08 \\
\hline Route 119 & Maintenance sand & $\mathrm{W}$ & 31.2 & 4.5 & -- \\
\hline Route 119 & Maintenance sand & $\mathrm{W}$ & 20.1 & 4.7 & -- \\
\hline Route 2 & Maintenance sand & $\mathrm{W}$ & 11.7 & 4.1 & -- \\
\hline Route 2 & Maintenance sand & $\mathrm{W}$ & 14.4 & 4.7 & -- \\
\hline Interstate 495 & Maintenance sand & $\mathrm{W}$ & 12.3 & 4.8 & -- \\
\hline Interstate 495 & Maintenance sand & $\mathrm{W}$ & 12.9 & 4.5 & -- \\
\hline Interstate 95 & Maintenance sand & $\mathrm{W}$ & 12.5 & 6.9 & -- \\
\hline Interstate 95 & Maintenance sand & $\mathrm{W}$ & 11.8 & 6.7 & -- \\
\hline Interstate 95 & Road salt (sodium chloride) & $\mathrm{W}$ & 5.2 & $<0.5$ & -- \\
\hline Interstate 495 & Roadside grasses & $\mathrm{W}$ & 76.6 & 0.5 & -- \\
\hline Interstate 495 & Roadside grasses & $\mathrm{W}$ & 67.7 & $<0.5$ & -- \\
\hline Route 119 & Pine needles & $\mathrm{W}$ & 29.3 & $<0.5$ & -- \\
\hline
\end{tabular}


Table 19. Distribution of particle sizes and concentrations of 32 elements measured in samples of soil collected near seven highways in Massachusetts, 2005-07.

[Latitude and longitude: in degrees, minutes, and seconds; <, actual value is less than the value shown; mm, millimeters; ppm, parts per million; \%, parts per hundred; -- no data]

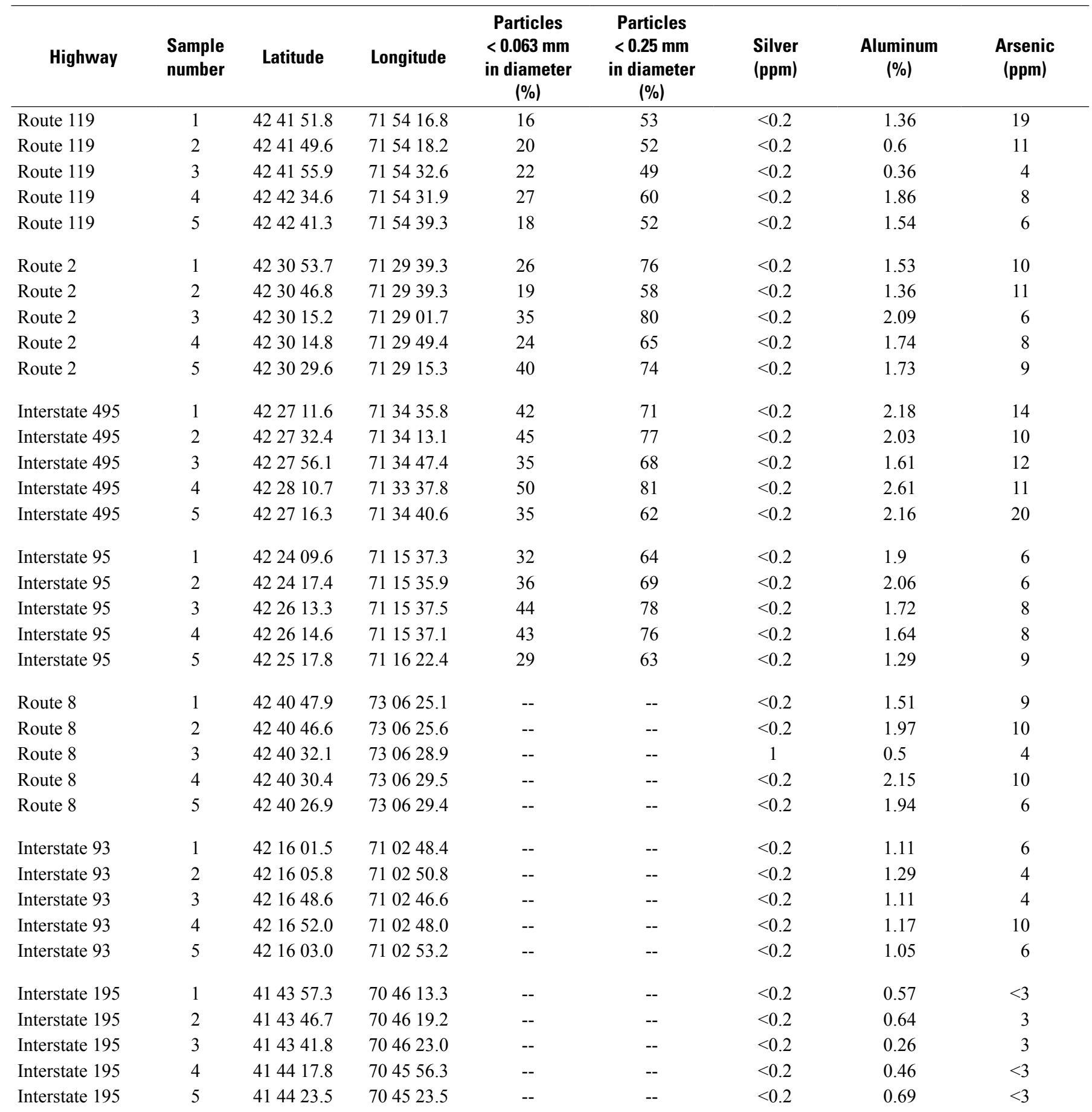


Table 19. Distribution of particle sizes and concentrations of 32 elements measured in samples of soil collected near seven highways in Massachusetts, 2005-07.-Continued

[Latitude and longitude: In degrees, minutes, and seconds; <, actual value is less than shown; mm, millimeters; ppm, parts per million; \%, parts per hundred; -- no data]

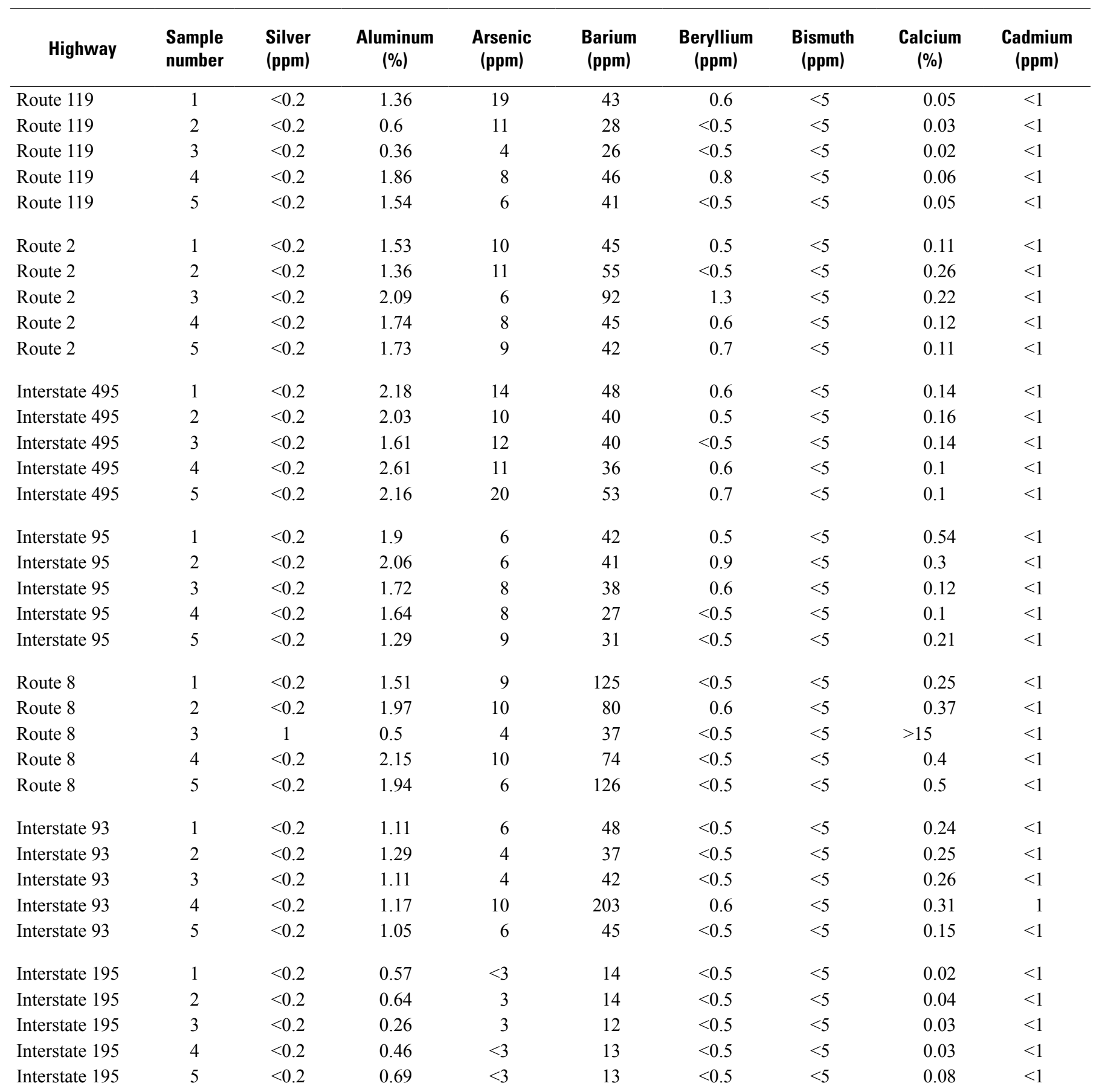


Table 19. Distribution of particle sizes and concentrations of 32 elements measured in samples of soil collected near seven highways in Massachusetts, 2005-07.-Continued

[Latitude and longitude: In degrees, minutes, and seconds; <, actual value is less than shown; mm, millimeters; ppm, parts per million; \%, parts per hundred; -- no data]

\begin{tabular}{|c|c|c|c|c|c|c|c|}
\hline Route 119 & 1 & 2 & 413 & 11.2 & 1.62 & 0.22 & 20.4 \\
\hline Route 119 & 2 & 3 & 1540 & 14.3 & 1.61 & 0.16 & 19.7 \\
\hline Route 119 & 3 & 1 & 784 & 12 & 0.73 & 0.11 & 15.3 \\
\hline Route 119 & 4 & 3 & 649 & 10.5 & 1.84 & 0.19 & 26.1 \\
\hline Route 2 & 1 & 4 & 384 & 11 & 1.53 & 0.17 & 22.4 \\
\hline Route 2 & 2 & 8 & 655 & 15.2 & 1.82 & 0.31 & 22.4 \\
\hline Route 2 & 3 & 6 & 408 & 20.1 & 1.85 & 0.15 & 29.7 \\
\hline Route 2 & 4 & 4 & 407 & 12.6 & 1.62 & 0.16 & 22.1 \\
\hline Route 2 & 5 & 4 & 564 & 11.6 & 1.73 & 0.14 & 24 \\
\hline Interstate 495 & 4 & 5 & 240 & 7.9 & 2.05 & 0.16 & 25.7 \\
\hline Interstate 495 & 5 & 4 & 527 & 11.7 & 2.31 & 0.22 & 25.5 \\
\hline Interstate 95 & 1 & 10 & 209 & 27.3 & 2.51 & 0.17 & 18.9 \\
\hline Interstate 95 & 2 & 7 & 521 & 20.6 & 2.25 & 0.13 & 26 \\
\hline Interstate 95 & 3 & 4 & 276 & 9.6 & 1.41 & 0.11 & 23.9 \\
\hline Interstate 95 & 4 & 3 & 246 & 11.5 & 1.42 & 0.1 & 20.9 \\
\hline Interstate 95 & 5 & 5 & 1090 & 21.9 & 2.29 & 0.11 & 12.6 \\
\hline Route 8 & 1 & 12 & 158 & 32.1 & 2.98 & 0.18 & 30.7 \\
\hline Interstate 93 & 4 & 8 & 390 & 167 & 3.53 & 0.2 & 18 \\
\hline Interstate 93 & 5 & 4 & 183 & 79.8 & 1.91 & 0.15 & 20.9 \\
\hline Interstate 195 & 1 & 1 & 298 & 4.5 & 1.01 & 0.06 & 9.3 \\
\hline Interstate 195 & 2 & 1 & 447 & 5.9 & 1.03 & 0.07 & 13.4 \\
\hline Interstate 195 & 3 & 1 & 548 & 6.9 & 0.76 & 0.05 & 11.8 \\
\hline Interstate 195 & 4 & $<1$ & 250 & 3.5 & 0.47 & 0.05 & 7.6 \\
\hline Interstate 195 & 5 & 1 & 253 & 2.7 & 0.45 & 0.06 & 10.5 \\
\hline
\end{tabular}


Table 19. Distribution of particle sizes and concentrations of 32 elements measured in samples of soil collected near seven highways in Massachusetts, 2005-07.-Continued

[Latitude and longitude: In degrees, minutes, and seconds; <, actual value is less than shown; mm, millimeters; ppm, parts per million; \%, parts per hundred; -- no data]

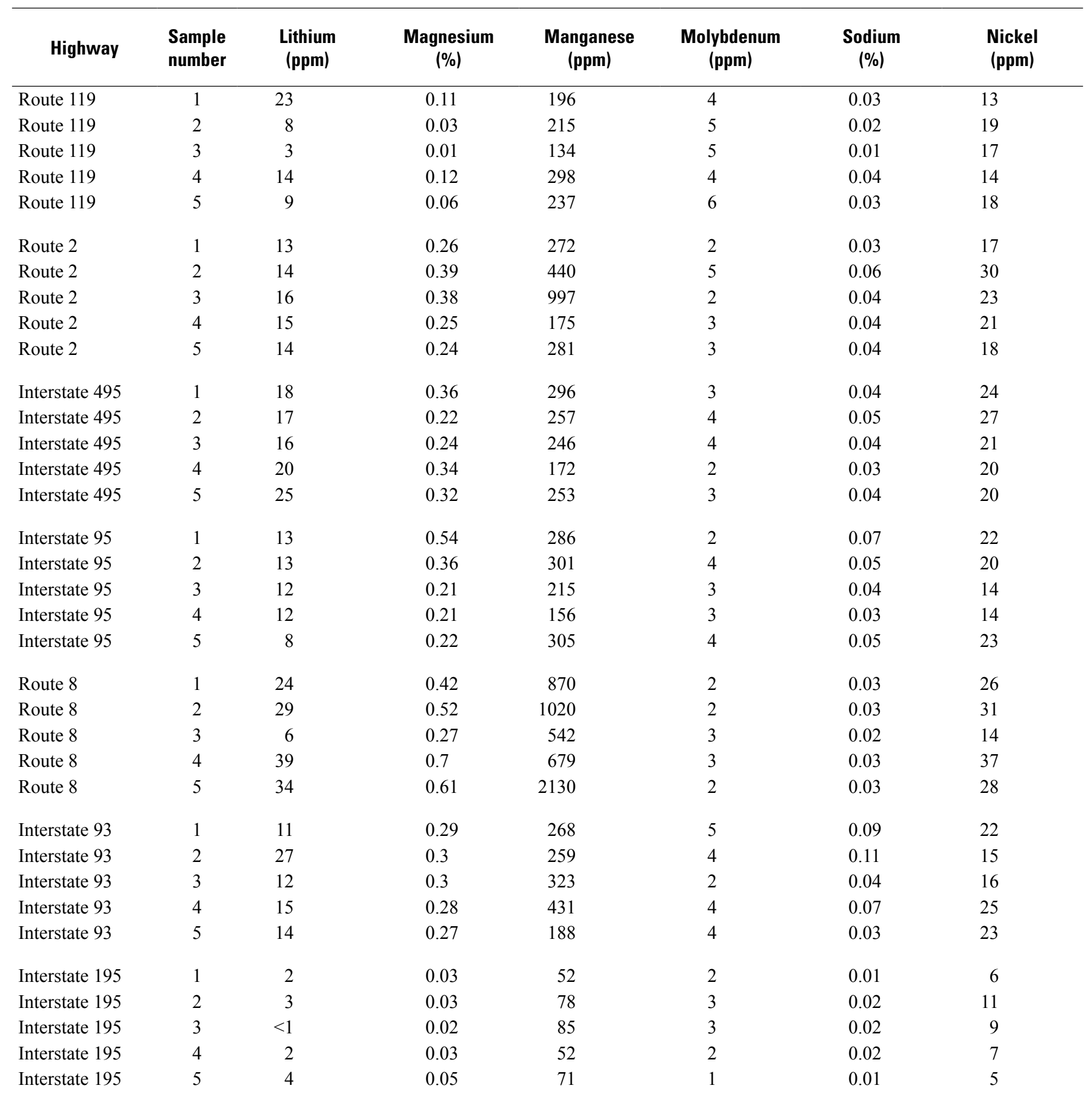


Table 19. Distribution of particle sizes and concentrations of 32 elements measured in samples of soil collected near seven highways in Massachusetts, 2005-07-Continued

[Latitude and longitude: In degrees, minutes, and seconds; <, actual value is less than shown; mm, millimeters; ppm, parts per million; \%, parts per hundred; -- no data]

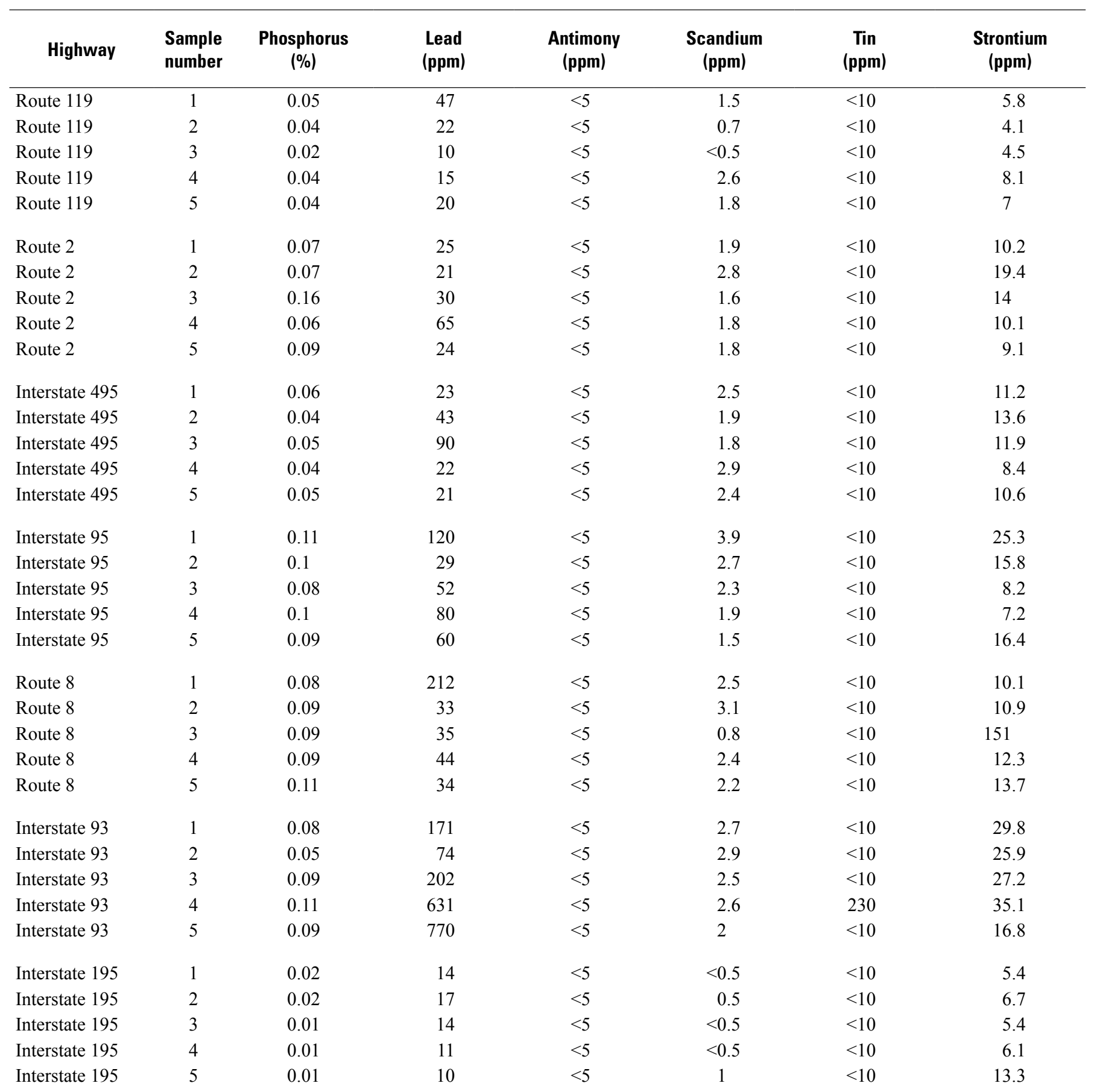


Table 19. Distribution of particle sizes and concentrations of 32 elements measured in samples of soil collected near seven highways in Massachusetts, 2005-07-Continued

[Latitude and longitude: In degrees, minutes, and seconds; <, actual value is less than shown; mm, millimeters; ppm, parts per million; \%, parts per hundred; -- no data]

\begin{tabular}{|c|c|c|c|c|c|c|c|}
\hline Highway & $\begin{array}{l}\text { Sample } \\
\text { number }\end{array}$ & $\begin{array}{c}\text { Thallium } \\
\text { (\%) }\end{array}$ & $\begin{array}{c}\text { Vanadium } \\
\text { (ppm) }\end{array}$ & $\begin{array}{c}\text { Tungsten } \\
\text { (ppm) }\end{array}$ & $\begin{array}{c}\text { Yttrium } \\
\text { (ppm) }\end{array}$ & $\begin{array}{l}\text { Zinc } \\
\text { (ppm) }\end{array}$ & $\begin{array}{l}\text { Zirconium } \\
\text { (ppm) }\end{array}$ \\
\hline Route 119 & 1 & 0.05 & 26 & $<10$ & 5.2 & 29.3 & 1.7 \\
\hline Route 119 & 2 & 0.03 & 20 & $<10$ & 3.8 & 13.1 & 1.6 \\
\hline Route 119 & 3 & 0.02 & 7 & $<10$ & 3.1 & 13.7 & 1.3 \\
\hline Route 119 & 4 & 0.08 & 25 & $<10$ & 6.8 & 46 & 1.8 \\
\hline Route 119 & 5 & 0.07 & 31 & $<10$ & 5.7 & 29.4 & 3.1 \\
\hline Route 2 & 1 & 0.08 & 25 & $<10$ & 6.7 & 30.7 & 1.7 \\
\hline Route 2 & 2 & 0.11 & 30 & $<10$ & 9.4 & 36.6 & 3.6 \\
\hline Route 2 & 3 & 0.1 & 29 & $<10$ & 10.1 & 53.4 & 1.7 \\
\hline Route 2 & 4 & 0.1 & 33 & $<10$ & 7.6 & 30.9 & 2 \\
\hline Route 2 & 5 & 0.09 & 27 & $<10$ & 7.9 & 28.3 & 1.9 \\
\hline Interstate 495 & 1 & 0.11 & 34 & $<10$ & 8.6 & 36.2 & 2.2 \\
\hline Interstate 495 & 2 & 0.13 & 41 & $<10$ & 6.8 & 26.7 & 4.3 \\
\hline Interstate 495 & 3 & 0.1 & 34 & $<10$ & 4.7 & 54.2 & 2.5 \\
\hline Interstate 495 & 4 & 0.13 & 38 & $<10$ & 7.2 & 32.4 & 4.2 \\
\hline Interstate 495 & 5 & 0.09 & 33 & $<10$ & 7.6 & 34.6 & 2.6 \\
\hline Interstate 95 & 1 & 0.21 & 81 & $<10$ & 13.9 & 58.2 & 5.1 \\
\hline Interstate 95 & 2 & 0.14 & 51 & $<10$ & 18.4 & 40 & 2.8 \\
\hline Interstate 95 & 3 & 0.09 & 27 & $<10$ & 9.8 & 35.2 & 1.8 \\
\hline Interstate 95 & 4 & 0.08 & 34 & $<10$ & 7.2 & 30.6 & 1.5 \\
\hline Interstate 95 & 5 & 0.1 & 48 & $<10$ & 5.9 & 43.1 & 2.2 \\
\hline Route 8 & 1 & 0.02 & 19 & $<10$ & 13.7 & 199 & 3.3 \\
\hline Route 8 & 2 & 0.03 & 25 & $<10$ & 15.3 & 104 & 3.2 \\
\hline Route 8 & 3 & 0.01 & 14 & $<10$ & 5.2 & 74.7 & 0.8 \\
\hline Route 8 & 4 & 0.03 & 33 & $<10$ & 8.4 & 112 & 3.1 \\
\hline Route 8 & 5 & 0.03 & 29 & $<10$ & 6.9 & 106 & 2.8 \\
\hline Interstate 93 & 1 & 0.09 & 42 & $<10$ & 9 & 51.2 & 3.6 \\
\hline Interstate 93 & 2 & 0.1 & 36 & $<10$ & 10.1 & 36.5 & 3.4 \\
\hline Interstate 93 & 3 & 0.1 & 36 & $<10$ & 9.2 & 74.4 & 4.8 \\
\hline Interstate 93 & 4 & 0.08 & 40 & $<10$ & 9.4 & 435 & 5.4 \\
\hline Interstate 93 & 5 & 0.07 & 60 & $<10$ & 9.9 & 67.8 & 4.4 \\
\hline Interstate 195 & 1 & 0.03 & 16 & $<10$ & 2.4 & 6.8 & 1.6 \\
\hline Interstate 195 & 2 & 0.04 & 17 & $<10$ & 2.8 & 6.3 & 4.5 \\
\hline Interstate 195 & 3 & 0.04 & 12 & $<10$ & 2.1 & 5.8 & 1.3 \\
\hline Interstate 195 & 4 & 0.04 & 8 & $<10$ & 2.4 & 8.1 & 2.3 \\
\hline Interstate 195 & 5 & 0.05 & 14 & $<10$ & 3.6 & 6.1 & 0.9 \\
\hline
\end{tabular}


竞焉

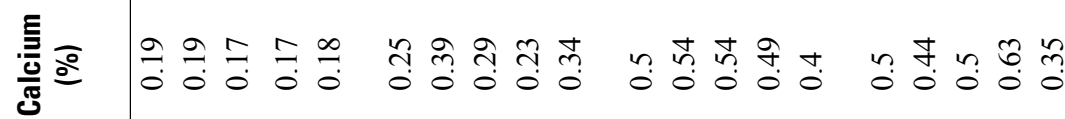

章言

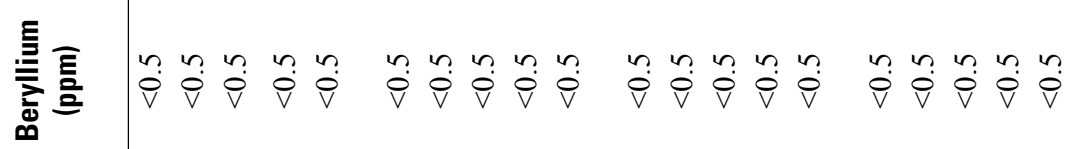

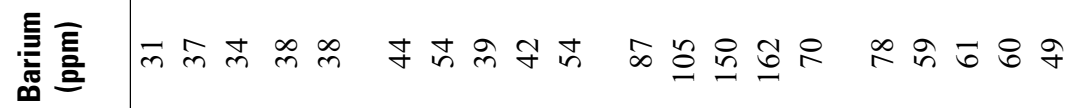

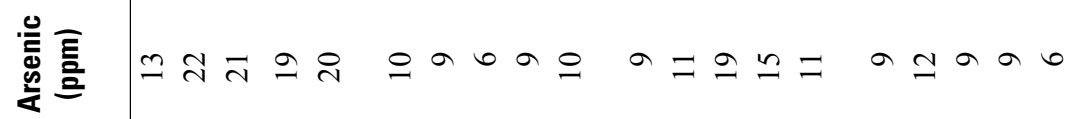

应

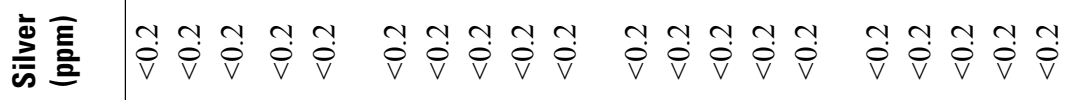

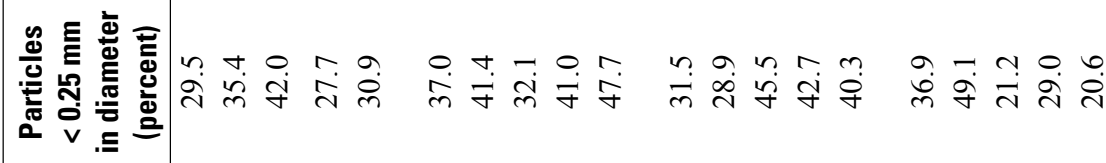

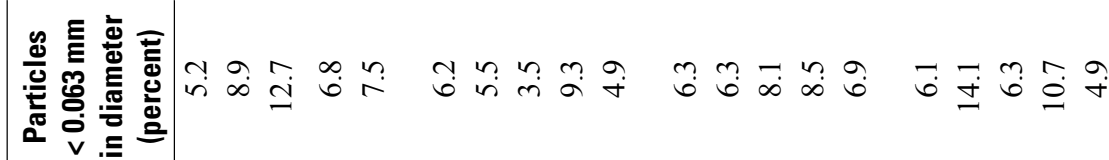

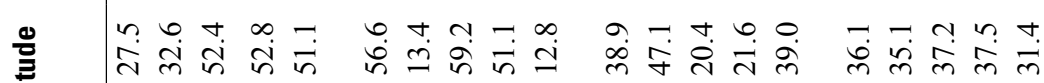

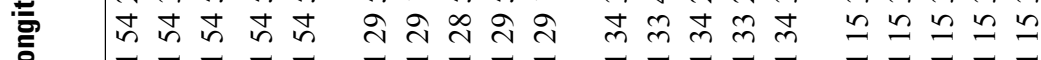

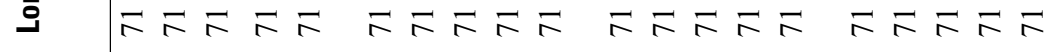

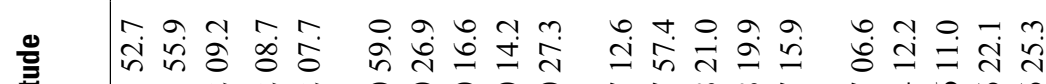

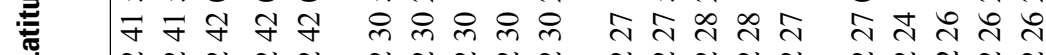

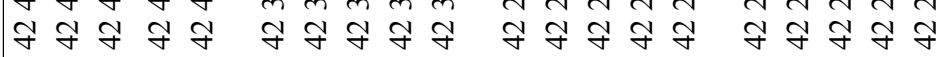

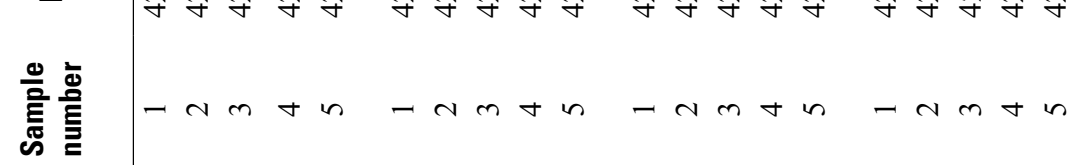

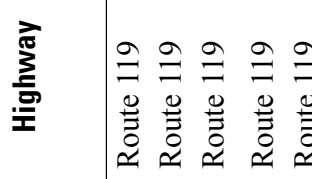

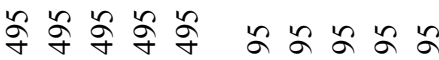

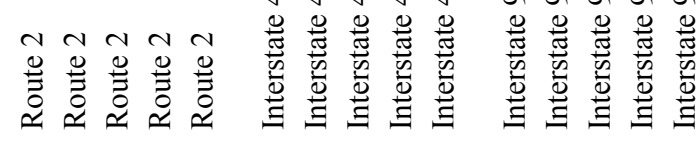




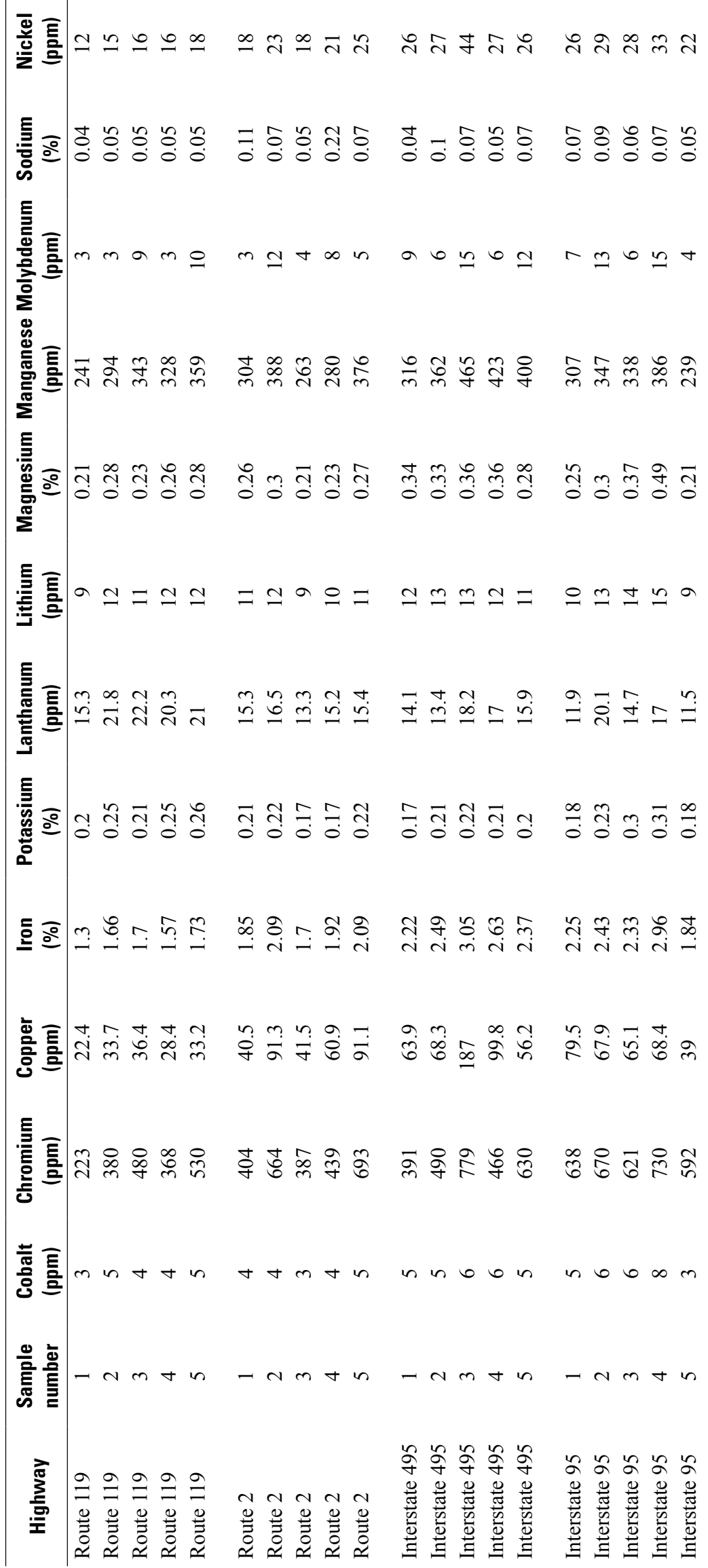




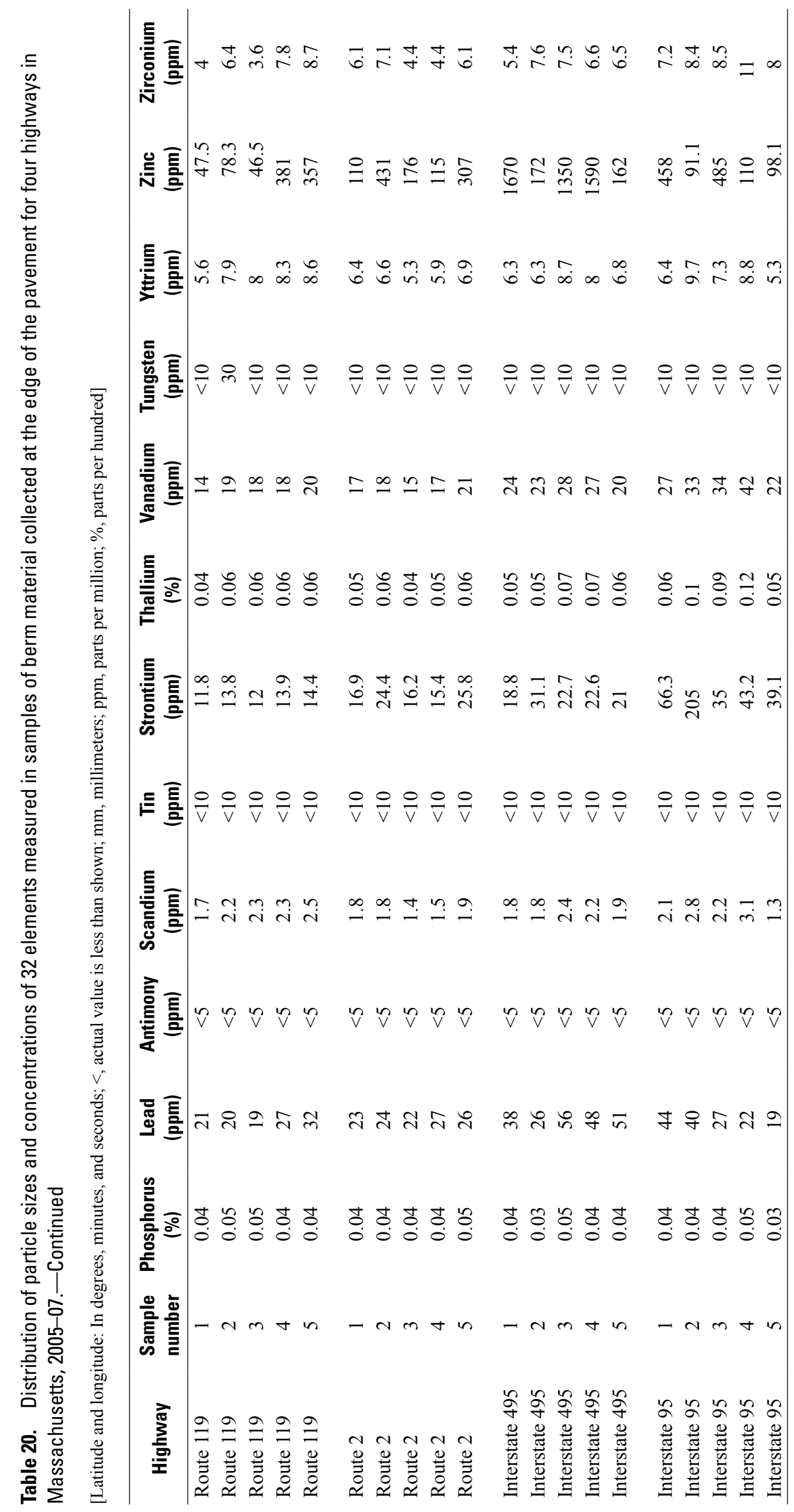


Table 21. Concentrations of selected polyaromatic hydrocarbons and phthalate compounds in samples of suspended sediment, roadside grasses, and dry pine needles collected from four highways in Massachusetts, 2005-07.

[Values are in micrograms per kilogram ; <, less than the value shown; $\geq$, greater than or equal to the value shown; mm, millimeters in diameter; W, whole sample; -R, replicate sample; --, no data; E, the recovery or variation in recovery of the analyte was outside the acceptable range, or concentration reported is less than laboratory reporting level and is qualified as estimated]

\begin{tabular}{|c|c|c|c|c|c|c|}
\hline Highway & Sample type & $\begin{array}{c}\text { Particle-size } \\
\text { fraction }\end{array}$ & $\begin{array}{c}\text { 124-Trichloro- } \\
\text { benzene }\end{array}$ & $\begin{array}{l}\text { 12-Dimethyl- } \\
\text { naphthalene }\end{array}$ & $\begin{array}{l}\text { 16-Dimethyl- } \\
\text { naphthalene }\end{array}$ & $\begin{array}{l}\text { 1-Methyl-9H- } \\
\text { fluorene }\end{array}$ \\
\hline Route 119 & Suspended sediment & $<0.063 \mathrm{~mm}$ & $<2,850$ & $<2,850$ & $<2,850$ & $<2,850$ \\
\hline Route 119 & Suspended sediment & $\geq 0.063 \mathrm{~mm}$ & $<10,200$ & $<10,200$ & $<10,200$ & $<10,200$ \\
\hline Route 2 & Suspended sediment & $<0.063 \mathrm{~mm}$ & $<1,840$ & $<1,840$ & $<1,840$ & $<1,840$ \\
\hline Route 2 & Suspended sediment & $\geq 0.063 \mathrm{~mm}$ & $<2,010$ & $<2,010$ & $<2,010$ & $<2,010$ \\
\hline Interstate 495 & Suspended sediment & $<0.063 \mathrm{~mm}$ & $<2,580$ & $<2,580$ & $<2,580$ & $<2,580$ \\
\hline Interstate 495 & Suspended sediment & $\geq 0.063 \mathrm{~mm}$ & $<5,020$ & $<5,020$ & $<5,020$ & $<5,020$ \\
\hline Interstate 95 & Suspended sediment & $<0.063 \mathrm{~mm}$ & $<3,460$ & $<3,460$ & $<3,460$ & $<3,460$ \\
\hline Interstate 95 & Suspended sediment & $\geq 0.063 \mathrm{~mm}$ & $<1,540$ & $<1,540$ & $<1,540$ & $<1,540$ \\
\hline Interstate 495 & Roadside grasses & W & -- & $<200$ & $<200$ & $<200$ \\
\hline Interstate 495 & Roadside grasses $-\mathrm{R}$ & W & -- & $<200$ & $<200$ & $<200$ \\
\hline Route 119 & Pine needles & W & -- & $<250$ & $<250$ & $<250$ \\
\hline Route 119 & Pine needles $-\mathrm{R}$ & $\mathrm{W}$ & -- & $<250$ & $<250$ & $<250$ \\
\hline Highway & Sample type & $\begin{array}{l}\text { Particle-size } \\
\text { fraction }\end{array}$ & $\begin{array}{c}\text { 1-Methyl- } \\
\text { phenanthrene }\end{array}$ & 1-Methylpyrene & $\begin{array}{c}\text { 236-Trimethyl- } \\
\text { naphthalene }\end{array}$ & $\begin{array}{l}\text { 26-Dimethyl- } \\
\text { naphthalene }\end{array}$ \\
\hline Route 119 & Suspended sediment & $<0.063 \mathrm{~mm}$ & $<2,850$ & $<2,850$ & $<2,850$ & 610 \\
\hline Route 119 & Suspended sediment & $\geq 0.063 \mathrm{~mm}$ & $<10,200$ & $<10,200$ & $<10,200$ & $<10,200$ \\
\hline Route 2 & Suspended sediment & $<0.063 \mathrm{~mm}$ & $<1,840$ & $<1,840$ & 813 & $<1,840$ \\
\hline Route 2 & Suspended sediment & $\geq 0.063 \mathrm{~mm}$ & $<2,010$ & $<2,010$ & $<2,010$ & $<2,010$ \\
\hline Interstate 495 & Suspended sediment & $<0.063 \mathrm{~mm}$ & $<2,580$ & 1,340 & $<2,580$ & $<2,580$ \\
\hline Interstate 495 & Suspended sediment & $\geq 0.063 \mathrm{~mm}$ & $<5,020$ & $<5,020$ & $<5,020$ & $<5,020$ \\
\hline Interstate 95 & Suspended sediment & $<0.063 \mathrm{~mm}$ & 1,820 & $<3,460$ & $<3,460$ & $<3,460$ \\
\hline Interstate 95 & Suspended sediment & $\geq 0.063 \mathrm{~mm}$ & $<1,540$ & $<1,540$ & $<1,540$ & $<1,540$ \\
\hline Interstate 495 & Roadside grasses & $\mathrm{W}$ & $<200$ & $<200$ & $<200$ & E63.4 \\
\hline Interstate 495 & Roadside grasses $-\mathrm{R}$ & $\mathrm{W}$ & $<200$ & $<200$ & $<200$ & E55.1 \\
\hline Route 119 & Pine needles & $\mathrm{W}$ & $<250$ & $<250$ & $<250$ & $<250$ \\
\hline Route 119 & Pine needles $-\mathrm{R}$ & $\mathrm{W}$ & $<250$ & $<250$ & $<250$ & $<250$ \\
\hline
\end{tabular}


Table 21. Concentrations of selected polyaromatic hydrocarbons and phthalate compounds in samples of suspended sediment, roadside grasses, and dry pine needles collected from four highways in Massachusetts, 2005-07.-Continued

[Values are in micrograms per kilogram ; <, Less than the value shown; $\geq$, greater than or equal to the value shown; mm, millimeters in diameter; W, whole sample; -R, replicate sample; --, no data; E, the recovery or variation in recovery of the analyte was outside the acceptable range or concentration reported is less than laboratory reporting level and is qualified as estimated]

\begin{tabular}{|c|c|c|c|c|c|c|}
\hline Highway & Sample type & $\begin{array}{l}\text { Particle-size } \\
\text { fraction }\end{array}$ & $\begin{array}{c}\text { 2-Ethyl- } \\
\text { naphthalene }\end{array}$ & $\begin{array}{l}\text { 2-Fluorobiphenyl, } \\
\text { surrogate } \\
\text { (percent recovery) }\end{array}$ & $\begin{array}{c}\text { 2-Methyl- } \\
\text { anthracene }\end{array}$ & $\begin{array}{c}4 \mathrm{H}- \\
\text { Cyclopenta[def] } \\
\text { phenanthrene }\end{array}$ \\
\hline Route 119 & Suspended sediment & $<0.063 \mathrm{~mm}$ & $<2,850$ & 79 & $<2,850$ & $<2,850$ \\
\hline Route 119 & Suspended sediment & $\geq 0.063 \mathrm{~mm}$ & $<10,200$ & 76.6 & $<10,200$ & $<10,200$ \\
\hline Route 2 & Suspended sediment & $<0.063 \mathrm{~mm}$ & $<1,840$ & 104 & $<1,840$ & $<1,840$ \\
\hline Route 2 & Suspended sediment & $\geq 0.063 \mathrm{~mm}$ & $<2,010$ & 91.3 & $<2,010$ & $<2,010$ \\
\hline Interstate 495 & Suspended sediment & $<0.063 \mathrm{~mm}$ & $<2,580$ & 55.5 & $<2,580$ & $<2,580$ \\
\hline Interstate 495 & Suspended sediment & $\geq 0.063 \mathrm{~mm}$ & $<5,020$ & 86.1 & $<5,020$ & $<5,020$ \\
\hline Interstate 95 & Suspended sediment & $<0.063 \mathrm{~mm}$ & $<3,460$ & 53.8 & $<3,460$ & $<3,460$ \\
\hline Interstate 95 & Suspended sediment & $\geq 0.063 \mathrm{~mm}$ & $<1,540$ & 83.5 & $<1,540$ & $<1,540$ \\
\hline Interstate 495 & Roadside grasses & $\mathrm{W}$ & $<200$ & 120.9 & $<200$ & -- \\
\hline Interstate 495 & Roadside grasses $-\mathrm{R}$ & $\mathrm{W}$ & $<200$ & 118.2 & $<200$ & -- \\
\hline Route 119 & Pine needles & $\mathrm{W}$ & $<250$ & 105 & $<250$ & -- \\
\hline Route 119 & Pine needles $-\mathrm{R}$ & $\mathrm{W}$ & $<250$ & 102.9 & $<250$ & -- \\
\hline Highway & Sample type & $\begin{array}{l}\text { Particle-size } \\
\text { fraction }\end{array}$ & $\begin{array}{l}\text { 910-Anthra- } \\
\text { quinone }\end{array}$ & Fluorene & Acenaphthene & Acenaphthylene \\
\hline Route 119 & Suspended sediment & $<0.063 \mathrm{~mm}$ & 1950 & $<2,850$ & $<2,850$ & $<2,850$ \\
\hline Route 119 & Suspended sediment & $\geq 0.063 \mathrm{~mm}$ & 5,420 & $<10,200$ & $<10,200$ & $<10,200$ \\
\hline Route 2 & Suspended sediment & $<0.063 \mathrm{~mm}$ & 3,610 & $<1,840$ & $<1,840$ & 719 \\
\hline Route 2 & Suspended sediment & $\geq 0.063 \mathrm{~mm}$ & 1,460 & $<2,010$ & $<2,010$ & $<2,010$ \\
\hline Interstate 495 & Suspended sediment & $<0.063 \mathrm{~mm}$ & 3,500 & $<2,580$ & $<2,580$ & $<2,580$ \\
\hline Interstate 495 & Suspended sediment & $\geq 0.063 \mathrm{~mm}$ & 3,260 & $<5,020$ & $<5,020$ & $<5,020$ \\
\hline Interstate 95 & Suspended sediment & $<0.063 \mathrm{~mm}$ & 7,870 & $<3,460$ & $<3,460$ & $<3,460$ \\
\hline Interstate 95 & Suspended sediment & $\geq 0.063 \mathrm{~mm}$ & 1,340 & $<1,540$ & $<1,540$ & $<1,540$ \\
\hline Interstate 495 & Roadside grasses & $\mathrm{W}$ & -- & $<200$ & $<200$ & 913 \\
\hline Interstate 495 & Roadside grasses $-\mathrm{R}$ & $\mathrm{W}$ & -- & $<200$ & $<200$ & 864 \\
\hline Route 119 & Pine needles & W & -- & $<250$ & $<250$ & $<657$ \\
\hline Route 119 & Pine needles $-\mathrm{R}$ & $\mathrm{W}$ & -- & $<250$ & $<250$ & $<852$ \\
\hline
\end{tabular}


Table 21. Concentrations of selected polyaromatic hydrocarbons and phthalate compounds in samples of suspended sediment, roadside grasses, and dry pine needles collected from four highways in Massachusetts, 2005-07.-Continued

[Values are in micrograms per kilogram ; <, Less than the value shown; $\geq$, greater than or equal to the value shown; mm, millimeters in diameter; W, whole sample; -R, replicate sample; --, no data; E, the recovery or variation in recovery of the analyte was outside the acceptable range or concentration reported is less than laboratory reporting level and is qualified as estimated]

\begin{tabular}{|c|c|c|c|c|c|c|}
\hline Highway & Sample type & $\begin{array}{l}\text { Particle-size } \\
\text { fraction }\end{array}$ & Anthracene & $\begin{array}{c}\text { Benzo[a]- } \\
\text { anthracene }\end{array}$ & Benzo[a]pyrene & $\begin{array}{c}\text { Benzo[b]- } \\
\text { fluoranthene }\end{array}$ \\
\hline Route 119 & Suspended sediment & $<0.063 \mathrm{~mm}$ & $<2,850$ & $<2,850$ & 1770 & $<2,900$ \\
\hline Route 119 & Suspended sediment & $\geq 0.063 \mathrm{~mm}$ & $<10,200$ & $<10,200$ & 4,130 & $<10,200$ \\
\hline Route 2 & Suspended sediment & $<0.063 \mathrm{~mm}$ & $<1,840$ & 2,850 & 3,260 & 8,240 \\
\hline Route 2 & Suspended sediment & $\geq 0.063 \mathrm{~mm}$ & $<2,010$ & $<2,010$ & 1,950 & 2,930 \\
\hline Interstate 495 & Suspended sediment & $<0.063 \mathrm{~mm}$ & $<2,580$ & 4,340 & 4,320 & 9,090 \\
\hline Interstate 495 & Suspended sediment & $\geq 0.063 \mathrm{~mm}$ & $<5,020$ & $<5,020$ & 4,660 & $<6,420$ \\
\hline Interstate 95 & Suspended sediment & $<0.063 \mathrm{~mm}$ & $<3,460$ & 8,090 & 9,070 & 22,800 \\
\hline Interstate 95 & Suspended sediment & $\geq 0.063 \mathrm{~mm}$ & $<1,540$ & $<1,540$ & 1,740 & 2,860 \\
\hline Interstate 495 & Roadside grasses & W & $<200$ & E68.2 & $<200$ & $<200$ \\
\hline Interstate 495 & Roadside grasses $-\mathrm{R}$ & W & $<200$ & E88.6 & $<200$ & $<200$ \\
\hline Route 119 & Pine needles & W & $<250$ & $<250$ & $<250$ & $<250$ \\
\hline Route 119 & Pine needles $-\mathrm{R}$ & $\mathrm{W}$ & $<250$ & $<250$ & $<250$ & $<250$ \\
\hline Highway & Sample type & $\begin{array}{l}\text { Particle-size } \\
\text { fraction }\end{array}$ & Benzo[e]pyrene & $\begin{array}{c}\text { Benzo[ghi]- } \\
\text { perylene }\end{array}$ & $\begin{array}{l}\text { Benzo }[k]- \\
\text { fluoranthene }\end{array}$ & $\begin{array}{c}\text { Bis(2-ethyl- } \\
\text { hexyl) } \\
\text { phthalate }\end{array}$ \\
\hline Route 119 & Suspended sediment & $<0.063 \mathrm{~mm}$ & 2,160 & $<2,850$ & $<2,850$ & 24,300 \\
\hline Route 119 & Suspended sediment & $\geq 0.063 \mathrm{~mm}$ & 3,520 & $<10,200$ & $<10,200$ & $<10,200$ \\
\hline Route 2 & Suspended sediment & $<0.063 \mathrm{~mm}$ & 5,040 & 3,880 & 3,040 & 74,400 \\
\hline Route 2 & Suspended sediment & $\geq 0.063 \mathrm{~mm}$ & 1,890 & $<2,010$ & $<2,010$ & 21,600 \\
\hline Interstate 495 & Suspended sediment & $<0.063 \mathrm{~mm}$ & 5,520 & 4,020 & 3,370 & 23,800 \\
\hline Interstate 495 & Suspended sediment & $\geq 0.063 \mathrm{~mm}$ & 4,130 & $<5,020$ & $<5,020$ & $<17,900$ \\
\hline Interstate 95 & Suspended sediment & $<0.063 \mathrm{~mm}$ & 13,300 & 8,950 & 8,560 & 106,000 \\
\hline Interstate 95 & Suspended sediment & $\geq 0.063 \mathrm{~mm}$ & 1,770 & $<1,540$ & $<1,540$ & 13,900 \\
\hline Interstate 495 & Roadside grasses & W & $<200$ & $<200$ & $<200$ & -- \\
\hline Interstate 495 & Roadside grasses $-\mathrm{R}$ & W & $<200$ & $<200$ & $<200$ & -- \\
\hline Route 119 & Pine needles & $\mathrm{W}$ & $<250$ & $<250$ & $<250$ & -- \\
\hline Route 119 & Pine needles $-R$ & $\mathrm{~W}$ & $<250$ & $<250$ & $<250$ & -- \\
\hline
\end{tabular}


Table 21. Concentrations of selected polyaromatic hydrocarbons and phthalate compounds in samples of suspended sediment, roadside grasses, and dry pine needles collected from four highways in Massachusetts, 2005-07.-Continued

[Values are in micrograms per kilogram ; <, Less than the value shown; $\geq$, greater than or equal to the value shown; mm, millimeters in diameter; W, whole sample; -R, replicate sample; --, no data; E, the recovery or variation in recovery of the analyte was outside the acceptable range or concentration reported is less than laboratory reporting level and is qualified as estimated]

\begin{tabular}{|c|c|c|c|c|c|c|}
\hline Highway & Sample type & $\begin{array}{c}\text { Particle-size } \\
\text { fraction }\end{array}$ & Chrysene & $\begin{array}{c}\text { Dibenzo[ah]- } \\
\text { anthracene }\end{array}$ & $\begin{array}{l}\text { Dibenzo- } \\
\text { thiophene }\end{array}$ & $\begin{array}{c}\text { Diethyl } \\
\text { phthalate }\end{array}$ \\
\hline Route 119 & Suspended sediment & $<0.063 \mathrm{~mm}$ & $<2,850$ & $<2,850$ & $<2,850$ & $<2,850$ \\
\hline Route 119 & Suspended sediment & $\geq 0.063 \mathrm{~mm}$ & $<10,200$ & $<10,200$ & $<10,200$ & $<10,200$ \\
\hline Route 2 & Suspended sediment & $<0.063 \mathrm{~mm}$ & 7,530 & $<1,840$ & $<1,840$ & $<1,840$ \\
\hline Route 2 & Suspended sediment & $\geq 0.063 \mathrm{~mm}$ & $<2,560$ & $<2,010$ & $<2,010$ & $<2,430$ \\
\hline Interstate 495 & Suspended sediment & $<0.063 \mathrm{~mm}$ & 7,890 & $<2,580$ & $<2,580$ & $<2,580$ \\
\hline Interstate 495 & Suspended sediment & $\geq 0.063 \mathrm{~mm}$ & $<5,430$ & $<5,020$ & $<5,020$ & $<5,020$ \\
\hline Interstate 95 & Suspended sediment & $<0.063 \mathrm{~mm}$ & 18,300 & $<3,460$ & $<3,460$ & $<3,460$ \\
\hline Interstate 95 & Suspended sediment & $\geq 0.063 \mathrm{~mm}$ & 2,540 & $<1,540$ & $<1,540$ & $<1,540$ \\
\hline Interstate 495 & Roadside grasses & $\mathrm{W}$ & E44.2 & $<200$ & -- & -- \\
\hline Interstate 495 & Roadside grasses $-\mathrm{R}$ & W & E75.9 & $<200$ & -- & -- \\
\hline Route 119 & Pine needles & $\mathrm{W}$ & $<250$ & $<382$ & -- & -- \\
\hline Route 119 & Pine needles $-\mathrm{R}$ & $\mathrm{W}$ & $<250$ & $<378$ & -- & -- \\
\hline Highway & Sample type & $\begin{array}{l}\text { Particle-size } \\
\text { fraction }\end{array}$ & Fluoranthene & $\begin{array}{l}\text { Hexachloro- } \\
\text { benzene }\end{array}$ & $\begin{array}{l}\text { Indeno[123-cd]- } \\
\text { pyrene }\end{array}$ & Naphthalene \\
\hline Route 119 & Suspended sediment & $<0.063 \mathrm{~mm}$ & $<3,260$ & $<2,850$ & $<2,850$ & $<2,850$ \\
\hline Route 119 & Suspended sediment & $\geq 0.063 \mathrm{~mm}$ & $<10,200$ & $<10,200$ & $<10,200$ & $<10,200$ \\
\hline Route 2 & Suspended sediment & $<0.063 \mathrm{~mm}$ & 13,700 & $<1,840$ & 3,530 & $<1,840$ \\
\hline Route 2 & Suspended sediment & $\geq 0.063 \mathrm{~mm}$ & 4,660 & $<2,010$ & 1,440 & $<2,010$ \\
\hline Interstate 495 & Suspended sediment & $<0.063 \mathrm{~mm}$ & 14,900 & $<2,580$ & 3,740 & $<2,580$ \\
\hline Interstate 495 & Suspended sediment & $\geq 0.063 \mathrm{~mm}$ & 10,700 & $<5,020$ & $<5,020$ & $<5,020$ \\
\hline Interstate 95 & Suspended sediment & $<0.063 \mathrm{~mm}$ & 34,700 & $<3,460$ & 8,930 & $<3,460$ \\
\hline Interstate 95 & Suspended sediment & $\geq 0.063 \mathrm{~mm}$ & 5,190 & $<1,540$ & 1,240 & $<1,540$ \\
\hline Interstate 495 & Roadside grasses & $\mathrm{W}$ & E109 & -- & $<200$ & E39.0 \\
\hline Interstate 495 & Roadside grasses - $\mathrm{R}$ & $\mathrm{W}$ & E147 & -- & $<200$ & E13.9 \\
\hline Route 119 & Pine needles & $\mathrm{W}$ & $<250$ & -- & $<250$ & $<250$ \\
\hline Route 119 & Pine needles $-\mathrm{R}$ & $\mathrm{W}$ & $<250$ & -- & $<250$ & $<250$ \\
\hline
\end{tabular}


Table 21. Concentrations of selected polyaromatic hydrocarbons and phthalate compounds in samples of suspended sediment, roadside grasses, and dry pine needles collected from four highways in Massachusetts, 2005-07._Continued

[Values are in micrograms per kilogram ; <, Less than the value shown; $\geq$, greater than or equal to the value shown; mm, millimeters in diameter; W, whole sample; -R, replicate sample; --, no data; E, the recovery or variation in recovery of the analyte was outside the acceptable range or concentration reported is less than laboratory reporting level and is qualified as estimated]

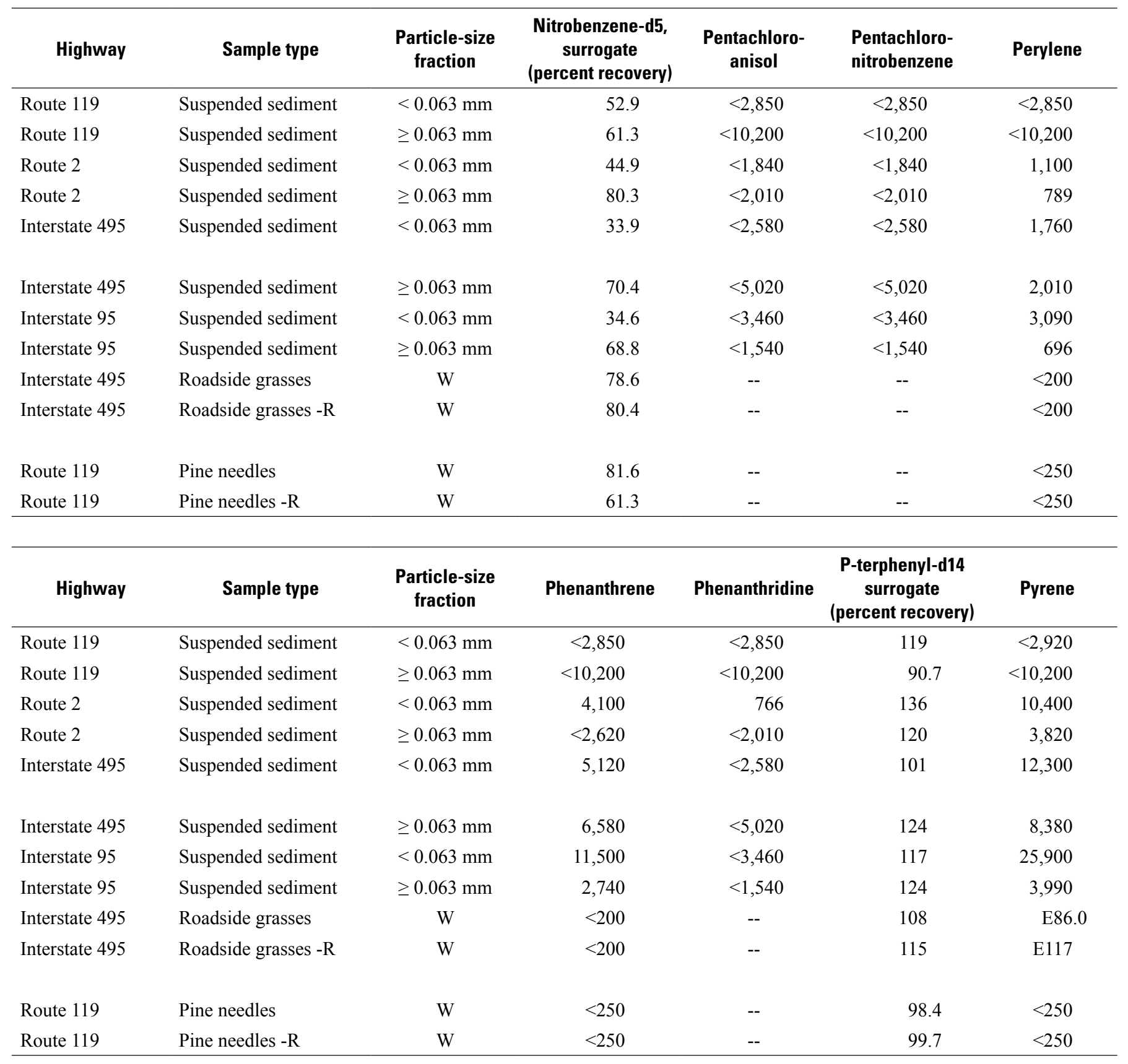


THIS PAGE INTENTIONALLY LEFT BLANK 
Prepared by the Pembroke and West Trenton Publishing Service Center.

For more information concerning this report, contact:

\section{Director}

U.S. Geological Survey

Massachusetts-Rhode Island Water Science Center

10 Bearfoot Road

Northborough, MA 01532

dc_ma@usgs.gov

or visit our Web site at:

http://ma.water.usgs.gov 
